\title{
Heinrich Kunstmann
}

\section{Beiträge zur Geschichte der Besiedlung}

Nord- und Mitteldeutschlands mit Balkanslaven

Verlag Otto Sagner München · Berlin · Washington D.C.

Digitalisiert im Rahmen der Kooperation mit dem DFG-Projekt „Digi20“

der Bayerischen Staatsbibliothek, München. OCR-Bearbeitung und Erstellung des eBooks durch den Verlag Otto Sagner:

http://verlag.kubon-sagner.de

( $)$ bei Verlag Otto Sagner. Eine Verwertung oder Weitergabe der Texte und Abbildungen, insbesondere durch Vervielfältigung, ist ohne vorherige schriftliche Genehmigung des Verlages unzulässig.

«Verlag Otto Sagner» ist ein Imprint der Kubon \& Sagner GmbH. 


\title{
SLAVISTISCHE BEITRÄGE
}

\author{
BEGRÜNDET VON \\ ALOIS SCHMAUS \\ HERAUSGEGEBEN VON \\ HEINRICH KUNSTMANN \\ PETER REHDER $\cdot$ JOSEF SCHRENK \\ REDAKTION \\ PETER REHDER
}

Band 217 


\section{HEINRICH KUNSTMANN}

\section{BEITRÄGE ZUR GESCHICHTE DER BESIEDLUNG NORD- UND MITTELDEUTSCHLANDS MIT BALKANSLAVEN}

\section{VERLAG OTTO SAGNER · MÜNCHEN}




\section{Bnyorlscho Staztikj' lost:ok A.iunchson}

ISBN 3-87690-385.8

(C) Verlag Otto Sagner, München 1987

Abteilung der Firma Kubon \& Sagner, München 
Zuwellen galt es, den gordischen Knoten mit dem Schwerte zu durchhauen. Denn es liegt mehr im interesse der wissenschaft, uber schwierige Punkte zuerst uberhaupt eine, wenn anch kühne Ansicht aufzustellen. als dieselben blas mit einew kritischen Kreuze zu bezeichnen, da aur jene Weise der Widerspruch. das belebende Element der Porschung. geweckt wird.

Hugo Schuchardt-Brevler 402. 


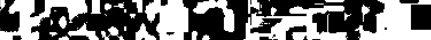

in 10 Int $\rightarrow$ I $\Rightarrow 2$

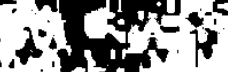

A

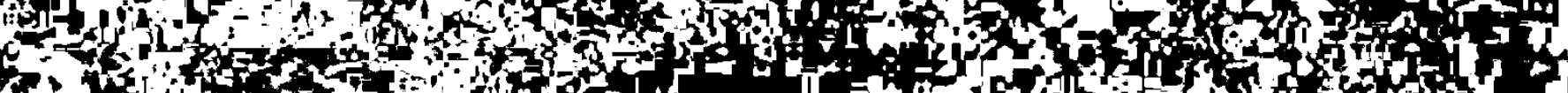
* a

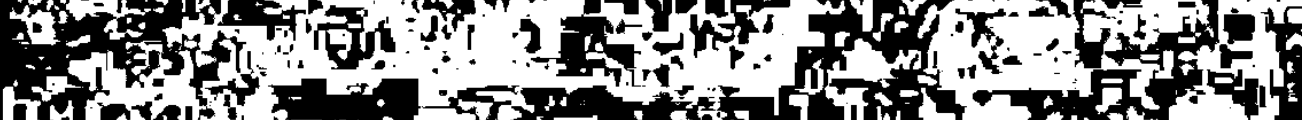

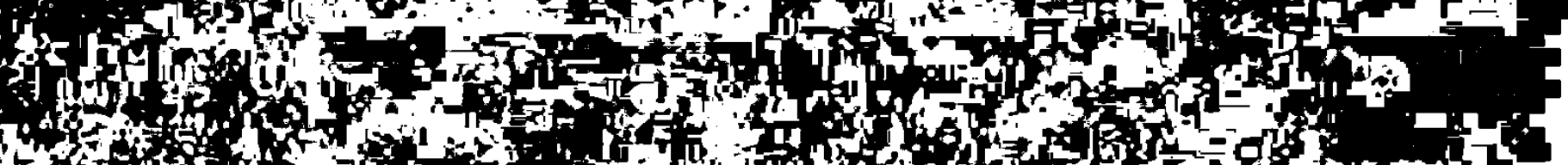

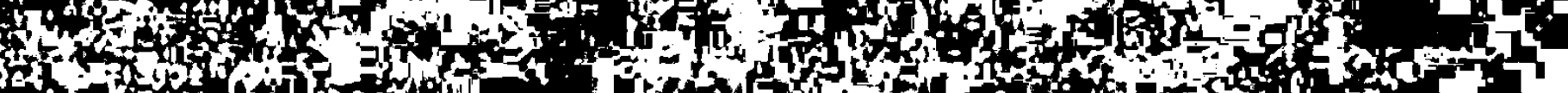

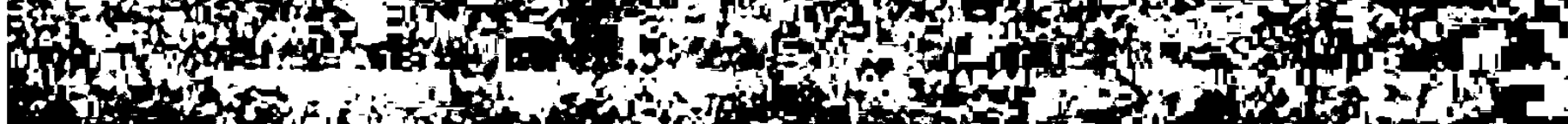
(2), R,

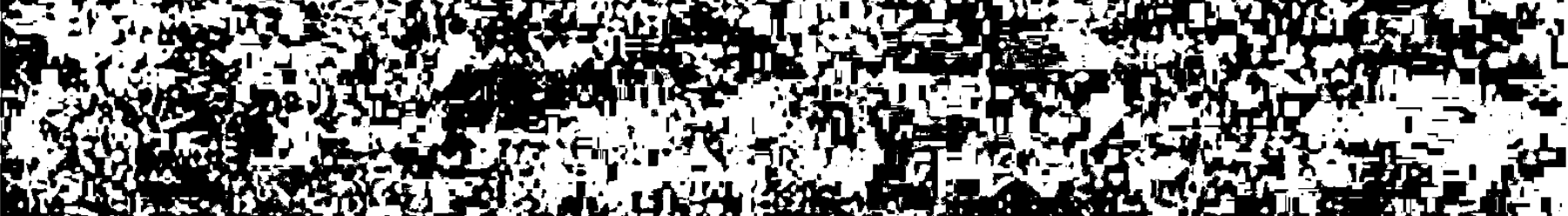

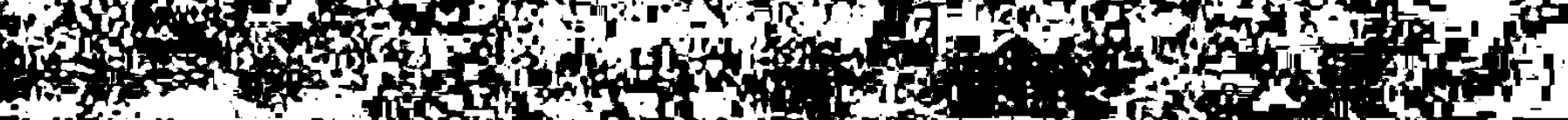
ition.

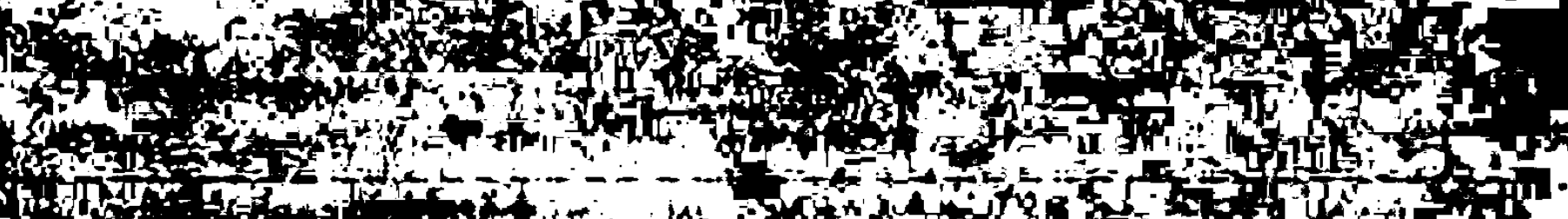
If $x_{1}=2$

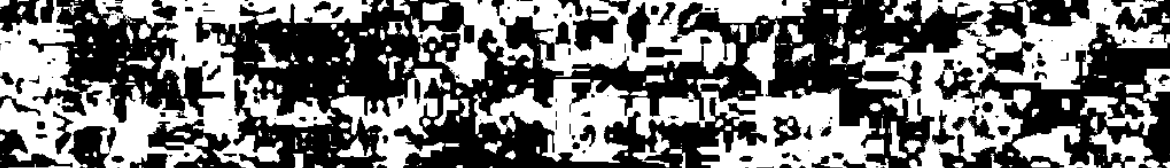
Fing and (1)

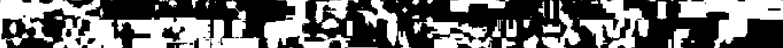

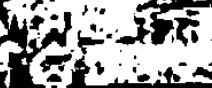
Ty tonf

1

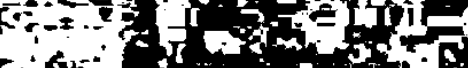

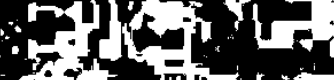

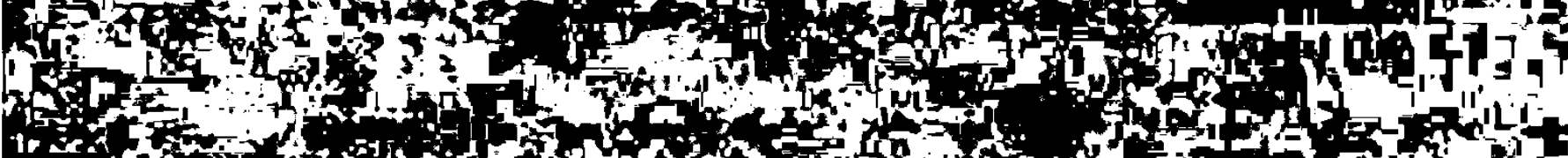

(5)

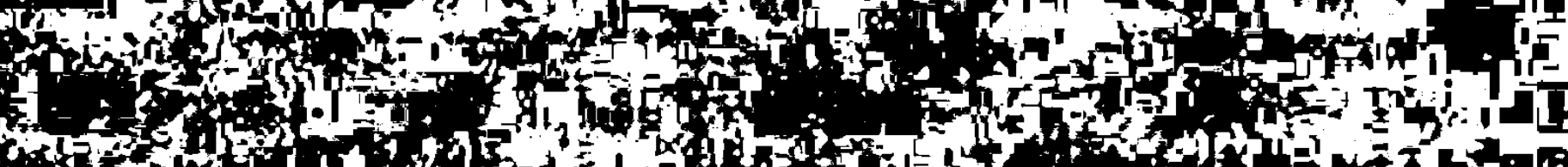

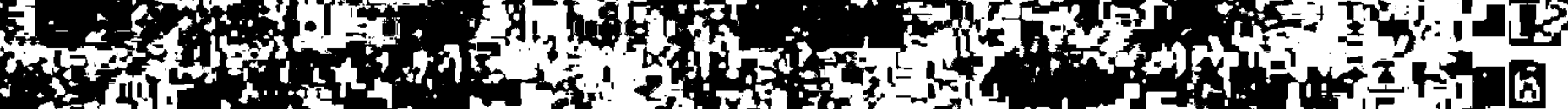

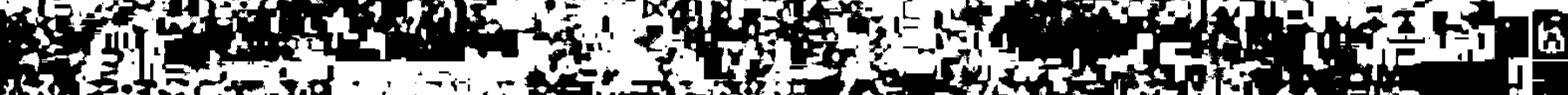

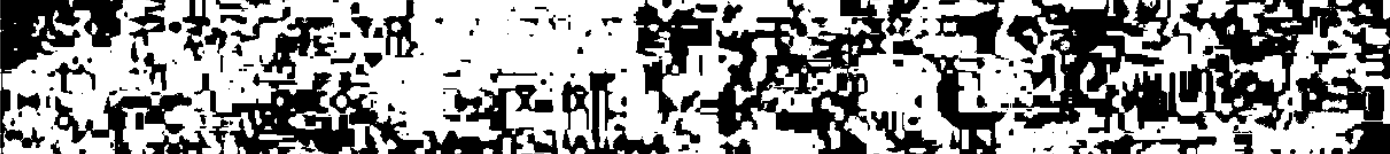

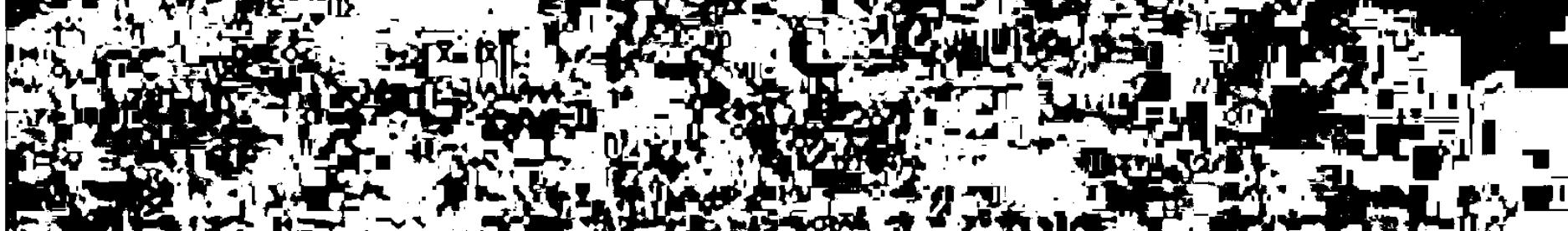
年 isco -

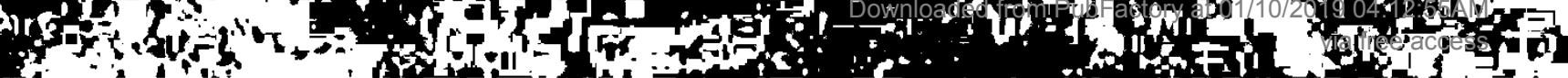


Vorwort

Die zu diesem Band zusammengestellten 27 Einzeluntersuchungen verstehen sich als Bausteine einer allerdings noch in weiter Ferne liegenden Synthese der slavischen Besiedlung Deutschlands. Bis auf wenige Ausnahmen konzentrieren sich alle Artikel darauf, die Zuwanderung balkanslavischer Ethnika wahrscheinlich zu machen. Im Vordergrund stehen daher nicht onomastische Deskriptionen. sondern neue Etymologien, von denen einige gewiß überraschen werden. Nebenbel ergaben sich außerdem Lösungen verschiedener ethnonymischer Rătsel. die der Geographus Bavarus aufgab.

Der im Titel und auch sonst verwendete Terminus Balkanslaven hat nlchts zu tun mit neuzeitlichen Südslaven, sondern ist Sammelbezeichnung rar jene Protoslaven, die seit dem 6. Jhd. n. Chr. de Balkanhalbinsel ubernuteten und im Laufe der Zeit entweder auf ihr seshaft wurden oder aber nach Norden weiterzogen.

Die den Einzeluntersuchungen nachgestellten beiden Resūmees (28-29) nankieren das zentrale Thema sowohl Hnguistisch und historisch als auch forschungsgeschichtlich. Neue, die grundlegende These stützende Beobachtungen werden fallweise en revue publiziert.

Vorllegender Band verdankt sein Entstehen vielen individuellen und Institutionellen Kraften. So Insbesondere der Deutschen Forschungsgemeinschart. die zur nicht immer einfachen Materialbescharrung mit einer Sachbeihlle beitrug. Gebuhrend zu danken ist ebenfalls zahlreichen Bibllothekaren, von denen namentlich Frau G. Frank von der UB Erlangen fur ihre selbstlose Hilfsbereitschaft hervorzuheben lst. Zum Kreis der Förderer dieser Untersuchungen gehört ferner das Institut fur Slavische Philologie der Ludwig-Maximilians-Universităt München. das mir auch nach meinem Ausscheiden aus dem Lehrbetrieb stets freundschaftlich gesonnen blieb. Zuletzt und doch in erster Linie bedanke ich mich bei Herrn Prof. Dr. Peter Rehder cür dessen immerwăhrende muniflcentis in IItteris; auf ihn. meine ich. trifrt das Ennius-Wort zu: Amicus certus in re incerta cernitur. 
Inhaltsverzeichnis

Vorwort

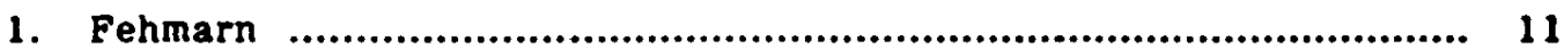

2. Wagrien in Holstein ................................................................ 17

3. Ostholsteins Ukleisee .............................................................. 21

4. Abodriti. Obodriti. Praedenecenti .................................................. 25

5. Mecklenburg und Wismar ............................................................ 45

6. Mecklenburgs Zirzipanen und der Name der Peene ....................... 51

7. Rethra. Redarier. Arkona .......................................................... 57

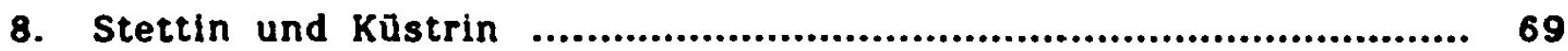

9. Colberg. Kolberg. Kolobrzeg …....................................................... 75

10. Der Name der Kaschuben ............................................................ 79

11. Drevani. Derevljane. Dervanus ...................................................... 85

12. Ottos des Großen marca Lipâni .................................................... 91

13. Belcsem in der Altmark .............................................................. 95

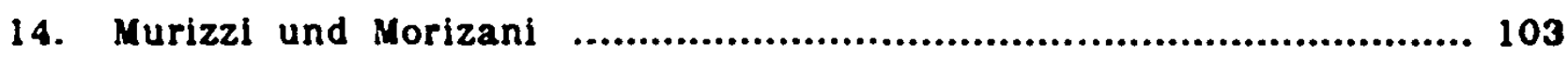

15. Doxani. Dassia. Dosse .............................................................. 109

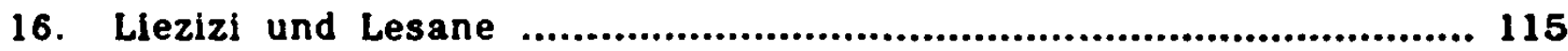

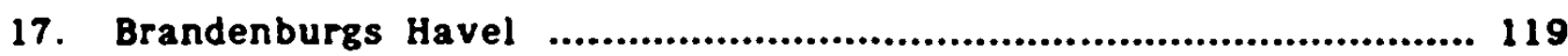

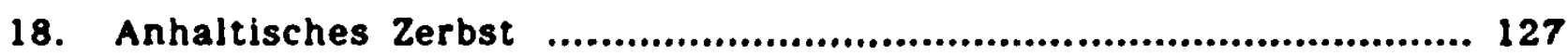

19. Der anhaltische Landschaftsname Serimunti ................................ 133

20. Scheuder bei Dessau .................................................................. 141

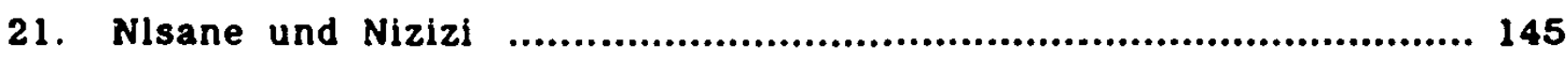

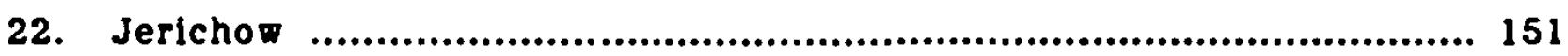

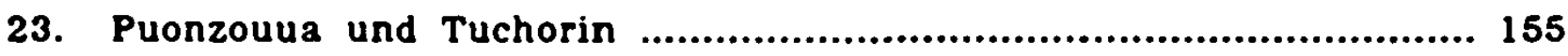

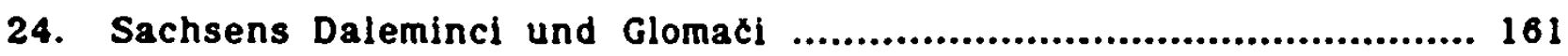

25. Die sorbischen Milzener ........................................................ 169

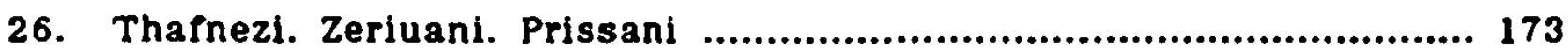

27. Serben und Sorben ......................................................... 183

28. Was sich aus den Untersuchungen ergibt .................................... 191

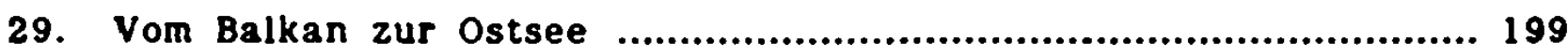

Bibliographische Anmerkungen $z u$ bereits publizierten Arbeiten ........... 207

Literaturverzeichnis und Siglen ...................................................... 209

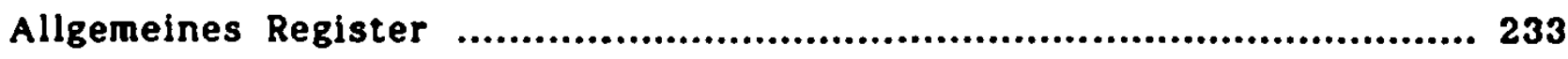

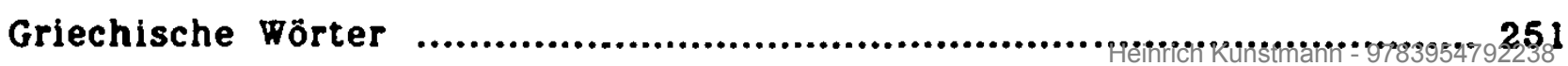




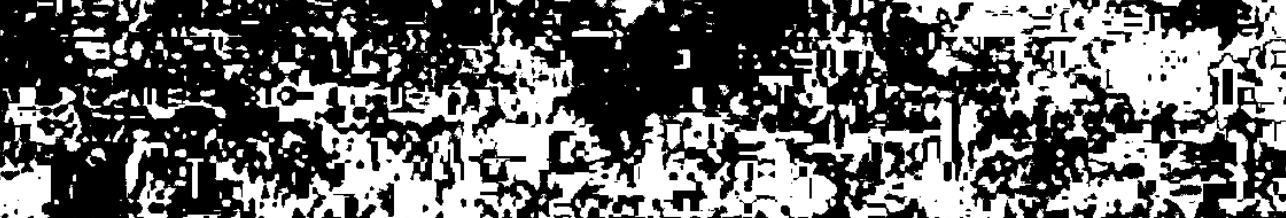

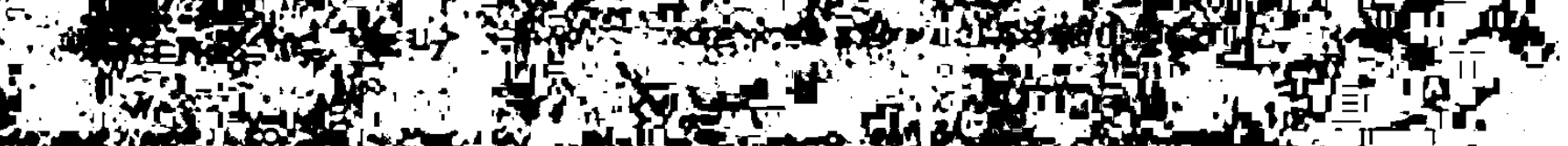

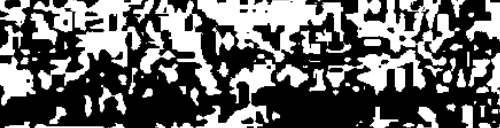 \\ ,}

xer.

- 3

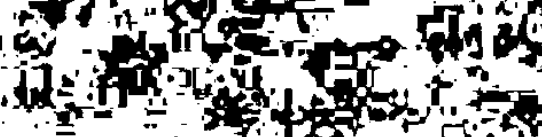
:

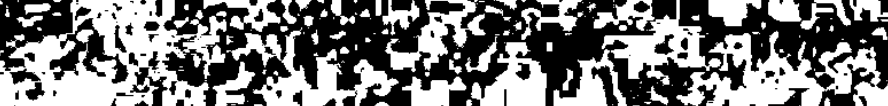

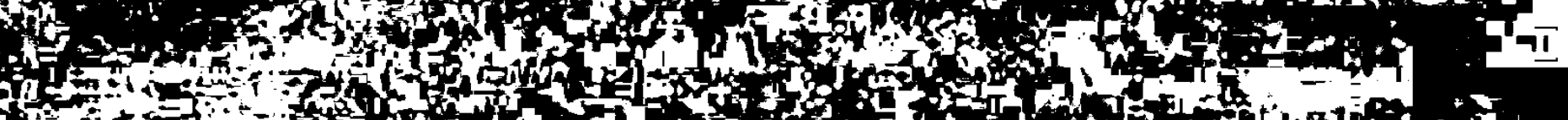

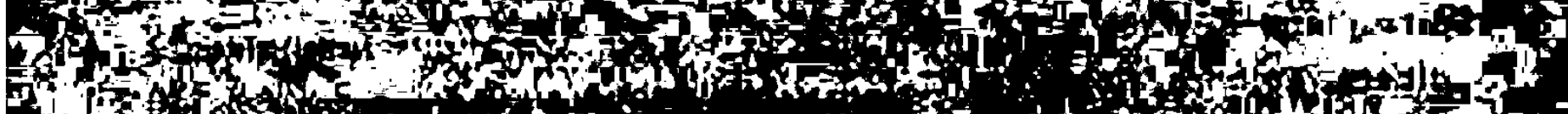

\section{3 a}

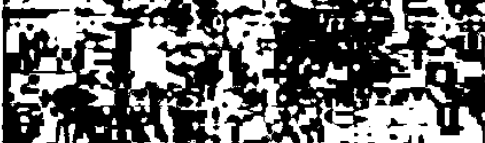

In

20,

$+4$

rind

16

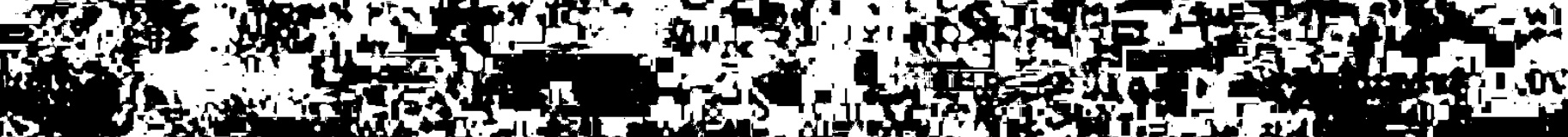

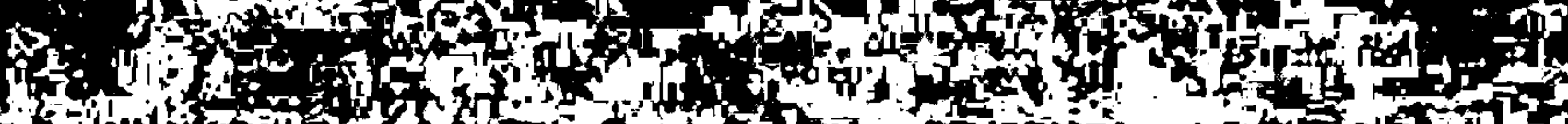

3 disnis

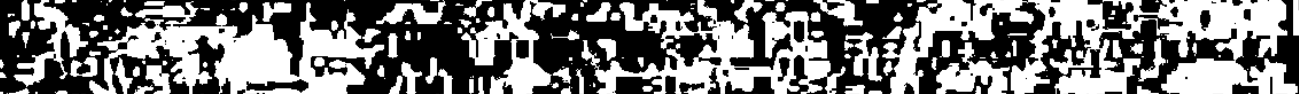

1.

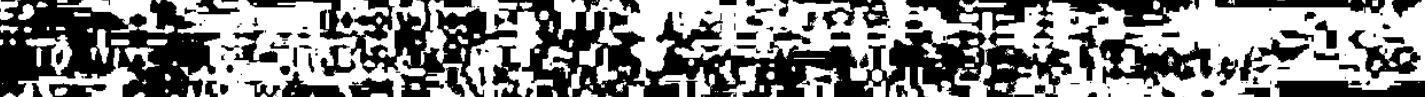

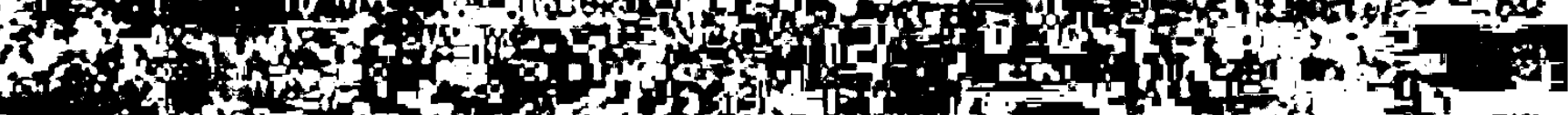

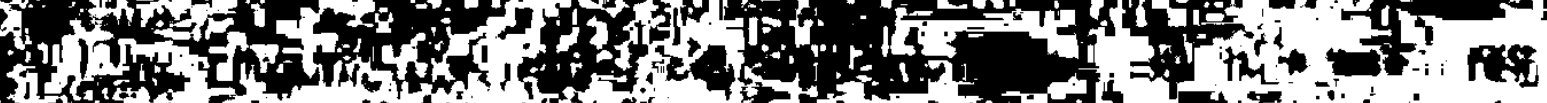

6.

6.

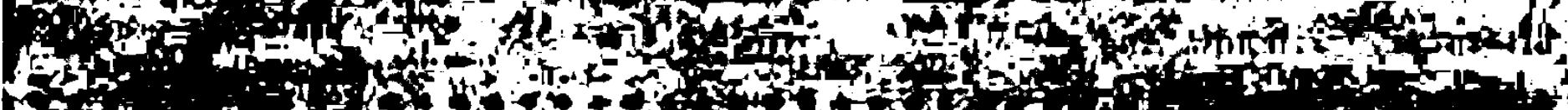
DAf

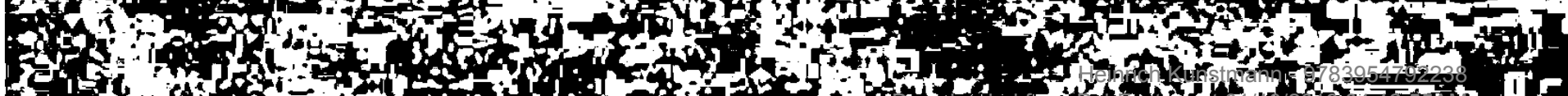
3 (5) 


\section{Pehmarn}

Für Gertrud

Die frühmittelalterliche Geschichte der großen ostholsteinischen Insel ist In vollliges Dunkel gehüllt. Ihre früheste Erwăhnung erfolgt um 1075 durch den "Tacitus des germanischen Nordens" (Hampe) und Verfasser einer "Hamburger Kirchengeschichte", den Bremer magister scolarum Adam. Zu verdanken sind inm auch erste Nachrichten zur Besiedlung Fehmarns mit Slaven." Unbeantwortet bleibt allerdings die Frage nach der Stammeszugehorigkeit dieser Slaven, da sowohl abodritische als auch wagrische in Betracht gezogen werden kann. Obgleich schon seit der Zeit der Kolonisation Wagriens unter Graf Adolf II. von Holstein (1143) auch deutsche Bauern die Insel besiedelten. scheint sich das slavische Element auf inr lange Zeit behauptet zu haben, dafür spricht der alte slavische, noch Ende des 19. Jhds. erkennbare Dorftypus des Rundlings (wiepert. Vasmer 1934). AuBer einigen wenigen archăologischen Bodenfunden ${ }^{2}$ ist Jedoch der Name der Insel das am weitesten In die Vergangenheit zurūckweisende geschichtliche Zeugnis. Wichtige Belege zur Erhellung des Inselnamens sind diese:

Ende 11. Jhd. insulae... quarum prima Fembre vocatur (Adam v. Br.): Ende 11. Jhd. Imbra (ders.): Ende 12. Jhd. Insulae..., quarum una Vemere vocatur (Helmold v. Bosau); Fimbre (ders.; Wlener Hs., 16. Jhd.): 1231 Imbrae, Ymbrae, Ymbria: 1234 apud Ymbriam; 1249 Imbre (lat. Gen.): 1259 de Vemeren; 1278 Datum Ymbrie; 1264-1289 de Vemeren. de Femeren. de Ymbria: 1267 de Imbria; 2u 1279 de Ymbria; 1307 in Imbriam; 1320 terre Ymbrie: 1320-1 Terre Imbrie: 1327 in terra nostra Ymbrie: 1328 to Vemeren: 1328 terre Ymbre: 1329 Fimbriam: 1329 terre Ymbrie; 1333 to Vemeren; 1336 in terra Veemeren; 1356 terre sue Cymbrie: 1420 in Fymmern: 1445 vp deme lande Vemeren; 1448 Imbria. terram Fimbrie, Ymbria. Fimbriam; um 1510 paa Fymmeren: 1513 aff Femeren; 1550 up Vhemern; 1579 Hymbria. Himbria: 1585 des landts Femern: $1651 / 2$ die Insul Femern oder Fimbria wird von etlichen Cimbria parva geheissen von den Kimeris, Kimbris: 1743 die Insul Femern; 1854 Fehmern; 1908 Fehmarñ.

1 Zur Geschichte und Topographie der Insel vgl. Handbuch der histor. Statten Deutschlands. Bd. I. Stuttgart ${ }^{3} 1976,50$ P.: G. Laage: Topographischer Atlas Schleswig-Holstein und Hamburg. Neumünster 41979. 48 fl.: SlowStarSlow II. 257 P. s.v. Imbra: W. Kowalenko.

2 Vogel 1972. 59: zu Burg a.F. und Westermarkelsdorf; K. W. Struve 1981. Bd. I, 23 ff.: über Burg a.F.

3 Nach Laur 1964, $156 \%$., und Schmitz 17. Am ausfuhrlichsten ist Laur. Die vorliegende Auswahl soll lediglich den Wandeiler kumentieren. 
Es glbt elne Relhe von Versuchen, den Namen Fehmarns zu deuten. GroBe Popularitat erwarb sich der von R. Much (1925, 134 P.), der glaubte, in Vemere liege die slavische Präpositionalkonstruktion ' $v$ mor'e 'im Meer' vor, die zu lat. imber 'Regen' als allgemeiner Bezelchnung fūr 'Wasser' latinisiert worden sel. Aus slavistischer Sicht ist diese Ansicht freilich unhaltbar. Zum vieldiskutlerten Deutungsversuch wurde dann der von R. Ekblom (1954), der Fehmarn mit dem Ethnonym der Kimbern und dem Jutischen Landschaftsnamen Himmerland bzw. Himmersyssel in Verbindung brachte. Laut Ekblom soll dies über dle slav. Form 'Imbra oder 'v Imbre geschehen sein, die ihrerseits wiederum auf german. 'Himbra zurückgehe. Aus mehreren Gründen hat man auch dlese Deutung verworfen. Verschledenemal hat sich der Fehmarn-Problematik W. Laur angenommen (1960, 1964. 1967). der, bel begründeter Skepsis gegenüber den bisherigen Versuchen. letztlich die Vermutung äuBerte. Fehmarns Name erkläre sich aus dem ger-

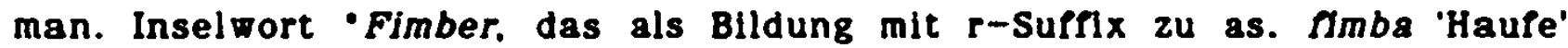
gehöre. Bel der latinisierten Form Imbr(i)a könne es sich laut Laur aber auch um ein dänisches 'Imber handeln, das auf Wendungen wie "a Fimbre > all Imbre beruhe (Laur 1967, 94). Vielleicht gehöre diese Form zu nord. ' himmer. 'immer 'llcht, hell'. Laurs eigentllcher Etymologie, die von einer alten niederdeutschen (oder nordischen) Grundform - Flmber < as. Amba + r-Surfx ausgeht, tritt im Prinzip auch A. Schmitz (18) bei. Beide Gelehrte glauben überdies, daß mit as. Amba bedeutungsmăßig die Bezeichnung Knuust 'aufgeschichteter Haufe; Erhöhung. Bodenerhebung (in der Ostsee)' korrespondlere, ein volkstümlicher Name fur Fehmarn, der eine Art Terrainbezeichnung ist. Der aktuelle Stand der Forschung macht offenbar, daB der fragliche Inselname weiterhin problematisch ist.

Wie verschledene Beiträge dieses Buches bewußt machen, konnten in einigen Fallen die wirklichen Etymologien einfach nicht ermittelt werden, well die noch immer tiefverwurzelte Auffassung von der slavischen OstWest-Migration den Blick rar dle wahren Hintergrunde verstellte. Nicht anders war dies im Fall der Ostseeinsel Fehmarn, die nămlich ihren Namen

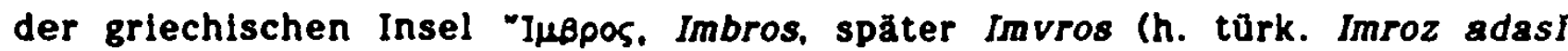
bzw. Gókfeada) verdankt. Imbros, Schwesterinsel von Lemnos, zăhlt zu den nördlichen Sporaden der Agăis und bewacht wie Tenedos vom Süden her die Offnung des Hellespont. Sie ist von diesem nur $18 \mathrm{~km} \mathrm{nw}$ und etwas weniger von der Spitze der Thrakischen Chersonesos (= Halbinsel Gallipoli) entfernt. Die unvergleichlich wichtige Position an 
Propontis und Pontos hat Imbros verständlicherweise schon im frühen Altertum das politische und strategische Interesse insbesondere Athens eingetragen: Die Resonanz seiner Bedeutung drückt sich an der von Homer (Illas 13.33-4, 753) über Herodot $(5,26-6,104)$ und Thukydides $(3,5.5$, 28) zu verfolgenden Erwăhnung des Inselnamens aus4.

Die historischen Notierungen des Namens Fehmarn zeigen, daB dieser als Dublette vorliegt. d. h. mit konsonantischem und vokalischem Anlaut: Fembre//Imbra. Bel allen bisherigen Oberlegungen war die Frage nach der Herkunft des anlautenden $\boldsymbol{l}$ - bzw. $\boldsymbol{v}$-gewissermaßen das ausschlaggebende Kriterium dafür, ob der strittige Inselname slavischer oder germanischer Provenienz ist. Doch war es ein gravierendes MiBverständnis, wenn man von einem präpositionalen Kompositum ' $v$ mor'e (richtiger wohl: $v$ v mor'il) ausging. da im gegebenen Fall überhaupt keine Prăposition, sondern eine v-Prothese vorliegt, deren Aufgabe es ist. wle im Slavischen hăung. den vokalischen Anlaut zu unterbinden. Die Verschmelzung der Prothese mit dem Grundwort ist jedoch nicht einheitlich verlaufen, da sich neben dem Typ mit Prothese lange noch die ursprüngliche vokalische Version halten konnte. Solche "Inkonsequenzen" sind im Slavischen keine Ausnahme. vgl. hier etwa Habola neben Obula (S. 120 P.). Unabhängig davon, ob der Anlaut von Fehmarn eine slav. Präposition oder Prothese ist. wird natürlich weiterhin die phonetische Qualităt von $f-b z w . v-$ den Ausschlag geben.

W. Laur, der anlautendes $\boldsymbol{l}$ - zunächst far den Reflex von slav. $\boldsymbol{v}-$ hielt. folgerte treffend, $d a B$ wenn der anfangs stimmlose german. Reibelaut f- bereits im Altsăchsischen (Altniederdeutschen) anlautend zu $v$ - lenisiert und im Spătmittelalter wieder zu $\rho$ - wurde, dann mußte - wegen der Schreibung mit $v$ - - auch slavisches $v$ wie $\rho$ ausgesprochen werden (Laur 1960, 401). Spăter hat Laur seine Meinung geăndert, weil ,gerade dle altesten Formen ein $P$ aufweisen", was bedeute, daß sie bereits an der Entwicklung $f>v>f$ teilgenommen hätten (Laur 1964, 162: ebenso Schmitz 18). Danach müsse der Inselname vor dem Altniederdeutschen entstanden. also germanischen, wenn nicht sogar vordeutschen Ursprungs sein.

Anlautendes $f$ - begegnet nur als vordeutsches $f$ - oder in entlehntem Wortgut, vgl. ruo3. fllu, fater. Doch beginnt anlautendes $\rho$ - bereits im Alt-

- Zur Geschichte von Imbros und seinem Namen vgl. Oberhummer 1898; Fredrich 1908; Pauly RE 17. Hbbd. 1914, 1105 ff.einfiredrich:-Pibibippson. KIrsten IV, 1959, 220 ff.; Kl. Pauly II. P3 \$ \&. 
hochdeutschen zu elnem schwach stimmhaften Spiranten erwelcht zu werden: graphischer Ausdruck dieser Lenislerung ist eben die Schreibung mit $v-(u-)$, die sich allerdings schon im 9. Jhd. durchzusetzen beginnt, auch wenn daneben die Schreibung mit $l$ - weiterhin bestehen bleibt (v. Kienie 105 1.; Braune, Eggers 128). Ab Ende des 9. Jhds. nimmt $v$ - zu; im 10. und 11. Jhd. wechseln $\boldsymbol{f}$ - und $v$ - ziemlich regellos, wobel $\boldsymbol{f}$ - uberwiegt (dies., ebda.). Der a lte ste Beleg des Inselnamens ist Fembre, er stammt von Adam von Bremen, făllt also in das Ende des 11. Jhds. Das jedoch heiBt. daB $v$ - hier durchaus schon von $l$ - wiedergegeben werden kann. auch wenn das Altsăchsische (Altniederdeutsche) in diesem Punkt vielleicht nicht mit dem Althochdeutschen gleichzusetzen ist. DaB german. $f$ bereits im Altniederdeutschen anlautend $z u v$ werden konnte, răumt auch Laur (1964, 162) ein. Legt man dem Altniederdeutschen, wie allgemein angenommen, eine Dauer von etwa 800 bis 1150 zugrunde, kann es eigentlich nicht uberraschen, zu 1076, also zur Zelt der Entstehung von Adams Klrchengeschichte, eine Schreibung mit $\boldsymbol{p}$ - statt $v$ - vorzufinden. Das gilt erst recht för die „zweltălteste" Schreibung mit $t$-. Helmolds Flmbre (exc. Vindob. = Anfang 16. Jhd.).

Gegen den möglicherweise berechtigten Einwand, das Altniederdeutsche dürfe nicht mit althochdeutschen Maßstäben gemessen werden, kann ein wichtiges Argument ins Feld geführt werden, nămlich Adam von Bremen. Dieser Autor, der Fembre und Imbra promiscue gebraucht (und auBerdem Fembre. Imbra und Ymbria far drei verschledene Inseln halt), war weder Niederdeutscher noch Altsachse, sondern stammte entweder aus der Gegend von Würzburg oder Bamberg (Wattenbach. Holtzmann 1978, 566 TP.). Für inn, der erst um 1066-7 nach Bremen gekommen ist, erweist sich somit das Altränkische als „zuständig". Das Altfränkische aber ist In der hier interessierenden Frage dem Althochdeutschen sehr ahnlich: wăhrend es anlautend in alterer Zeit stets $\boldsymbol{f}$ - schreibt, wird nach und nach, wohl unter lateinischem Einfluß, dafür $v-(u-)$ Immer hăufiger (Franck 1971, 98 P.).

Das Argument, der Inselname Fehmarn sel wegen Adams Fembre. wegen der Schreibung mit $P$ - in voraltsăchsische oder sogar in vordeutsche Zeit zu setzen. Ist aus den erwähnten Gründen nicht stichhaltig. Vielmehr reiht sich Fehmarns Name in die gewiB stattliche Reihe derjenigen Falle ein, in denen anlautendes slav. $v$ - Im Deutschen durch 1 - ersetzt wird:

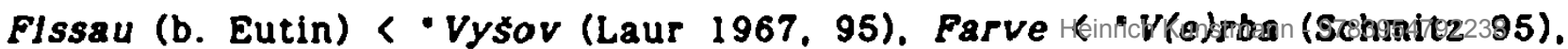
FItschkau < Vyseckovo (Trautmann I, 168). 
Unproblematisch sind die anderen. bel der Obernahme des griech. Inselnamens Imbros erst ins Slavische, dann ins Altniederdeutsche entstandenen lautlichen Verănderungen. Keines Kommentars bedarf so das schon griechische betazistische Schwanken von $b \leftrightarrow v$ in Imbros//Imvros. Slavische Praxis ist gewiB die Eliminierung des griech. Suffixes -os: Imbros $>$ Imbr-//Imvr-. Andererseits ist der Wandel $m b>m(m)$ durch Assimilation Fembre > Vemeren - Praglos niederdeutsch, ebenso wie die Vokalalternation $i / / e$ in $F / 1 / m b r e / / V / e / m e r e n$, da $i$ vor Nasal und Konsonant in e überzugehen pflegt (Schmitz 19). Im übrigen ,geht die heutige Form Fehmarn auf den nd. Wandel von er $>$ ar zurück" (ebda. 20). Auch braucht es nicht zu überraschen, wenn die 1 . Silbe von Imbros im Slavischen nicht nasaliert wurde, da Ausnahmen bekannt sind, die zeigen, daB $I$ (und $u$ ) vor Konsonant nicht immer Nasale ergeben (Shevelov 324 f.).

Es gibt verschiedene Parallelen $z$ wischen der agăischen Insel Imbros und der Ostseeinsel Fehmarn. die Preilich ein Zufall sein können und nur der "Kuriosităt" halber erwähnt werden. Da lst beispielsweise dle nahezu gleiche Größe beider Inseln: Imbros $=225 \mathrm{qkm}-$ Fehmarn $=185 \mathrm{qkm}$. Ahnlich sind sich beide auch in ihrer Lage vor dem Festland und darin. daB ihre Meeressunde 2 wischen Insel und Festland nicht über $90 \mathrm{~m}$ tiep sind. Bekannt ist sodann die Nitteilung Adams von Bremen, die uberliefert. daB Pehmarns Slaven noch Ende des 11. Jhds. von Piraterie und Răuberel lebten: Ambae igitur hae insulae pyrratis et cruentissimis latronibus plenae sunt. et qui nemini parcant ex transeuntibus. Omnes enim. quos alll vendere solent. Illi occidunt (Cáp. IV, 18) ${ }^{5}$. Daß Slaven Piraterie und Seerăuberei betrieben, ist nicht allein für Fehmarn bekannt, sondern aus erheblich früherer Zeit auch für das Agăische Meer. Nikephoros 1., Patriarch von Konstantinopel (806-815), hat einen einschlägigen Fall, der sich um 766/69 zutrug und unmittelbar Imbros berührt, ausdrücklich erwăhnt: Kwv-

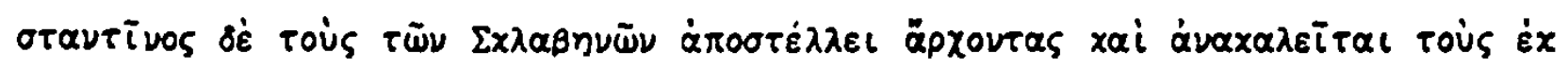

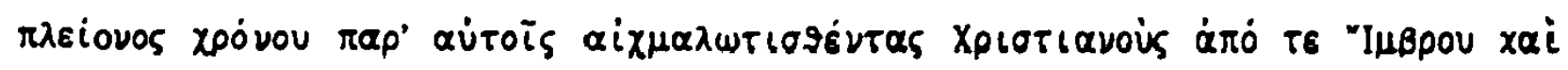

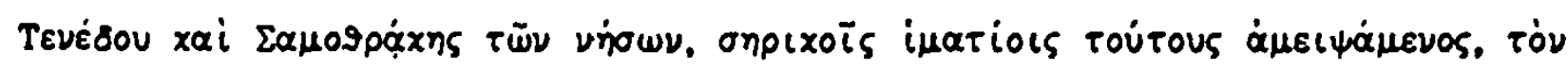

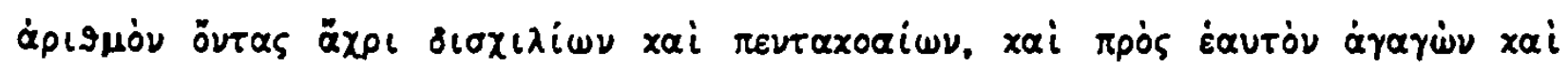

- "Diese beiden Inseln sind voller Raubschiffer und grausamer Seerăuber, die keinen Vorüberfahrenden schonen. Während andere sie gewöhnlich verkaufen, töten sie alle". - Daß Adam von 2 wei Inseln spricht, ergibt sich dadurch, daß er, wie oben gesagt. Fehmarn undrimbranargorscheredene Inseln hält. 


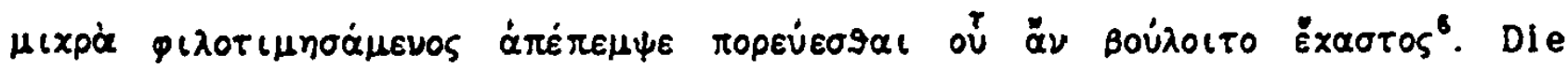
Schwierigkeiten, die Kaiser Konstantinos V. Kopronymos im geschilderten Fall hatte, wurden zumeist durch Slaven aus Makedonien und Thessalien verursacht, aus Gebleten also, aus denen wahrscheinlich die Wagrier gekommen waren, die Nachbarn oder sogar Ahnen von Fehmarns slavischer Bevölkerung.

- Nicephori, archiepiscopi Constantinopolitani, opuscula historica. Ed. C. de Boor. Lipsiae 1888. S. 76, 22-29. - ${ }_{n}(768 / 69$ n. Chr.) Konstantín entlăßt die Slawenhăuptlinge und ruft die seit längerer Zeit von innen gefangen gehaltenen Christen aus den Inseln Imbros. Tenedos und Samothrake zurück, nachdem er sie gegen seidene Stoffe eingetauscht hatte, ihre Zahl belief sich auf 2500. Er lieB sie zu sich bringen, machte ih-

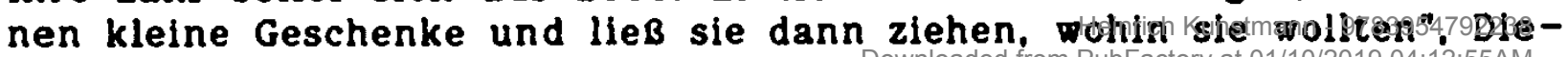
terich II. 86. 


\section{Wagrien in Holstein}

Der Landschaftsname Wagrien beruht auf der Stammesbezeichnung der slavischen Wagrier, deren Sitze in Ostholstein 2 wischen Trave und Schwentine lagen und im Westen bis an den Limes Saxoniae relchten, die von Karl d. Gr. veranlaßte Grenzzlehung zwischen den Siedlungsräumen der Sachsen und Slaven. Den Urkunden zufolge sind die wagrier ein vermutlich nicht sehr großer Tellstamm der Abodriten und zăhlen zur polabo-pomoranischen Sprachgruppe. Die erst ab der Mitte des 10 . Jhds. belegten Wagrier werden im 11. Jhd. Bestandtell des abodritischen dukats, der seinerseits im 12. Jhd. von deutschen Fürsten übernommen wird. Zentrum des somit nicht langlebigen wagrischen Stammes ${ }^{1}$ war Starigard, das heutige Oldenburg (Aldinburg) in Holstein, in dessen năchster Năhe sich Putlos (h. Gemeindetell von Oldenburg) befand. wo laut Helmold von Bosau bis zur Mitte des 12. Jhds. eines der slavischen Hauptheiligtümer war: Sein dem Gotzen Prove gewidmeter Hain wurde 1149 zerstört: Proves Name. der auf den in Sirmium geborenen römischen Kaiser M. Aureiius Probus zurückgeht. ist ein deutlicher Hinweis auf die Donau- oder Ost-Abodriten, in deren Spuren divus Probus wohl an die Ostsee gelangt ist ${ }^{2}$. Eine der slavischen Hauptburgen Wagriens war Scharstorf, h. ein Gut bel Plön ${ }^{2}$. Kurioserweise hat man die Wagrier auch dafür in Anspruch genommen, identisch zu sein mit den $\mathrm{Va}-$ răgern, den angeblichen Begründern des russischen Staates, und der Ostsee die (altrussische) Bezeichnung Varjazskoe more gegeben zu haben. Diese im 16. Jhd. Sigmund von Herberstein unterlaufene Verwechslung von Wagriern und Varägern ist selbst in der Gegenwart noch nicht völlig wirkungslos".

Es lassen sich folgende Notierungen des Stammes - und Landschafts namens anfuhren:

1 Zu seiner Geschichte vgl. insbesondere die Hamburger Diss. von M. Glaser (1983), die sich vornehmlich mit den sledlungsgeschichtlichen, wirtschaftlichen und sozialen Faktoren dieses slav. Kleinstammes auseinandersetzt.

Z Zur Deutung dieses Namens vgi. In meinem Buch .Die Anfănge der russischen Geschichte in neuer Sicht" ("1988) das Kapitel "Beobachtungen auf dem Gebiet der slavischen Mythologie".

3 Fürer zu vor- und fruhgeschichtlichen Denkmalern. Bd. 10: Hansestadt Lübeck-Ostholstein-Klel. Mainz 1972. $205 \mathrm{fP}$.

- Vgl. V. B. Vilinbachov: Ob odnom aspekte istoriografhl variazskoj3dproblemy. In: Skandinavskij sbornik 12. 1967 (Taddinn)om 393 ar. at 01/10/2019 04:12:55AM 
10. Jhd. Taaris (Widukind v. Corvej): Ant. 11. Jhd. Wari (Thietmar); Ende 11. Jhd. Aldinburg civitas...Sciavorum, qui Waigri dicuntur, per Waigros (Adam v. Bremen 74, 103); 1150 regioni Slaviae Waghere (Kop. 17. Jhd.); 1189 in partes Wagriae; Ende 12. Jhd. Wairis, Tagiri, Wagricae, per Wagirorum provinciam. Wagirensium provinciam. Wairensis provinciae, in Tagiram, in Tagira. in Wagirensi terra (Helmold v. Bosau); 1213 in Tagria (Orig.): 1418 to... Wageren; $1651 / 2$ von dem Wagerlande, das Land Wagern, Wager- oder new Holsten Lande. Wagren, Wageren'.

Schon 1929 vertrat Vasmer (Schriften II, 803 f.) die Ansicht, daB der Volksname Wagrl mit anord. Vägr 'Meeresbucht' zusammenhänge: Vasmer hat dlese Meinung 1934 und 1954 in zwei weiteren Beiträgen wiederholt und seine Argumentation verfeinert. Ganz åhnlich, doch noch entschiedener argumentlerte 1953 der österreichische Germanist W. Steinhauser, so daß es heute festzustehen scheint, daB es sich bel dem Namen Wagriens um eine wikingerzeitliche oder altgermanische Obernahme des Bewohnernamens - Wāgwarijoz, anord. 'Vágverjar 'Bewohner am Meer' (Laur 1960. 400; Schmitz 21: u.a.) handelt. Die latinisierten Formen Wagrica, Wagira. Wagria, Waigri vom Ende des 12. Jhds. sollen durch Ausfall des anlautenden von - warijoz entstanden sein. das im Deutschen mit dem entlehnten lat. Suffix -äri- (-arius) > -er zusammenfiel (Schmitz l.c.). Der slavische Stammesname bedeute demnach 'Bewohner am Meer, am Wasser: Meer- bzw. Buchtanwohner'.

Dagegen ist zunächst einzuwenden, daß die urnordlsche Zusammensetzung - Wăg- - warijōz nirgendwo belegt, sondern eben erschlossen ist. Bedenklich stimmt sodann das Manipulieren mit dem sumixalen Element - $\$ \boldsymbol{a -}$ rijozz, das erst eingeschoben und dann tellweise wieder reduziert wird. Solche Erklărungen sind im Grunde viel zu kompliziert, um wahrscheinlich zu sein. Skeptisch gegenüber der herrschenden Etymologie aber macht in erster Linie der Umstand, daß die Wagrier als Subethnikon der von der mittleren Donau zugewanderten Abodriten sehr wahrscheinlich ebenfalls vom Balkan stammten und genauso wenig wie diese einen Grund hatten, ihren mitgebrachten Namen zugunsten einer germanischen Bezeichnung zu ändern. Daß einer der östlich an Wagrier und Abodriten angrenzenden Slavenstämme, die Zirzipanen. mit Sicherheit aus Makedonien an die Ostsee gekommen waren (vgl. S. 51 ff.), bestărkt weiter darin, auch für die Wagrier balkanische Herkunft anzunehmen. 
Rund $120 \mathrm{~km}$ nördlich von Serrae, dem Zentrum der makedonischen Zirzipanen. hatte im Gebiet zwischen oberem Strymon (Struma) und Rhodopengebirge der thrakisch-paionische Stamm der Agrianer seine Siedelplătze. Offenbar geht auf sie der Name der holsteinischen Wagrier zurück. Der Name der Agrianer 1st verhältnismäBig gut belegt: erstmals nennt ihn He-

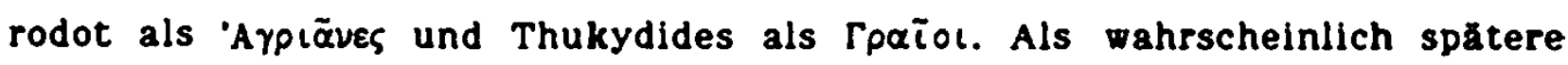

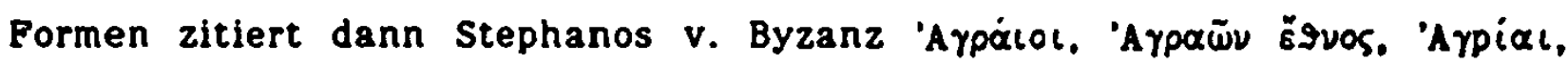

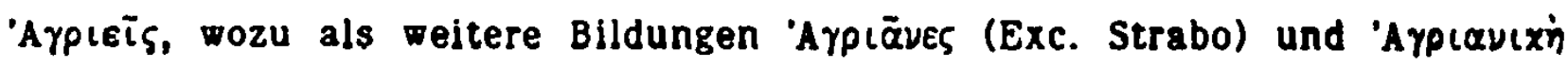
$\chi \dot{u} p \alpha$ (Hes. lex.) hinzukommen (Glossar B I. 263 f., 306). DaB die Obernahme von Agrial. Agraloi u.a. Ins Slavische Wagri u.a. ergeben konnte, ist kaum zu bezweifeln. AuBer der gegen vokalischen Anlaut wirksam gewordenen $v$-Prothese gibt es im Grunde kein weiteres Problem. Für prothetisches $v$ - vor od gibt es $z$ war nur wenige, regional begrenzte Beispiele wie ac. und slovak. vajce ' $\mathrm{Ej}$ ' (nc. vejce) (Shevelov $242 \mathrm{fr}$.), doch scheint $v$-Prothese insbesondere bel Balkanvolkern hăunger $z$ u sein, vgl. den serbokr. FIN Vojusa < Aũos. lat. Aous. Als prominente Belspiele selen überdies der poln. FIN Warta = Warthe und der gemeinslavische PN Vratislav erwăhnt. Sowohl das Hydronym Warta als auch Vratislav< Varti-slavı gehen auf das griech. Adjektiv opgós zurück, dem zu einer frühen Zeit, als die Slaven noch fremdes 0 als $a$ ubernahmen, prothetisches $v$ - vorgesetzt wurde. Die Richtigkeit dieser Beobachtung bestätigt der griech. PN 0p90$x \lambda \bar{n} s$. der, was man bisher nicht erkannte, der Prototyp fur die hybride slavische Lehnübersetzung - Vartislavs > Vratislav war (Kunstmann ${ }^{2} 1987$ ).

Wenn Slaven an der Ostsee unter dem leicht abgewandelten Namen der thrakischen Agrajol oder Agrianes auftraten, dann entspricht das wie Im Fall der paionischen Zirzipanen einer Herkunftsbezeichnung. Gewisse etymologische Aspekte des thrakischen Ethonyms können die Slaven Jedoch zusătzlich zur Obernahme motiviert haben. Das Grundwort Agri- - -anes ist ein typisches Suffix zur Ethnikabildung (Jacobsohn 1930, 82) - hăngt möglicherweise mit griech. 'aүpós 'Acker. Feld' zusammen (Mayer II. 3: Georgiev 1977. 72 l.: Duridanov 134), so daB sich unter Agrianes eben auch 'Feldbewohner' verstehen lassen. AuBerdem assozilert der Name griech. áy-

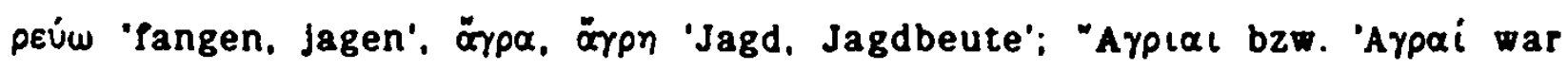
als bekanntes Jagdrevier Vorort von Athen (Grasberger 347) und Eviapia bezeichnete die 'glückliche Jagd, den glücklichen Fang (des Fisches)'. Die

- Zu erwăhnen ist in diesem Zusammenhang noch der Name des 'Axpráunc.

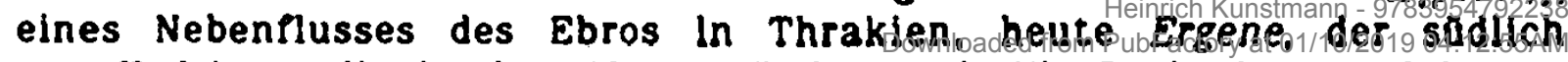
- von Hadrianopolis in den Ebros mündet, vgl. Kl. Pauly I. 143. schramm 
mit dem thrakisch-paionischen Stammesnamen verbundenen etymologischen Aspekte 'Ackerbauer' und 'Jäger' können für anonyme slavische Sledler im Quellgeblet des Strymon In der Tat Beweggründe gewesen sein. sich den Namen ihrer thrakischen Vorgänger anzueignen?

Slavengruppen haben sich am Strymon (Struma) schon früh niedergelassen, insbesondere am Unter- und Mittellauf dieses Flusses. Diese slavi-

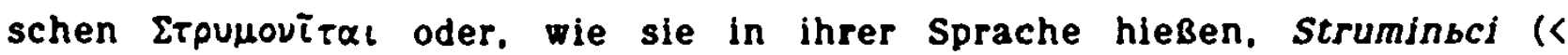
strumins + -bci) waren im 7 . Jhd. sehr aktiv an der versuchten Eroberung von Thessalonike beteiligt und machten uberhaupt, offenbar wegen ihrer militärischen Stärke. Byzanz sehr zu schaffen. Ende des 7. Jhds. und erneut um die Wende vom 8. zum 9. Jhd. wurden sie Byzanz unterworfen (Rajković 1958). Bis ins 9. Jhd. hinein betrieben sie im Agăischen Meer Plraterie (SlowStarSlow V, 441 P.: W. Swoboda), was nun sehr an die Schicksale der Bewohner von Imbros (S. 15f.) und die geographische Năhe 2 wischen Wagrien und Fehmarn denken läBt. Auch der Name des ostholsteinischen Baches Stramin, der aus dem Klostersee in die Ostsee mündet (Schmitz 412 p.), könnte Zusammenhänge mit der Strums, dem thrakischen

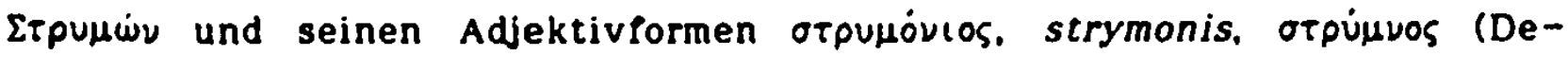
tschew $483 \mathrm{fP}$.) suggerieren. Sicherlich wird es gelingen, weitere onomastische Indizien für die balkanische Herkunft der wagrischen Slaven zu eruieren.

1981, 248, denkt an Angleichung des Hydronyms an den Namen des Volkes der Strymonquellen.

7 Zur Geschichte der Agrianer vgl. Pauly RE 1. Hbbd. 1893, 891: Kl. Pauly I. 143 P.: v. Barloewen 89 (3.4), 111 (7), 115 (6): Danov 1976, 105 f.: Papazoglu 1969, 79-81; Hammond, Griffith 1979jeinRegunsispiridonov923983. $96,104 \mathrm{l}$. 


\section{Ostholsteins Uklelsee}

Der verhältnismäßig kleine ostholsteinische Ukleisee, der im Uklei-Bach zwischen Massow und Naugaard in Pommern eine Namensparallele hat, liegt nördlich von Eutin und östlich des erheblich größeren Kellersees. Die Belege für diesen Seenamen sind nicht sehr zahlreich und setzen ziemlich spät eln:

1429 stagnorum...Pywerlink et Vkele ac YJensee; 1429 Vkele;

1440 Vkeleyne; 1856 Uklei-See'.

Die Deutung dieses Namens scheint nicht die geringsten Schwierigkeiten zu bereiten, da sich alle Etymologen darin elnig sind ${ }^{2}$, daB das Hydronym auf den urslavischen Fischnamen ukleja zurückgeht. der so ungerăhr in allen slavischen Sprachen vertreten ist: russ. ukleja, uklejka, ukr. uklija, bulg. okléj. skr. ùklija. c. úkleje, uklej. slovak. ukleja, poln. uklej. osorb. wukIJja. wuklica, nsorb. hukleja. huklej (Vasmer REW III. 179). Der Name dieses karpfenartigen Fisches mit der botanischen Bezeichnung Cyprinus alburnus ist durch slavische Vermittlung aber auch ins Deutsche entlehnt worden. und zwar als uk(e)iei. ukiel und ückelei ins Mnd.. Nnd und Ostniederdeutsche (Schmitz 416; Kluge 801); im Deutschen ist zwischen $k$ und $l$ mitunter der Sekundärvokal e entstanden. Als okle haben das Wort von den Slaven außerdem die Ungarn übernommen ${ }^{3}$. Die Karriere dieses slavischen Fischnamens ist somit erstaunlich.

Erstaunlich ist frellich auch, daß fast alle etymologischen Wörterbücher der slavischen Sprachen zur Herkunft dieses Fischnamens schweigen. Brückner (593) ebenso wie Skok (III. 540) oder Vasmer (III. 179) teilen zwar die Pakten mit, sagen aber nichts, was den Ursprung des Wortes erhellen kōnnte. Einzig Machek (668) macht deutlich, daß sowohl das slavische als auch das verwandte litauische Wort aukšlé unklar sind. Trotz der "unsicheren Vergleiche" (Vasmer l.c.) bei Loewenthal (TuS 8, 176; 11, 60) stellt sich somit heraus, daß die Etymologie dieses slavischen Fischnamens in Grunde offen ist.

1 Nach Laur 1967, 204; Schmitz 416 P.

2 Elne Ausnahme bildet M. Rudnickl: Nazwy rzeczne Gildnica, ukleja. Sapolnia i pokrewne. In: Onomastica 9, 1964, $193 \mathrm{fl}$. hier: $195 \mathrm{Mr}$. Rudnicki stellt die Sippe zu slav. $k s / s$ u.

3 MNYTESz III. 21 . Hier wird allerdings Entlehnunginausundem Dewtechen

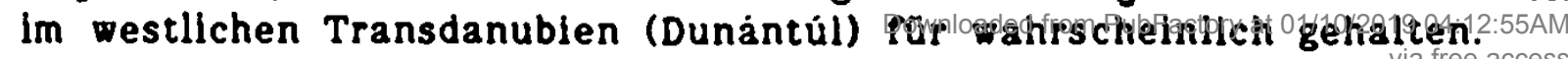


Urslavisches "ukleja geht ohne jede Frage auf griech. $\varepsilon u ̈ x \lambda \varepsilon i \alpha, \dot{\eta}$, att.

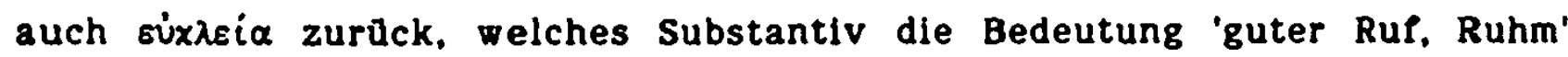
hat. Dazu gehören das Adj. $\varepsilon \dot{U}-x \lambda \varepsilon \dot{\eta} \zeta$ ( $x \lambda \dot{\varepsilon} \circ \varsigma$ ) und die adverbiale Form $\varepsilon \dot{u} \times \lambda \tilde{\varepsilon} \omega \varsigma$ 'rühmlich, ruhmvoll, berühmt'. Zum lautlichen Wandel bel der Obernahme Ins Slavische ist nichts weiter zu sagen, als daB anlautendes $\varepsilon v$ - regelgerecht $\mathrm{zu}$ slav. $u$-werden mußte, was mit der während des 6.-7. Jhds. erfolgten Monophtongierung der u-Diphtonge zu tun hat (Shevelov $272 \mathrm{lf}$. 633). Eine andere Frage ist die semantische Seite.

Wie konnte $\varepsilon u ̈ x \lambda \varepsilon\llcorner\alpha$ 'guter Ruf, Ruhm' $z$ u einem slavischen Fischnamen werden? Wahrend ihres Aufenthaltes auf dem Balkan haben die Slaven in dessen griechischen Landschaften gewiß Bekanntschaft gemacht mit den Traditionen des Artemis-Eukleia-Kultes, der überall dort gefeiert wurde. wo der Monatsname Eukleios gebräuchlich war, so etwa auf Korkyra, in Byzantion und Tauromenion, aber auch in Korinth und Delphi (Pauly RE 11. Hbd. 1907, 996 ff.: Nilsson 1955, I, 493 \&.. Anm. 11: Kl. Pauly I. 618 (f.). Eukleia als Epitheton der Artemis hat sich verselbständigt. Als Natur- und Fruchtbarkeitsgöttin war die Tochter von Zeus und Leto auch Herrin der Tiere (nórula inpüv). Von hier aus ergeben sich Bezüge zu den Fischen, denen, als Nachwirkungen fremder Kulte in altgriechischen Ländern, sogar Heiligkeit nachgesagt wurde (Nilsson II. 121 u.a.). Eine andere bemerkenswerte Erscheinung ist sodann die Verbindung der Artemis mit dem Wasser. mit Quellen, Sümpłen und wasserreichen Niederungen, so namentlich auf dem Peloponnes und in Arkadien. wo sie sich darin mit den ihr nahestehenden Großen Göttinnen und dem Gott des Wassers, Poseidon, berührt. Oft werden Quellen bei den Tempeln der Artemis erwähnt, sie wird aber auch mit Flüssen in Verbindung gebracht. "Ebenso charakteristisch ist es, daß Haine und Heiligtümer der Artemis oft in niedrigen und sumpfigen Geländen lagen, wo die Vegetation üppig war...Artemis heißt

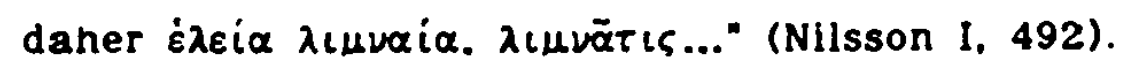

Interessanterweise ist der Name Uklei zweimal, In Ostholstein und in Pommern, ebenfalls mit dem Element Wasser verbunden. Die vorerst nicht zu beantwortende Frage ist, ob die Gewässer ihren Namen vom Fisch haben oder der Fisch von den Gewåssern. Wahrscheinlich ist letzteres der Fall. doch ist anzunehmen, $d a B$ sich hinter der eigenartigen Namengebung noch unerklărte Reminiszenzen des alten griechischen Artemis-Eukleia-Kultes verbergen. Auch ist daran zu denken, daß Ostholsteins Schwentine gewiB nicht zurälig 'heiliger Fluß' bedeutet und "es in Magrien mabsscheinlich 
neben helligen Hainen und Feldern auch Flüsse und Seen gab, die als Wohnstäten von Gottheiten angesehen wurden" (Schmitz 409). 


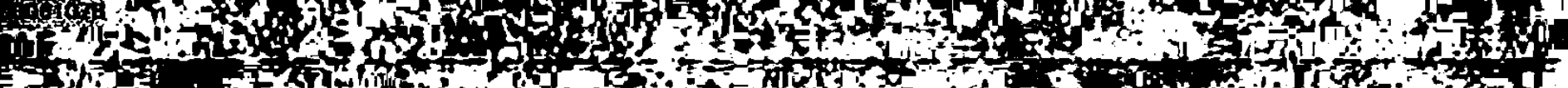
rof 16nd

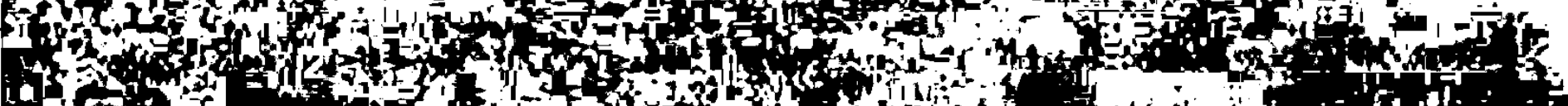

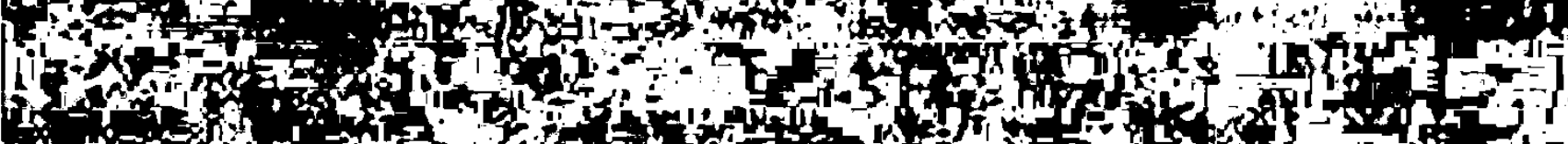
$\therefore$ on

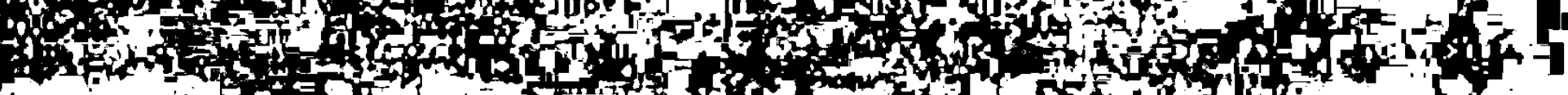

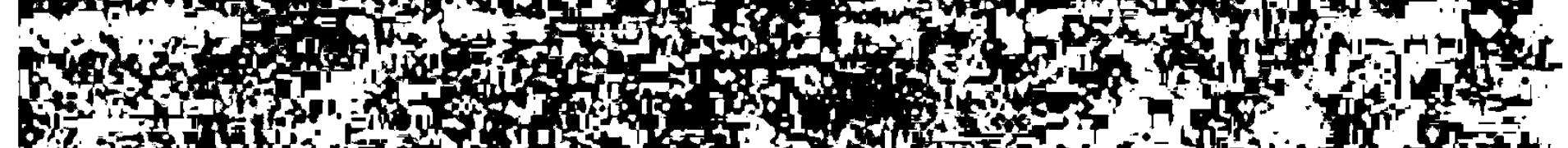

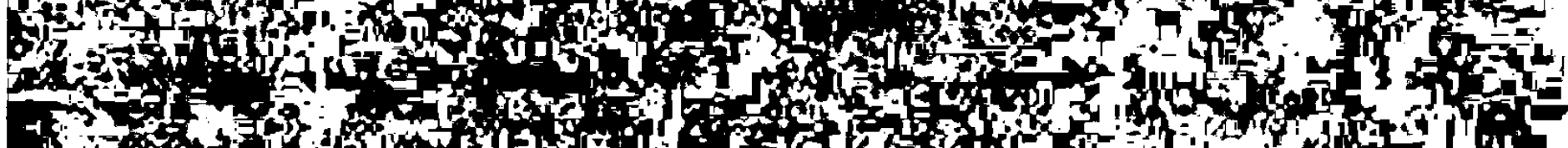

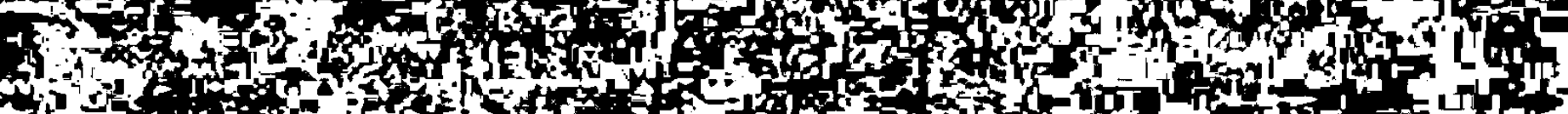

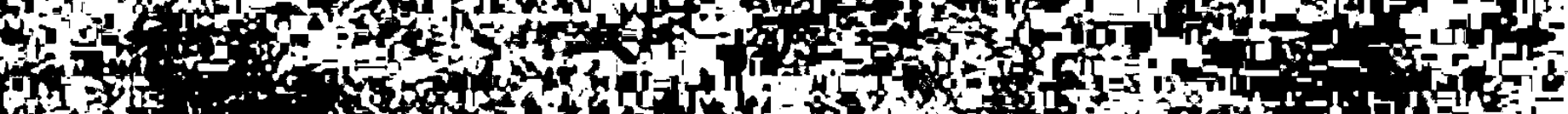

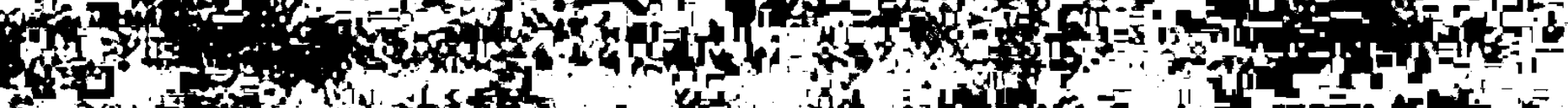

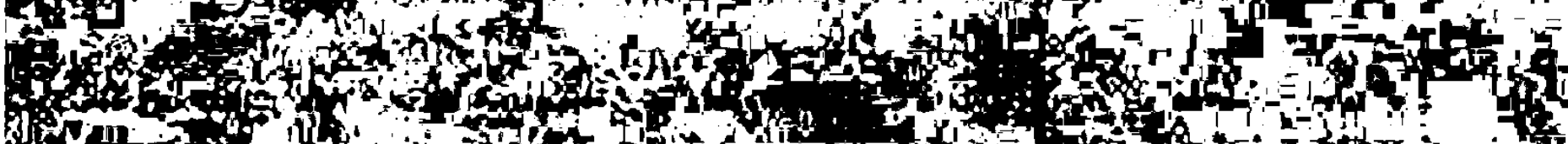

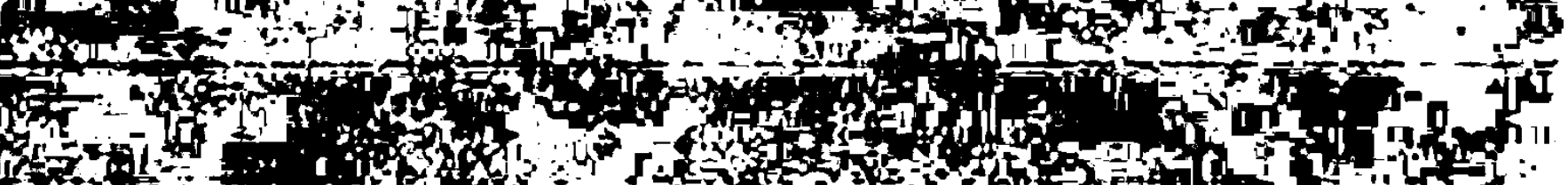

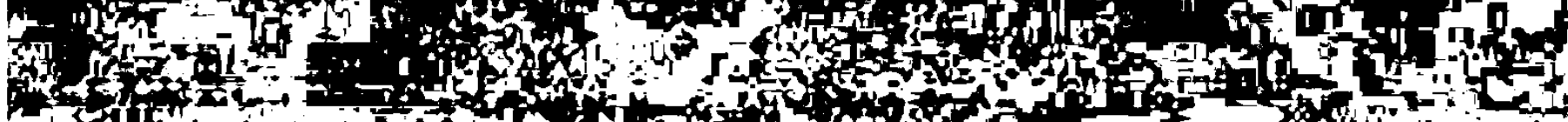
fold

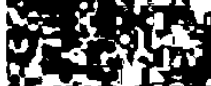
2.

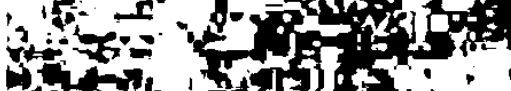
arte of s. 10 rintivitis

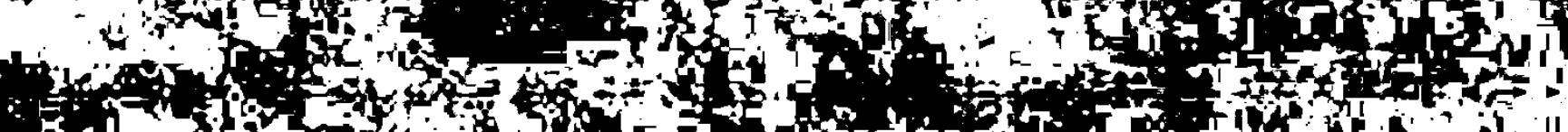

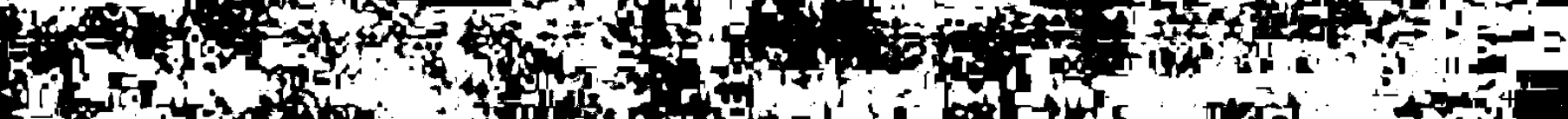

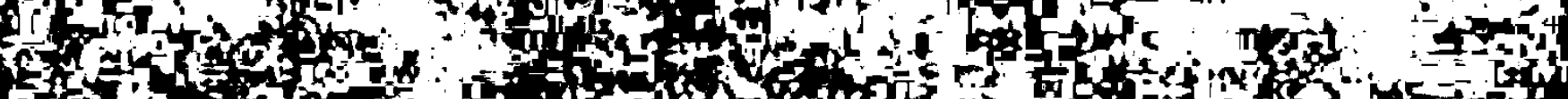

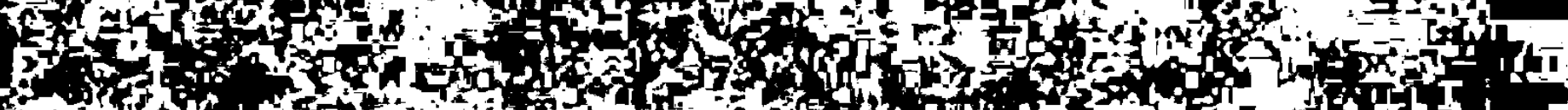
14 30 H

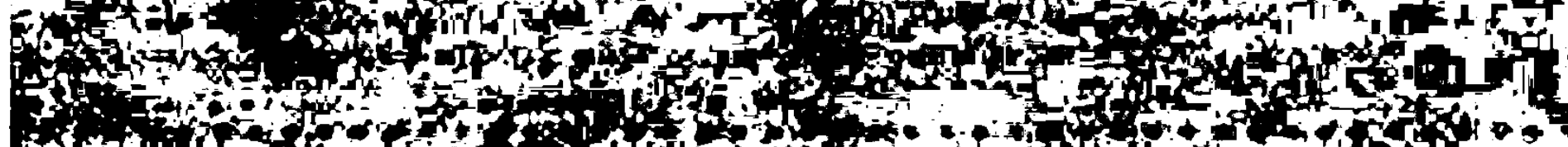

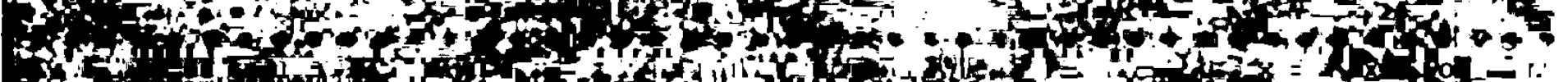
34 . Aox w

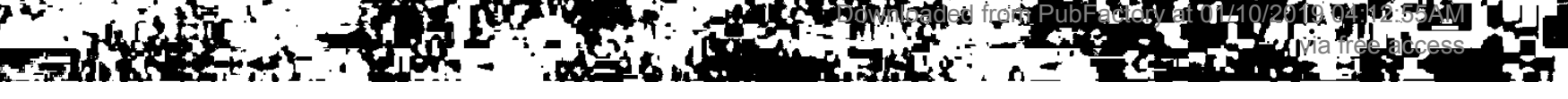




\section{Abodriti. Obodriti. Praedenecenti}

Um die Mitte des 9. Jhds. gehörte der nordwestslavische Stamm der Abodriten. der nach Ausweis des Geographus Bavarus nur 53 Burggemeinden zählte. gewiß noch $z$ den kleineren ethnischen Formationen. Den archăologischen Fakten zufolge ${ }^{1}$ soll er im 7., wenn nicht schon gegen Ende des 6. Jhds. in den Raum zwischen Limes Saxoniae im Westen, unterer Elbe im Süden und Warnow im Osten zugewandert sein. Das im wesentlichen aus Keramik bestehende Fundmaterial zirkelt Jedoch den abodritischen Siedlungsraum nicht exakt genug ab. so daß gegenüber anderen gentilen Elnheiten der Slaven nicht immer scharf differenziert werden kann. Festzustehen scheint, daB unter dem Oberbegriff Abodriti oder Obodriti mehrere slavische Formationen verstanden werden können, von denen die namengebende gens ihr Zentrum mit den Hauptburgen Mecklenburg und Schwerin um Wismar hatte (vgl. 49\%.), während östlich an sle die Warnower angrenzten. Nicht auszuschließen ist ferner. daB die Tagrier mit ihren Burgen in Lübeck und Oldenburg sowie die Polaben um Ratzeburg und die Linionen (Gliniane) an der Unterelbe zu den Abodriten zu zăhlen sind.

Die historischen Nachrichten über die Abodriten setzen mit Einhards Vita Caroli Magni und den Annales regni Francorum verhältnismäßig früh ein, genau gesagt 2 u 789. In welchem Jahr Karl der Große zusammen mit den Abodriten gegen die slavischen Wilzen zu Felde zog (Ernst 1976. 154 ff.). Wir wissen auch, daß sle in der Folge des Slavenaufstandes von

1 An neuerer archăologischer Literatur sowohl zur abodritischen als auch wagrischen Geschichte sei genannt: Geschichte Schleswig Holsteins. H. Jankuhn: Die Frühgeschichte. Neumünster 1957; K. W. Struve: Die slawischen Burgen in Wagrien. In: Offa 17/18, 1959-61, 57 fl.: R. Schindler: Die Datierungsgrundlagen der slawischen Keramik in Hamburg. In: Prähistorische Zeitschrift 37, 1959, 187 fl.: G. Kossack: Beiträge zur Ur- und Prühgeschichte Mecklenburgs. Ein Forschungsbericht. In: Offa 23, 1966, 7 \%.: K. W. Struve: Slawische Funde westlich des Limes Saxoniae. In: Offa 28, 1971, $161 \mathrm{fl}$. : V. Vogel: Slawische Funde in Wagrien. Neumünster 1972; K. W. Struve: Ziel und Ergebnisse von Untersuchungen auf drei slawischen Burgwallen in Ostholstein. In: Ausgrabungen in Deutschland. III. Mainz 1975, 98 ff.; 0 . Harck: Spätslawische Grabfunde in Norddeutschland. In: Offa 33, 1976, 132 ศf.; K. W. Struve: Die Ausgrabungen auf dem slawischen Burgwall von Oldenburg in Holstein in den Jahren 1973 bis 1975. In: Offa 32, 1975, 7 K.; $K$. $W$. Struve: Die Burgen in Schleswig-Holstein. Band 1: Die slawischen Burgen. Pläne. Neumünster 1981 (2 Teile). 
983 Hamburg zerstörten ${ }^{2}$ und ihre späteren Fursten Niklot und Pribislav zu Stammvätern des Herzogtums Mecklenburg wurden (Hamann 1962, 4 fl.). Obgleich insgesamt also die Nachrichten uber die Abodriten bis weit hinein in das Hoch - und Spätmittelalter reichlich flieBen und der Geschichte dieses slavischen Ethnikon eine breitgestreute wissenschaftliche Aufmerksamkeit zuteil geworden ist $\mathrm{t}^{3}$, blieben doch entscheidende Dinge im Dunkel, voran die Frage nach der Bedeutung des Namens der Abodriten und ihrer Herkunft.

Kurzgeschichte der Abodriten-Etymologie

Fast die gesamte Eilte der slavischen, insbesondere der polnischen Etymologen hat sich rund 150 Jahre darum bemüht, für den Namen der Abodriten eine plausible Erklärung zu finden. Die Hauptstationen dieses etymologischen Denkens, die letztlich den heutigen Forschungsstand erklären, seien hier skizzenhaft nachgezeichnet.

Begonnen hat der bunte Reigen von Etymologien mit Safarik, der den Namen der Abodriten kurzerhand und willkürlich in Bodrici umformte. was von ihm als Patronym zu einer Wurzel bedr bzw. bodr = vigil. strenuus verstanden wurde (Safařik 1837, I, 901 If.). Safaríks Umdeutung, die. nebenbei gesagt, dazu führte, daß sich im russischen Sprachgebrauch die unrichtige Form bodrici als Dublette zu obodrici einbürgerte und bis heute hält, hat erstaunlicherweise eine breite Anerkennung gefunden, obwohl ihr exakt auf das Jahr der oberfränkische Altertumsforscher und Keltologe Johann Kaspar $Z$ eu $B$ eine weitaus faszinierendere und in verschiedenen Varianten immer wieder diskutierte Etymologie entgegenstellte. Zeuß dachte nămlich an ein Kompositum ob-odriti, dessen zweiter Teil einen Hinweis auf den Flußnamen der Oder (poln. Odra) enthalte (Zeuß 1837, 654). Die

- Habbe 1906; Carsten 1948; Schindler 1959; Lotter 1977, 50 f.

- Es seien folgende neuere Arbeiten allgemeinen (a). topographischen (b) und historischen (c) Charakters genannt: a. Reallexikon der German. Altertumskunde. I. Berlin-New York 1973, 13 fl.: Archäologie (R. Grenz), Geschichte (K. Zernack): Lex. d. MA I, 47 f.: Archäologie (H. Hinz). Geschichte (W. H. Fritze); b. H. Skalová 1965; c. W. Fritze 1982, 111 lf.; H. Bulin 1958; SlowStarSlow I, 415 fl.: G. Labuda; ebda. III, 440 f.: ders.; Procházka, V., 1962; Lowmianski 1964-73, II, 69 lf.; Zernack 1967. 215 ff.; Lotter 1974; ders. 1977, 82 ff.; Petersohn 1979, 17 fl., 47 fl. u.a.; Bohm 1980; Salivon 1981: Herrmann J., 1985 (Rege) prich Kunstmann- 9783954792238 
Ansicht, die Abodriten stammten von der Oder, ist somit die Erfindung eines deutschen Gelehrten.

Die Oder-Version verallgemeinerte in der Folge Josef Perwolf dahingehend, $d a B$ er in $o b$ - die Präposition für 'Jenseits' und in -odr-icj< - odra + Suffix - ici die Bezeichnung für 'Wasser, Fluß' sah (Perwolf 1883. 595 f.). Für Perwolf ergab sich daraus die Bedeutung: 'die jenseits eines Gewässers SeBhaften'. Konkret an den Fluß Oder, also nicht an 'Wasser' im allgemeinen knüpfte dann wieder A. Brückner an (1900, 1, 207). Doch verwirft Brückner diese Ansicht später und bringt den Namen eigenartigerweise mit obdarti bzw. obterti in Verbindung (1924-5, 213 f.).

Mit dem tschechischen Altertumsforscher $L$. Niederle, der sich gegen die Oder-Lösung ausspricht, kommt erstmals die Ableitung von einem Personennamen ins Gespräch. Niederle dachte dabei an einen nirgends nachgewiesenen PN Obodro, dessen Nachkommen dann eben die Obodrici gewesen sein sollen (Niederle III. 124 If.). Vermutlich ging Niederles PN "Obodrb auf die "Erfindung" P. Kühneis (1982, 5) zurück, der schon 1902-3 mit Hilfe der Prothesis oder Präposition (?) o- 'sehr' und bŭdrũ 'wachsam, tapfer' unbekümmert die Pormen 'Obŭdrici. 'Obodrici. 'Bŭdrici. -Bodrici 'die Wachsamen' u.a. ins Leben rie?.

Vermutlich hat Perwolfs Ansicht noch ein halbes Jahrhundert später

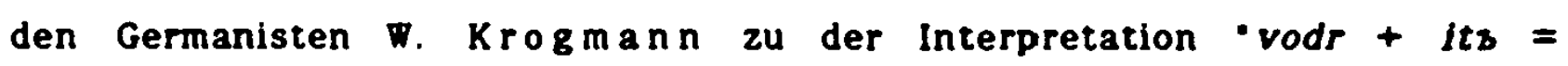
'Leute. die am Wasser wohnen' angeregt (Krogmann 1938). Krogmanns unhaltbare Deutung wurde unverzüglich von $M$. Vasmer zurückgewiesen, der sich selbst diesem Problem gegenuber auffallend reserviert zeigte und eine „Anknüpfung an den Namen der Oder (poln. Odra) (für) schwierig" hielt. Vasmer dachte eher an einen Personennamen, freilich ohne zu sagen, an weichen (Vasmer 1939).

ZeuBens Oder-Version erwles (und erweist!) sich als unausrottbar. auch wenn es in der Folge $z u$ gewissen Differenzierungen kommt. Eine gründlichere Oberlegung ist dabei T. Lehr-Splawlaskl zu verdanken. der deutlich machte, daß es ja verschiedene slavische Gewässer- und Ortsnamen gibt - etwa Odry, Odrov, Odr u.a. - die ebensogut wie die Odra in Betracht zu ziehen wären (Lehr-Splawinski 1947). Doch diese berechtigten Bedenken răumt daraue $H$. Schall aus, um unbefangen erneut an die Oder zu denken (Schall 1958, 272). Dieser Auffassung schliebt sich dann auch der Historiker H. Lowmiathski an. der sogar noch einen Schritt weiter geht und die Heimat der Abodriten micht/uamanunterbaras 23 der 
Oder, sondern in ihrem schlesischen Abschnitt sucht (Lowmianski 1964-73. II. 74).

Einen völlig neuen und durchaus originellen Aspekt brachte dann M. Rudnlckl In die Diskussion. Rudnicki, der sich gegen die OderTheorie ausspricht, meinte nun, das Element -it- in Abodrit-sel nicht Suffix, sondern Bestandteil einer Wurzel -drit, hinter welcher man die idg. Wurzel $\cdot d h r-e i-t_{0} \cdot d h r o i-t_{0} \cdot d h r-i-t=$ 'Sumpr u.a vermuten dürfe. Den ersten Tell, also "obo-, erklärte Rudnicki jedoch als Prăfix In der Bedeutung von 'beide, beider(seits, -seitig)'. Beide Telle des Namens zusammen erbrāchten dann den Ansatz -Abo-dhreit-o-s, woraus ein -Obo-dritz (dazu 1. Pers. Plural: Obo-drit-i) entstanden sel, und 2 war in der Bedeutung von 'Bewohner zu beiden Seiten eines Sumpfes, inmitten von Sümpfen lebend'. Das veranlaßte letztlich Lowmianski (II, 77), die ersten Abodriten "grob genommen" ( $z$ grubsza) mit den Bewohnern Schlesiens zu Identifizieren.

Mit Rudnickis Ansicht polemisierte später S. Urbanczyk. der zwar keine elgene Etymologie gibt, aber energisch bestreitet, daß das abschlieBende Element -it in Abodrit uberhaupt slavisch sei. DaB das Formans -itf bei slavischen stammesnamen sonst unbezeugt ist, hatte bereits Trautmann (1950, 111 P.) erkannt. Urbanczyk selbst glaubte vielmehr an fremde Herkunft des Namens (Urbanczyk 1966).

Abermals an die Oder und den als Variante dazu mehrfach belegten slavischen Flußnamen Obra. (der wahrscheinlich mehr mit den Awaren als mit den Abodriten zu tun hat). dachte der polnische Indogermanist $\mathrm{J}$ a n otrebski (1966), dessen Formel lautete: $o b$-odr-ici die jenseits der Oder Ansäßlgen'.

Die zeitlich wohl letzte Beurtellung des fraglichen Ethnonyms stammt von dem tschechischen Geographen O. Pllar. der die Nort- und Osterabtrezi des Geographus Bavarus als 'severni Bodrci'. 'Vodrci' oder auch 'v Odrcl' bezeichnet und damit berelts bekannte Deutungsversuche wiederholt (Pllaŕ 1974).

Laßßt man ausgefallene Erklärungen auBer Betracht, so ergibt sich in der Summe, daß zur Deutung des Abodriten-Namens heute im wesentlichen drei mehr oder weniger fundierte Interpretationen zur Verfögung stehen: 1. Ableitung vom Flußnamen der Oder (Odrs), 2. Herleitung aus obo-drits = 'beiderseits eines Sumpfes wohnend' sowle 3 . Blldung von einem nicht erwiesenen Personennamen (-Obodro?). Es zeigt sichricallendings 72 ach 22 daß 
In der bisherigen Geschichte der Abodriten-Etymologisierung zwei Motivationen federführend waren, nämlich die Assoziation von Wasser (Ostsee) und die von Herkunft aus dem Osten (Oder).

Was bedeutet der Abodriten-Name?

Die Schreibvarianaten des Abodriten-Namens sind, wie das Glossar (A I. 3 ff.) für die Zeit vor 900 belegt, zahlreich und vielfăltig. Im wesentlichen begegnen lolgende Versionen:

Abdriti - Abitrices - Abitriti - Abodritae - Abodrites - Abo-
driti - Abotri - Abotridae - Abotridi - Abotritae - Abotriti -
Abroditae - Abroditi - Abrothidi - Abrotidae - Abrotides -
Abrotidi - Habitriti - Nortabtrezi - Obodriti - Obotriti.

Die mit Abstand hăufigste Schreibvariante ist Abodriti. gefolgt von obodriti, die beide in Quellen auch nach 900 immer wieder verwendet werden. Frühe Notierungen wie in den Annales Fuidenses oder Bertiniani zeigen zudem. daß die Dubletten Abodrityobodriti in ein und demselben quellenwerk promiscue vertreten sein können. Andererseits läßt sich aber auch die konsequente Verwendung nur einer Form leststellen. so zum Beispiel in den Annales Einhardi (Abodriti) oder in den Annales Lundenses (Obodriti). Insgesamt verdichtet sich der Eindruck, daß - von ausgesprochenen Entgleisungen wie Habritl. Abitriti. Abroditi (umgestelltes - r-?) abgesehen - das Nebeneinander der Formen Abodriti/Obodriti stets dominierend war.

Oberraschend ist allerdings auch, daB für das 10. und selbst noch das 11. Jhd. Bildungen mit inlautendem - $p$ - statt - $b$-aufscheinen. Diese beachtenswerte Schreibwelse findet sich sowohl bel widuklnd von Corvey. bei welchem es zweimal Apodriti (51.5; 84, 10: dazu Variante appodriti) heißt, als auch bei Thietmar von Merseburg. der neben Abdriti und Abotriti auch Apodritse (I, 10) bzw. Apodriti (IV, 19) schreibt. Hierbel ist wohl an săchsische Reflexe zu denken.

Aus der Vielfalt divergierender Schreibweisen kristallisieren sich hinsichtlich der konsonantischen und vokallschen Usancen gewisse Besonderheiten heraus. Beim Konsonantismus Pallen diverse Schwankungen ins Auge. die sich mit Urbaticzyk auf die Formel $b / p, d / t$ und $t / c(=t s)$ bringen lassen. Im Blick auf den Vokalismus aber ist zu sagen, daß die Notierungen mit anlautendem a- schon immer und von vielen Forschern als die alteren gegenüber den o-Schreibungen beurteilt wurden. Urbahkezghan siekre54R223 er 
a-Version mögliche Symptome des slavischen o in einem fremden phonologischen System oder aber einen Reflex des noch nicht abgeschlossenen Obergangs von slav. $a>0$.

Es ist nun zu sagen, daß keine aller bisherigen Oberlegungen die wirkliche Bedeutung des Abodriten-Namens erbracht hat. Richtig vermutete zwar Urbaticzyk, daß das Ethnonym nicht von autochthonem slavischen Sprachmaterial gebildet ist, doch hat der Name, wie andere glaubten, weder mit der Oder (Odra) noch mit irgendwelchen Sümpien (obodritz) und schon gar nichts mit einem erfundenen Personennamen (Obodrb) zu tun. Das Wort stammt vielmehr aus dem Griechischen und ist die slavische wiedergabe von ăratpls, - isos.

Für besagtes Wort gibt es vorerst nur einen einzigen literarischen Beleg. den alle prominenten Lexika verzeichnen und der auf den byzantinischen Schriftsteller Ioannes Tzetzes, einen Gelehrten aus der Periode

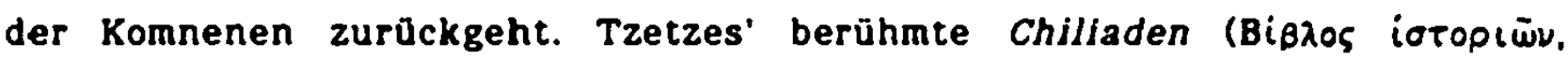
auch .Historien" genannt (Tuscul. Lex. 814 ff.), die einen Teil ihres kolossalen Wissens wahrscheinlich heute nicht mehr vorhandenen Lehrbüchern verdanken (Haussig 1966, 452), enthalten VII, 436." folgende Verszelle:

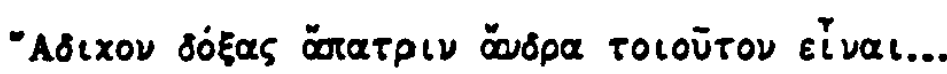

Es ist hier von einem gewissen Kleitomachos die Rede, der laut Tzetzes

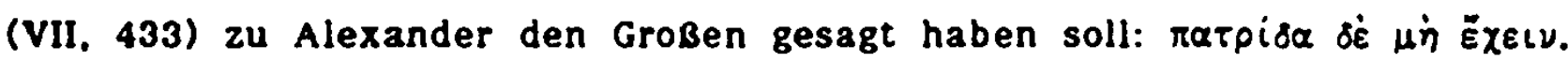
Kleitomachos, der wegen seines Nationalbewußtseins gerühmte Athlet, war Thebaner. Theben aber war von Alexander zerstört worden, was. Im Blick auf unsere Belange verdeutlicht. daB äratocs somit 'ohne Vaterland' be-

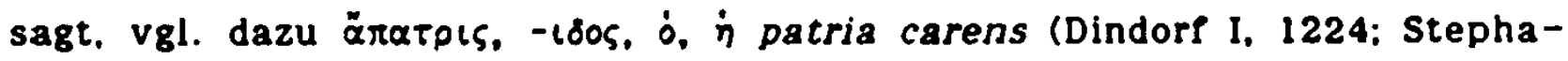
nus I. 1224): 'ohne Vaterland, dessen Vaterland unbekannt ist' (Pape I. 282): 'der kein Vaterland hat, dessen Vaterland unbekannt ist' (Passow $I$, 302): 'without country' (Liddell-Scott 1, 181). Damit unterscheidet sich äratpıs bedeutungsmäßig natürlich von dem häufiger belegten $\dot{\alpha} \pi \dot{\tau} \tau \omega \rho$ (z. B. Stephanus I, 1224), das, als Pendant zu $\dot{\alpha} \mu \dot{\eta} r \omega \rho$ carens matre gebildet, entweder carens patre oder spurius ('unehelich': auch ropvorevńs) (DuCange. Lat. I, 308) bedeutet. Mit äratpls inhaltlich eng zusammenhängt dagegen das offenbar ebenfalls nur einmal, dafür erheblich früher belegte substan-

- Ioannis Tzetzae Historiarum variarum Chillades. Hsg. Th. KieBling. Leipzig 1926 (ND: Hildesheim 1963). 256. - In der Edition ne. Napoll 1968. Pindet sich die betrefrended Steille asubat VII0/2 4288:12:55AM 
tiv áraroia, $\dot{\eta}$. das soviel wie exsilium (Stephanus 1, 1224) besagt ${ }^{2}$. Nach Ansicht von Prof. Dr. Winfried Bühler, dem Leiter des Thesaurus Linguae Graecae in Hamburg. kann aber auch äratpls bereits elne antlke Blldung sein. über deren Alter sich vorerst jedoch nichts sagen läBt.

Wahrscheinlich ist ärarpls von rarpis, isos, $\dot{\eta}$. geblldet, welches Wort sowohl 'vaterländisch' ( $\gamma \alpha i \alpha, \alpha i \alpha, a ̈ p o u p \alpha)$ als auch - substantiviert 'Vaterland' und - bei späteren Schriftstellern - 'Vaterstadt' bedeuten

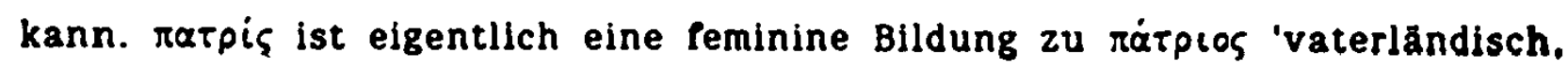
althergebracht, gebräuchlich' (Frisk II. 481 P. s.v. $\pi \alpha$ trip). Bemerkenswert

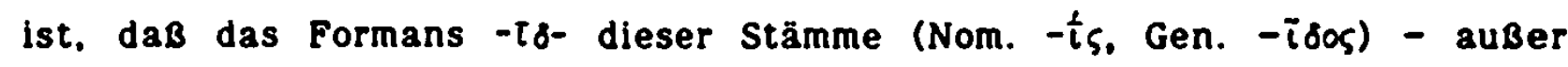
einer gewissen deminuierenden Wirkung ( $\chi \varepsilon\llcorner\rho i \delta-/ \chi \varepsilon\llcorner\rho-$ u.a.) - insbesondere die Zugehörigkeit bezeichnet (Schwyzer I, 465, 509 f.) und zur Bildung von

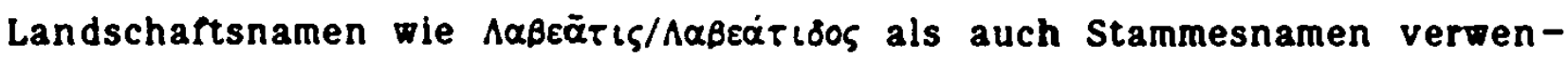

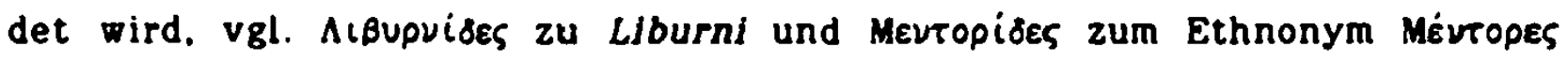

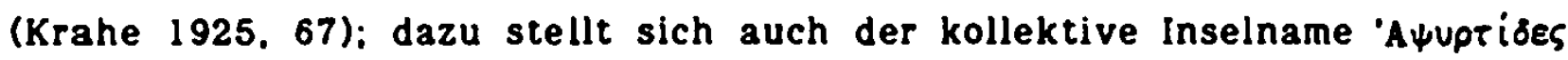
als Ableitung vom Namen der Hauptinsel "Aqupros (ebda.). Hinsichtllch des Abodritennamens ist dieser griechische Usus vielsagend. Daß bei der Bildung von ärarpls von ratpis auszugehen ist, legt auch Tzetzes' Kleitoma-

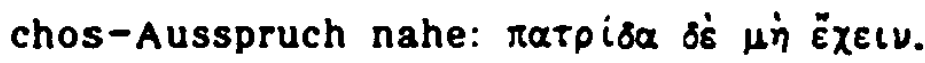

Anlautendes $\alpha$ - von äratpls ist sogenanntes Privativum, eine Nega-

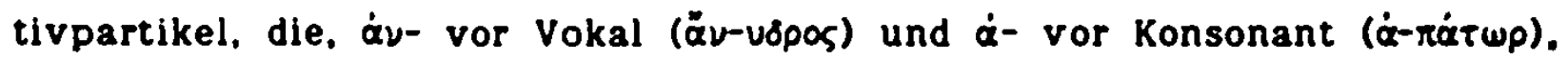
etwa lat. In-bzw. german. un-entspricht (Schwyzer 343) und dle Bedeu-

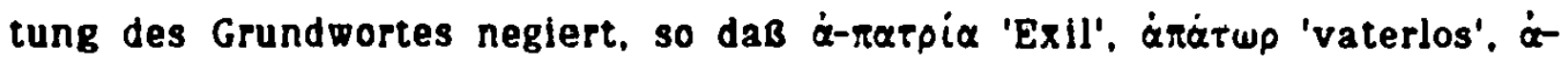

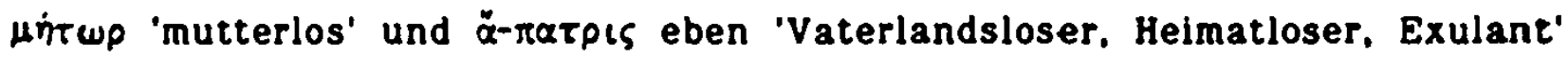
bedeuten.

ărarpls ist im gewissen Sinne und bei nicht zu verkennender seman-

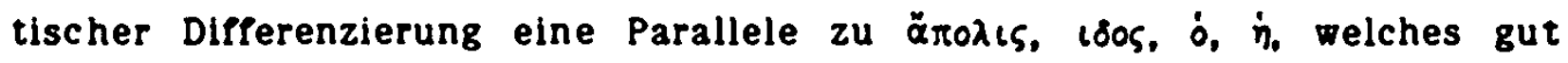
belegte Substantiv (Stephanus II. 1534) ebenfalls soviel wie 'ohne Vaterland (auch von Låndern), heimatlos, verbannt, vaterlandslos' u.a. ausdrückt (Pape 1, 312: Passow 1, 342: Gemoll 104). Der Begriff Qrodis ist noch heute als Apolide für den Staatenlosen in der deutschen Rechtssprache gebrảuchlich (Creifeld 1978, 68). Aber nicht nur årodis, sondern auch

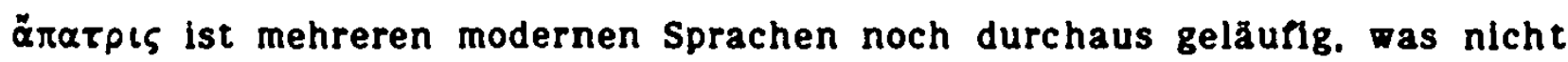

- Nach A. Boeckh: Corpus Inscriptionum Graecarum. Berlin 1828-77.

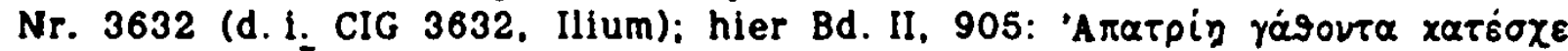

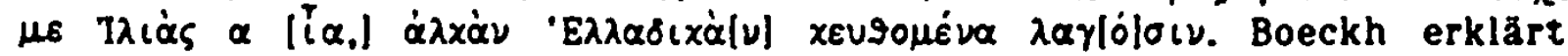

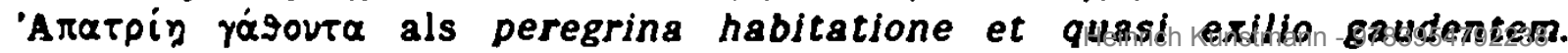
Dazu sagt er ferner: 'Aratpia vox inusitgodod trom PubFactory at 01/10/2019 04:12:55AM 
allein der deutsche Apatride", sondern auch franz. apatride zeigt, worunter das Franzosische personnes arrachées a leur pays versteht, die seit 1920 den Nansen-PaB erhalten?. Aksl. bezgradsniks z.B. bezeichnet Vaillant (IV. 307) als apatride, und 2 war im Gegensatz $2 u$ gradsniks 'citoyen'. Als apatryda kennt aber auch das Polnische diesen Begriff, das damit einen bezpanstwowiec oder eine osoba nie posiadajaca obywatelstwa zadnego passtwa bezeichnet.

Der Abodriten-Name ist somit eine ziemlich genaue Entsprechung des Nom. Plur. von ärarpls $=\dot{\alpha} \pi \dot{\alpha} \tau \rho \iota \delta \varepsilon$. Auch ist er ein ausgesprochenes Lehnwort, was im Blick auf die ansonsten im Slavischen vorherrschenden Herkunftsbezelchnungen eine gewisse Ausnahme darstellt. Die Obernahme des griechischen Wortes ins Slavische war mit verschiedenen Lautveränderungen verbunden, die noch einiger Erläuterungen bedürfen.

a. Vokallsmus: Bei der Obernahme von ărarpıs ins Slavische hat man es mit nur zwel Vokalen, mit $s$ und $i$ zu tun. Unberücksichtigt bleiben können die Endungen der obliquen casus, da diese in den tradierten Formen meist schon latinisiert sind. Anders als mit dem Vokal $i$, der in allen Varianten unangetastet bleibt, verhält es sich mit der zweimaligen Vertretung des a-Lautes, dessen Quantität im griechischen Original beidemal kurz ist: ärärpıs. Kurzes $ð$ wird im Slavischen bekanntlich auch in Lehnwörtern zu o: Eatavās > sotona, păgānus > poganz. Zwar setzt der Wandel von $a>0$ bereits im 9. Jhd. ein, doch wird er erst im 11.-12. Jhd. abgeschlossen. In den trühesten, aus dem 9. Jhd. stammenden Belegen des Abodriten-Namens ist er Im Inlaut schon vollzogen: $A b / O / d r i t i$.

Anders verhalten sich die Dinge beim anlautenden a-. Hier stehen sich von Anfang an und ohne erkennbaren Grund Abodriti und Obodriti gleichrangig gegenüber. Anlautendes a-bleibt in diesem Fall also länger erhalten. Möglicherweise bietet sich folgende Erklärung an: alpha privativa sind, außer in Fälen "metrischer Dehnung". prinzipiell kurz". Das alpha

- Vgl. Meyers Enzyklopädisches Lexikon. Mannheim 1971: "(gr.) selten für Vaterlandsloser, Staatenloser"; Duden. Das Fremdwörterbuch. Mannheim, Wien. Zürich ${ }^{3} 1974,70$.

- Vgl. O. Bloch. W. v. Wartburg: Dictionnaire étymologique de la langue rançaise. Paris ${ }^{3} 1960,29 ;$ A. Dauzat, J. Dubois, H. Mitterand: Nouveau dictionnaire étymologique et historique. Paris 1964, 543.

- Slownik wyrazów obcych. Tarszawa 1955, 46.

- Zu diesen schwierigen sprachwissenschaftlichen Problemen im übrigen

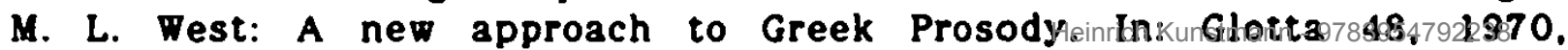
$185 \mathrm{ff}$. 
privativum von ărăpls lleße sich viellelcht als halblang beurtellen, da. wie Schwyzer sagt, „ein Vokal als Träger des Wortakzentes etwas lănger ist als In nichthauptakzentiger Silbe" (S. 392). Langes $a$ aber ergibt In der Regel im Slavischen a. Die unter Akzent andersartige Quantităt könnte daher beim Wandel von anlautendem $s>0$ vielleicht eine retardierende Rolle gespielt haben. Natürlich sind hierbei aber auch spätere Lautprozesse zu berücksichtigen.

Wenn Urbaticzyk hinter der Anlautsalternation $8-10-$ Schwankungen vermutet, die sich mit unterschiedlichen phonologischen Systemen erklären. so mag das im Prinzip richtig sein. nur sind hier mehrere phonologische Systeme in Betracht $2 \mathrm{u}$ ziehen. sowohl das griechische als auch das slavische und deutsche, wahrscheinlich überdies dialektale.

b. Konsonantismus: Die Inkonsequenzen in der Schreibweise der Vokale und Konsonanten drücken sichtbar die Unsicherheit der lateinischen Chronisten. Annalisten und scribae gegenüber dem völlig unverständlichen Wort Abodriti/Obodriti aus, dessen ursprüngliche Bedeutung in 9. Jhd. und später wohl selbst den Slaven nicht mehr bekannt war. So gesehen kann es nicht überraschen. wenn dieses Wort in ein und derselben Quelle unterschiedlich wiedergegeben wird.

Bei der Beurteilung der konsonantischen Veränderungen gibt es insgesamt keine großen Hindernisse. Als problemlos erweisen sich die promiscue gebrauchten Formen $A b o / t / r i t i$ und $A b o / d / r i t i$. wenn man bedenkt, daB gemeinalthochdeutsches $t$ im grammatischen Wechsel mit $d$ steht (Braune. Eggers 8 102. S. 100), so daB die ständigen Alternationen auch als deutsche "Unsicherheiten" gelten können. Unkompliziert ist ferner der Wandel

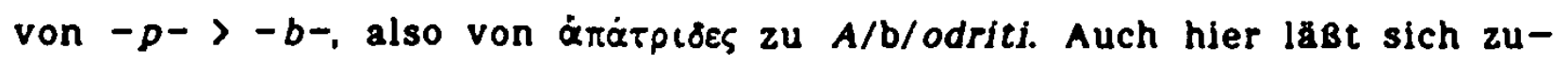
nächst allgemein an die Im Spatalthochdeutschen gegebene Tendenz zur Konsonantenschwächung (Lenierung) denken, so wie auch im späteren Oderdeutschen dle unverschobene Fortis $p$ der Lehnwörter im allgemeinen durch die Lenis $b$ wiedergegeben wird (ebda. 8 133. S. 123 f.). Im Fall von ¿rásploss > A/b/odriti ist jedoch daran zu erinnern, daB gerade fremdes $p$ und hier besonders griechisches $P i$ im Slavischen nicht selten als $b$

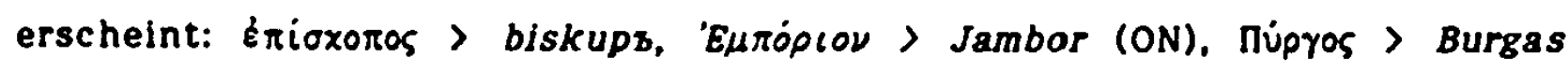
(ON). $\Delta(\iota) \alpha \mu \pi 0 \lambda(s)$ Jambol. Auch der Kaschuben-Name gehört vielleicht hierher (S. 79 ff.). Wie unsicher und schwankend der Gebrauch von $p$ bzw. $b$ war. machen im ubrigen die noch Im 10. und 11. Jhd. anzutreffenden Formen Apodritae u.a. bel Widukind und Thietmar deutllchnstmann-9783954792238 
Zusammenfassend lät sich sagen, daß die lautlichen Verănderungen von $\dot{\alpha} \pi \dot{\alpha} \tau p l \delta e s>$ Abodriti teils auf slavischen, tells auf deutschen Vorgängen beruhen. Schwerwiegende Einwände oder gar unüberwindliche Hindernisse phonetischer Art gibt es gegenüber dieser Etymologie nicht, im Gegentell, es überrascht im Grunde, wie vorzüglich sich der griechische Prototyp trotz mehrfacher Transformationen - griech. > slav. > deutsch + Latinisierung der Endung - konserviert hat. Im Blick auf den abodritischen Sledelplatz Wismar ( $($ lopapos) und die innerhalb der Abodriten-Dynastie offenbar lange Tradition griechischer Eigennamen (S. 46 f.), aber auch auf die in Nord- und Mitteldeutschland ja nicht seltenen slavischen Ethnound Toponyme griechischer Provenienz (Thalnezl. Prissani. Fehmarn. Zirzipanen. Stettin usf.) kann mit Sicherheit davon ausgegangen werden. daB der Name der Abodriten im Umkreis des byzantinischen Reiches aufgekommen ist $^{10}$. Es ist kein Name, der, wie sonst ublich, die Herkunft von Slaven ausdrückt. sondern ein Lehnwort. das an die Abwanderung einer wohl kleineren slavischen Gruppe denken läßt, die sich als 'heimatlos' bezeichnete.

\section{Die Donsu-Abodriten oder Praedenecenti}

DaB es sich bei den árárpıses = Abodritl um einen gelehrten Graezismus à la Leucopolis (TelBenburg I. E.) oder Parthenopolis (Magdeburg) handeit. scheidet aus mehreren Gründen aus. Das ergeben auch die folgenden Ausrahrungen.

Die Annales regni Francorum. die sogenannten Fränkischen Reichsannalen, berichten zum 25. Dezember 824 uber einen Stamm der Abodriten, der unmöglich identisch sein kann mit jenem an der Ostsee sledelnden. Der Chronik zufolge erschienen an eben diesem Tag die Abgesandten der Abo-

10 Diese 2 wingende Folgerung wurde von T. Witkowski (1983) ins "Reich der Phantasie" verwiesen, weil ihm eine Erklärung des Abodriten-Namens aus dem Griechischen ${ }_{\text {fur }}$...siedlungshistorische Schlüsse volllig abwegig und ungeeignet" schien (so ders. in: Herrmann, J., 1985, 496 f.). Dabei wird von ihm die Richtigkeit der obigen phonetisch-etymologischen oberlegungen nicht nur nicht bestritten, sondern im Gegenteil vollends bestätigt. Seine Warnung an alle Historiker, Archäologen und Vertreter anderer nicht philologischer Disziplinen, diese Erklärung aus dem Griechischen ernst zu nehmen und daraus vielleicht siedlungsgeschichtliche

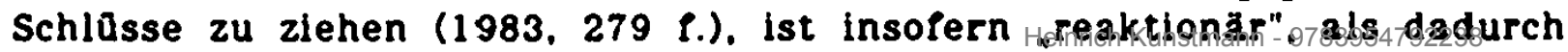
der progressus in studis behindert wifdnloaded from PubFactory at 01/10/2019 04:12:55AM 
driten am Aachener Hof Kaiser Ludwigs des Frommen, beschwerten sich uber die Bulgaren und baten den Kaiser um Millĭărhilfe:

Caeterum legatos Abodritorum, qui vulgo Praedenecenti vocantur et contermini Bulgaris Daciam Danubio adiacentem incolunt, qui et ipsi adventare nuntiabantur (165 l.).

Daraus ergibt sich, daß ein Stamm von Abodriten, vulgo auch PraedenecentI genannt. seine Wohngeblete in nächster Năhe der Bulgaren, in Dazien und an der Donau hatte. Diese Angaben erlauben eine verhältnismäßig genaue Lokalisierung der Abodriten-Wohnsitze. Der Atlas zur bulgarischen Geschichte (Atlas po brlg. istor., 10) zum Beispiel setzt diese nördlich von Belgrad an.

Die Praedenecenti werden in den Frănkischen Reichsannalen schon vordem einmal erwähnt, und zwar fur den November 822. als Ihre Gesandten in Frankfurt vor Ludwig dem Frommen erschienen:

In quo conventu omnium orientalium Sclavorum, id est Abodritorum. Soraborum. Wilzorum. Beheimorum, Marvanorum. Praedenecentorum. et in Pannonia residentium Abarum legationes cum muneribus ad se directas audivit (159).

Aufschlußreich an dieser Aufzählung slavischer Stämme ist die geographische Reihenfolge, die offenbar von Norden nach Süden verläuft. Dieser Anordnung läßt sich entnehmen, daß unter den Abodriti hler die ostseeslavische gens verstanden wird, während die Praedenecenti mit dem Im balkanischen Dazien siedelnden Stamm gleichzusetzen sind ${ }^{\prime \prime}$.

Die Uberwiegende Mehrzahl der Gelehrten 1st heute der Meinung. daß die sogenannten Donsu-Abodriten und die Praedenecenti ein und derselbe Stamm waren, worüber zuletzt ausführlich H. Bulín (1960; 1968) gehandelt hat. Die uberwiegende Mehrzahl der Gelehrten ist aber auch der Meinung. daß eben diese Donau-Abodriten identisch sind mit den Osterabtrezi des Geographus Bavarus, die von diesem außerdem genannten Nortabtrezi aber den Abodriten-Stamm an der Ostsee meinen.

Daß das Abodriten-Ethnonym in den Annales regni Francorum in Form von Abodriti und Praedenecenti, beim Geographus Bavarus dagegen als Nortabtrezi und Osterabtrezi ${ }^{12}$ aufscheint, hat verschiedene Erklărungen gefunden. Wăhrend A. Brückner die Osterabtrezi für elne willkürliche Vari-

11 Irreführend ist die Angabe der Quellen zur karolingischen Reichsgeschichte I (Darmstadt 1977), wo im Register S. 479 die Praedenecenti als "elbslawischer Stamm" bezeichnet werden.

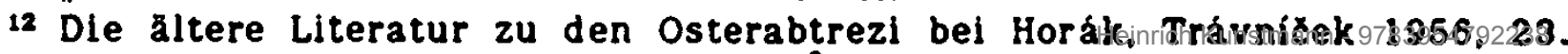

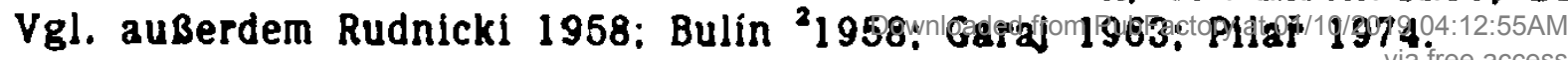


ante zu den Nortabtrezi hielt (1919, 36), dachte der tschechische Historiker H. Bulín (1960) an eine, von inm nicht năher begründete Obertragung des Namens der Ostsee-Abodriten auf den Balkan-Stamm durch den frănkischen Reichsannalisten ${ }^{13}$. Man hat den Namen der Donau-Abodriten etymologisch aber auch mit dem Bodrog (Bodrok), einem rechten NebennuB der Theis im ungarischen Komitat Bács-Bodrog in Verbindung gebracht (so schon Safařik 610). vgl. dazu auch Budrug nuvius (Glossar A II, 188). In diesem Zusammenhang wird aber auch wieder die alte Oder-Theorie transparent, wenn man bel den Donau-Abodriten etymologisch ebenfalls die kroatische Odra (Odagra), einen rechten Zufluß der Kulpa (Kupa) in Erwagung zleht (SiowStarSlow III. 441 f.: W. Swoboda).

In Jedem Pall ist wincenty Swoboda beizupnichten, der meinte, „der Schlússel zur Lōsung dieses Problems sel die Etymologie des Namens der Donau-Abodriten" (ebda.). Es sind nun allerdings zwei Etymologien in Betracht zu ztehen, die von Abodriti und Praedenecenti.

Noch zu sagen ist, daB dle Sitze der Praedenecenti von der Wissenschant beim alten serbischen Branicevo, dem ehemaligen VIminacium. also an der Mündung der Mlava in die Donau vermutet werden ${ }^{14}$. Elner der ersten. die dle Praedenecenti mit den Branicevci (< Branicevo) in Verbindung brachten, war Joseph Marquart (1903, 139 భ.), der sich dabei von Mas'ūdis Branitābin leiten LeB $^{13}$. Die Ansicht, daß es zwischen Praedenecenti und Branikevci einen - auch etymologischen - Zusammenhang gebe, hat sich in der Folge insbesondere durch L. Niederle weiter verbreitet und bis zum Erscheinen der einschlägigen Arbeit von H. Bulin (1960) gehalten. Bulín selbst verwarf die These. daB Praedenecenti und Branicevci identisch seien. und versuchte seinerseits, die Praedenecenti mit den Danubianern savoúblol - des sog. Pseudo-Kaisarios aus Nazlanz (Dialog 110) in Verbindung zu bringen. Bulín schwebte dabel eine Kombination von Dunaj + slav. Präposition pred- vor, woraus sich nach seiner Ansicht eine Bildung wie Preddunajevci oder cech. Preddungici ergeben hătte. Danach sel an Bewohner "vor dem Fluß, vor der Donau" zu denken.

12 Die von Bulín (1960) vorgenommene Unterscheidung 2 wischen Obodriti = Ostseeslaven und Abodriti = Donauslaven ist vollig unhaltbar.

14 Vgl. Enciklopedija Jugoslavije II, Zagreb 1956, 176 \&.: M. J. Dinić.

10 Vor Marquart haben schon die Herausgeber der Annales regni Francorum, G. H. Pertz und F. Kurze, auf de Verbindung zwischen Praedenecenti

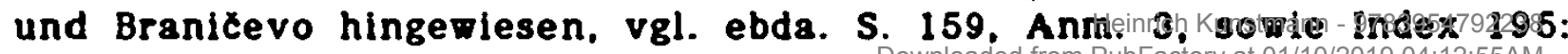
Praedenecenti Sclavi (incolse pagi Branitschewo). PubFactory at 01/10/2019 04:12:55AM 
Bulín erwăhnt eine Reihe von alteren Deutungen (1960, 24 ९.), unter welchen lediglich die Fortunát Durychs besticht, der nămlich in Praedenecenti die slavischen Wörter Prednie cety (pluky) zu erkennen glaubte und damit der wirklichen Etymologie verblüfend nahe war (Safarík 612. Anm. 41). auch wenn das Wort cety (ceta) hier weniger in Betracht kommt. An Prednécovci, Prednécenici oder auch eine korrumpierte Form für Pribinovci. also das Volk Pribinas, dachte wiederum der tschechische Rechtsgelehrte V. Vanécek (1949, 51 ९.), der damit die Sitze der Praedenecenti in der Gegend von Nitra in der Slovakei ansiedelte.

In den Frănkischen Reichsannalen (824 XII 25) werden die Praedenecentj mit dem adverbialen Zusatz vulgo versehen. welche Angabe in aller Regel ein hinweis auf ein landessprachliches, das heiBt nicht-lateinisches Wort ist. Im gegebenen Kontext bedeutet vulgo soviel wie slavice. 'slavisch'. so daß davon ausgegangen werden kann. Praedenecenti als ein siavisches Wort zu verstehen. Demnach ist sein erster Teil gewiB nichts anderes als das Adjektiv predbnb bzw. prédbnz. eine Blldung also von der Präposition prédb (< urslav. 'perdb) + Suffix -bn’b (Wojtyla-Swierzowska 1974. 127 ff.). Die Bedeutung dieses Adjektivs gibt Miklosich (Lex. 728) mit $\dot{0} \pi \dot{0}$, anterior an, was dem grundlegenden temporalen und lokalen Sinn von pred- = ante 'vor' entspricht (ESSJ I, 170 \%.). Für das Altkirchenslavische werden noch folgende Bedeutungen mitgeteilt: 1 . primus, prior, 2. 'früher, vorig', prior, 3. 'der Erste. Vordere, Bedeutsamste': magnus, princeps (SJS III, 434). Zum besseren Vergleich sei auch das altrussische predbnii, predbnii angezogen. wofür u.a. die Bedeutungen predydusci (praeteritus), starejsij, starsij genannt werden (Sreznevskij II. 1642 1.). Die altrussischen predbnii können aber auch die predki, oi rarépes. patres bezeichnen. Damit ist es so gut wie sicher, daB der erste Teil von Praedene-centi die Bedeutung von die Alteren. Ersten. Früheren. Vorderen. Vorherigen. im ubertragenen Sinn vielleicht auch die Bedeutendsten haben kann.

Was aber besagt der 2 weite Teil von Praedene-centi? Durychs Vermutung - cety cohortes - kann nicht gut zutreffen, da die lat. Schreibweise der Annalen auf elnen slavischen Nasal. nämlich helles - $\varepsilon-$ schließen läßt. Da lat. $c(t s)$ die Vertretung für slav. $c$ sein kann, kommt für den 2. Teil von Praedene-centi mit großer Wahrscheinlichkeit nur das feminine Substantiv çdb (Nom. Sg.) bzw. dessen Nom. Pl. çdi in Betracht. Das Kollektivum $\varepsilon_{\varepsilon d b}$. das angeblich nur im süd- und Ostslavischen vorkommt be- 
deutet äugponol homines (Mlk!., Lex. 1130), Leute, Gefolgschaft (družina), Kriegsschar, Volk. Kinder". Die von den Frănkischen Reichsannalen zwelmal gebrauchte Form Praedenecenti. die aksl. prêdbnejs ç̨li (Nom. Pl.) entsprechen würde, bezeichnet demnach die alten, trüheren Gefolgschaften, die alteren Volks(gruppen).

Ohne weiter darauf einzugehen oder Schlüsse daraus zu ziehen, ist schon M. Rudnickl (1959, 253) zu dem fast gleichlautenden Ansatz gelangt: Predenecenti (sic!) (=-Predbnije-ç一dy?). Eine andere Interpretation des fraglichen Wortes liegt den Oberlegungen V. Georgievs $(1986,14)$ zugrunde. der zwar ebenfalls von prédonja çedb bzw. Pl. prédsnje cfdl ausgeht, die Stelle aber anders deutet. nămlich als .Abodriten, dle für gewöhnlich (obiknoveno) prědbnja (-ě) cędb (prednata = znatnata celjad) genannt wurden". Allerdings wird dabei lat. vulgo unrichtig beurteilt, da dieses Adverb, wie schon gesagt. eindeutig auf ein landessprachliches, nicht-lateinisches Wort verweist. Fraglich ist es auBerdem, ob man dem Adjektiv predbnij hler den Sinn von ,angesehen“ beimessen kann. Dieses "elitåre" Epitheton (oi roũ $\pi \alpha \lambda \alpha \tau i o v$, Mikl.. Lex. 728) mag auf die von Georgiev angezogene altrussische Stelle vom Erzbischof von Novgorod zutreffen, nicht aber auf ein ganzes Ethnikon.

Gegen die hier vertretene Deutung von Praedenecenti wendet Witkowski (1983, 277 P.) ein, daB dafur - Predinenjencendi zu erwarten sel, also deutliche Reflexe der slavischen Nasalvokale und $d$ statt $t$ Dafor. daB lateinische Schreiber die slavischen Nasale nicht immer im Sinne der Slavisten transliterierten, gibt es soviele Beispiele, daß es sich erübrigt. diese hier zu zitleren. Und wenn statt des slav. $d\left(c_{q} / d / i\right)$ ein $t$ erscheint, so Ist dies das Resultat der oberdeutschen Tenuesverschiebung, was bei einem rrånkischen Annalisten durchaus zu erwarten ist. Daß die slavische Deutung von Praedenecenti auch von witkowski nicht restlos verworfen wird. zeigt seine Oberlegung. für dieses Wort die Bedeutung von "vorangegangene

16 Vgl. Slownik praslowianski II. 191 f. Danach ist das Kollektivum cedb < Eedo 'Kind' + Suffix entstanden. - Zu möglichen Inhalten und Bedeutungen dieses Begriffes vgl. noch: aksl. $c_{f} d_{b}=$ druzyna. Leute: serb.ksl. (14. Jhd.) ceds $\rho$. = Kinder, Gesinde; mazed. (dial.) Cet, czt = FamiIle; aruss. $c_{a d b / / c_{f} d b} f$. $=$ Kinder, Leute, Volk. Gefăhrten, Kriegsschar: ukrain. Cadb $=$ Kinder. Nach Slow. prasl. 192 sind die russ. Wörter höchstwahrscheinllch aksl. Entlehnungen. Dazu auBerdem Vasmer. EWB III. 298: aruss. Cadb f. Kinder. Menschen, Volk. Berneker 1924, 154: abg. çdb f. (Supr. 134, 1) Gefolge. - Etimologiceskij slovar' siavjanskich ja-

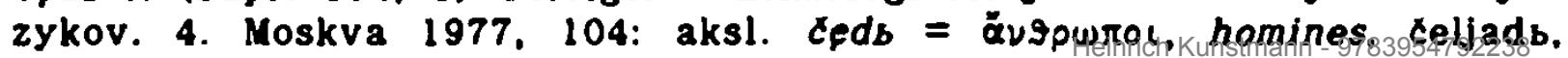

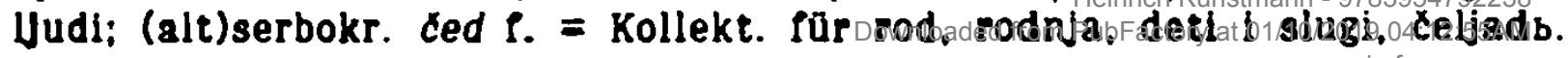


Gruppen" im Sinne von "Vorausabtellungen" vorzuschlagen. Es fragt sich allerdings, ob diese ja dem militärischen Begriff der Avantgarde nahekommende Auslegung mit dem oben erwähnten Inhalt der Reichsannalen in Einklang zu bringen ist. Wenn Witkowski weiter meint, die Praedenecenti selen kein Beweis für die Süd-Nord-Tanderung der Abodriten. dann läßt er sowohl die Osterabtrezi des Geographus Bavarus als auch die Tatsache auBer acht, daB die Annales regni Francorum ausdrücklich die Existenz von Abodriten an der Donau nachweisen und damit mittelbar die Entstehung des Ethnonyms Abodriti im Bereich des byzantinischen Imperiums bestätigen.

Wieder anders beurtellt der amerikanische Historiker Imre Boba (1984) die Praedenecenti. Für ihn sind diese kein ethnischer oder politischer Name. hinter welchem sich die Osterabtrezi des Geographus Bavarus vermuten lassen, vielmehr versteht er darunter einen Spottnamen (nickname). der sich auf die vorangehenden Marvani bezieht, weshalb die Stelle zu 822 laut Boba so zu lesen sel: In quo conventu omnium orientalium Sclavorum. id est Abodritorum. Soraborum. Wilzorum, Beheimorum. Marvanorum praedenecentorum... (Boba 35). Für Boba bedeutet die Bildung praedenecenti soviel wie praedones Sclavi 'räuberische Slaven' (ebda.). wobei er von einer lateinischen Bildung 'praedo-neco u.ä. ausgehen möchte. Dagegen spricht In erster Linie das Adverb vulgo, das Ja, wle schon gesagt, ein nichtlateinisches, also wohl slavisches Wort annonciert. Auch ist einzuwenden. daß die Herleitung (des Wortes Praedenecenti) von einem lateinischen praed(a) oder praed(ari) nach den lateinischen Wortbildungsgesetzen unmöglich ist..."17. Bobas Deutung ubergeht außerdem das Element -enec, auch wäre ein Praesenspartizip -entes und nicht -enti zu erwarten. Das Wissen. daß sich weder von der a-Konjugation (praedo) noch vom Deponens (praedor) eine Form Praedenecenti bilden läßt. darf man den Lateinkenntnissen eines Verfassers der Reichsannalen schon zumuten. Wenig wahrscheinilich ist auch Prof. Bobas Vermutung. der Geographus Bavarus benutze die Begriffe Nortabtrezi und Osterabtrezi nur zur Unterscheidung zweier benachbarter Abodriten-Stämme an der Ostsee, so daB es lediglich einen einzigen Stamm von Abodriten gegeben habe. Das jedoch wird von den

17 So Frau Dr. Theresia Payr, die Leiterin des Mittellateinischen Worterbuches an der Bayerischen Akademie der Wissenschaften (Schreiben vom 9.7.1987). 
Quellen nicht bestätigt. auch schlieBt die Reihenfolge im Geographus Bavarus eine Gleichsetzung von Nort- und Osterabtrezi aus.

Slaven am „auBersten Ende des westlichen Ozeans"

Die Deutung des Begriffes Praedenecentl als 'aite Gefolgschaften. Prühere Volksgruppen' legt nun ireilich nahe, daß diejenigen Abodriten, von denen die Fränkischen Reichsannalen zu 822 und 824 berichten, der ursprüngliche, der ältere Stamm waren, von dem noch zu Beginn des 9. Jhds. Teile an der unteren Donau, in Dazien saßen. Von eben diesem Stamm mit der griechischen Bezeichnung Vateriandslose, Heimatlose. Exulanten muß sich irgendwann eine Gruppe oder ein Teil abgesondert haben und nach Norden. bis an die Ostsee abgewandert sein. Wann dies geschehen ist. bleibt ungeklărt, auch wenn nicht auszuschlleBen ist, daB die durch die AwarenStürme verursachten Unruhen auf dem Balkan die treibende Kraft für die Aufsplitterung des Abodriten-Stammes gewesen sein könnten. Die bewegte Geschichte des alten serbischen Branicevo in Mösien, in dessen Nähe immer wleder die Sitze der Abodriti-Praedenecentl vermutet werden. paBte vortrefnich in das Bild: 411 wird Branizevo durch die Hunnen, 583 (?) durch die Awaren eingenommen, 601 erobern es die Byzantiner zurück (Zakythinos 1979. 31. 52 \&.), und far das Jahr 1198 wird es zusammen mit Nis (provincia Nisi et Vranisove) ein letztes $\mathrm{Mal}$ als unter byzantinischer Herrschaft stehend erwāhnt (SlowstarSlow III, 402: T. Wasilewski).

Aup eine Süd-Nord-Wanderung der Abodriten weisen womöglich auch gewisse Toponyme in Böhmen und Polen hin, so beispielsweise das am rechten Ufer der Jizera gelegene Dorf Obodr (ma. ta Obodr̆. v Obodři, do obodře, Obodřickej) und der polnische Flurname obodrowska (laka) pod m. ujsciem (1726-8 pratum Obodroviense), die Profous (III, 244) allerdings zum nirgends belegten PN - Obodr stellt. Dieser erschlossene, schon von Niederle in die Diskussion gebrachte Name geht sehr wahrscheinlich auf P. Kühnel $(1982,5)$ zurück, der diesen zu Beginn des Jahrhunderts auf wenig überzeugende Weise aus 0 - 'sehr' und bưdrŭ 'wachsam' zu 'Obưdrici 'die Wachsamen' bildete.

Der These von der ursprünglichen Einheit der Ostsee- und DonauAbodriten, wie sie Henryk Lowmianski vertrat, kann man durchaus beitreten, nicht beitreten kann man nun jedoch, nachdem die priechissche Her- 
kunft des Abodriten-Ethnonyms geklärt 1st, Lowmianskis Ansicht, dleser Stamm habe dereinst in Schlesien gesessen (1964-73, II, 69 fl.). Hervorzuheben ist allerdings auch, daß die "Urheimat" der Abodriten keineswegs an der unteren Donau, in der alten Provinz Dacia zu suchen ist, denn hier wurden oder haben sie sich ja bereits Vaterlandslose, Heimatlose. Exulanten genannt, was auf eine åltere, nicht năher bekannte Heimat schließen läßt.

Wahrscheinlich haben um 590, vielleicht noch früher slavische Stämme die südwestliche Ostseeküste erreicht. Dafür spricht der überaus bemerkenswerte Bericht des byzantinischen Historikers Theophylaktos Simokattes. der in seiner "Universalgeschichte" (223) von drei slavischen Gesandten zu erzāhlen weiß, die etwa $591 / 2$ aus ihren entlegenen Wohnsitzen "am

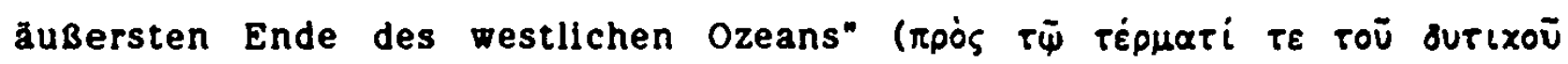

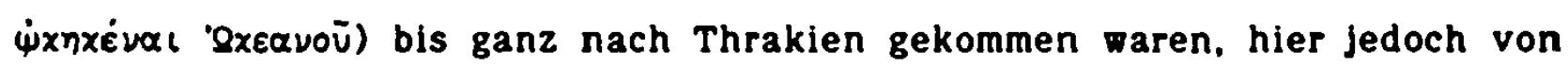
byzantinischen Vorposten aufgegriffen und Kaiser Maurikios vorgeführt wurden. Versteht man, wie das mehrere Historiker tun ${ }^{10}$, unter "westlichem Ozean" die Ostsee und setzt dessen "ăußerstes Ende" mit Ost-Holstein gleich, dann könnte dieser byzantinische Historiker des 7. Jhds. möglicherweise sogar von Slaven berichten, die zum Stamm der vor kurzem erst vom Balkan an die Ostsee abgewanderten Abodriten gehörten. Noch ein anderes wichtiges Detail enthālt der Bericht des Byzantiners: die Angabe nămlich der Entfernung. Von ihren Wohnsitzen an der Ostsee bis nach Thrakien waren die drei Slaven 15 Monate unterwegs. Diese erhebliche Entfernung war auch der Grund, warum die slavischen Stammeshäuptlinge an der Ostsee die mit reichen Geschenken ergangene Einladung des Awarenkhans ausgeschlagen hatten, mit ihm an einem Feldzug teilzunehmen (Theophyl. Simoc. a.a.o.). Abgesehen davon, daB diese Bemerkung die Teilnahme von Slaven an Feldzügen der Awaren zu bestătigen scheint, besticht an dem Bericht des Theophylaktos, der insgesamt als zuverlässig und mehr historisch als ethnographisch interessiert gilt (Muller K. E. 1980, 479 fl.), daß der in Thrakien gegen Kaiser Maurikios operierende Awarenkhan ausge-

10 Vgl. Herrmann. J., 1971, 256, der das Ereignis in das Jahr 595 setzt und von südwestlicher Ostseekủste" spricht. Auch H. Jankuhn (Anm. 1. S. 98) entnimmt der byzantinischen Quelle, daB um 590 also die Ostseeslawen bereits am Ostseeufer ansässig gewesen (zu) sein scheinen". Fur die Datierung des Ereignisses wichtig ist, daB die Offensive der byzantinischen Truppen unter Kaiser Maurikios gegen die A A begann. vgl. Zakythinos 1979, 53. 
rechnet slavische Streitkrâte als Partner zu gewinnen sucht, die sozusagen diametral entgegengesetzt an der Ostsee zu Hause waren und bel der Schwerfalligkeit eines Heereszuges (Troß!) einen noch lănger als 15 Monate wahrenden Anmarsch gehabt hătten. Lassen sich hinter diesem Vorgang nicht vielleicht Zusammenhănge zwischen Ostsee- und Donau-Abodriten vermuten? Aus dem Bericht des Theophylaktos sei noch nachgetragen, daB die von den Byzantinern gefangengenommenen drel Slaven erzăhlten, der Awarenkhan hătte ihren Stammeshăuptlingen relche Geschenke gemacht, die diese 2 war angenommen, das Bundnis aber eben mit dem Hnweis auf die welte Reise ausgeschlagen hătten. Die gefangenen Slaven seien zum Khan in Marsch gesetzt worden, um ihre Hăuptlinge zu rechtfertigen, doch der Khan habe das Gesandtenrecht miBachtet und den Gesandten den Rôckweg abgeschnitten. Das alles weist doch sehr deutlich darauf hin, daB zwischen dem Awarenkhan und den slavischen Gentilaristokraten am .auBersten Ende des westllchen Ozeans" mehr als nur eine Einladung dieser zur Betefligung an einem Feldzug bestanden hat.

Ein interessantes Detail, das abermals rar Kontakte zwischen Slaven an der Ostsee und Awaren in Thraklen spricht. sind die von J. Herrmann (1972) In die Debatte gebrachten Funde byzantinischer Goldsolidi Insbesondere bei Blesenbrow im Kreis Angermünde. Ob diese uber 200 Goldmünzen aus der 2. Hăırte des 6. Jahrhunderts (Kaiser Just/nian) mit den von Theophylaktos Slmokattes erwăhnten ,reichen Geschenken" des Awarenkhans an die Slaven „am ăußersten Ende des westlichen Ozeans" etwas zu tur haben, dörfte sich allerdings nicht ganz leicht entscheiden lassen.

Unter wieder anderen Gesichtspunkten von Belang sind schlieBllch auch die leider sehr konzisen Reisenotizen des ansonsten unbekannten Byzantiners Laskaris Kananos, der zu Beginn des 15. Jhds. das Land der E9גabouvia bel Lübeck, genaugenommen also das Gebiet der OstseeAbodriten besuchte ${ }^{10}$. Laskaris Kananos, der von Schweden uber Riga, Reval

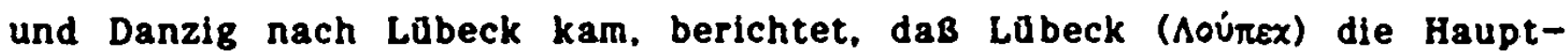

19 Zu Laskaris Kananos vgl. K. Krumbacher: Geschichte der byzantinischen Litteratur. "21879, 422, der "aus inneren Gründen" diese Reise far die Zeit 2 wischen 1397 und 1448 ansetzt; in die Jahre zwischen 1412 und 1418 verlegt die Reise dagegen der russische Historiker A. Vasil'ev: Laskarb Kanan, vizantjskij putesestvennik XV veka po Severnof Evrope I v Islandiju. In: Sbornik statej $v$ cest prof. V. P. Buzeskula (= Sbornik Char'kovskogo istoriko-fllologiceskogo obscestva pri Char'kovskom universitete, 21). Char'kov 1914, 397 $\%$. Noch anders, nămlich in die Jahre

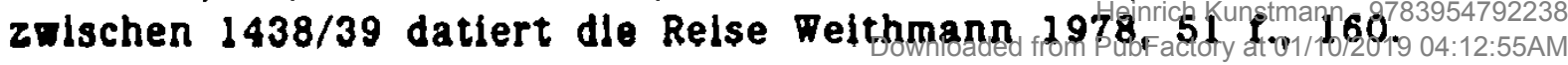


stadt dieses slavischen Gebietes sel und aus eben dieser Gegend an der Ostsee die Zygioten, Jene im Hochland des Taygetos lebenden Slaven stammten. Selbst wenn Laskaris Kananos nicht viel mehr als die elnem Fremden auffallende allgemeine Ahnlichkelt der Sprache der Slaven von Lübeck mit der Jener slavischen Gebirgsbewohner vom Taygetos gemeint haben $\operatorname{kann}^{20}$. so bestätigt sein Bericht doch expressis verbis, daB noch rund 300 Jahre nach dem großen Wendenkreuzzug von 1147 und der nachfolgenden Unterwerfung der Abodriten durch Heinrich den Löwen bei Läbeck Slaven. Abodriten also, gelebt und ihre Sprache gesprochen haben.

20 Vgl. dazu K. Sathas: Documents inédits relatifs a l'histoire de la Grece au Moyen Age. Paris 1880-90. I, XXII P.; Vasmer 1941, 18 f.; Weithmann 1978. 160. 


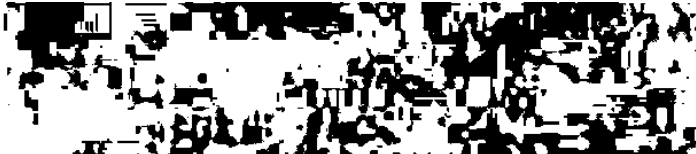

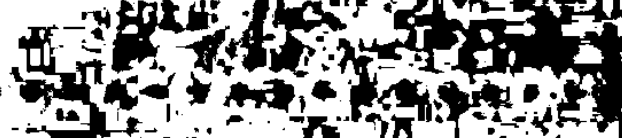

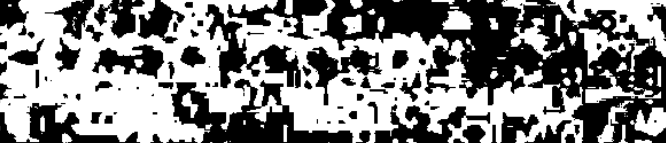

so.

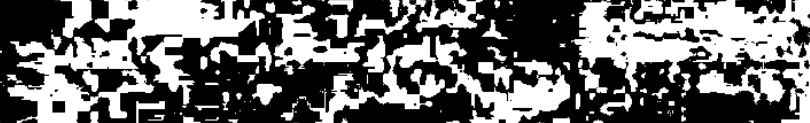

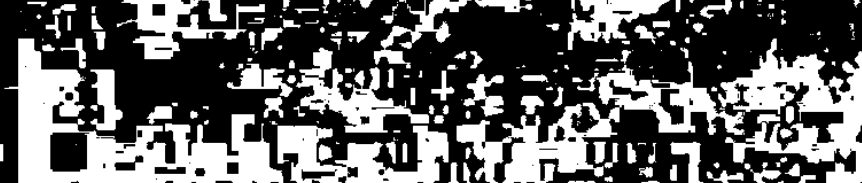

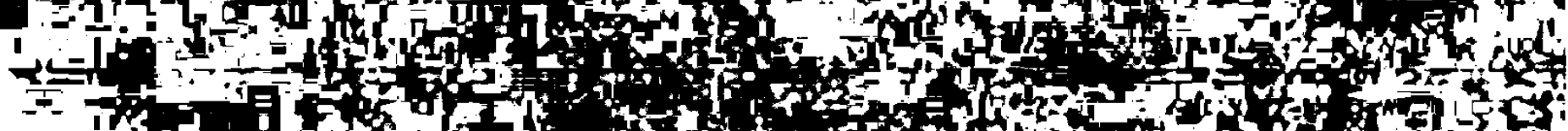

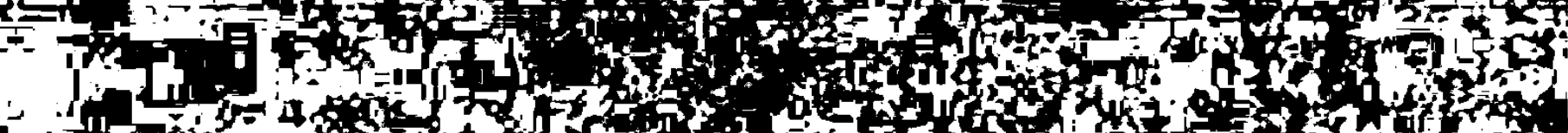

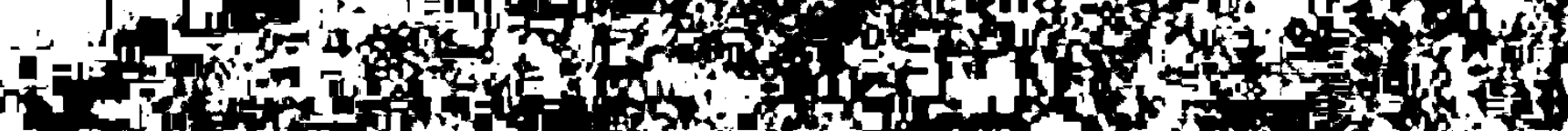
con

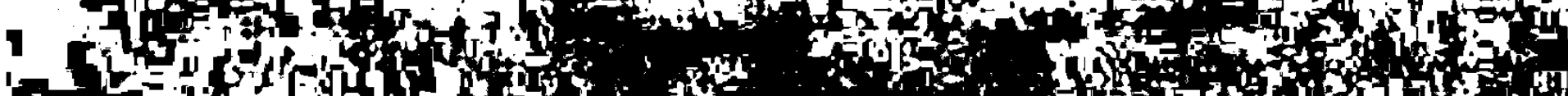

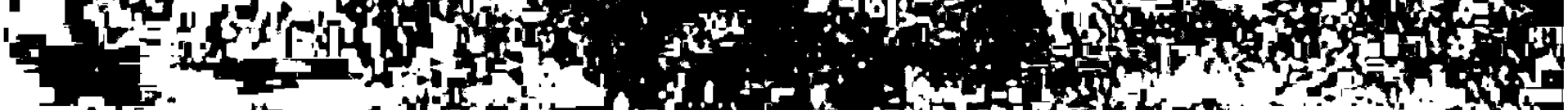

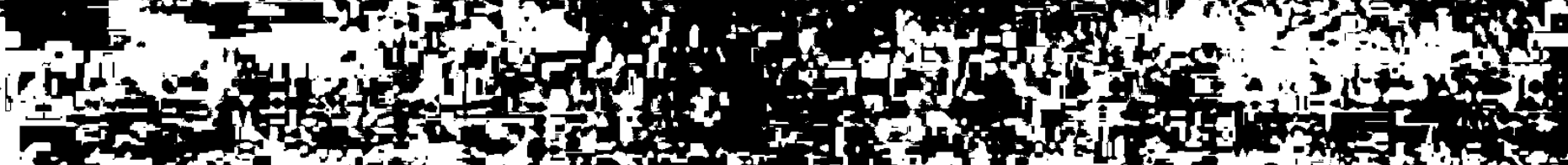

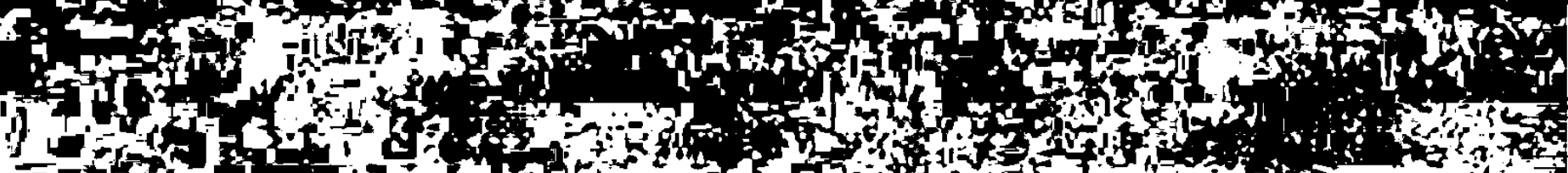

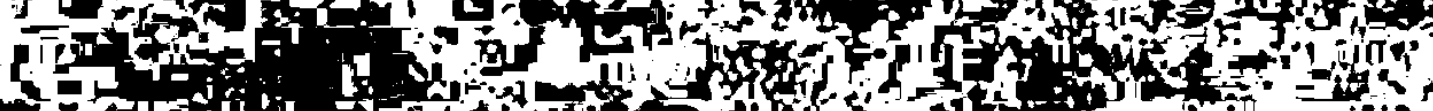

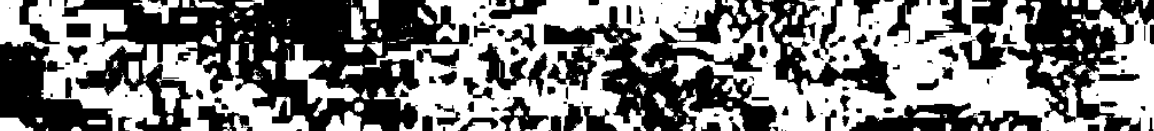

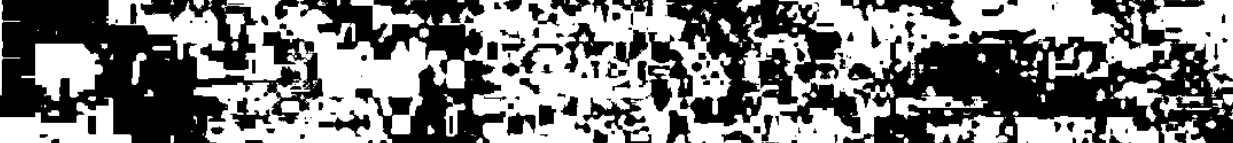

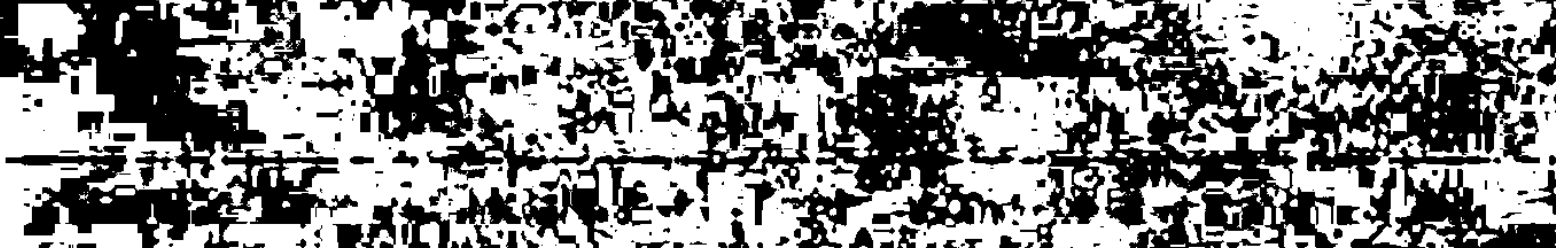

(3) .

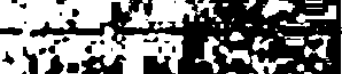

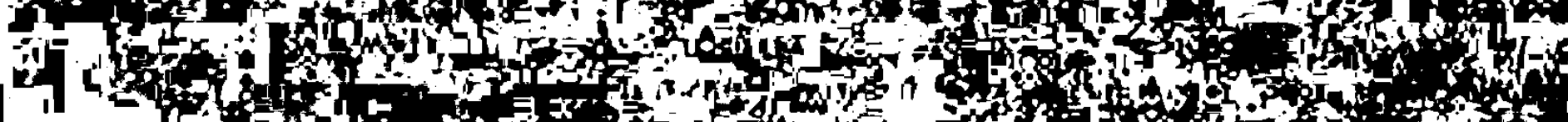

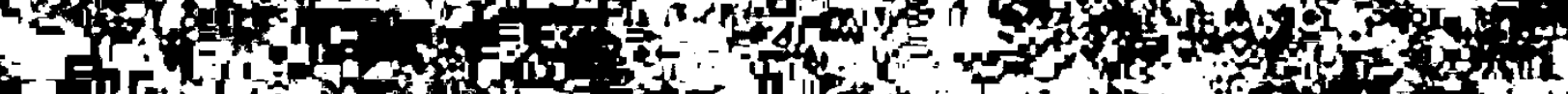

3. (3)

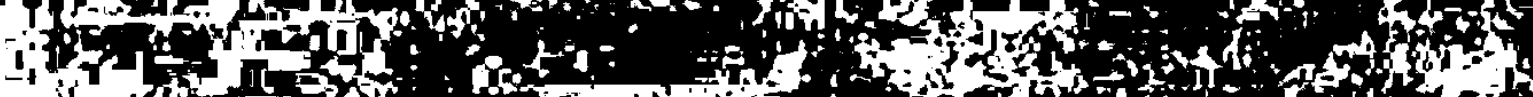

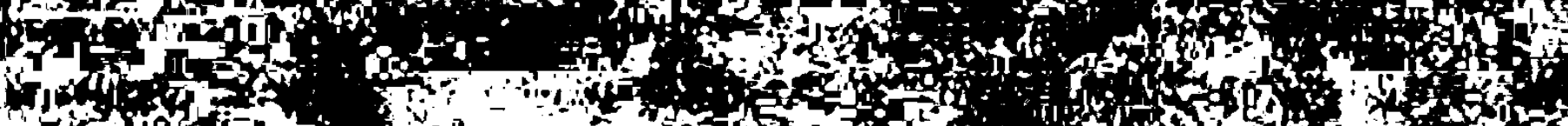
(1)

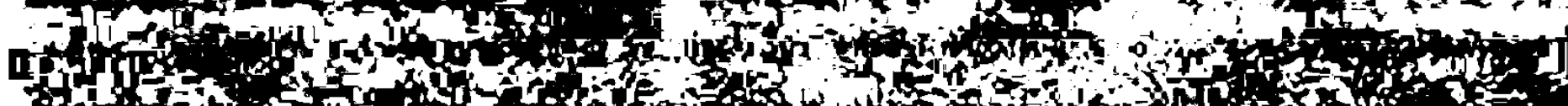
(f)

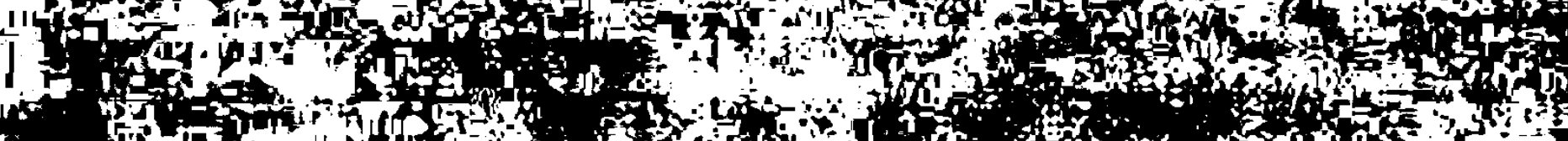

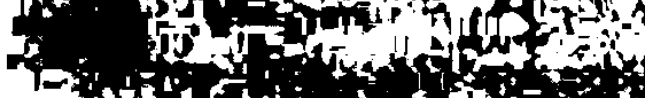
(e)
(1)

30

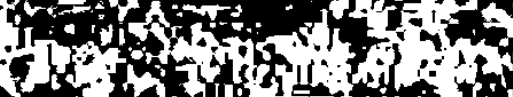

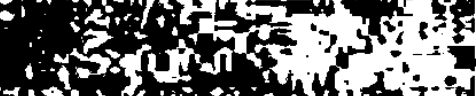
Tof 0 ond

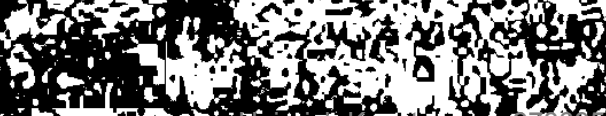

intis

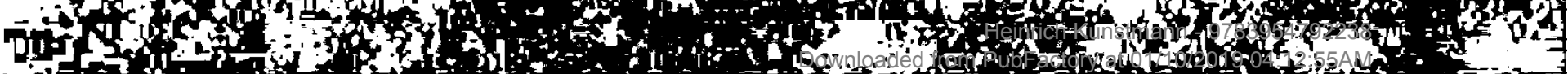
100 Th 


\section{Mecklenburg und Wismar}

Die Mecklenburg, eine dereinst große Burg beim heutigen Dorf gleichen Namens, $8 \mathrm{~km}$ südlich von Wismar, war, Adam von Bremen zufolge. Hauptsitz der Abodriten. Die erste Burganlage mit einem Durchmesser von etwa $170 \times 110 \mathrm{~m}$ und einem uber $5 \mathrm{~m}$ hohen Wall (Herrmann, J. 1972. 313) war im 7. und 8. Jhd. gewiß größer als die holsteinische Oldenburg, das Stammeszentrum der Wagrier. Die Ausgrabungen haben erwiesen, daB dle Mecklenburg vielleicht schon in der 1. Hälfte des 7. Jhds. auf der Spitze einer Halbinsel angelegt, 680 erstmals erneuert und in der Folge sowohl umgebaut als auch erweitert wurde (Donat, P. 1984: Hermann, J. 1985, 210 P.). Mit der Mecklenburg in Verbindung stand die Kaufmannssiedlung Reric, die 808 von den Dănen zerstört wurde. Urkunden und Chroniken bestătigen die Mecklenburg seit dem 10. Jhd. als Sitz der Abodritenfürsten, doch war sie zu dieser Zeit, wie die archäologischen Forschungen erbrachten, "bereits seit Jahrhunderten Vorort des Stammes und damit Sitz des Stammesfürsten" (Herrmann ebda.).

Die urkundliche Oberlleferung des Namens der Mecklenburg ist auffallend einheitlich und beschränkt sich auf wenige Varianten: Neben der Ersterwăhnung von 995 als Michelenburg (DO III. 172) liegt das absolute Schwergewicht der Notierungen bel Adam von Bremen und Helmold von Bosau. weshalb eine Gliederung der Belege nach diesen beiden Autoren angebracht ist:

Adam: Obodriti. qui nunc Reregi vocantur, et civitas eorum Magnopolis (II, 18 (21)): in Magnopolim, quae est civitas inclita Obodritorum (III. 19 (20)): Michilinburg (III. 32 (33)): Magnopolis (III. 50 (51)): Nlchilenburg (ebda.):

Helmold: in Magnopoil.... quae est inclita Obotritorum civitas (1. 20: wie Adam III, 19 (20)): in Magnopolf, id est Mikilenburg (1. 23): Mikilinburg (1, 2): Mikilinburg (1, 13, 14, 15); Mikillinburg (1. 69, 87 1.): Magnopolis ipsa est Mikilinburg (I. 87): Mikilinburg (1. 93): Mikilenburg (II. 98 f.): Mekelenburg (II. 109, 110)'.

Die Zusammenstellung zelgt, das der Name der abodritlschen Burg in drei Grundvarianten vorkommt, als Mikilinburg und Michilinburg ${ }^{2}$ sowie in lateinischer Form als Magnopolis, die erstmals von Adam von Bremen verwendet wird. Sowohl Mikilinburg als auch Nichillinburg sind Komposita von

1 Nach Brüske 207 f.

2 Bei Arnold von Lübeck flndet sich Nichelenburg (III. 4). 
ahd. bzw. asă. mikil, michil, mi(h)kil, mih(h)il, mihhal usf. 'groß, bedeutend' (Schützeichel 1974, 127) und dem Grundwort-burg, so das sich die Bedeutung ergibt: Mecklenburg $=$ 'große, bedeutende Burg'. Die von Adam und in der Folge auch von Helmold und anderen gebrauchte Form Magnopolls wird von der Wissenschaft als gelehrte latinisierende oder gräzisierende Volksetymologie beurteilt (2.B. Bach II/2, 493). Die Bildung des Namens Mecklenburg scheint somit problemlos $z u$ sein und den nicht seltenen alten ONn wie Mihllunfeld, Michllinstat, Mikulunhurst (FörstemannJellinghaus II, 286 ( .) zu entsprechen, obwohl nicht zu übersehen ist, das der Name Mecklenburg singulär ist. Die Etymologie des fraglichen Burgennamens ist jedenfalls germanisch, auch wenn versucht wurde, eine hypothetisch gebildete Porra Mechlin mit slav. mech 'Moos' in Verbindung zu bringen (SlowStarSiow III, 188: Nalepa), was aber gewiB verfehlt ist.

Man hat Mecklenburgs Namen allerdings auch als Obersetzung aus dem Slavischen verstanden. Insbesondere $M$. Vasmer glaubte in seinem Artikel uber .Slavische Befestigungen an der deutschen Ostseeküste" (1933) in Mecklenburg ein abg. velii grads 'große Burg' (Vasmer. Schriften II. 724) vermuten zu dūrfen, welcher Meinung auch andere Gelehrte wie z.B. W. Brüske (207) waren. Diese Ansicht stutzte sich in Grunde auf eine Konjektor des Textes von Ibrāhim ibn Ja'qübs Bericht über die Slavenlande aus den Jahren 965/6. Doch besagte Konjektur, die an einer schwierigen Stelle die Lesart wiligrad vorschlug. wurde bereits von Trautmann (I. 22) als .zweifelhafter Pall" bezeichnet und schließlich als unbegründet verworfen (SiowStarSlow VI, 361: Leciejewicz).

Unabhängig von der problematischen Textstelle bei ibn Ja'qüb scheint es geraten, erneut die Vermutung zu außern, daß Mecklenburgs Name möglicherweise doch keine autochthone asă. Bezeichnung. sondern eine Lehnubersetzung sein kơnne. Dieser Verdacht stutzt sich auf diverse Argumente.

Die Mecklenburg war Stammsitz der slavischen Abodriten, folglich sollte man. ăhnlich wie far Holstelns Oldenburg (Aldenburg, Slavica lingua Starigard, hoc est antiqua civitas, sita in terra Wagirorum Helmold 1, 23). auch far sie einen slavischen Namen erwarten kōnnen. Da der Stammesname der Abodriten selbst griechisch ist, hat moglicherweise auch ihr Vorort eine griechische Bezelchnung gehabt. Hinzu kommt, daß mehrere Namen der abodritischen Gentilaristokratie alles andere als einen slavischen Eindruck machen. $\mathrm{Da}$ ist beispielsweise der hypothetische Abodritenfürst Missizla 
aus der 1. Hălfte des 10. Jhds., dessen Name zurecht als Mstislav̧ gedeutet wird (SlowStarSlow III. 325: Urbanczyk), doch handelt es sich dabei gewiB um keinen autochthonen slavischen PN, sondern eher um eine Lehnübersetzung von $\Delta\llcorner\times \alpha \iota 0 \times \lambda \bar{s} s$ u.å. Auch der Name des bekannten Abodritenfursten Gotescalcus, den Vasmer ebenso wie den der abodritlschen Fürstentochter Tofa für nordisch hielt (Schriften II, 612), kann Obersetzung von Eeósounos sein bzw. auf griech. Tápos 'Staunen. Verwunderung' zurückgehen. Nach dem gewaltsamen Tod seines Vaters Gottschalk ubernahm 1066 dessen altester Sohn Butue, auch Buthue, die Herrschaft über den Stamm der Abodriten. Man deutet seinen Namen als Budivoj oder Budvoj (SlowStarSlow I. 172: Moszytiski). Falls diese Slavisierung richtig ist, liegt abermals eine Lehnubersetzung vor. nămlich die von 'A réotparos. Dabel ist Jedoch keineswegs sicher, daB Butue, Buthue mit Bud(1)voj gieichzusetzen 18t, da dieser Name ebensogut mit dem illyrischen Toponym Butus, Boirova, Bougón zu tun haben kann: es ist dies das kroat. Budva (mit roman. d. vgl. Mayer I, 103), das seit dem 11. Jhd auch Starigrad (civitas antiqua) hies (SlowStarSlow I, 182 f.: Kowalenko). Auch der Name des AbodritenFürsten Nakon (2. Hälfte 10. Jhd.), von den sich die Dynastie der Nakoniden ableitet, wirkt wenig slavisch (SlowStarSlow III. 348: G. Labuda), dafar unso mehr griechisch, da eine Verbindung mit váxos 'vlles, Bocksfell' zu bestehen scheint, vgl. dazu die Toponyme Nókos, Nakona (Grasberger 166 P.) u.a. (Pape, Benseler II, 973 (.). Verdăchtig wirkt ebenfalls der Name des Gentilaristokraten Drasco, Thrasuco. Thrasco (8.-9. Jhd.), den man gern als Drozko wiedergibt (SlowStarSlow I, 387: L. Moszytiski), obwohl nicht auszuschließen 1st, daß hier auch an das Etymon $\theta p a ̈ \sigma-\sigma \alpha, \theta p o \dot{s}-\alpha=$ Femininum von Opọ̧̄ (Detschew 210 f.) gedacht werden kann. vgl. dazu auBerdem Opaoxias. $\dot{o}=$ Opaxias 'von Thrazien her wehender wind' (Pape. Benseler 1, 516). Aber auch der Name des Abodriten-Pahrers Gneus (Beginn 11. Jhd.), der im allgemeinen zu Gnév slavisiert wird (SlowStarSlow II. 113: Labuda), scheint eher dem nicht seltenen griech. PN Tuaios oder seinem röm. Pendant Gnejus, Gnaeus, Cnēus (Pape. Benseler 1, 254) nahezustehen. Griechische Spuren, das bedürfte einer systematischen Analyse, weisen noch einige andere abodritische Personennamen auf, was insgesamt an eine recht åhnliche Situation bei den tschechischen Premysllden denken lăßt (Kunstmann 1987).

Nach Aussage der Archăologie war der Burgenbau bei den Abodriten des 6. bzw. Anfang des 7. Jhds. auffallend „entwickelt", was der Beobach- 
tung entspricht, daß dleser Stamm gesellschaftllch zu den am meisten fortgeschrittenen Nordwestslaven gehörte. Dleser allgemeine Entwicklungsvorsprung wurde "viellelcht aus einem fortgeschrittenen ehemaligen Siedlungsgebiet mitgebracht" (Herrmann, J., 1972, 313). Dieser verblüffende Schluß der Archäologie vereinbart sich vortrefnich sowohl mit der These von der Herkunft der abodritischen Slaven aus elnem griechisch-byzantinischen Gebiet als auch mit der schon an anderer Stelle mitgetellten Beobachtung, wonach Teile der griechisch-byzantinischen Burgenterminologle von den Slaven ubernommen wurden, so zum Beispiel Vysegrads, das fraglos eine Lehnübersetzung von 'Axpórodis 1st. gewiß auch russisch ostrogs 'Festung. Gefängnis', eine auf ostryj = äxpov verweisende Bildung (Vasmer REW II. 287), and verschiedene andere. Zur griechisch-byzantinischen Burgenterminologie zu rechnen ist aber auch das far Böhmen und Măhren belegte Toponym Velehrad, das als vermuteter Sitz von Method, $h$ ein Dorf $6.5 \mathrm{~km}$ von Uherské Hradisté entfernt (Hosák. Srámek II. 671), große Bedeutung gehabt haben soll (Stanislav 1978, 68; SlowStarSlow VI. 358 f.: Weqdzkl). Der Name begegnet ebenfalls in der Umgebung von Brūnn (Hosàk. Srámek II. 671) und, viellelcht als Obertragung des mährischen Toponyms. als dvir Velehrad (Hor Welehrad) in Böhmen (Profous IV, 488). Dleser Burgenname scheint nur bei den Westslaven vorzukommen und auch das nur vereinzelt.

Velehrad lat ohne Frage aus urslav. - velsjs gords entstanden. doch spricht manches, ja alles dafur. daß die urslav. Bildung wiederum auf ei-

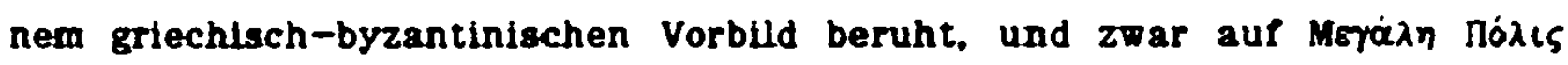

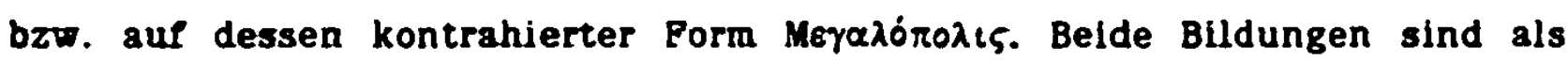
Namen mehrerer Städte im Innern von Byzaclum bekannt. Unter eben diesem Namen am bekanntesten wurde Jedoch die um $368 / 367$ v. Chr. auf Betreiben von Epameinondas in Arkadien gegrundete Bundeshauptstadt Mera-

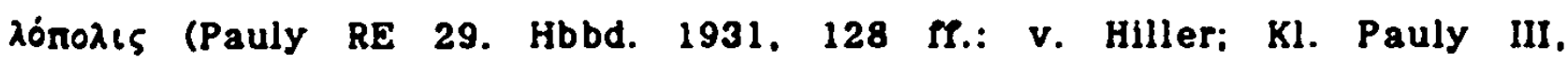
1140 (P.). Mit ihr kamen Slaven - Preilich erheblich spăter - In Berührung. Nach der slavischen Invasion der Peloponnes (Charanis 1972) dürften sich Ende des 6. Jhds. die ,ersten Slawenschwärme zunächst vor allem in Elis und im nordwestlichen Arkadlen niedergelassen haben" (Stadtmüller 1976. 110; Waldmuller 169). Die slavischen ONn in Arkadien - Vasmer zăhlt 94 von thnen auf (1941, 150 (f.) - dokumentleren dle slavische Siedlung. Im Becken von Megalopolis an der Stelle der alten Bundeshauptstadt (Weithmann 191, 150) gleichen Namens entstand dann der slavische Ort Bexi- 
yootn, dessen Name schon von mehreren Forschern, darunter von Kopitar. für die slavische Obersetzung von altgriechischem Meraxórodis gehalten

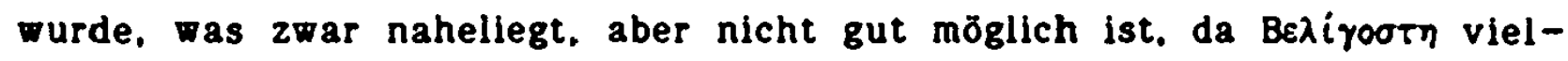
mehr Veligostb bzw. Veiigoste entspricht. $\mathrm{Zwar}$ schreibt die Chronik von

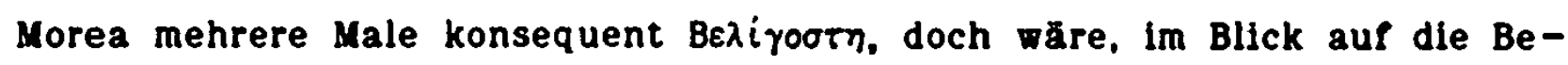
sonderheiten dieser Chronik und ihre Oberlieferung (Schmitt. J., 1902. XV If.; Tuscul.-Lex. 161), noch eingehend zu prüfen, ob für Vellgoste nicht vielleicht $\cdot$ Veligords zu konjizieren ist.

Es ist aus besagten Gründen mehr als wahrscheinlich, daß die altslavische Burgenbezeichnung - Veligords auf griechisch Meraiórodis zurückgeht. Andererseits spricht auch manches dafür, daß slavisches - Veligords zum Vorbild fur asä. Mikilinburg usf. wurde, daß der Name Mecklenburg also eine zweifache Lehnübersetzung darstellt. Adams Version Magnopolis wăre dann eine gewiß unbewußte "Revitalisierung" des griechisch-lateinischen Prototyps.

Als Nebenbucht der Mecklenburger Bucht liegt zwischen Klützer Ort und der Insel Poel die Wismarsche Bucht. An ihrem Südrand befindet sich die Stadt Wismar, einer der bedeutenden Ostseehäfen (zur Geschichte vgl. SlowStarSlow VI, 658: Leciejewicz). Die Oberlieferung ihres Namens setzt im Grunde spät ein: 1229 Wyssemaria; 1230 Wissemaria: 1253 Wismaria: dazu: 1167: Aqua, quae Wissemara dicitur; 1211 portus, qui dicitur Wissemer. Wăhrend diese Notierungen die heutige Stadt Wismar betreffen. meinen die folgenden das alte slavische Dorf: 1260/72 Antigua Wissmaria; 1266 molendinum situm apud Antiquam Wysmariam; 1279 ecclesia Antiquae Wismariae (Trautmann ${ }^{2} 1950,166$ ). Trautmann (I. 51) hat dieses Toponym zum alten slav. PN - Vysemer gestellt, zu welchem der apoln. PN Wyszemir u.a. gehört (Svoboda 93). Dieser Ansicht schloB sich auch E. Rzetelska-Feleszko an (SlowStarSlow VI, 657), die $M$. Rudnickis an sich bemerkenswerte Herleitung des Namens von keltischem Vis-marus nicht tellte. Eine "Rekonstruktion" als Wyszomierz (mit possess. -jb). unter der Wismars Name in SlowStarSlow VI. 657. aufscheint, ist jedoch gewiB verfehlt.

An den obigen Belegen fallt auf, daß der Name des alten slavischen Dorfes regelmäig Wissmaria lautet, also kein $-e-z$ wischen $s$ und $m$ enthält. Das kann bedeuten, daß in den Formen Wiss/e/mer das - e- sekundăr ist. Epenthetisches e kann hier auf deutschen Einnuß zurückgehen, es kann allerdings auch slavische volksetymologische Anpassung an den besagten PN Vyšemir sein. Zu beachten ist weiter, daB als ursprüngliches 
Suffix - mar anzunehmen 1st, aus dem zwar leicht - mer, nicht aber -mir werden konnte. Auch ist kaum an ein possessives -jb im Auslaut zu denken. da dieses weder die historischen Belege noch die heutige Form Wismar zelgen.

Wismar ist der von Slaven an die Ostsee Ubertragene Name der home-

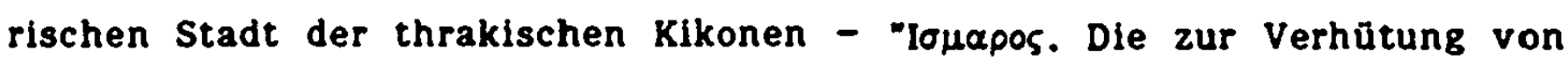
vokalischem Anlaut vorgesetzte $v$-Prothese und der Verlust der griech. Suffixendung - os sind die einzigen slavischen "Maßnahmen", die von Ismaros $>\cdot V$-ismar-z $>$ Wismar geführt haben. Der ausgesprochen thrakische

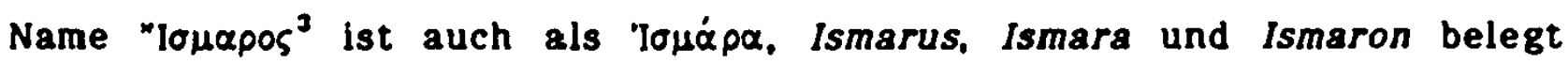
(Detschew 217), wobel die Bildungen auf-mara den slavischen Formen Wiss-maria in der Tat auffallend ähnlich sind.

Ismaros war laut Strabon (VII, 331 irg. 44) neben Xanthol und Maroneia eine der drei Kikonen-Städte (Danov 1976, 117), von denen letztgenannte angeblich die Folgesiedlung des von Odysseus (Od. 9. 140) zerstōrten Ismaros ist. Wahrscheinlich ist jedenfalls, daB Ismaros nahe bei

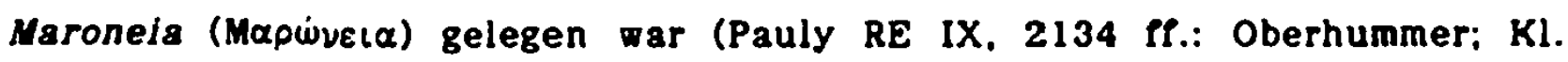
Pauly II, 1465), wofür auch der an der Küste Thrakiens 2 wischen Maroneia

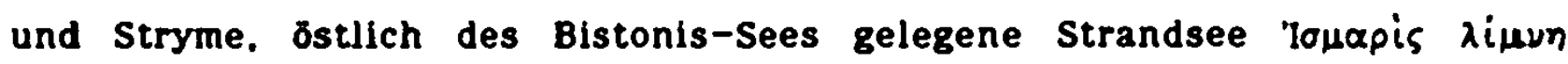

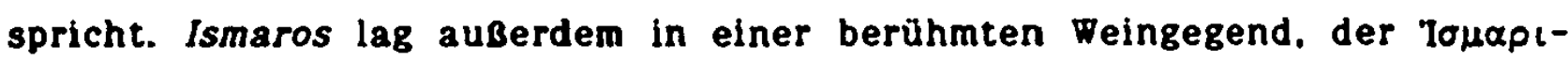
xós oivves flndet bei Vergil. Properz und Ovid Erwähnung.

Die Obertragung des thrakischen Namens Ismaros an die Ostsee ist insofern bemerkenswert. als die Slaven bei ihrem Eintreffen von diesem längst zerstōrten Ort natürlich nur durch mündliche Oberlieferung erfahren konnten. Ismaros ist gewiB nicht das einzige Beispiel dieser Art, da, wie separat gezeigt werden soll, auch andere slavische oNn auf antike stätten zurückgehen, deren Namen den Slaven nur durch Hörensagen bekannt geworden seín können. Verschüttetes antikes Namensgut lebt somit in veränderter Form an anderer stelle weiter.

3 Er begegnet mehrmals auch als PN, so etwa für den Sohn des Ares

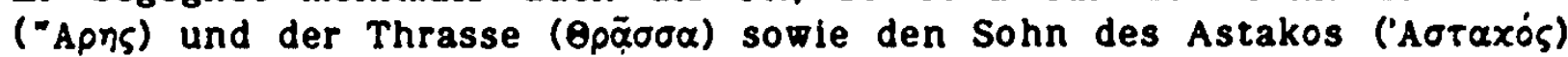

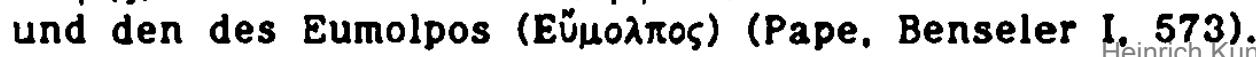




\section{Mecklenburgs Zirzlpanen und der Name der Peene}

Der nordwestslavische Stamm der Zirzipanen gehörte nach Auskunft des Geschichtsschreibers Adam von Bremen (11. Jhd.) neben Kessinern. Tollensern und Redariern $z u$ den vier wilzisch-lutizischen Hauptstămmen (Brüske 1983, 9 ff.). Obwohl sie zum sog. Lutizenbund gehörten, bekriegten und besiegten die Zirzipanen in einem Bürgerkrieg (1057-60) die übrigen Mitglieder dieses Bündnisses. Doch gingen sie im Zuge der Kolonisationspolitik der mecklenburgischen und pommerschen Fürsten ihres alten Siedlungslandes verlustig. so daB mit dem 13. Jhd. der Name dieses Stammes für immer erlischt. Gesiedelt hatten sie, wie Urkunden belegen, zwischen der oberen Recknitz. Trebel. Nebel und Ostpeene, oberhalb Demmin und Kummerower See (Herrmann, J., 1968, 23 l.; ders. 1974, 8, 11: Brủske 1983, 10).

Man wird kaum der Behauptung widersprechen. daß der Name der Zirzipanen zu den rätselhaftesten aller slavischen Stämme sowohl Nordwestals auch Mitteldeutschlands gehört. Auch wird man den Verdacht hegen, es handle sich bei diesem Ethnonym überhaupt um keine slavische Blldung. Wie sehr der ungewöhnliche Name den mittelalterlichen Annalisten. Chronisten oder scribae zu schaffen gemacht haben muB, drückt sich in fast allen ubberlieferten. hier nur teilweise angezogenen Belegen aus:

zu 884 Circipinensis provincia (Sax. gest. Dan. 142, 20. MGH SS 29):

zu 955 Zcirizspani (An. Sangall. maior. 78, MGH SS 1):

zu 965 Zerezepani (MGH DO 1, 412, 10):

zu 973 Zirzipani (MGH DO II, 41, 35):

zu 982 Cyrcipensis palus (Sax. gest. Dan. 159, 5).

Verwirrend geht es auch in späteren, selbst in kaiserlichen und päpstlichen Urkunden zu:

1170 czirzepene (CPD Nr. 28, Dipl. Friedr. 1.):

1170 Chircepene (MUB Nr. 91. Dipl. Friedr. I.);

1197 Cirzipen (MUB Nr. 162. Papst Coelest. III.).

Niederle (III, 137) notiert außerdem die Varianten: prov. Zirzipa. Scircipene, Cirpania, Cyrspania und Szyrszopenia.

Einigermaßen konsequent wird der Name von den norddeutschen Chronisten Adam von Bremen, Helmold von Bosau, aber auch von Arnold von Lübeck geschrieben. Adam verwendet dabei vorwiegend die From Circipant (lib. II, 21: III, 20, 22): mit geringfügigen Abweichungen (Cyrcipani) gebrauchen diese auch Helmold und Arnold. Normierend scheint hierbei die Chronik Adams gewesen zu sein. 
Der große Formenrelchtum. mit dem die mittelalterlichen Denkmăler das komplizierte Ethnonym umschreiben, spiegelt den Schwierigkeitsgrad wider, den die lateinische Graphik zu bewaltigen hatte. Auffallend ist die Reserve der Etymologen gegenüber dem unslavisch wirkenden Stammesnamen. Im Grunde "regiert" noch heute eine schon von Safařik (II. 895) geăußerte Ansicht, die sich ohne nennenswerte Abstriche über Niederle (III. 137) bis auf Lehr-Splawinski (1958, 293 fr.; ders. In: SlowStarSlow I, 306) behaupten konnte. Danach soll der Zirzipanen-Name ein Kompositum aus der Präposition čez (crêss, crêss < urslav. 'kerss) und dem Hydronym Peene sein. Unter den črezpénjane habe man daher die jenseits der Peene Wohnenden $z u$ verstehen.

An dieser Etymologie stören jedoch zwei Dinge. In erster Linie die Tatsache, daß die slavische Prăposition cersz. cerzz (c. acc.) in aller Regel nicht Präfix sein kann (Slownik praslowiatiski II, 164 f.). An eine prănxale Konstruktion vom Typ crez-pén- ist in so früher Zeit unter keinen Umstănden zu denken. Statt dessen drängt sich der Verdacht auf. daß die genannte Deutung von der lautlich und syntaktisch recht ăhnlichen latelnischen Präposition circa, circi(ter) oder auch citra beeinflußt wurde. Ein Satz Adams von Bremen verdeutlicht das: Clrcipanj quj habitant citra Panim Muvium. Tholosantes et Rethri, quj ultra Panim degunt (lib. III, 22). Auch haben wohl die Siedlungsgebiete der Zirzipanen jenseits der Peene einen entscheidenden Anteil an dieser Etymologie. Weiter stört an ihr, daß es In den lateinischen Denkmalern nicht einen einzigen Beleg far den Gebrauch des slav. Suffixes -jane gibt. In den weitaus meisten Fallen wird der Nom. Pluralis mit der lat. Endung - $i$ (-panj) gebildet. Lehr-Splawinskis Konstruktion - crezpenjane hat in den schriftlichen Quellen somit keinen Rückhalt.

Die etymologische Fehleinschătzung der Zirzipani beginnt mit dem ersten Buchstaben. In deutsch-slavischen Kontaktzonen hat die littera $z$ nicht nur den Lautwert $c(t s)$, sie kann ebensogut Vertretung für $s$ sein: Zauche < Sucha, Zolchow < Sulchov. Zettlitz < Sedlec usf. Man kann also statt Zirzi- auch Sirsi- lesen. Diese erste Erkenntnis gab den AnstoB zur Identifizierung des eigenartigen Ethnonyms: Es spricht sehr vieles dafür. daB sich hinter den mecklenburgischen Zirzipanen in Wirklichkeit der Name des nordgriechischen-ostmakedonischen Stammes der Elploraioves oder Eıporaioves verbirgt. Dieser gut belegte Stammesname ist ein Kompositum aus dem ON Siris und dem Volksnamen Paiones. 
Als Zentrum der Eıpcoraioves nennt Herodot VIII, 115, die Stadt Eipls, deren Name Llvius XL, 4, 2. mit dem Plural ad Siras wiedergibt. Die Stadt Siris oder Sirra, auch Seres. Serra oder Serrhai helBt heute Serrä und liegt an der Südwestecke des Piringebirges, etwa zehn Kllometer nordostlich der unteren Struma (Schramm 1981, 353). Der früh und oft erwähnte Ort war in der Antike Hauptsitz der Maioves oder Påonen. in christlicher Zeit Bischoisplatz und unter Byzanz hauptstadt eines Themas: Ëot

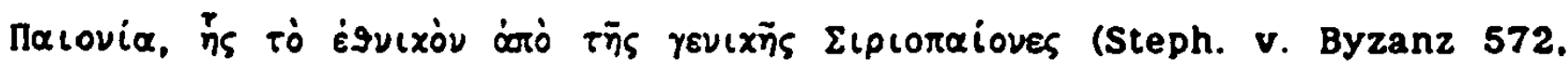
13). Viel später leiteten die Serben ihren Stammesnamen volksetymologisch vom ON Siris bzw. Seres ab: zu 1503 heibt es ots Sera ze srbblje (Danicic III. 268). Im Slavischen wurde der Name der Stadt zu Serezb und Seresb. in gekürzter Form auch zu Serb oder Serb (Danicić ebda.). Dabei setzt das Slavische nicht die antike Form Sir-, sondern die jüngere, auf vulgärlateinischem Lautwandel $\mid>e$ beruhende Version Ser- fort (Schramm 1981. 353 ).

Die Paiones, lat. Paeones (Pauly RE 36. Hbd. Sp. 2403 fr.), ein schon Homer (II. II. 848) bekannter Stamm, sind weder ethnisch noch sprachlich eindeutig zu beurteilen. Das sog. Paionische ließ die Gelehrten an lllyrische oder thrakische, auch griechische oder sogar kleinasiatisch-phrygische Herkunft denken (Solta 1980, 35 f.).

Frei ubersetzt bedeutet der Name der mecklenburgischen zirzipanen also Pảonen a us Siris. Dabei gibt die Bildung Zirzipanen nicht ganz getreu den alten und gut belegten Insassennamen Eเpเoraioves 'Einwohner von Slris' (Herod. 5, 15; Steph. v. Byz. s.v. ETpLs) wieder, vielmehr scheint Zirzipanen eine Nachbildung aus dem $O N$ Siris und dem Stammesnamen Paiones zu sein. Dahinter kann sich sogar eine Absicht verbergen. Wie bekannt, haben gelehrte Spekulationen zu Beginn des 2. Jhds. $n$. Chr. die

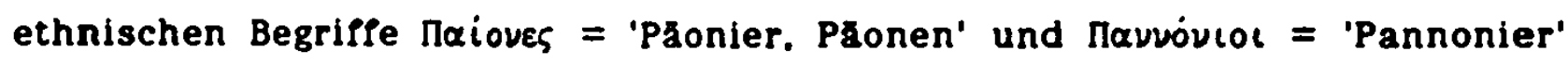
vermengt. Einer der Ersten, die dies taten, war vermutlich Plutarchos ${ }^{1}$. Vollends brachte dann beide Ethnika Appianos (Illyr. 14) durcheinander. Auf die unzulässige Vertauschung hat später Cassius Dio (XLIX 36) hingewiesen (vgl. Graf 1964, 14). Doch wird auch danach nicht immer exakt zwischen beiden Ethnika unterschieden, wie einschlägige stellen etwa bei Stephanos von Byzanz ${ }^{2}$ u.a. zeigen. Der als 'Päonen aus Siris' zu verste-

1 Vgl. A. Mócsy: Pannonia. Stuttgart 1962 (= Sonderdruck aus Paulys RE). Sp. 520.

2 So etwa 224, 9; 458, 6; 480, 9-13; 572, 14. 
hende Name der mecklenburglschen Zirzipanen läßt demgegenüber keine Zweifel aber die Herkunft seiner Trăger aufkommen.

Grundsătzlich lassen sich unter den Belegen des mecklenburgischen Stammesnamens zwei Schreibvarianten unterscheiden: Zirzi-pani und Zerez(e)-pani. Im ersten Fall ist die 2. Silbe des oN Siris zu zirzi- (= Sirsi-) umgestellt, während der zweite Typ, also Zerez(e)- oder auch Zcirizs-. die ursprüngliche Lautung bemerkenswert genau wiedergibt. Die Umstellung In Zirzi-pani beruht z. T. auf Ausspracheerleichterung, da eine Konsonantenhăufung $-z p-/-c p-(=-t s p-)$ zu vermeiden war; ansonsten steht Zirzi- natülich unter dem Einnuß von lateinisch circi-

Um welche Slaven es sich in jenen aus Ostmakedonien bis nach Mecklenburg abgewanderten „Păonen aus Slrls” gehandelt hat, läßt sich natürIIch nicht mehr mit Sicherheit feststellen. Vielleicht ist es aber nicht verfehlt. sie mit jenen slavischen Stammesverbänden in Verbindung zu brin-

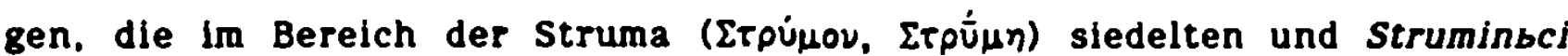
oder Strymoniten (SlowStarSlow V. 439 f.: Zakythinos 1979. 74) hießen. Sie wurden bekannt wegen ihrer Beteiligung an den Angriffen auf Saloniki im 7. Jhd.

In seiner Beschreibung des Xerxes-Feldzuges sagt Herodot (VII, 113):

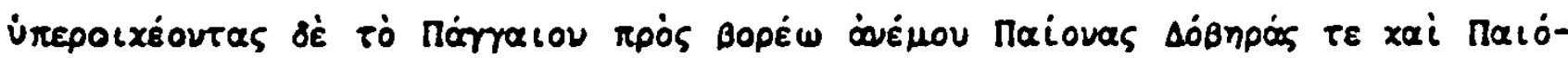

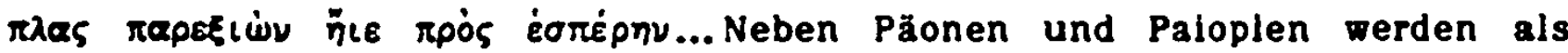
welterer makedonischer Volksstamm In Paionien (Pauly RE 9. Hbd. Sp. 1249 (.) somit die Dobéres genannt. Inre Hauptstadt, Dobéros neben Dobers, sucht man in der Năhe des Dojran-Sees, aber auch im Quellgebiet der strumlca (Kl. Pauly II, 110). Ob die Doberer erst ein paionischer, spater thrakisch Uberschichteter Stamm waren (Mayer 1957-9, I. 126: II, 41). wird sich wohl kaum mehr feststellen lassen. Unweit westlich der mecklenburgischen Zlrzipanen begegnet der bekannte Badeort Doberan. Spiegelt sein Name das Ethnonym der paionischen Doberer wider? Die Notierungen dieses ON - 1177 Doberan neben villa Slavica Doberan (heute Althop bei Stadt Doberan), 1171 claustrum Doberan (ofters), 1192 Jocus monasterij in Doberan, 1319 Antiqua curia Doberan (Trautmann 1950, 49) - weisen in allen Fällen überraschend konsequent die Schreibung mit "Fugen"-e- auf, was sich vielleicht als Reflex von griech. $\eta$ bzw. $\varepsilon$ verstehen läßt. Schon Bach zeigte sich skeptisch (1954, II, 2, 238), ob Doberan zu slav. dobry gehöre. Auch wenn Trautmann meint, "altes "Dobrane" sei "Identisch mit ac. Dobřené. Dobřane..." und gehöre „zu Dobre”. ist doch festzuhalten, daß 
nicht ein einziger Doberan-Beleg ohne .Fugen"-e- Ist. Statt von "dobrane ist daher wohl besser von - dober-jane auszugehen. Trautmanns Erklärung. "der Ort sel nach der auffallend freundlichen Landschaft um Doberan benannt" worden. wirkt doch wenlg überzeugend (1950, 49).

Man war selt Jeher der Meinung. zwischen dem Namen der Peene und dem zweiten Glied des Ethnonyms Zirzi-pani müse es einen Zusammenhang geben. Zunăchst Ist zu sagen, daß das Hydronym verhăltnismäßig gut belegt ist: zu 789 ad Pana fluvium (MGH SS I, 34 = Frag. ann. Chesnii); Penis, Peanls, Panis (Adam v. Bremen): Panis, Penis, Penus (Helmold v. Bosau); Pyana (Chronica Poloniae Maioris). Diese und weitere Schreibarten haben zu der nahezu einhelligen Ansicht beigetragen, die Peene verdanke ihren Namen slav. péna, poln. pjana 'Schaum'3. Dagegen gibt es gewisse Bedenken. well das Substantiv péna in der Bedeutung von Schaum schwerlich zum Flußnamen werden konnte, hauptsăchlich aber deshalb, weil die Peene ein kleiner FluB ist. der "ungewöhnlich langsam fließt...so daB von Schaum nicht die Rede sein kann" (Stleber). Geht man jedoch davon aus, daB das Wort Peene in Zirzi-pan(l) = Siris-paion(es) enthalten ist, dann liegt es nahe. das Hydronym mit dem Landschaftsnamen Pajonia in Verbindung zu bringen. Am UmwandlungsprozeB Paionia > Pe(a)n(is), Pean(is) können mehrere Sprachen mitgewirkt haben, wobei lestzuhalten ist. daß im Blick auf die Konsonanten so gut wie keine Verănderung eingetreten ist. Was den Wurzelvokal anlangt. so wird im gesprochenen Latein griech. aj an lat. ae angepaßt und dieser Diphthong zu $e$ weiterentwickelt (Schramm 1981. 308). Auch das Germanische bezeugt seit dem 7 . Jhd. einen sehr annlichen ProzeB, denn germ. ai wird im As. stets zu e monophthongiert (v. Kienle 1969, 24: Braune-Eggers 1975. 42 $\mathrm{N}$.). In erster Linie kommt bei diesem Vorgang aber doch wohl das Slavische in Betracht, da es fraglos Slaven gewesen sein mußten, die den Landschaftsnamen Paionia nach Mecklenburg verpflanzten. Bekanntlich wird im Slavischen $a i>e$. vgl. gr. $\lambda \alpha_{l}(F)$ os, lat. laevus > slav. lévs 'link'. so daß regelgerecht pén-entstehen konnte. Der o-Laut in Paion-stört nicht. da o nach $i$ wiederum ein 'e erbrachte, vgl. mor'e, pol'e//selo, mesto u.a. Im ubrigen bedurfte es kelnes besonderen volksetymologischen Eingriffes. um pen-mit péna 'Schaum' zu assozileren. DaB man den ostmakedonischen Landschaftsnamen, der sich vielleicht von idg. 'poi-/'paj- 'Gras, Wiese' herleitet (Mayer 1957-9, II.

3 Trautmann I, 17: Shevelov 1964, 168; Stieber in: Jezyk polski 54, 1975. 375. 
85). schon bald nicht mehr verstand. liegt auf der Hand. Möglicherweise spiegelt eln Tell der Belege wie Panis, Peanis oder Pana den sog. lechitischen Umlaut von $e$ > $a$ wider: urslav. péna > poln. piana (Urbaticzyk in: SlowStarSlow IV, 70). Die Schreibung -ee- in Peene geht wohl aup Zerdehnung zurück (Lasch 1974, 35 \%1.). Der Name der Peene als kleiner, zur Zeit der slavischen Landnahme entweder namenloser oder den Neusledlern unbekannter Fluß ist höchstwahrscheinlich Sekundărbenennung durch Slaven. Das neue Hydronym ist sowohl als Teil eines Ethnonyms als auch als Herkunftsbezelchnung zu verstehen. Weder das Ethnonym noch das Hydronym konnen natürlich auf das Konto der sog. Nordillyrier verbucht werden, wie sie noch Vasmer. Krahe und Pokorny vorschwebten. Allein der konkrete topographische Bezug auf die makedonische Stadt Siris läßt dies schwerlich zu. 
7. Rethra. Redarier. Arkona

Von den vier nordwestdeutschen Stämmen. die Ende des 10. Jhds. den so bezeichneten Lutizen-Bund eingingen (Brüske 1983; Hellmann 1960), soll nach Meinung verschiedener Forscher der Stamm der Redarier tonangebend gewesen sein. Dieser Stamm, der nicht ganz zu Recht der abodritischen Mundartengruppe zugerechnet wird', besaß ein zu seiner Zeit weithin bekanntes heidnisches Heiligtum, dem zeitgenossische Chronisten wie Thietmar von Merseburg. Adam von Bremen und Helmold von Bosau thre Aurmerksamkeit schenkten und dieses entweder Riedegost (Thietmar II. cap. 17/23) oder Rhetre (Adam 11. cap. 19; Helmold 1. cap. 2) nannten ${ }^{2}$. Diese offenbar berūhmte westslavische Kultstäte, die man sogar für die "Hauptstadt des Lutizenbundes" hielt (Brüske 11, 63) - Adam nannte sie jedenfalls metropolis Sciavorum (III. cap. 50) -. wurde sehr wahrscheinlich um 1127 durch Konig Lothar III. zerstört. An die Stelle von Rethra trat danach, in vermutlich gleicher oder ähnlicher kultischer Funktion. Arkona auf Rügen (Brüske 83 f.. 100). Die mit Rethra überkommenen Probleme beschăftigen seit langem Geschichtswissenschaft. Archăologie. Volkskunde. Religionswissenschaft und - nicht zuletzt - die Sprachwissenschaft ${ }^{3}$.

\section{Zur Lage von Rethra}

Seit nunmehr gut 600 Jahren wird Rethra von Archäologen. Sprachwissenschaftlern und Sagenforschern mit großer Energie und unglaublichem Einfallsreichtum gesucht, allerdings - um es vorwegzunehmen - ohne sichtbaren Erfolg. Einer der ersten, die sich mit neuzeitlichen archäologischen Methoden auf die Suche nach Rethra begaben. war der bedeutende Berliner Prähistoriker Carl Schuchhardt, der schon 1921 glaubte, die slavische Kultstäte auf dem Schloßberg von Feldberg in Mecklenburg. ठstlich von

1 So Jedenfalls Lehr-Splawinski in seiner Besprechung des Buches von Brüske in: Wiener slavistisches Jahrbuch 5, 1956, $164 \mathrm{f}$.

2 Der Einfachheit halber wird im folgenden der Form Rhetra der Vorzug gegeben, auch wenn Adam Rhetre schreibt, wozu noch Stellung genommen wird.

J Außer den Stichworten Radogost (Urbanczyk). Radogoszcz (Moszytiski. Strzelczyk) und Redarowie (Labuda) in SlowStarSlow IV. 450 f.. 477 fr.. seien an neuerer Literatur noch genannt: Herrmann. J., 1985 (Register); Schmidt. R. 1974; Lowmiariski H., 1978, 1979; Dralleinl1984stmann-9783954792238 
Neustrelitz, erkannt zu haben (Schuchhardt 1926, 28 Pl.). An Rethras Lage mitten im alten Redariergau, das heißt in der Năhe des Wanzkaer Sees zwischen Neubrandenburg und Neustrelitz, dachte später Eckhardt Unger (1952; 1959), der zum Jahr 1958 sage und schreibe 29 Orte aufzählte, an denen Rethra bereits vermutet oder gesucht wurde (Unger 1958). An das Lieps-Gebiet bei Prillwitz sudlich des Tollense-Sees hat sich dann - zum Teil die Untersuchungen von Wossidlo (1909) wieder aufnehmend - Paul Beckmann mit volkskundlichen Mitteln herangetastet (Beckmann 1959). Erneut mit archäologischen Methoden wurde 1967 der Schlobberg auf dem Feldberg angegangen, auf dem Joachim Herrmann umfangreiche Sondagen vornehmen lleß, deren Resultat es war, daß für das 7.-8. Jhd. tatsåchlich eine Burg vom Typ der wilzischen Höhenburgen nachzuweisen ist, diese Burg aber nicht Identisch sein kann mit Rethra (Herrmann. J. 1970)`. Einen weiteren Versuch, Rethra und zugleich die Sitze der Redarier zu lokalisieren, unternahmen unter historischen und archäologischen Gesichtspunkten Schroeder und Hornemann, dle zu der Oberzeugung gelangten, daß die Redarier-Sitze an der unteren Peene lagen und Rethra möglicherweise der Bauerberg bel Lassan im Kreis Wolgast gewesen sein könnte (Schroeder. Hornemann, 1972/3). Auf der Suche nach Rethra dachte zuletzt Lothar Dralle an dlejenigen Landschaften, in denen die Müritzer und Doxani saBen. vor allen an die nördlichen Săume des Waldgebietes Besut und Lletze. Dralle lokalisierte Rethra daher in die Nähe des Großen stechlin (Dralle 1984).

Die Deutungen der Namen Rethra und Redarier

Der Anreiz, das etymologische Rätsel Rethra zu lösen und damit zugleich den Sinn des Stammesnamens der Redarier 20 ermitteln, muBte verlockend sein. da die Zahl der Deutungen nicht gering ist. Bei Licht besehen ist es Jedoch so, daß man sich bislang eher um die Lősung des Ethnonyms Redarler bemüht und den $O N$ Rethra beiseite geschoben hat. Die heutige Melnung uber Rethra/Rethre geht immer mehr dahin. daß dies „falsche Schrei-

- Dazu weiter: H.-H. Muller: Das Tierknochenmaterial aus der slawischen Burg auf dem Schlobberg bel Feldberg. In: Slavia Antiqua 16, 1970, 71 If.; E. Lange: Ergebnisse der pollenanalytischen Untersuchungen zur Ausgrabung am Schlobberg von Feldberg. In: ebda. 85 fl.; dies.: Der Bei-

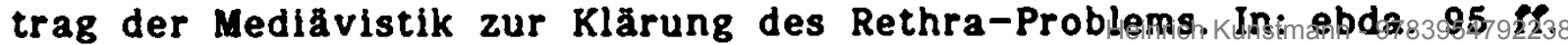


bungen deutscher Chronisten" seien (witkowski 1968, 414). während das Heiligtum In Wirklichkeit 'Redigosc geheißen habe (ebda. 413 ९.).

Eine der ersten Etymologien stammt noch von Safařik, der an urslav. 'ratb 'Krieg' anknüptte, so daß die Redarier 'Krieger, Kämpfer' gewesen seien (1837. II, 897). Eine besonders wichtige, bis heute vieldiskutierte Interpretation geht auf Trautmann zurück, der das Ethnonym - Retari aus - Ratari (= urslav. 'ortajb, vgl. osorb. u. serbokroat. ratar) erklärt (1950. 125). was soviel wie 'Pfiüger. Bauern' bedeutet. Dieser Ansicht sind - mutatis mutandis - in der Folge auch Lehr-Splawinski. Sulowski und Stieber'. Gegen die Auslegungen Trautmanns und anderer wendet sich sodann Teodolius Witkowski. der seinerseits sowohl an eine Herleitung von dem gemeinslav. Verb 'raditi 'raten', als auch an Zusammenhänge mit slavischen Formen eür 'rot'. wie etwa russ. redryj oder urslav. 'ruda 'Erz' u.a. denkt (1968. 408). Danach hält Witkowski die Bedeutungen von 'Ratgeber' bzw. 'Leute des Rates (Orakels)' oder aber 'Redryje (< 'Rsdbryje/Rzdbryje) im Sinne von 'rothaarige Menschen' für die möglichen "richtigen". Die Bedeutungen von 'Kämpler: Bauern. P९lüger' weist Witkowski zusammen mit Schlimpert zurück (1969, 529 fl.).

Noch anderer Meinung sind E. Eichler und H. Walther, die den Stammesnamen der Redarier als 'Riad-wariōs 'Riedmănner, -leute' aufrassen. somit an Blldungen wie 'Angriwariōs 'Wiesenlandbewohner' oder 'Baiwariōs 'Bewohner des (alten) Bojerlandes' denken (1966. I, 281 P.). Diese Ansicht verwirft jedoch Witkowski (1968, 412), und zwar mit der Begründung. die Meinung Eichlers und Walthers setze voraus, der slavische Stamm der Redarier habe nur einen deutschen Namen gehabt. Bemerkenswert nahe ist indes Witkowski der Lösung des Problems gekommen. wenn er in dem Stammesnamen der Redarier die Bedeutung von 'Ratgebern' oder 'Leute des Rates (Orakels)' vermutete (1968, 408). Allerdings ist Witkowski zu dieser Deutung gewissermaßen auf "Umwegen" gelangt.

- Zu Lehr-Splawihski vgl. Pußnote 1. hier: S. 163: Ratari < ratari < ortari. Den urkundlich zu 936 belegten Landschaftsnamen Radwere interpretiert Lehr-Splawinski als Zusammensetzung aus or- 'pflügen' und dror- 'Geblet', also urslav. 'or-dvorbje > westslav. radvofe 'Pflüggebiet'. Vgl. dazu Witkowski 1968, 412. - 2. Sulowski: O synteze dziejów Wieletów-Luciców. In: Roczniki historyczne 24, 1958, 134. 2. Stieber: Die slawischen Namen in der Chronik Thietmars von Merseburg. In: Onomastica Slavogermanica III, 1967 (Berlin). 110: „M.E. nannten sie sich "Retari 'Bauern'". 
Die bisherigen Deutungen der Namen Rethra und Redarier

Es ist zunăchst ein Wort zur eigentlichen Funktion, von Rethra vorauszuschicken (vgl. Wienecke 1940; Reiter 1973. 185 ९., 192). Nach den Beschreibungen, die wir von Thietmar und Adam besitzen, war Rethra ein Ort. an dem der Orakelkult gepflegt wurde. Nach Adam von Bremen erhielten zu diesem Tempel nur diejenigen zutritt, die „opfern oder Orakelsprüche einholen wollen" (II. 21l18l. S. 54: pons ligneus...sscrificantibus sut responsa petentibus via conceditur). AufschluBreich ist dabei das von Adam benutzte Wort responsa/responsum. das bekanntlich die Bedeutungen von 1. Antwort. 2. Orakelspruch, Ausspruch, Gutachten und 3. Rechtsbescheid hat (Stowasser 430). Erheblich detalllierter als Adam berichtet Thietmar uber Riedegost/Rethra. Sein Bericht beschreibt nicht allein die Orakelkultstäte. durch inn wird uns auch die Art des Orakels, nämlich das Pferdeorakel uberlfefert (Reiter 1973, 195 u.a.), eine an sich schon merkwürdige Sache, da die Slaven ja doch kein ausgesprochenes Reitervolk waren. Sehr scharfsinnig hat Thietmars Bericht nun der Historiker Klaus Zernack entnommen, daß Rethra im Prühen 11. Jhd. nicht nur religlöse (Orakel)Funktion gehabt hat, sondern das hier auch ein polltisches Zentrum lag. das als placitum comune (= Ding) möglicherwelse den Volksversammlungen des ganzen Lutlzenbundes diente. Zernack zieht dabei auch den bekannten Ibrahim-Bericht aus der 2. Hälfte des 10. Jhds. heran. Zernacks Resultat, nach welchem das placitum als politische instanz. gewissermaßen statt dominus eine Art von oberstem politischen Organ darstellte. uberzeugt nicht nur, sondern wird durch das im folgenden Vorgebrachte bestätigt. Das Rethra der Ostseeslaven war also neben einer Orakelstatte zugleich das, was man Im Altrussischen als věce (vece) bezelchnet und darunter namentlich die Volksversammlung im alten Novgorod versteht. Vasmer (REW I, 195) stellt urslav. 'vétio - Miklosich und Preobrazenskij folgend - zu vet 'Rat, Vertrag'. was uberraschend genau der Bedeutung von griech. 'pirrpa entspricht'. Die nicht zu unterschătzende sachliche obereinstimmung zwischen vece (vece) und Rethra wird noch an anderer Stelle zu durchleuchten sein.

- Zum ac. sigmat. Aorist vece (vecéti) vgl. Slova a dẻjiny. Praha 1980. 22. Ansonsten V. Machek 1968, 687, der beim Verbum vétiti von vêts ausgeht und an 'voik-to- (zu lit. veikti) 'verhandeln' denkt, was sachlich abermals mit dtsch. dingen 'sprechen, handeln bel Gericht' und Ding 'Versammlung' korrespondiert. 
Rückblickend aberrascht es, daB bel der kolossalen etymologischen Energie, die aufgebracht wurde, um das Rătsel des Wortes Rethra zu 10 sen. dessen Bedeutung auch nicht annăhernd erkannt wurde. Dieses Wort ist nämlich keine Verbalhornung, auch keine Entstellung, sondern ein erstaunlich prăzise uberliefertes Wort, hinter dem sehr konkrete Inhalte stehen. Es ist weder keltisch noch nordisch, weder germanisch noch deutsch oder mittelniederdeutsch, es ist aber auch nicht slavisch, sondern - griechisch,

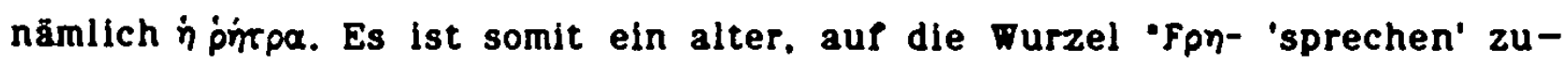
rückgehender Ausdruck für rechtlich bindende Erklărungen und Vereinbarungen, dessen ursprüngliche Bedeutungen 1. Worte. Sprache, Rede; sermo. oratio, 2. Verabredung, Vertrag. BeschluB, Gesetz (Passow II/2, 1335: Gemoll 665) und, was damit zusammenhăngt, 3. besonders: Orakelspruch: dictio. i.e. Oraculum (Stephanus VII. 2381: Pape II. 841) sowie 4. der Ort zum Reden, die Volksversammlung (Passow II/2, 1335; Pape II. 841) waren. Die in $\dot{p} \dot{r} p \alpha$ enthaltene enge Verbindung 2 wischen Gesetz. Orakelspruch und Volksversammiung zeigt sich prägnant an der berühmten 'Großen Rhetra'

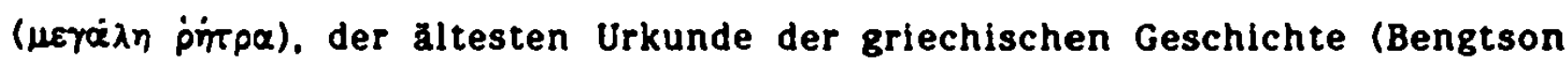
1977. 115), die bel Plutarch (Lyk. 6) im Wortlaut uberliefert und wahrscheinlich in die Form eines delphischen Orakels gekleidet ist. Das aus dem 8. oder auch 7. Jhd. stammende Grundgesetz Spartas legt Bestimmungen über den 'Rat der Alten' (repovoia) und die Volksversammlung lest und räumt dieser entscheidende Gewalten ein (Lex. d. AW. 2627). Wegen ihrer grundlegenden Bedeutung richtet de Forschung immer wieder ihren Blick auf die auch p̄̄̄tpaı genannten ungeschriebenen Gesetze des Lykurgos'. Im weiteren Sinne schließt p̈rtpa ein .Gesetz" ein. „sofern es als unabănderliche, im Wege des Orakels eingeholte Entscheidung der Götter angesehen wird" (Kl. Pauly IV, 1415).

Zwei signifikante, der griechischen Rhetra zugeschriebene Merkmale Orakelspruch und volksversammlung - treffen auch auf die Rethra der Ostseeslaven zu: Kultstäte und polltische Instanz (Zernack). Wenn die Orakelstätte von Adam auch metropolls Sclavorum genannt wird, so drücken sich darin beide Funktionen aus. Damit ist wohl

7 An neuerer Literatur vgl.: J. H. Oliver: Demokratia, the Gods, and the Free World. Baltimore 1960, 12 Pf. (mit Lit.): D. Butler: Competence of the Demos in the Spartan Rhetra. In: Historia 2, 1962, 385 \%.: G. L. Huxley: Early Sparta. London 1962, 44 fr.: F. Kiechle: Lakonien und Sparta. München, Berlin 1963, 142 M.; A. H. M. Jones: The Lycurgan

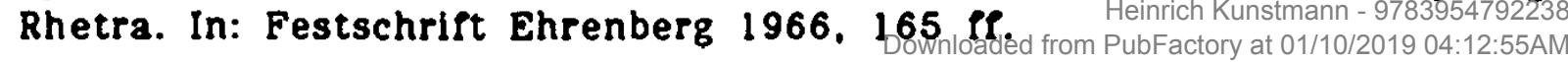


schlussig bewlesen, daß das slavische Rethra nach Wort und Inhalt nichts anderes sein kann als griech. bintpa. Zwar schreibt Adam nicht Rethra. sondern Rethre, doch spiegelt sich darin offenbar nur der Wandel $\alpha>\eta$ des ionisch-attischen Dialekts wider. In welchem das fragliche Wort ṕñ lautet. A. Brückner”, der Adam unterstellte. Thietmars Mitteilungen "vertauscht" zu haben, dürfte damit kaum recht haben, da vielmehr anzunehmen ist, daß Adams Rethre auf einer anderen Quelle als Thietmars Riedegost beruht.

\section{Thietmars Riedegost}

Die Angaben Adams von Bremen und Thietmars von Merseburg zu Rethra weichen voneinander ab. Während Adam unter Rethre den Ort versteht und die an diesem Ort verehrte Gottheit Redigast nennt, bezeichnet Thietmar den Ort Riedegost und den Götzen Zuarasici. Abgesehen davon, daß der Name Zuarasicl nicht gerade einen slavischen Elndruck macht, besteht zwischen beiden Chronisten Obereinstimmung hinsichtlich des Namens Redegost, der einmal eben Ortsname - Redegosc < - gostb + -jb - das andermal Personenname ist. Man hat in Redegost, Radigast, Radogast u.a. daher auch einen Zweitnamen fur Zuarasici erkennen wollen (Urbaticzyk 1947. 19 గr.). was indes eine unbegründete Vermutung bleibt. Da sich Adams Rethre, wie gezeigt, nicht aus Thietmars Riedegost herleiten kann, was noch Brückner und viele andere nach Ihm glaubten, konzentrlert sich der Blick auf den Eigennamen Redegost.

Entscheidend ist, ob dieser slavischen Ursprungs ist oder nicht. Unbestritten ist dessen $z$ welter Teil -gostb 'Gast. Fremder, angereister Kaufmann', der wohl urverwandt ist mit gotisch gasts 'Gast' und lat. hostis 'Fremder, Feind'. Weniger klar ist das erste Glied, also rad-. das man sowohl mit slav. 'rads 'gern' als auch mit dem Verbum 'raditi 'wollen, sich bemühen, sich kümmern' zusammengebracht hat, so daß Radogast als 'gern (gesehener) Gast' gedeutet, aber auch zum 'Gott der Kaufleute' wurde (SlowStarSlow IV, 450: Urbanczyk). In diesem Zusammenhang erinnert man sich der wohl ältesten Notierung dieses Namens, jenes Apsáraotos der byzantinischen Quellen, der schon Gegenstand vieler Oberlegungen war.

- Brückner behauptete, Adam von Bremen habe nichts weiter gewußt als das, was er bei Thietmar gelesen habe, so sei bei Adam eben aus der Stammesbezeichnung Redarier der Tempelort Rethra geworden, vgl. Archiv f. sl. Ph. 14. 1892. 164. und Brückner 1980, 240 feinrich Kunstmann-9783954792238 


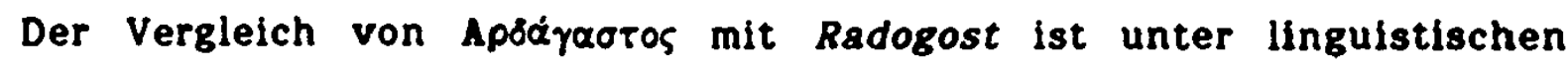
Gesichtspunkten problemlos: Um 800 erfolgte die Umstellung der vokalisch anlautenden Silbe ard-In rad-, auch ist der Wandel $a>e$ im Umkreis der Liquida $r$ und $l$ keine Seltenheit, so daB aus Ardagastos ohne Schwierigkeit eln slav. 'Radogostb und Redegost u.a. entstehen konnten. Nicht auszuschlleben ist dabei auch eine gewisse volksetymologische Beeinflussung durch slav. 'rads 'gern'. Etymologisch unklar bleibt dennoch die Silbe ard-. die wohl kaum auf urslav. 'ords (Vasmer 1941, 290) beruht, wie es auch offen bleibt, ob ard-aus iranisch arda-entstanden ist, was noch Nieminen meinte (Machek 1968, 504 ९.).

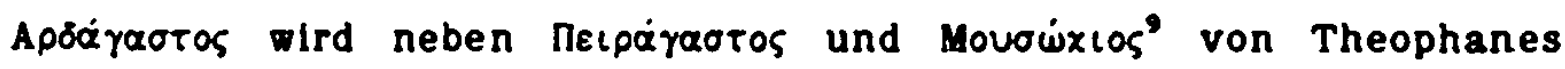
Homologetos (254, 11) und Theophylaktos Simokattes (I. 7, 5 u.a.) als einer von Jenen slavisch-vlachlschen Truppenfuhrern genannt. die gegen Ende des 6. Jhds. an der unteren Donau in Kämple mit Kaiser Mauriklos und Priskos verwickelt waren. Laut Theophylaktos Puhrte Ardagastos einen großen Beutezug gegen Byzanz an und drang bis Adrianopolis vor, wo inm allerdings eine Niederlage widerfuhr ${ }^{10}$. Der PN Ardagastos ist wohl weder slavischer noch iranischer Provenienz. sondern leitet sich mit einiger Wahrscheinlichkeit von dem thrakischen Hydronym Arda her (Georgiev. V., 1977. 244 P.). so daß er sich als 'Fremder, Gast von der Arda' deuten läßt. Das Gebiet der Arda. eines etwa $200 \mathrm{~km}$ langen Nebenflusses des Hebros im Kernland der thrakischen Odryser, war häufig Durchzugsgeblet der Slaven auf ihren Eroberungskriegen gegen Byzanz. Die Ableitung des PN Ardagastos von dem FIN Arda wird dadurch wahrscheinlich, daB der slavische Führer bei Adrianopolis (Glossar B I, 289 ศY., II, 3 N.) geschlagen wurde. und die byzantinische Stadt (h. türk. Edirne) an der Mündung von Tundza (Tonzos) und Arda In die Marica (Hebros) llegt. Der Name Ardagastos kann somit einem historischen AnlaB entsprungen sein. Kompositorisch erinnert die Bildung Ardagastos auBerdem an den Namen des Gepiden-Königs Ardaricus und des arianischen Germanen und römischen Gene-

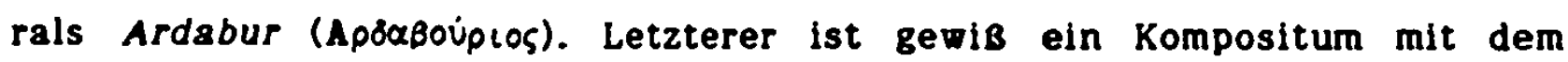

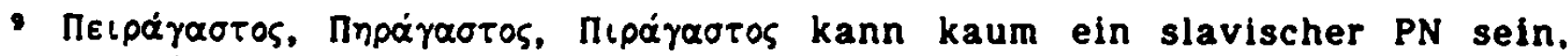
eher ist an eine teilweise griechische oder thrakische Bildung mit nupc-, חipo- u.a. zu denken, vgl. 2. B. Piroborus (Detschew 369, 386): zu Movoiuxios, Movoouxos, Musacius u.a. vgl. Kunstmann ${ }^{2} 1987,154$.

10 Glossar A I. 122 ९.; Zástêrová 1971. 74, 78 ९.: Szádeczky-Kardoss 1972. 73. 78; Lowmianski 1964-73, II, $392 ~ \mu$. 
häuflg Personennamen bildenden thrakischen Formans - bur 'Mann' (Detschew 1957, 80).

Bedenkt man nun, daß die slavische Mythologie antike Heerführer und Staatsmănner wie Traianus, Caesar (Julius-Lanze!), Probus u.a. zu numina erhob und sogar slavische Stämme nach antiken Heerfürern benannt wurden" , dann wăre zu erwägen, ob nicht auch elgene Truppenführer oder Gentilaristokraten der Slaven kultische Verehrung erlangen konnten. Vielleicht wurde diese jenem Ardogastos in der von Thietmar Riedegost genannten Kultstätte zutell.

\section{Der Name der Redarier}

Man hat, wie schon gesagt, etymologische Zusammenhänge vermutet $z w i-$ schen dem ON Rethra/Rethre und dem Namen der Redarier, also des slavischen Stammes, der in Rethra seine Orakelstätte hatte und hier wohl auch Volksversammlungen abhielt. Die Zahl der Schreibvarianten des Ethnonyms Redarier ist so groß und vielfältig. daß es unmöglich ist, sie alle aufzuzählen. Mehrere Notierungen finden sich in SlowStarSlow IV. 477 Pf.; vgl. neuerdings auch D. Zoladz 1981. Sieht man von gelegentlichen Formen wie Riaderi (936) oder Riedere (965) ab, dann überwiegt im Prinzip die Anlautsílbe Re-: Redarii (Widukind, vor 973; Thietmar, vor 1018; Helmold, um 1170). Retharil. Retheri. Rederi (Adam, alle um 1075). Ein auffallender Unterschied besteht in der Schreibung von - $d$ - und - $t(h)-$. Witkowski erkannte darin eine Auswirkung der niederdeutschen Entwicklung von th> d. die in 12.-13. Jhd. einsetzte (Witkowski 1968, 409). In jedem Fall bemerkenswert ist, daß die Schreibungen mit - $d$-vorwiegend bei sächsischen Chronisten begegnen, eben bei Widukind von Korvey und Thietmar von Merseburg. weshalb vielleicht mit Dialekteinwirkungen $z u$ rechnen ist.

Witkowskis Ansicht (1968, 408), der Stammesname der 'Redari < $R a-$ dari habe 'Ratgeber' oder 'Leute des Rates (Orakels)' bedeutet, stützt sich auf das gemeinsiavische Verbum raditi. Wenn Rethra. die Orakelstätte der Redarier, sich aber von ṕrtpa herleitet, dann ist es weitaus wahrscheinilcher. daB die von Adam überlieferten Formen Retharii. Retheri usw nicht auf raditi beruhen, sondern die ja nur wenig entstellte Wiedergabe von griech. p̈ñtwp, opos. PI. p̈rropes sind, und dies im Sinne von 'Sprecher. Red- 
ner. Volksredner. Wortfährer'12. Gleichbedeutende epische Dublette zu p̈rrwo Ist p̈ñtnp (Pape II, 841; Frisk II. 654). Diese Etymologisierung besagt somit. daB sich die Redarier, Retharier < ṕṙopes als stamm der Orakel-Sprecher verstanden oder von anderen so genannt wurden.

"Unter lautlichem Aspekt wirft" die Herleitung des Redarier-Namens von griech. ṕrtwp in der Tat, keine spezinschen Probleme aur" (witkowski 1983, 278). Auch der Wandel von $0>a$ in der SchluBsilbe stellt kein unlösbares Problem dar. Wahrscheinlich handelt es sich hierbel um Anpassung an dle ahd. Völkernamen-Bildung au -ari, -äri (Braune, Eggers 188 f.) oder aber an die as. nomina agentis auf - ari, -eri, -iri (Lasch 195). Moglicherweise hat auch die niederdeutsche Besonderheit eine Rolle gespielt. zerdehntes 0 orthographisch mit a wiederzugeben (dies. 64 凡.. $88 \mathrm{ff}$. ).

Durch pinwwe, das ist noch zu sagen, waren unzăhlige Assoziationsmōglichkeiten gegeben, die zu volksetymologischen Umdeutungen geradezu herausforderten. Das betrifft sowohl das Slavische als auch das Deutsche. So konnte es eben im Slavischen Anklänge an raditi 'raten' oder 'rads 'froh. gern' geben. Wesentlich vielfaltiger waren die Verwechslungsmöglichkeiten durch deutsche Bedeutungen wie 1. reden: ahd. ręd(i)ón und rędinōn, as. rediōn, mhd. ręden: 2. Rede: ahd. radia/ręd(i)a, reda, redha, redea, redia. radia: 3. raten: ahd. rātan, as. rādan, mhd. raden oder 4. Rat: ahd.. mdh. răt.

\section{Arkons aut Rügen}

Wāhrend der Wirren in der 2. Hälfte des 11. Jhds. wurde Rethra, der Haupttempel der Redarier, im Jahre 1068 vom Bischof von Halberstadt erobert (Brüske 83 ff.; Lotter 1977, 55). Gegen Ende des 11. oder zu Beginn des 12. Jhds. wurde dann Arkona auf Rügen zum Hauptheiligtum der Slaven $z$ wischen Elbe und Oder's. Doch flelen Arkona und seine Kultstatte 1168 der Vernichtung durch die Dänen anheim. Genau wie Im Palle Rethras blieb auch die Lage des Tempels von Arkona unbekannt, denn die Vermu-

12 Als Berufsbezeichnung stammt das Wort aus der attischen Amtssprache, vgl. Fraenkel 1910-2, 2, 9.

13 Nach Strzelczyk übernimmt Arkona 'um 1100' die Rolle Rethras, vgl. Helmoida Kronika Slowian. Tarszawa 1974, 195. Anm. 487. Dazu auch Brüske 100. - Im allgemeinen zu Arkona SlowStarSlow I, 47 I.: VII. Suppl. 372 ff.: W. Lositski: Lex. d. MA I. 952 f.: Hinz. Dralle (mit Lit.). Im Glossar A Pehlt das Stichwort Arkona. 
tungen Schuchhardts (1926, 13 f.) haben die Grabungen der Jahre 1969 bis 1971 nicht bestätigt (Herrmann, J., ${ }^{2} 1974,177$ ff.). Die hinter dem $46 \mathrm{~m}$ hohen Kreidefelsen am Nordkap der Insel Rügen erwartete Tempelburg erwies sich nicht als die gesuchte Kultstătte, sondern als Rest eines älteren Befestigungswalles. Möglicherweise ist der "Tempelbereich wohl schon ins Meer abgestürzt" (H. Hinz). Arkona war wie Rethra der Platz eines Pferde-Orakels, auch befand sich hier das überlebensgroße Standbild des Gottes Svantevit, einer Gottheit vielleicht des Krieges und der Felder (Ackerbau) (Reiter 1973, 195 凡.).

Genau wie bei Rethra bereitete bislang auch im Fall von Arkona die Etymologie einige Schwierigkeiten. Brückner hielt das Wort für rugisch. für ein Rellktwort also der germanischen Rugier (1929, 315, Anm. 1). Für Mikolaj Rudnicki lieB sich Arkona weder aus dem Germanischen noch dem Slavischen erklären, da "sowohl der Stamm ark-, als auch das Sufflx -ona (nur) südlich der Alpen und Karpaten vorkommen". Rudnicki schwebten als vergleichbar Formen wie Ver-ona. Sal-ona, Ank-ona vor (SlowstarSlow I, 47). Vasmer wiederum leitete Arkona aus dem Nordischen her, wobei er an anord. arkn, erkn eine 'Art Seehund' dachte (Schriften II, 867). Diese und viele andere Deutungsversuche haben das Rätsel des Wortes Arkona nicht gelöst. Fest steht allein, daß es unmöglich slavischer Provenienz sein kann.

Bel der Beurteilung der altesten Notierungen dieses ON zeigt sich. daß offenbar nur Helmold von Bosau die Form mit auslautendem - a verwendet: Archona (urbs principalis Rugianorum; 214, 15-20). Oberraschenderweise gebrauchen die nordischen Quellen last einhellig die Form ohne -a. Die vermutlich 2 wischen 1185 und 1222 entstandenen Gesta Danorum des Saxo mit (späterem) Beinamen Grammaticus (MGH SS 29) schreiben zweimal Arcon (98, 40; 103, 25). dreimal Arkon (116, 50; 117, 45; 122, 5) und einmal Archon (85, 20). An dänischen Quellen seien noch genannt: die zwischen 1240/70 entstandene Knýtlinga saga (MGH SS 29), die zweimal Arkun vermerkt (301, 20; 313, 10). sowie die aus dem 13. Jhd. (?) stammenden Annales Danici Colbazenses (MGH SS 29), die ebenfalls Arcun gebrauchen (175, 20) (Brüske 197 f.). Damit ist eindeutig erwiesen, daß der ON Arkona ausschließlich und nur ein einziges Mal von Helmold als Femininum verstanden wird. Wie es dazu gekommen ist. läßt sich nicht sagen, auch wenn es dafür verschiedene Erklărungen gibt. Beispielsweise könnte an einen slavischen Genetiv des Singulars gedacht werden: izb Arkons 'aus 
Arkon'. Vorstellbar wăre aber auch eine slavische Feminisierung mit Hilfe des Surfixes $-a$, vielleicht Im Sinne von "Arkona svetyni".

Klammert man die also nur einmal belegte Variante Arkona aus, ergibt sich als wohl ursprünglich die Form Arkon. Dabei ist inlautendes -kvermutlich die niederdeutsche Vertretung far slavisches ch. Auch wenn ch dem Niederdeutschen im Grunde Premd ist, wird es gelegentllch trotzdem beibehalten (Chrabrovo/Chrabrow). Hăufig wird es Jedoch sowohl im Anlaut (kasch. Chilonô/Kielau) als auch im Inlaut zu $k$, wie sich 2.B. an dem Plöner ON Kaköhl (villam Kukole. 1287) zeigt. der auf slav. chochol, chochsls 'Schopp. Ende' oder einen ăhnlich lautenden PN Chochol zurückgePürt wird ${ }^{19}$. Obwohl die Vertretungsverhăltnisse in diesem Punkt noch gesonderter Untersuchungen bedürfen. scheint es doch so, daß slav. - ch- im Inlaut insbesondere nach Konsonanten in - $k$ - umlautet, vgl. etwa ParchotIn: 1230 Parketin, heute Berkenthin". welches Beispiel gerade Arkon(a) nahekommt. Im übrigen ist freilich auch die durch das Lateinische bedingte Schreibweise von $c h$ und $c(k)$ in Betracht zu ziehen: Caganus/Chaganus /Kaganus, Cadola/Chadajoh usf. Damit wird es mehr als wahrscheinlich. daB sich auch Arkon(a) - genau wie Rethra - aus dem Griechischen herleitet. und zwar von dem ursprünglichen Partizip ó äpxwv, ouros.

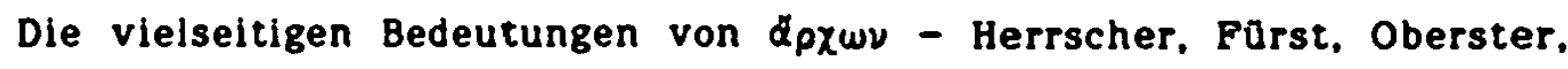
Gebieter. (An)Führer, Obrigkeit, ja sogar Allmacht, Gottheit (ró äpxwv) - er-

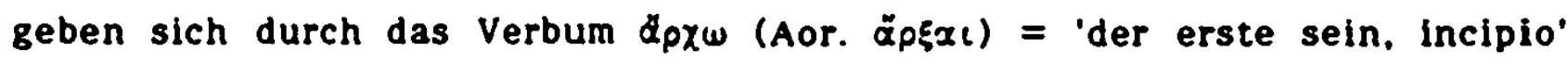
(Gemoll 129: Frisk 1. 159). Der Titel des Archont(en), in Athen die erste obrigkeitliche Würde. wird in späterer Zeit, insbesondere in der byzantinischen Kirche, auch Bezeichnung für hohe würdenträger ${ }^{27}$. In byzantinischgriechischen Quellen ist doxwy bemerkenswerterweise mitunter auch der Titel für slavische Gentilaristokraten (Kunstmann ${ }^{2} 1984$. 303; SlowStarSlow VII. Suppl., 370 f.: W. Swoboda).

14 Weniger ist hier wohl an die byzantinische Praxis zu denken, slavische ONn, die auf Konsonanten enden, durch Anfügen eines - a zu grăzisie-

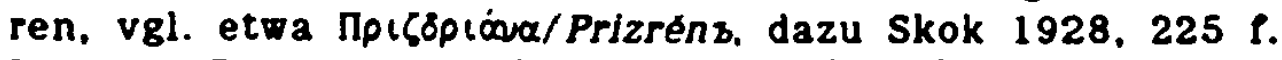

1s Laur 1967, 127; zur nd. Vertretung. Pür slav. ch ebda. 34. - Zum Problem auBerdem Trautmann 1948. 39; Schwarz, E. 1960, $284 \mathrm{ff}$.

16 Laur 1967. 68: polabeslav. Parkotin = ON zu einem PN Parchota. - Vgl. auch Schlimpert 1972, 268: Topchin = ma. topkin.

17 Liddell. Scott I, 254: Ev. Matt. 9.18: ruler of a synagogue. - Eine Aufzăhlung der byzantinischen würdenträger bei Beck 1959, 113. - Zum weltlichen Archontat Kl. Pauly I, 517 ff.: A. Mannzmann; Bengtson 1977. 596 (Reg.). 
Das Verbum $\alpha \rho \chi \omega$ als Medium verweist außerdem auf den Beginn des Opferns, der Opferhandlung, einer Tätigkelt, die eng mit dem Verbum (dep.

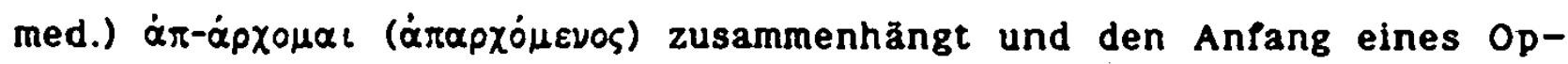
fers (primitias offero) bezeichnet. Im weiteren Sinne ließe sich auch damit der Hinweis aup eine Kult- und Opferstătte verbinden. Zutreffender ist es Jedoch, für Arkon(a), die prominente heidnische Kultstătte in der Nachfolge Rethras, die Bedeutung von Herrscher. Gebieter, princeps (<`primi-ceps) anzunehmen ${ }^{1 *}$. deshalb. well dadurch sowohl die Pührende religiöse als auch die zu vermutende politische (vece) Funktion zum Ausdruck kommt. Für beide Funktionen wăre Arkon(a) als Bezeichnung eines princeps, also dessen. 'der die erste stellung einnimmt'. in der Tat vortrefflich gewählt. In Helmolds von Bosau Formulierung urbs (terrae lllus) principalis dicitur Archona (214, 20) scheint diese Bedeutung sogar anzuklingen.

Daß die Slaven "im weiteren Ostseebereich" keine Orte griechisch benannten. wie T. Witkowski meinte (1983, 279), ist eine Behauptung, die sich mittlerweile mehrfach widerlegen läßt.

10 Dazu auch die Bedeutungsangaben in: A Patristic Greek Lexicon. Ed. G. W. H. Lampe. Oxford 1961, 241: in gen., ruler; Thesaurus Graecae Linguae (Dindorf), Sp. 2136: Praepositus, Moderator, Rector, Magistratus.

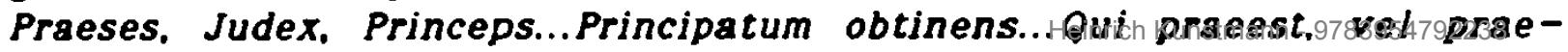
fectus est: Liddell. Scott I. 254: ruler. ${ }^{2}$. 


\section{Stettln und Küstrin}

Zum Kreis der im Mittelalter angesehenen Ostseezentren Usedom. Kolberg. Wollin gehörte gewiß auch stettin, poln. Szczecin, das von einer in der 2. Hälfte des 8 . Jhds. entstandenen Siedlung während der 20 er Jahre des 13. Jhds. zu einer der bedeutendsten Burgen Westpommerns heranwuchs. Stettins Burg, am linken Hōhenufer der Oder gelegen, schützte die Mündung dieses wichtigen Flusses und überwachte den hier norierenden Fischfang, vielleicht auch eine frühe hafenähnliche Anlage (SlowStarSlow VI, 519 lf.: L. Leciejewicz, H. Chlopocka). Nach 972 soll die Burg zusammen mit Westpommern zeitweise in den Herrschaftsbereich des Polenherzogs Mieszko I. einbezogen gewesen sein. Festzuhalten ist Jedoch, daß der Name Stettins, was lange von Linguisten und Historikern angenommen wurde (z.B. Rospond 1947: Lehr-Splawinski 1960), nichts mit der civitas Schinesghe in der sog. Dagome-iudex-Regeste zu tun hatte (Kunstmann 1984, 306 fr.).

Die eigenartigerweise nicht sehr zahlreichen frühen Belege des Toponyms sind folgende:

1133, 1159/77 (castrum) Stetin; 1188 Stetyn: 1240 Stetin (Landschaft); 1243 monasterium in Stetyn; 1251 stityn; Stitinum (Saxo Gram.: Annales Colbacenses): Stittin (Annales Ryenses): Burstaborg (Knytlinga saga): Burstenburgh (Ex Annal. Waldemariannus)2.

Die Diskussion um die Bedeutung dieses Ortsnamens kann nunmehr die stolze Laufzeit von über 400 Jahren aufweisen, nämlich seit dem Erscheinen der bekannten pommerschen Chronik von Thomas Kantzow ${ }^{2}$, der in der ersten Hälfte des 16. Jhds. behauptete, der Name Stettin bedeute soviel wie lat. cllpeus (älter: clupeus), also 'Erzschild, Rundschild'. Diese natürlich auf urslav. 'scitz, aruss. scitz, russ. scit, bulg. stit, skr. stît, c. stit, poln. szczyt u.a. und damit auf die Lage des Ortes am Hōhenufer der Oder abhebende Etymologie ist eine der beiden Standard-Deutungen, die bis in die unmittelbare Gegenwart aktuell geblieben sind. Die zweite nicht auszurottende Erklärung zielt auf das feminine poln. Substantiv szczec bzw. szczotka. altpoln. szczota < "sceta ab, das ein Sumplgras (bagienna trawa) bezeichnet, dessen Bedeutungen 1. Borste, Borst. 2. Karde oder Weberdistel (bot. Dipsacus) sind. Auf dieses Gewächs, das an der Stelle gewachsen sein

2 Nach Trautmann II. $86 \%$., und Grucza in SlowStarSlow V, $518 \%$.

2 Des Thomas Kantzow Chronik von Pommern in hochdeutscher Mundart. Hsg. G. Gaebel. Stettin 1898. Bd. II. 
soll, an der die fragliche Siedlung entstand, gehen gewiß auch dle volksetymologischen nordischen Namen Burstaborg und Burstenburgh zurück.

Neben diesen beiden "Haupt"-Etymologien gibt es gut ein Dutzend weiterer Erklärungen von geringerem Stellenwert, wobei die PNn Szczota. Szczeta, Szczet und Szczek oder Szczeka noch am haufigsten in Betracht gezogen werden ${ }^{3}$. Führende polnische Onomastiker wie Franciszek Grucza oder Witold Maticzak sprechen sich heute fur die von M. Rudnicki schon 1951 vertretene Ansicht aus, daB Stettin oder richtiger desssen polnisches Vorbild Szczecin aut besagtes Sumplgras zurückgehe, das, wie Trautmann (II. 86 f.) meinte, auch zum Bau von Palisadenwehren an Flüssen und Bächen verwendet worden sein soll (wopür freilich keine verläßlichen historischen Nachrichten vorliegen). Rudnicki schloB seinerzeit allerdings auch nicht restlos aus, daß Stettins Name ebensogut vom maskulinen PN 'SCeta. poln. Szczota hergeleitet werden könne. Insofern ist es also durchaus richtig, daß Stettins "Name nicht vollig geklärt ist" (SlowStarSlow V, 518 ९.: E. Grucza).

Bel der Beurteilung von Stettin/Szczecin ist mit Grucza davon auszugehen. daß sowohl die ältesten Belege des Namens als auch seine deutsche Vertretung nicht für ein $i$, sondern ein $e$ in der Wurzel sprechen. Auslautendes - in - mit neudeutschem Akzent Stettín - setzt auBerdem slav. - in und nicht das Formans - bn fort. Als ursprüngliche Form kristallisiert sich daher 'Scetin heraus, der nach Palatalisierung von $t i>c i$ exakt heutiges poln. Szczecin entspricht. Schwieriger zu beurteilen ist der erste Tell des Toponyms, das Grundwort 'scet-. dessen Lautgruppe $s c$ - daraup schlieBen läBt, daß sie auf 'skj-beruht. Bekanntlich wird der Lautwandel 'ski-> - $s c$ - in das 5.-8. Jhd. gesetzt (Shevelov 211. 299 f.). Somit bleibt die Frage nach dem Ursprung des Vokals $e$ in 'scet, der vor palatalen Konsonanten meist aus $-\boldsymbol{g}$ entstanden ist (2.B. Vondrák I, 102 l.). Für das Grundwort ergibt sich als Basisform folglich 'skiat- > 'scet-.

Der ON Stettin < urslav. 'Scet-jns geht auf den griech. Inselnamen Exıåsos, byzant. auch Exıasia, zurück, der frei übersetzt etwa Schatteninsel bedeutet. Vom Grundwort $\sigma x i \alpha, \dot{\eta}$, dor. $\sigma x\llcorner\dot{\eta}$ 'Schatten' gebildete Topo-

- Gute informierende Obersichten über die Geschichte der stettinDeutungen bieten F. Grucza (SlowStarSlow V. 518 f.) und W. Mathczak: Etymologia nazwy Szczecin. In: Slavia Occidentalis 32, 1975, $32 \mathrm{fP}$. Vgl. außerdem A. Belchnerowska, H. Bugalska, E. Jakus-Dąbrowska, B. Wiecek: Nazwy miast Pomorza Srodkowego. In: Homa. E.. 1976, 81 fl.; auch Rymut 1980, 236. 
nyme sind im Griechischen häuflg. vgi. die Namen des arkadischen Gebirges

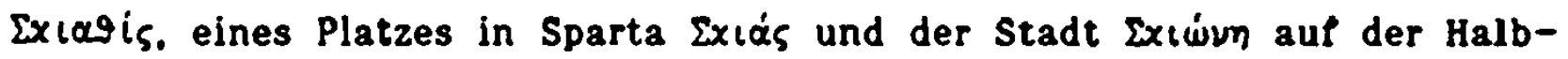

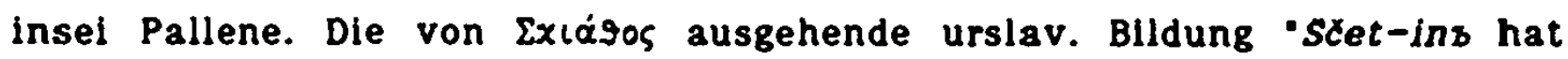
nur die erste Silbe, also das Grundwort ubernommen, nach bekannter slavischer Praxis dagegen das griech. Sump -os abgestoßen und durch das elgene slavische Formans - ins ersetzt.

Skiathos ist die westlichste der sog. Nördlichen Sporaden vor der $\mathrm{Ku}-$ ste von Magnesia, die ein nur $4 \mathrm{~km}$ breiter Kanal vom Festland trennt. Die gleichnamige antike Stadt der Insel liegt an einem guten Hafen im Sudosten und wird wegen ihrer günstigen Lage ofter als Flottenstutzpunkt genannt. Die Insel gehörte dem 1. und 2. attischen Seebund an. war Stützpunkt Athens gegen Philipp und wurde 338 v.Chr. makedonisch. Im byzantinischen Reich gehörte Skiathos zur Eparchie Thessalien des Themas Makedonien. kirchlich Jedoch zur Metropolis von Larissa*. Welcher Art die Beziehungen der Slaven zu Skiathos waren. wissen wir nicht im einzelnen. doch spricht vieles dafür. daß Slaven aus Thessalien und Makedonien, die häufig die ăgäischen und selbst weiter entfernte Inseln als Piraten uberfielen. auch diese Insel vor Magnesia heimsuchten. Der Bericht der Miracula s. Demetrii (II/I) uber derartige slavische Piraterie-Unternehmen läßt den Schluß zu. daß um 615 auch Skiathos von Slaven uberfallen wurde. wobei möglicherweise die Bevölkerung der Insel zugrunde ging', da auf Ihr. als in den 80er Jahren des 7. Jhds. der byzantinische Admiral Sisinnios hier 2 wischenlandete. seit vielen Jahren kein Leben mehr war (Waldmüller 1976. 343). Man ist an åhnliche Vorgänge auf Imbros, einer anderen Insel des ăgăischen Meeres, erinnert (Vgl. Fehmarn).

Ahnlichkeiten $z$ wischen dem ägäischen Skiathos und dem pommerschen Stettin ergeben sich aus der Lage beider am Meer und den ăußerst günstigen Bedingungen für Hafenaniagen. Dafür. daß das Toponym Stettin von Slaven aus dem Griechischen ubernommen worden ist. sprechen wenigstens 2 wei weitere Argumente. Insbesondere ist dabei die durch die Vita Ottos von Bamberg für Stettin bezeugte Verehrung des Gōtzen Triglav in Betracht zu ziehen (Kahl 1964. Register), da dieser Name ganz gewiB keine

- Zur Geschichte weiter: C. Fredrich: Skiathos und Peparethos. In: Mitteilungen des kaiserl. deutsch. Archåologischen Instituts. Athenische Abteilung. Athen 1906, 99 ff.; Pauly RE II. Reihe, 5. Hbbd.. 1927. 520 1.: Fredrich: Philippson. Kirsten IV. 41 fl.; Kl. Pauly V. 228.

- Vgl. Vizantiski Izvori za Istoriju Naroda Jugoslavije. Beograd I. 1955. 215. Anm. 64 . 
autochthone slavische Bildung, sondern eine Lehnübersetzung von TpEis $x \varepsilon-$ paiai darstellt und durch Slaven in den Norden verpflanzt worden ist. Das andere Argument, das eine Zuwanderung von Slaven aus dem griechischen Sprachkreis nach Pommern wahrscheinlich macht. Ist' die für stettin nachgewiesene burgstådtische Volksversammlung des vece (Zernack 233 ff.). das. wie an anderer Stelle dargelegt wird (Kunstmann ${ }^{1} 1988$ ), einen griechischen verfassungsgeschichtlichen Hintergrund hat.

Problematisch ist der Name der rund $95 \mathrm{~km}$ südlich von Stettin gelegenen Stadt Küstrin. heute poln. Kostrzyn. Der Prühmittelalterliche Siedelplatz lag an wichtiger strategischer Stelle an der Mundung der Warthe in die Oder. Die Prühesten, wenngleich reichlich spăt einsetzenden Belege dieses Toponyms sind zu 1234 terra Custerin und zu 1249 Kosterin. Unklar ist, ob damit auch die ONn Küstrinchen. Kr. Templin, am Küstrin-See (1320 prope villam Costeryn jacet stagnum Costeryn) und ein wüst gefallenes 'Kosterinek, 'Kostrinek (1345 in Slavicails villa Kustrinkin) lautlich zusammenhängen". Wahrscheinlich gehört zum rraglichen ON-Typ aber poln. Kostrzyh In der Wojewodschaft Poznan (vordem Gnesen), das seit dem 12. Jhd. bekannte deutsche Kostrschin: 1191 in Costrinensi provincia; 1257 Costrin?. Dle Herkunft von Küstrin, Kostrzyn und verwandter Blldungen wird Im allgemeinen mit dem slavischen Pllanzennamen kostérb (Berneker I. 583 P.) oder 'kosters (Trautmann II. 49 P.) 'Tresper'. vereinzelt auch mit dem PN Kostrza (Rymut 1980, 115 f.) in Verbindung gebracht. -kosterb, 'kostbr-, 'kostr-, poln. kostra, kostrzyca dial. 'Hanr u.a., os. (ns.) kostrjawa, kostrawa, koscerwa, kosterwja 'Trespe' ist laut Berneker eine Ableitung von kostb mit den gemeinsamen Grundbedeutungen 'spitz. spitzig; struppig, zottelig'. Im Blick auf den Namen Küstrin kőnnen alle diese Bedeutungen nicht absonderlich berriedigen.

Den ursprünglichen Kern Küstrins bildete eine heute unaurfindbare Burg auf einer Insel. Aufgabe dieser Burg war es, einen millitărisch und wirtschaftlich wichtigen Knotenpunkt von Wasserwegen und LandstraBen

- Alle Belege nach Trautmann II. 49 \%., wo auBerdem sehr ahnnlich gebildete ONn aufgefuhrt werden: 'Kosterina, 'Kosterin = Stadt Berent (1284 Costerina: 1291 Custrin); Coszczerzyn (1466) = Stadt Leba; "Kosternica = Kösternitz (1299 Custernitz) im Kr. Belgard und ebenso (1577 Costernitze) im Kr. Schlawe, vgl. auch: zu 1248 fluvius Costernitz im Kr. Templin.

7 Nach Rymut 1980, 116. Dabel ist die altere, noch im 19. Jhd. gebräuchliche Form Kostrzyn, deren Erweichung zu Kostrzyn von Rymut mit großpolnischem Dialekteinfluß erklärt wird. 
von und nach Stettin, Lubusz, Santok und Brandenburg zu überwachen". Der Ort erhielt daher schon früh, d.h. vor 1262 Stadtrechte (SlowStarSlow II. 489: A. Wedzki). Diese Bedeutung von Küstrins Burg macht es wahrscheinlicher, daß in dem Namen nicht eine Pllanzenbezeichnung. sondern

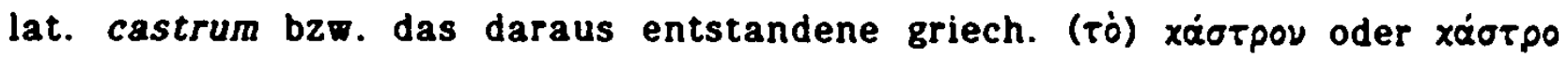
enthalten ist, also ein in Spätantike und Frühmittelalter häufig verwendeter Begrifl für Akropolls- oder Zitadellen-Anlagen. Der Vokalwandel von a $>0>u>u$ erklärt sich zum Tell aus dem Slavischen $(a>0)$. zum Teil aus dem Deutschen ( 0 > $u$; wie Zorn//zürnen u.a.). Die sufnxale Endung -ins ist wiederum slavische Zutat und ersetzt wie bel skiath-os//"scetins griechische bzw. lateinische Formantien. Nicht ganz einfach zu beurteilen sind dagegen die Belege Custerin und Kosterin, bei denen möglicherweise zur Umgehung einer Konsonantenhăufung der Vokal e eingeschoben wurde; allerdings könnte in Küstrin//Kostrzyn das fragliche -e- auch synkoplert worden sein. was dann freilich eher auf den Pflanzennamen 'kosterb u.a. schließen ließe. Nicht außer acht zu lassen ist jedoch. wie gesagt. die große historische Bedeutung der Küstriner Burg. An der Nordspitze der Insel Skiathos beispielsweise befand sich das mittelalterliche Kastro(n). eine befestigte, erst 1829 verlassene Stadt (Phillppson, Kirsten IV. 43). Ob sich Stettin zu Küstrin wie Skiathos zu Kastro(n) verhielt. wird sich wohl kaum mehr ermitteln lassen. Griechische Provenienz des ON Küstrin ist auch deshalb nicht von der Hand zu weisen. well der Name der Warthe, poln. Warta (Kunstmann ${ }^{3} 1987$ ), an deren Mündung die stadt liegt. ebenso wie der der Netze, poln. Notec, aus dem Griechischen erklărt werden können'. Dies und weltere Beobachtungen lassen darauf schließen, daB In den Gebieten zwischen Oder. Warthe und Netze slavische Gruppen seBhaft geworden sind, die aus griechischsprachlichen Gegenden des Balkans zugezogen waren.

- Küstrin lag im Bereich der pomoranisch-polnischen Sprachgrenze. dazu Trautmann I, 16, II. 50.

- Vgl. den Abschnitt "Oder. Netze, Warthe" in Kunstmann ${ }^{2} 1988$. 


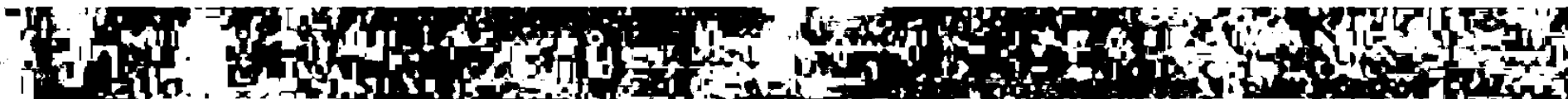

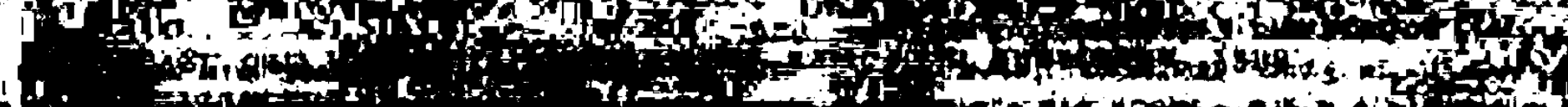
to Fllat

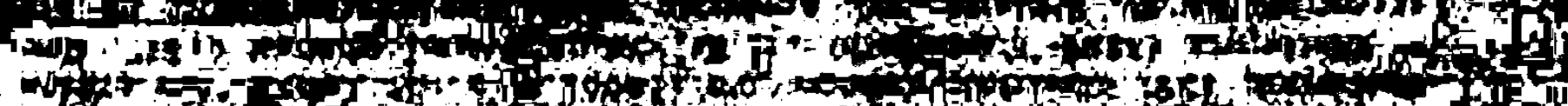
Wot a 5.A

-

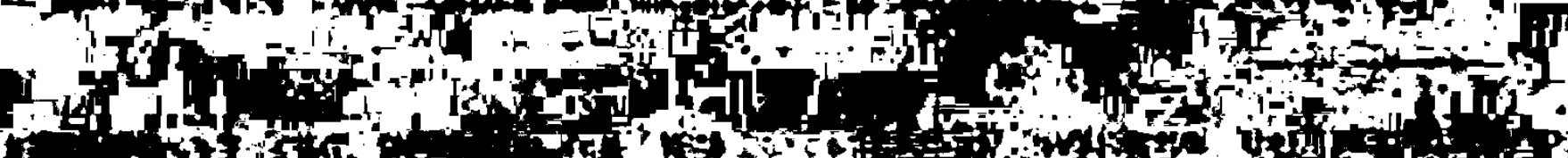
(c) 15 "

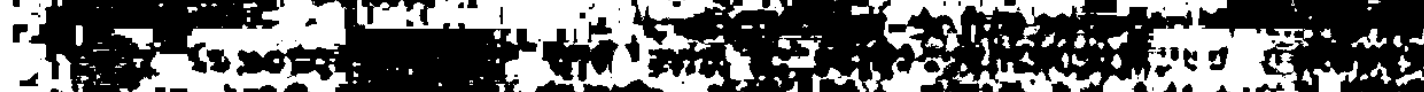
ofing von?

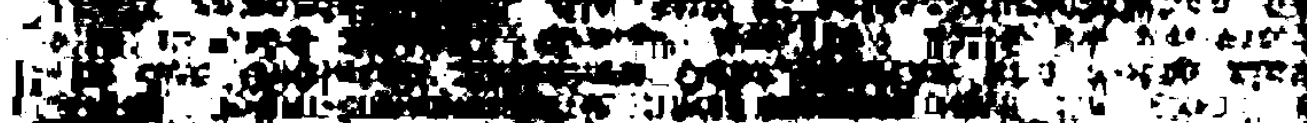
H: - L W

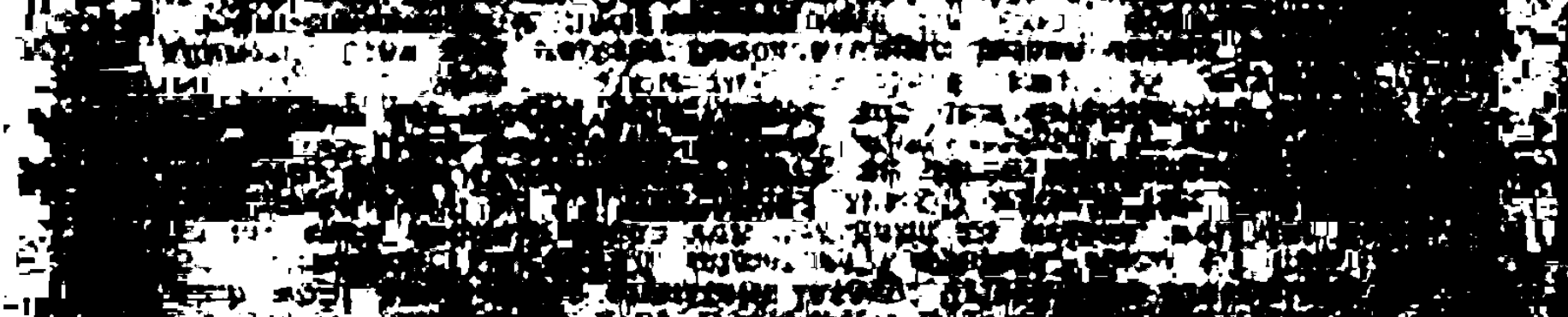
-11 - 11

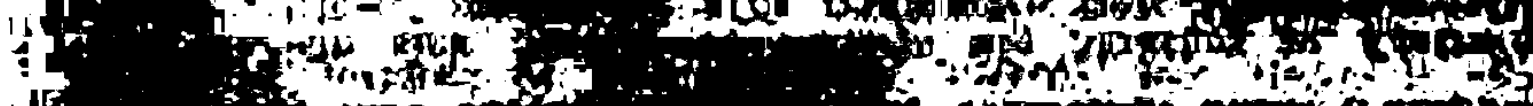

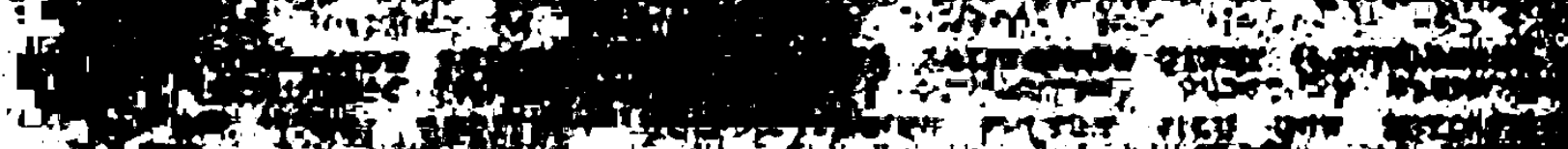

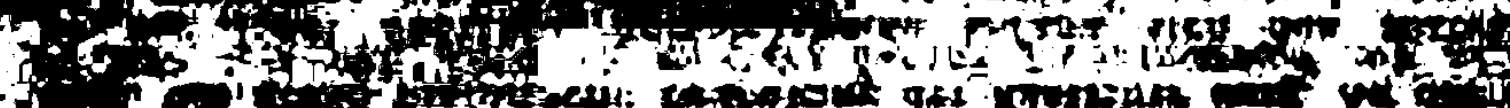

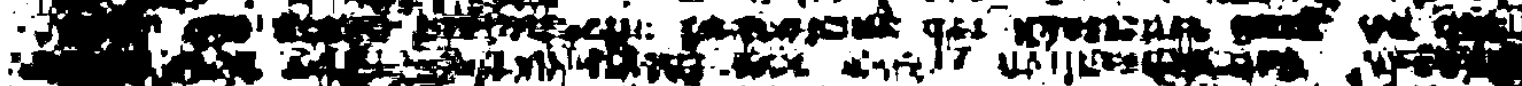

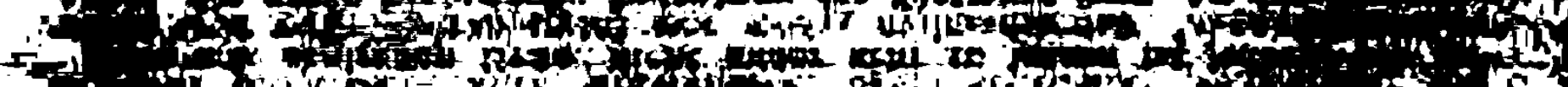

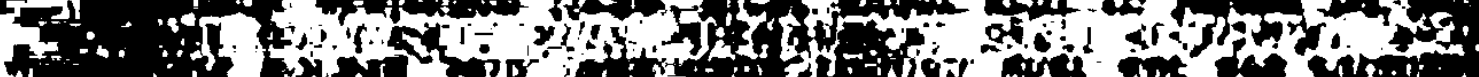

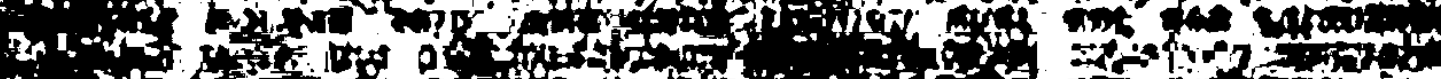

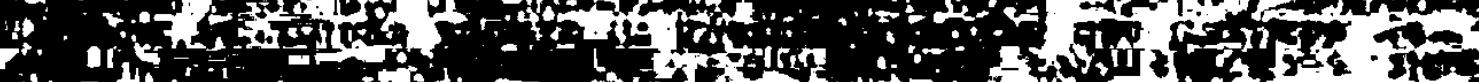
in.

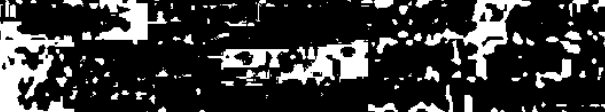
rot

If

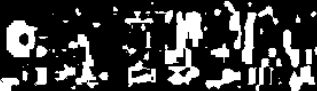
11 4 11 4

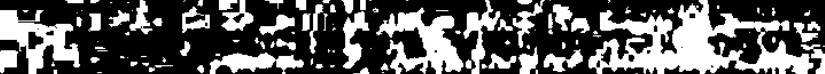

a Pan

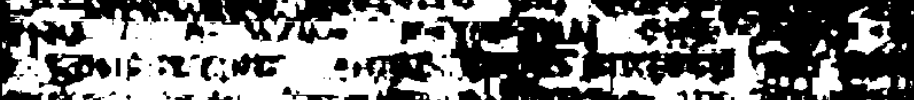

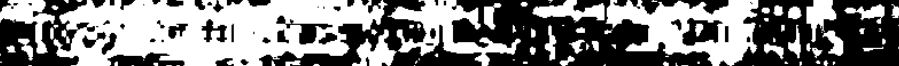

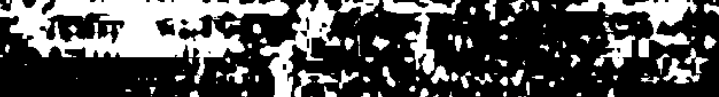

$$
\text { and }
$$

4 tit? tentalle $=$

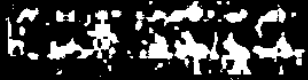
vitis 21

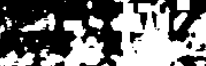

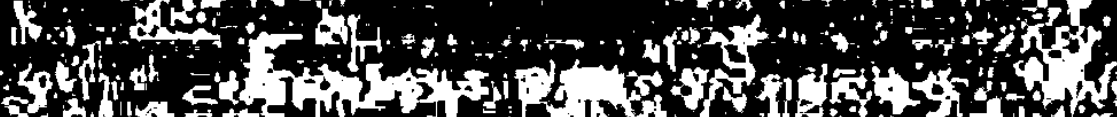
Fin low 年W 


\section{Colberg. Kolberg. Kolobrzeg}

Ein schwer zu beurteilendes Toponym ist Kolberg, das an zwel, geographisch weit auseinanderliegenden stellen begegnet. einmal als colberg im niedersorbischen Kreis Beeskow-Storkow, zum anderen eben als Kolberg. heute poln. Kolobrzeg, an der Mündung der Persante in die Ostsee. Beide Namen sind lautlich völlig identisch, auch wenn mit Sicherheit an zwei verschiedene Siedelvorgãnge zu denken ist.

Zuerst zum Dorf Colberg, dessen niedersorbische Lautung Kolobreg ist. wofür jedoch die historischen Belege ausstehen (Muka 1927-8, III, 152: Trautmann II. 115). Kolobfeg deutet Muka als 'Pfahlufer. Pfahldamm', wobei auf 'kolo- bzw. 'kols 'Pfahl' abgehoben wird. Ahnlich, wenngleich mit Zurückhaltung denkt Trautmann, für den insgesamt „die ON mit "kolo- im Dunkel bleiben".

Was die historischen Belege anlangt, so ist in Pall der Stadt Kolberg die Lage unvergleichlich besser. was fraglos eng mit der bedeutsamen geschichtlichen Rolle dieser an einer der älesten Burgen Pommerns entstandenen Siedlung zusammenhängt, in der man - wohl zu Unrecht - biswellen auch die Hauptstadt der Kaschuben sieht (Natanson-Leski 1959, 445). Aus archăologischer Sicht ist die Siedlung im 7.-8. Jhd. aufgekommen. ihre Burg vielleicht erst um die Mitte des 9. Jhds. (SlowStarsiow II. 445 1.: Leciejewicz), die, als frühmittelalterliche Hafenburg beurteilt (ebda.: W. Kowalenko), die wichtigen Festlandswege von Stettin nach Danzig und uber Gnesen nach Posen zu beschützen hatte. Salzgewinnung. Eisenbearbeitung. Fischfang. Bernstein waren die Grundlagen intensiver Handelsbeziehungen Kolbergs zu Skandinavien und Westeuropa. Schon im Jahre 1000 kam es hier auf Betreiben des Polenherzogs Bolestaw Chrobry zur Gründung eines Bischofsitzes ${ }^{1}$.

Aus den zahireichen historischen Belegen für Kolberg seien folgende zitiert:

2u 1000 salsa Cholbergiensis; 1128 Colbrege (Vita Ottos v. Bamberg): 12. Jhd. Cholbreg (Gall. Anon.) sowie Colobreg, Colobrega. Colubrega: 1140 Cholberg: 1140, 1176, 1255, 1274, 1284, 1297

1 Zur Geschichte von Kolberg vgl. U.a. W. Kowalenko: Najdawniejszy Kolobrzeg (VIII-XIII w). In: Przeglad Zachodni 1951, 7/8, 538 fl.; Petersohn 1979. $424 \%$. (u. Reg.). wo namentlich die Kultbeziehungen zwischen Mogilno bei Gnesen und Kolberg zur Sprach hein Kommenthann-9783954792238 
Colberg: 1159, 1177 Coluberch: 1175 Choleberch: 1180 Choleberga:

1184 Colubriech: 1253 Cholberge; 1254, 1257 Colbergensis; 1255 Colbergenses: 1255, 1257, 1288 Colbergh: 1293, 1297 Colberch $^{2}$.

Trotz der nicht geringen Schwankungen in den Schrelbvarianten ist gut erkennbar, das 2 wischen drei- und zweisilbigen Formen zu unterscheiden ist. wobei letztere vermutlich sekundär und durch Vokalschwund (-0-) aus ersterer entstanden ist. Eben so erklärt sich deutsches Kolberg aus slav. -Kolobregz. Wahrscheinllch, ja Past sicher ist weiter, daB das zweite Wortglled. - bregb. durch deutsche Volksetymologie zu -berg umgestellt worden ist.

In der Forschung dominieren zwei Etymologisierungsversuche ${ }^{3}$, von denen der ăltere in 'kolo eine Präposition sah, die, auf 'bregz 'Ufer' bezogen, etwa 'ringsum Ufer. von Ufer umgeben' ausdrückt. Stărker durchgesetzt hat sich demgegenüber in der heutigen polnischen Forschung die Meinung, daB, wie schon gesagt, der erste Tell von -Kolo-bregz auf urslav. 'kols 'Pfahl' beruhe. Kolberg also der Name für eine Palisadenstätte über dem Meeresufer sel (Górnowicz 1980, 79; Rymut 1980, 112). Dagegen einzuwenden ist. daß der gleichlautende niedersorbische ON Colberg wohl kaum mit einem Platz an einem (Meeres-)Ufer zu tun haben dürfte. Nicht übersehen läBt sich außerdem dle weitverbreitete Skepsis der Fachwelt gegenüber allen bisherigen Deutungen. was letztlich besagt. das es für Kolberg/Kolobrzeg keine gesicherte etymologische Deutung gibt (so Trautmann II. 115: Rymut 1980, 112: SlowStarSlow II. 445: Zagórski; RzetelskaFeleszko 1986, 80 P.).

Es ist bekannt, daB die mit "kolo gebildeten ONn 2 war gerade in Pommern besonders hăufig sind, für sie aber bislang keine begründete Erklárung gefunden ist (Trautmann II. 115: Staszewski 148). Eine solche Erklärung konnte es freillich auch nicht geben, solange die Zuwanderung der Slaven vom Balkan nicht in Erwägung gezogen wurde. Das erste Glied von -Kolo-bregъ hat weder mit der Präposition 'kolo 'um. herum' noch mit dem Substantiv 'kolb 'Pfahl' zu tun. ja es ist überhaupt nicht slavisch, sondern die Vertretung von griech. xaגós 'schön'. Dieses Adjektiv - in Zusam-

2 Nach Trautmann II. 115; SlowStarSlow II, 445: Zagórski; Rymut 1980, 112.

3 Abgesehen wird hier von Deutungen wie sie z.B. W. Griebenow: Der Name Kolberg. In: Unser Pommernland 9, 1924, 239 f., gab. der für ein altgerm. kol (zu Quelle) plädierte; unglaubwürdig ist auch Staszewski 148 ९., der unter Berurung auf M. Rudnicki (wo?) behauptet. Kolobrzeg sei soviel wie brzeg $z$ kolem. dragiem. was auf ein von pommerschen Slaven betriebenes Signal- und Warnsystem hinweilske kunstmann - 9783954792238 
mensetzungen werden die Formen $x \alpha \lambda 0_{-}$und $x \alpha \lambda \lambda_{\iota}$ - verwendet -, lst ein ausgesprochen produktives Bildungselement, das in unzăhligen Orts- und Personennamen des gesamten griechischen Sprachraumes begegnet, vgl.

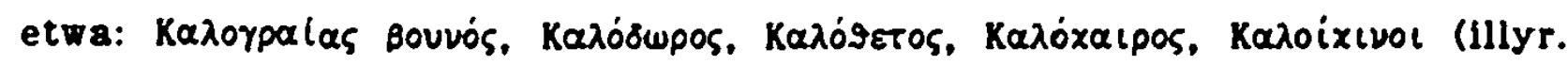

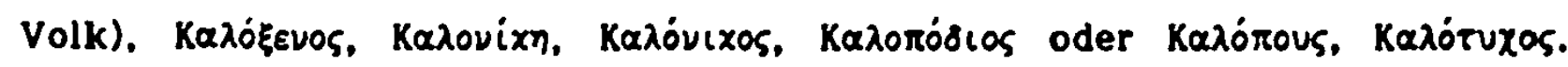

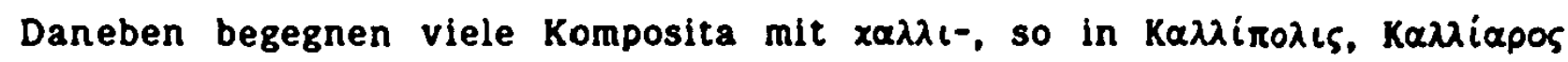

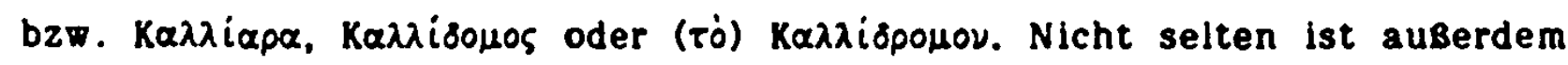

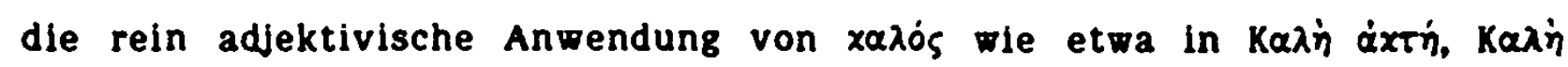

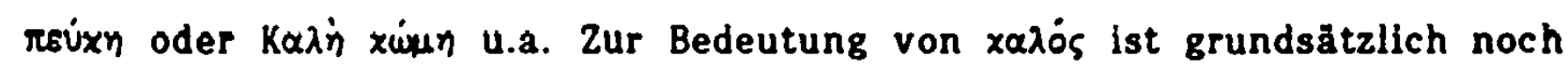
zu sagen, daß damit eine āußere Gestalt als 'schōn, hübsch, stattlich' oder ein besonderer 2 weck als 'tauglich, passend, nutzlich' beurteilt wird (Gemoll 405). Bemerkenswert im Blick auf die hăufigen ONn lst ferner der adverbiale Gebrauch von $\dot{\varepsilon} \nu x_{\alpha} \bar{\varphi}$, was 'am passenden Ort, an günstig gelegener Stelle, vorteilhaft, passend, zweckmäßig' besagt.

Slav. 'Kolobregz hat seine genaue Entsprechung in einem griech. ON.

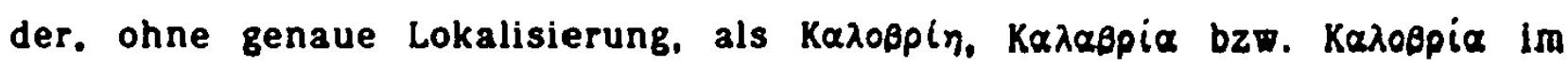
Euvéxßnuos (rec. Parthey 96) des byzantinischen Grammatikers Hierokles ( 1. Hälfte d. 6. Jhds.) und im sog. Breviarium (4.5; 185, 4) des Konstantinopeler Patriarchen Nikephoros I. (806-15) als Kastell in Thrakien erwăhnt wird. Höchstwahrscheinlich handelt es sich dabel um eine hybride Bildung aus dem griech. Element xalo- und dem von Strabo sowie Stephanos v. By-

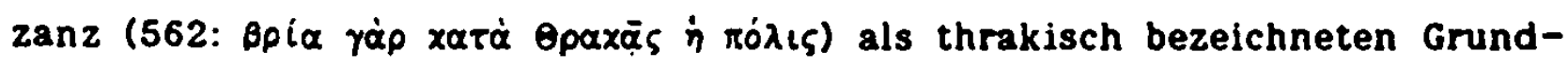
wort $-\beta \rho \vdash \eta,-\beta \rho\llcorner\alpha$ in der Bedeutung von 'Burg. Stadt' (Duridanov 11. 20 u.a.). Die Bildungen mit $-\beta \rho(\eta,-\beta p \iota \alpha$ sind in Thrakien sehr hăuflg, Georglev (1977, 188 f.) nennt allein 14 bzw. 17 Fälle dieses Typs, so zum Bei-

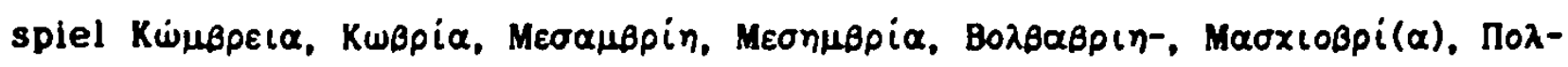

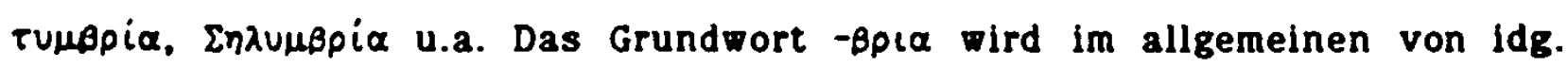
- yrija hergeleitet und $2 \mathrm{u}$ tocharisch $r i(A)$ bzw. rije (B) sowie awest. var gestellt; als Bedeutung nimmt man sowohl 'Burg. Stadt' als auch 'Kastell, Festung. (Festungs-)Turm' an (Georgiev 1977, 188). 'Kolobregs bedeutet demnach 'Schönstätt': daB -Bpin unter deutschem ElnfluB volksetymologisch zu - berg umgedeutet wurde, kann eigentlich nicht uberraschen.

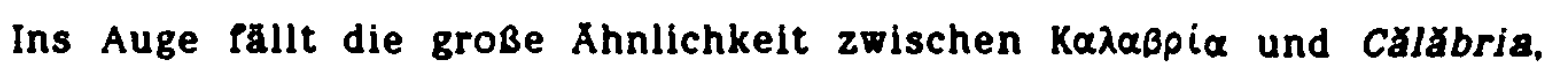
dem Namen der dem ionischen Meer zugekehrten Küste im südöstlichen Italien. der erstmals zu etwa 300 v. Chr. für Rhinthon bezeugt ist (Hesych.).

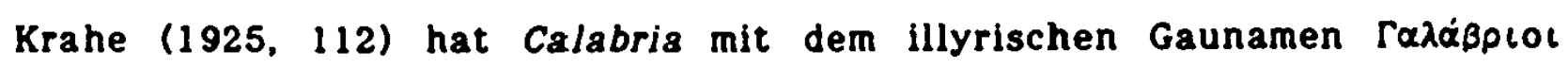
(Strab. 7, 316) in Dardanien in Verbindung bringen wollen, was vielleicht 

10. Der Name der Kaschuben

Wolfgang Gesemann zum 28.V.1985

Die literarische Oberileferung des Kaschuben-Namens setzt auffallend spät ein. Er fehlt in der Völkertafel des Geographus Bavarus (Mitte 9. Jhd.) uberhaupt, und die Erwähnung von Gušsanin oder Hasjabin bei Al-Mas*ūdi (1. Hälfte 10. Jhd.) bzw. von Hasābin oder Chašabin bei Ibrăhìm ibn Ja'qūb (2. Hălfte 10. Jhd.) trifft laut Labuda (1960. I, 54 f.) mehr auf donaulăndische Ethnika als auf Kaschuben zu. Genau genommen fallen die frühesten urkundlichen Notierungen des Namens erst in die Mitte des 13. Jhds. (SlowStarSlow II, 390: Sulowski: Dobrowolska 1958. 334 f.), doch ist es aus verschiedenen Gründen völlig auszuschließen, daß der Name erst im 12. oder 13. Jhd. aufgekommen sein soll. Vielmehr lst mit Sulowski (391) davon auszugehen, daß der Name bereits zur Zeit der slavischen Stämme. also noch im Frühmittelalter entstanden ist. Lücken in der schriftlichen Tradierung schließen mündliche Oberlieferung natürlich nicht aus.

Bemerkenswert ist ferner, das sel nur am Rande erwähnt, daß das ursprüngliche Siedlungsgebiet der Kaschuben nicht mehr aufflndbar ist. Geht

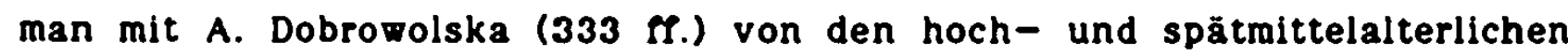
Notierungen des Kaschuben-Namens aus. will es scheinen, daß er dem gesamten Ostseegürtel, von der holsteinischen Unterelbe uber Lüneburg bls zur Unterweichsel, ja bis hinein in die baltisch-slavischen Gebiete bekannt war. Eng mit der Verbreitung des Namens hängt die Frage nach der Richtung zusammen, In die er sich ausgebreitet hat: Griff er von Westen nach Osten aus, also von Mecklenburg nach Danzig, oder aber umgekehrt von Osten nach Westen, der vermeintlichen Ost-West-Landnahme der Slaven folgend? Die Ratlosigkeit der gelehrten Welt gegenuber den Kaschuben drückt sich nicht zuletzt in den wenigstens fünf "Wlegen" oder "Vaterlăndern" aus, die man den Kaschuben schon zwischen Elbe und Belgarder Land an der Persante zugewiesen hat (Dobrowolska 346 f.).

Als einziger "sicherer" Anhaltspunkt bleibt somit der Name der Kaschuben. Dabei ist es einerlei, ob er ein ethnischer oder topographischer Begriff ist, entscheidend ist sein etymologisches Aussagevermögen. Man hat sich schon unendlich viel Mühe gegeben, den Kaschuben-Namen zu etymologisieren, dennoch gehört er weiterhin. wie A. Dobrowolska richtig be- 
merkt (334), zu den verwickeltsten Problemen der Toponomastik. Die meisten Deutungen brachte das 19. Jhd. mit sich: A. Naruszewicz beispielsweise stellte den Namen zum Ethnonym der westslavischen Kizyni. Chyzane, während W. Hanow an kasza, das angebliche Hauptnahrungsmittel der Kaschuben, dachte; Sz. Matusiak wiederum deutete ihn aus lat. casa und deutsch huba und schloB auf eine Bezeichnung far Landbesitz. Neben diesen und anderen, allerdings hoffnungslos abwegigen Deutungen, wurde die etymologische Diskussion um den Kaschuben-Namen schon früh von einem ethnographischen Argument, nämlich der Tracht der Kaschuben, beherrscht. Richtungweisend war hierbei die Chronica magna seu longa Polonorum, die in Handschriften des 15. Jhds. das kaschubische Ethnos folgendermaßen beschreibt: est quaedem gens slavonica, quae Cassubitae dicuntur: et hi a longitudine et latitudine vestium, quas plicare ipsos propter earum latitudinem et longitudinem oportebat, sunt appellati. Nam huba in slavonico plica seu ruga vestium dicitur, unde Casshubii, id est plica rugas interpretantur (MPH II. 470). Dieser typisch volksetymologischen Deutung. nach welcher also die Kaschuben von ihrer In Falten gelegten Kleidung ihren Namen hätten. schloß sich in der Folge nahezu wörtlich der Chronist Jan Dlugosz an: Kassubyanye aplicatione rugarum in vestimentis, quibus primum vestiri consueverant (Huba enim in Polonico seu Slavonjco dicitur ruga. Kasz autem dicitur plica in modo imperativo (Dlugosz I. 58; nach Dobrowolska 342). Diese Etymologie konnte sich, wie das von L. Krzywicki verfaBte Stichwort Kaszuby der Wielka Encyklopedia Powszechna (Warszawa 1914) zeigt, buchstäblich bis ins 20. Jhd. hinein halten. An die Kleider der Kaschuben hielt sich schlieBlich auch der erste "Kaschubologe" und Dialektforscher Krzysztof C. Mrongowiusz (Mraga), dessen worterbuch kaszuba als $k a-+$ szuba versteht und in szuba einen besonders von $\mathrm{Ka}-$ schuben getragenen Pelz (kozuch) sieht (Dobrowolska 348). Auch wenn dies im Grunde eine volksetymologische Variante zur Großpolnischen Chronik und zu Dlugosz ist, schlieben sich ihr in der Folge viele Sprachwissenschaftler an. Nicht ohne Bedeutung dürfte dabel die Autorität A. Brückners gewesen sein. der die völlig verfehlte Etymologie von Mrongowiusz in seinem Slownik etymologiczny jezyka polskiego von 1927 gewissermaßen sanktionierte: nazwa od ubioru ... od szuby $z$ przedrostkiem ka- (ebda. 222). Eigenartigerweise teilte Brückners anfechtbare Meinung später auch Max Vasmer, obgleich dieser rund zwanzig Jahre vor seinem Russischen etymologischen wörterbuch (I. 544), offenbar ohne dle Tragmeite seingra $_{23} B e-$ 
obachtung erkannt zu haben, die Praglos richtige Lösung des KaschubenNamens gefunden hatte. Dle an die Kaschuben-Tracht anknuppende Deutung - von der Großpolnischen Chronik aber Dlugosz und Mrongowiusz bis hin zu Brückner und Vasmer - erfullt zwar, das ist nicht zu verkennen. gewisse ethnologische Voraussetzungen, da die Kaschuben in der Tat gefaltete Klelder trugen, doch ist es sehr unwahrscheinlich, daß dieses .modische" Attribut einen ganzen Gruppennamen abgegeben haben soll.

Die verdienstvolle Arbeit von Agnieszka Dobrowolska aktualisiert noch eine andere. weniger beachtete Erklärung des Kaschuben-Namens. Es ist die des gelehrten Pfarrers Stanislaw Kujot, der in seinem Buch Pomorze Polskie (Poznan 1874) auf Selte 312 sagt: naz®a kaszubskiej ziemi...pochodzi...od kaszubóm, które oznaczaja na Pomorzu wody niezbyt glebokie. wysoka trawa porosie. Diese Ansicht wird in der Polge vom Siownik Geograficzny Królestwa Polskiego (III. 904 f.) übernommen: Ihr treten sowohl A. Dobrowolska als auch der Historiker Natanson-Leski (1959, 445) bel. Demnach besage das Tort kaszuby soviel wie mokradla 'Sumproöden (mit hohem Gras bewachsen)', moczary 'Moraste' oder auch blota 'Moore'. Gegen Kujots Meinung läßt sich jedoch einwenden, daß kaszuby in der mitgeteilten Bedeutung eine lexikalische Rarităt ersten Ranges darstellt und es unwahrscheinlich ist, daB ein derart seltenes Wort auf elner Strecke von Lüneburg bis Riga rär einen slavischen Stamm namengebend geworden sein soll.

Der Kaschuben-Name ist weder ein ethnischer noch topographischer Begriff, auch kein administrativer oder landschaftsbezogener Name, sondern eine Herkunftsbezeichnung. Zugrunde llegt das griechische Ethnikon Kaoowroi bzw. Kaoowraiol (Jacobsohn 1930, 93, Anm. 1). Die altere Stammesbe-

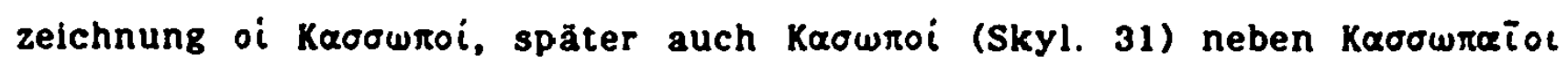
(Strabo 7.7 .1 p. $321: 7.7 .5$ p. 324 P.), woraus lat. Cassopaei und deutsch Kassoper, Kassopaier, ist eine Welterbildung vom Namen der Hauptstadt des

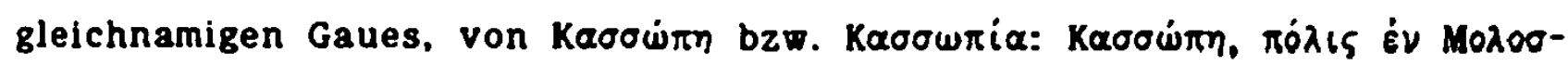

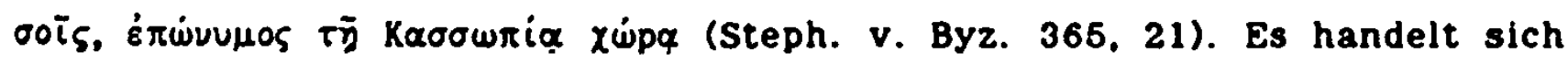
also um die südlichste, bis zum Golf von Ambrakia ausgrelfende Küstenlandschaft des Epeiros'. Unmittelbar mit dem Namen der Kassopaler hăngt naturlich der Name des Hafens an der NO-Küste von Korkyra (Korfu).

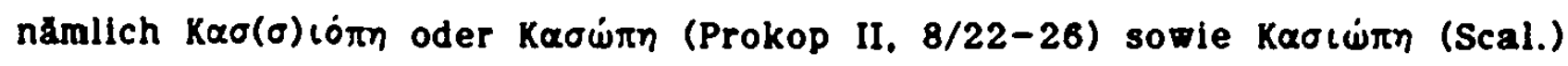

1 Paulys RE X, 2332 If. Suppl. IV, 879; Kl. Pauly III KIrsten 1956. II/1.2. 214 $\mathbf{~ f .} 220$ PS. Downloaded from PubFactory at 01/10/2019 04:12:55AM 
zusammen, worunter heutiges Kassiopē, der bekannte Oberfahrtshafen nach Italien zu verstehen ist. Dem Kassoper-Namen stehen gewiB aber auch die

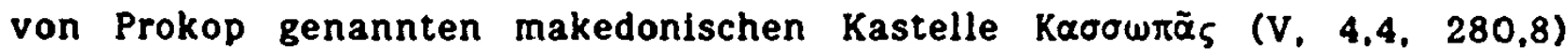

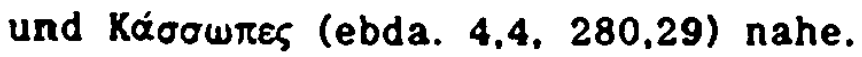

Den Namen der ehemals im Land der Molossi ansässigen Kassopaier haben slavische Sippenverbände gewiß während ihres Vordringens auf die Balkanhalbinsel kennengelernt. Gerade für die hier in Betracht zu ziehende westliche Landschaft Im Epeiros hat man seit langem auffallend dichte Slavensiedlungen erkennen können². Allein für das Gebiet um Joánnina (Janina) hat die Sprachwissenschaft an die 334 slavische Ortsnamen festgestellt (Vasmer 1941, 20-56), eine Zahl, die den nicht unerheblichen slavischen Siedlungsanteil deutlich werden läßt.

Einen Zusammenhang zwischen den Namen der epirotischen Kassopaiern und den slavischen Kaschuben ahnte, wie schon bemerkt, bereits der bedeutende deutsche Slavist Max Vasmer, der in seiner 1933 erschienenen Untersuchung „Der Burgundername bei den Westslaven"3 u.a. Peststellte: Merkwürdig ist die Obereinstimmung desselben (d.i. des Kaschuben-Namens

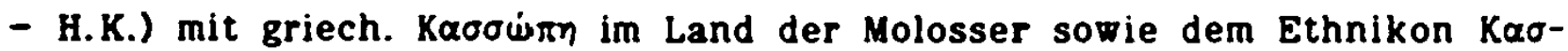

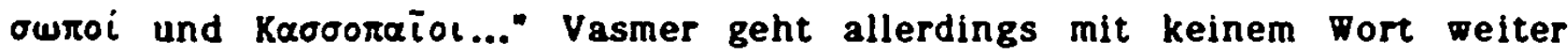
auf dlese "merkwürdige Obereinstimmung" ein, sondern verweist lediglich auf drei seiner nicht lange vordem erschienenen Arbeiten zur Frage der sog. Nord-Illyrier`. was natürlich besagt, daß Vasmer in der KaschubenFrage an Zusammenhänge mlt der damals von ihm nachdrückllch vertretenen Nord-Illyrier-These gedacht haben muB. Da diese These jedoch nicht hielt, was sie zunächst versprach, aber auch eine slavische Süd-Nord-Migration für ihn völlig undenkbar war. schloß sich Vasmer dann in seinem Russischen etymologischen wörterbuch offensichtlich lieber der (restlos verfehlten) Kaschuben-Etymologie Brückners an.

Die lautliche Seite des Kaschuben-Namens bedarf noch verschiedener Bemerkungen. Insbesondere Ist zum Wandel von griech. -ss- bzw. $-s-z u$ slav. - $s-$ zu sagen, daß dieser mit großer Wahrscheinlichkeit aup - sizurückzurühren ist. Zwar enthält der Landschaftsname Kaøowirn diese Lautgruppe nicht, doch ist sie eindeutig im Namen der Hafenstadt Kao-

2 Stadtmüller 1934: Philippson, Kirsten 1956, II/1, 288, Anm. 74.

3 In: Sitzber. d. PreuB. Akad. Phil. hist. Kl. IV, 197 1f.; jetzt: Vasmer 1971. II. 597.

- Vasmer '1929, ${ }^{2} 1929,1931$; jetzt Vasmer 197/ $554 \mathrm{ff}$. 


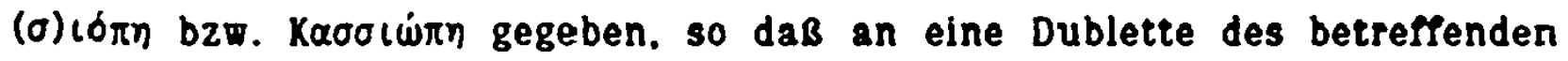
Grundwortes gedacht werden kann. Dle Lautgruppe -si- ist auch in ver-

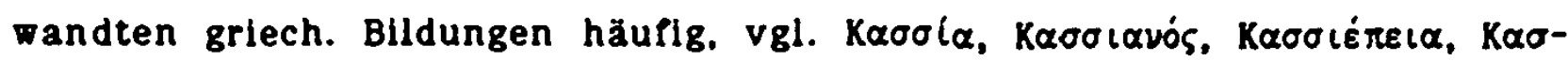

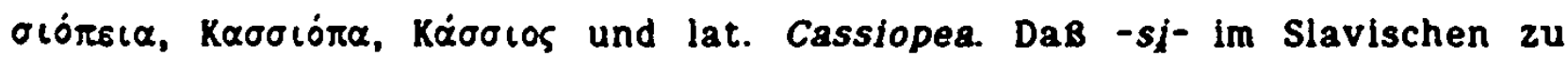
-s- führte, ist hinlänglich bekannt. Sehr wahrscheinlich ist $k a s-$ somit aus $k a s(s) i-$ entstanden. Die spezifisch nordwest-slavische Tendenz, $s$ statt s zu entwickeln - vgl. poln. szary. szady. wszego//aksl. sĕrz, sèdz. VbSb (Rozwadowski 1923, 184 f.) -. kann hierbel zusätzlich forderlich gewesen sein. Nicht restlos auszuschließen ist, nebenbei gesagt, daß es im Mittelalter sogar beide Formen, also $k a s(s) u b$ - und $k a s u b$ - nebeneinander gegeben hat. Lateinische Formen wie Cassubae, Cassubi. Cassubia (MPH II. 955) neben Kasubitae (MPH III, 819) lassen keine eindeutige Unterscheidung zu, auch wenn im Prinzip die altpoln. Ligatur - ss-den Lautwert - $s-$ (sz) wiedergibt, vgl. Targossa//Targosza, Krotossa//Krotosza (Bulle v. 1136). Ob es den Kaschuben-Namen im MA tatsächlich als Dublette Ka(s)ub-//Kasub- gegeben hat, wäre noch eingehend zu prüen. raglos aber ist die (noch) heute geläufige Form Kasub-aus Kas(s)i- entstanden. Problemlos ist in Kaśub- der Vokal -u-. der aur griech. Omega zurückgeht, und langes $\bar{o}$ im Slavischen bekanntlich oft als $\bar{u}$ gehōrt wurde, allerdings erst in späterer Zeit, da es vordem in $y$ überging (Shevelov 1964.

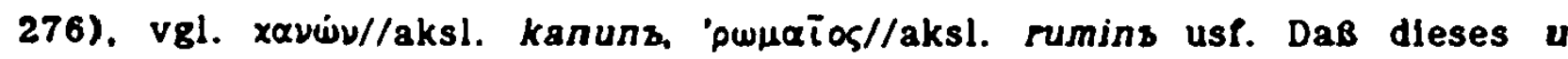
nach $i$ und $j$ nicht $2 u i$ wurde, entspricht der Beobachtung, nach weicher fremdes $u$ und ju im slavischen erhalten bleiben, vgl. aksl. bljudo < got. blups, stuzdb < slav. "tudjo, got. piuda. - Scheinbar gegen die Regel verwandelt sich auch griech. $-a-$ nicht in slav. -0-, ein Vorgang. der im allgemeinen in die Zeit um 800 gesetzt wird. Vorwiegend in Fremdwörtern bleibt ursprüngliches, also fremdes $a$ im Slavischen jedoch hăung erhalten, vgl. $\pi \dot{\alpha} \sigma \alpha \alpha / / a k s l$. pascha. macedonicus//makedonssks usf. - Zum Wandel von griech. $\pi$ zu slav. b. also $K \alpha \sigma(t) w \pi->k a s u b-$ ist noch zu sagen, das slav. p im Prinzip zwar ursprachliches p fortsetzt, aber auch eine stattliche Anzahl von Abweichungen bekannt ist, das heiBt. wo statt des zu erwar-

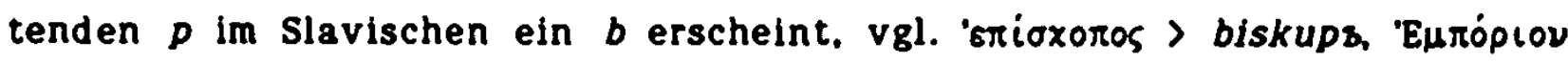

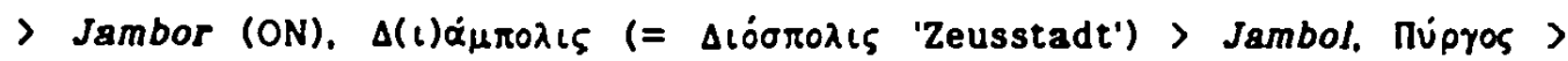
Burgas (ON). ' $\alpha \pi \alpha \dot{\alpha} p \iota \delta \varepsilon s>$ Abodriti usf.

Die phonetische Seite des Kaschuben-Namens laBt dessen Herleitung aus griech. $K \alpha \sigma \sigma(\ell) \omega \pi-$ u.ä. somit als durchaus plausibel erscheinen.

Die Herleitung des Kaschuben-Namens vom altepirotischen gthnonym der Kassopaier fügt sich im übrigen vortremlich in das Bild von dere 
kunft der Polen'. Wenn, wie vermutet, der namengebende (Teil)Stamm der Polen, die Opolini des Geographus Bavarus, aus dem Umfeld der in der An-

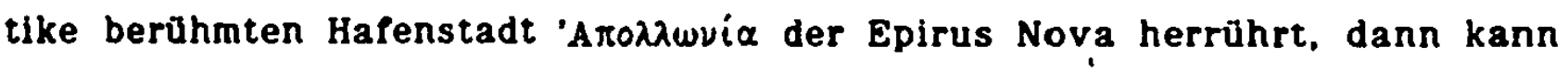
es eigentlich nicht überraschen, die Wurzel des Kaschuben-Namens nur 100 km südlich von Apollonia in der Epirus Vetus freigelegt zu haben. 
11. Drevani. Derevijane. Dervanus.

Die Drevani ${ }^{1}$, ein westslavischer Polabenstamm, haben im Mittelaiter das Gebiet des hannoverschen Wendlandes und der linkselbischen Altmark bewohnt. Wann sie in dieses Gebiet eingewandert sind. lassen die Quellen offen, doch wird auf Grund archäologischer Zeugnisse angenommen, daB ihre Landnahme nicht viel später als in der 2 . Hälfte des 8 . Jhds. erfolg$t^{2}$. Das später zum Landschaftsnamen reduzierte Ethnonym hat sich bis heute in den Bezeichnungen Drawehn. Drawän. Drawein u.a. erhalten. Infolge besonderer geschichtlicher Umstände "konnte sich das slavische Element (hier) bedeutend länger selbständig erhalten als óstlich der Elbe, da hier keine gewaltsame Unterwerfung und planmäBlge Germanisierung der Slaven erfolgte. Als ehemalige Bundesgenossen Karls d. Gr. gegen die Sachsen genossen (die Drevani) im Gegenteil besondere Vorrechte und Vergünstigungen. Als wertvolle Unterstützung ihrer Selbständigkeit darf wohl die Anordnung Karls d. Gr. zum Schutze ihrer Sprache angesehen werden" (Kaiser 1968, 11). Ihre Sprache, die noch Ende des 17. und zu Beginn des 18. Jhds. gesprochen wurde, hat seither das lebhafte Interesse der slavischen Sprachwissenschaft gefunden. wie zuletzt die bedeutende Untersuchung von E. Kaiser und das monumentale Werk von $R$. Olesch ${ }^{3}$ auf eindringliche Weise bestätigen.

Oberraschend ist allerdings, daß die Belege des Namens der Drevani verhältnismäßig spät einsetzen, nicht sehr zahlreich sind und eigentlich erst im Spätmittelalter auftreten. Der älteste Beleg ist die Erwähnung zu 1004 Claniki in Dreuani (DH II, Nr. 87, 20; Orig.), in weicher Claniki das heutige Clenze meint. Danach folgen erst wieder im 14. Jhd. und später die Notierungen: 1330/52 up den Drevenen: 1360 vor deme dreuerschen dore to Luchow: 1368 vp den Drauenen; 1395 vppe den Drauenen: 1564 de Dravenn u.a. (Kaiser 1968, 115. Anm. 292). Die auffallend geringe quellenmäßige Oberlieferung dieses Namens hat Niederle seinerzeit damit erklärt.

1 Diese alteste belegte Form wird hier als Norm benutzt.

2 Zur Geschichte der Drevani vgl. außer Niederle III, 75, 130 f.. 177, insbesondere Strzelczyk 1968 und dens. In Lex. d. MA III. 1369 f.; dazu auch der Sammelband Slowianszczyzna polabska mifdzy Niemcami a Polska. Pod redakcja J. Strzelczyka. Poznan 1981.

3 Vgl. namentlich dessen Thesaurus linguae dravanopolabicae. I-III. Köln. Wien 1983-4, in dessen Bd. I. XLII-LVII, sich ein erschöprendes ${ }_{4}$ hiteraturverzeichnis findet. 
daß die linkselbischen Slaven bald unter deutschen Einfluß gekommen seien. während die rechtselbischen sich diesem länger widersetzen konnten (Niederle III, 130 f.). Es gibt dafür gewiß aber noch andere Gründe.

Der Name der Drevani kennt verschiedene Parallelbildungen. Einmal den ON Drawehn (h. poln. Drzewiany) (Rospond 1951, I, 63; II, 467) im ehemaligen Kreis Köslin (h. poln. Koszalin), der zu 1400 als Dravene belegt ist (Trautmann II, 104). Sodann den mittelwestrussischen Stammesnamen der wolhynischen Derevljane bzw. Drevljane. Typologisch gehört hierher aber ohne Frage auch die frühmittelalterliche, als Personenname verstandene Bezeichnung Dervanus für einen ansonsten unbekannten Sorbenrürsten. Erwähnenswert sind außerdem ähnlich lautende Bildungen in der im 13.-14. Jhd. entstandenen sog. Chronica Poloniae Maioris (Kürbisómna 1959, 15 ff.), namlich Drewnyanye bzw. Drawnane und Drewnanye (MPH II. 470). Allerdings geht es in diesen Fällen um die altpolnische Obersetzung des altnleddtsch. Insassen- oder Landschaftsnamens Hoit-satium, mhd. Hoizsaezen $=$ Holsten, $\mathrm{später}$ Holstein. Die Bildungen Drew/n/yanye, Draw/n/ane. Drew/n/anye weisen interessanterweise ein epenthetisches $-n-$ auf, das sowohl den Drevani und Derevljane als auch Dervanus fehlt.

Man ist sich in der wissenschaft seit jeher darin einig. daB die Namen der niedersăchsischen Drevani wie auch der ostslavischen Derevljane und des sorbischen Stammesfürsten Dervanus aup ein und demselben Etymon beruhen, d.h. von urslav. - dervo, aksl. drévo. russ. derevo + suffix -jane bzw. -ěne gebildet sind und soviel wie 'Waldbewohner. Waldsassen' bedeuten. Für die westslavischen Drevani und ihre ostslavische Parallele gelten naturgemå die unterschiedlichen Auswirkungen der um 800 erfolgten Liquidametathese, die bei dem zu etwa 630 genannten Fürsten Dervanus freilich noch nicht elngetreten ist. Hinsichtlich der Drevani fällt auf, daB dabei "bis 1360 konsequent e, ab 1368 konsequent $a^{\text {" geschrieben }}$ wird (Kaiser 1968, 115, Anm. 292), was bereits an eine Grundform 'drzven.

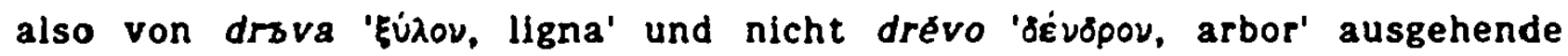
Blldung denken ließ (ebda.). Diese - semantisch kaum ins Gewicht Pallende - Anderung des Ansatzes ist vielleicht nicht einmal erforderlich, da sich der Wechsel $e>a$ hler offenbar aus dem Deutschen zu erklären scheint: Vor Konsonant wird -er- nämlich aụ nordniedersăchsischem und ostfälischem Sprachgebiet zu -ar- (Lasch 1974, 58 ff.), was offenbar nach 1300 der Fall ist, zeitlich also mit der Beobachtung von $E$. Kaiser in etwa übereinstimmt. 
Es gibt eine Reihe von Argumenten, die die Richtigkeit der bisherigen Etymologlsierung des Namens Drevani in Frage stellen. Wie schon an anderer Stelle kurz aufgezeigt (Kunstmann 1985, 242 \%l.), trifft dies auch auf die Namen der ostslavischen Derevljane und des Sorbenfürsten Dervanus zu. Mit einiger Wahrscheinlichkeit ist in allen drei Fallen nămlich an eine balkansprachliche Grundlage zu denken.

Der Name der Derevljane, die im 9. und 10. Jhd. südlich des Pripjetb. an Gorynb. Sluc und Teterevb ihre Siedelplätze hatten, wird erstmals von Konstantinos Porphyrogennetos, also um 950, und zwar als $\Delta \varepsilon p \beta \lambda \varepsilon v i v o c$ erwăhnt. Möglicherweise verbirgt sich hinter dieser Bildung sogar der Prototyp. da ja für die Mitte des 10. Jhds. mit russischem polnoglasie oder auch einfacher Liquidametathese gerechnet werden kann. Mehrmals werden die Derevljane dann im historischen Kontext von der PVL genannt: Sie gebraucht im wesentlichen die Singulare Derevljanins oder Drevljanins und die Plurale Derevljane oder Drevljane, zu denen als orthographische Varianten auch die Formen Derevzljane sowie Drevjanja gehören. Die entsprechenden Adjektivbildungen sind: derevljansskyi, derevsskz, -yi, mit den orthographischen Varianten derevenskyi, derevensskyi. derevjansskyi und derzvbskz (Gröber, Müller 1977-86, I.1, 190 f.). Für das Land, das die Derevljane bewohnten, gebraucht die PVL entweder den Begriff Derevbskaja zemlja oder aber das als pluraletantisches Neutrum zu verstehende Substantiv Derevs, von welchem sich die Adjektive derevbsks und derbvbskb herleiten.

Wie den Namen der polabeslavischen Drevani hălt man auch das Ethnonym Derevljane für eine Forestis-Bezeichnung. deren Etymologie einfach zu sein scheint. da es dafür m.w. noch keine andere Auslegung als 'dervI-janinz, -jane 'Waldbewohner' gegeben hat (z.B. Vasmer REW I, 341; SlowStarSlow I. 338: Lehr-Splawinski, u.a.). Diese auf urslav. • dervo gestützte Deutung geht im Grunde auf die PVL zurück, die in ihrer Begründung Drevljane zane sédosa vo lésé (6) - ahnlich wie der Annalista Saxo (Holcete dicti a silvis quas incolant) - 2 war vom Wald, nicht aber von Bäumen spricht. Dennoch muBte der Bezug auf autochthones slavisches Sprachgut so überzeugend wirken, daB an eben dieser Etymologie seither keine Zweifel aufkommen konnten.

Die Erklărung der PVL, so uberzeugend sie wirkt, kann allerdings auch volksetymologisch sein. Ein gravierender Einwand gegen sie ist der von der PVL verwendete angebliche Landesname Dereva der bei. Licht be- 
sehen, Ja gar keine Bezeichnung für ein Land, sondern der Nominativ Plurails von derevo ist und bestenfalls soviel wie 'Bäume' bedeutet. Die Bildung Dereva, so scheint es, wollte schon dem altrussischen Chronisten nicht recht gefallen, weshalb er an anderer Stelle das Gebiet der DerevUane als Derevbskaja zemlja bezeichnete, was ohne Frage klar und eindeutig ist, während Dereva 'Bäume' als Name für das Land eines Stammes doch merkwürdig bleibt. Weiter făllt auf, daß die PVL nicht einen zu erwartenden (alt)russischen Nom. Pl. drevesa oder derevbja gebraucht, sondern eben die formal und semantisch nicht ganz verständliche Bildung Dereva. So wächst der Verdacht, daß das neutrale Pluraletantum Dereva auf einem schon von der PVL nicht mehr verstandenen femininen Landesnamen beruht, der einen Genuswechsel erfuhr und volksetymologisch umgedeutet wurde.

Es spricht einiges dafür, daß Dereva eben nicht slavischer Provenienz ist. sondern auf den illyrischen ON Derva bzw. Derba zurückgeht, aus dem mit Hilfe des Zugehōrigkeitssuffixes -ano- das Ethnikon $\Delta \varepsilon p \beta a v o i$ entstanden ist (Krahe 1925, 42). Die formale Nähe zwischen den illyrischen $\triangle \varepsilon \rho B \alpha-$ voi und den slavisierten $\triangle \varepsilon p \beta \lambda \varepsilon v i v o$ von Kaiser Konstantinos läßt sich ebensowenig übersehen wie die zwischen dem lllyrischen ON Derva/ Derba und dem altruss. Landesnamen Dereva. Illyrischem Derva llegt laut Krahe (1955. 104) und Mayer (1957-9, I, 44: II, 39) 'derv- zugrunde, das 24 idg. 'dereu(o)- 'Baum (Eiche), Wald' zu stellen ist. Das aber besagt, daB die Namen der Illyrischen Dervani und altrussischen Derevljane wie auch der polabeslavischen Drevani semantisch identisch sein können. Und das Toponym Dereva der PVL kann demnach ebensogut die Heimat der altrussischen De-

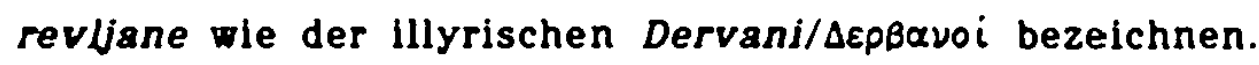

Die Sitze des verhältnismäßig kleinen, aber gut bekannten, erstmals

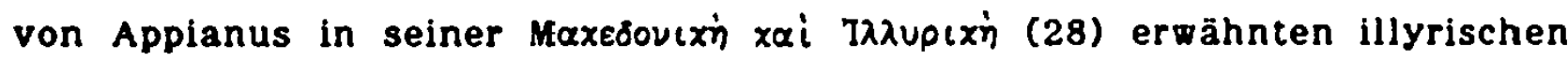
Volkes der Dervani oder auch Derbani lassen sich nicht mehr genau lokalisleren. Wăhrend es für Tomaschek noch "fast sicher" war. daß die Dervani das Gacko polje an der hercegovinisch-montenegrinischen Grenze bewohnten (Tomaschek 1880, 559 f.: ånnlich Patsch in Pauly RE 9. Hbd. 1903. 237). Ist es laut Mayer (1957-9, I, 44) fraglich, ob sie wirklich nach Montenegro gehörten. Mayer selbst denkt an nördlichere Wohnsitze, da die Dervani sich nach Niederwerfung der Delmater 33 v. Chr. dem herannahenden Augustus vor Schrecken freiwillig ergaben (Cons 1882, $146 \mathrm{f}$; Gardthausen 1891, 328), was es wahrscheinlich macht, nördlichere Sitze anzu- 
nehmen". Einen guten Dienst bei der Lokalisierung kann der illyrische ON Anderva leisten, da er gewissermaßen ein Oppositum zu Derva darstellt vgl. dazu Idg. 'ans- 'in Richtung auf, entlang' (Schramm 1981, 316) - und soviel wie 'gegenüber Derva' (Krahe 1925, 79) bedeutet. Anderva, Anderba, auch Andarba, schon zur Römerzeit unter diesen Namen bekannt, ist Identisch mit dem heutigen NIksic in Montenegro. Anderbs, also im südlichen Teil von Dalmatien gelegen, war Kastell an der strategisch wichtigen StraBe von Narona nach Scodra (Pauly RE 2. Hbbd. 1894, Sp. 2122 f.: Tomaschek).

Dafür, daß die ostslavischen Derevljane vom Balkan zugewandert waren, sprechen außer der Namensgleichheit mit den Illyrischen DervanI aber auch andere Faktoren. Die Derevljane grenzten, wie bekannt, Im Westen an die Buzane. einen erstmals vom Geographus Bavarus, dann wieder von der PVL erwähnten slavischen Stamm, dessen Name sich nicht unbedingt von dem Hydronym Bug herleitet, sondern ebenfalls auf illyrische Elemente zurückgefuhrt werden kann (Kunstmann ${ }^{1} 1985,239$ f.). Auch der wolhynischpolnische ON Belz (< Illyr. 'Buls u.a., ebda. 240 f.), der russische bzw. polnische ON Doksicy, Dokszyce (ebda. 245 ff.) und der russ. ON Mozyrb (ebda. 242) plädieren für balkansprachliche Grundlagen. Schlieblich verweist der Name der Region Wolhynien selbst, der ja die Derevljane zugewiesen werden. mit großer Wahrscheinlichkeit auf das sudillyrisch-neuepirotische Toponym Aùiüva bzw. Valona (ebda. 257 re.). Alles das zusammen labt die Vermutung elner Zuwanderung der ostslavischen DerevlJane vorn Balkan gewiß nicht unbegründet erscheinen.

Die hier vertretene These, nach welcher die polabeslavischen Drevani und die ostslavischen Derevljane ihre Namen nicht urslav. 'dervo, sondern Illyrischem - derv- verdanken, wird durch eine der altesten Benennungen eines slavischen Gentilaristokraten, durch Fredegars zu 631/32 genannten Dervanus dux gente Surbiorum ${ }^{3}$ weiter gestutzt. Dervanus, im allgemeinen als PN beurteilt, wird von Schlimpert (1978, 213) zu den Kurz- und Zunamen gestellt. Die Tatsache jedoch, daß der "Name" absolut singulär ist und

- Wilkes 1969. 170, der die Derbanl mit den Deuri identifiziert, meint. ihre Sitze seien im oberen Tal der Vrba zu suchen, suddich der bel Jajce beginnenden Schlucht (Region Bugojno und Gornij Vakuf); laut wilkes entspricht diese Lokalisierung Appians Erwähnung der Derbani als Nachbarn der Delmatae.

- Auf einem Druckversehen beruht bei Schlimpert 1978, 213, die Angabe 931/32; auBerdem wird hier dreimal Deruanus geschrieben, während die Fredegar-Edition von Krusch eindeutig Dervanus hatich Kunstmann-9783954792238 
weder vor noch nach Fredegar jemals wieder begegnet (ebda. 38 und besonders 214), spricht uberzeugend dafür, daß Dervanus eben keln Personenname, sondern vielmehr eine Herkunftsbezeichnung ist, die nur zu ihrer Entstehungszeit und auf ihren Träger bezogen von Bedeutung war, mit dem Verlust des Wissens aber von ihrer Herkunft unterging. Fredegars Dervanus dux drückt nicht, wie ursprünglich vermutet (Kunstmann 1980), die Bedeutung von 'dervbhb dux 'senior dux' aus, sondern bezeichnet mit Hilfe des latelnischen Zugehörigkeitssuffixes - ānus - Romānus, urbānus - die Herkunft elnes slavischen Gentilaristokraten eben aus Derva/Derba. BekanntIlch diente dieses Surnx zur Bezeichnung von Ethnika oder Bürgern und Bewohnern von Orten: Alb-änus, Tuscul-ānus. Troi-ānus usf. Entscheidend aber ist, daB Fredegars Dervanus als slavischer Eigenname keinen rechten Sinn ergibt, da ja doch dieser Stammesfürst kaum 'Hölzerner' oder 'Baum'Fürst geheißen haben dürfte. Ausgesprochen sinnvoll ist es dagegen. Dervanus als Bezeichnung für die Herkunft dieses Sorben-Fürsten aus der Gegend von Derva zu verstehen, was im übrigen vorzüglich mit der Beobachtung ubereinstimmt, nach welcher Teile der mitteldeutschen Sorben/ Serben aus Dalmatien gekommen sind ( $\mathrm{vgl}$. 187 P.).

Die Oberlegungen über die ostslavischen Derevljane und die Herkunftsbezeichnung Dervanus legen letztlich den Schluß nahe, daß auch das polabeslavische Ethnonym Drevani ursprünglich kein Forestis-Name war. sondern die Herkunft dieser Slaven aus Derva in Dalmatien ausdrückte. 
12. Ottos des Grosen marca Lipâni.

Am 26. August 956 vermachte Otto I. dem Kloster Quedlinburg sechs Dörfer, von denen seine Tochter Mathilde. die sich in eben diesem Kloster befand, unterhalten werden sollte. Alle Dörfer im Umkreis von Salzwedel gelegen, gehörten vielleicht zu einem größeren Territorium, das die Urkunde DO I 184 als marca Lipâni bezeichnet:

Noverint omnes fideles nostri presentes quam etiam et futuri, qualiter nos quasdam res nostre proprietatis in marca Lipani, hoc sunt ville VI sic nominate: Liubeme, Klinizua, Sebene. Tulci, Kâzina, Kribci, cum omnibus apendicils ad monasterium Quidilingaburg in honore sancti Petri constructum pro karissimae filiae nostrae Mahtilde victu et vestitu perpetuo iure possidendas donamus...

Die Erwăhnung sowohl der sechs Dörfer als auch der marca Lipâni ist einmalig. nicht eine elnzige andere Urkunde erwāhnt sie wieder, so daß zu sagen Ist: ohne Ottos $d$. Gr. Dokument wüBte die Nachwelt nichts von ihnen.

Der Terminus marca Lipâni läßt womöglich den Schluß zu. daß wir es mit einer größeren territorialen Einheit, eben einer marca zu tun haben. Der Begriff marca kann zur Zeit Ottos Feldmark oder Gemarkung bedeuten (Steinberg 1962, 277), er kann aber auch eine Markgrafschaft bezeichnen (ebda.). 994, also nur kurze Zelt spăter, wird unter marca gelegentlich sogar pagus verstanden (ebda.), und auch Heßler (1957, 133) reiht die marca Lipâni unter die Gaue ein. Preilich ohne daß damit Năheres uber den territorialen Umfang gewonnen wäre. Ungenau ist allerdings auBerdem die Lage dieser marca. Tenn Labuda meint (SlowStarSlow III, 62), daB Salzwedel, dessen Name erst für 1112 belegt ist, vordem den slavischen Namen - Lipiany gehabt habe, so ist das eine völlig unbegründete Vermutung. Weniger unsicher ist vielleicht die pauschale Lokallsierung der marca Lipâni zwischen den Drawähnen im Testen und dem Land Belcsem im Osten. Im Zusammenhang mit dem AusmaB dieser marca stellt sich natürlich auch die Frage, ob Lipâni als Bezelchnung für einen eigenen slavischen Kleinstamm zu verstehen ist. Doch auf diese Frage wird es wohl nie eine Antwort geben, da. wie gesagt, die Erwähnung dieser Lipâni singulăr ist. Auffallen muß jedoch, daß der Name Lipâni niemals als Stammesname verwendet wird. was bel der großen Verehrung der Slaven fur die Linde doch etwas aberrascht. Somit ist festzustellen, daß die „Bedeutung der Bezeichnung marca Lipâni noch ungeklärt ist" (Schulze, H. K. 1973, 148:inrich Kunstmann-9783954792238 
Die Etymologie von Lipânı bereitet keine Schwierigkeiten, wenigstens seit Brückner $(1879,1)$ versteht man darunter 'Lindenwaldner' oder vermutet einen Kult, der mit dem Baum der Linde $z u$, tun hat (SlowStarSlow III. 62: Urbaticzyk). Das Etymon lipa scheint zudem durch den Namen der Dingstätte „zur Linden" im Groß-Biederstedter Holz. Kreis Salzwedel, bestătigt zu werden'. Allerdings liegt die Malstătte außerhalb des für die marca Lipâni anzusetzenden Gebietes (Steinberg 1962, 277), auch dürfte eine so allgemeine Bezeichnung des Ortes oder vielmehr des Baumes, an dem das Recht vollzogen wird. kein ganz sicherer Anhaltspunkt für die Bestimmung des fraglichen slavischen Siedelgebietes sein.

Es wäre nämlich denkbar, daß die marca Lipâni ihren Namen gar nicht dem slavischen Baumnamen lipa verdankt, sondern auf Ulpiana. $\Lambda_{1}-$ $\pi \varepsilon i o \nu<0 \dot{\lambda} \lambda \pi i \alpha \dot{\nu \alpha}$, den Namen einer berühmten alten Stadt im Dardanerland zurückgeht. Antikes Ulpiana wurde im Serbischen zu Lipljan, das heißt statt der regelgerechten Umwandlung von $u i-$ in ! bzw. Ib trat volksetymologische Anlehnung an slav. Lipa ein (Mayer 1, 349; Popovic 1960, 109). UJpiana war In römischer Zeit eine der wichtigsten Burgen im Inneren der Balkanhalbinsel und eine der größeren Städte an der Straße Thessaloniki Sirmium bzw. von Ratiaria über Naissus nach Lissus (weiter Pauly RE 2. Reihe, 17. Hbbd., 1961, 564 fl.: B. Saria). Während der Völkerwanderungszeit wurde Ulpiana vernichtet, doch von Kaiser Iustinian I. wieder errichtet und mit dem neuen Namen Iustiniana Secunda bedacht. Die alte Bezeichnung UJpiana erwies sich allerdings als bestăndiger, denn unter dem alt-neuen Namen Lipljan entstand später in der Nähe des römischen castellum an der Sitnica, also auf dem heutigen Kosovo Polje eine serbische Burg. die dank ihrer Lage an der Grenze zwischen Serbien und Byzanz große militärische und wirtschaftliche Bedeutung erlangte ${ }^{2}$.

Es läßt sich freilich vorerst nicht beweisen, daß der Name der marca Lipâni auf antikem Ulpiana bzw. dessen slavischer Adaption Lipljan beruht. doch ist diese Vermutung auch nicht restlos unbegründet, da die Namen jener sechs Dörfer in Ottos d. Gr. Urkunde allesamt - mit Ausnahme vielleicht von Liubeme - nicht gerade slavisch aussehen. Man hat bereits verschiedene Versuche unternommen, diese Namen zu etymologisieren: der

3 So schon F. Kühns 1865, II. 55, Anm.114: Schultze, J., 1957, 92 f.: SlowStarSlow III, 62: Labuda.

2 Jirecek 1911, I, 239; Urosevic. A., 1953-4; StowStarSlow III, 62: Kowalenko. 
letzte und seriöseste stammt von Ruth Steinberg bzw. deren lingulstischer Beraterin Lore Baumert. Auch wenn hier nicht versucht werden soll, die Herkunft der sechs Ortsnamen näher zu bestimmen, so seien doch gegenuber den bisherigen Interpretationen einige abweichende eigene oberlegungen zur Debatte gestellt.

Der ON Tulci etwa, den Steinberg zu slav. tulec 'kleiner Kסcher' stellt, kann sich ebensogut, wenn nicht sogar besser, auf illyrisch taul-

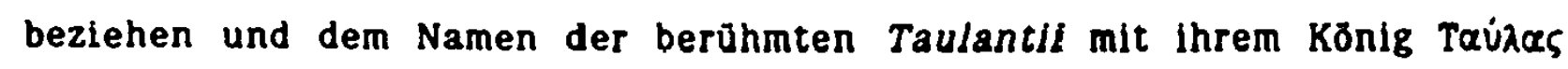
nahestehen (Krahe 1925, 38 f.). Die 2. Silbe von Tulci ist ohne Frage als plural. Suffix - bci zu verstehen, so daB sich die Form - Tulbci erschließen läßt. was soviel wie 'Leute aus dem (ehemaligen) Taulantier-Reich' besagen könnte. Im gegebenen Zusammenhang kann aber außerdem der für Dalmatien oft belegte römische Name keltischer Provenienz Tullus in Betracht gezogen werden (Alföldy 1969, 314; Holder II, 1982. 1984: Tuilus). Kâzina, ein weiterer ON der marca Lipâni, kann unmöglich zu polabeslav. karc 'gerodete Stelle' gesetzt werden (Steinberg). Weit mehr käme der für Salona belegte PN Casinia (Alföldy 73) in Frage. der gewiß auf römische Familien zurückgeht, die im 1. Jhd. n. Chr. aus Casinum nach Salona zugewandert sind (wilkes 1969. 232. Anm. 1). Noch besser lleße sich Kâzina aber mit dem griech. PN Kacivas 'der Glănzende, Ausgezeichnete' in Verbindung bringen. - Der Dorfname Klinizua, den steinberg zu slav. klinec 'kleiner

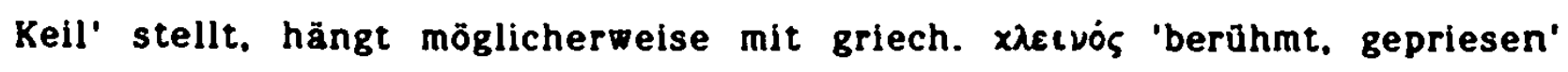

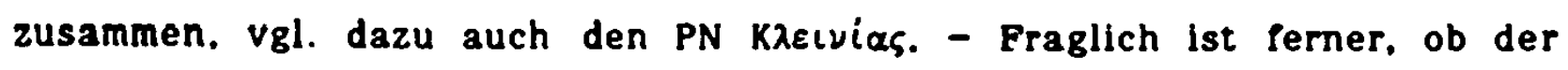
ON Kribci mit slav. krivz 'krumm' zu tun hat. Vielleicht ist hier eher an das mittelalterliche Zupanat Krbava östlich der Lika zu denken, das seinen Namen angeblich dem unterirdischen Fluß Krbava verdankt (Dickenmann '1966. I. 197) und auf 'kivavs 'blutig' beruhen soll. Bei Konstantinos

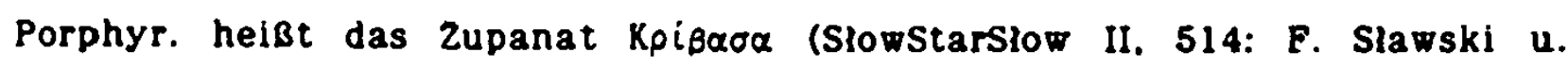
V. Franci( ). Nicht ausgeschlossen werden kann weiter, daß der Dorfname Kribci, der zweifellos wieder das Formans -bci enhālt, auBerdem Betazismus $v>b$ aupweist und irgendwie mit dem etymologisch ebenfalls noch dunklen Stammesnamen der russischen Krivicl zu tun hat.

Wenn es gelingen sollte, einige der fraglichen sechs Ortsnamen etymoiogisch mit balkansprachlichen Toponymen in Verbindung zu bringen, würde die Wahrscheinlichkeit, daß der Name Lipâni nicht auf lipa, sondern dem antiken Stadtnamen UIpiana beruht. konkrete Konturen bekommen. 
woy

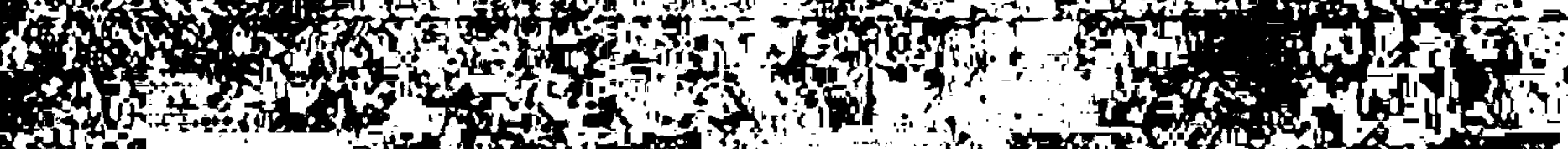
F,

515

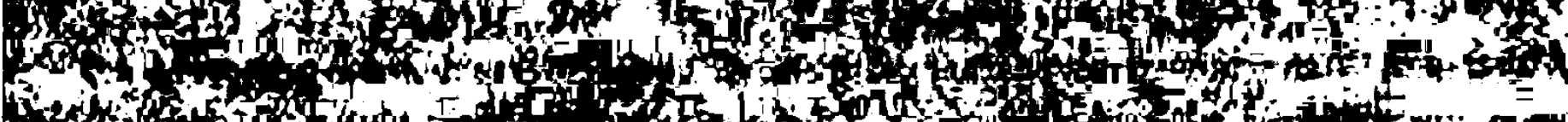

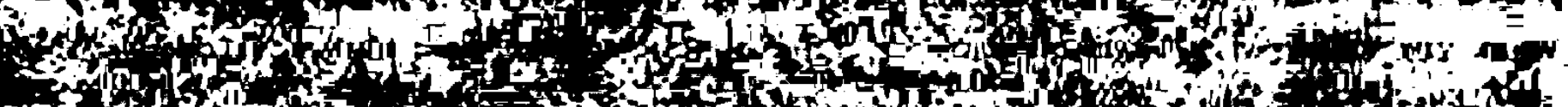

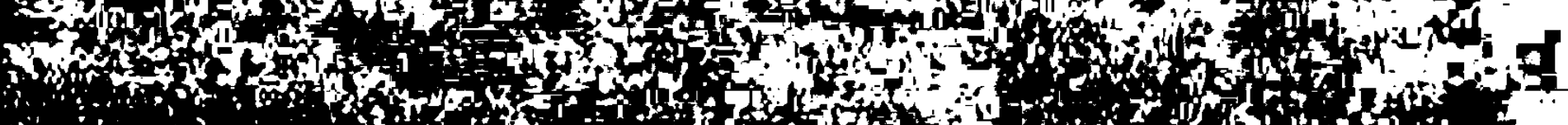
iflowy

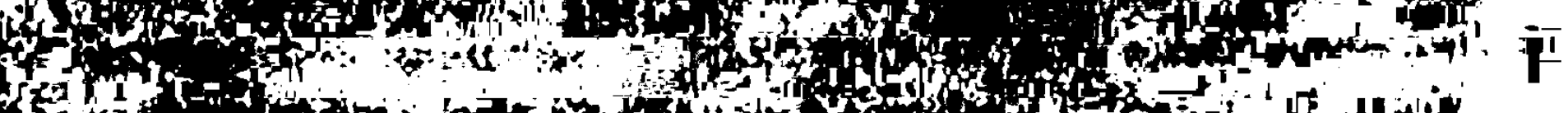

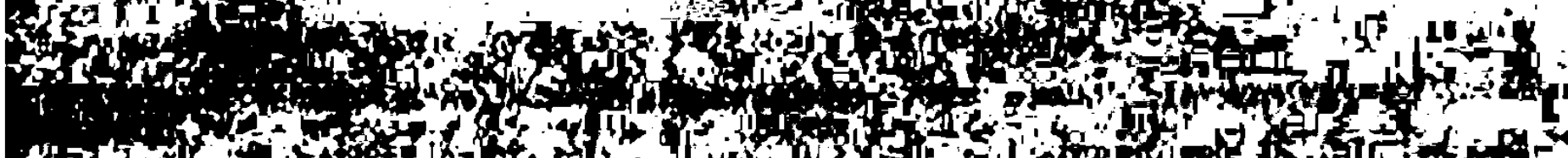
40 of

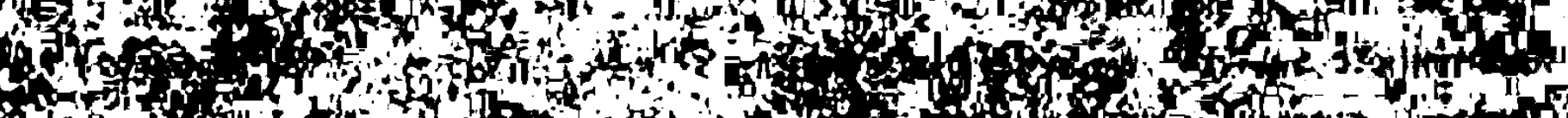

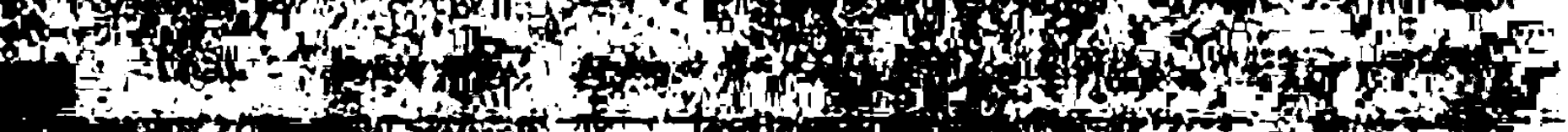

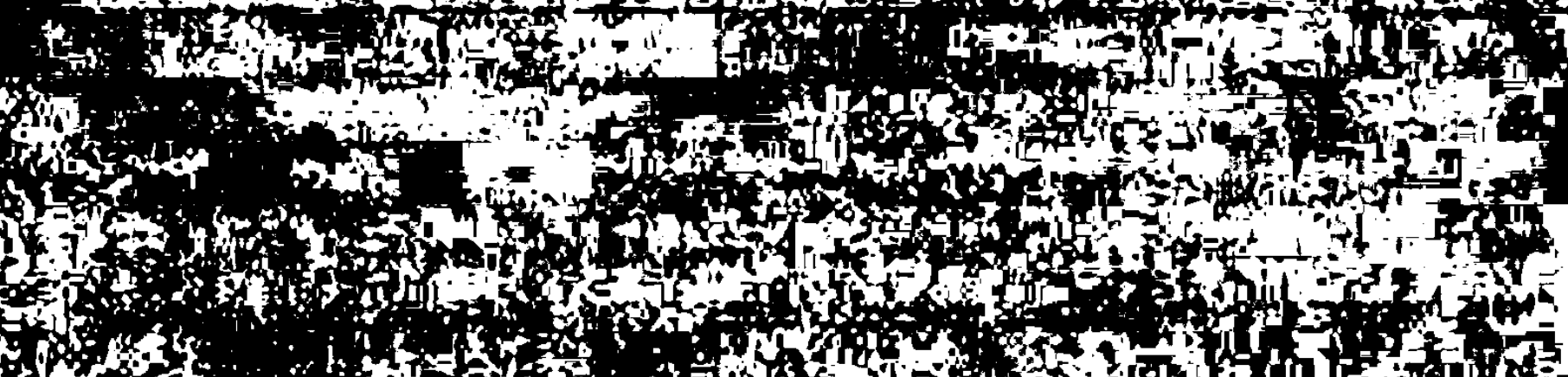

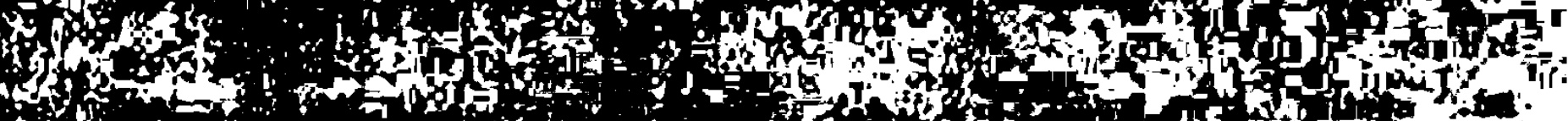

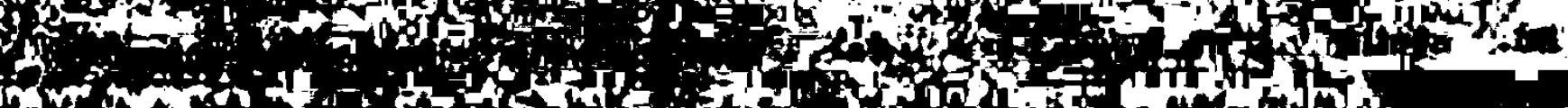

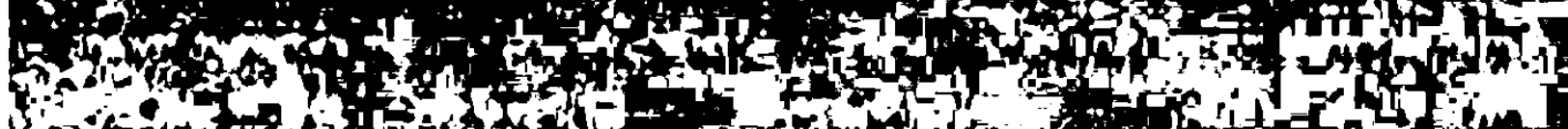
Fon

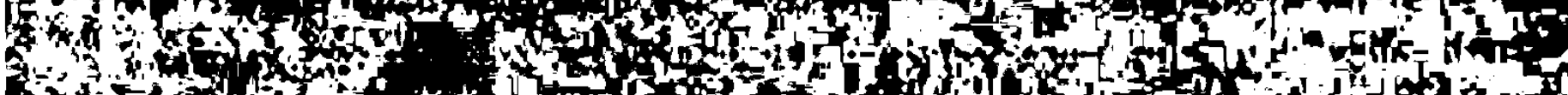

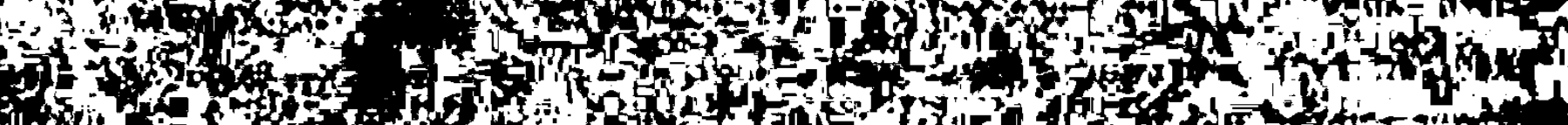

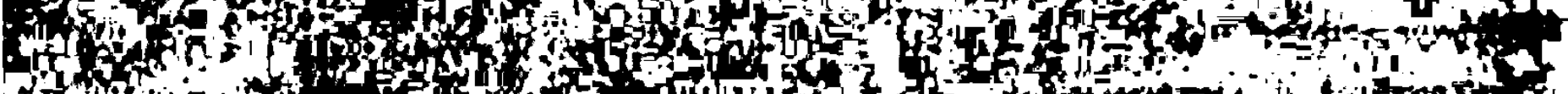

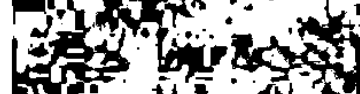

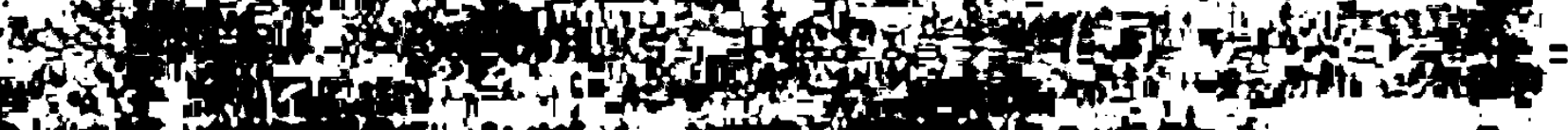

$F_{1}$

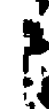

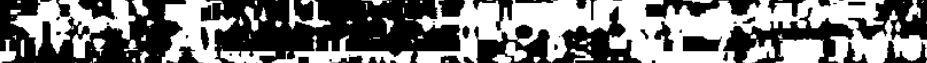

A

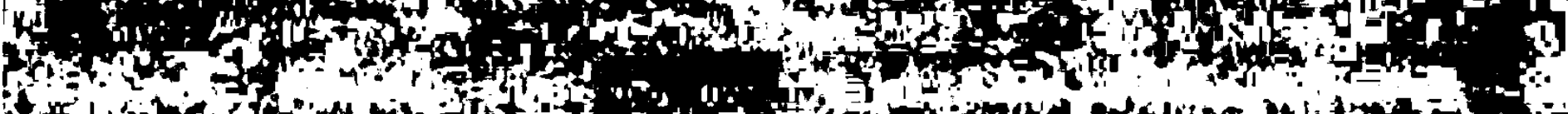
xat lo Pfor is

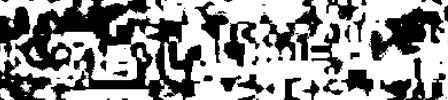

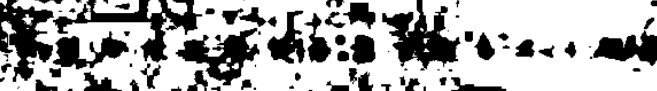




\section{Belcsem in der Altmark}

Die hier verwendete Form Belcsem ist nur eine von last unzähligen Versionen dieses Landschaftsnamens, die aber den Vorteil bietet, weniger kompliziert zu sein. Vorauszuschicken ist ferner, daß im folgenden vor allem die Rätsel des vielgestalten Namens gelöst und weniger die mit ihm verbundenen historisch-territorialen Fragen beantwortet werden sollen.

Der fraglos von einem slavischen Ethnikon bewohnte mittelelbische Kleinbezirk Belcsem wird von der Wissenschaft links der Elbe angesiedelt. und zwar an der Grenze $z u$ den Drawähnen im Nordosten und den rechtselbischen Liezizi im Osten. Im großen und ganzen glaubt man somit, ihm das Gebiet 2 wischen Ohre-Elbe und Biese in der östlichen Altmark zuweisen zu können’. Die Altmark ist der älteste, westlich der Elbe gelegene Teil der Mark Brandenburg. in den vielleicht schon während des 7 . Jhds. slavische Siedler eingewandert sind ${ }^{2}$. Wie die Annales regni Francorum (56) mitteilen, erreichte Karl d. Gr. im Jahr 780 dle Ohre-Mündung an der Elbe: Et pervenit usque ad...nuvium. ubi Ora confluit in Albia. ibique omnia disponens tam Saxoniam quam et Sclavos. Damit wird nicht nur das Vorhandensein von Slaven in dem fraglichen Gebiet bestätigt, sondern auch der Beginn der noch in karolingischer Zeit vollendeten Einbeziehung der Altmark in das Reich. In ottonischer Zeit wird sie dann Teil der Markgrafschaft der Nordmark und verbleibt nach dem Slavenaufstand von 983 als Rest der Mark unter deutscher Herrschaft (Lex. d. MA I, 479: H. K. Schulze). Unerklärlich ist die augenfällige Diskrepanz zwischen slavischen ONn und slavischen Bodenfunden: Während im Osten der Altmark slavische Toponyme verhältnismäßig selten sind, nach Westen hin Jedoch zunehmen. ist es im Blick auf die Bodenfunde genau umgekehrt, das heißt, sie sind im Osten, wo nur wenige slav. ONn aufscheinen, hăufiger, in der mittleren und westlichen Altmark hingegen ausgesprochen gering ${ }^{3}$. Dieses MiBverhältnis $z$ wischen Toponymie und Archäologie könnte beispielsweise Ausdruck unterschiedlicher Zeitstellungen in den Siedelbewegungen sein.

Die nicht geringen Schwierigkeiten des Landschaftsnamens Belcsem spiegeln sich in den urkundlichen Belegen, wobei die älteren aberwiegend

1 Vgl. Heßler 1957, 39 ff.; Bathe 1940; J. Hermann 1985, 8.

2 So jedenfalls H. Walther in: J. Herrmann 1985, 42.

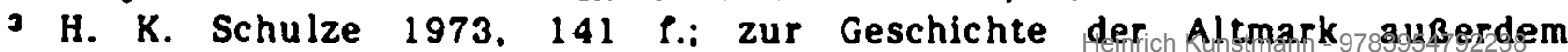

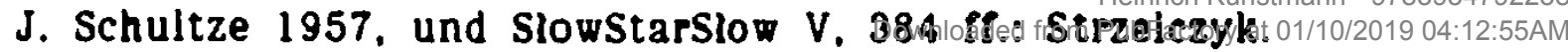


auf Abschriften von Chroniken oder Annalen beruhen, also zeitbedingten Schreibformen unterliegen, die naturgemäB nicht immer frei sind von Fehlern (Bathe 1967, 629). Die nachfolgenden Belege stützen sich aup die sorgfältig bearbeitete und kommentierte Zusammenstellung durch Max Bathe (ebda. 629-31)4:

zu 814 Belkesheim (Förstemann: Belckesheim: unecht?); zu 938 Belxam (Ann. Corbey): zu 980 (?) belcseim (Förstemann: Beleseim): zu 983 Belxem (Annalista Saxo): zu 993 Belsamis oder Balsamis (Urk. d. 17. Jhds.): zu 1002 (?) Belshem (falsum d. 12. Jhds.); zu 1006 belcsem: zu 1012-23 Belkishem (Förstemann: Belckishem); zu 1052 Belcesheim; 11. Jhd. (?) Belxa (vielleicht für Belxā = Bel$x a m) ; 12$. Jhd. Belsheim: zu 1150 (?) Balsamorum regio (Annal. Pegavienses: 3 mal); zu 1160 Balsamis; zu 1160 Balsemerlande,... quae dicitur (Helmold); Balsamorum. in terra palustri (Helmold); um 1161 Balsmarlant; zu 1194 Balsamie; balsamie, per bannum (Formel: zwischen 1383 u. 1500 rund $7 \mathrm{mal}$ ): zu $1436 \mathrm{Balsem}, \ldots$. in dem-banne; 1473 Balsamie....banni terre (4 mal); zu 1507 Balsames -. Commissarius - Bannes; zu 1525 Balsam.... des - Bannes.

Die Deutung dieses eigenartigen Namens bewegt die Wissenschaft wenigstens seit Safařik (I, 906), der inn 2 war erwähnt, es aber offensichtlich nicht wagt, dafür eine Etymologie zu geben. Anders ZeuB, der Belcsem für einen slavischen Landschaftsnamen hält. den er Pragend so erklärt. wie die Fachwelt dies noch heute tut: "Bjelozemja, Bjela zemja, WeiBland?" (ZeuB 661. Anm.). Dagegen wendet später Jellinghaus ein (Förstemann II. 1498). daß bela zemja "das organische $k$ in Belkes-heim ganz unberücksichtigt lasse". Jellinghaus selbst denkt an ein deutsches Grundwort - heim und einen slav. PN Belk, hinter welchem sich der Name eines slavischen Dynasten verbergen könne. Mit J. Koblischke ist Jellinghaus sich darin einig. daß der Landschaftsname schon vor Karl d. Gr. geprägt sein müsse. Unschlüssig ist hingegen A. Brückner (1879, 1, 87), der belckesheim zu den "vermeintlich slavischen Namen" stellt. ohne selbst eindeutig Stellung zu nehmen. Unannehmbar ist in neuerer zeit der Vorschlag von $R$. Turek, der den Namen mit den Bethenici des Geographus Bavarus in Verbindung bringt, was lautlich einfach unmöglich ist (Turek 1952, $39 \mathrm{ff}$.). Eine bemerkenswerte Beobachtung ist Jedoch HeBler zu verdanken, der nämlich treffend erkannte, daB die Entwicklung des Praglichen Namens in zwei Richtungen gegangen ist. Während Belcsem u.ä. zu Belkesheim führte, ist der Typ Belsheim in Balsamia u.ä. übergegangen. HeBlers Ansicht zufolge

1 Es werden auch die Zitierungen bei Förstemann-Jellinghaus ON I. 353.

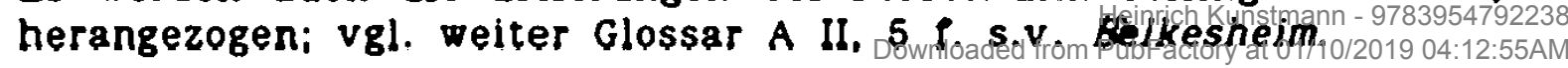


war die lautliche Entwicklung mit einer sachlichen Anderung verknüpft, da unter Balsamia, Balsamerland U.a. nicht mehr der ursprüngliche Gau, sondern der Archidiakonat Balsamien oder Balsam-Bann des Bistums Halberstadt gemeint war. Heßlers Auffassung schloB sich im Prinzip auch v. Polenz an (1961, 163. Anm 2.). Jedenfalls ist HeBler insofern zuzustimmen. als die Belege des strittigen Namens zwei Grundtypen erkennen lassen, einen mit und einen ohne $k$ bzw. $c$.

Im gegebenen Fall interessiert in erster Linie, ob Belcsem uberhaupt ein slavischer oder, besser gesagt, ein eingedeutschter slavischer Landschaftsname ist. Einige Forscher wie z.B. der in dieser Frage von Kupka (1936) ausgehende H.K. Schulze $(1973,142)$ bejahen dies, während andere sich dagegen aussprechen, wie etwa T. Lehr-Splawinski (SlowStarSlow I, 111), für den der Name "von unklarer Herkunft (und) eher nichtslavisch" ist. Ganz besonders eingehend und gründlich hat sich mit dem Landschaftsnamen in jüngerer Zeit Max Bathe (1967) befaBt, der zu der Oberzeugung gelangte, daß dieser nicht slavisch, sondern eine Kombination aus dem Stammesnamen Belgae und dem Grundwort - heim sel. So erklärt Bathe Belxem aus urgerm -Belg(i)s-o-haima(m), worunter eine Stammes- oder Personengruppenbezeichnung $z u$ verstehen sei, die vermutlich schon in den ersten Jahrhunderten vor Christi Geburt gebildet und vielleicht von Slaven zu - Bel-o-zemja umgedeutet worden ist. Weiter meint Bathe, diese Belgae oder - Belg(i)sos (mit Ableitungssuffix - (i)s-) könnten aus einem Gebiet rechts des Rheins nach Osten abgewandert sein: immerhin habe sich schon Caesar berichten lassen, daß die Belgae dereinst rechts des Rheins saßen. Für Bathe hat auch das Hydronym Balsam, ein kleines Gewässer, das unweit von Nienburg in die Biese mündet. nichts mit dem Landschaftsnamen zu tun. sondern ist eine suffixale Ableitung vom Namen des Bilsen-Krautes. Gegen eine slavische Herkunft von Belcsem u.a. Puhrt Bathe (633) namentlich zwel Argumente ins Feld: 1. wenn man von einer slav. Grundform Bela ausgehe, wäre im Deutschen $z$ wischen $/$ und $z$ noch lange ein Vokal erhalten geblieben: 2. gibt es keine Belege, die anlautendes slavisches $z$ durch deutsches cs (Belcsem) oder $x$ (Belxem) wiedergeben. Die sehr gelehrten Ausführungen Bathes demonstrieren anschaulich, in was für phantastische Höhen sich Onomastik erheben und das Naheliegende aus den Augen verlieren kann.

An Zuwanderung eines gallischen Stammes der Belgae in das pragliche

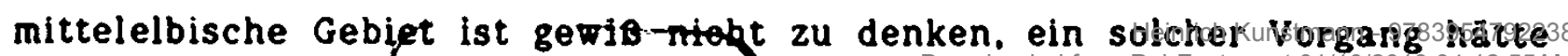
$\left|\begin{array}{cc}\text { … } & 7 \\ \text { !ot:ak }\end{array}\right|$ 
Praglos onomastische oder archäologische Spuren hinterlassen. Onomastische und archäologische Spuren hinterlassen haben hier jedoch die Slaven. Die in der Onomastik biswellen zu beobachtende Praxis, premde Volker zu bemühen oder gar neue Ethnika zu erfinden, um eine These zu stützen, ist im vorliegenden Fall allerdings nicht erfolgversprechend, da dem Toponym Belcsem und seinen Varianten mit absoluter GewiBheit slavische Bildungen zugrundellegen, die alle lautlichen Probleme auf verhältnismäBig einfache Weise losen. Die Grundform dieses Landschaftsnamens ist nämlich nicht - Bela zemja, sondern -Velbzemja, das erste Glied des Namens bedeutet also nicht •bel- 'welB', sondern 'velb-'groB'. Das Element - velb- erklärt nun den einen der beiden Namenstypen, und $z$ war den ohne $k$ : Belshem. Belsheim, Belsamls, Balsem usf. Die Balsam-Bildungen, das sei nur am Rande gesagt. beruhen höchstwahrscheinlich auf deutschem EinfluB, da der Wandel $e>a$ eine bekannte mitteldeutsche Erscheinung ist (Lasch 1974. 59 ff.). Anders verhält es sich mit dem Typ. der ein k-Element aufweist: Belkesheim. Belkisheim. Belcsem. Belxem usw. Hier liegt natürlich nicht slav. 'velb-. sondern die daraus durch spätere suffixale Erweiterung entstandene Dublette 'velskb- 'groB' vor. Das Nebeneinander von 'velb-und - velskb-, auf das die Typen Belshem und Belcsem mitsamt ihren Varianten zurückgehen, ist der handfeste Beweis dafür, daß dem Toponym nur die Bedeutung von 'groß' zugrunde llegen kann. da aus 'bel- 'weiß' niemals ein Belkesheim zu erklären wäre.

2u den beiden Einmănden Bathes gegen eine Slavizităt des Landschaftsnamens ist noch mehr zu sagen. Das Argument, bel einer Grundform - Bela zemja hätte sich $z$ wischen $I$ und $z$ aup lange Zeit ein Vokal gehalten. ist gegenstandslos. weil nun von einer Grundform 'velbzemja auszugehen ist. Dieses Kompositum ist analog zu aksl. velbmoza 'Großherr', aruss. velbmuzb, velbmoza 'optimas, primus' (Sreznevskij I, 240 f.) oder serbokroat. velbmoż, velbmozaninb, velbmožb 'optimatum unus' (Danicic I, 106 ff.) gebildet. was zugleich besagt. daB der Halbvokal $b$ an der Naht zwischen beiden Glledern im Deutschen kurzfristig untergehen muBte. Im übrigen ist der von Bathe reklamierte Vokal noch in jenem auf 'velsks beruhenden Typ gut erkennbar, vgl. Belk-e-sheim. Belk-i-sheim. Beic-e-sheim usw. Dabel kann $e(>I)$ Reflex sowohl von slavisch $-z(\cdot v e l b k-b)$ als auch von slav. $-a(\cdot v e l b k-a)$ sein: in letztem Fall kann an mittelniederdeutsche Schwächung von $a>$ e gedacht werden (Lasch 61 ff.). Was Bathes zweiten Einwand anlangt, wonach cs und $x$ unmöglich slay 
Ist zu sagen, daß hier ein grandioser Irrtum vorliegt, da der Lautwert von cs und $x$ völlig verkannt wird: Es handelt sich dabel doch nur um Grapheme von ks bzw. kz! Für Belcsem und Belxem ist folglich Belbk-zem zu lesen: nach Abfall von - $b$ (oder $-a$ ) sind $-k-$ und $z-z u$ cs $(c=k)$ bzw. $x(=k s)$ verschmolzen. Belde Einwände Bathes sind somit uberzeugend ausgerăumt.

Belcsem und alle übrigen Formen setzen sich daher aus der Bestimmung "velb-."velbks- und dem Grundwort zemja zusammen. Letzteres wurde bel einem Teil der Belege $z u$ - heim oder - hem eingedeutscht. DaB heim und - hem bedeutungsmäBig auf slav. zemja zurückgehen, zeigt sich an den Tautologien Balsemer-land oder Balsmar-lant. Der EindeutschungsprozeB hatte den Abfall des Auslautes -ja. aber wohl auch eine Art Genuswechsel von fem. slav. zemja zu masc. dtsch. - heim zur Folge. Im Blick auf den Auslaut -ja ist noch $z u$ bemerken, daß zemja ursprünglich überhaupt ein konsonantischer Stamm war. vgl. slovak. zem sowie die russ. Akkusativkonstruktionen názem 'zur Erde', ozem 'gegen die Erde' (Vasmer REW I, 452 P.).

Der Bedeutungswandel von 'velb 'groß' $z \mathrm{u}$ 'bel- 'weiB' beruht ohne Frage aup einem Betazismus. Dieser ist jedoch ein vorwiegend aus dem Griechischen und (Vulgär)Latein, aber auch aus dem Deutschen und hier namentlich dem Schlesischen und Bairischen (Schützeichel 1955, 204 P.) bekannter lautverändernder ProzeB (vgl. weiter Kunstmann '1983, 126 P.). der sowohl in intervokalischer Position als auch im Anlaut eintritt (Leumann 1977, 159). Auch wenn die Auswirkungen des Betazismus im Siavischen noch nicht abschlieBend beurteilt werden können, darf angenommen werden, daß gerade in der Onomastik so manche Fehleinschätzung unerkannt geblieben ist. Speziell den Fall Belcsem < - Velbzemja berühren die

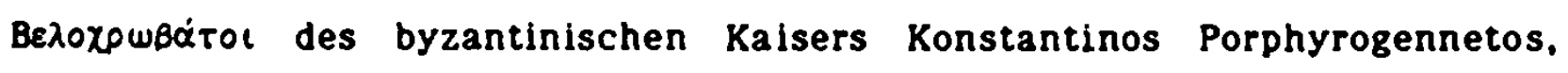
hinter welchen nicht. wie bisher immer angenommen, 'WeiBkroaten'. sondern eben 'Velbchrōbátol 'Großkroaten' stehen (Kunstmann 1984). Ebenso verhålt es sich mit der Beleknegini Thietmars von Merseburg, die keineswegs eine 'weiße Fürtin', sondern eine 'Velbksnfgyai, also eine 'Großfurstin' war, welcher Titel ihr als Gemahlin des ungarischen Grobfürsten Géza (Györffy 1984, 723 ff. u.ö.) zustand.

Slav. 'velb-. 'velbkb- bedeutet in aller Regel zwar 'groB', doch kann

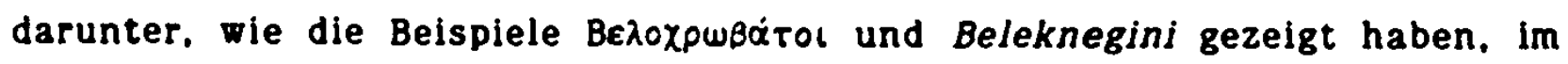
übertragenen Sinne ebenfalls 'alt' $z$ u verstehen sein. Dainsch Korfimann defr 
nischen Praxis nahe, wo sich magnus, maior, maximus bisweilen nicht auf Körpergrōße oder Besitz. sondern eben auf das Alter beziehen, vgl. maiores 'dle Alten, Alteren; der Senat', maiores natu 'die älteren Leute'. Ahnliches

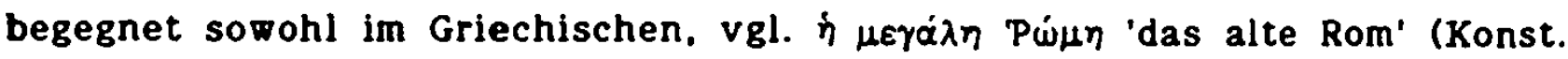
Porph. DAI 21, 32), als auch in anderen idg. Nationalsprachen, in denen z.B. grandfather, grandmother, grand-père, grand-mère, groothere, grootvrouwe und Großvater. Großmutter usuell geworden sind. Uberträgt man dies aup Belcsem, so zeigt sich, daß der Sinn dieses Landschaftsnamens nun weder 'Weißland' noch 'GroBland', sondern 'Altland' ist. Es kristallislert sich also eine bedeutungsmäßige Obereinstimmung zwischen slav. Belcsem und dtsch. Altmark heraus, die gewiB überrascht. Handelt es sich um eine Obersetzung? Wenn ja, wurde -Velbzemja ins Deutsche oder Altmark ins Slavische übertragen? Diese Frage ist zunächst schwer zu beantworten, auch wenn feststeht, daB slav. 'velb-sehr alt, auf jeden Fall alter ist als dessen suffixal erweiterte Dublette 'velbkb-, die erst in historischer Zelt ungewöhnlich produktiv geworden ist und die ältere Form - velb- last völlig verdrängt hat (Zareba 1976). Die Verwendung von - velb- läBt also auf ein relativ hohes Alter der slav. Bildung - Velbzemja schließen. Andererseits sind die Begriffe slav. zemja und ahd. marc(h)a. mhd. marke nicht völlig identisch. Aksl. zemja (zemlja) bedeutet 'Erde. Land: Boden: terra: regio, provincia, patria, territorium...' (SJS I, 1966. 670 ९.): aber auch ahd. $\operatorname{marc}(h) a$ ist ein mehrdeutiger Begriff, der ursprünglich den Grenzsaum und erst danach das Geblet an der Grenze meinte (Rössler, Franz II, 708; Haberkern, Wallach II, 413), im Prinzip also 'Grenze' zum Inhalt hatte. Dies konnte sich ebenfalls auf kleine Einheiten wie eine Feldmark beziehen. Gerade hier waren Bedeutungsberührungen zwischen slav. zemja 'Land' und mhd. marca 'Feldmark. Gemarkung' denkbar'. Möglich sind außerdem Zusammenhänge zwischen slav. -Velbzemja 'Altland' und Altmark 'Antiqua marchia, Olde Marck', die sich aus der Gliederung des Slavenlandes ergaben, wie sie bekanntlich von Helmold von Bosau angedeutet werden: sunt autem in terra Slavorum marcae quam plures, vgl. dazu J. Schultze 1957, 79 \&. Die ursprüngliche Bedeutung von Belcsem läßt sich somit als 'altes (slavisches) Land an der (mittelelbischen) Grenze zwischen Slaven und Sachsen' kommentieren. Die Enträtselung des Landschaftsnamens Belcsem eröffnet eine nicht uninteressante

- Zum Gebrauch des Begriffes marca auf mitteldeutschem Gebiet in ottonischer Zeit vgl. Steinberg 1962, 277. Downloaded from PubFactory at 01/10/2019 04:12:55AM 
sledlungsgeschichtliche Perspektive, die von der Geschichtswissenschaft weiter untersucht $\mathrm{zu}$ werden verdient. 


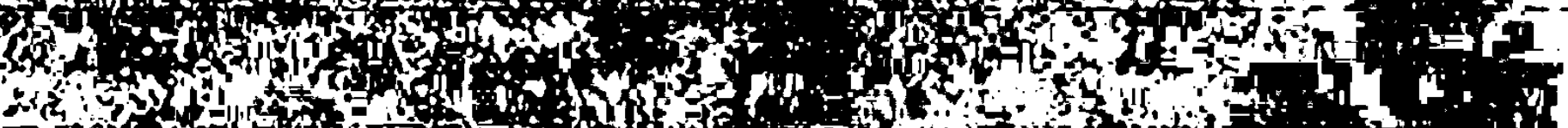

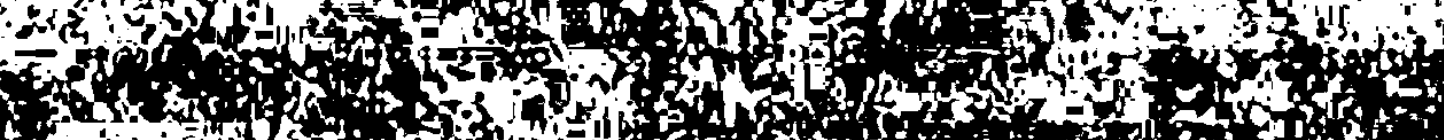

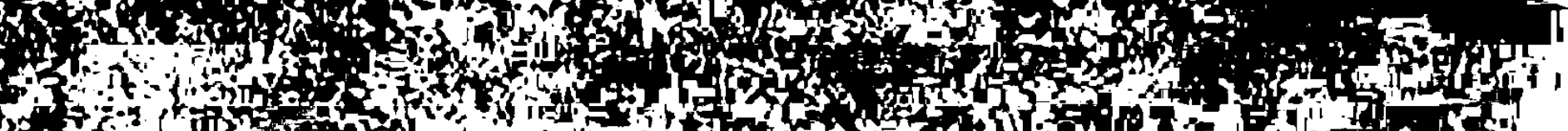

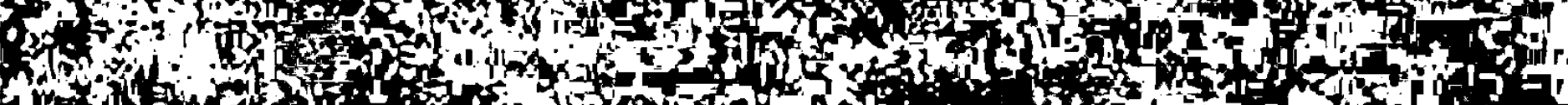

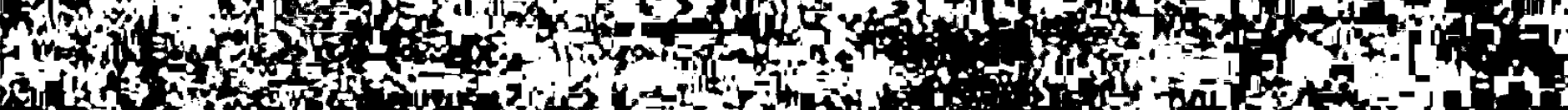

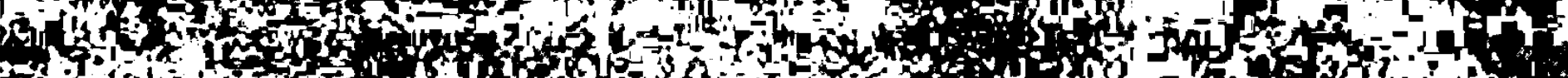

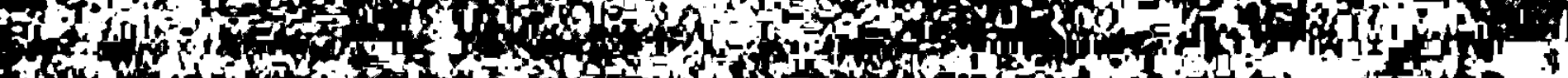
if

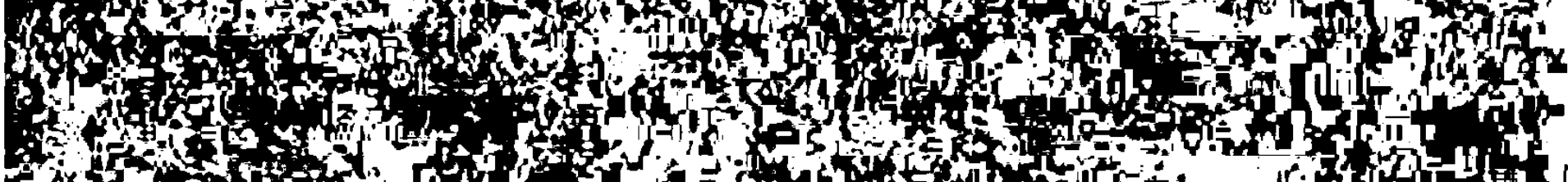

$x_{0}+3$

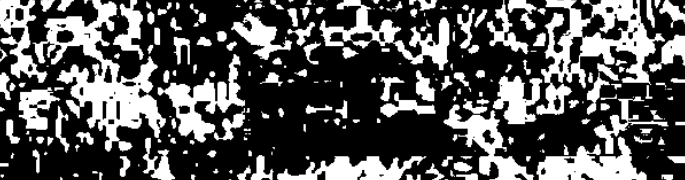

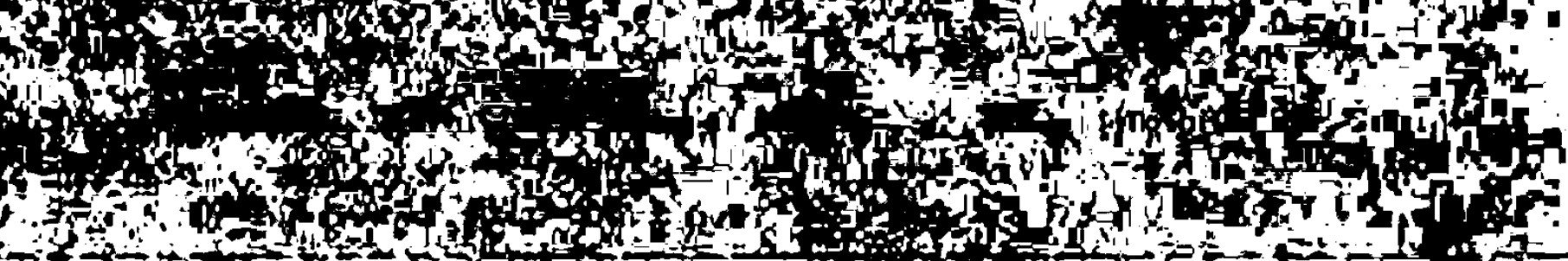
ari ii (1) $+3$ 15 A inte

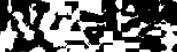

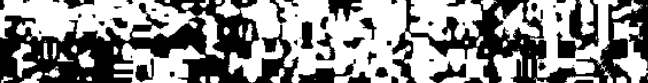

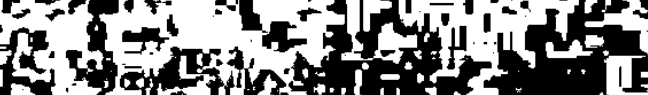
follow

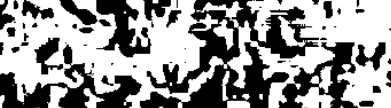
40 7. a 1.

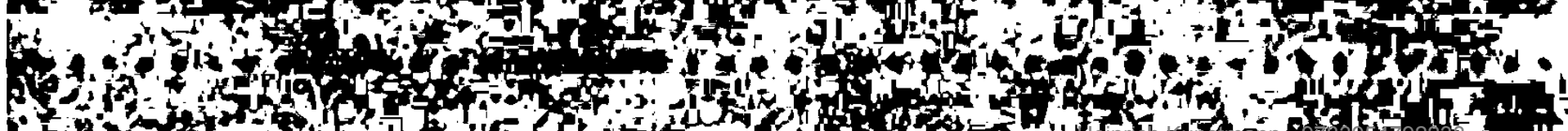

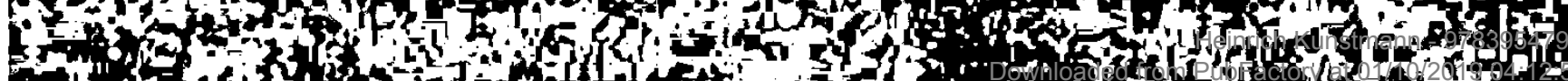

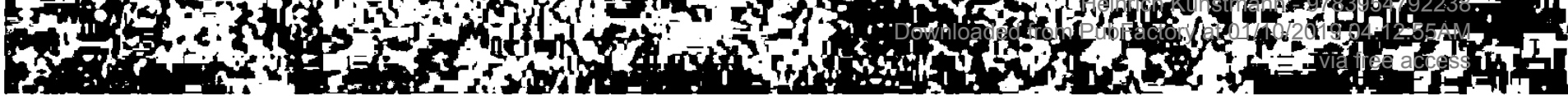




\section{Murizzi und Morizani}

Es sind hier zwei Namen und zwei slavische Ethnika zu unterscheiden, die von der Forschung gelegentlich verwechselt oder in einen Topf geworfen werden, wie etwa von Niederle (III, 140 f.), aber auch von Brüske (1983, 191 (f.). Dabei ist sowohl der namentliche als auch der siedlungsgeographische Unterschied zwischen beiden offensichtlich. Zum einen hatten nämlich die in ottos d. Gr. Gründungsurkunde für das Bistum Havelberg erstmals zu 946 erwähnten Nurizzi ihr Siedlungsgebiet im Lande Müritz. das rings um den gleichnamigen See, den größten Norddeutschlands, gelegen war'. Andererseits gelten die schon vom Geographus Bavarus genannten Morizani als ein wilzischer Kleinstamm und Slavengau, der an der mittleren Elbe gegenüber Magdeburg saß und dessen Vorort vielleicht Leitzkau war². Mit einiger Wahrscheinlichkeit haben daher die Murizzi der mecklenburgischen Seenplatte mit den Morizani an der mittleren Elbe nichts zu tun.

Unter den Belegen für die Murizzi und den mit ihnen zusammenhängenden Bildungen ist grundsätzlich $z u$ unterscheiden zwischen dem Land (I), dem FluB (II) und den Orten (III):

1. 946 (provincia) Murizzi (DO I, 76): 1160 provincia Morizi: 1171 Moriz. Mvriz: 1186 terra Noriz; 12. Jhd. barbarorum natio Moriz (Ebbonis Vita Ottonis III, 4);

II. tusschen der Muretzenn unde deme Colpyne; 1273 Muriz stagnum; 1273 squa Muriz:

III. 12. Jhd. praedium Morize (Helmold 1, 18): 1328 nemus Muritz (abgegang. Flurn.); 1329 Muryz (h. Ostseebad Müritz); 1352 curia Muritze.

Als namenstiftendes Element von I und III sieht man in aller Regel das Hydronym (II) an. Obereinstimmend leitet man auch den FluB- und Seenamen Müritz von Morica ab. was wohl seine Berechtigung hat, nur ist zu bezwelfeln, ob tatsăchlich beide Ethnonyme, also Murizzi und Morizani, Ihre Namen dem Hydronym 'Morica verdanken.

Wie schon S. Urbaticzyk erkannte (SlowStarSlow III, 301), muB eine Ableitung von Murizzi aus Morica gewisse 2 weifel wecken. Aus verschie-

1 Brüske 1983, 192 f. Zur Geschichte der Murizzi ausfuhrlich Labuda In SlowStarSlow III, 301 ff.; auBerdem Dralle 1981, Reg., sowie Herrmann, J., 1985, Reg.

2 Dleser Auffassung steht Kahl 1964, 106 f., skeptisch gegenüber. Zur Lokalisierung weiter HeBler $34 \mathrm{fP}$.

3 Nach Trautmann 1950, 108, und Udolph 1979, 216. Heinrich Kunstmann-9783954792238 
denen Gründen. Festzuhalten ist, daß dle ottonische Urkunde fur Havelberg mit Murizzi - genau wie bel Zemzizi. Liezizi und Nielitizi - elnen slavischen Nom. Pluralis Morici < Morbci (Nom. Sg. Morbcb) wiedergibt. was besagt, daß Murizzi nicht gut von 'Morica, sondern vielmehr von 'Mora. - Mura oder Muora gebildet worden ist. Der Stammesname Murizzi, wäre er von Morica abgeleitet, hätte sonst - Moricbci oder ähnliches ergeben.

Anders verhält es sich mit dem norddeutschen FIN Müritz. der, wie allgemein angenommen, fraglos auf Morica zurückgeht, doch ist dabei auch zu bedenken, daß - -ica ein Deminutivsuffix ist, das meist kleinere Nebennüsse bezeichnet, vgl. Kupica und Kupa, Savica und Sava oder Drinica und Drina (Dickenmann 1966. I. 30). Genau so verhält es sich im Fall der Mura, dtsch. Mur, $(454 \mathrm{~km})$, einem li. NebenfluB der mittleren Drau, und der slovenischen Murica, dtsch. Mürz. $(98 \mathrm{~km})^{\star}$. Vor diesem Hintergrund wird es nun wahrscheinlich, daß die norddeutschen Murizzi Slaven gewesen zu sein scheinen, die aus dem Gebiet der pannonischen Mura kamen und sich folgerichtig 'Morici, 'Muorici nannten, während sie die heutige Müritz. nach welcher auch der Müritzsee seinen Namen hat, als 'kleine Mur' = - Morica bezeichneten.

Die verhältnismäßig früh einsetzenden Belege tür die Morizani zeigen. daß dieser Name von der Mitte des 9. bis an das Ende des 12. Jhds. urkundlich gut vertreten ist. Die Vielfalt der Schreibweisen läBt aber auch erkennen, welche Schwierigkeiten er seinen Schreibern verursacht hat:

Mitte 9. Jhd. Morizani (Geogr. Bav.); 937 Mortsani (DO I. 14): 948 Moraciani (DO I. 105): 965 Moresceni (DO 1. 298); 975 Mrozini (DO II. 115): 992 Morazena (DO III. 106); 995 Morozini (DO III. 171): 995 Morazani (DO III. 180); zu 1007 Morezini (Thietmar); 1011 Mrozani (DH II. 237); 1114 Morschene (Reg. Magd. I. 910); 1161. 1188 Moraciani (DH Anh. I, 460, 656)'.

Ungeklärt blieb bislang die Frage, ob zu den Morizani auch die Bewohner einiger benachbarter Dörfer gehörten. deren Namen eine gewisse Ahnlichkeit mit dem fraglichen Ethnonym suggerieren. Gemeint sind die Orte

Beide seit dem 9. Jhd. gut belegt, vgl. Bezlaj 1956-61. II. $41 \mathrm{f}$.

- Nach HeBler 1957, 34. Anm. 8. - Eine andere Frage ist die Beurteilung der Belege Moraciani, Morazena und Morazani. die sich vom Typ Morizani ja durch ein $-8-$ in der mittleren Silbe unterscheiden. Man denkt bei diesen Formen eher an Herleitung von Moraca, das als alter FluBname sowie Ortsname und Gaubezeichnung in Montenegro, aber auch als Bergname Morac in Makedonien vorkommt. Morat ist nach Duridanov (1975. 13. 266) möglicherweise illyrisch und geht auf vorslav. 'Maraki(s) zurück. Die slavische Ethnika-Bildung ist Moracanin (Skok I, 44), was haargenau Moraciani entspricht. 
Marzahne im Westhavelland (1186 Marzane, 1230 Mortzane), Mortzan bei Berlin (1375, 1357 Mortzane), Marzehns im Kreis Zauche-Belzig und das wüst gefallene Martzan bel Stendal (1334). Während Trautmann (1949, 102) diese Toponyme zu den Morizani rechnet und Eichler (1962, 365) fragend Namensübertragung erwägt. meint R. E. Fischer (1970, 75 ff.; 1976, 167 P.), daB Marzahne usf. von den Belegen her nicht mit Morizani in Verbindung zu bringen sei. Fischer selbst erklärt Marzahne aus Marcane, das sich von urslav. 'morka 'Sumpr oder aber von asð. 'mark- 'Mark' herieite, so daß an 'Sumpf-' bzw. 'Grenzbewohner' gedacht werden könne. Fischers Argumente sind jedoch nicht unbedingt stichhaltig, da Marzane usf. ebensogut durch Synkope der 2. Silbe entstanden, der Name also sehr wohl zu Morizani gestellt werden kann. Eine Synkopierung der 2. Silbe zeichnet sich schon sehr Prüh an dem Beleg Mortsani von 937 ab.

Etymologisch werden die Morizani mit dem FIN 'Morica 'Müritz' in Verbindung gebracht und als 'Moricane 'Leute von der Müritz' gedeutet (SlowStarSlow 111. 302: Urbańczyk). Dlese Etymologie trifft grundsätzlich wohl zu. nur fällt auf. daß im Bereich der mittelelbischen Morizani weit und breit kein Gewässer dieses Namens begegnet. Folglich wird ein anderes. ahnlich lautendes Hydronym der Namenspatron gewesen sein. In Betracht zu ziehen ist m.E. in erster Linie Kărntens Mürz. die slovenische Murica, ein linker NebenfluB der Mur. Der schon bei den Murizzi aurgekommene Verdacht, daB die Slaven aus dem Stromgebiet der Mur nach Nordund Mitteldeutschland zugewandert sein könnten, verdichtet sich.

Die Annahme von slavischer Zuwanderung aus dem Mur-Gebiet wird durch Jenen, in einer ottonischen Urkunde zu 981 erwähnten Bezirk Mezumroka unterstrichen, der sich längs der Elbe von Belgern bis zur Muldemündung hingezogen haben (HeBler 1957, 24 ff.) oder aber Grenzmark gegen die östlichen lausitzischen Gaue gewesen sein soll (Helbig 1960, 34)6. Wenn Heßler und Helbig darin übereinstimmen, daß Mezumroka eine Grenzmark gewesen sei (Helbig 34) bzw. vom Namen her "die Lage des NiziziBezirkes zwischen den Marken bezeichnet habe" (HeBler 24), dann gehen

- Im Gegensatz zu anderen, die Mezumroka als Tellgebiet der Nizizi einschätzten, war HeBler der Meinung. es handle sich hierbei nur um einen anderen Namen fur Nizizi (HeBler ebda.). Dazu sel bemerkt. daß die Konjunktion vel der ottonischen Urkunde neben 'oder' mitunter auch 'und' bedeuten kann (terris agitare vel undis), so daß moglicherweise von zwei verschiedenen Gebieten die Rede ist, vom Gebiet der Nizizi und der Mezumroka. 
diese Ansichten von elner elnschlägigen Arbelt Elchlers (1956) aus, in welcher Mezumroka als Sumpigebiet oder aber als Zwischen- bzw. Grenzland erklärt wird, da das 2 . Glied, also mroka, auch aus ahd. marca 'Grenze' entstanden sein könne'. Mezumroka entspricht nun Jedoch auffallend genau dem Namen Jenes kroatisch-slavonischen $\mathrm{Z}$ wischenstromlandes. das kroat.-kajk. Medimorje. stok. Medumurje heißt und das Land zwischen Mur und Drau bezeichnet (Skok 1971-4, II, 399). In lateinischen Denkmälern wird dieses Land Insula Muro-Dravana, im Ungarischen (Dráva-)Mura$k \delta z$ (mit postpos. $k \delta z=$ inter) und im Deutschen Murinsel genannt. Die Ethnika-Bildungen von diesem kroatischen Gebletsnamen sind kajk. Medimorec (m.), Medimorka ( $f$.$) und stok. Medumurac (m.), Medumurka ( \mathrm{f}$.). Daß dem elbischen Landschaftsnamen Mezumroka die femininen Formen Medimorka oder Medumurka zugrundellegen, ist vielleicht nicht ganz so wahrscheinlich wie die Annahme, daB das zweite Glied die Deminutivform Murka. Morka von FlN Mura, also der Mur ist. Deminutivisches Murka 'kleine Mur' ist analog gebildet wie z.B. drâvka zu Drava (Skok II, 486). Mezumroka an der Eibe kann demnach eln noch an die alte pannonische 2wischenstation der Slaven erinnernder Name sein, der, frei übersetzt und dtsch. Sprachgebrauch folgend, soviel wie 'kleine Murinsel' zu bedeuten scheint.

Wie dle historischen Vorgänge des 6. Jhds. n. Chr. zeigen, war die Pannonia secunda, also das Gebiet zwischen den Flüssen Drau und Save, Im Blick auf die Wanderung und landnehmende Expansion der Slaven von eminenter Bedeutung. Schon im Herbst 567 haben archäologischem Befund zufolge der große Awaren-Khan Bajan und sein Heer hier gehaust (Bóna 1971, 289). Da die während des 6. und 7. Jhds. in den Mur-Drau-DonauRaum eingesickerten Slaven die Hilfsvölker der Awaren - az avarok segédnépel (Bóna 1984, 1,1, 318) - gewesen zu seín scheinen, kann wohl davon ausgegangen werden, daB Slaven unter dem Druck der Awaren gegen Ende des 6. Jhds. dieses Geblet wieder verlassen haben. Wie bekannt erreichten noch vor 580 die ersten vom Balkan vorstoBenden Slaven das Murtal und das ostliche Kärnten; auch von ihnen können sich Teile nach Norden abgesetzt haben. Für eine fruhe slavische Besiedlung der Region an

- Mezumroka wird von Eichler und Witkowski (J. Hermann 1974, 10) als Jüngere slavische Landschaftsbezeichnung verstanden.

- Murka ist auBerdem die Bezeichnung far ein kleineres, nur aup der $_{38}$ Mur verwendetes Boot. 
der Mur spricht ebenfalls die von Fredegar zu etwa 630 genannte marca Vinedorum des slavischen Großfürsten Wallucus (Kunstmann 1980, 173 fl.). Die FluBlăufe der oberen Drau und Mur sowie der Mürz bis zum Lungau wurden noch vor der karolingisch-bairischen Kolonisation zu Beginn des 9. Jhds. von Slaven besiedelt (SlowStarSlow V, $28 \mathrm{ff}$.: W. Swoboda). Abwanderungen von Slaven aus dem Gebiet $z$ wischen Drau und Mur sind somit wenigstens vom Ende des 6 . bis zum Beginn des 9. Jhds. denkbar.

Es ist demzufolge nicht auszuschlleßen, daß unter den norddeutschen Murizzi 'Leute von der Mur' zu verstehen sind. wăhrend die Müritz Deminutiv zum pannonischen FIN Mura 'Mur' ist. der Name der elbischen Morizani aber auf die kărntnische Murica 'Mürz' zurückgeht. 


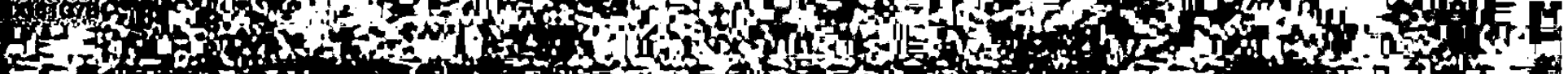

40 a

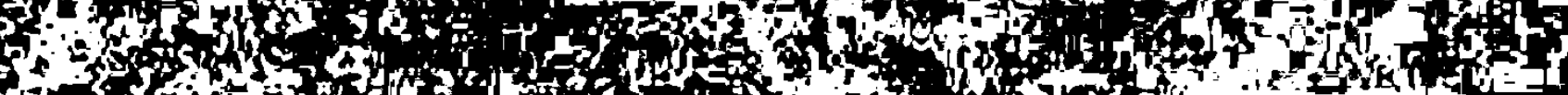

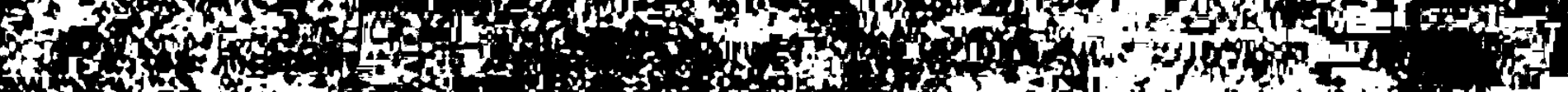
(1) 30 (10)

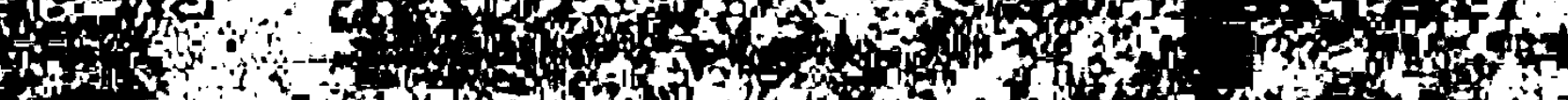

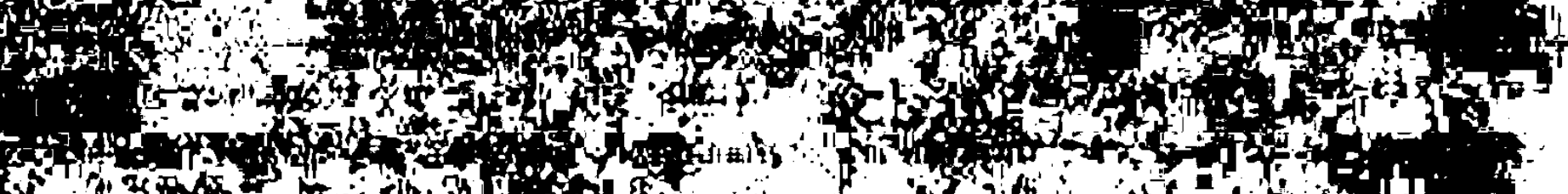
for 2. (1)

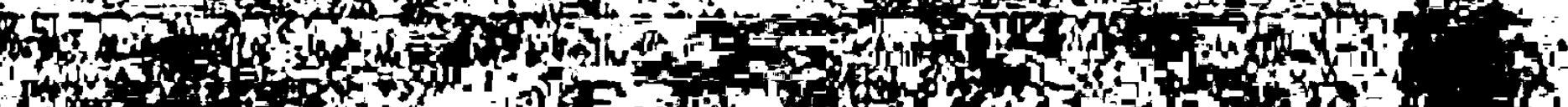

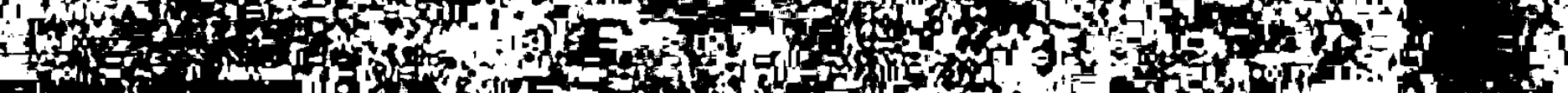
Te

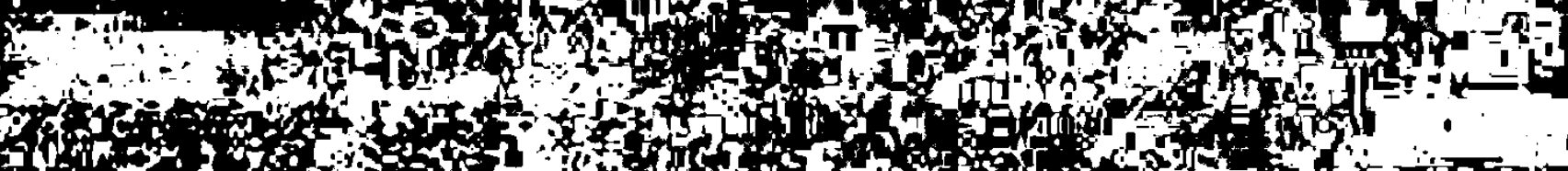

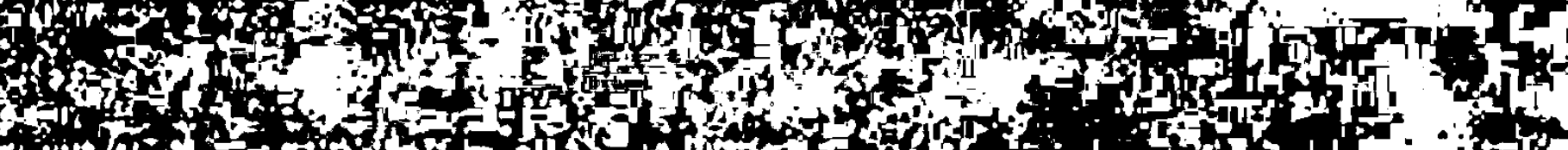
r.

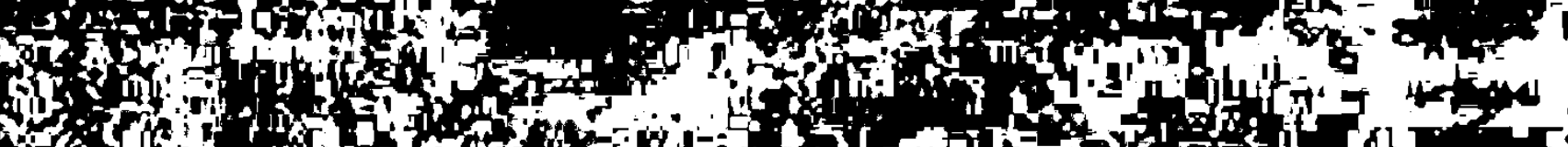

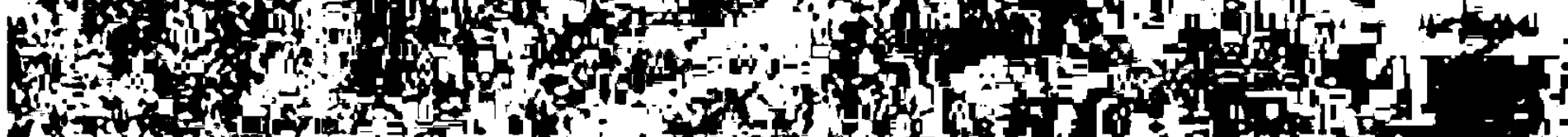

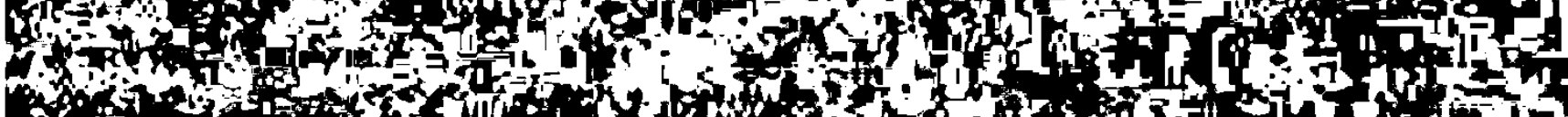

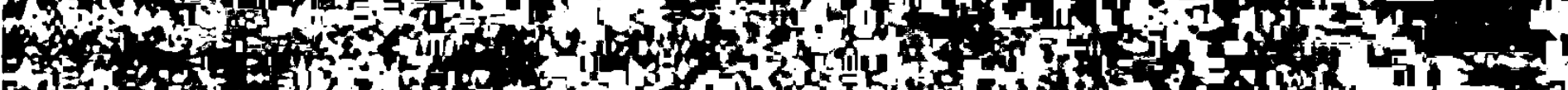

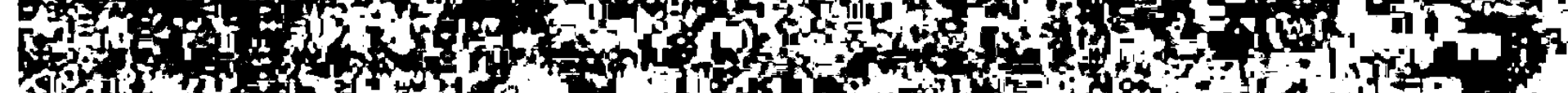

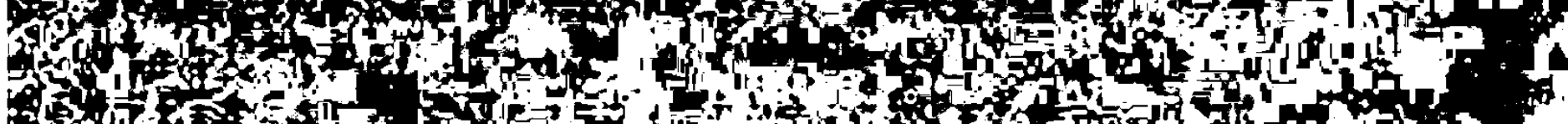
(5)

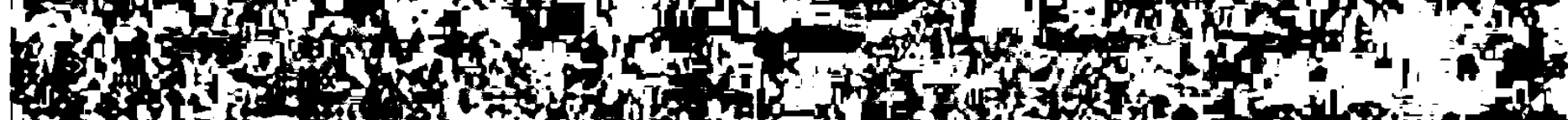

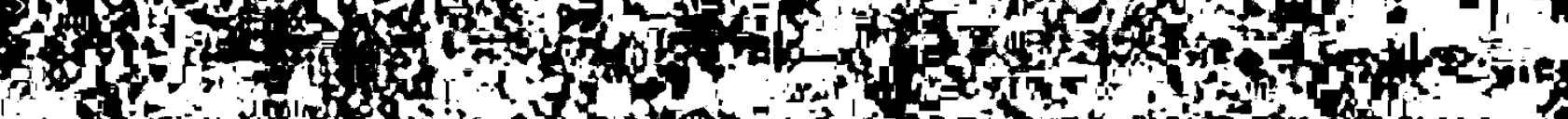
ind ETh if 
16. Doxani. Dassia. Dosse

Diese drei und weitere mit ihnen verbundene Namen begegnen auf deutschem Sprachgebiet ausschlieblich im brandenburgischen Havelland. Sle sind im wesentlichen Gau- und Flußnamen, doch kommen sie vereinzelt auch als Ortsnamen vor.

Für Gaunamen hält die Forschung im allgemeinen die Formen Doxani. Dassia und Desseri. Doxani, nur einmal zu 1074 bei Adam von Bremen erwähnt, enthält mit Sicherheit das slav. Sufflx -jane, das, nach Ansicht von Fischer (1976, 58), an den Flußnamen 'Dosa 'Dosse' angehängt. soviel wie 'Dosseanwohner' bedeutet, also auch als Stammesname verstanden werden kann. Doxani läßt auf eine Ausgangsform 'Doks-jane oder 'Doksane schließen. Als asä. Gegenstück zu den slavischen Doxani verstehen Fischer und Schlimpert (1971, 664) den Namen Desseri. der in dieser Form 24948 und als Dessere für 1150 sowie 1179 belegt ist. Desseri, das aus 'Dasswäriōs bzw. 'Dassārjōz entstanden sein soll (Fischer 1976. 58), ist nach Meinung von Fischer und Schlimpert $(1971,664)$ möglicherweise die ursprünglich germanische Bewohnerbezeichnung, die der gleichbedeutenden slavischen Bildung Doxani, einer Lehnprägung aus dem Altsächsischen, gegenuberstehe. Als dritte Gaubezeichnung wird der fur 948 (DO I 105, Orig.) und in den Bestătigungen dieser Urkunde $(1161,1188)$ belegte Name Dassia angesehen, der, wiederum nach Pischer (1976, 58 P.), in dieser Porm nicht aus dem Asä. erklärt werden könne, sondern aus dem FIN - Dosa 'Dosse' mit slav. Suffix $-\not j-j a$ entstanden sei: 'Dosbj-ja zem'a 'Land an der Dosse'.

Das ausschlaggebende Grundwort bei den bereits erwähnten und noch zu erwähnenden Formen scheint der Name der Dosse, eines Nebennusses der Havel in der Prignitz. zu sein. Die Prühesten, im Grunde jedoch spăt einsetzenden Belege dieses Hydronyms sind: 1172 iuxta...Doxam (Helmold 40): 1274 dossa; 1284 infra dosam². Fischer (1976, 58, und vordem mit Schlimpert 1971, 666 P.) hält den Gewässernamen Dosse für germanisch bzw. altsächsisch; zwar sei er pür das Altsächsische, wo er -Dass- oder -Daks- gelautet habe, nicht belegt, doch müsse er daraus ins Slavische übernommen worden sein, dafür spreche der Wandel von germ. $a>$ slav. 0 . Der heutige Name Dosse sei dann während der deutschen Besiedelung dle- 
ses Gebietes im 12. Jhd. aus dem Slavischen ins Deutsche (rück)übertragen worden. Auf Jeden Fall aber gehöre das wahrscheinlich vorgermanische Wasserwort, dessen Etymologle unklar bleibe, nach Fischer und Schlimpert (1971. 667) einer sehr alten Sprachschicht an. Von der Dosse zu unterscheiden ist natürlich der bei Oranienburg in die Havel mündende FluB Dossow. dessen Name entstellt zu 1238 belegt ist: fluvius, qui dicitur Massowe, influat in Obulam; 1772 Dosse (Fischer, Schlimpert 1971, 664). Wie in dem nachfolgenden glelchlautenden Ortsnamen handelt es sich fraglos um eine Erweiterung von - Dos(s)- durch das slavische Suffix - ov.

Der ON Dossow benennt einen Ort an der Dosse im Kreis Wittstock. der 1273 als Dosse und 1325 als major Dossa bestătigt wird. Die Endung -ow (-ov) kommt infolge Analogie zu den hăufigen ONn mit-ow erst im 16. Jhd. auf (Fischer. Schlimpert 665). Das nămliche Toponym war Bezeichnung elner wüstung südlich von Oranienburg: 1412 daz halp dorfl dosszow (dies. 664).

Die Toponyme und Hydronyme des brandenburgischen Havellandes. so wie sie besprochen wurden. sind zwar fur das deutsche Sprachgebiet einmalig. doch gibt es $z u$ ihnen Parallelen in Form mehrerer vom Grundwort Doks- bzw. Dox- gebildeter Ortsnamen in Nordböhmen (vgl. Kunstmann '1987, 41 f.). Sie begegnen überwiegend auf dem Gebiet zwischen Roudnice an der Elbe und Doksany an der Eger: AuBer Doksany nw. von Roudnice gehören dazu Doksy (dtsch. Hirschberg) nö. von Dubá (dtsch. Dauba) sowie Doksy nw. von Unhosit. w. von Prag (Profous I. 416 (r.). Der Wortsippe nahesteht sehr wahrscheinlich auch Duchcov (dtsch. Dux), ac. Tockczaw (1240) (Profous I, 492 f.). Profous fürte diese Namen auf vorslavisches -dokz-zurück, und auch Flajshhans (1930, 44-6) hielt das Grundwort für nichtslavisch. Der richtigen etymologischen Deutung am nächsten kam jedoch erst E. Schwarz. der 'dokz- mit dem venetisch-illyrischen Wort -daksa 'Tasser. Meer' zusammenbrachte (Schwarz 1950, II. 217 Pf.; ders. 1969). Nach Schwarz konnte die vorkeltische Form •daksa für idg. 'doksa in Böhmen und Mitteldeutschland „entweder direkt - wenn das Vorkeltische noch im 6. Jhd. gesprochen worden sein sollte - oder durch germanische Vermittlung den im 6. Jhd. einwandernden Slawen ubermittelt werden..." (Schwarz 1969, 78). Gegen Schwarz argumentierte schon Bilek (1960), daB es in Brandenburg keine lllyrischen Sledlungen gegeben habe ${ }^{2}$, was wieder-

2 Bilek selbst schloß sich im Prinzip der Etymologie von Profous an und

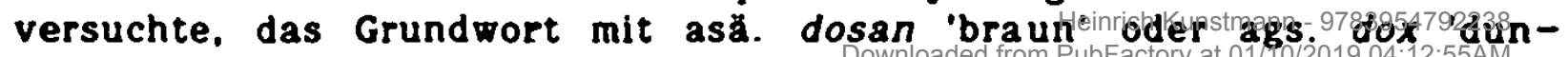
kelfarbig' in Verbindung zu bringen. was indes aur gewisse 
um R. E. Fischer (1976, 57) für nicht stichhaltig hielt, da die strittigen Namen zu den sog. alteuropäischen Gewässerbezeichnungen, also zu einer vorindogermanischen Schicht $z u$ rechnen selen.

Es ist nun allerdings so, daB die von Doks-oder Dos-gebildeten brandenburgischen Namen nicht nur in Böhmen Parallelen haben, sondern. was bislang unbekannt war (Kunstmann 1'1985, 245 fr.), auch In Nordwestrußland. Das bestätigt der ON Doksicy, poln. Dokszyce, Kr. Borisov (Gouv. Minsk), heute Rayonhauptstadt der Region Vitebsk. Der Name Doksicy, poln. Dokszyce, wiederholt sich zweimal, zum einen heißt so ein Gut im Kreis Vilejka. Gouv. Wilna, zum anderen ist es ein Gutsname bei Wilna (RGN II. 49; vgl. auch Slow. Geog. Król. Polsk. II. 93). Zur Namensippe gehört sehr wahrscheinlich auBerdem der ON Doksina (Burakovo), Kr. Kirillov, GroB Novgorod. Interessanterweise gibt es dazu im Kreis Rezica, Gouv. Vitebsk. noch einen Bach namens Dassa, der dem brandenburgischen Hydronym Dosse auffallend ähnlich ist (RGN I. 562).

Somit zeigt sich, daß die Pragliche Namensippe an drei, geographisch weit auseinanderliegenden europäischen Punkten - in Mitteldeutschland. Böhmen und in NordwestruBland - vorkommt. Das schlieBt natürlich eine germanische Lösung. wie sie Pischer und Schlimpert vorschwebt, völlig aus $^{3}$. Auch Schwarzens Vorstellung. wonach Germanen das einschlăgige Wort an die Slaven weitergegeben hätten, wird nun unwahrscheinlich, da diese 'Vermittlung' wohl kaum auch aup nordwestrussisch-polnisch-litauischem Boden stattgefunden haben kann. Ebensowenig kann man an Jene Nordillyrier denken, an die noch Pokorny. Krahe und Vasmer glaubten. Da sich die Wortsippe aber auch nicht aus dem Slavischen deuten lāßt. gibt es nur éine Erklärung.

Illyrisches 'daksā ist nicht, wie Schwarz vermutete, von Germanen den Slaven vermittelt, sondern von Slaven aus dem Illyricum sowohl ins Brandenburgische als auch nach Böhmen und NordruBland ubertragen worden. Wie eine Hesych-Glosse erkennen lảßt. ist $\delta \alpha \dot{\xi} \alpha \alpha$ ein altes epirotisches Wort in der Bedeutung von 'Meer'. Nach Mayer (I, 110 P.; II, 36) geht die Grundform 'dazā 'Meer' auf idg. ' $d(h) e \hat{g}(h)$ zurück, vgl. auch Mayer 1936. 186 ?. Aus dem Illyrischen erklārt sich nun auch die Vielfalt der Formen

Schwierigkeiten stöBt.

- Erst recht wird damit Vasmers Deutung unannehmbar, der 1933, ohne

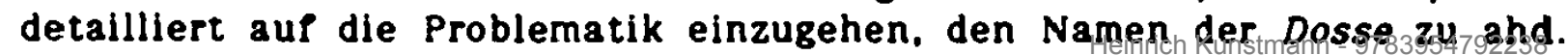
dahs. mnd. das 'Dachs' stellte, jetzt in: Kasmer fro Sehriftent 1/.105990 019:55AM 
Dox-, Doss- und Dos, da die lllyrische Spirans sowohl durch $s$ und ss als auch $x$ wiedergegeben werden konnte (Mayer I, 111); sie konnte außerdem - wie in den PNn Dazas, $\triangle \alpha ́ \zeta 0 \zeta$ (Krahe 1925, 85 ९.) neben Dasa, Dassius u.a. - mit Hilfe von $z$ ausgedrückt werden. Der Wandel von $a>0$ in den brandenburgischen, böhmischen und russischen Vertretungen dieses Wortes ist selbstredend slavisch begründet. Das illyrisch-epirotische Wort •daksā ist mit Sicherheit heute noch in dem Namen der nördlich von Dubrovnik am Kanal llegenden Insel Daksa enthalten (Skok 1950. I. 246 fl.), die in mittelalterlichen ragusanischen Urkunden auch Daxa oder Axa hieB (Jirecek 1916, 9; ders. 1902, I, 61: Bartoll 1906, 304). Zur Wortsippe zu stellen ist gewiß auch der von Polybios (VIII. 15.2) überlieferte Name des

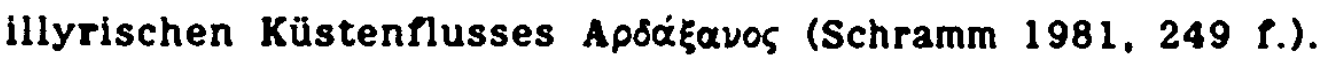

Gesondert sei auf den havellăndischen Gaunamen Desseri. Dessere zurückgegriffen, In welchem Fischer und Schlimpert $(1971,664 ; 1976,58)$ einen altsächsischen Völkernamen sehen und aus 'Dasswariōs oder 'Dassārjōz erklăren wollten. Auch dieses Toponym läßt sich nun einwandfrel aus dem Illyrischen deuten, da thra ohne Frage der Name der lllyrischen $\Delta \dot{\varepsilon} \xi \alpha p o$ i

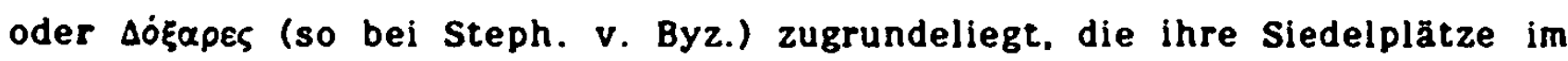
nördlichen Epirus bzw. südlichen Illyrien hatten". Das Suffix - ar-diente im Illyrischen zur Blldung adjektivartiger Zugehörigkeitsbezeichnungen (Krahe 1928). Mit dem Formans - ar- ist außerdem der illyrische Stammesname Dassaretae, $\Delta \alpha \sigma \sigma \alpha \rho \bar{r} \tau$ l gebildet: $\Delta \alpha \sigma \sigma-\alpha p-\bar{\tau} \tau-\alpha l$. Die Dassaretae waren elner der bedeutendsten Illyrischen Stämme, dessen Sledelgebiet sich von der Stadt Lychnidos am gleichnamigen See bis zur Stadt Antipatria am unteren Apsos erstreckte (Pauly RE 8. Hbbd. 1901, 2221 f.: Philippson)' Wenn der Wandel $a>e$ im Namen der havelländischen Desseri als typisch altsăchsisch beurteilt wurde (Fischer, Schlimpert 1971, 666), so ist zu sagen, daB dieses Schwanken $z$ wischen $a$ und $e$ wahrscheinlich schon lllyrisch ist (Krahe 1928), was allein das Nebeneinander von $\delta \alpha \xi$ - und $\delta \varepsilon \xi-z u$ erkennen gibt.

Somit zeigt sich, daß die brandenburgischen Hydronyme Dosse (Doxa) und Dossow (Doss-ow) ebenso wie die im Grunde ethnonymischen Gaunamen Doxani und Desseri eindeutig Illyrischer Provenienz sind, das heißt, von

- Ober sie berichtet Stephan von Byzanz (225) nach Hekataios. DemgemāB waren sie ein Tellstamm der Xáoves und den Encheleern am Lychnitissee (h. Ochrida) benachbart, vgl. Krahe 1928, 272 f.; nach anderen lebten

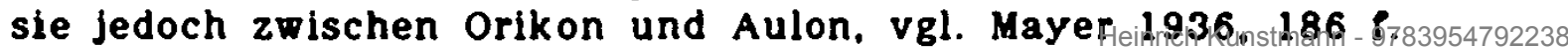


Slaven nach Mitteldeutschland gebracht wurden. Der Gauname Dassia aber ist nicht, wie Fischer meinte, aus 'Dosbj-ja (zem'a) entstanden, sondern ein neugebildetes Kompositum aus Dass - und lat. Supfix - ia, das nach dem Vorbild des verbreiteten Typs Francia. Germania und anderen Låndernamen eingerichtet ist. Natürlich ist es nun auch nicht so, daß die Dosse den Doxani den Namen gab, sondern die slavischen Doks-jane oder -Doksane sowohl den FluB als auch den Gau mit dem aus Illyrien mitgebrachten Toponym bedachten. 

16. Liezizi und Lesane

Die Sitze des weletischen Kleinstammes der Liezizi werden von HeBler (1957. 38 f.) an der unteren Havel und im Elbwinkel vermutet. Vor HeBler unterschied Bottger (1876, 85, 98) auf Grund der Schreibvarianten Liezizi und Ligzice zwei verschiedene Stämme, die er weiter súdlich in der Năhe der Lausitzer suchte. Die Urkunde DO I, 76 von 946 macht jedoch wahrscheinlich, daß in der auf die Zemzizi folgenden provincia Liezizi Havelberger Grundbesitz gelegen hat. Die Schwierigkeiten beginnen nicht erst mit der Lokalisierung dieses slavischen Kleinverbandes, sondern schon mit der Tradlerung seines Namens, der in seinen ältesten Notierungen sehr unterschiedliche Bildungen aufweist:

937 in Mortsani et Ligzice et Heueldon (DO I. 14: 937 IX 21): Ligzicze (DO I. 16: 937 X 11): 946 (provincia) Liezizi (DO I. 76: 946 V 9): zu 1008/9 Lizzizi (nach SlowStarSlow III. 45: G. Labuda); auBerdem: Lisici. Liczici'.

Dieses bescheidene Material enthält eine Reihe von Rātseln. voran die Frage, ob Liezizi und Ligzice überhaupt ein und denselben stamm meinen. Von den geographischen Angaben der Belege her gesehen, spricht natürlich vieles dafür, daß dies so ist. Andererseits uberrascht doch die Schreibweise mit - $g$ - in Ligzice und Ligzicze. Handelt es sich dabei um einen rein orthographischen ProzeB, bei welchem vielleicht $g$ für $f(i)$ steht? Bis zur Klärung dieses Problems ist es geraten. sich an die weniger komplizierten Formen Liezizi oder Lizzizi zu halten.

Außer A. Brückner, der in den Liezizi Nachkommen eines lis 'Fuchs' sieht (Brückner 1879, 2. Anm. 5), hat man sich offenbar fü die Etymologie dieses Namens nicht sehr interessiert. was vielleicht mit der nicht besonders hervorstechenden Rolle dieses slavischen Verbandes in der Geschichte zu erklären ist.

Die Belege, soweit sie aberhaupt in Betracht zu ziehen sind, legen den Schluß nahe, daß der Pragliche Stammesname aus der Wurzel 'Lis- und dem slavischen Suffix $-i c i<-b c j$ besteht. Ds asă. I ofter auch einem ahd. e gegenübersteht, kann hinter Liez- ebenfalls •Les- vermutet werden.

1 Letztere laut Böttger IV. 98 ९., 133 f., der im gegebenen Zusammenhang auch noch Lusici erwähnt. was wohl unter dem Aspekt seiner Lokalisierung der Liezizi geschieht, gewiB aber verfehlt ist. vgl. dazu Niederle III. 144. Anm. 3. 
so daß sich für Liezizi neben 'Lisici ebensogut 'Lesici lesen läßt. Von entscheidender Bedeutung ist wieder einmal die Frage, welchen slavischen Laut hier $s(z)$ vertritt. Mit großer Wahrscheinlichkeit darf angenommen werden, daß das Ethnonym 'LJšicl oder eben 'Lesici gelautet hat, und zwar deshalb, weil sowohl $s$ häufig Ersatz für $s$ ist, als auch die Kombination si (sb, si) im Slavischen zu $s$ fuhrt. Doch damit läBt sich auch bereits erraten, was unter 'Lisici oder 'Lesici zu verstehen ist, nämlich 'Le ute von Lissus'. Es geht somit um jene antike stadt südlich von Scodra, die heute serb. Ljēš, aiban. Lesh, Lezhë und ital. Alessio heiBt. Im Blick auf die hier zur Debatte gestellte Dublette 'Lisici//"Lesici ist zu sagen, daB das Schwanken $z$ wischen $i$ und $e$ in den mitteldeutschen Formen auch auf die antike Dublette Liss-//Less-zurückgehen kann. Die prototypische Variante Liss-//Less- spiegelt einen regelgerechten romanischen Obergang wider (Mayer 1957-9. I. 212; Schramm 1981. 284 P.). was besagt, daB Lissdie antike und ältere. Less-hingegen die jüngere, romanische, vielleicht vulgärlatelnische Variante darstellt. Dementsprechend lauten dle adjektivisierten Formen Lissium und Lessium (Popovic 1960, 110). Möglicherweise erklären sich aus Lessium die slavischen Formen Lessb u.ä. sowie albani-

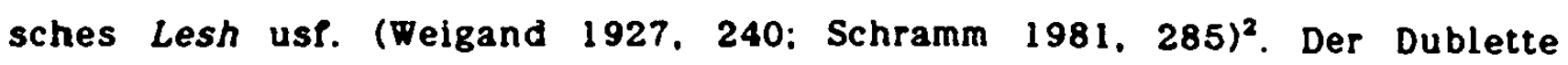
Lissium//Lessium liegt der nämliche romanische Lautwandel wie in Sirmium//Sermium (vgl. S. 137 f.) zugrunde.

An der Peene-Mündung gegenüber der Insel Usedom lokalisiert man das ebenfalls kleine westpommersche Ethnikon der 'Lesane: 1136 Lesane; 1216 Lessan; 1177 Lessaz (= Lok. Pl.): 1194 Lissani: 1230 Lassan (h. Las$s a h n)^{3}$. Man deutet 'Lešane 'Waldleute' aus slavisch 'lěsz + Suffix -janinz. was m.E. aber durchaus nicht so sicher ist, da man sich bei dem Allerweltswort 'lěss 'Wald' ein wesentlich häufigeres Vorkommen dieses Forestisnamens erwartet. Oberdies könnte der Beleg LIssani (1194) mit i als Wurzelvokal mit dem oben angesprochenen Schwanken $z$ wischen 'Lisici und - Lesici zu tun haben. Der Name der westpommerschen 'Lěsane ließe sich ohne Schwierigkeiten auf den antiken Stadtnamen Lessus oder Lessium zu-

21 Unklar bleibt dabei weiterhin. ob slav. Lešb zu albanisch Lesh oder umgekehrt Lesh zu Lessb geführt hat. vgl. dazu im einzelnen Weigand 1927. 240. Sowie Popovic 1958, 318, und Cabej 1961, 244 \&.

${ }^{3} 1$ Nach Trautmann 1950. 90 f., und SlowStarSlow III. 47: Urbanczyk. Lassan mit a als Wurzelvokal kann sich aus der im Mittelniederdeutschen nicht seltenen Vertretung von $e$ durch a erklären, vgl. Lasch $1974, \$ 78$ (S. 60). 
rückführen. Im übrigen entspricht - Lésane typologisch genau -Nisane, wăhrend 'Lisici//'Lesici eine Parallele In 'Nisici hat (vgl. S. $145 \mathrm{fP}$.).

Das alte, an der Drina-Mündung und der wichtigen adriatischen Küstenstraße situierte Lissus (Tomaschek 1880, 548 \%f.; v. Sufnay 1924, 27 f.: Mócsy 1970. $18 \mathrm{ff}$.) wurde im 4. Jhd. von Dionysios I. von Syrakus als griechische Kolonie gegründet, deren „Akrolissos” 213 Philipp von Makedonien eroberte. Nachdem Lissus $167 \mathrm{v}$. Chr. römisch geworden war, wurde es $\mathrm{zu}$ einer der bedeutendsten Siedlungen in Illyricum. Als Hafenstadt und Verkehrsknotenpunkt spielte die Stadt im Krieg Caesars gegen Pompejus eine wichtige strategisch-logistische Rolle. Vermutlich wurde sie $33 \mathrm{v}$. Chr. zur colonia erhoben. Nach der Aufteilung des Imperiums fiel Lissus dem oströmischen Reich zu (Kl. Pauly III. 679). Bei Lissus verlief die sog. Jirecek-Linie, also die Grenze zwischen dem südöstlichen griechischen und dem nordwestlichen lateinischen Teil (Popovic 1959. 71). Wie Scodra gehörte auch Lissus nach der Reform Diokletians zur provincia Praevalitana. und so wie das anhaltische Toponym Scheuder auf Scodra zurückgeht, verdanken die mitteielbischen Liezizi. möglicherweise auch die westpommerschen Lesane dem alten adriatischen Küstenort Lissus ihre Namen. 

ato

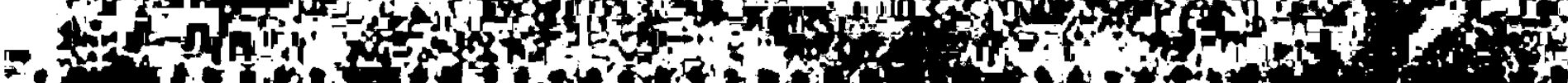

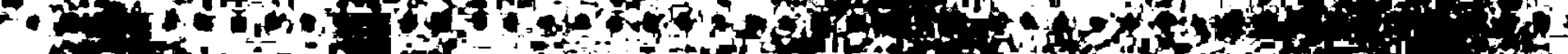

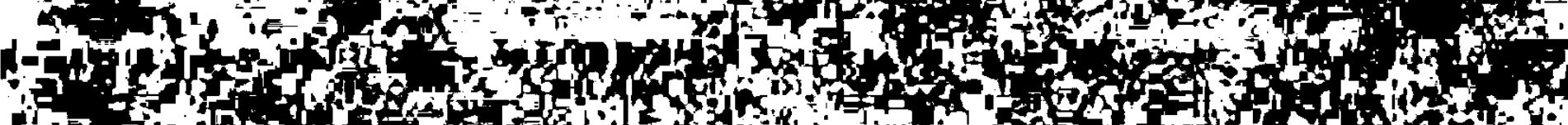

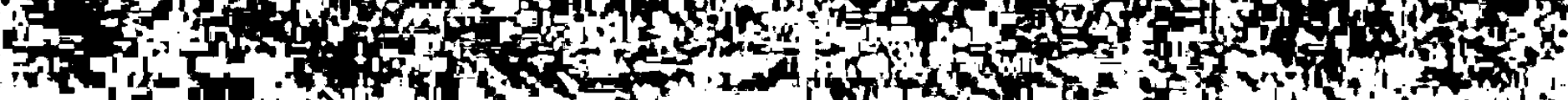
14 a El, $=4$

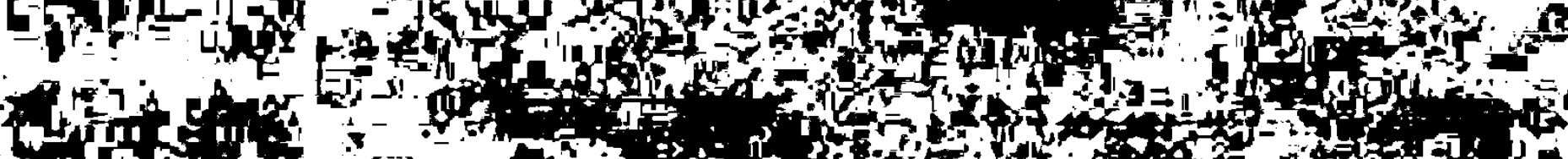

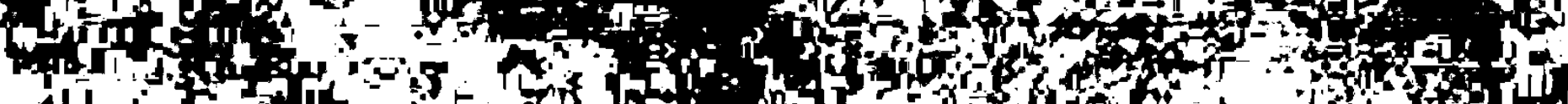
of

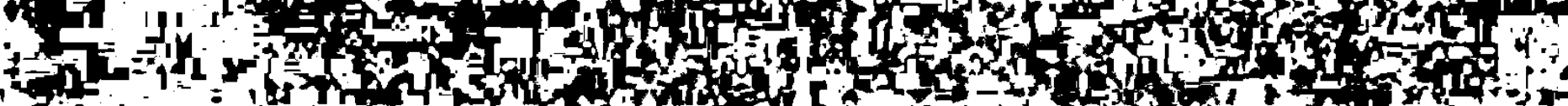
afd 1.

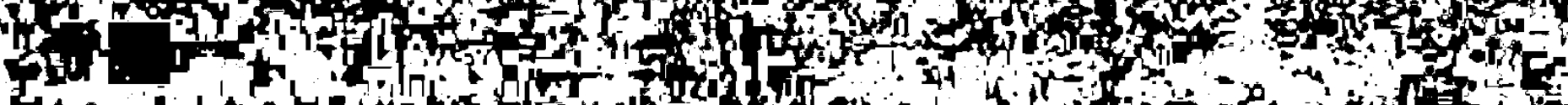

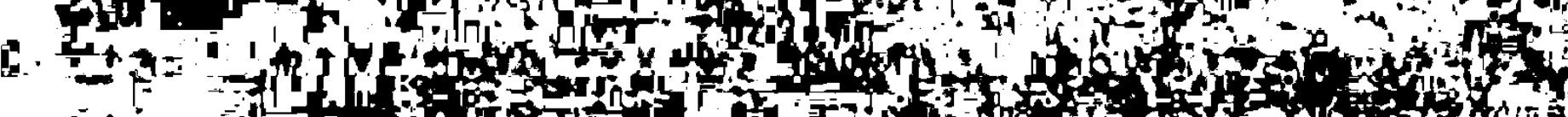
$=4$ - $=4$.

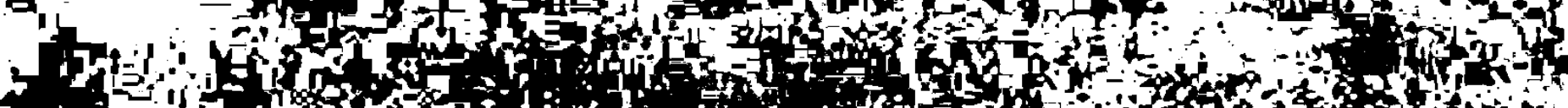

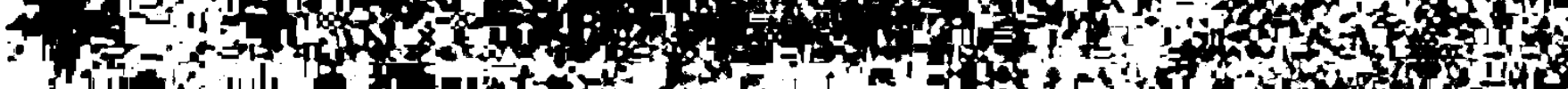

If

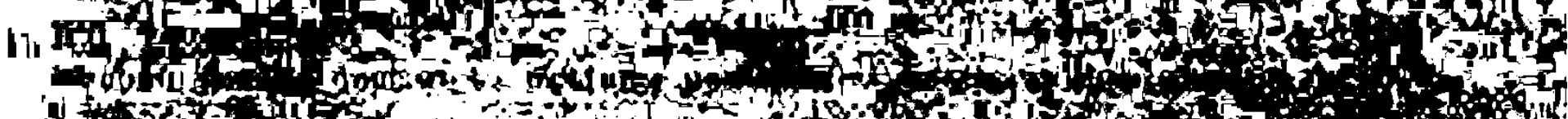

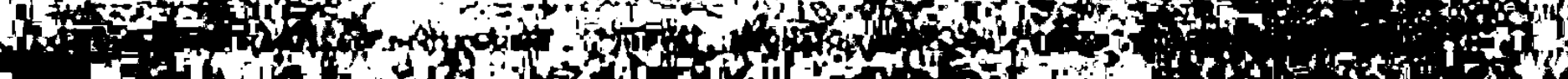

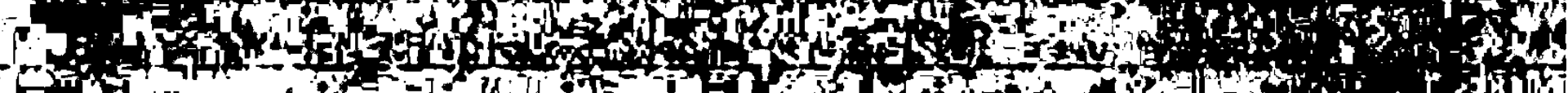
-4

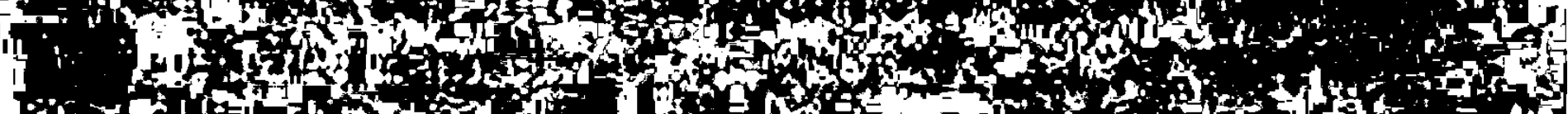

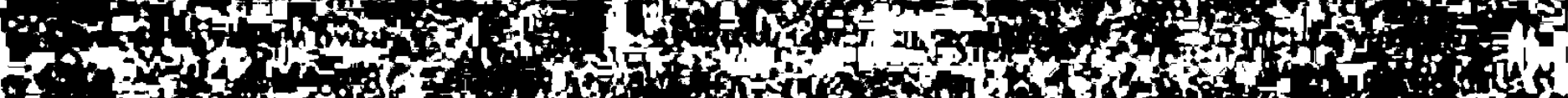

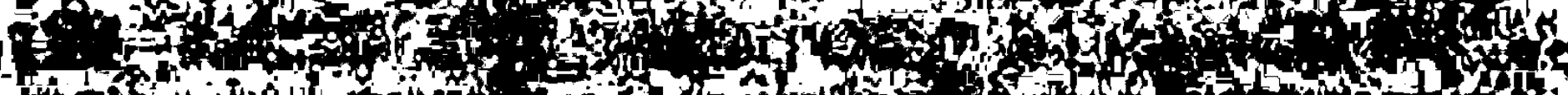
inga

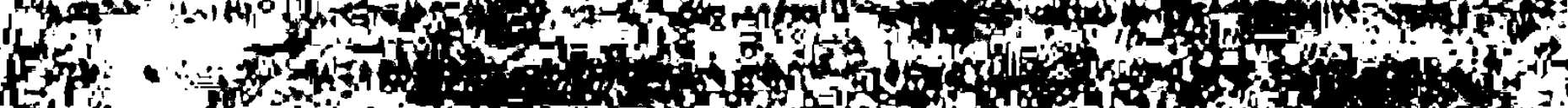

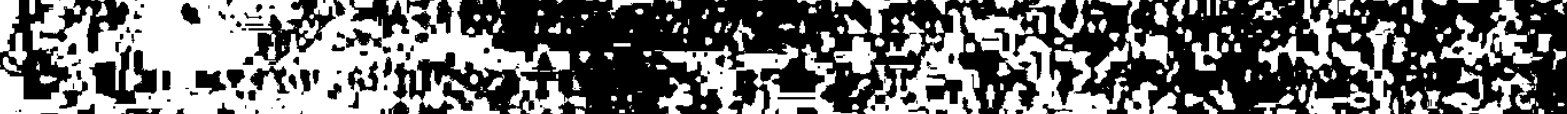

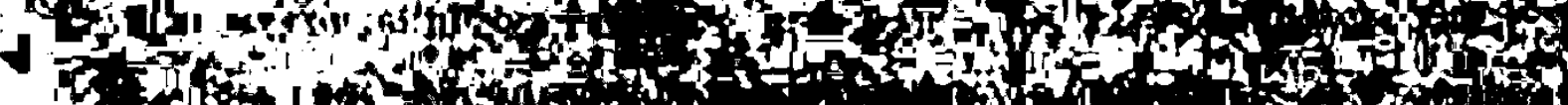

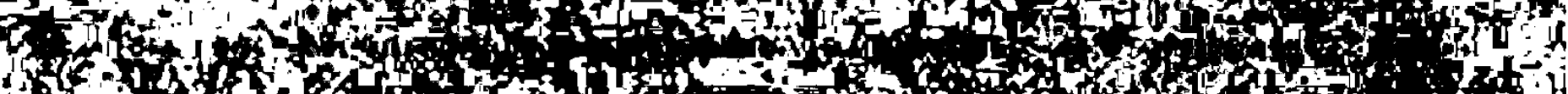

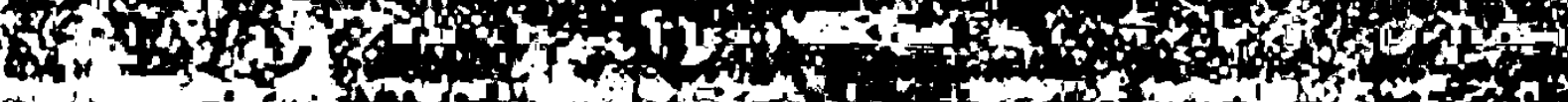

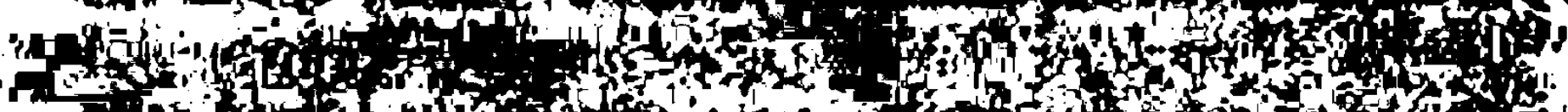
fo

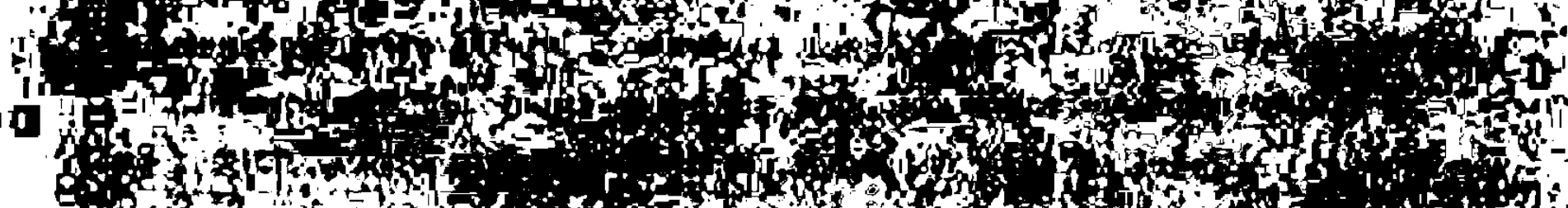

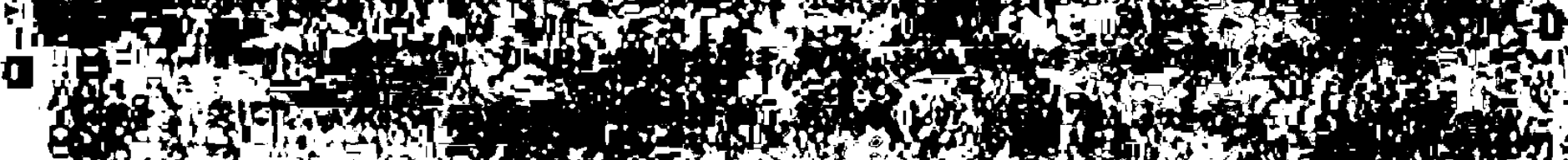
Pros

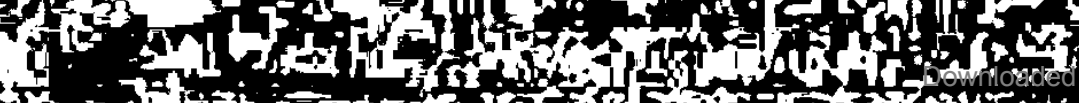




\section{Brandenburgs Havel}

Die $340 \mathrm{~km}$ lange Havel, die sich von der Mecklenburgischen Seenplatte bis Havelberg erstreckt, ist ein bedeutender rechter NebennuB der mittleren Elbe. Knapp $14 \mathrm{~km}$ vor seiner Mündung in dlese lag auf einer Insel havelberg, ein alter slavischer Burgward in wichtiger strategischer und verkehrspolitischer Lage, der laut Helmold (cap. 37) zeitweise Sitz der slavischen Brizani alias Prissani gewesen seln soll (vgl. S. 178 fl.). Die siedlungsgeschichtllchen Vorgänge, die im Bereich der Havel unter verschiedenen slavischen Gruppen wie Brizani. Neleticl oder Stodorane stattgefunden haben. sind heute kaum mehr zu durchschauen'.

Dank der vorzüglichen Quellenlage ist der Name der Havel und der davon gebildeten Formen zahlreich und vielseitig belegt. $\mathrm{Zu}$ unterschelden ist zwischen Hydronym, Stammes - und Landschaftsnamen sowle einem Ortsnamen:

Hydronym: 789 Habola; 981 Haueia; um 1075 iuxta Habolam; 1114 inter...Havelam; 1159 prope Hauelam; 1161 Hauela; 1188 terra de Havela; 1204 in Obula; 1205 aqua obula; 1288 obulam; 1351 Havelen (Acc.); 1351 opper Hawelle; 1378 ab Obula, que dicitur Cotzinre Havele; 1394 In der Havele:

Ethnonym: um 845 Hehfeldj (GB); um 900 Haereldan; 937 Heueldun; 948 Heueldun; um 967 Sciavos, qui dicuntur Hevell; zu 940 Heveld: 973 Heuoldo; 981 in pago Heuellon; 993 in prouincla Heuellon; 1010 Heveldon; 1013/4 Hevellum; zu 997 Stoderaniam. que Hevellun dicitur; zu 1011 ex provincia Hevellun; um 1075 Heveldi, qui luxta Habolam Huvium sunt; 1161 in pago Heveldun; 1188 Heveldun:

Landschaft: 1216 terre de Havelant: 1281 Hauelland;

Ortsname: 946 Havelberg; 968 ultra...Haualbergensem: 1013/4 Havelbergensis aecclesiae; zu 983 in Hawelbergium; 1150 hauelbergensi ${ }^{2}$.

Die vier verschiedenen Formen machen deutlich, daß Ethnonym, Landschafts- und Ortsname mit - feld, -land bzw. - berg gebildete Komposita zum Hydronym Havel sind, dessen Deutung hier im Vordergrund stehen soll. Um nicht die vollstăndige Geschichte der Havel-Etymologie aufzurollen, sei der Einfachheit halber gesagt, daB einer der ersten Forscher, die eine

1 Hinsichtlich Siedlung und Geschichte der Haveller sel auf folgende neuere Literatur verwiesen: A. Krenzlln: Deutsche und slawische Siedlungen im inneren Havelland (1956). In: Krenzlin 1983, 103 1 .; H. Ludat: Branibor, havolanská dynastie a Premyslovci. In: CSCH 17, 1969, 498 Pf.; SlowStarSlow II. 197: A. Wedzki; Dralle 1981.

2 Nach Fischer, Schlimpert 1971 bzw. Fischer 1976, 61 P. 
wissenschaftlich fundierte Erklărung gaben, der deutsche Historiker Herbert Ludat war, der schon 1936 erkannte, daß das Hydronym mit slav. ' $a b l s$. 'obsls 'rund, längllch' zu tun haben könne (Ludat 1969, 16 ff.). Ludats Etymologie, auch wenn sie das Geheimnis des Wortes nicht luftete. wird in der Folge von anderen Gelehrten wie Nalepa und Urbaticzyk erneut aufgegriffen und vervollkommnet. Die These von der slavischen Abstammung des Havel-Wortes ist dabel lange nicht so alt wie die von der germanischen, die sich von $K$. Zeuß (1837) und $C$. Müllenhoff (1887) uber J. Koblischke (1910), E. Schwarz (1929) und M. Vasmer (1933) bis hin zu Fischer-Schlimpert (1971) verfolgen läBt, die ihr gewissermaßen den letzten Schliff gaben?.

Bei der Erklärung des Wortes Havel ist laut Fischer und Schlimpert (1971. 62) von der germ. Turzel hab- und dem Suffix - (u)la auszugehen. die zusammen die Form - $H a b(u) l a$ erbrachten. Bedeutungsmåßig gehöre der Name zu nhd. HaM und Hafen. Die germ. Form soll bis zum 10. Jhd. von den Slaven als $O b$ bla übernommen worden sein. was lateinische Urkunden des 12./14. Jhds., in denen Kanzleiformen des 10. Jhds. erhalten blieben. zu bestảtigen scheinen. DaB Obsla die slav. Version von Hab(u)la war. werde auch durch die Namen der Havel-Seltenarme und Zuflūsse Woblitz bzw. Wublitz wahrscheinlich gemacht, die nämlich nach Ausfall von o und mit $v$-Prothese aus obslica entstanden selen.

Die in den Spuren Ludats wandelnde slavische These hat durch Naiepas Abhandlung von 1957 und Urbanczyks Ausführungen von 1964 (SlowStarsiow II. 196) einen beachtlichen Auftrieb erfahren. Der slavischen These zufolge erklärt sich der havel-Name aus dem Grundwort -Obs/a. dessen vokallscher Anlaut durch prothetisches $h-v$ - oder $j$ - abgesichert worden sel. Auch seien die Vokale o, e, u in Habola, Havela, Obula Reflexe des Halbvokals b. Gut erkennen lasse sich der slavische Hintergrund an den Belegen Abola, einer Nebenform von Habola'. und Obula sowie an dem

3 Die Oberzeugung von der german. Havel splegelt sich selbstredend in unzähligen Kompendien und Abhandlungen wider, so z.B. In Kluges EWB $\left({ }^{20} 1967\right)$. S. 280, s.v. Haff. ebenso bel Bach 1978, II/1, 218 \%.. oder Bretschneider 1981, 5 \%. Anders Jedoch H. Bahlow: Deutschlands geographische Namenwelt. Frankfurt 1985, 204, wo Havel völlig unbegründet für ein Moorwort gehalten wird.

- Hier geht es um die Formen Habola bzw. Abola der Annales regni Francorum (MGH Scrip. rer. germ. Ed. G. H. Pertz. Fr. Kurze. Hannover 1895. S. 84). Die in Solssons und St. Omer entstandenen Abschriften $C 2$ und C 3 der Annales haben für Habola die Form Abols. Fischer-Schlimpert erklären gegen Nalepa, der das $h$-als hyperkorrekte Anfügung im Deut-

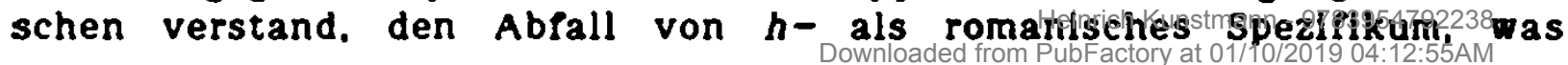


Gewăssernamen Wublltz bzw. Jublitz (= $j$-Prothese), der aus slav. Oblica entstanden sel.

Es gibt Gründe, den Namen der Havel weder für germanisch noch fur slavisch zu halten. Gegen germanische Provenienz spricht die unbestreitbare Tatsache, daß der Name der Havel absolut singulăr ist, und bel dem nicht seltenen Etymon Hafen, Haff eine gröBere Anzahl von gleich-oder ăhnlichlautenden Hydronymen zu erwarten wăre. Das aber ist nicht der Fall. AuBerdem făllt auf, daß die Slaven bel den Namen der Havel-Nebengewässer $v$ - und $j$-Prothesen verwenden (Wublitz. Jublitz). was in Grunde völlig unnötig erscheint, da in germ. Haf(f) ein im Anlaut bereits ngeschlossenes" Wort vorlag. Die slavische Praxis suggeriert vielmehr ein "offenes", ein vokalisch anlautendes Wort. Gegen das germ. Etymon Haf(f) spricht aber auch, daB, wie schon Ludat vermutete, in diesem Fall viel eher slav. Chabs/a zu erwarten gewesen wäre, weil insbesondere im Anlaut germ. $h$-durch slav. ch-wiedergegeben wird. Sehr wahrscheinlich ist das anlautende $h$-deshalb sekundär und mittelniederdeutsche oder bereits althochdeutsche Prothese (Braune, Eggers 144; Lasch 188 f.).

Gegen eine slavische Herkunft des Havel-Namens spricht in erster Linie die Dominanz des Vokals $a$ im Anlaut, was ja wohl besagt, daB dieser nicht gut aus slav. o entstanden sein kann. sondern primār ist und im Slavischen erst nach 800 zu o wurde (Obula). Fur ein a im Anlaut und gegen slav. 'obs/s plädiert ferner das Ethnonym Heveld mit seinem in der 1. Silbe einhelligen $e$, das doch eher auf Abschwaschung von a im Mitteldeutschen als auf einen slavischen Lautprozeß schließen läBt.

Insgesamt gewinnt man daher den Eindruck, daß der weder germanische noch slavische Prototyp des Havel-Namens eine doppelte volksetymologische Anpassung erfahren hat. im Mittelniederdeutschen an das Etymon Hafen, HaßY. im Slavischen an die - sowohl fur Polen (Nalepa 1957) als auch RuBland' nachgewiesenen -

möglicherweise zutrifft.

- An russischen Beispielen vgl. Vobiovica. Fluß unweit d. Vjatka, Kr. Slobodsk, G. Vjatka: Voblovka, Oblovka, r. Nbn. d. Ilovec, Desna-Bass., G. Smolensk; Voblja, r. Nbn. d. Oka, Kr. Zarajsk, G. Rjazan' (WdRG I, 329). Vielleicht gehört hierher auch der Typ Vobolb, FluB im Kr. Ponevez, G. Kaunas, wo auBerdem der ON Vobolbniki (Pl.) vorkommt. Laut Ludat (1936), der sich auf eine Auskunft $\mathrm{E}$. Dickenmanns beruft, ist der Namentyp Vobla, Voblica auch auf südslavischem Gebiet anzutreffen, vgl. den ON Obla Brda. Kr. Sarajevo (Ludat 1969, 21, Anm 29). 
Der Name der Havel ist mit großer Wahrscheinllchkeit griechischer Provenienz und geht auf das Thema $\alpha u \lambda$ - zurück, das sowohl in den femi-

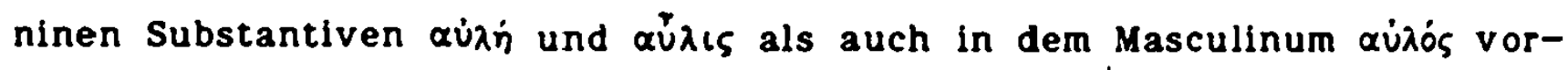
liegt. Somit ist von Ubernahme ins Slavische und Obértragung durch slavische Siedler nach Brandenburg auszugehen. Griech. $\alpha u \lambda$ - wurde über • aul- > - $a y I->\cdot a v I-$ ins Slavische übernommen, also ohne Monophtongierung des anlautenden griech. Diphtongs, was im Slavischen während des 6.-7. Jhds. ansonsten hăufig der Fall ist. Von dieser Regel gibt es zahlreiche, vielleicht spätere Abweichungen, die bestätigen, daß die fremden Diphthonge su- und eu- eben nicht immer monophthongiert werden. vgl. aksl. (j)evan-

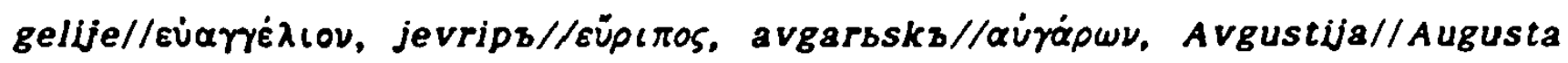
usw. (Miklos., Lex. 1149, 2). Im vorliegenden Fall von ausschlaggebender Bedeutung ist nun jedoch, daß bei Obernahme des griech. au-als av- ins Slavische $z$ wischen $v$ und dem Polgenden Konsonanten der sekundäre Halbvokal s entstehen konnte: avsgusts//aürovoros (Miklos.. Lex. 2); Avsksi-

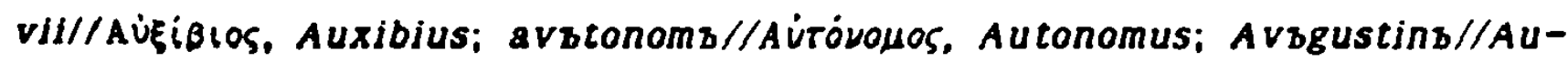

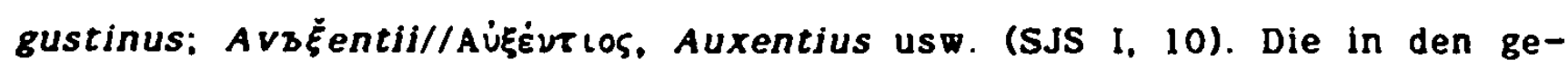
gebenen Beispielen gut erkennbare Entstehung des Halbvokals $z$ erklärt plausibel die historischen Formen $H a b / o / l a, O b / u / l a$ u.a. Für eben diese Formen ist also keineswegs eln germanisches Suffix - $(u) 1$ - vorauszusetzen (Bach II/1. 218 f.).

$\mathrm{Zu}$ beachten sind nun allerdings die semantischen Besonderheiten. Es lst nämlich, wie soeben gesagt, von zwei unterschiedlichen Bedeutungen auszugehen, und zwar von 1. $\alpha \dot{v} \lambda \dot{\eta}, \alpha \dot{v} \lambda l \varsigma$ und 2. $\alpha \dot{v} \lambda \dot{o} \varsigma$. Dabei sind $\alpha \dot{v} \lambda \dot{\eta}$ in der Bedeutung von 'äußerer oder innerer Hof. Wohnung' und das semantisch nahestehende $\alpha \tilde{\lambda} \lambda \iota \varsigma$ 'Aufenthaltsort, Nachtlager (Im Freien), Stall, Hürde. Nest'“ sogenannte 1-Ableitungen der in $i-\alpha u \dot{w}$ 'ruhen, übernachten' noch erkennbaren Wurzel (Frisk I, 186). Inhaltlich hierher gehören überdies Évaúxiov 'Aufenthaltsort' sowie das durch Hypostase von $\dot{\varepsilon} \nu \alpha \dot{v} \lambda \bar{y}$ ( $\omega \tilde{\nu}$ ) 'im Hof befindlich, zu Hause' entstandene Substantiv Ěvaudos 'Behausung' (ders. I. 510). - Etymologisch und semantisch von $\alpha \dot{u} \lambda \dot{\eta}, \alpha^{\top} \dot{\lambda}(\varsigma$ unterscheiden sich

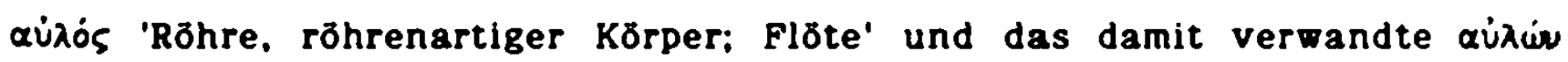
m.f. 'höhlenartige Gegend, Schlucht, Tal, Graben'. Bedeutungsmäßig hierher

- Dazu gehört außerdem die lat. aula, ein in der Antike atriumartiger Hop bzw. eine Hothalle, im frühchristlichen Abendland ein groBer kirchlicher Raum und seit der Merowingerzeit ein profaner Saalbau, dem dann auch die karolingische aula regia entspricht (LexMA I. Hel2344n GrarBiadirgg).2238 
gehört auch das durch Bahuvrihikomposition von aủios und adverbalen $\dot{\varepsilon}$ entstandene Ẽvauios, das sowohl 'mit Flote versehen' als auch 'FluBbett. Gießbach' bedeutet (Ebda.).

Griech. $\alpha \dot{\lambda} \lambda \dot{\eta}$ scheint offenbar in den Turksprachen Karriere gemacht zu haben, das zeigen osmanisches (türkeitürkisches) havly und av/y in der Bedeutung 'ein Hof vor dem Haus, Vorwerk. Gehöft, ein mit einer Mauer umgebener Platz'. wozu auch tarantschi höla 'Hor. h\&yli 'Haus.Heim' sowie osmanisch awla 'Hof'. kasachisch aula 'Heuschuppen. Heuboden' gehören. In allen dlesen Fällen nimmt man Entlehnung aus griech. $\alpha \dot{u} \lambda \dot{y}$ an (Rảsanen 157. 32)'. Die Grundbedeutung von 'Hof. Wohnung' andert sich wăhrend der Spätantike mehr und mehr in 'Landgut. Landhaus, Landsitz' und schließlich in 'Residenz eines Herrschers. Palast' (Znvós $\alpha \dot{u} \lambda \dot{\eta}$ ). vgl. KI. Pauly I, $754^{\circ}$. Aúdn் zur Bezeichnung von groBen, reichen häusern wurde als Begriff und Einrichtung offensichtlich auch von den Barbarenfürsten des Balkans übernommen. $O b$ dies ebenfalls auf die Residenzen der Awaren-Khagane zutrifft. ist zwar denkbar, aber nicht belegt. Mit Sicherhelt wissen wir dagegen dank der Mitteilungen von Schriftstellern wie Georgios Monachos (Hamartolos). Leon Grammatikos, Skylitzes-Kedrenos, Johannes Zonaras und namentlich Theophanes Homologetos, daß die Residenz der Bulgaren-Khagane in den quellen als $\alpha \dot{\lambda i n}$ bezeichnet wird. Dies trifft vor allem auf

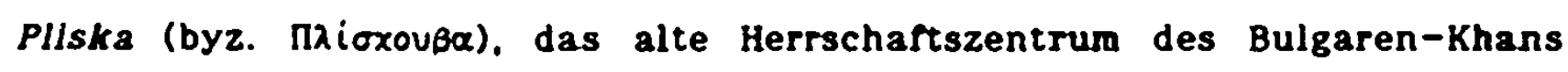
Krum zu. Ober die Einnahme und Zerstörung seiner aủin Pllska durch Kaiser Nikephoros I. (811) berichtet detallliert Theophanes (485, 14; 490, 26:

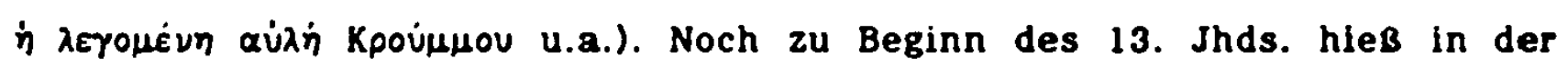
Nahe von Sliven eine Festung $A v l l$. deren Name ohne Frage abermals aùin wiedergibt (Jirecek 1978, 282). Auch der Name der ostslavischen Ullicl er-

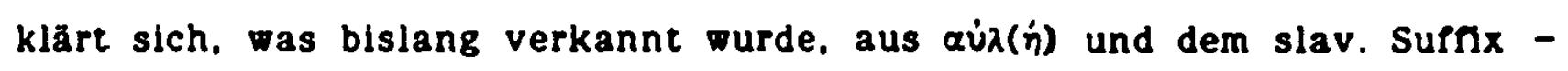
iCi. mit dem Unterschied freilich, daß der griech. Diphthong au- in diesem Fall zu $u$-monophthongiert wurde."

Wie nun hat man sich den semantischen Bezug zwischen $\alpha \dot{\lambda} \lambda \dot{y}$ und der Havel vorzustellen? Bei der in Spătantike und Frühmittelalter aurkommen-

7 Laut Lokotsch 1975, 12, geht auch rumän. avlie 'Park' auf osman. avly zurück.

- Der Begriff schlug sich außerdem in verschiedenen Toponymen nieder: $A \dot{u} \lambda \dot{\eta}=a$. Ort in Arkadien, b. Kastell auf der Südseite des Haimos:

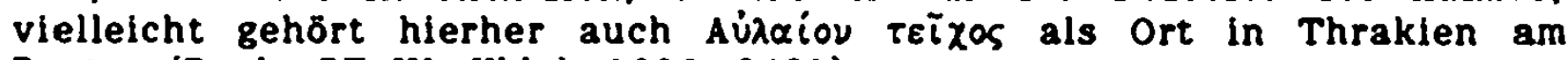
Pontos (Pauly RE IV. Hbbd. 1896, 2401).

- Ausfuhrlicher darüber in Kunstmann ${ }^{1} 1988$ Kapitel 2: „Die sogenannten Stămme der Ostslaven". 
den Bedeutung von $\alpha \dot{u} \lambda \dot{\eta}$ als Sitz eines Vornehmen könnte man unter Umstănden davon ausgehen, daß ein slavischer Gentllaristokrat seinen im Bereich der Havel gelegenen Ansitz $a v b l s$ nannte und dieser Name im Laufe der Zeit auf den Fluß überging. Der Burgward Havelberg. ein früher Siedelplatz an markanter Stelle, von dem aus Wasser- und Landwege zwischen Havel und Elbe zu kontrollieren waren. könnte so eine $\alpha \dot{\lambda} \lambda \dot{n}$ gewesen sein.

Wahrscheinlicher als die Herleitung des Hydronyms Havel von griech.

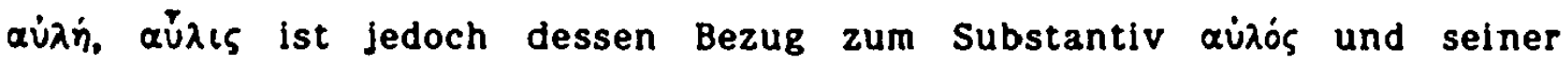
Grundbedeutung 'längllcher. Innen ausgehöhlter Gegenstand. Röhre: Kanal'.

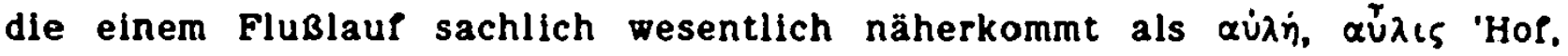
Wohnung'. Ohne exakt $z w i s c h e n ~ \alpha \dot{u} \lambda o ́ s$ und $\alpha \dot{v} \lambda \dot{\eta} z u$ unterscheiden, hat bereits Rozwadowski im Prinzip richtig erkannt, daB das - in seinen Augen - indogermanische Thema aul-sowohl in slavischen als auch baltischen und sogar germanischen Flußnamen vorkommt ${ }^{10}$. An baltischen Beispielen nennt Rozwadowski so etwa den mehrfach bezeugten FIN U1a, UHa, Ulanka, an slavischen die Ulica bel Plock und Vitebsk, auch die Tuhle als re. Zunuß der Spree bel Berlin u.a." Als germanisches Hydronym dieses Typs werden erwähnt: 1. die Ohlau, ein ll. Zufluß der Stör im Bereich der Elbe, sowie 2. die Aula (Aule), ein 11. NebennuB der Fulda in Hessen. Letztere ist für das 8. und 9. Jhd. als Ovlaho, auch Oulaho (778), Owilah (um 860; FIN und $O N$ ) und für das 12. Jhd. als Oveli (1182) belegt (Förstemann. Jelllnghaus I, 301). Tas die beiden germanischen Repräsentanten dieses Typs, also Ohlau in Stormarn und Aula in Hessen anlangt. so ist in beiden Fällen slavische Vermittlung nicht restlos auszuschlieBen ${ }^{12}$. Auch die von Rozwadowski angefuhrten baltischen Hydronyme lassen sich ohne Schwierigkeiten aus dem Slavischen erklären. Und wenn Rozwadowski sich hinsichtlich des vermeintlich indogermanischen Themas aul-auf die bel Egli

10 J. Rozwadowski: Studia nad nazwami wód slowiańskich. Kraków 1948, $216 \mathrm{Pl}$.

11 Gründlich erfaBt diesen FlN-Typ für den ostslavischen Bereich das WdrG IV, $678,680 \mathrm{f}$. wo Ula $(5 x)$. Ulla $(2 x)$. Ulica $(4 \mathrm{x})$ und Ulicka (1x) nachgewiesen werden.

12 Hinsichtlich der hessischen $A$ ula sel an die berühmte Mitteilung des Fuldaer Abtes Sturmi erinnert, der auf der Suche nach einem geeigneten Platz far sein Kloster "eine große Menge von Slaven" sah. die in der Fulda badeten und "ihre Leiber wuschen" (Vita Sancti Sturmi, c. 7). Das Problem der Fulda-Slaven, von denen auch in einem Brief Bischofs Wolfger von Würzburg an Kaiser Ludwig den Frommen (aus den Jahren 82630) die Rede ist (SlowstarSlow II. 75: G. Labuda), verdient noch gründlich in Augenschein genommen zu werden. 
(Nomina geographica, 1893, 63) erwähnten Aulon-Toponyme In der Bedeutung von $A \dot{u} \lambda u ́ n=$ Tal berief, dann wird damit erneut nicht so sehr der idg. als vielmehr der griechische Aspekt deutlich, da nämlich ausnahmslos alle Aulon-Toponyme griechischen Ursprungs sind. Zu guter Letzt sel auch noch an das Toponym Volyns erinnert, von welchem sich der Landschaftsname Wolhynien herleitet und die mittelwestrussischen Volynjane Ihren Namen haben: Sowohl Volynb als auch der Name der pommerschen OstseeInsel Wollin sind slavische Prägungen von griech. $\alpha \dot{v} \lambda \omega \dot{\nu}$ (Kunstmann '1985, 247 ff.).

Der Name der brandenburgischen Havel laßBt sich somit als eine von Slaven übermittelte und lautlich abgewandelte Entsprechung zu griech. aủiós in der ursprūnglichen Bedeutung 'Röhre: Tal, Graben' verstehen. 
15,

Sel (a)

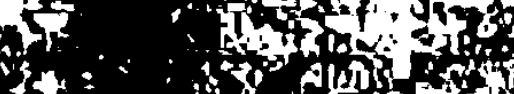

(1)

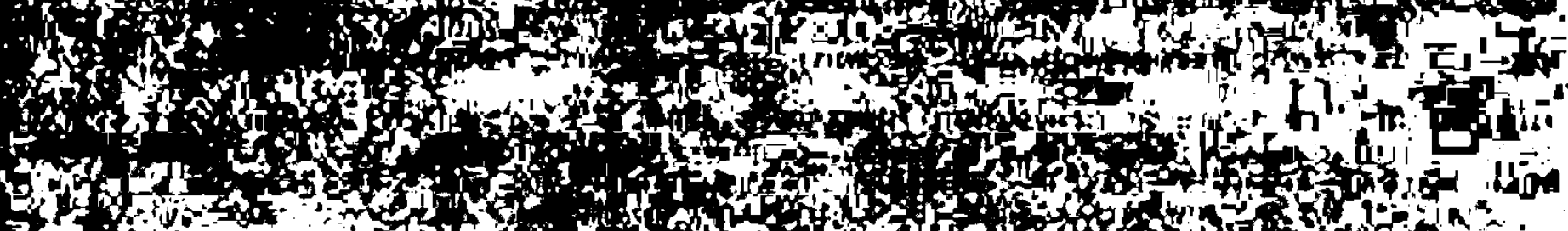

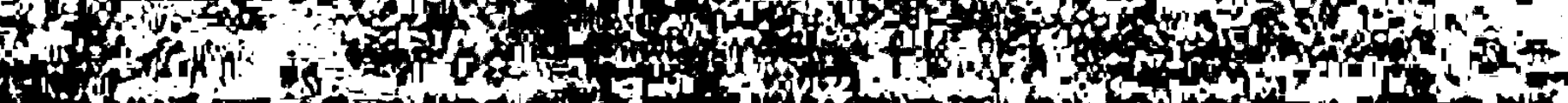

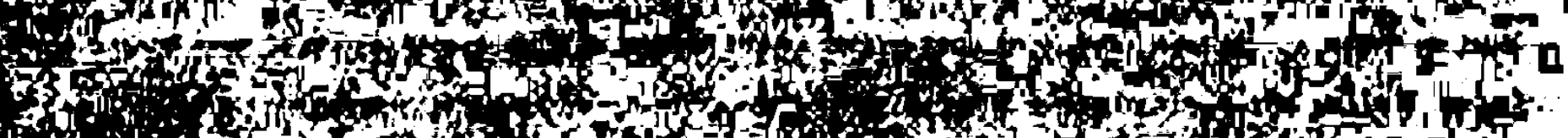
+1.

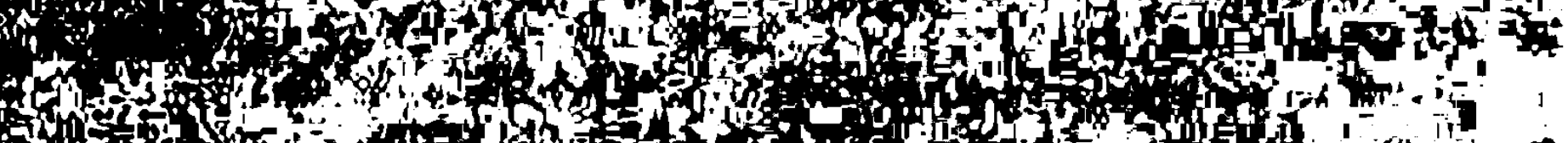
of

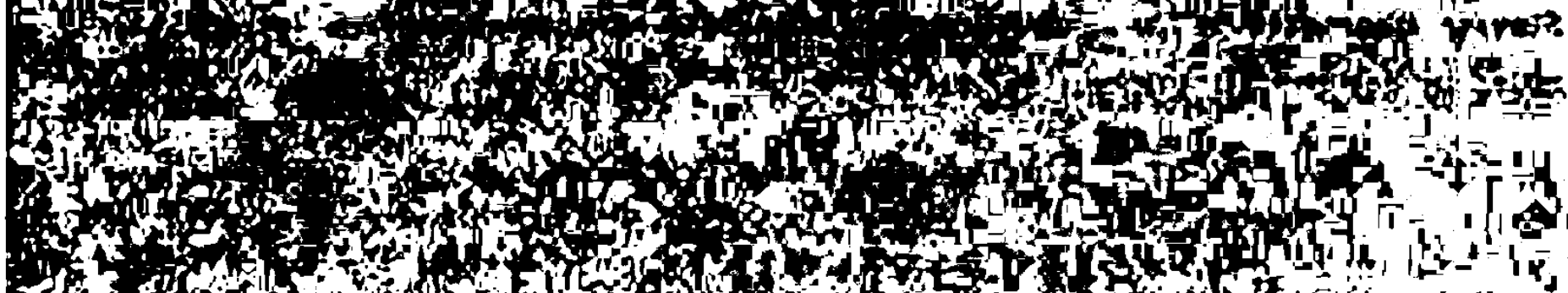
He 3 or

Hes ons

of (5)

(3) Sor 15.

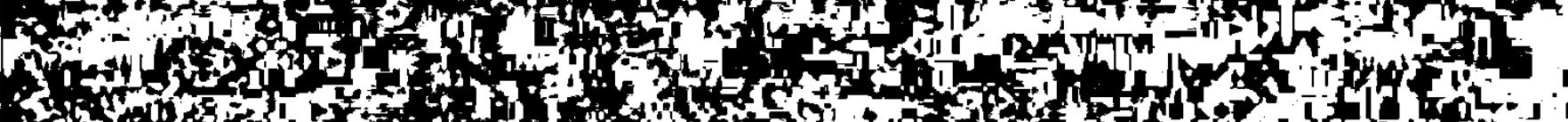

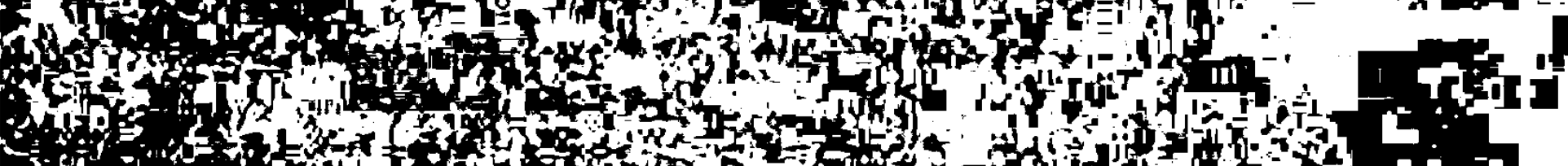

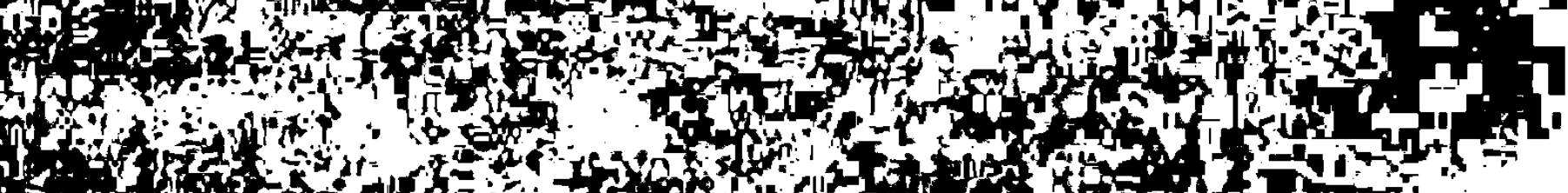

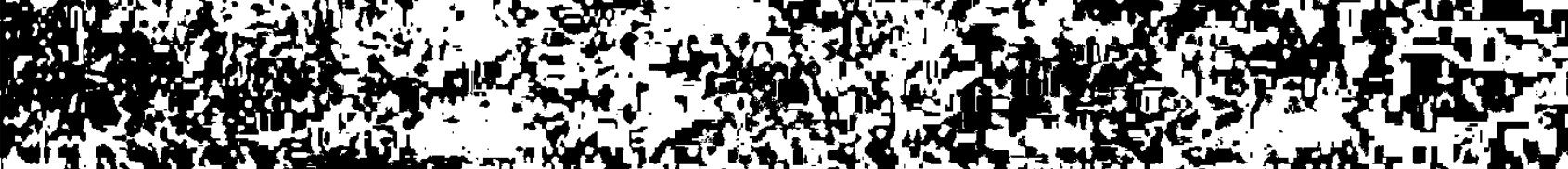
Tris

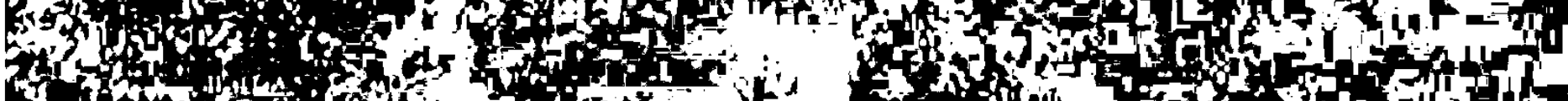
Af $R$ R

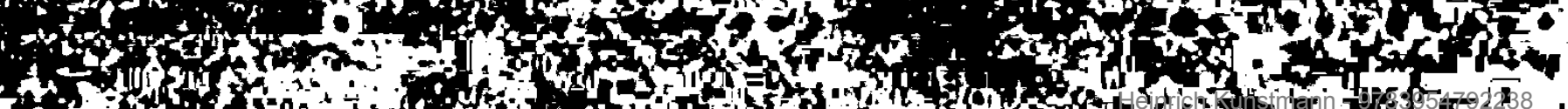

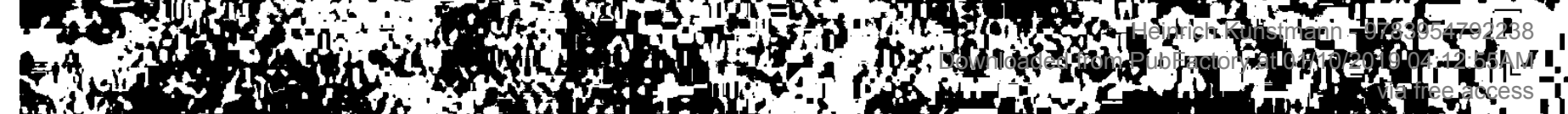




\section{Anhaltisches Zerbst}

Hinter den frühesten Belegen des Toponyms Zerbst verbergen sich $z$ wel Begriffe, der Name des aus einem Burgward hervorgegangenen Hauptortes (urbs) sowie die Bezeichnung des gleichnamigen Gaues (provincia, terra) (Heßler 1957, 33 f.). Auch wenn sich kaum mehr mit Sicherheit feststellen lassen wird, wer von beiden der namengebende Teil gewesen ist, wird man vermuten dürfen, daß der Name von einem Punkt, von einem ersten Siedelplatz ausgegangen ist und sich auf die Landschaft übertragen hat. Dies entspricht im allgemeinen den frühen Siedelvorgängen. Die åltesten urkundlichen Belege für den Orts- und Gaunamen setzen mit Otto d. Gr. eín. genauer gesagt mit der Grūndung des Bistums Brandenburg 948:

948 Cieruisti (DO I. 105) = provincia; 973 Kiruisti (DO II, 30): 1003 in territorio Zerbiste (DH II, 48); 1012/18 Zirwisti (zu 1007: Thietmar VI. 33) = urbs; 1161 Ciervisti (CDA I, 460) = provincia: 1188 Zierwisti (ebda. 656); 1264 Scerwlst (ebda. II. 289) = terra'.

Die Beschreibung der Diözese Brandenburg nach Gauen (DO I, 105: 948 $X$ 1) macht deutlich, daß sich der Gau Cieruisti zwischen den Territorien der slavischen Moraciani (vgl. S. 104) und Ploni (SlowStarSlow III. 150: A. Wedzki) befunden haben muB. Nach einer modernen Beschreibung „erstreckte sich das Siedlungsgebiet südlich von Moraciani an der Zerbster Nuthe und an der Elbaue (Nuthegebiet). Seine Grenzen waren im Norden und Osten die Flămingwălder, Im Süden dle Elbe. Im Nordwesten grenzte das Siedlungsgebiet an das Ehle-Ihlegebiet" (Hermann, J., 1968, 36). Das zentrale Gebiet dieses Gaues muß demnach der Raum zwischen Elbe und Nuthe gewesen sein. Damit kristallisiert sich ein Gebiet heraus, das siedlungsgeschichtlich von besonderem Interesse ist. Aus germanistischer Sicht (Lasch 1974, 20) handelt es sich hier um das Ostanhaltische mit seinem Mittelpunkt Zerbst, das als Kolonialland gilt im Vergleich mit dem Westanhaitischen, das großenteils alter deutscher Boden war ${ }^{2}$. Von historischer

1 Nach Eichler 1966, 23, und Schultheis 1968, 86 P.

2 Diese auf linguistisch-dialektsprachliche Kriterien gestützte Einteilung wird von archäologisch-historischen Beobachtungen bestätigt, vgl. Im Historischen Handatlas von Brandenburg und Berlin, Abt. II (1964), die Kartierung der Spätgermanischen und frühslavischen Zeit. Bearbeitet $v$. Adriaan von Müller. Hier insbesondere Blatt 4, auf dem die absolute Dominanz der linkselbischen Siedlung wăhrend der Zeitstufen 380-650 (und 750) hervortritt, wohingegen rechtselbisch um Zerbst ein auffallendes Sledlungsvakuum erkennbar ist. 
Warte (Helbig 1960, 33) beurteilt man den Praglichen Gau als Altsiedelbereich des sorbischen Gebietes, also als Prühes slavisches Siedelland. Das entspricht im großen und ganzen dem sogenannten altsorbischen Westrlügel, worunter insbesondere die slavistische Onomastik den Raum zwischen Elbe und Saale bzw. Mulde versteht. „Die altsorbische Namengeographie zeigt eine deutliche Teilung des Sprachgebietes in einen sogenannten 'Westhügel' 2 wischen Saale und Elbe und in einen sogenannten 'Ostflügel' zwischen Elbe bzw. Schwarzer Elster und Böbr bzw. Kwisa (Queis). Flüssen, die ehemals das altsorbische Sprachgebiet im Osten gegen das altpolnische abgrenzten" (Eichler, Witkowski in: Herrmann, J., 1985, 48). Man wird insofern in Zerbst und seinem Gau eine Art von nördlichem 'Ausläufer' des altsorbischen Westnügels sehen dürfen. Mit dem Begriff Westflügel verbindet sich die Aurfassung, die ursprünglichen Sitze der sorbischen stämme seien im Eibe-Saale-Gebiet gewesen ${ }^{3}$. Anders Schuster-Sewc (1972, 221). der an einer Ost-West-Ausdehnung der Sorben festhält. Dle Feststellungen von Germanistik. Geschichtsforschung und Slavistik aber plädieren m.E. überzeugend für ein sorbisches Altsiedelland an Elbe und Saale.

Eine andere Frage ist die nach der Bedeutung des Toponyms Cieruisti = Zerbst. Unbestritten sind dabei zwel Faktoren, nämlich, daß der Name aus dem Grundwort Cleru- sowie dem Suffix - isti besteht. das aus urslav. - iskio entstanden ist und -iste entspricht (Vaillant 1974, $422 \mathrm{Ir}$.). Die in den Belegen häufiger auftretende Endung - isti. also mit auslautendem $-i$ statt - $e$ kann zwei Erklärungen flnden: entweder sie ist aus einer alten Lokativ-Konstruktion mit Präpos. vo hervorgegangen, oder aber sie ist als lateinischer Nom. Pl. und Insassenname verstanden worden. Nicht so eindeutig wie das Suffix wird dagegen das Grundwort Cieru-beurteilt.

Ein Teil der Forscher wie etwa Niederle (1919,115) sieht in Cierueinen Reflex von Serb- oder Srb-. also des Serben-/Sorbennamens, so daB - Serb-iste bzw. -Srb-iste ein alter Name für das Sorbenland sei. Doch schon mit Hey $(1893,227)$ bahnte sich eine völlig andere Deutung dieses Namens an. Hey, der seine Ansicht später mit K. Schulze wiederholte (Hey, Schulze 1905, 53). Interpretierte Zerbst als 'cerviste 'Heustelle. Schobernleck'. Doch diese Ansicht setzte sich gegenüber der folgenden, von Trautmann initilerten (Trautmann 1949, 58 (.) nicht durch. Trautmann gelangte nämlich zu dem Ergebnis, daß Zerbst nichts mit dem Sorbennamen zu tun

3 Zur Sonderstellung des Westnügels im Namenwortschatz vgl. Eichler ${ }^{2}$ 1965: 1968, 123: 1976, 70. 
habe (ders. 1948, 14), sondern aus altem cirvisce hervorgegangen sei. das seinerseits auf polab.-pommoranisches 'cirv́ 'Made' (nso. cerw') zurückgehe. Trautmanns Deutung schloß sich in der Folge mit besonderem Nachdruck E. Eichler an, der in Cleruistl ein auf asorb. clív gestūtztes • cirvišce zu erkennen glaubt (Eichler 1965, 253), wobel ciŕv das Insekt Cochenille bezeichne, eine spezielle „Schildlaus, aus der ein roter Farbstoff gewonnen wurde" (Eichler 1966, 23). Diese Schildlaus-Etymologie wird auch von anderen Gelehrten gutgeheißen (Schultheis 1968, 86 f.; Nalepa in: SlowStarSlow I. 303 s.v. Czerwiszcze). Doch es fallt schwer, dieser Etymologie zu folgen, da es gegen sie nicht allein linguistische, sondern mehr noch sachliche Vorbehalte gibt.

Die Schildlaus-Version ( Sorben-Komponente $\left(<\cdot s f b_{b}\right)$ im Grunde nur in der Beurteilung des anlautenden Konsonanten $c$ - (Cieruisti), hinter dem die einen ein $c-$, die anderen ein $s$-vermuten. Dies ist der Kern des Problems, das nachfolgend erneut überprüft werden soll. Zunăchst ist zu sagen. daß die Mehrzahl der Belege das fragliche Toponym mit $\boldsymbol{C}$-oder aber $\boldsymbol{Z}$ - schreibt; die Versionen mit $K$ - und $S c$ - sind die Ausnahme, wie gezeigt wird. Elchler hält das $C$ (ts) der Urkunden far frühe Wiedergabe von slav. c (Eichler 1966, 23), welcher Meinung auch Schultheis (1968, 86) ist. der $C$ - als mittelniederdeutschen Ersatz für die slavische Affrikata begreift. Die Richtigkeit dieser beiden Ansichten läßt sich bezwelfeln. da, wie gut bekannt, deutsches $c$ und $z$ ja ebenfalls Vertretungen von slav. $s$ sein können. Die Beispiele dafür sind keineswegs so "wenige". wie Schultheis (87) meint. im Gegenteil. sie sind gerade im Anlaut ausgesprochen zahlreich, und zwar sowohl in Nord- und Mitteldeutschland als auch in Nordostbayern. Schultheis selbst zieht für eine Vertretung von $s$ durch $z$ folgende Belege an: 961 Zurbici< 'S Trbici = Zörbig: 1176 Zuche < 'Sucha = Zauche: 1317 de Zuchwiz< 'Suchovec = Zauchwitz; 1290 Zolgowe, 1375 Czolchov = Zolchow. Allein diese Beispiele bestätigen, daß für Zerbiste, Zierwisti oder Zirwisti ebensogut Serbiste oder Sirvisti gelesen werden kann. Nicht weniger gut läßt sich aber auch die Vertretung von s durch $c$ belegen: 1290/1305 Cyngst < 'Séniše $=$ Zingst $($ Trautmann 1949, 84); 1324, 1353 Cyrowe $<'$ Sirov $=$ Zierov (ders. 1948, 73): 1312 Cyrsowe, 1354 Zyrsowe, 1342 Cyrezsowe, 1345 Cyrrezowe $<$ Sirosov $=$ Zierzow (ebda. 118). Trautmanns verdienstvolle Materialsammlung bietet ungezählte weitere Beweise dafür, daß slav. $s$ insbesondere im Anlaut sehr wohl durch $\boldsymbol{c}$ oder $z$ vertreten werden kann. 
Bescheiden sei noch an die slavischen Zirzipanen erinnert, deren Name, wie gezeigt (S. 51 ff.), auf die paionischen Sirispaiones zurückgeht. Der nämliche Lautersatz ist aber ebenfalls in Nordostbayern anzutreffen. Was einige ausgewählte Beispiele bestätigen: 1249 Cedeliz, 1329 Zedlitze, 1400 Czedlitz $<\cdot$ Sedllc. $\cdot$ Sedlec = Zettlitz; 1263 Zeniste, 1290 Cyngst < Sénisce = Zingst: 9. Jhd. Cicorni ('Sykorsns = Zeickhorn (Schwarz 1960, 256 fl.).

Zwei Schreibvarianten für Zerbst weichen scheinbar von der Norm der Vertretung von $s$ durch $c$ bzw. $z$ ab: Kiruisti und Scerwist. Zuerst zu Kiruisti, worin man gern eine Stütze der These sieht, daß slav. $\varepsilon$ (nicht s) durch $c$ vertreten werde (Schultheis 86 ). Der Anlaut von Kiruisti ist ohne Frage als Zetazismus $z u$ erklären, betrachtet man jedoch die Urkunde DO II 30 (973 VI 5) genauer, zeigt sich, daß der hăufig ein $k$ einsetzende scríba mit diesem Zeichen sowohl slav. $c$ als auch $s$ ausdrückt: Neietiki $(2 x)=$ Neletici: Cholidiki = Cholidici: In pago Nikiki $=$ NIsici (vgl. S. 145 fr.). Das freilich besagt, daß $k$ hier nichts anderes ist als eine Vertretung für $c$ (bzw. $s$ ), die ihrerseits wiederum für slav. s stehen kann. Unter allen Prühen Zerbst-Belegen ist Kiruisti auBerdem ein ausgesprochener Einzelfall. dem keine besondere Bedeutung zugesprochen werden kann. Auch in Scerwist. der anderen Abweichung. ist Praglos ein Serv- enthalten, da auch zc $(=s c)$ - gerade wieder im Anlaut - Vertretung für slav. s sein kann: 1356 in villa desolata Zcynschs < 'Senisce = Zingst (Trautmann 1949, 84) oder 1371 Zcoberitz < Sobor- = Zöberitz (Richter 1962, 110).

Es llegt somit kein zwingender Grund vor, anlautendes $c$ - bzw. z- als Ersatz für slav. $c-z$ halten. Ein anderes Problem stellt das graphisch als - $u$ - aufscheinende $-v-$ in Clervisti dar, das bei nur einer Ausnahme - 1003 Zerbiste - in der Tat sehr konsequent verwendet wird (Schultheis 87). Darin spiegelt sich m.E. genau wie in dem Ethnonym Zeriu-ani (S. 177 lf.) ursprüngliches 'serv- wider, während es beim Serben-/Sorbennamen $z u$ einem systematischen Betazismus gekommen ist. DaB auch in Zerbiste und schlieBlich in Zerbst selbst Betazismus vorliegt, ist wohl weniger hyperkorrekt (Schultheis 87), als vielmehr mit dem mitteldeutschen Wandel von $v>b$ zu erklären", der gerade far das Gebiet um Aken als 'durchgängig' bezeugt ist.

Der stărkste Einwand gegen die Etymologen-Meinung. Zerbst sei Sìdelplatz von Schildlăusen gewesen, ergibt sich jedoch in sachlicher Hin- 
sicht. Allein, daß eine slavische Siedlergruppe sich ausgerechnet nach diesem Insekt benannt haben soll, wirkt eingenartig, um so mehr, als ein analoges theriophores Ethnonym Pür Mitteleuropa kaum nachzumeisen sein dürfte. Fraglich ist ferner, ob die Slaven im 7.-8. Jhd. schon auf einer zivilisatorischen Stufe standen, die eine Nutzbarmachung von Schildläusen wahrscheinlich erscheinen läßt. Auch der kulturgeschichtliche Hintergrund spricht eher gegen die Zerbster Schildlaus-Theorie.

Das Nutzprodukt des Insekts Cochenille, auch Nopalschildlaus oder Scharlachwurm genannt, ist bekanntlich dle Scharlachfarbe. Die ursprüngliche Heimat dieser Schlldlăuse war Mexico, von wo sie erst nach der Entdeckung von Amerika nach Europa kamen. Der mexikanischen Spezies verwandte Gattungen sind der Coccus polonicus sowie die Porphyrophora polonica (L). die namentlich in Polen. RuBland. Schweden. Ungarn und Nordostdeutschland zu Hause waren, um Johannis gesammelt wurden ${ }^{3}$ und ein nicht unbedeutendes handelsobjekt darstellten. Nach 1492 wurde das osteuropäische Insekt von der erheblich ausgiebigeren mexikanischen cochenille verdrängt (Jakubski: Kaøecki 1935).

Zum Beweis dafūr. daß sich der Name der bei den Slaven verbreiteten Schildlaus $=\cdot{ }^{\circ}$ brvb auch in der Toponymie niederschlug, fahrt Schultheis (86) die polnischen ONn Czerwiszcze und Czerwiec sowie das cech. Toponym Cervenéves an. Gegen Czerwiszcze ist einzuwenden, daß das Suffix-iszcze im Polnischen fehlt, eine Ausnahme bilden Entlehnungen aus dem Kleinrussischen wie z.B. dworzyszcze 'Meierhor: das einschlăgige poln. Sufflx ist vielmehr -isko: gradowisko. chmielisko. grochowisko usf. Auch cech. Cervenéves ist nicht unbedingt beweiskräftig, da der Name, far 1318, 1322 als Czirwynywsi belegt. aus $z$ Crviny Vsi entstanden ist, was besagt, daß hler ein PN Crva vorliegt, der wiederum eine Sekundärform von crv 'Wurm' ist (Profous I. 339) und nichts mit Schildläusen zu tun hat. Wenn aber, wie entsprechende Arbeiten (Jakubski, Kawecki) bestätigen, die wirtschaftliche Nutzung der Schildlăuse überwiegend In Polen und wohl auch in Weißrußland zu Hause war, dann aberrascht es doch einigermaßen, daß die polnischen Belege für dieses Insekt und den aus inm gewonnenen Farbstoff so ungewöhnlich spät einsetzen, nămlich erst im 15. Jdh.: A. zoolog. Bed.:

- Angeblich sollen daher die Monatsnamen cech. Cerven und cervenec rühren; anders Berneker 1924, I, 173; angeblich geht darauf auch der Name Cervonnaja Ruś zurück, was Vasmer REW III, 318, wohl zu Recht. bestreitet. 
1437 Cirwecz kermes; 1472 Cziruecz grana tinctoris maiora. B. Farbstoff: 1412 An dem "czirwicz vorlust ist worden; 1429 'czirwicz; 1437 'czerwicz; 1441 czirwyecz; 1441 cirwecz; $1412-49$ 'czirwicz; 1471 Czirwczem und Czirvyecź.

Sichere Anhaltspunkte dafür, daß Slaven Im Anhaltischen die wirtschaftliche Nutzung von Schildläusen betrieben haben, gibt es nicht. Auch spricht der frühe Beleg von 948 eher gegen als für eine solche Annahme. Die Schildlaus-Etymologie beruht im Grunde auf nur einem einzigen Buchstaben, dessen ursprünglicher Lautwert unterschiedlich bewertet wird. Ein entscheidendes Argument, das zur m.E. unfreiwillig komischen SchildlausEtymologie geführt hat, war, daß es in der slavischen Toponymie den ethnonymischen Typ Srbiste u.ä. nicht zu geben scheint. Eben deshalb empfand Hey die Deutung von Cleruisti als Srbiste bzw. Serbiste 'Ort der Serben/Sorben' als Volksetymologie; ähnlich dachte wohl auch Skok (1938, 230). Dabei hat gerade Skok gezeigt (270), daß in einer in 14. Jhd. entstandenen slavischen Obersetzung des Johannes Zonaras genau dieser Typ als Srobisce und Srobbcisce vorkommt. Unter beiden ist die von Konstanti-

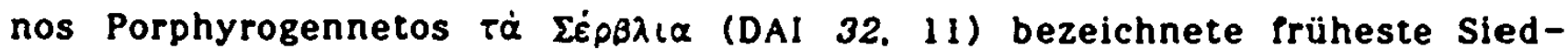
lung der Serben in Thessalien (vgl. S. 186) zu verstehen. Dieser erste serbische Wohnsitz auf byzantinischem Gebiet heißt in der Folge wechselnd Servia, Serbia, slav. Srbica, türkisch Serfidze und Seifldze. Auch wenn die einzigen Belege für den Typ 'Sţbisce aus dem 14. Jhd. stammen, zeigt sich doch, daß elne derartige Blldung formal-morphologisch möglich ist. Und selbst ohne diese späte Bestätigung ließe sich sagen: Das Fehlen eines frühen Beleges ist noch kein Beweis dafür, daß es die Form nicht wirklich gegeben hat.

Alle Fakten zusammen genommen machen es mehr als wahrscheinlich, daß das anhaltische Toponym Zerbst als 'Serbiste, 'Stbisce 'Serben-(oder) Sorbensiedlung' und nicht als 'ctviste 'Ort von Schildläusen' zu deuten ist. Daß hier im Ostanhaltischen, am altsorbischen Westflügel Serben genannte Slaven landnehmend waren, erste Siedelzellen bildeten, ist historisch plausibel. 


\section{Der anhaltische Landschaftsname Serimunt1}

In meraoriam Johannes Holthusen

Als erster unternahm Gustav Reischel, gestatzt auf Konigsurkunden vorwiegend des 10. Jhds.. eine ausfohrliche Beschreibung der geographischen Ausmaße besagter Landschaft (Reischel 1932). Auch die auf Reischel folgenden, diesen nicht wesentlich korrigierenden Lokallsierungen von HeBler (1957. 32 f.) und Helbig (1960, 33 f.) stimmen im großen und ganzen darin uberein. das das Zentrum der Landschaft Serimunti zwischen dem Unterlauf der Saale Im Westen, dem Unterlauf der Mulde Im Osten und der Elbe im Norden 19g. „vermutlich ohne diese im Osten siedlungsmäBig zu erreichen* (Helbig 1960, 33). .Der nōrdlichste Bereich dieses Wohngaues erscheint auch als Zltici" (Helbig), wăhrend südllch an Serimunti dle Landschart Coledicl grenzt, auf welche wiederum eln zitici genannter pagus folgt. Zwischen Coledici und zltici scheint die Puhne eine naturliche Grenze gebildet zu haben. Die Landschart Serimuntl beurtellt man als ausgesprochenes Altsiedelland des sorbischen Gebietes, in dem .sich Past ausschlleblich die sorbische Besiedlung vollzogen hat" (Helbig). Das Altsiedelland Serimunti befindet sich somit in dem von der Sprachwissenschaft als 'Westnügel' bezeichneten Teil des sorbischen Sledelgebietes. Wegen seiner altertamilchen Namengebung gilt das Geblet zwischen Saale und Mulde (Niederle III. $113 \mathrm{nf}$.) als Kerngebiet des altsorbischen Westrugels (Eichler 1968, 123; der. 1976; anders: Schuster-Sewc 1973).

Der Landschartsname SerimuntI ist verhältnismäBig gut belegt, im wesentlichen rar die Zeit der Ottonen. Den frühesten Beleg enthält allerdings die berahmte Orosius-Bearbeitung durch Konig Alfred (um 890). In der Serimunti als Sermende wiedergegeben wird (Pritsak 1981, 688). Die Notierung des Landschaftsnamens in den ottonischen Königsurkunden sieht Im Detail PolgendermaBen aus:

MGH DO I Nr. 64:945 in pago SeromuntI (Kop.d.15. Jhds.): Varlanten: Sermunti A, Sermunt B):

Nr. 69: 946 in pago Serimuntilante (Orig.);

Nr. 134:951 in p8go Serimunt (nachgez. Orig.):

Nr. 278: 965 in pago Sirimunti (Kop.d. 15. Jhds.; Variante: Sirmunt D).

MGH DO II Nr. 28: 973 contra marcham Serimode (Orig.):

Nr. 30: 973 Sirmunti (Orig.):

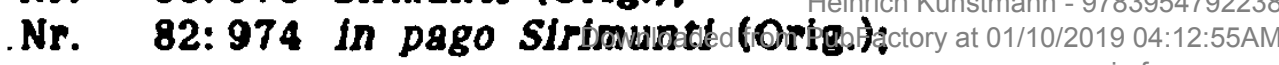




$$
\begin{aligned}
& \text { Nr. 91: } 974 \text { in pago Seremode (Orig.) } \\
& \text { Nr. 177: } 978 \text { in pago Zirmute (Orig.) } \\
& \text { Nr. 185a: } 979 \text { in pago Sirmuti (Orig.). }
\end{aligned}
$$

MGH DO III Nr. 26:986 in pago Zirimudis (Kop.v. Ende d. 14. Jhds.);

Nr. 102: 992 in pago Sirimunti (Orig.)!

Auffallend an diesen Belegen ist, wie schon Naumann (1961, 822) erkannte, daB anfangs die Formen aup - nti vorherrschen, ab 973 die ohne - $n-$. In diesem Zusammenhang ist noch jener ON Sermuth zu erwähnen, der als Klein- und Groß-Sermuth im Kreis Grimma vorkommt und an der Mündung der Zwickauer Mulde in die Freiberger Mulde liegt. Die Belege dieses ON setzen freilich erheblich später ein, d.h. erst ab dem Ende des 13. Jhds.: 1286 Sermút, 1331 Sermut, 1340 Sermút, 1373 Sermuth, 1368 Czeremut. 1404 Sermud, 1420 Sermut u.a. (nach Naumann 1962, 187 f.). DaB in diesem Fall der Typ -mut, also ohne - $n$ - zugrunde liegt, machen die Notierungen deutlich. Wie Naumann $(1962,188)$ und Eichler $\left({ }^{2} 1962,54\right.$ (.) vermutet haben, könnte es sich um Obertragung des Landschaftsnamens Serimuntl auf den ON Sermuth handeln. Unentschieden bleibt dabei aber die Frage, ob die Entnasalierung von - munti> -muth ein ags. bzw. nd. oder ein slav. Prozeß war, auch wenn Naumann mehr für dle letztere Möglichkeit plädiert ${ }^{2}$.

Hier interessiert in erster Linie die Etymologie des Landschaftsnamens Serimunti, den Eichler und Witkowski (in: Herrmann 1974, 9; 1985. 11) zusammen mit Daleminci und Rochelinze als "vorslawischen Namen" bezeichnen. Auch Naumann (1961, 823) glaubt. Serimunti und Sermuth einer "vorslawischen Sprachschicht" zuweisen zu müssen. Die Etymologie von Serimunti hat eine alte Tradition. sie beginnt im Grunde mit Safarik (1837. II, 912), der dafür die Formen Zirmunti, Zirmunty ansetzte, diese mit litauischen ONn wie Zirmuny. Zirmunty verglich und so - völlig unbegründet - aur den mask. PN Zirmunt schloB. An einen PN dachte auch Hey (1893, 218), der im ersten Glied ein zbrb (poln. zer), aksl. łeéti 'schlingen, fressen' und im zweiten ein asl. matiti, ac. mutiti, nc. moutiti 'herumrühren' vermutete. was zusammen einen PN Zeromut ergebe, der - quelle Idée! ein 'Kind. weiches im Essen herumrührt' bezeichne. Am Landschaftsnamen Serimunti hat immer wieder der für das sorbische Sprachgebiet uberraschende Nasal - $p$ - in vermeintlichem -mpt- lasziniert, so etwa Brückner

1 Nach Naumann 1961, 822.

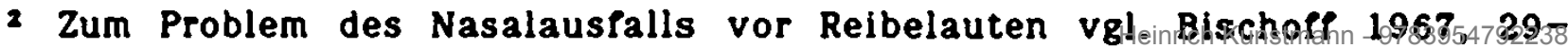
34. $226 \ell$. 
(1922/23, 389), der - munti zu -mąt (poln. Przemet, cech. Olo-mut-ici) stellte. oder Schwarz (1929, 133), dem ebenfalls eln mit -mpts geblldeter PN vorschwebte.

EIne vőllig neue Oberlegung brachte dann P. Knauth' In dle Diskussion. Indem er den Namen als .Mündung der Sarja, eines Teils der unteren Mulde" erklärte, welcher Ansicht auch Vasmer (1971, II, 697, 804) beitrat. Unklar bleibt dabel jedoch, ob es den Namen Sarja In diesem Zusammenhang uberhaupt je gegeben hat. Rudnicki (1959-61, II, 186) sah in ersten Teil des Landschartsnamens den 1dg. Stamm 'ser-, im zwelten dagegen ein -mpt-: "mpt-. das er zum poln. Typ Ostro-mp/pcko stellte und so fur Serimunti auf eine Form Sierimpt kam. Auf Schwarz gestūtzt, hielt Schall (1963, 390) Serimunt fur eine aus dem Balto-Slavischen herzuleitende Bezeichnung fur 'Wasser-Wirbel', die sachlich sehr zutreffend sel, da es um die Einmündung der thüringischen Saale in die Elbe geht. Die bisher umPassendste, hỏchst gelehrte und von profunder Materialkenntnis zeugende Arbeit zum gegebenen Problem ist Jedoch Horst Naumann (1961) zu verdanken. der von einer germ. Porm - Ser(l)-munt(h) ausgeht, die angeblich die Bedeutung 'Mündung annăhernd glelcher Flüsse' gehabt habe. Naumann hält - Ser rar die Bezeichnung eines FluBabschnittes bei gleich großen Flüssen. wogegen schon Fischer (1967, 110) zu Recht einwendete: „Solch eine Bezelchnung ist bel Serimunt und Sermuth, das am ZusammennuB von Elbe und Mulde liegt, nicht erhalten" (vgl. auch Fischer. Schlimpert 1971, 674). Verschiedene Male hat zum Problem auBerdem Elchler Stellung genommen (21962. 54 l.: 1966, 19): selne Hypothese läuft im Grunde auf eine germanische Herkunft des ganzen Namens hinaus. wobei far inn die idg. Wurzel 'ser- 'nießen' klar ist; unklar bleibt jedoch, ob im 2. Glied eine Entsprechung zu altsăchs. muth 'Mund', altfries. mutha 'Mündung' zu suchen ist oder nicht. $Z u$ guter Letzt sel noch jene alte, volllg abwegige Etymologie erwăhnt, die Serimunti mit Saramati gleichsetzt". Davon leiten sich dann die Fehlübersetzungen von Havlík (1964, 61: Sarmaté) oder Pritsak (1981, 688: Sarmatians) her.

Die bisherigen Deutungen zeigen, das die Etymologie von Serimunti weiterhin offen ist (ăhnlich Popowska-Taborska in SlowstarSlow $v, 148$ ). Auch Naumanns vielversprechende Hypothese von $\operatorname{Ser}(l)$-munt(h) $=$ 'Mündung annăhernd gleicher Flüsse' krankt letztlich daran, daß elne derartige 
Bezeichnung einfach unbekannt ist. Trotzdem, das sei vorweggenommen. kommt Naumann (1961, 823) der Wahrheit noch am năchsten, nicht eigentlich mit seiner Etymologie, sondern mit dem Verdacht, es kōnne „sich bei Serimunt um einen nichtslavischen Namen mit volksetymologischer Umdeutung...handeln". Und wenn Fischer (1967, 110) meint, "die Form -munt könne nur durch Volksetymologie erklärt werden". so trifft auch er den Kern der Sache.

Auffallend an den zitierten Belegen des Landschaftsnamens SerimuntI ist, daß die überwiegende Mehrzahl der Notierungen die Endung - $t$ aufweist. Dies legt nahe, daB - ti den Nominativ Pluralis des slavischen Suffixes $-b c b(<-b k o)$, d.h. $-b c i$ vertritt. Die stimmlose dentale Affrikata $c$ (ts) des Slavischen wird vor hellem Vokal $-i$ nicht selten mit Hilfe des lateinischen Graphems - ti ausgedrückt. Diese Praxis gilt auch für das Althochdeutsche, vgl. die Nortabtrezi und Osterabtrezi des Geographus Bavarus, für die bekanntlich $-a b(0) t r(i) t j z u$ lesen ist. Die ahd. dentale Affrikata $z$ in -abtrezi spiegelt somit den lat. Nom. Pl. Abodriti = slav. Abodricl wider. Für die lat. Vertretung - ti von slav. -ci gibt es unzählige Beispiele, vgl. den Stammesnamen der slav. Wilzen, der, in zeitgenössischen deutschen Quellen Wiftzi. Wilzi. Wiltze oder Wilci geschrieben. In lateinischen Annalen meist mit Wilti wiedergegeben wird: cum wiltis et Abodritis (Ann. poetae Sax.): Sciavi, qui dicuntur Wilti (ex chronico Moissiacensi): Wilti genere (vita Hludovici imp.) (alle nach Glossar A 1. 7, 14). Ganz ähnlich: Dalamanci (Widukind 27, 10; Hs. A: Dalamanti, später -ci): Dalamantiam (Widukind 29, 25 und 50, 1: Hs. B 2 a: Dalamanciam): Sclavi, qui vocantur Dalmatil (= Daleminci; Ann. Fuldenses 94). Die Beispiele sind so zahlreich, das die Vertretung von slav. -ci durch lat. - ti in mittelalterlichen Denkmălern als găngige Norm erscheint.

Gesonderte Beachtung verdient nun der Vokal - $u$ - in der Pănultima des Landschaftsnamens Serimunti. Man hat. wie schon gesagt. in - $u$ - immer wieder den slavischen Nasal - $p$ - vermutet. Abweichend von dieser Ansicht sel nunmehr gesagt, daß man - $u$ - hier als Reflex des slavischen Halbvokals $-b-2 u$ verstehen hat. Diese nicht unbegründete Behauptung låkt sich durch Beispiele belegen. So etwa geht der Stammesname der Serben/ Sorben auf urslav. 'ssrbs ( 'ș̣bs) zurück; der darin enthaltene Halbvokal der vorderen Reihe, also b. wird bei Fredegar (155, 10) durch - u-vertreten: gente Surbiorum. Hierher gehört auch Fredegars (157, 15) dux Wallu-

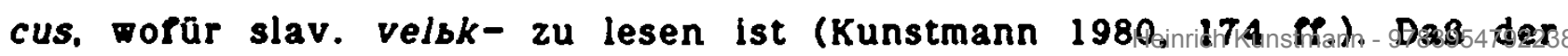


dem Deutschen und Lateinischen fremde Halbvokal b als dunkler Vokal $u$ oder 0 gehört und wiedergegeben werden konnte, machen auch viele weitere Beisplele deutlich: Slavi Surbi (Ann. poetae Sax. zu 789), Surbi (Ann. Mett. priores zu 789), Sciavi Surbi (Chron. Reginonis zu 780) (Glossar A I 9.

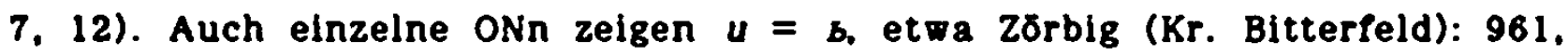
1009 Zurbici, 1015 Curbici, 1156 Zurbice, 1207 Zurbeke; ăhnlich: 1136 provincia Swurbelant (Kop. 15. Jhd.) (alle nach Eichler ${ }^{2} 1962,111 \mathrm{KP}$.).

Beide Oberlegungen zusammen ergeben, daB sich hinter - unti nichts anderes als der Nominativ Pluralis des zusammengesetzten slavischen Suffixes -bnbci (Nom. Sing. - bnbcb) verbirgt, ein Suffix also, das Herkunft oder Zugehörigkeit ausdrückt, aber auch zur Ethnikabildung dient. In Serimunti liegt somit eine ahnliche Bildung vor wie in dem von der Sprachwissenschaft ja ebenfalls verkannten slavischen Stammesnamen der Dal(b)mbnbci 'Dalmatiner' (vgl. S. $161 \mathrm{fP}$.). Wenn in diesem Zusammenhang behauptet wird. das Suffix -bc (sic) sel dem Altsorbischen nicht bekannt (Eichler '1962. 46), dann wird das durch die "neuen" Tatsachen widerlegt. DaB das Suffix -bnbcb weder in Dal(b)mbnbci noch in 'Serimbnbci eine Ausnahme darstellt, zeigen auch verschiedene andere slavische Ethnonyme Mitteldeutschlands, deren Bildung von der Sprachwissenschaft nur noch nicht durchschaut wurde, so z.B. Rochelinze oder Bechelenzi (ex chron. Moissac. zu 811). rür die zweifelsohne Rochel-bnbci bzw. Bechel-bnbci zu lesen ist. Im Fall der 'Serimbnbci hat außerdem, das steht außer Frage, eine volksetymologische Eindeutschung stattgefunden, d.h. die unverstăndliche Endung - mbnbci wurde mit der verständlichen Bedeutung -mündung in $\mathrm{Zu}$ sammenhang gebracht. So ist Serimunti im Grunde aberhaupt kein Landschaftsname. sondern ein die Herkunft bezeichnender Völkerschaftsname, der im Laufe der Zeit, nachdem die ursprüngliche Bedeutung verlorenging. eben auf die Landschaft übertragen wurde.

Ahnllch wie im Fall der aus Dalmatien stammenden Daleminci hat man auch bei den Serimunti bislang die etymologische Zăsur falsch gesetzt, well man das slavische Suffix -bnbci nicht erkannt hat. DaB man 'Seri-mbnbci statt - Serim-bnbci trennte, geht in erster Linie auf das volksetymologische Konto (-mündung). Somit bleibt dle Bedeutung des ersten Telles des Wortes zu klären. Was bedeutet Serim-? Dies zu erraten, fallt eigentlich nicht mehr schwer, denn es kann sich im Grunde nur um den Namen der alten

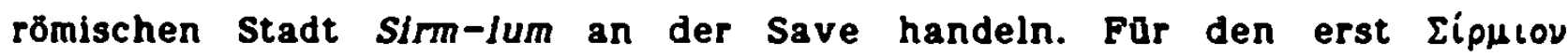

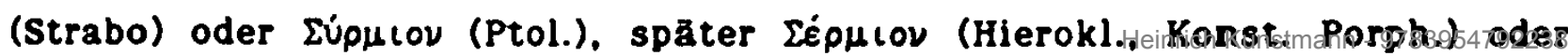


Eepueiou (Theoph.) geschriebenen Ort der Pannonia Inferior wird seit dem 5. Jhd. aberwiegend die Version Sermium gebraucht, was auf einen vulgärlateinischen Lautwechsel von $i>e$ schließen 1āBt (Mayer 1957-59, I. 307: II. 135, 146 f.). Daraus ergibt slch weiter, daß die Slaven nicht alteres Sirmium, sondern jüngeres Sermium als 'Serms übernommen haben (Melich 1929. 110) und durch Liquidametathese zu 'Srëms gemacht haben (Schramm 1981. 166 .). Bekanntlich hat sich diese Form in der Folge zu kroatisch Srijem, Gen. Srijêma (ekav. Srêm, ikav. Srîm) weiterentwickelt (Skok 19714. III. 320).

In den anhaltischen Serim-unti scheint sich sowohl altes slavisches - Serm(z) als auch die bereits umgestellte Version 'Srém( gen. Es spiegelt sich darin gewissermaßen der Zustand vor und nach der Liquidametathese. Das fast wie ein 'polnoglasie' wirkende Serim- ist für das mitteldeutsch-slavische Sprachgebiet kein Einzelfall. Ahnliches begegnet in dem Landschaftsnamen Colodici, Colidicl, neben welchem der ON Colditz steht (Naumann 1961, 825). Möglicherweise gehören auch dle Talaminzi, Deieminzi mit ihren Nebenformen Talmenze. Dalmince hierher. Das nåmliche Phānomen liegt vermutlich außerdem in den Völkerschaftsnamen Zeriuani und Serauici des Geographus Bavarus vor. vgl. S. 177, 185. Doch begegnet die ragliche Blldung auch anderwärts, so beispielsweise als in Seremo in der lateinischen Dukljanin-Chronik (317) oder in altungarisch Szerem (jünger Szerém: Melich 1929. 110 N.: Kniezsa 1963. 34). Orrenbar kommt diese Bildung vorwiegend unter gemischtsprachigen Verhaltnissen zustande.

Noch ein Wort zum săchsischen ON Sermuth. Ob es sich bei lhm um Obertragung des vermeintlichen Landschaftsnamens Serimunt/ handelt, wird sich ebensowenig beantworten lassen wie die Frage, ob in Sermuth wirklich das - $n$ - ausgefallen ist. Realistischer scheint die Annahme einer anderen sufflxalen Bildung zu sein, und zwar die mit einfachem $-b c b=\cdot s e r m b c b$.

Serimunti verweist in Wirklichkeit also auf 'Leute aus Sermium. Sermienser', auf slavische Zuwanderer aus dem Save-Donau-Geblet. In die Problematik um die slavische Besiedlung des sorbischen Altsiedellandes zwischen Saale. Mulde und Elbe bringt diese Feststellung gewiB einen neuen Akzent. Die Einwanderung von Slaven aus dem alten Sermium in das Elbe-Saale-Geblet ist ein analoger Vorgang zur Immigration von Slaven in das Gebiet sudlich von Posen. DaB der polnische ON Srem. dtsch. Schrimm. 
und andere polnische Toponyme tatsåchlich auf slavische Zuwanderung vom Balkan schließen lassen. wurde bereits gesondert gezeigt (Kunstmann 21984, 317 (f.) $)^{5}$.

- Vgl. dazu ferner H. Kunstmann: Gniezno und Warta. In: Dle Welt der Slaven 32, 1987, 302 fl.: ders.: Die balkansprachlichen Grundlagen eini-

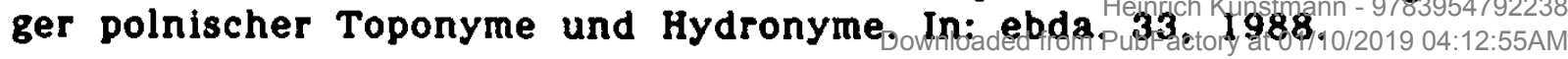




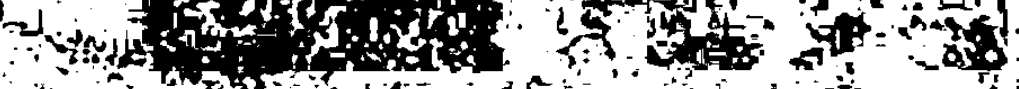

-4 की
sin

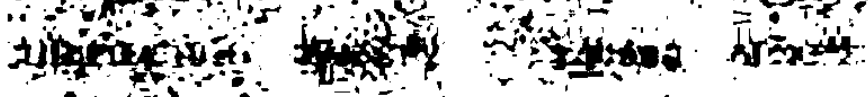

$$
\text { not }
$$

ond of

a

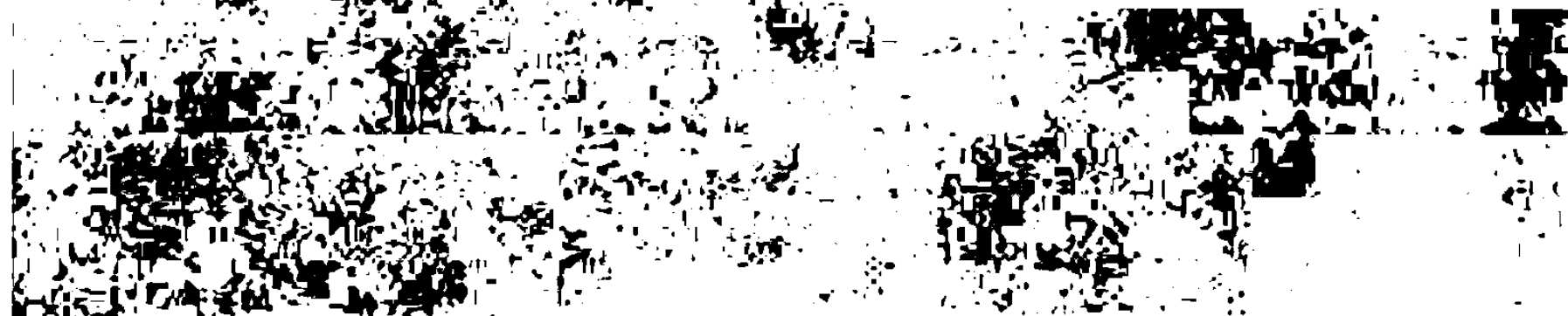

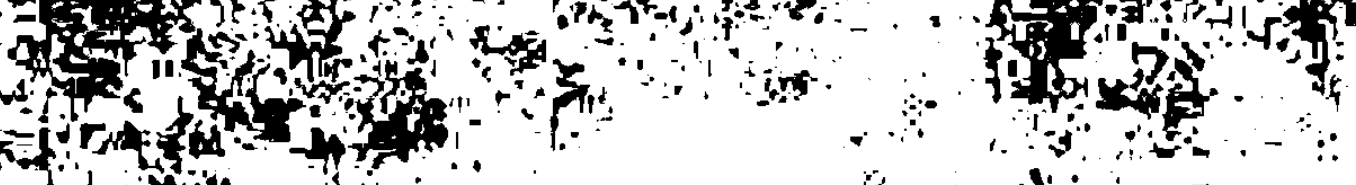

P.t.

ing

$\because 4$

(1)

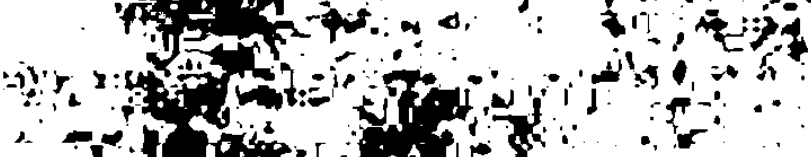

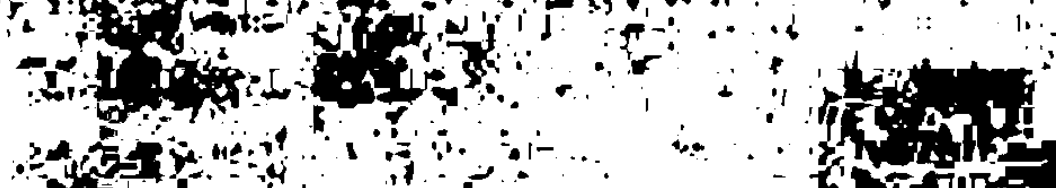

and

of

(x). I

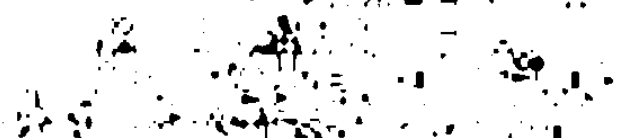

Ato

Hot

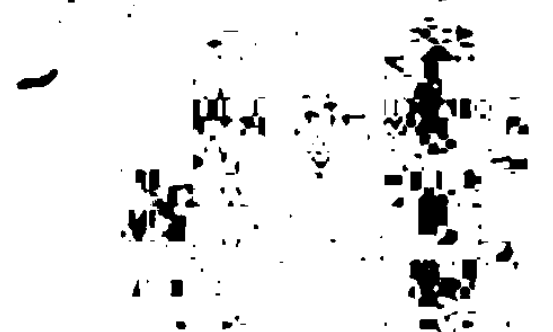

hive

龺

8

$\$$

and

man a

ats

$\operatorname{loc}_{40,0}$

$\rightarrow$ If 
20. Scheuder bei Dessau

Südwestlich von Dessau. Kr. Halle, und östlich von Köthen liegt der kleine Ort Scheuder. dessen Namen Elchler für "vorslawisch" hält (Eichler 1968, 124). "Vorslawisch" ist nach Eichler ein Sammelbegriff far Sprachschichten. die dem Slavischen vorangegangen sind, also für Germanisch, Keltisch oder uberhaupt für Alteuropäisch sowie Indoeuropăisch (ebda. 118). Daß man im Raum zwischen Saale und Mulde, der zum Kerngebiet des altsorbischen Westnügels zăhlt, eine altertümliche Namengebung erwarten kann, ist raglos richtig. doch hat Scheuder weder mit dem Germanischen noch dem Keltischen etwas zu tun, auch läßt es sich nicht gut zum Alteuropäischen rechnen, doch hängt es, wenn auch in einem anderen Sinne, mit dem Indogermanischen zusammen. Scheuder erweist sich als ein besonders anschaullches Beispiel dafür, wie der oftmals in die Irre führende Begriff "vorslawisch" den Blick far die Deutung scheinbar unlösbarer Toponyme verstellt.

Mangels besserer Informationen müssen die von Eichler (ebda.) mitgeteilten Belege für Scheuder ausheifen: 1314 Scudere, 1320 Scudere, 1335 Skudere. Mehr als diese drei, noch dazu spat einsetzenden Notierungen scheint es vorerst nicht zu geben. Allerdings gibt es auch keine nennenswerten Lösungen, denn „vorslawisch" heißt ja doch: alles unklar. Deutung so gut wie ausgeschlossen. Auszuschließen war eine Deutung in der Tat. solange man nicht erkannte. daB die Slaven Nord- und Mitteldeutschlands vom Balkan zugezogen waren. Erst diese Erkenntnis öffnete die Augen fur die Erklärung verschiedener unklarer, eben "vorslawischer" Orts-. Landschafts - und Stammesnamen.

Scheuder erklärt sich als die überraschend gut erhaltene Vertretung von slav. 'Skzdr-, das aus romanischem Scodra, Exódpa entstanden und als alban. Shkodër, serbokroat. Skadar, ital. Scútari bekannt ist'. Tell die Slaven in der ersten Silbe ein - - - substituierten, laBt sich vermuten, daB sie. wie Schramm (1981, 362 1.) es ausdrückt, eine regionalbarbarische Form ubernommen haben, die, ahnlich wie Doclea > Duklja oder -Tocla > Tuklaca (ebda. 240), von romanisch Scodra > slav. 'Sk $\bar{u}_{2} d r->$ 'Skbdr- und

1 Teigand 1927, 96: Mayer 1957-9, I. 315 f., II. 107 P: Popoyik 1958.

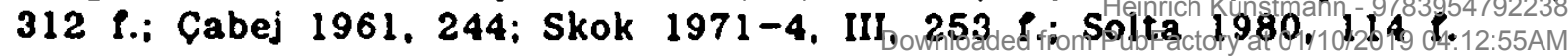


Skadar fuhrte (Schramm 1981, 118) ${ }^{2}$. Im Grunde geht es hier also um elne Form der Romanisation, die gerade in der Gegend um Lissus und Doclea. also zu beiden Seiten der heutigen Nordwestgrenze Albaniens festen FuB gefaBt hat (ebda. 240).

Zur Entstehung des ON Scheuder gibt es nun eigentlich kaum mehr etwas zu sagen. DaB anlautendes $s k$ - von Scodra im Deutschen uber skzu sch- ( $\xi)$ wurde, ist hinlänglich bekannt. Der Diphthong - eu- ist mit großer Wahrscheinlichkeit EinfluB des Polabeslavischen, das $u$ In aller Regel zu eu diphthongiert, vgl. gleupè, cheude, meucho, l'eudi usf. (Vondrák I. 126).

Scodra, am Südostufer des Skutarisees gelegen, war in vorrömischer Zeit Zentrum des Illyrischen Stammes der Labeaten ${ }^{3}$, danach Hauptstadt des illyrischen Königreiches`. Durch die Teilung Dalmatiens unter Diokletian wurde Scodra Hauptstadt der provincia Praevalitana, spăter gehörte es zur byzantinischen Provinz Dyrrhachion. Scodra war somit eine bedeutende und wichtige Stadt, das ergab sich allein aus deren Lage an der altesten, von den Römern angelegten Küstenstraße, die „Salona mit Tragurium, Scardona und Jadera einerseits. Salona mit Narona und Scodra anderseits verband" (Tomaschek 1880, 497). Die letzte Nachricht uber den in Scodra seit dem 4. Jhd. bestehenden Bischofsitz stammt von 602, danach herrscht Schweigen. was gewiß mit der Zerstörung der Stadt während des großen Ansturms von Awaren und Slaven in Verbindung steht. Die Anwesenheit von Slaven in der näheren Umgebung von Scodra ist angeblich seit dem 6 . Jhd. bezeugt, auch nimmt man slavische Siedlungskontinuität bis ins 11. Jhd. an (SlowStarSlow V. 188 f.: W. Soboda). In anhaltischem Scheuder spiegelt sich somit der Name elner bedeutenden illyrisch-römischen Balkanstadt wider.

2 Anders Popovic 1958, 313, Pür den Scutarum, Scutari auch als volksetymologische Anlehnung an scutarius 'Schildträger, macher' oder byz. oxourápios zu erwägen ist.

3 Der Reflex dieses Stammesnamens in dem nordwestrussischen Hydronym Lovatb bestätigt nicht nur die "Streuung" der slavischen Wanderung vom Balkan nach Nordwest- und Nordosteuropa, sondern verweist auch - zusammen mit weiteren Argumenten - auf gewisse namentliche Berührungen zwischen Ilmen- und Skutarisee (Kunstmann ${ }^{2} 1985,390$ ff.).

- Einige Eorscher wollen in den ersten Bewohnern von Scodra Thraker sehen, vgl. Fluß in Pauly RE II. 3. Hbbd. 1921,828 \%. Aus der Dacia Mediterranea ist in der Tat ein Ort Exospia bekannt. weshalb Detschew 1957. 459, das praevalitanische scodra für einen Bemeis dep $_{\text {th }}$, Testausbreitung hält. Umgekehrt denkt Krahead 935, 96 , 


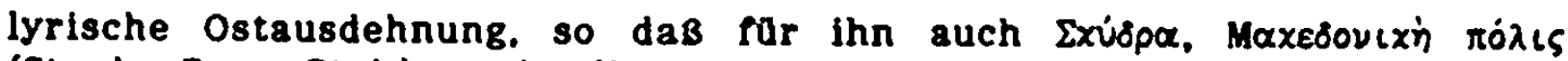
(Steph. Byz.: Ptol.) sowle die regio Scodrihensis in Dacien und das in

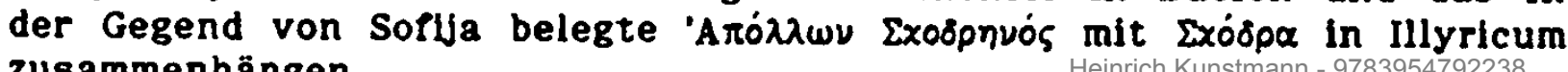
zusammenhängen. 



\section{Nisane und Nizizi}

Der Name Nisane ist die slavische Bezeichnung für eine an der Elbe um Dresden. südöstlich der Daleminci gelegene Landschaft'. Der Name muB aber nicht, wie oft angenommen (SlowStarSlow III. 407: J. Nalepa), ein Ethnonym sein, er kann ebensogut aus einem alten slavischen Insassennamen hervorgegangen sein. $A b$ der 2. Hälfte des 10. Jhds. ist er verhältnismäBig gut belegt:

948 duarum regionum Behem et Nisenen (DO I, 437, unecht, 12. Jhd.): 968 Nisinen (ebda. 449. Transsumpt von 1250); 971 Nisane (ebda. 406, Orig.): 996 Nisenin (DO III, 186, Orig.): 1012/18 (2u 984. 1004) Niseni. Nisani (Thietmar IV, 5. VI, 10); 1013 in Niseni (DH II, 269, Orig.): 1068 in pago Nisani (DH IV, 212. Orig.): zu 1083. 1112 Nisen (Annal. Pegavienses) ${ }^{2}$.

Die Behauptung. in Nisane liege kein Stammes-. sondern ein Insassenname vor. stützt sich auf die Beobachtung. daß das vermeintliche Ethnonym mutatis mutandis mehrere Male an geographisch verschiedenen Punkten aufscheint. ohne daß es sich dabei um Stammes-oder Landschafts-. sondern eben um Ortsnamen handelt:

1. 1251 Nisene; 1314 villa Nysen; $1346 / 1495$ Neisen, Neissen: 1367 Nysenne. Heute NeuBen, südlich von Belgern ${ }^{3}$;

2. 1293 Neisen; 1393 Neysen; 1408 Neysein; 1520 Eyssen (sic). Heute Naisa bei Bamberg":

3. etwa 1370-1397 Nytzane villam. Heute Nitzahn im Krels Jerichow II $^{3}$ :

4. 1319 de Nezene: 1322 de Nytsene: 1327 de Netzene: 1328 Nitcene. Name eines abgegangenen Dorfes bei Köslin".

Auch die Nizizi (SlowStarSlow III. 408: J. Nalepa) gelten im allgemeinen als ein slavischer Stamm, dessen ziemlich ausgedehnter Bezirk sich die Elbe entlang von Belgern bis zur Muldemündung hingezogen haben (Heßler 1957. 24 (f.) und Grenzmark gegen die ostlichen lausitzischen Gaue gewesen sein soll (Helbig 1960, 34). Dank einer günstigen Urkundenlage ist auch der Name Nizizi zurriedenstellend belegt:

1 Mit ausführlichen geschichtlichen Daten Eichler. Walther 1970. Zur archåolog. Selte Coblenz. W. ${ }^{2} 1977$.

2 Nach Eichler '1962, 359 und 1966, 14.

3 Nach Eichler '1962, 359.

- Nach Zlegelhofer, Hey 1911, 14; Schwarz 1960. 272.

- Nach Trautmann 1949, 104.

- Nach Górnowicz 1976. 48. 
965 de provintia Sciavorum Nizizi nominata (DO I. 446, unecht. 11. Jhd.): 965 Nicicl (ebda. 303, Kop. 15. Jhd.); 973 Nidkike in quo Beigora (DO II. 30, Orig.): 981 in pago Nikiki vel Mezumroka dicto (ebda. 195, Kop. 12. Jhd.); 996 Nizizi (DO III. 186, Orig.); 997 Nizizi (ebda. 244, Orig.); 1004 provintia Nizizi (DH II. 88. Orig.): zu 1018 Nicici (Thietmar VII, 22); 1069 in pago Niciza (DH IV, 224, Orig.): um 1073 in pago regioneque Nietci (ebda. 149)?

Der Name der Nisane bereitet, wie es scheint, keine etymologischen Schwierigkeiten, da der Bezug zu slav. nizb 'unterer Teil; abwărts' von Anfang an fur viele Etymologen so naheliegend und eindeutig war, daß einfach keine anderen oberlegungen aufkommen konnten. So wurden denn die Nisane $\mathrm{zu}$ 'Nizane, das heiBt $\mathrm{zu}$ 'Bewohnern einer Niederung' (Eichler 1962, 359; 1966, 14; Schwarz 1960, 272; Górnowicz 1976, 42). Niederles Schreibweise Nißané statt Niżane (III, 120) wird daher als angeblich nicht der Oberlieferung entsprechend mehrmals von Eichler gerügt.

Etymologisch nicht ganz so unkompliziert wie die Nisane ist hingegen der vermeintliche Stammesname der Nizizi, den Eichler sowohl zu slav. nic 'abschüssig. steil'. vgl. poln. nic 'li. Seite des Tuches'. weißruss. nic 'Rückseite' stellt, als auch mit siav. 'nik-, niknpti 'sich senken', vgl. cech. poniknouti 'sich beugen', ponikva 'Ort, wo das Wasser in der Erde verschwindet' in Beziehung bringen möchte. Eichler räumt allerdings auch Urverwandtschaft mit niz ein. so daß sich unter Nizizi letztlich wiederum Nisane 'Bewohner einer Niederung' verstehen lassen (Eichler 1966, 14). An eine Form Nizici in der nämlichen Bedeutung (mieszkathcy niziny) dachte der poln. Linguist M. Rudnicki (1961, 184), der damit gegenüber Nizici einen Unterschied macht.

Die Belege Nikiki (981) und Nidkike (973) wirken auf den ersten Blick ungewöhnlich, sie sind Praglos jedoch dem mitteldeutschen Zetazismus (Bathe 1960) verpnichtet, was indes nicht unbedingt, wie Eichler meint. darauf schlleßen låßt, daß sich hinter den Graphemen - $k$ - bzw. - dk-die Lautwerte $c$ oder $c$ verbergen. Immerhin steht $k$ nicht selten fur $z$ vgl. Biderike/Biderize, Salebeke/Salebize, Colebeke/Colebize usf. (Bathe 120 f.). Für Nikiki und Nidkike kann also ohne weiteres ebenfalls Nizizi (bzw. Nizize) gelesen werden.

Es făllt auf, daß Bewohnernamen wie Nisane bzw. Nizici bei den Siaven in alter und neuer Zeit auBerordentlich selten. ja last unbekannt zu sein scheinen. Sle begegnen weder in Bohmen (Profous) noch in Măhren 
(Hosák. Srámek), aber auch Im Altpolnischen (Slownik staropol.; Slow. staropol. nazw. osob.) oder Serbokroatischen (Skok 1971-4; Gorner 1963) sowie in Russischen (Sreznevskij: RGN) und Altklrchenslavischen (Slov. Jaz. star.) ist der Typ bis auf wenige Ausnahmen offenbar nicht anzutreffen. Und von einer Verwendung gar als Stammesname kann uberhaupt nicht die Rede sein. Dabei låßt sich bei dem elementaren Begriff von Niederung u.a. doch erwarten, daß der Typ produktiv geworden wäre. Auch wenn die Dinge hier nicht im einzelnen zu untersuchen sind, scheint es, daB die slavischen Sprachen zur Bezeichnung von Niederungen und deren Bewohner andere Grundwörter bevorzugen, so 2.B. das Tschechische, das hierfur insbesondere dül verwendet (Profous V. 530), vgl. 'Dol'ane 'Talbewohner' (poln. Dolany) als Oppositum zu 'Vysecane. -Vysocane bzw. 'Vyshane 'Bewohner einer Höhe' (Eichler '1962, 360, 365).

AuBer der unbestreitbaren Tatsache. daß der Typ - Nizane im Slavischen nicht produktiv geworden ist, gibt es ein weiteres Argument. das gegen die Deutung von Nisane als 'Nizane 'Bewohner einer Niederung' spricht, und dies ist In erster Linie morphologischer Natur. Im gegebenen Fall ist nămlich nicht die Form - Nižane, sondern vielmehr - Nižnjane o.ä. zu erwarten, das heiBt eine Bildung vom Adjektiv aksl. nizbnb. Pl. nizbnil 'inferior(es), untere(r)' (Slov. Jaz. star. II, 423 \%l.; Miklosich EWB 216. ders. Lex. 449). Dieser regelgerecht gebaute Typ - Niznjane liegt vereinzelt vor. so etwa in den karpatoukrainischen ONn Niznjane. die Ortsteile von Zaluź'je (Kr. Mukacevo). Bereznoje Maloje (Kr. Vel'ký Berezný) und Rokitovcy (Kr. Medzilaborce, Slovakei) bzw. eine Siedlung von Bukovec (Kr. Svalova) bezeichnen (RGN VI, 170). Dabei scheint es sich jedoch um neuere Bildungen zu handeln.

Aus obigen und weiteren Gründen fallt es schwer, an die Richtigkeit der Deutung von Nisane als Nizane 'Bewohner einer Niederung' zu glauben. Das trifft nicht nur auf die săchsischen Nisane, sondern ebenso auf die Ortsnamen NeuBen (Belgern). Naisa (Bamberg), Nitzahn (Jerichow) und Nezene (Köslin) zu.

Ausschlaggebend bei der Beurteilung von Nisane ist Ja doch. welchen slavischen Laut darin das $-s$ - vertritt. Unter dem suggestiven Eindruck des vermeintlichen Etymons nizs hat sich die etymologische Forschung von Anfang an auf - $z$ - versteift, ohne $z u$ bedenken, das das Graphem $s$ in fruher Zeit auch andere Laute vertreten konnte, so z.B. altsorbisches $s$ (Eichler. Walther 1966-7. II. 36 ll.. 41). Die graphische Yertretung von $s$ 
durch $s$ lăßt sich ohne Mühe nachweisen, man vergleiche auf daleminzischem Sprachgebiet beispielsweise Teslce $=$ Döschütz und Dösitz (く・Těs-). Borus u.a. = Borus oder Gohlis, Golus u.a. = Golus. Die nämliche Vertretung findet sich im havellandischen Polabeslavischen, vgl. etwa Roskow = Roskov, Päwesin $=$ Posin oder Weseram $=$ Vserąby (Fischer R. E., 1976. 286 f.). Da diese Vertretung von $s$ durch $s$ auch von fast allen anderen slavisch besiedelten Territorien Deutschlands bekannt ist, ist nicht einzusehen. warum Nisane hierbei eine Ausnahme bilden soll. Allerdings ist auch noch keinem Forscher - außer vielleicht Niederle - der Gedanke gekommen, hinter Nisane nicht Nizane 'Bewohner einer Niederung'. sondern Nisane 'Leute von (aus) Nis zu vermuten!

Wenn mit Nisane in Wirklichkeit Nisane gemeint sind, dann spricht das dafūr. daß unter Nizizi wiederum 'Nišci 'Leute von Niś' zu verstehen sind. da ja auch die Vertretung von $s$ durch $z$ nichts Ungewöhnliches ist. Sie ist nicht allein vom Sprachgebiet der Daleminci (Elchler. Walther 19667. II. 36; dies. 1975-8, II, 41), sondern ebenso aus dem Havelland gut bekannt (Fischer R. E.. 1976. 286 ff.). Damit wird letztlich offenkundig, daB die bisher unzutreffend etymologisierten Namen Nisane und Nizizi bei Licht betrachtet Slaven bezeichnen, die aus der Stadt oder aus der Gegend von Nis. dem antiken Naissus oder Naloob̧ der Rōmer und Byzantiner zugewandert sind.

Einige der mittellateinischen und mittelgriechischen Schreibweisen far Naissus lassen erkennen, wie sehr ihnen Nisane und Nizizi nahestehen: provincia Nisi et Vranisove (1198), Niz (1168), Niczh (Ende 11. Jhd.), Nissa: Nloos (Konst. Porphyr.: Anna Komn.). Nioos, Nñoos (byz.)• Der Wurzelvokal i zeigt dabei slavisierte Gestalt'. Als Bezelchnung für die Bewohner der Stadt Nis sind im Serbokroatischen die Bildungen Nisanin. Niseveanin. Niševljanin. Niševac. Pl. Nisevci (Skok 1971-4. II, 519) Im Gebrauch. Die ältere, wenn nicht älteste Form davon ist gewiß Nisanin, während im Fall von Nisevac. Nisevcanin usf. eine lautphysiologisch bedingte Erweiterung durch - ev- eingetreten ist, die einen unmittelbaren AnschluB des Suffixes - bcb an den palatalen Spiranten $s$ vermeidet. Da das Formans - bcb erwiesenermaßen zu den häufigsten Ortsnamensuffixen auf serbokroa-

- Vgl. weiter Pauly RE 16. Bd. 1935. 158 fl.: M. Fluß; Jirecek 1877. 87; Schramm 1981,308.

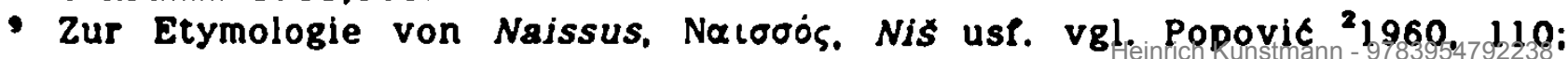

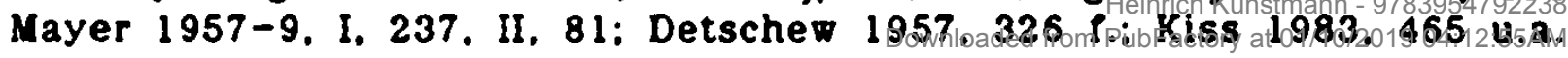


tlschem Sprachgebiet zăhit (Görner 1963, 42, 44 If.), ist anznehmen, daB es früher einmal auch einen nicht belegten Insassennamen 'Nišbcb. Pl. - Nišbi gegeben hat.

Naissus, Nalooós, das spätere Nis an der Nišava, war wegen seiner günstigen verkehrsgeographischen und strategischen Lage neben Serdica (Sofija) die wichtigste spätrömische und frühbyzantinische stadt der Provinz Dacia Mediterranea. Seit Diokletians Reform gehörte es zur neugebildeten Provinz Dardania. Naissus war Geburtsstadt Konstantins d. Gr., auch wurde die Stadt, wohl wegen ihrer vortremichen Befestigungsanlagen, verschiedene Male von römischen Kaisern aufgesucht. Naissus war wichtiger Verkehrsknotenpunkt an der Kreuzung von sechs Straßen, von denen die aus Sirmium (Mitrovica) kommende, über Singidunum (Beograd) und Serdica (Sofija) nach Konstantinopel fürende ohne Frage die bedeutendste war (Jirecek 1877, 87 If.: SlowStarSlow III, 402 P.: T. Wasilewski). 441 wurde die Stadt durch Attila verwüstet. doch von Iustinian I. zum Teil wieder aufgebaut. Mit einem Heer von nie zuvor gesehener Stärke uberschritten 550 die Slaven die Donau und gelangten durch das Tal der Morava bis nach Naissus, wagten es aber nicht, die Stadt anzugreifen, da Germanus. Magister militum per Thraciam. die römischen Streitkräfte befehligte. Erst mit Hilfe der Awaren gelang es dann den Slaven. um 616 die Stadt doch noch zu erobern. Sie lieBen sich im tiefer gelegenen Tal der Morava nieder und nannten sich seither Moravane.

Mit dem Namen Nisane und Nizizi. die typologisch exakt Lesane = - Lessane und Liezizi $=\cdot$ Ljšbci (vgl. S. 115 ff.) entsprechen, stellt sich den In Nord- und Mitteldeutschland namentlich nachweisbaren Städten Sirmium. Scodra, Lissus und Siris als weitere prominente Balkanmetropole nun auch Naissus, Nacooós, Niš an die Seite. 
(n)

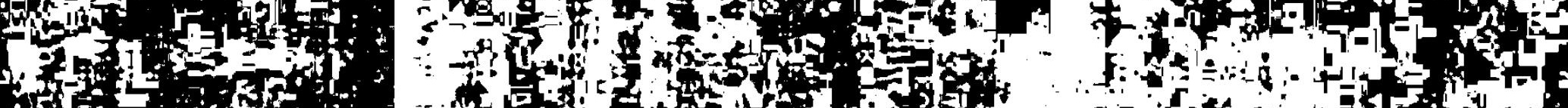

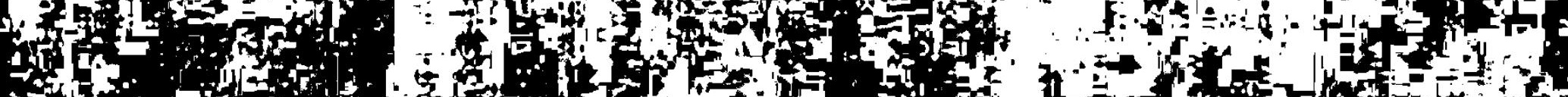
H

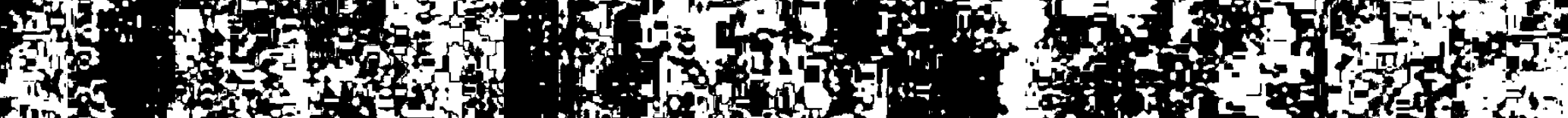

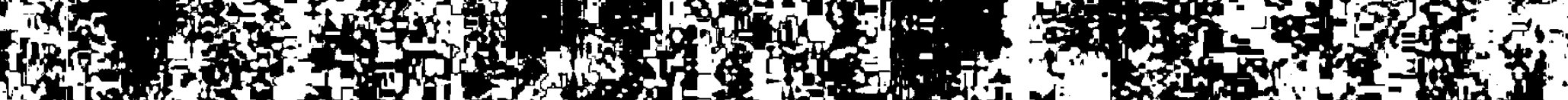

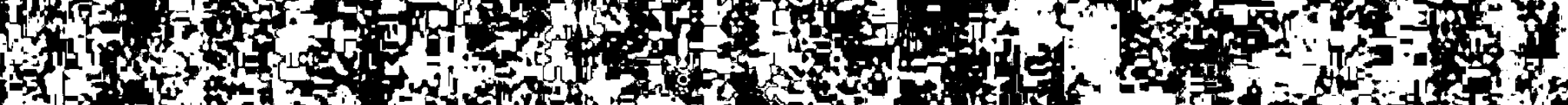
Bit

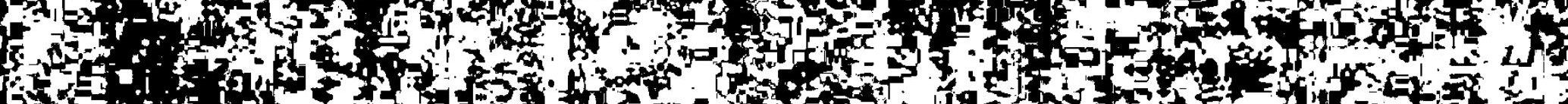

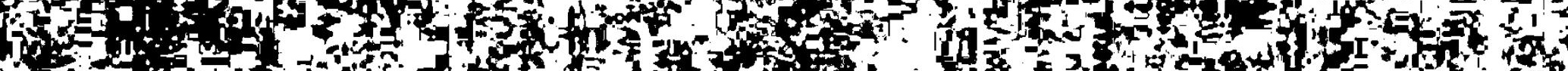
a

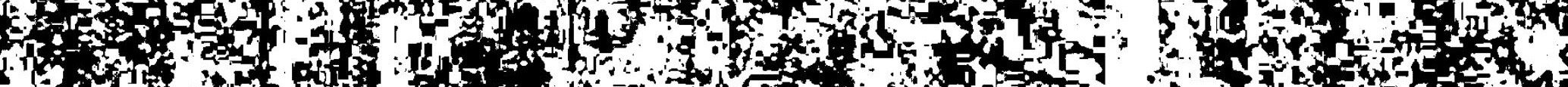

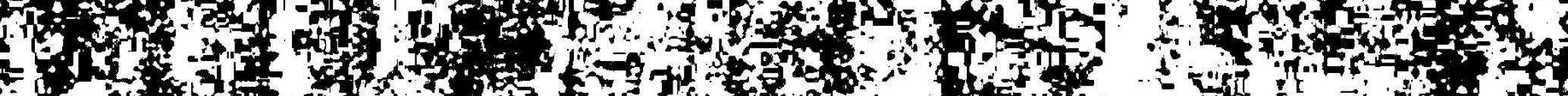

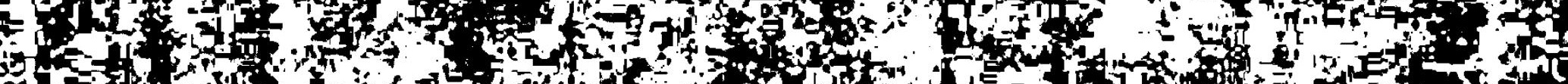

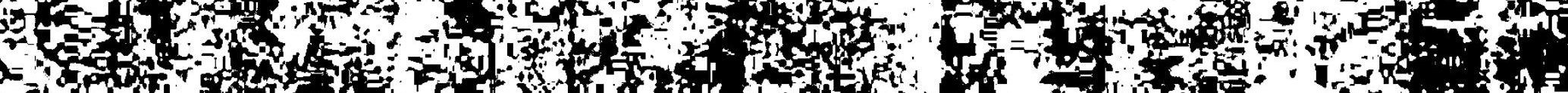

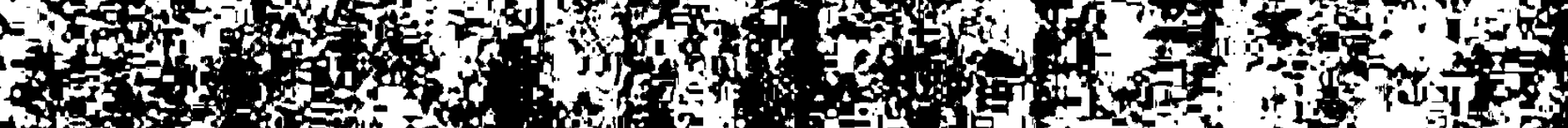
W. W. W.

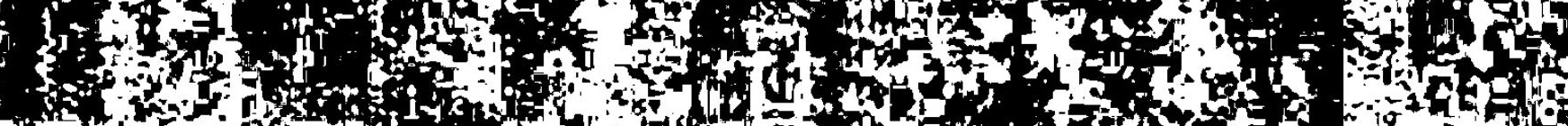

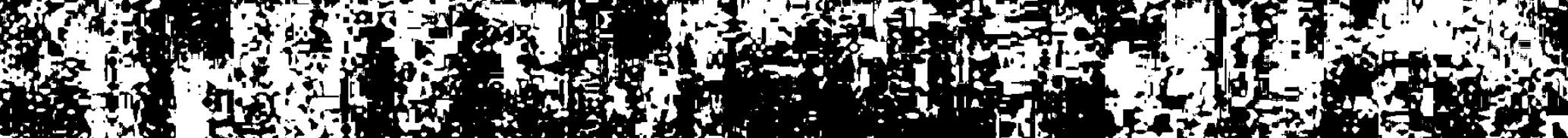
W 


\section{Jerichow}

Der mittelelbische Bezirk Jerichow wird als das Kerngebiet der slavischen Morizane angesehen. Von seinen 93 Stadt- und Landgemeinden sowie Gutsbezirken haben rund 72 slavische Ortsnamen, zu denen noch schätzungsweise 100 slavische Wüstungen kommen (Trautmann I, 22). Die Herren des rechtselbischen Landes Jerichow, die Jerichower, waren im 12 . Jhd. das bedeutendste Magdeburger Ministerialengeschlecht (Claude 1972-5, II. 267): man hat in ihnen sogar slavische Edle sehen wollen, was indes nicht $2 u$ belegen ist (Schulze, H. K., 1963, 148 P.).

Die Wiedergabe der historischen Belege für Jerichow folgt Brückner (1879, 35) und Trautmann (I, 101); auch wenn diese Daten der Präzisierung bedürfen, lassen sie doch einigermaßen die lautlichen Qualitäten erkennen:

1144 jerichow; $1144 / 59$ Jerchow: 1148 castrum et villa Jericho: 1173 de Jerichowe; 1183 iericho; 1224. 1293 jerichow: 1225 iericow; 1263 Jericho; 1295, 1370 iericho; 1317 jericohowe; 1424 ihericho.

Den Belegen ist eine erstaunliche Konstanz sowohl des Vokalismus als auch des Konsonantismus $2 u$ entnehmen. Der Name Jerichow, möchte man sagen, ist vom 12. Jhd. bis auf unsere Tage ohne nennenswerte Anderungen geblieben. Fast problemlos scheint auch die Etymologie dieses Toponyms zu sein: Spätestens seit Trautmann (I, 101) gilt Jerichow als Ableitung von PNn wie Jaroch oder Jerich. Damit steht man wieder einmal vor jenem so bellebten onomastischen Kunstgriff. schwer oder nicht Erklărbares auf Personennamen zu beziehen, ohne daß es dafür historische oder sonstige Gründe gibt. Skepsis gegenüber vielen solchen Deutungen ist begreiflich, auch im gegebenen Fall, in weichem nicht der geringste Hinweis auf einen Urahn Jaroch u.a. vorllegt.

Der PN Jaroch als Kurzform von Jaroslav ist mit seinen Varianten bei den Westslaven nicht selten, weshalb auch ein hăufiges Vorkommen des Ortsnamentyps Jerichow zu erwarten wăre. Doch das Gegentell ist der Fall: Bei den Tschechen finden sich uberhaupt keine Beispiele (Profous) und bei den Polen offensichtlich nur wenige (Slow. starop. nazw. Osob.)' Ein ande-

1 Fraglich ist. ob die russischen ONn Erichi (Gouv. Vjatka; poln. Jerychy), Erichino (Dorf 1. Gouv. Vologda), Erichova (Gouv. Smolensk) sowle die beiden Erichovo (Kr. Jaroslavl' u. Smolensk) überhaupt hierher gehōören (RGN III, 231). Erichovo ist von dem Arghäologen J $_{0}$ Fa 
rer Einwand gegen elne Herleitung von Jerichow < Jaroch ergibt sich aus dem - 1 - der 2. Silbe, da ja ein Wandel von $0>1$ aur Schwierigkeiten stöBt. Daß -1 - in Jerichow ursprünglich war, ist wahrscheinlich, dafar sprechen auch die wohl durch Vokalschwund $\mid>b>$ entstandenen Belege wie Jarchow. Diese und weitere Gründe lassen den Verdacht aufkommen. daß Jerichow überhaupt nichts mit dem Kurznamen Jaroch u.a. zu tun hat.

Mitteldeutsches Jerichow assozilert auf den ersten Blick natürlich den Namen der biblischen Oasenstadt Jericho. mit der die Slaven aber gewiB nie in Berührung gekommen sind. Das Toponym Jerichow kann aup ganz andere Weise zustande gekommen sein. und zwar uber den antiken ON Oricum. 'Qpixóv, 'Qpixós, das heiBt uber den Namen der neuepirotischen Hafenstadt im südlichen winkel des Golfs von Valons. Orikon. das durch Caesar und den Bürgerkrieg weithin bekannt wurde ${ }^{2}$. kann die Basis für mitteldeutsches Jerichow abgegeben haben, indem an die Stelle der lat. bzw. griech. Suffixe - um. -os, -ov das slavische Ortssuffix -on trat, während der vokalische Anlaut o- mit Hilfe einer $j$-Prothese beseitigt und $o$ - nach $j$ in je- verwandelt wurde. Auch der Wandel von - $k-z u-c h-$ ist im Siavischen keine Seltenheit. wenngleich hier in erster Linie wohl die lateinische Schreibweise $c$ bzw. ch fü $k$ in Betracht kommt. Besonders bemerkenswert ist nun allerdings, daB aus Orikon im Laufe des fruhen oder hohen Mittelalters in der Tat Jericho wurde. Die mōglicherweise durch das biblische Jericho beeinfluBte Namensänderung (Jirecek 1916, 184) bestătigen folgende Belege:

(nach) 1149 Urbs Iericho (Buschhausen, H.. 1976. 134. Anm. 102):

1199 provincia Jericho et Canino (Acta Albaniae I. 36): Ieplxi்

(Anna Komn. Alex. I, 14, 3; II, 3, 1) 3 .

Wann genau die Umwandlung von Orikon in Jericho vor sich ging. läbt sich nicht mehr feststellen, doch steht auBer Zweifel, daB das Slavische dabei den entscheidenden AnstoB gegeben hat. da es zur Assoziation mit dem biblischen Namen Ja erst durch die Beseitigung des vokalischen Anlautes und den damit verbundenen Wechsel von $0>e$ kommen konnte. Die Verän-

Zusammenhang mit der Varäger-Problematik für nordisch erklărt worden. vgl. Vasmer Schriften II. 816.

2 Im Bürgerkrieg dlente Orikon erst Pompejus als Plottenstation, wurde dann aber von Caesar. der die Stadt uber das Akrokeraunische Gebirge erreichte. kampllos eingenommen. Orikon ist das spätere Palaeokastro. vgl. weiter Pauly RE 35. Hbbd. 1939, 1059 fl.: Joh. Schmidt; Kl. Pauly IV. 343 I.: Patsch 1904, 70-4: TIR K 34. 95.

J Die antiken Belege bei Mayer 1957-9, I, 2950 oded from PubFactory at 01/10/2019 04:12:55AM 
derung von $0>e$ vor weichen Konsonanten wird in die Zeit zwischen 850 und 950 gesetzt (Shevelov 1964, 423, 634). Doch ist der Name Orikon vermutlich schon vordem von Slaven an die mittlere Elbe verphanzt worden, wo er dann ebenfalls zu Jericho(w) wurde. Die Singularität des mitteldeutschen Toponyms Jerichow spricht eher für als gegen eine Obertragung des antiken Namens Orikon. 
23. Puonzouua und Tuchorin

Die erstmals zu 976 bezeugte Kleinlandschaft Puonzouus wird zu beiden Seiten der Weißen Elster in deren Mittellauf lokallsiert (SlowStarSlow IV, 422: Wedzki). Natürlicher Mittelpunkt dieses Gaues ist wohl das schon einige Zeit vordem genannte Zeitz (967) gewesen (Helbig 1960, 35) ${ }^{1}$. Im Norden grenzte Puonzouus an den sog. Stamm der Chuticl und im Nordwesten an das Territorium Tuchorin. Die Belege dieses Gaunamens sind auffallenderweise nicht sehr zahlreich: 976 in pago Puonzouua dicto (DO II, 139); 995 provincia quanda Ponzouua dicta (DO III, 163): Dors. 12. Jhd. Ponzo$w e^{2}$. Die spärlichen Belege und die offenbar schon im Hochmittelalter aussetzenden Nennungen sprechen dafür, daß dieser Name nur wenig verbreitet und nicht lange in Gebrauch gewesen $z u$ sein scheint. Fast läBt sich sagen. Puonzouua wird uberhaupt nur ein einziges Mal genannt. denn die Zweiterwāhnung in der Schenkungsurkunde Ottos III. ist, wie auch die Formulierung erkennen läBt, aus der Urkunde Ottos II. transsumiert worden.

Den Namen der Kleinlandschaft bringt man gern mit dem Toponym Bosau in Verbindung (z.B. Patze, Schlesinger 1968, 332, 379, u.a.), was lautlich frellich nicht ohne weiteres möglich ist. Anders beurteilte Puonzouua Eichler, der 1963 (457) noch der Meinung war, den Landschaftsnamen könne "man mit keinem slawischen Etymon überzeugend erklären; er dürfte ebenfalls vorslawisch sein". In seinem zusammen mit H. Walther verfaBten Buch von 1984 vertritt Eichler dann allerdings eine völlig andere Ansicht: „Bei Annahme eines nichtgermanischen, primär siawischen Toponyms mit einer auf Dental endenden Wurzel lleBe sich an slaw. potb. russ. put', oso. puc 'Teg. Furt, Brücke'. ide. 'pnt(h)... denken. was etwa als Bezeichnung für die alte Elsterfurt dienen konnten (Eichler. Walther 1984, 127: vgl. ebda. S. 126 ff.). Beide Autoren weisen als Alternativ-Etymologie auch auf urslav. " $p p c$ - (neben 'ppk- und 'puk-) 'platzen, sprengen, knallen' hin, was nach ihrer Ansicht eine Gewässerbezeichnung an der Weißen Elster gewesen sein könnte. Semantisch wirkt dies jedoch weniger überzeugend. Dagegen wird man der Erklärung von Puonzouua

1 Vgl. auch HeBler 1957, 147 \%., wo die Gauorte verzeichnet sind.

* Nach Eichler. Walther 1984, 126. - Ob die für das 14. Jhd. belegte Form Pozowe den Gaunamen oder aber das Toponym Bosau (älter Posa) meint. ist die Frage. 
als urslav. 'pptb + Sufnx - ova > aso. 'Pot'ova durchaus zustimmen kōnnen. Im Grunde erwartet man $z$ war nach - $t^{\prime}$ das Suffix -eva, doch kann im vorliegenden Fall auch die im Polabeslavischen nicht erweichte Form ppt 'Weg' eine Rolle gespielt haben (vgl. 1174 pant = Trautmann I. 26). Das bei ONn häufige Sufflx - ovo könnte sich in seiner femininen Prägung ursprünglich auf sorb. zemja (terra, provincia) oder ein anderes feminines Aquivalent bezogen haben.

Daß Puonzouua auf die alte Elsterfurt abhebt, wie Eichler und Walther meinen, ist wenig wahrscheinlich, da urslav. 'pptb. soweit sich erkennen läßt, nicht eigentlich die Bedeutung von Furt hatte, wofür doch viel eher brod u.ä. zu erwarten wäre. Eindeutig scheint dagegen die Bedeutung von 'Weg. Straße' vorzuliegen, so daß sich Puonzouua sinngemäß als 'Straßengau' oder 'Land der Straßen, Wege' wiedergeben läßt. In der Tat Ist es so, daB im Bereich von Weißer Elster und Zeitz mehrere bedeutende Altstraßen zusammentrafen. was durchaus sinnvoll zur Namengebung Puonzouua = 'Gebiet der Straßen' Pühren konnte. So etwa liegt Zeitz an der Stelle der Weißen Elster, wo der wichtige alte Handelsweg nach Böhmen den Fluß durchquerte (SlowStarSlow VII. 278: Strzelczyk). Dazu gehörte auBerdem die in Westostrichtung von Burgwerben (Merseburg) nach Zeitz verlaufende Heerstraße (Patze. Schlesinger 1968, 287). Auch die "Regensburger Straße" ist in diesem Zusammenhang zu nennen, da einer lhrer Aste von Auma über Gera nach Zeitz-Pegau-Zwenkau führte (ebda. 288) ${ }^{3}$. Von nicht weniger groBer Bedeutung waren neben der West-Ost-Trasse die Nord-Süd-Verbindungen, von denen eine, nämlich die "Frankenstraße" nach Erfurt und von hier über Bamberg nach Nürnberg verlief. Besondere Beachtung verdient ein weiterer Nord-Sūd-Zweig, und 2 war der, der von Leipzig über Zeitz und Gera nach Schleiz führte. wo er sich in zwei Trassen aufspaltete: Während sich die eine von Schleiz uber Gefell nach Hof und von da über Bayreuth nach Nürnberg wandte, behielt die andere von Schleiz ab die bisherige Wegerichtung auf Bamberg bei und passierte die Stationen Nordhalben, Kronach. Lichtenfels, Staffelstein; bel BreitengüBbach mündete dieser Straßenzug in die alte "Frankenstraße" ErfurtNürnberg ein (Bruns, Teczerka Kap. IIlb, Nr. 33, VI Nr. 5; dazu Karten 20,

3 Zur Bedeutung von Zeitz im mittelalterlichen Fernhandel und zur Lage an Altstraßen vgl. außerdem $\mathbb{W}$. Schlesinger in Handbuch d. histor. Stätten Deutschlands. Bd. 11. Provinz Sachsen Anhalt. Hs\&ich Kangrimeköger. Stuttgart 1975. $519 \mathrm{fl}$. 
27, 32). Dle Existenz dieser Straßen Ist zum Tell zwar erst für das Spătmittelalter bezeugt, doch handelt es sich dabei wahrscheinllch um ein schon erhebllch früher begangenes Wegesystem, das möglicherwelse schon im Neollthikum den sächsisch-thüringischen mit dem frănkischen Raum verband.

Vor diesem Hintergrund kann die Bedeutung des slavischen Landschaftsnamens Puonzouus als 'Land der Wege, Straßengau' elgentlich nicht uberraschen. Besonders aufschlußreich ist nun freilich, daß diejenige StraBe, die von Zeitz nach Bamberg verllef, aus Puonzouua kam und in den Banzgau einmündete. was besagt, daß in Puonzouua und Banzgouwe zwei phonetisch nur unmerklich varilerende Bezeichnungen für ein und denselben Begriff, eben 'Straßengau' vorliegen. Ahnlich wie das PuonzouuaGebiet um Zeitz war auch Banz ein wichtiger Knotenpunkt von AltstraBen (Kunstmann 1981, 21982). Damit bestătigt sich nicht allein die Deutung von Banz < "ppts als richtig, sondern abermals der eng damit zusammenhăngende Name Pontius der bekannten Forchheimer Sage (Kunstmann 1979) als höchstwahrscheinlich. Die von Oberfranken an die TeiBe Elster führende Trasse erweist sich somit als eine vermutlich schon früh von slaven begangene Route. Im Fall des alten Wallfahrtsortes Banz ist noch der Umstand von Interesse, daß schon aksl. pptbniks die Bedeutung von 'viator, Pilger. Wallfahrer, osoliópos (SJS 111, 536 f.) hatte und tschechisches pout$k a$ ( pout') seit alters Wallfahrt hieß. Es lohnte sich, eine denkbare Verbindung mit der frühen Geschichte der Banzer Wallfahrt năher zu untersuchen.

Die Verwendung von potb für onomastische Zwecke ist bei den Slaven zwar nicht gerade 'produktiv', sie ist aber auch keineswegs vereinzelt, wie Beispiele bei Trautmann, Kranzmayer und Profous zeigen, worüber noch an separater Stelle gehandelt wird. Dies könnte damit zu tun haben, daß urslav. potb im Grunde im Slavischen ein isoliertes Wort ist, also ohne entsprechendes Verbum und uberhaupt kein autochthones slavisches Wort, sondern ein Lehnwort aus dem Griechischen ist".

Nordwestlich an Puonzouus schloB die Landschaft Tucharin an, deren Zentrum der gleichnamige Burgward war, aus welchem die heutige, südöstlich von Weißenfels und nordwestlich von Zeitz gelegene stadt Teuchern

- Vgl. dazu meinen demnăchst in der Welt der Slaven erschelnenden Artikel .Urslav. 'potb 'Teg. StraBe' und andere slavischerighodotnzme 
hervorging (HeBler 153; SlowStarSlow VI. 198: Strzelczyk) ${ }^{3}$. Zum Unterschied von Puonzouua ist das Toponym Tucharin sowohl als Name des Gebietes und Burgwards als auch als Orts- und Geschlechtername seit dem 10. Jhd. bis auf den heutigen Tag gut und häufig belegt:

Gebiet (Burgward): 976 in pago Ducharin (DO II, 139): 2u 981 (1012/18) Tuchurini pagus (Thietmar): 1004 in teritorio Tucherin (DH II, 66): 1040 in pago...qui vocatur Tuchorin (DH III, 60): 1042 burgwardus Thvchorin (DH III. 91):

Ort und Geschlecht: 1068 in suburbanio Trcheri (DH IV, 210): (zu 1079/1080) 1150 Bet(h)ericus de (castelio) Tuchern (Ann. Pegav.): (1135) 15. Jhd. in Thuchrini: (1140) 15. Jhd. villa Tucherin: 1168-1174 Gozwinus de Tucherin: Tuchern. Tucheren. Tuchirn: 1181 l. Ekkehardus de Thucherin. Túchere, Tuchern: 1184 fl. Hermannus de Tuchirin. Tuchern. Tuchorne, Thucheren. Túchere: 1196 Otto. Echardus. Herimannus de Tuchern(e). in Thucherne: 1235 in Thücheren: um 1300 de Thucheren; 1317 in pago oppidi Thvchirn: 1350 in Tuchern: 1378 Tuchern: 1466 dorf Teuchern: 1487 Tewchern (marckt): 1494 zcw Deuchirn: 1530 stettiein Teuchern: 1538 Tewchern; 1548 Teichern: 1616 Teuchern: 1651 von Teichern usw."

Die Oberlieferung des Namens ist sehr einheitlich, bis auf die Schreibung Tuch/u/rini bei Thietmar von Merseburg. wo das zweite - u- sehr wahrscheinlich auf ein aus $a$ entstandenes 0 hinweist, das seinerseits in $u$ umlautete. Die Etymologie dieses Landschaftsnamens ist unklar (SiowStarSlow VI. 197: Popowska-Taborska), auch wenn seit langem und neuerdings wieder von Eichler und Walther $(1984,307)$ eine Ableitung vom slav. Appellativ tuchor 'dumpfiger, moorbrüchiger Wald' angenommen wird: allerdings schränken beide dahingehend ein, daß das asorb. Appellativ "wohl nur" im Namen des Taucherwaides (Kr. Bautzen) und eben im ON Teuchern erhalten geblieben sei. Nach Eichler und Walther liegt dieses Appellativ vielleicht auch in $c$. ONn wie Touchoriny. Tuchorice und dann wohl ebenso im poln. ON-Typ Tuchorza vor.

Die auslautende Silbe des Toponyms, -in. läßt annehmen, daß hier ein Possessivadjektiv vorliegt, das mit Hilfe von slav. -ins zu einem Maskulinum (kaum Femininum) auf $-a$ oder $-i$ gebildet wurde und den Besitz eines - Tuchar-ja oder - Tuchar-i. (b) anzeigt. Als Besitz kommt dabel eher der Burgward als das Land In Betracht. Die Wurzel Tuch- liegt zwar erschlossenen slavischen PNn wie 'Tuchomir. 'Tuchomysl oder 'Tuchorad zugrunde (Svoboda 1964, 89), doch ist im vorliegenden Fall vielmehr von

- Zur Geschichte von Teuchern vgl. außerdem Handbuch d. histor. Stätten Deutschlands. Bd. 11. Provinz Sachsen Anhalt. Stuttgarths $9755_{7007}$

- Nach Eichler. Walther 1984, 306 \&. 
- Tuchar-a. -i oder - Tuchor-a, -1 auszugehen. Genau dieser Ansatz aber

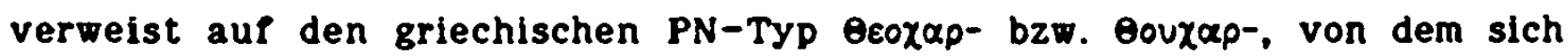

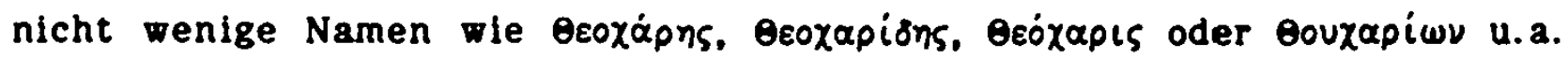

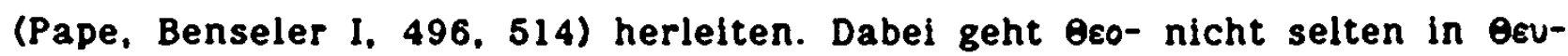
aber - vgl. Eéoruls neben eeüruls oder exóswpos neben exúswpos -, so daß Im Slavischen eo über eu regelgerecht $z u \quad u$ monophtonglert werden konnte. Der slavische PN - Tuchar-a, $-i$ bzw. Tuchor-a, -i kann demnach sowohl aus $\theta \varepsilon \cup x \alpha \rho l-w \nu$ als auch aus $\theta \varepsilon \circ \times \alpha \rho l-\delta \eta \bar{s}$ oder $\theta \varepsilon \circ \times \alpha \rho l-\varsigma$ entstanden sein. Bel der Obernahme ins Slavische wurde das jewellige griech. Suffix eliminiert. Die griech. PNn setzen sich aus 8xo- 'Gott' und $x \alpha p i s$ 'Huld, Dank. Lohn' zusammen. Alte slavische Namen wie Bohochval, Bogochval, Bohdiek usf. (Svoboda 80 ) sind genau genommen ins Slavische lehnubersetzte Varianten des genannten griech. Prototyps.

Der aus dem PN 'Tuchar' und Possessivsufnx - ins geblldete Landschaftsname Tucharin lăßt sich somit ursprünglich als .Besitz eines Tuchar' (oder Tuchor')" verstehen.

Der fremde PN ist im Slavischen 2 war nicht produktiv geworden, weil Ihn spăter lehnübersetzte Aquivalente wie Bogochvai u.a. ablösten, doch llegt er gewiB auch noch in Eech. ONn wie Touchoriny (dtsch. Taucherschin) ( Túchorina oder Tuchorice vor (Profous IV, 348 f.), die Profous ebenfalls aus - Túchora + -ina bzw. -ice erklărt?. Daß der griech. PN eróxapis u.a. nicht allein in das Slavische Eingang fand, sondern auch in das Germanische, zeigen die Namen der Vandalin Teucharia (Theucaria. Theucharia) und des Vandalen (?) Teucharius (Theuchario. Theucario. Theucorio). die zurecht als ungermanisch empfunden wurden und ohne zweifel ebenfalls von den genannten griechischen Prototypen herzuleiten sind".

7 Profous stellt die Wurzel allerdings zu $c$. tusiti, poln. tuszyt 'slibovat. doufat', was semantisch und formal m.E. nicht überzeugen kann.

- Schönfeld 1965, 223, erkennt im ersten Glied richtig Theo- ${ }^{2}$ oghngend das zweite verfehlt zu german. -harioz-Dogestellitimvirdictory at 01/10/2019 04:12:55AM 


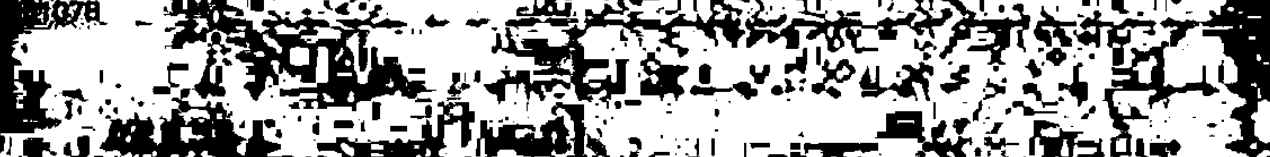

W 18

15.

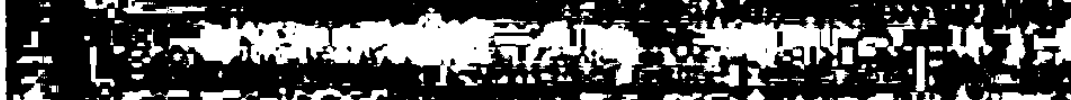

Sil

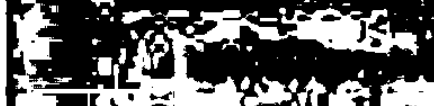

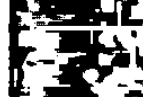

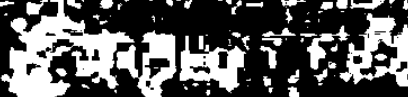

$x=$

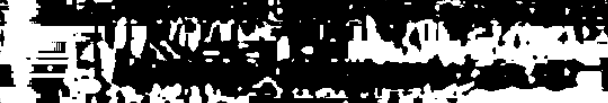

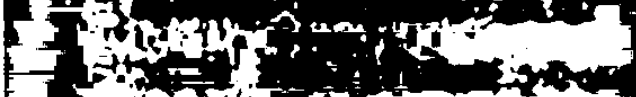

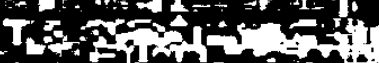

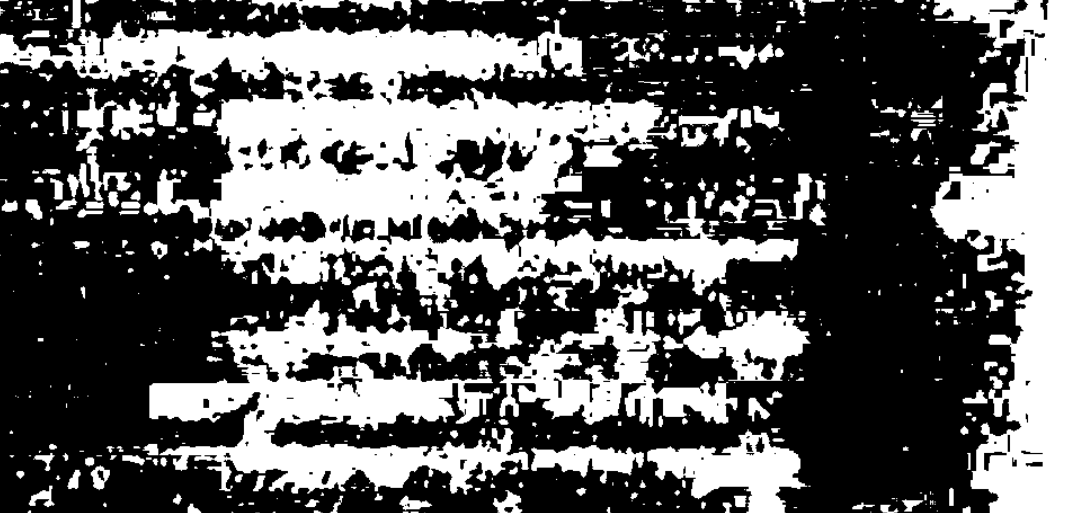

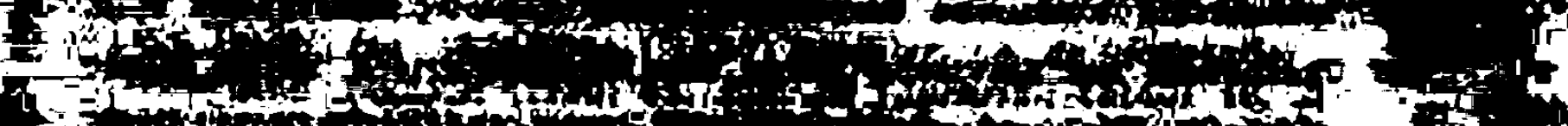

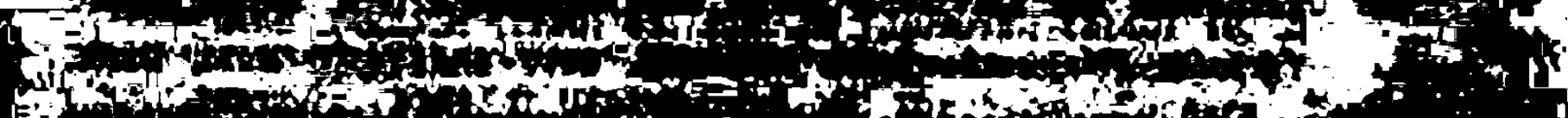

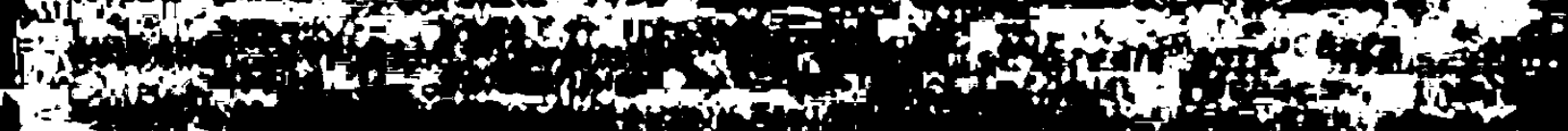

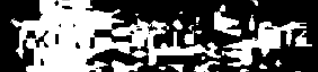

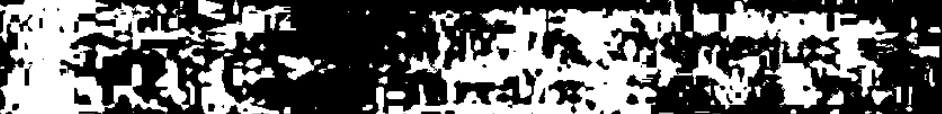

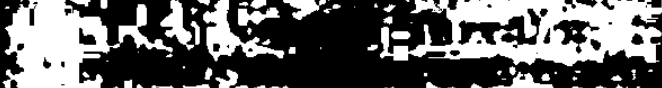

thet

औin

\&

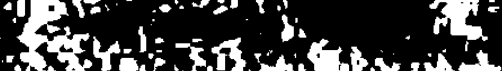

M

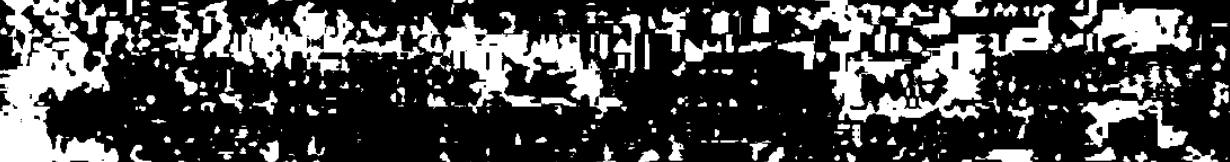

tring

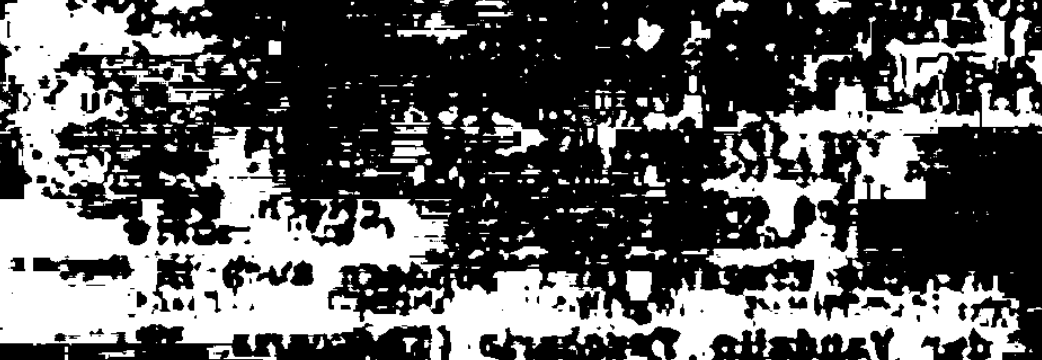

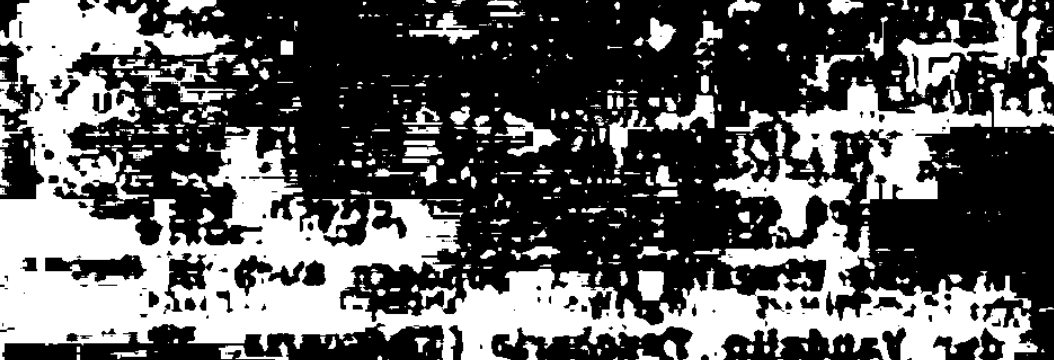

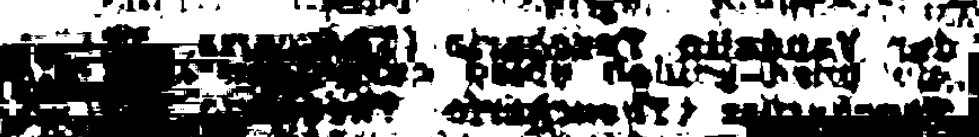

2

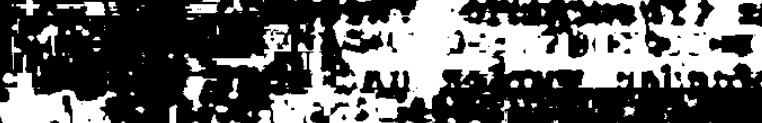

on

-

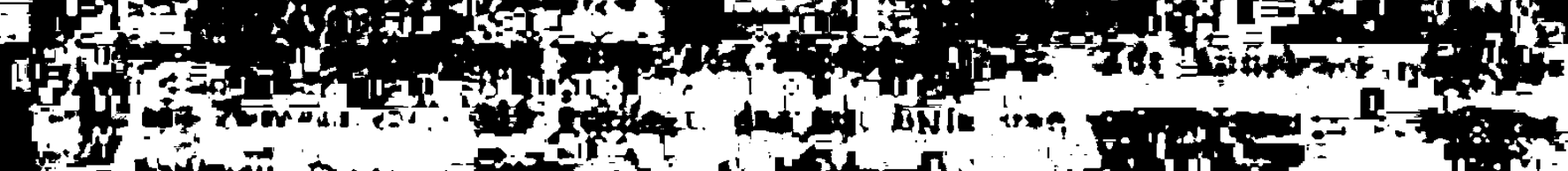

IN

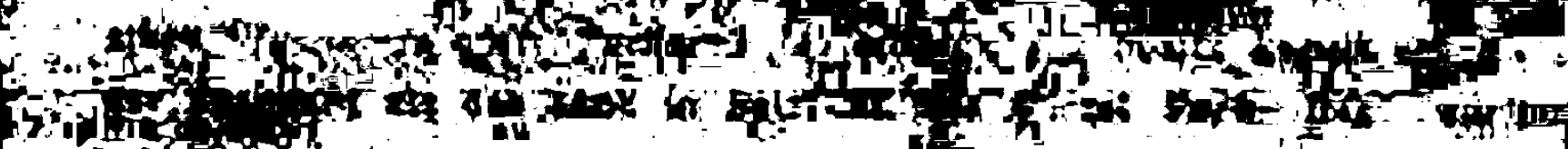

4 , P.

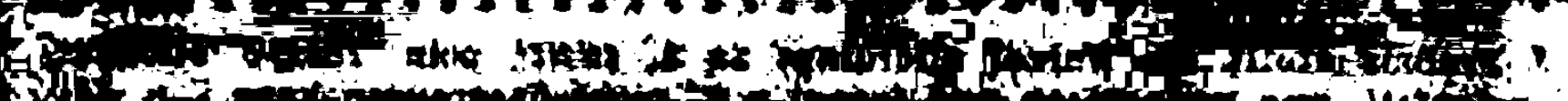

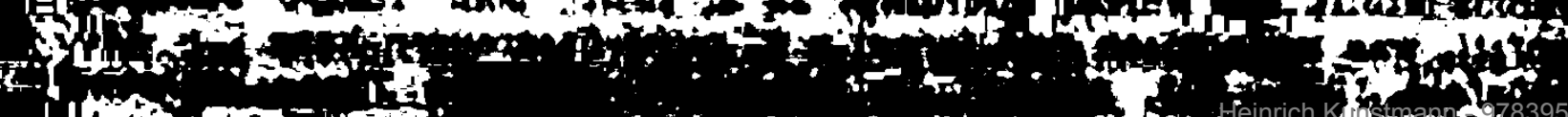

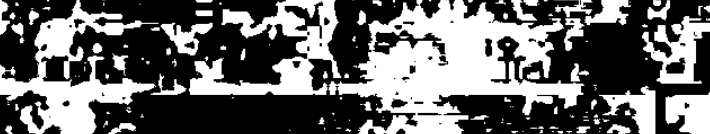

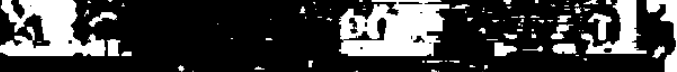

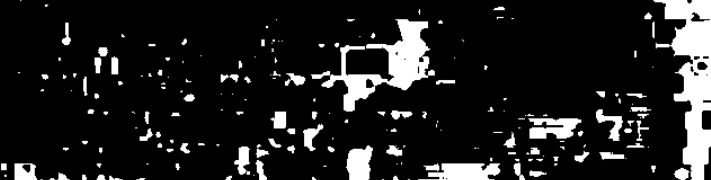

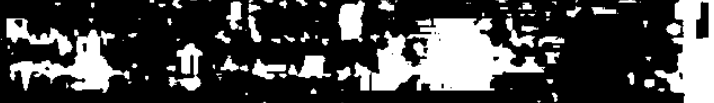

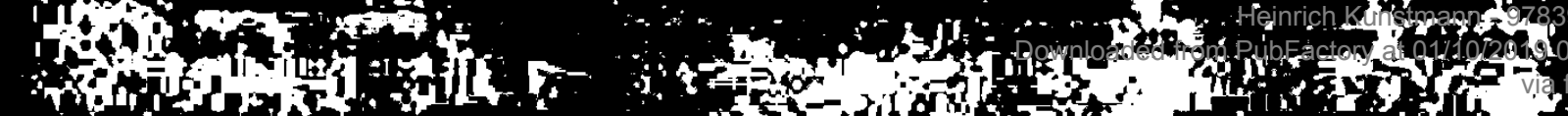


24. Sachsens Daleminci und Glomaci

Der sogenannte Stamm der Daleminci ${ }^{1}$ war in Wirklichkeit wohl eine kleinere Formation von Slaven, die anfänglich irgendwo in der ehemaligen Mark Meißen siedelten und sich allmählich aur das sächsische Land zwischen Elbe und Freiberger Mulde ausdehnten². Daß es sich tatsăchlich nur um eine sehr kleine Siedelgruppe handelt, läßt sich den Angaben des Geographus Bavarus entnehmen, der fur sie lediglich 14 Burggemeinden angibt. Die Landnahme der Daleminci wird in das 6. und 7. Jhd. gesetzt (Walther 1967. 100). Da ihr Name nach dem 12. Jhd. zu erlöschen scheint, und weil Cosmas von Prag schon zu Beginn des 12. Jhds. die Mark Meißen als Zribla bezeichnet, nimmt man an (Eichler 1976, 69), daß der Sorben-Name auch auf das Gebiet der Daleminci übertragen worden ist. Wahrscheinlicher freilich ist es, daB 2 wischen Sorben und Daleminci ursprunglich uberhaupt kein ethnischer, sondern nur ein nomineller Unterschied bestand.

Die Etymologisierung des Daleminci-Namens war für die gelehrte Welt von jeher attraktiv. Es ist jedoch unmöglich, aber auch unnötig. minutiös den ganzen Einfallsreichtum zu beschreiben. der sich bei der Deutung dieses Namens schon entfaltet hat'. Die Oberlegungen der Gelehrten besonders nachhaltig beeinnuBt $z u$ haben scheint die bekannte stelle in der chronik Thietmars von Merseburg (975-1018): in provintiam, quam nos Teutonice Deleminci vocamus, Sclavi autem Glomaci appellant (Thiet. lib. I, 3,5). Die Behauptung. Delemincl (d.1. Daleminci) sei die deutsche, Glomaci dagegen die slavische Bezeichnung ein und desselben Ethnikons, hat sich bis in die unmittelbare Gegenwart gehalten ${ }^{4}$ und natürlich auch in der einschlägigen historischen Literatur ihren Niederschlag gefunden. Allerdings handelt es sich dabei um ein Mißverständnis Thietmars, da, wie sich zeigen wird, der Unterschied zwischen den Namen der Daleminci und Glomaci ganz anderer Natur ist.

1 Als Normen werden hier die Blldungen Dalemincl und Glomaci gebraucht.

2 Vgl. weiter Eichler, Walther 1966-7. II, 7-21, wo auch die siedlungsgeschichtlichen und anderen historischen Grundlagen besprochen werden. Zur archäolog. Seite Coblenz. W. 1959, '1977, '1977.

3 Dazu die älere Literatur in Holtzmanns Edition der Thietmar-Chronik S. 6. Anm. 2, sowie die einschlägigen Arbeiten von Eichler, Schwarz u.a.

- Vgl. 2.B. Zakrzewski 1917, 18; Brückner 1929, 316, Anm. 1. Von einer völlig verfehlten Etymologie ausgehend. kommt zuletzt Labuda (1968) zu dem SchluB, daB Daleminci und GlomaCi Identisch sefiein. Kunstmann-9783954792238 
AuBer der soeben zitierten Stelle bei Thietmar gibt es för den Daleminci-Namen im wesentlichen folgende Belege:

zu 805 super Hwerenofelda et Demelchion, Demelcion (Chron. Moiss.. MGH SS 1, 307): Mitte 9. Jhd. Surbi ...Iuxta illos sunt quos uocantur Talaminzi, qui habent ciuitates XIIII (Geogr. Bav.); zu 856 Dalmatas ( $=$ acc. pl.) (Ann. Fuld. 47): 24880 Sciavi, qui vocantur Dalmatil (ebda. 94): um 890 Dalamentsan (Alfred d. Gr.: Havlík 1965, 78: Pritsak 1981, 688): um 960 Dalamantia. Dalma(n)tia. Daiamanci, dazu Varianten: Daiamanti (später: -ci), Dalmati. Dalmatae, Dalanci. Dalmatii (Widukind. Gest. Sax. 27. 29. 50 f., 56); zu 968 in provincia quae dicitur Talemence (Orig. 4a); zu 971 provincia Dalaminza (DO I. 406): zu 981 in pago Daiminze seu 2lomekia vocato (DO II. 195; Kop. 12. Jhd.): 24983 in pago Dalaminza (DO II, 270); zu 1013 in pago Dalaminci (DH II, 269): zu 1012 (terminos) Dalmantiae (Ann. Quedl.; MGH SS III, 81): zu 1046 in pago Dalmatia dicto (DH III, 156): zu 1064 in pago Deleminze. Talmence (DH IV, 118, 131): zu 1065 in pago. qui dicitur Talmence (DH IV. 140): zu 1069 in pago Dalmice (DH IV, 227): zu 1074 in pago Thaiemenche (DH IV, 275: 12. Jhd.): zu 1090 in regione Thalaminci (DH IV, 410): $2 \mathrm{u} 1095$ in regione Thaleminci (DH IV. 441): zu 1159 in pago Dalminza (Orig. 14): zu 1162 in provincia. que dicitur Dalminze (Orig. 68); 241168 in pago Dalaminza (Chart. Bosav.: 14. Jhd.); zu 1170 in pago Daleminza (ebda.)."

Mit der Problematik des Daleminci-Namens eng verbunden sind auch Thietmars Glomaci = slav. Glomaci, die von anderen Quellen bald zlomekia (981: Hs. d. 12. Jhds.) oder Zlomizi. bald Giomuzi. Glomuci est fons oder Glomici genannt werden. Durch Veränderungen im Anlaut entstanden weiter - als Vorläufer des heutigen ON Lommatzsch - die Formen de Lomacz (vor 1190). de Lomaz(c) (1206, 1226), Lomatsch (1308) u.ả. (Eichler 1975, 69)'. Die entscheidende, die Wissenschaft seit langem beschäftigende Frage ist. ob Daieminci und Glomaci lautlich miteinander zu tun haben oder. wie schon Thietmar meinte, zwei verschiedene Namen für ein und dasselbe Ethnikon sind. Elchler, der eine solche "Kontinuität" zunächst in Frage stellte (1962). kam später jedoch 24 dem Ergebnis (1975), daß zwischen Daieminci und Glomaci sehr wohl ein Zusammenhang besteht.

Für Eichler ( $\left.{ }^{3} 1962,45 ; 1975,71\right)$ ist der Daleminci-Name allerdings ein "vorslawisches Substrat". das heiBt, der Name einer ansonsten unbe-

- Nach Eichler ${ }^{3} 1962.34$ f.: Orig. = Originalurkunde des Landeshauptarchivs Dresden. - Vgl. auch die Notierungen Im Glosar A III, 297 \%. wo allerdings die Rubrizlerung der Daleminci unter dem Lemma Dalmatae irresuhrend ist; auch vermiBt man hier die relevante Forschungsliteratur (E. Schwarz, Elchler u.a.) zum Thema.

- Die Formen mit anlautendem Z- (Zlomekia. Zlomizi) erklären sich als Zetazismus, vgl. Elchler 1975, 69, Anm. 10. - Der heutige ON Lommatzsch ist durch Wandel von $\boldsymbol{g}>\boldsymbol{h}$ sowie Elndeutschung aus aso. - Gsomac entstanden. 
kannten vorslavischen Bevölkerung, mit dem die im 6 . Jhd. in das fragliche Gebiet einrückenden Slaven bekannt wurden. Somit liege Obernahme und Slavisierung älteren Namengutes, vielleicht germanischer oder sogar "alteuropäischer" Herkunft vor (Eichler 1964, 19). Konkret denkt Eichler $\left({ }^{3} 1962\right.$, 48) dabei an eine "alteuropäische" Grundform 'Dal(e)ment, die, in Anknüplung an E. Schwarz, die Fortfuhrung eines alten venetischen Stammesnamen sein könne. In Eichlers Augen war diese Ansicht von Schwarz "die befriedigendste Erklärung des Namens, auch wenn die Bildungsverhältnisse noch genauerer Untersuchungen bedürfen" (1962, 48).

Wie Eichler hat auch E. Schwarz mehrmals zur Problematik des Daleminci-Namens Stellung genommen ${ }^{7}$ und dabei an eine präkeltische, aber jedenfails indoeuropäische Stammesbezeichnung gedacht, die von den Germanen übernommen und an die Slaven weitergegeben worden sei. Wegen der gemeinsamen, aư dem Etymon 'dhe(i)- 'saugen, săugen' beruhenden etymologischen Basis •delm- 'Schar. die neuerdings 2 war bestritten wird (Crepajac 1975, 65 P.). stand es für Schwarz lest, daß der Daleminci-Name im Kontext "einer Anzahl von indogermanischen Sprachen (zu sehen sei H. K.), die von der Ostsee bis zur Adria eine Verbindung herstellten" (Schwarz 1965, 363). Nach Schwarz soll der Name schon im 1. Jhd. vor Christi Geburt an die Germanen gekommen sein.

Eichler und Schwarz sind sich somit im Prinzip darin einig. daß dem Daleminci-Namen nicht nur ein vorslavisches, sondern auch vorgermanisches Substrat zugrunde liege, das auf ein nicht nāher bekanntes oder sogar verbürgtes Volk von 'Schafhütern' zurückgehe. Die naheliegende Lösung des Problems wurde also zugunsten eines geheimnisvollen Volkes verkannt.

Es geht hier natürlich nicht um die Etymologie von Dalmatia, Dalmatae oder Delmatae (dazu Mayer 1957-9, I, 117 fl.; II. 35 fl.), sondern aus-

7 Hier interessiert vorrangig Schwarzens Arbeit von 1965, doch vgl. auch denselben in: Zur germanischen Stammeskunde. Hsg. E. Schwarz (WdF 249). Darmstadt 1972. XXVIII: "Von den Daleminziern in Sachsen, einem sorbischen Stamm, läßt sich wahrscheinlich machen, daß ihr Name mit dem indogermanischen Dalmatae 'Schamirten' zusammenhängt und sich über die germanische bis in slawische zeit gerettet hat": Perner E. Schwarz: Sprachforschung und Siedlungsgeschichte in Sachsen. In: Fs. par W. Schlesinger. Hsg. H. Beumann. Köln-Wien 1973, I, 109: "Für den oft genannten Stamm der Daleminzier läßt sich eine Anknupplung an den Landesnamen Dalmatia und damit eine Ableitung von idg. 'dhelm'Schar vornehmen, so daB eine Verbindung mit einem vorkeltischen Hirtenvolk bestünde". 
schlleblich darum. ob die Im Fruhmittelalter in Sachsen siedelnden slavischen Daleminci diesen ihren Namen hier vorgefunden, also, wie Schwarz und Elchler meinen, von einem ,alteuropăischen”, prăkeltischen oder anderen unbekannten Volk ubernommen oder aber aus Dalmatien mitgebracht haben. An eine Obertragung des Balkan-Wortes durch Slaven läßt slch natürlich nur dann denken. wenn entsprechende slavische Sprachspuren nachgewiesen werden kỏnnen. Das dies der Pall ist, zeigt sich einmal an den in obigen Belegen auffallenden Formen $D a l / a / m, D a l / e / m$, Del/e/m, dle einen Voksleinschub nach der Liquida aufweisen. Elchler geht auf diese Erscheinung nicht weiter ein, während Schwarz dafur eine weit hergeholte Erklărung bereithält: Er denkt an einen, in idg. Sprachen an sich denkbaren vokalischen Bindevokal. der in 'dal-am das Suffix an die Wurzel anbinde. Das fragliche Phănomen läBt sich Jedoch auch aus dem Slavischen erklăren. $\mathrm{Zu}$ vergleichen ist damit nämlich ein in rühen serbokroatischen Urkunden deutllches Schwanken 2 wischen den Formen Dalmat- und Da/bmat-. Letztere ist gut belegt:

Dalsmatje (1199?; Miklos. 1858, 9): dalbmatbskye strany (1208-15; Safaŕ. 1868, 24): Dalbmaciju (1208-15; ebda. 8): Dalbmacie (122228; Mlklos. 1858, 11): Dalbmacie (1234-40; ebda. 25): Dalbmacie (1235: Safar. 1870, 13): vs Dalbmatiju (14. Jhd.; SJS I. 460 f.): Dalbmatz (= Dalmattus; 14. Jhd.; ebda.); Dalsmbci (1444; Miklos. $1858,429)^{\circ}$.

Diese Beispiele machen deutllch, das die Llquida hier ursprünglich weich ausgesprochen wurde, was offenbar zu elner Art halbvokallschem Nachschlag fuhrte: 1'. Daß dleser halbvokalische Nachschlag - Insbesondere in tremden Ohren - als voller Vokal gehört werden konnte, llegt gewissermaBen auf der Hand. Vielleicht spielen hler aber auch Auswirkungen der slavischen Llquidametathese mit herein (vgl. Serimunti, Zerluani. Seraulci u.a.). Man wird in diesem Phănomen kaum ,alteuropäische”, vorkeltische oder vorgermanische symptome, sondern eindeutig slavische Sprachpraxis zu erkennen haben.

Das eigentliche Problem des Daleminci-Namens steckt Jedoch in dessen zweitem Tell. in Dal(e)-minc(i). DaB man das fragliche Ethnonym bislang verkannt hat. liegt in erster Linie eben daran. Schwarz meinte seinerzeit (1965, 264), das in $-m i / n / c-$ enthaltene - $n$ - spreche gegen eine Ableitung

- Zu dlesen Formen vgl. auBerdem Danicle 1863-4, 1, 255: Rjexnik hrvatskoga Ill srpskoga jezika...Obradill D. Daničć...Zagreb 1884-6, 242, - Mi-

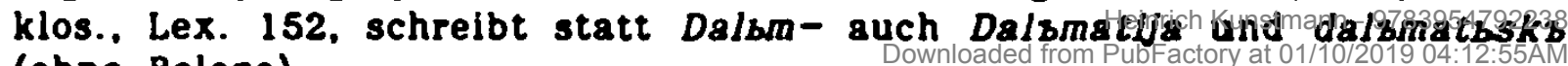
(ohne Belege). 
von Dalmatien, da ein - nt-Suffix In Völkernamen kaum vorkomme. Eichler dachte dagegen "mit Sicherheit" an eine - nt-Bildung. vielleicht in Form von -Dalm-nt-. was auf einen alten Gewässernamen zurückverweise. Daß -minzi bzw. -manci nicht auf einen Nasal - $q-$ schließen läBt, wurde bereits von Eichler erkannt, der zurecht sagt, daB dleser Nasal meist durch -en-vertreten werde. Es gibt $z$ war in romanisch-friaulischen Substantiven wie dálmine. tálmine = dalmăta 'Holzschuh' (aus Dalmatien) (Meyer-Lübke 1972. 229) einen $n$-Einschub, doch ist damit nicht die Form -minc- erklärt. Das - nt-Element ist außerdem in der altserbischen schreibweise Dalmantija statt Dalmatja enthalten, doch auch dieser Beleg (Safarík 1870. 59: Danicle 1, 255) führt nicht weiter, da er singulär ist und aus reichlich später Zeit (um 1503) stammt. Damit bleiben sowohl - n- wie auch - ntunerklärt. so daß es eine plausible Erklärung für den zweiten Teil von Dal(e)-minc(i) nicht gibt.

Die Lösung des Problems stellt sich auf einer ganz anderen Ebene ein: Seltsamerweise wurde bei allen bisherigen Deutungsversuchen die etymologische Zäsur einfach falsch gesetzt, denn es ist nicht Dal(e)-minc(l). sondern Dal(e)m-inci zu trennen, was besagt, daß von einem Grundwort Dalm- (< 'dheim 'Schaf'?) und einer suffixalen Endung -inci auszugehen 1st. Damit werden die heiß umkämpften Formantien - $n$ - und - $n t-$ gegenstandslos.

DaB das bisher von keinem Etymologen erkannte Suffix - inci wiederum slavischer Provenienz ist, läßt sich kaum bestreiten, denn dahinter verbirgt sich natürlich das suffixale Element $-b n b c b=$ Nom. Sing. bzw. dessen Nom. Plur. - $b n b c l$. Das zusammengesetzte Suffix - bnbcb besteht zum einen aus dem außerst produktiven slavischen Adjektivsuffix - bn(0), das sich nicht immer leicht von anderen $n$-Suffixen (-ina: -ins, -ina, -ino) unterscheiden laBt und Art sowie Stoff oder auch den Ursprung bezeichnet (Vondrák 1924, I, 531; Valllant 1974. 451 ff.). Weiter kommt das Element $-\Delta C b(<--s k O)$ in Betracht, das mit Vorliebe adjektivische Wörter wie juns > junbcb oder miads > mladbnbcb substantiviert und - was im gegebenen Zusammenhang besonders wichtig ist - die Zugehörigkeit zu einer Gruppe, namentlich aber Herkunft und Nationalität ausdrückt (Miklosich 1864. 2 f.). Das gleichlautende Suffix zur Deminutivbildung ist davon natürlich fernzuhalten. Das die Zugehörigkeit zu einer Gruppe oder einem Stamm ausdrückende Suffix -bcb ist zwar fast allen slavischen Sprachen bekannt, doch dient es vorwiegend im Südslavischen zur Bezeichnung der 
Herkunft: Es lst auch "das hăuflgste ON-Suffix auf serbokroatischem Sprachgebiet", das dle größte Anzahl von ONn liefert'. Es wird im Serbokroatischen auch bevorzugt zur Bezeichnung der Zugehörigkeit und zur Ethnikabildung verwendet, vgl. Bosanac, planinac, Banijanac, Srbijanac u.v.a.m. (Skok 1971-4, I, 38 P.; Görner 1963, 15 Tr.).

Für den Daleminci-Namen sind folglich die Formen Dal(b)mbnbcb = Nom. Sing. 'der Dalmatiner' bzw. Dal(b)mbnbci $=$ Nom. Plur. 'die Dalmatiner' anzusetzen. Es llegt also eine hybride, halbslavisierte Bildung von Dalmatae oder Delmatae vor ${ }^{10}$, die $2 \mathrm{u}$ einem im Illyrischen nicht seltenen Typ gehört. mit dessen Hilfe Stammesnamen und Ethnika zu Ortsnamen gebildet

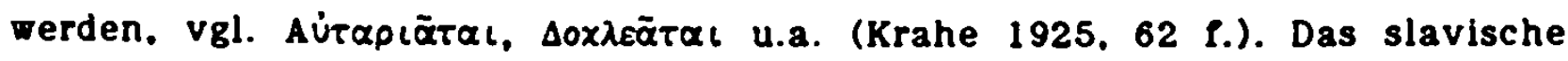
Zugehörigkeltssuffix - bnbci wurde somit - nach Abfall des autochthonen Formans -atae - unmittelbar an das Grundwort Dalm- angefügt. Nicht völlig auszuschließen ist. daß Dal(b)mbnbci auch auf die ON-Formen $\Delta$ á$\mu L O \nu, \Delta \varepsilon \lambda \mu i v i o \nu$ oder Delminium zurückgeht, denn ebensogut konnten die in Illyrischen ONn häufigen Sufflxe -iviov bzw. -inium durch slav. -bnbcb ersetzt werden.

Der somit vollig "korrekt" gebildete Daleminci-Name ist demnach eine Herkunftsbezeichnung und hat nicht das geringste mit einem "alteuropäischen". vorkeltischen oder vorgermanischen Volk $z u$ tun. Er wurde von Slaven, die in das Land 2 wischen Elbe und Freiberger Mulde eingewandert waren, zur Bezeichnung ihrer Herkunft aus Dalmatien gebraucht. Dalmatien war das alte Kernland der Kroaten, von denen sich vielleicht schon im 6. oder 7. Jhd. Telle abgespalten und nach Norden abgesetzt haben. DaB Kroaten zusammen mit Serben nach Nord- und Mitteldeutschland abgewandert sind. wird neuerdings auch von anderen Sprachwissenschaftlern erkannt oder für denkbar gehalten (Herrmann. J. 1985, 27). Nicht weit westlich vom Siedlungsgebiet der Daleminci entfernt begegnen wenigstens drei ONn, die eindeutig auf den Stammesnamen der Kroaten schließen lassen: Groß- und Klein-Korbetha nỏ. Weißenfeld. Korbetha n. Merseburg und die wüstung Chorwete (1181/1214; dazu der FIN dle Körbzige) nnw. Altenburg (Eichler '1965, 103 P.). Aber auch ostlich des Siedlungsgebletes der Daleminci sollen sich laut König Alfred Kroaten befunden haben: Ond be ea-

- Görner 1963, 42. 44 fl.: Ethnika von ON auP - bcb: Popovic '1960. 552.

10 Zum Wechsel Dal-//Del- vgl. Mayer 1957, I, 117 f. - Ober den ehemallgen illyrischen. im mittleren Dalmatien siedelnden Volksstamm der

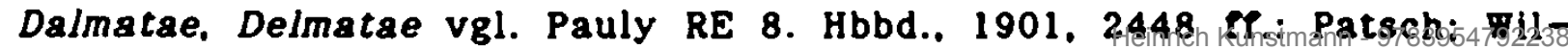
kes 1969 u.a. 
stan Dalamentsan sindon Horigti (Horigti oder Horoti = Kroaten) (Pritsak 1981. 688$)^{11}$.

Thietmars Behauptung, Deleminci sei die deutsche und Glomaci die slavische Bezeichnung für ein und denselben Stamm ist nun dahingehend zu korrigieren, daß unter Daleminci $=D a J(b) m b n b c i$ gewissermaßen das Ethnonym zu verstehen ist, wăhrend Glomac(i) der aus Dalmatia entstandene Landschaftsname Ist. Die Endung $-i$ von Glomaci ist fraglos als lat. Nom. Plur. in der Bedeutung 'Dalmatiner' zu verstehen. DaB Glom- aus Dalm- entstehen, also $d i>g l$ werden konnte, erkannte auch Eichler (1975. 71 (.). obgleich dieser 'Dalm- für ein vorslavisches Substrat hielt. Laut Eichler wurde 'Dalm- infolge Liquidametathese $z u$ 'Dlom- und auslautendes - $t i$ von Dalma/ti/a zu aso. - c. Eichlers Deutung ist im Prinzip zuzustimmen. Es zeigt sich nun aber auch, daB Thietmars Glomac(i) durchaus mit jenem singulären dalmatinisch-bosnischen $O N$ Glamoc zu tun haben. für den sich die wissenschaft schon seit langem interessiert. In der spezifisch südslavischen Bildung Glamoc. die bemerkenswerterweise auch einige Male als Dlamoc belegt ist ${ }^{12}$. hat bereits Petar Skok den Landschaftsnamen Dalmatia erkannt (Glas. zem. muz. Bosn. i Herceg. 29. 1912, 128 P.), seine Ansicht jedoch später widerrufen (ebda. 31, 1918, 152; 1971-4, 1, 377). und zwar mit dem Argument, dalmatinisches Glamoc habe In den săchsischen Glomaci eine Parallele. Da auch Skok von einer Nord-Süd-Wanderung der Slaven uberzeugt war, konnte Glamoc für ihn nicht gut aus Dalmatia entstanden sein ${ }^{13}$. Tenn nun jedoch der Daleminci-Name die hybride, halbslavisierte Nachbildung von Dalmatae oder Delmatae ist. dann werden

Skoks Einwände gegenüber der Herleitung von südslavischem Glamoc aus Dalmatia nicht nur gegenstandslos, sondern seine ursprüngliche, lautlich stichhaltige und überzeugende Deutung vollauf "rehabilitiert". Die Entwicklung von Glamoc über Diamoc aus Dalmatia wird erneut von Ljiljana Crepajac bestätigt (1975).

$11 \mathrm{Zu}$ eben diesem vermeintlichen Stamm von Kroaten nun Kunstmann 1987, 28, $39 \mathrm{fl}$.

$12 \mathrm{Zu} 1332$ Miklos. 1858, 102; zu 1357 Wenzel, Acta extera II, 487; zu 1404 Pupic 1858, I, 50.

13 Vollig abwegig Lehr-Splawithski (SlowStarSlow II, 111). der Glomac- aus urslav. 'glum- 'zart' herleiten möchte. Die ebenso verfehlte Etymologisierung von Schütz 1957. 21, wo Glamoc zu gláma 'steiniges Gebirge' gestellt wird, wurde vermutlich L. Pintar (AfslPh 35, 1914, 623 .) nachemprunden. 
Der săchsische Daleminci-Name sowie sein lautlich abgewandeltes Pendant Glomaci, aus welchem der heutige ON Lommatzsch hervorging, sind somit ein schlagender Beweis dafur, daß aus Dalmatien zugewanderte Slaven Im Gebiet 2 wischen Eibe und Freiberger Mulde seßhaft geworden sind. 


\section{Die sorbischen Milzener}

Die Milzane, Milzenj, Milzini oder Milzener, wie sie eingedeutscht heißen, gelten als die Vorfahren der Obersorben, deren Hauptburg man im allgemeinen in Bautzen, slav. Budysin. lat. BudissIna oder Budissa, vermutet. Ihr Land (Hermann, J. 1985, 357 $\mu$. u. Reg.), fălschlich immer wieder Milsko genannt, soll im Westen Nisane und Glomaç, im Osten verschiedene schlesische Stämme zu Nachbarn gehabt haben. Setzt man die terra Milze der Dagome-iudex-Regeste vom Ende des 10. Jhds. (vgl. Kunstmann, ${ }^{2} 1984$. 302 (f.) mit dem Milzenerland gleich, dann konnte dieses unmittelbar an den damaligen polnischen Staat Mieszkos I. stoßen ${ }^{2}$. Der Name der Milzener ist urkundlich verhältnismäßig früh und gut belegt ${ }^{2}$ :

um 850 Milzane (Geogr. Bav.); 968 Milczane; 971 Milzane; 992 (?) in terram Milze et a fine Milze recte intra Oddere (Dagom.-lud.Reg.): 1007 in pago Milzani: 1012/18 (zu 922 bzw. 932) Milzienos (Acc. Pl.): zu 1000-1004 Milzini, Milzieni. in Miizaniam. Miizine. Milzanie (Ann. Saxo): zu 1003 Sclavos Miikianos (Ann. Quedl.): 1012/18 (zu 1000-1010) Milcini. Milzientos, Miltizieni. Milzeni. Milcieni. Milzini, Milzienos (Thietmar): 1071 in pago Milsca: 1086 Milcianorum (Gen. Pl.); 1091 in regione Milce: um 1125 Milcianorum (Gen. Pl.); 1165 in pago Milzana u.a.

Die Erklärung dieses Ethnonyms beschäftigte die Gelehrten wenigstens seit Safarik, der an einen "mächtigen" Stamm glaubte, dessen Sitze vor der Völkerwanderung irgendwo $z$ wischen Tatra und Ostsee, wahrscheinlich an der Grenze zwischen Litauen und Polen gelegen sein sollen. Der Name der Milzener - Safarik nennt sie Milcane - beruhe daher auf lit. miİzinas 'Riese. Hủne, Gigant. Koloss'. Von eben diesem "mächtigen" stamm leiteten sich dann sowohl die sorbischen Milzener als auch die bulgarischen Milci in Da-

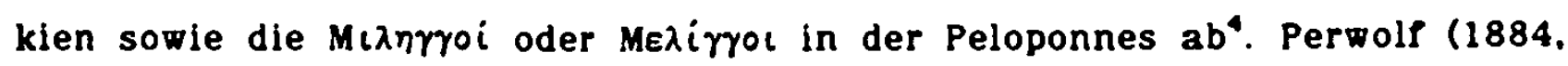
616) Pührte dann den Namen der Milzener auf einen PN Milek zurück, d.h. auf einen Typ wie Milobud oder Miloslav. Dieser Auffassung war in der

1 Die Angabe der Dagome-iudex-Regeste könnte sich freilich auch auf anderes beziehen, was noch gesondert untersucht wird.

2 Belege nach Eichler ${ }^{1} 1962,358 \mathrm{f}$. und 1966, 12 ?.

3 Als Burgname ist Milcany (Hostikovice bei Ceská Lipa) seit der 2. Hälfte des 14. Jhds, auch für Nordböhmen belegt, wobel Profous III, 73, an Obertragung aus der Oberlausitz denkt.

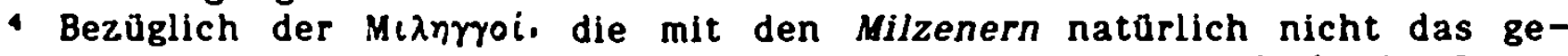
ringste zu tun haben, vgl. Vasmer 1941, 337: Reg.; Labuda in Slow-

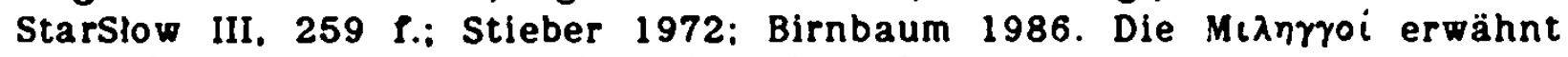
erstmals Konstantinos Porphyr. in seiner DAI. 
Polge auch M. Rudnickl (1958, 192). Auf einem Grundwort mil- beruht auBerdem der nktive Landesname -MIlsko, den Lehr-Splawinski und Nalepa aus der für 1071 belegten, aber sicher korrumpierten Form Milsca erschlieBen wollten". was Elchler für "die bisher fundierteste" Erklärung hielt (Eichler '1962, 359). Der „völlig verfehlte" Landesname "Milsko geht jedoch. wie Urbanczyk meinte (SlowStarSlow III, 256, 259), auf elne falsche Einschätzung des Belegs Wilsca zurück, worunter "in Wirklichkeit" Milça-ne oder Mellza-ne zu verstehen seien.

Man hat den Namen der Milzener einige Male auch zu mell 'seichter. sandiger Ort' gestellt, welche Ansicht erstmals Hey (1893, 267 f.) vertrat. Fundierter wird ein vermuteter Zusammenhang mit 'melsks von Urbanczyk (SlowStarSlow III, 256) begründet, der das Ethnonym als Melbcane rekonstruiert, worunter Bewohner einer Gegend an einem FluB namens 'Mélbcs oder Melbca zu verstehen selen. Urbanczyk schließt aber auch eine Grundform mil- nicht aus. Gegen eine Herleitung aus mel-hatte sich schon Eichler ausgesprochen (1962, 358 f.), der richtig erkannte, das alle Belege dieses Namens konsequent $-i$ - und nicht -e- wiedergeben. Nach Eichler selbst kann allerdings auch nicht ausgeschlossen werden, "daß ein älterer (vorsiawischer) Name umgestaltet wurde" (369) oder uberhaupt ein "vorslawischer Name" vorllegt (Eichler 1966, 13). Zur Diskussion stellte zuletzt H. Walther die Vermutung, den Namen der Milzener (hier Mil'cane) von elnem Flußnamengrundwort "mel abzuleiten (Elchler. Walther 1975-78. II. 129. Anm. 136), aus welchem Ansatz sich dann for ihn "eine "Millsa o.å." ergibt, die "der altere Name der oberen Spree...gewesen sein" müsse. Nebenbel drängt sich der Verdacht auf, daß hier ein nirgends belegter Flußname erfunden wird.

Fast alle bisherigen Deutungen befassen sich ausschlieBlich mit der Silbe mil- resp. mel-. während der .Bindekonsonant" $-z-z w i s c h e n$ Grundwort mIl- und Suffix -jane der Aufmerksamkeit zu entgehen scheint. Dabei Ist gerade dieser Laut von entscheidender Bedeutung für die Etymologisierung des Ethnonyms. Die aberwiegende Mehrzahl der Belege lăbt dafür plădieren. In $-z$ - die dentale Affrikata $-c-z u$ sehen. so daB die Lesart MilCane auszuscheiden hat. Hinter dem Laut - $c$ - lassen sich 2 wei phonetische Werte vermuten: - ts- und - $j-$. Letzterer ist mehr als wahrscheinlich. da ja vom Anlaut des Sufnxes -jane ausgegangen werden mus. So- 
dann ergibt sich elne Form von 'milt-jane; der $t$-Laut scheint noch in dem Beleg Mlltizieni anzuklingen. Das aber besagt, daß die dentale Affrikata $-c$ - ubber - $c$ aus $U$ entstanden ist, was im nämlichen Fall fũr das Ober- und Nledersorbische sowie für das Polnische. Polabeslavische. Tschechische und Slovakische bekannt ist (Shevelov 212-4, 303-4). Dieser Prozeß hat während des 5.-8. Jhds. stattgefunden (ders. 633). Im Blick auf - milt - uberrascht es jedoch, daß keine Liquidametathese eingetreten ist wie etwa in osorb., nsorb. mloko, poln. mleko < urslav. "melko oder poln. mlost, russ. molost < molsts u.a. Das läßt darauf schließen, daß sich zwischen - 1 - und - $t$ - ein Vokal befunden hat. was letztlich zu der Etymologie führt: Milzane, Milzeni usf. < Milbt-jane < Milit-jane. Zugrunde liegt somit eine hybride Bildung aus lateinisch milit-es und slavisch -jane oder -éne. Die Reduzierung von $-i->-b$ - erklärt sich aus der Akzentuierung der ersten Silbe. Der Name der sorbischen Milzener verweist somit auf Siaven, die vor ihrer Ansiedlung in Sachsen als milites '(FuB)Soldaten' in oströmischen Diensten gestanden haben.

Ein besonderes Problem stellt der Name der Miloxi dar, die der Geographus Bavarus mit 67 Burggemeinden zwischen Osterabtrezj (= DonauAbodriten) und den namentlich weiterhin unklaren Phesnuzi registriert, so daß keine auch nur annāhernd plausible Lokalisierung möglich ist. Schon Karamzin verstand unter den Miloxi soviel wie Milzani, was Dobrovsky zwar fūr unwahrscheinlich hielt (Horák. Trávnicek 1956, 24), andere Forscher aber wie Králíxek oder Nalepa (SlowStarSłow III, 259) durchaus uberzeugte. Lautlich sind die Miloxi besonders wegen des $x$-Lautes nur schwer mit den Milzenern in Einklang zu bringen. Die rătselhaften Miloxi lassen sich jedoch anders erklăren. Spätere, gewiß vulgärlateinische Nebenformen für miles sind die mehrmals bestätigten Bildungen milex und milis (Georges II. 917), von denen erstere eine auffallende Ahnlichkeit mit den Niloxi des GB aufweist. Wahrscheinlich spiegelt der Wandel von milex $>$ milox, also $e$ $>0$ oberdeutschen SpracheinfluB wider. Neben dem Bairischen (Weinhold 1867. 39 P.) kennt vor allem das Alemannische eine schon frühe Verschiebung von $e>0$ (Weinhold 1863, 19 f., 27 f.). Bedenkt man nun, daB der GB. wie Bischoff gezeigt hat (Bischoff 1974. Anm. 3), im alemannischen Raum (Reichenau?) entstanden oder abgeschrieben wurde ${ }^{6}$, dann läBt sich nicht restlos ausschließen, daß auch unter den Miloxi des GB 'Soldaten' zu verstehen sind.

- Ebenso E. Herrmann 1963, 78, und R. Nový 1968, 149. 
Slaven dienten als Söldner sowohl bel Langobarden als auch Byzantinern. Es waren dies stets angeworbene Freiwillige (milites voluntarib), die unter dem Kommando einheimischer Führer oder von Flüchtlingen standen (Jirecek 1911. I. 78 I.). „Diese Söldner unter den Fahnen von Byzanz waren wohl die ersten Christen unter den Slawen; Heiden duldete man im kaiserlichen Heer nicht mehr" (ders. 79). Besonders in byzantinischen Diensten haben es slavische Führer zu hohem Ansehen gebracht, wie der Fall des von Agathias erwähnten "Anten" $\Delta \alpha \beta p \alpha \gamma \alpha \dot{\zeta} \alpha \zeta$ zeigt, der sich in Reiteroperationen und Schiffsgefechten gegen die Perser hervorgetan haben soll. Agathias weiß auch von einem Slaven namens Svarum, der an Kămpfen gegen die kaukasischen Misimianen beteiligt gewesen ist. Und laut Theophylaktos soll unter Kaiser Maurikios ein Slave Tatimir als Befehlshaber einer römischen Abteilung an der Donau vorgestanden haben. Schon unter Kaiser Iustinian hat es sogar eine Art slavischer Reichstruppe gegeben (Stein. E. 1919. 120 fl.), die sich insbesondere in den Kämpfen um das von Goten eroberte Rom auszeichnete. In seiner Geschichte der Gotenkriege spricht Prokop von einer 1600 Mann starken Reitertruppe, die in der Mehrzahl aus Hunnen. Sklavenen und Anten bestand (Prokop I, Buch I. 1 P.). Laut Prokop (ebda. Buch III. 22, 3 ff.) wurden in Lukanien außerdem 300 Anten, also Slaven. mit Erfahrung im Gebirgskampl gegen die Goten eingesetzt. Oberhaupt dominierte in Iustinlans Expeditionsheeren das barbarische föderative Element: Bei der gegen das Vandalenreich ausgeschickten Armee beispielsweise war namentlich In der Kavallerie das zahlenmäBige Verhătnis von numeri foederatorum zu numeri militum ex catalogis 9:4 (vgl. Prokop IV. Buch I, 11, 5 (f.) ?.

Slavische Soldaten in byzantinischen Diensten sind nicht nur in frühbyzantinischer Zeit, sondern auch noch später die Regel, wie sich für das 9. und die folgenden Jahrhunderte zum Beispiel an den russischen Söldnern zelgt (Blöndal. Benedikz 1978, 32 ศl.). Daß slavische Söldner, die unter byzantinischen Fahnen standen. Ihre Berufsbezeichnung milites zu - milit-jane slavisierten und nach ihrer Entlassung und Abwanderung als Ausdruck ihrer Zusammengehörigkeit oder Herkunft verwendeten. ist sowohl realistisch als auch verständlich.

7 So Stein 1919, 123; anders Karayannopulos 1959, 40, der schon fur das 5. Jhd. einen schwächeren Anteil von Barbaren innerhalb der byzantinischen Armee annimmt. - Zur "romanischen Herkunft der europāischen Miliz" vgl. im ubrigen Tomaschek 1882-6, I. 491. 


\section{Thafnezi. Zeriuani. Prissani}

Die unschätzbare Völkertafel des sog. Geographus Bavarus (GB) aus der Mitte des 9. Jhds. Uberliefert elne stattliche Anzahl slavischer Völkernamen. von denen jedoch viele, ja die meisten bislang ungedeutet geblieben sind oder aber fehlgedeutet wurden. Zu den problematischen Namen gehören auch die im Titel genannten drel Völkerschaften, von denen der GB berichtet:

Thamezi habent ciuitates CCL.

VII. Zeriuani quod tantum est regnum ut ex eo cunctae gentes sclauorum exortae sint et originem sicut affirmant ducant.

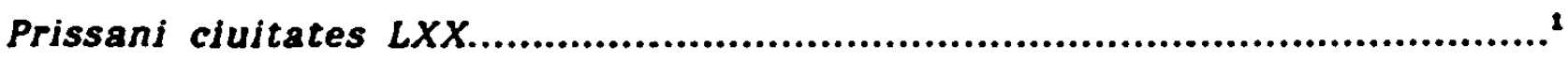
In erster Linie interessieren hier natürlich Herkunft und Bedeutung der drel Völkernamen.

\section{a) Thafnezi}

Ober die Bedeutung dieses aus slavistischer Sicht gewiß merkwürdigen Namens ist schon unendlich viel geschrieben worden ${ }^{2}$. frellich ohne dab es bislang zu einer auch nur annähernd befriedigenden Lösung gekommen ist. DaB der mysteriöse Name aber nicht unbedingt ein "onomastisches Monstrum" ist, wie ein prominenter Historiker meinte (wIdajewicz 1946, 88). werden die weiteren Ausfohrungen bestätigen.

Das In keiner Weise aus dem Slavischen zu erklärende Ethnonym hat die Gelehrten offenbar von Anfang an dazu verleitet. gewissermaBen willkürlich mit inm umzugehen. Safařik (1837, II. 556) war wohl der Erste, der sich uber die uberlieferte Lautabfolge hinwegsetzte und Thamezi kurzerhand zu Tanev'ci bzw. Tanf'ci umstellte, um dadurch den gewünschten "AnschluB" an das Hydronym Tanev, einen rechten ZufluB des San im gallzischen Gebiet von Lemberg zu bekommen. Safařiks "Deutung". die an den lautlichen Gegebenheiten restlos vorbeiging, hat sich noch $\mathrm{zu}$ Beginn dieses Jahrhunderts Lubor Niederle angeschlossen und durch seine Autorität gestutzt (IV, 150). Nicht weniger rigoros wie Safaŕik setzte sich dessen

1 Zellenlängen des Originals. Nach Herrmann. E. 1965, 221.

V Vl. Horák. Trávnicek 1956, 38; Lowmiański 1958, 15; Leśny in SlowStarSlow VI, 1977, 71 ?. 
Zeitgenosse K. ZeuB uber Lautbestand und Lautfolge des Namens hinweg. indem er durch Konsonanteneinschub die Thafnezi zu Tramezi machte und diese zum sūdslavlschen ON Travnik stellte (Zeuß 1837, 615). Ahnlich verfuhr Zeuß ubrigens auch mit den Prissani, aus denen bei ihm Prisrani und damit Bewohner von Prizren wurden (ebda.).

Doch nicht allein die Nestores der slavischen Altertumskunde verfuhren hie und da unbefangen mit dem überlieferten Wortmaterial. selbst im linguistisch aufgeklärten 20. Jahrhundert kommt es bel der Deutung des strittigen Ethnonyms sowohl zu "Gewalttătigkeiten" als auch zu mitunter kuriosen Auslegungen. Der polnische Historiker $K$. Tymieniecki beispielsweise (1946. 165 f.) verfăhrt "methodisch" ganz wie Zeuß, wenn er eigenmächtig ein $r$ einschiebt und so die Thamezi zu Drawczanie werden låst. Diesem Historiker zufolge sind die am Drawsko-See ansäßigen Drawczanie die Vorbewohner des späteren Landes Drahim (h. poln. Drawsko Pomorskie). Zu Tymienieckis verfehlter Etymologle bekennen sich in der Folge andere polnische Historiker wie etwa S. Zajaczkowski (1962, 90).

Das fraglos außerst schwierige Ethnonym Thamezi hat auch zu kurtosen etymologischen Deutungen angeregt. Dazu zählt gewiß die des bekannten brandenburgischen Historikers Fritz Curschmann, der unter Thamezi soviel wie Dephense 'Tlefensee' verstand und damit einen Ort im brandenburgischen Land Oberbarmin bzw. einen ON Tifenze (Dypensey) ${ }^{2}$ im Kreis Teltow in Verbindung brachte. Für Curschmann war der Name Thamezi aber noch mehr. namlich die ursprüngliche Bezeichnung rar die SpreeSlaven (Curschmann 1906, 160). Diese Ansicht wird von den Quellen jedoch nicht gestützt. Kurios ist wohl auch die "Deutung" des polnischen Historikers Zakrzewski. der den Namen der Thamezi von der Donau herleitete. dabel allerdings vergaß, den Verbleib von $\boldsymbol{f} 2 \mathrm{u}$ erklären (Zakrzewski 1917. 52). Ungeworhnlich ist ebenfalls die "Deutung" des polnischen Historikers E. Kucharski, unter dessen Feder die Thamezi zu Szczawnscy werden, zu einem Stamm (?), der die Karpatenübergănge beschützt und das Territorium der Lechiten von süden her abgeriegelt haben soll (Kucharski 1925, 8). Als restlos verfehlt ist in jüngster Zeit aber auch der Versuch des tschechischen Forschers 0 . Pilar̆ zu bewerten, der die Thafnezi volllig willkür-

3 Vgl. dazu Diepensee nw. Konnigs Wusterhausen (Teltow). In: Histor. Ortsnamenlexikon für Brandenburg. Tell IV. Teltow. Bearb. v. L. Enders. Weimar 1976, 50 If. 
lich in die Năhe eines Stammes (?) der Dulbinci und damit der bekannten Dulébi rücken wollte".

An autochthones slavisches Sprachmaterial knuppte in einer nicht publizierten Außerung der bekannte polnische Onomastiker T. Lehr-Splawinski an', indem er Thamezi mit Debnice gleichsetzte, wogegen bereits berechtigte Einwände erhoben wurden (ebda.). Wie Lehr-Splawinski vermutete der polnische Sprachwissenschaftler J. Nalepa, daB $\boldsymbol{C}$ in Thafnezi ein $b$ vertrete, was diesen Gelehrten auf die Dobna/Dobnica im Vogtland, einen ZunuB der oberen Weißen Elster bei Plauen brachte (Nalepa 1957-8).

Wie die hier nur abribartig wiedergegebene Geschichte der ThaineziEtymologie zeigt, ist es seit Safařik. seit nunmehr genau 150 Jahren nicht gelungen, dieses Ethnonym zu enträtseln. Es war nicht immer linguistisches Unvermögen, sondern meist auch der Trugschluß 'slavischer Stamm slavischer Name', der, zusammen mit der unbeirrbaren Oberzeugung von einer slavischen Ost-West-Wanderung, die Fehleinschatzung nicht allein des Thafnezi-Namens zur Eolge hatte.

Meine Deutung des Namens Thamezi ist in Grunde kurz und bündig: Das Grundwort Tharne- ist nichts anderes als die lateinisch-bairische Vertretung von griech. $\Delta a \dot{\varphi} \nu \eta$ 'Daphne'. des ursprünglichen Namens der berihmten Vorstadt von Antiocheia (Prokop V. 9. 29; Steph. v. Byz. 22), der spăter auf ein Kastell in Moesia inferior an der Donau übertragen wurde. Zur lautlichen Seite gibt es nicht viel zu sagen, außer daß anlautendes th- far $d$ - ein bekannter Reflex der 2. germanischen Lautverschiebung ist. der bei einem bairischen Geographen des 9. Jhds. naturgemäß zu erwarten ist. Elnfach erklärt sich auBerdem das slavische Surfix $-z i=-c i$ (= -bci), das man hier mechanisch an den fremden ON angehängt hat. Thamezi ist im ubrigen eine auffallend genaue Nachbildung der originalen griechischen bzw. lateinischen Einwohnernamen daquitns oder Daphnenses. Damit sind die Thamezi des GB auch schon kein "onomastisches Monstrum" mehr. Daß diese Etymologie uber jeden Zweifel erhaben ist, wird die nachfolgende Deutung des Namens der Prissani bestätigen (vgl. S. 178 ff.).

Es versteht sich von selbst, daB nicht der Name der Vorstadt von Antiocheia, sondern der gleichlautende des Kastells Daphne an der Donau far die Slaven namengebend gewesen ist. Die genaue Lage dieses Kastells

4 Pilaŕ 1974, 214 fr. - S. 281 sagt Pilaŕ freilich: "Der Name 'Thafenzi' /sic!/ (Duibincl?) låßt sich schwer enträtseln".

- Laut Kiersnowski 1951-2, 97. 
läßt sich nicht mehr bestimmen, da seine Ruinen offenbar vom Wasser der Donau fortgespult wurden (TIR L 35. 37 und Karte $=$ h/IV). Daphne, laut Jlrełek (1877, 160) heute Oltenics, wurde von Kaiser Konstantin d. Gr. am linken Donau-Ufer errichtet und war Sitz der ConstantinI Daphnenses sowie der Balistarii Daphnenses (Notit. Dignit. Or. VIll. 13. 14. 45. 46). Als befestigter Brückenkop? gegenüber Transmarisca, jetzt Tutrakan (Velkov 1980. 49 fl.). wo Konstantín eine Großfăhre und Valens (367) elne Schiffbrücke gebaut hatten, splelte Daphne beim Vorstoß der Romer gegen dle Goten eine eminente Rolle (Wolfram 1979, 72). Der strategisch wichtige Platz Transmarisca war für die Sicherung der römischen Donaugrenze von großem Gewicht und daher schon seit Domitian oder Trajan Auxillarlager6. Transmarisca war im 4. Jhd. auBerdem Station eines praefectus ripae der legio $X I$ Claudia, welche dle nach Konstantinopel rürende StraBe zu schützen hatte (KI. Pauly V. 925).

Daphne wurde von Konstantin d. Gr. als Gegenstück zu Transmarisca errichtet, weil inm die Stelle sehr geeignet erschien, den (Donau-)Strom von beiden Seiten aus $z u$ bewachen. Die Barbaren aber zerstorten im Laufe der Zeit das Bauwerk vollständig. worauf es Kaiser Justinian von Grund auf neu erbauen lleB" (Prokop V. lib. IV, 7. 7-9). Die weiteren Schicksale der Donaufestung Daphne sind unbekannt, doch ist anzunehmen. das das unter Iustinian (527-565) erneuerte Bauwerk in der Bolge abermals, und zwar endgültig zerstort wurde. Wāhrend der Regierungszeit Iustinians, der sich auf die Rückgewinnung der Besitzungen des ehemaligen rómischen Imperiums konzentrierte, verior Byzanz bekanntlich die Donaugrenze zeitweilig aus den Augen, weshalb sie seit etwa 530 immer hăunger von volkern aus dem Barbaricum, unter innen vorwiegend von Slaven bedroht wurde. Erste slavische Angriffe, es waren namentlich Raub- und Beutezüge. keine landnehmenden Aktionen, erfolgten während der Jahre 533 bis 551 (Niederle II. 434 If: W. Swoboda: SlowStarSlow II. 345 s.v. Justynian I Wielki). DaB der Name Daphne schon zu dieser Zeit von Slaven ubernommen wurde. ist kaum anzunehmen. Mit mehr Wahrschelnlichkelt ist dagegen an Jene Ereignisse zu denken, die später unter Kaiser Herakleios I. (610-641) stattfanden. Gedacht ist an die von Konstantin Porphyrogennetos uberlleferte Siedelgeschichte der Serben, die. in ihre alte linksdanubische Heimat zurūckkehrend, beim Oberqueren der Donau anderen Sinnes wurden und den 
Kaiser um neue Siedelplätze auf byzantinischem Gebiet baten. Obertritt und Rackkehr der Slaven Panden mit GewiBheit im Bereich der unteren Donau statt. Das aber könnte besagen, daB unter den Thamezi des GB eine Gruppe von Serben zu verstehen ist, die es aus der Gegend des Donaukastells Daphne in den Norden verschlug. Damit lieBen sich die Thamezi des GB als eine Art Synonym rur serben begreifen, wofur auch die verhaltnismäßig große Anzahl von 257 civitates sprăche (vgl. S. 181 f.).

\section{b) Zeriuani}

Der Name dieses Stammes ist nicht ganz so umstritten, wie der der Thafnezi. Ein Tell der Forscher identiflziert thn mit den von der PVL mehrmals erwähnten ostslavischen Severjane. was sowohl lautliche als auch geographische Erwägungen ausschliesen?. Für die Lesart Zeriuani = Séverjane plădierte insbesondere Tymieniecki (1946. 165 f.). dem Kiersnowski (1951-2. 94. 98 (f.) darin zwar folgte. den Sitz der Sêverjane aber nicht im Stromgebiet von Desna und Dnepr. sondern in Pommern in der Gegend von Kolberg und Belgard (h. Blalogard) sah. Von pommerschen Siewierzanie fehlt In den Quellen frellich jede Spur. Nicht weniger gewagt ist der Versuch M. Rudnickis, die Zeriuani als -Seri-vani zu deuten und darín einen Stamm (?) zu sehen. der im Gebiet der Weichselmündung, das heißt an den Flüssen 'Seria und $\cdot(P a)-s e r i a$, also an Dzierzgot $(=$ Sirgaune, Sorge) und Paslekl (Passarge) gelebt haben soll. Noch phantasivoller sind die Oberlegungen von Pilaŕ (1974. 242 f.). der in Zeriuani die prăpositionale Konstruktion $z$ Riuany sieht und glaubt, der Name bedeute .aus Rulana, Rana, Rugia”. also soviel wie "aus Rügen”. Diese Idee taucht ubrigens schon bei Horák/Trávniłek (1956, 39 f.) aư.

Andere Forscher sehen in Zeriuani dagegen den Namen der serben. Dies erkannt $z u$ haben. ist das unbestreitbare Verdienst des polnischen Orientalisten T. Lewicki (1956), der allerdings einen Schritt zu weit ging. wenn er glaubte. diese Serben seien die WeiBserben des Konstantinos Porphyrogennetos gewesen und ihre Wohnsitze in Großpolen und Pommern zu lokalisieren. Diese Ansicht Lewickis stieB auf Ablehnung. DaB unter Zeriuani Serben zu verstehen sind. haben grundsătzlich schon Garaj (1963), Rospond (1968. II. $12 \mathrm{ff}$.) und andere elngeräumt. Auch nach meiner Ansicht

T Zur Bedeutung von Séverjane vgl. Kunstmann '1988, Kapitel "Die sogenannten Stämme der Ostslaven". 
sind die Zeriuani $=$ 'Ser(i)v-ani $=$ 'Sp̣b-jane 'Serben'. was elnige elgene Bemerkungen erhărten. Der Vokal $i$ in anlautendem Zeriu- ist gewiB Nachschlag des silbilantischen $r$ und orthographischer Reflex dessen, was der Verfasser des GB akustisch gewahr wurde. Auf diese Weise entstand eine Art Pseudo-polnoglasie, das im Umfeld einer Liquida besonders in gemischtsprachigen Gebieten begegnet, vgl. 'Serimbnbci 'Leute von Sermium' (S. 138) oder 'Dal(b)mbnbci 'Dalmatiner' (S. 161 ff.) u.a. Bemerkenswert ist zudem der vermeintliche Vokal -u-, der in intervokalischer Position gewiB die Vertretung von $-v-b z w .-b-$ ist $^{\circ}$. Die Lautvertretung von $u$ far $v$ bzw. $b$ ist auch sonst nicht selten, man vgl. nur etwa Cieruiste. Kiruiste. Ciervisti. Zerbiste 'Zerbst' (Eichler 1966, 23). Kiersnowski meinte seinerzelt. die Endung -jane sei beim Serbennamen nicht ublich. Das ist im Prinzip richtig, nur steht m.E. nicht unbedingt lest, daß die Endung - ani uberhaupt das slavische Suffix -jane ist, da es sich ebensogut um den Nom. PI. des lateinischen Zugehörigkeitssuffixes - āni (-änus) handeln kann. Es scheint, daß der bairische Geograph auch in anderen Fällen das ihm vertrautere lat. Sufflx - ani dem slavischen -jane vorgezogen hat. Analoge Vorgänge liegen im Grunde auch in griechischen Ortsnamen wie

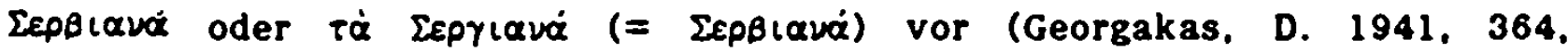
373 P.).

Man wird unter den Zeriuani des GB somit Serben zu verstehen haben.

\section{c) Prissani}

Abgesehen von Zeußens kurioser Deutung dieses Namens, der nach seiner Meinung die Bewohner von Prizren bezeichnet (Zeuß 615), bewegt sich die Etymologisierung der Prissani im allgemeinen zwischen urslav. • berza 'Birke' und 'bérgz (> 'brégz) 'Ufer' (Horák. Trávnicek 40 ९.). Die Version 'BreZane 'Uferbewohner' steht dabei vorwiegend in der Gunst einiger prominenter Sprachwissenschaftler und Historiker'. Innerhalb der polnischen Geschichtswissenschaft hat sich noch eine andere Deutung herauskristallisiert. die erwăhnenswert ist. weil sich mit ihr ein eigener Lokalisierungs-

- Theoretisch könnte sogar ein bairischer Betazismus vorliegen, vgl. Weinhold 1867, $137 \mathrm{f}$., was hier indes wenig wahrscheinlich ist.

- Lehr-Splawinski in SlowStarSlow 1, 169; Urbanczyk ebda. IV. 351; ahnlich Sulowskl ebda.; Ludat 1969, 12 \%: an eine Ableitung von 'bregs oder - berza denken dagegen R. E. Fischer und T. Witkowski 1967,671, 
versuch verbindet. Wojclechowski (1951, 143), Klersnowski (1951-2, 77, 81) und Lowmiatiski (1964-73, III, 175) nåmllch glaubten, das ragliche Ethnonym hänge mit Pyritz in Westpommern zusammen, so daß unter Prissani eigentlich Pyritane (poln. Pyrzyczanle) zu verstehen seien. Natanson-Leski (1959, 440, 448) dachte an dle "verkürzte" Form Pyrzanie. Doch weder Pyrzyczanie noch Pyrzanie hielt schon Urbatczyk für wahrscheinllch (SlowStarsiow IV, 351).

Die Form Prissani besteht aus zwel Teilen, aus Priss- und dem Sufflx -ani. das, wie schon im Fall der Zeriusni nicht slavisches -jane zu sein braucht, sondern wahrschelnllch das lat. Suffix -ani ist. Priss-. darin ist Urbanczyk zuzustimmen, hat als topographisches Element zu gelten. Dabei ist Priss- wohl kaum das Resultat einer Metathese aus ' berza oder 'bergz. da sonst, wie in gemischtsprachigen Zonen nicht selten, mit Periss- oder ăhnlichem zu rechnen wäre. Außerdem ist anlautendes $P$ - Praglos Vertretung für b, also, wie im Fall der Thafnezi < Daphneci, Ergebnis der 2. germanischen Lautverschiebung. Das Zeichen -ss-. Urbatczyk als Graphem für -z- "verdächtig". kann, wie im Altbairischen mehrmals, ebensowohl Verstärkung oder Doppelung von einfachem $s$ sein (Weinhold $161 \mathrm{f}$ ). Für Prissani ist folglich Brisani zu lesen.

Die in Prissani enthaltene Wurzel Bris- verweist auf den Stammesnamen der thrakischen Brisae, die Plinlus in seiner Naturalls historia (IV. 40) als bessischen Sonderstamm erwăhnt, wobei allerdings ihr Name zu Brigas oder auch Brygas entstellt wird. Schon Tomaschek (1893-4, I. 72; II/2. 17) erkannte die Korruptel und verbesserte sie zu Bpioal, Brisae ${ }^{10}$. Im ubrigen ist der Name in mehreren PNn enthalten, so etwa In Dentu-brisa (Duridanov 1985, 56, 116) und in makedonischem Bpiowv, vgl. auBerdem die etymologische Erklärung von Detschew (89 P.), der das Wort mit lat. brisa 'Weintrester' zusammenstellt.

Ober den Stamm der Brisae scheint nicht allzuviel bekannt zu sein. doch sollen nach Danov (Kl. Pauly I, 945 (.), einem hervorragenden Kenner thrakischer Geschichte, deren Sledelgebiet am Unterlaup von Nestos (Axios; Vardar) und Strymon sowie ostlich an den Hängen der Rhodopen gelegen sein. Das führt in elne Gegend, in welcher sich spăter Slaven niedergelassen haben, die mllitärisch so stark gewesen sein sollen, daß sie Byzanz

10 Daß Tomascheks Korrektur richtig war, bestätigt der Fund einer lat. Inschrift aus Diana Veteranorum. vgl. dazu H. G. Pflaum in der Zeitschrift Libyca 3, 1955, 135-154, und hierzu Bengtson 1959 135 pe. 
gefährlich wurden und unter Ihrer Agide das Strymon-Thema zu einem ausgesprochen slavischen Territorium wurde (Rajkovic. M. 1956). Es fallt nun allerdings auf, daß aus eben der Gegend an Nestos und Strymon slavische Gruppen in den Norden abwanderten, die im Bereich der Peene seBhaft wurden und als Zirzipanen (Eıpเoraioves) in die historischen Quellen eingegangen sind ( $v g 1$. S. $51 \mathrm{fr}$.).

\section{Zur Lokalisierung der drei Ethnika}

Die komplizierte Frage nach den Sledelgebleten der Thatnezi-. Zeriuanj und Prissani ist am besten uber Letztere anzugehen, weil sich für sie ein verhältnismäßig sicherer Ansatz ergibt, und zwar mit Hilfe von Helmold von Bosau, dessen Brizani wohl ohne Frage identisch sind mit den Prissanj des GB. Für eine Identität spricht in erster Linie natürlich die Gleichheit der Namen, aber auch der Umstand, daß die thrakischen Brisae ja südlich der Donau beheimatet waren. der GB aber nur Namen nördlich davon aufzählt (ad septentrionalem plagam Danubii). Das besagt, daß die PrissaniBrizani, deren Namen nur Slaven übertragen konnten. nördlich der Donau zu Hause gewesen sein müssen.

Helmold, der als einziger mittelalterlicher Chronist dle Prissani erwähnt, zitiert sie insgesamt dreimal: Brizanorum et Stodoranorum populi, hii videlicet qui Havelberg et Brandenburg habitant (72, 20); Brizani ceterique rebelles pacem postulaverunt (73, 25): omnem enim terram Brizanorum. Stoderanorum multarumque gentium habitantium iuxta Habelam et Albiam misit sub iugum (174.20). Daraus ergibt sich überzeugend, daB die Prissani-Brizani im Gebiet der Havel saßen und ihre Hauptburg vielleicht Havelberg war'. Moglicherweise sind auch im Bereich von Havel. Rhin und Dosse auftretende ONn wie Brisenlank. Briesenlang u.a. ${ }^{12}$ Relikte der Brizanf oder Brisanent3. Man darf somit die Brizani wie die Stoderanen zu

11 Sulowski in SlowStarSlow I, 169; anders H. Stoob, der die Brisanen in der Ostprovinz um Pritzwalk sucht, vgl. Helmold v. Bosau: Slawenchronik. Neu übertragen u. erläutert v. H. Stoob. Darmstadt 1973, S. 151 , Anm. 13.

12 Historisch. Ortslex. P. Brandenburg. Tell III. Havelland. Bearb. v. L. Enders. Weimar 1972, $48 \%$. Vielleicht gehört hierher auch der in den Quellen nur einmal zu 1320 erwăhnte Brisengowe in castris Tutenberg. Lobdeburg et Werrinberg, vgl. Eichler 1966, 3.

13 Zur Geschichte der Brizani/Brisanen vgl. Herrmann. J. 1985: Register 597. 
den Havel- und Spree-Slaven rechnen, also den wilzen. GewiB waren die Brizani aber kein slavischer Stamm, sondern eher eine kleine Gruppe von Zuwanderern, die vermutlich schon bald nach der endgüligen Unterwerfung Brandenburgs (1157) durch Albrecht den Băren ihren Namen verloren. Dem - wie sich immer wieder zeigt - gut informierten GB ist es zu verdanken. daß sich für die Prissani-Brizani eine kohărente Siedeldauer von immerhin 300 Jahren nachrechnen låBt.

Wenn. wie oben gezeigt, unter Zeriuani Serben zu verstehen sind, ergibt sich in der geographischen Reihenfolge der Zeriuani und Prissani sogar elne gewisse Logik, das helBt, den an Havel und Spree siedelnden Prissani folgen südlich davon zwischen Elbe und Fläming im pagus Cieruisti 'Zerbst' die Zeriuani. Daß unter den Zeriuani tatsăchlich Serben zu verstehen sind. ergibt sich nicht allein aus der Etymalogie, sondern vor allen Dingen aus der Sonderstellug dieses Ethnikons innerhalb des GB. In ihrem Fall wird nämlich nicht wie ublich eine genaue Zahl von Burggemeinden (civitates) gegeben. dafür die Größe dieses Stammes und seine einmalige Bedeutung für die Slaven mit einem eigenen Satz unterstrichen: tantum est regnum ut ex eo cunctae gentes Sclauorum exortae sint et originem, sicut afnrmant. ducant. Dieser unikale Satz bestätigt, daß die Serben um 850 den Ruf genossen, sowohl uber eln bedeutendes Herrschaftsgebiet (regnum) verfugt zu haben, als auch der Urstamm aller Slaven gewesen zu sein. Diese Charakteristik, da kann es kaum Zweifel geben, lāBt sich auf keinen anderen slavischen stamm als die Serben beziehen.

Auch die Thafnezi sollen laut GB ein größerer Stamm gewesen sein, da inm 257 Burggemeinden zuerkannt werden, was jedoch uberrascht, weil der Name ausgesprochen singulăr ist und nur vom GB erwähnt wird. AuBerdem gibt es auf nord- und mitteldeutschem Gebiet nicht einen einzigen onomastischen Anhaltspunkt fur diesen Namen, was sich bei 257 civitates vielleicht doch erwarten ließe ${ }^{14}$. Die singuläre Nennung dieses Ethnonyms in einem Schriftdenkmal von etwa 850 und sein onomastisches Vakuum rahren zu dem SchluB, daß die Bezeichnung Thamezl entweder nur vorubergehend In Gebrauch war oder aber, wie schon oben angedeutet. ein synonymes Wort far serben war. das zugunsten des ethnonymlschen oberbegriffes verdrångt und vergessen wurde. Wahrscheinlich bezieht sich

14 Auch wenn man, wie R. Nový (1968, 146), die Thamezl zu den Ostseeslaven zählt, lassen sich aus diesem Bereich keine einschlägigen Toponyme beibringen. 
daher auch die fur die Thamezi gegebene große Anzahl von Burggemeinden mit auf die Zeriusni oder serben. 


\section{Serben und Sorben}

Mit Ausnahme des sorbischen Etymologen H. Schuster-Sewc stimmt die Fachwelt darin überein, daß die Namen der Serben und Sorben etymologisch identisch sind', das heiBt, daß beide aus 'sbrbs > urslav. 'sfbs entstanden sind, im Südslavischen $S \dot{b} b(i n)$ und im Westslavischen sorb ergeben haben. Schuster-Sewc zufolge $(1972,221)$ ist diese nur schwer zu verkennende Obereinstimmung jedoch "rein zufällig”.

Ober die Landnahme der Sorben, deren mittellateinischer Name Surbi. dann Surabi und Sorabi ist. verlautet in den einschlägigen Quellen kein Wort, so daB sowohl die Zeit ihrer Zuwanderung nach Mitteldeutschland. als auch ihre frühere Heimat vollig im Dunkel bleiben. Daß Serben und Sorben nicht gut jene, von Plinius (Nat. hist. VI. 2, 29) und Ptolemaios (V. 9. 12) in der Don-Region zwischen Asowschem Meer und Wolga placierten EÉpßol oder Eipßol sein können². ergibt sich allein aus den verschiedenen Zeitstellungen zwischen den Nachrichten der antiken Schriftsteller und dem ersten Auftreten der Slaven im 6. Jhd. Slavische Serben werden uberhaupt erst zum Beginn des 7. Jhds. genannt (vgl. S. 186) ${ }^{3}$.

Dank der merowingisch-karolingischen Historiographie ist der Name der Sorben schon verhältnismäßig früh belegt. Der allererste Beleg stammt bekanntlich von Fredegar, der im Zusammenhang mit den Ereignissen um Samo berichtet: etiam et Dervanus dux gente Surbiorum. que ex genere Sciavinorum erant et ad regnum Francorum iam olem aspecserant, se ad regnum Samonem cum suis tradedit (Fred. 155, cap. 68, 10). Damit sind die Surbi 'Sorben' also schon für etwa $630 \mathrm{n}$. Chr. nachgewiesen. Die in dem "Namen" des Sorbenfürsten Dervanus enthaltene Herkunftsbezeichnung (vgl. oben S. 89 (.) ist auBerdem ein sehr wichtiger Hinweis darauf, daB die Sur-

* Vgl. etwa Trautmann 1947, 98, oder Eichler ${ }^{2} 1962,111$, wo ausführlich uber den Sorbennamen gehandelt wird.

2 Jenkins 132; Kretschmer: Pauly RE II. Reihe, II. Bd., 1669; Ditten 1978. 445.

3 Ebensowenig mit Slaven zu tun hat der von M. Rudnicki (II. 1961, 188) erwähnte, in der Nähe von Regensburg vermutete ON Serviodurum der Tabula Peutingeriana. Rudnicki ist darín zuzustimmen. daß Servio- die nämliche Wurzel wie Sorb-enthält, während - durum natürlich keltischer Provenienz ist. Mit Sicherheit stimmt mit Servio- und Sorb- aber auch der pannonische, an der Save nachgewiesene ort Seruitio, Serbitium (Rav. geogr. 217, 15), Servitti (It. 461) uberein. Allen zugrunde liegt lat. serv-. 
$b j^{\star}$ aus dem sũdlichen Dalmatien, und zwar aus der Gegend von Derva im Land der lllyrischen Dervani zugewandert sind, was geographisch genau mit gewissen Vorgängen der serbischen Siedelgeschichte übereinstimmt (vgl. S. 187). DaB aus dem Stamm der Serben/Sorben, der am Ende des 6. Jh. im mittleren Donaugeblet...stand..., eln Teil ausschied und nordwärts wanderte". wird nun auch seitens der Archäologie für wahrscheinlich gehalten (Herrmann, J. 1985, 27). Zu präzisieren ist hier bestenfalls, daß die aus Derva zugewanderten Surbi zu denjenigen Serben gehört haben werden, die Kaiser Herakleios durch den Kommandanten von Belgrad in Dalmatien ansiedeln lieb (vgl. unten).

Fredegars singulărem Beleg des Sorbennamens folgen für das 8 . und

9. Jhd. mehrere Notierungen in den Annales regni Francorum:

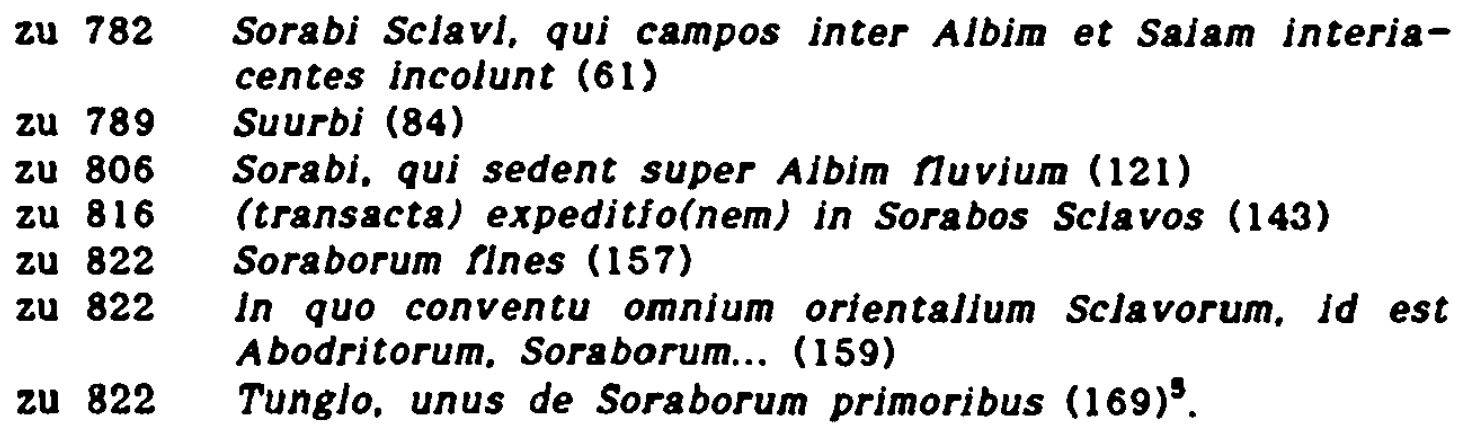

AuBer einmal Suurbi ${ }^{\bullet}$ weisen dlese Belege konstant die mittellateinische Form Sorabi auf, die ubrigens gleichermaßen fü die südslavischen Serben verwendet wird: zu 822 ad Sorabos, quae natio magnam Dalmatiae partem optinere dicitur (158); zu 823 quod relictis Sorabis (161).

Mögllcherweise sind auch unter den Surpe bzw. Surfe Alfreds des GroBen die mitteldeutschen Sorben zu verstehen (Havlík 1964, 78; Kötzschke 1961, 52): ihre Erwähnung geht vermutlich auf den königlichen Verfasser selbst zurück, da Orosius (5. Jhd.), sein Vorbild, sie noch nicht kannte (und auch nicht kennen konnte).

Gesonderte Aufmerksamkelt verdient die noch vor König Alfred entstandene Völkertafel des Geographus Bavarus (Herrmann, E. 1965, 220 ^.).

- Varianten der Fredegar-Codices sind gentesurbiorum und gentes urbium.

- Teitere frühe Belege bei Eichler 1966, 21.

- Die Schreibung Suurb erinnert, nebenbel gesagt, auffallend an die nordostbayrischen ONn 1303 Swurbz. (um) 1390 Swuerbs; 1317 Swurbz: 1231 Svurbez = Schwürbltz. Schwärzhof u. Schwür, die Schwarz $(1960,260)$ zu einem sehr seltsamen Beinamen 'Svrb 'Jucker' stellte, well ihm das w bzw. $v$ der fruhen Notlerungen unerklärlich war. Dabel ist doch bekannt. daß spätlatein. u graphisch hăung durch uu, vu u.a. wiedergegeben wird. DaB Swurbz mit dem Sorbennamen zusammenhãngt. ist wahrscheinlicher als der semantisch komische 'Jucker': im übrigen sind die heutigen Formen Schwurbitz u.a. gewiB Umdeutungen. 
die drel Ethnonyme aberliefert, die sich von ihrer Form her alle drel auf den Sorbennamen bezlehen:

1. Iuxta illos (i.e. Hehfeldi) est regio quae uocatur Surbi. in qua regione plures sunt quae habent ciuitates $L$.

Unter diesen im 1. Tell. Zeile 8-9, des GB erwähnten Surbi sind, entsprechend ihrer Nennung zwischen Heveler und Daleminci, ohne jeden Zweifel Sorben zu verstehen, was von der uberwiegenden Mehrheit der Gelehrten ebenfalls so gesehen wird.

2. Zeriuani quod tantum est regnum ut ex eo cunctge gentes Sclauorum exortae sint et originem sicut affirmant ducant. Auch die im 2. Teil, Zeile 3, der Völkertafel genannten Zeriuani entsprechen, wie gezeigt (S. 177\%.), mit großer Wahrscheinlichkeit dem Serben- oder Sorbennamen.

3. Serauici.

Die ohne Angabe einer Burgenzahl im 2. Teil, Zeile 7, erwăhnten Serauici hielt schon Karamzin für Serben, was jedoch Dobrovský mit dem Argument verwarf, diese hăten südlich der Donau gelebt (Horák, Tráunilek 45 \%.). An die Sorben dachte man freilich nicht. Unverkennbar ist in Jedem Fall die Ahnlichkeit zwischen der Form Serau-ici und den mittellat. Serab-ici oder Sorab-ici.

Alle drel zur Debatte stehenden Namen - Surbi. Zeriuani. Serauici - sind nach meiner Meinung Varianten ein- und desselben Serben- bzw. Sorbennamens. Die unterschiedlichen Schreibweisen gehen wohl auf verschiedene Oberlieferungen zurück: Dem Verfasser des GB wurden drei divergierende Namen hinterbracht, die er nach Gehör notierte, wahrscheinlich ohne zu ahnen, daß dreimal das nämliche Ethnikon gemeint war. Die Identităt der drei Namen läbt sich am "Grundwort" ablesen: 'Surb-, "Zer(i)v-. "Serav-; am meisten differieren lediglich die Suffixe $-i$, -ani und -ici, die zum einen den slavischen (oder lateinischen?) Nominativ Pluralis $-i$, zum anderen das sehr wahrscheinlich lateinische Zugehörigkeitssufix -ani sowie das zur Herkunftsbezeichnung (Bosanac. Moravec) verwendete slavische Suffix -bcl $(-b c b)$ repräsentieren.

Besonders aufschluBreich ist die sub 2 zitierte Bemerkung über die Zeriusni. deren "Land so grob ist. daß alle slavischen Stämme von ihnen abstammen und ihren Ursprung haben". Dieser Satz ist, wie schon gesagt (S. 181 f.), einmallg und kann sich auf keinen anderen Stamm als die Serben 
beziehen. Derartige "superlativische" Merkmale werden den Serben von verschiedenen mittelalterlichen schriftstellern nachgesagt. Bekannt ist beisplelsweise der Ausspruch des byzantinischen Historikers Laonikos Chalkondyles, der noch im 15. Jhd. in seiner die Zeit von 1298-1463 be-

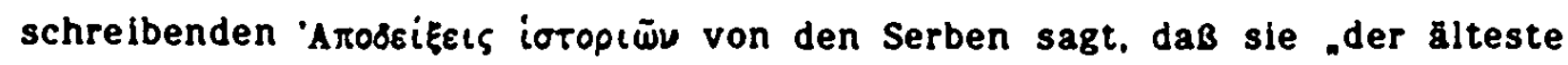

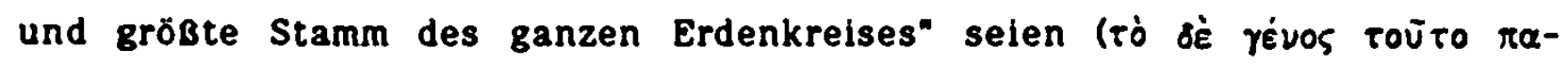

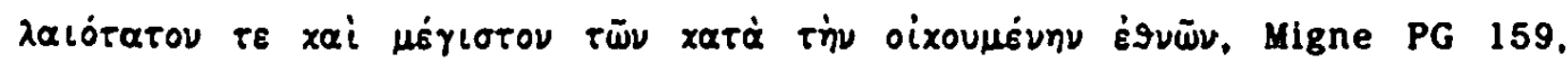
41)'. Chalkondyles meint damit natürlich die Serben auf dem Balkan; der ebenfalls die Größe des Serbenstammes akzentulerende Satz des GB bezieht sich hingegen auf die mitteldeutschen Sorben. Das aber läBt den SchluB zu. daB der ruhmvolle Leumund der Balkanserben schon vor 850 von Slaven ubertragen worden ist. Höchst aufschluBreich an der Laudatio des GB ist auBerdem die Behauptung. „alle slavischen ståmme" stammten von den Serben ab. worin sich m.E. eine deutliche Ansplelung auf die balkanische Herkunft der mitteldeutschen Slaven ausdrückt.

Laut Konstantinos Porphyrogennetos (DAI 32, 7-12) war einer der Söhne des serbischen Königs mit der Hălfte seines Volkes zum byzantinischen Kaiser Herakleios I. geflüchtet, der diesen Serben Land im Thema Thessalonike zumies. DaB sich mit diesem Vorgang der ON des strategisch bedeutenden Platzes Srbica, auch Srbciste, Serbia und Serfidze verbindet. ist zwar umstritten, aber durchaus denkbar (Zupanic 1927-8; ders. 1928; Skok 1938). Vielleicht haben tatsăchlich millitărische Qualltăten der Serben den Ausschlag bei ihrer Ansiedlung gegeben (Jenkins 132). Wie Konstantinos Porph. weiter berichtet, baten nun diese Serben Herakleios nach einiger Zeit, wieder in ihre alten Gefllde zurückkehren zu dürfen. Der Kaiser ließ sie gewähren. doch beim Oberqueren der Donau uberlegten es sich die Serben wieder anders und baten erneut un Asyl aup byzantinischem Boden. Durch den Strategen von Belgrad lieB innen Herakleios Paganien, also das Land der Zachlumer. Travuner und Kanaliter zuweisen, mit anderen Worten das spătere Serbien. Da dieses Land, wie die DAl berichtet, soeben von den Awaren gerăumt wurde. nimmt man an, daB die zweite und endgültige Ansiedlung der Serben um 626 stattgefunden hat. Damit aber wur-

7 Der Autor spricht an dieser stelle zwar von Triballern (Triballoi), meint damit aber, byzantinischem Brauch folgend. Serben, vgl. Jlrecek 1911. I. 26 1.: Radojicle 1957, 278. - Die Serben wurden von den Byzantínern aber auch Dalmater genannt (Jirecek 1911, 1, 114), so daB unter den „săchsischen" Daleminci (vgl. S. 161 M.) ebensowohl Serben-Sorben verstanden werden können. 


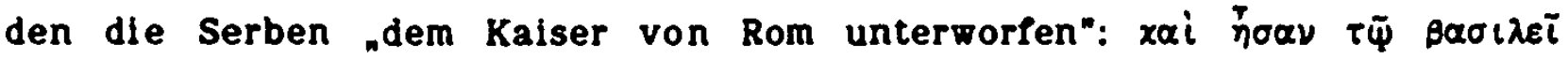

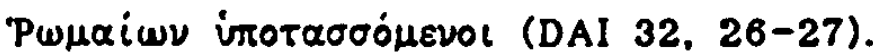

Der Bericht von Konstantinos Porph., mag er im Detall auch legendär sein, enthält doch sehr wichtige siedlungsgeschichtliche Elemente. Danach steht fest, daB es zwei serbische Siedelplätze auf dem Balkan gegeben hat, einen vorübergehenden in Thessalien und den ständigen in Dalmatien. Besonders wichtig ist der Hinweis auf Thessalien, da sich nun Berührungspunkte mit den vom GB zitierten Prissani abzeichnen, deren Name, wie gezeigt (S. 178 ff.), auf die thrakischen Brisae zurückgeht. Dle Sitze dieser Brisae aber werden zwischen den Unterläufen von Nestos und Strymon vermutet, was in groben Zügen Thessalien mit einbezieht. So gesehen kōnnen also die Prissani des GB ursprügllch Serben aus Thessallen gewesen sein.

Die Siedlungsgeschichte der Serben wirft weiter die Frage auf, wo diese die Donau uberschritten haben. Dies muß ja wenigstens $z$ weimal von Norden nach süden und einmal in umgekehrter Richtung geschehen sein. In diesem Zusammenhang bringen sich abermals der eminent wichtige DonauObergang Transmarisca-Daphne und mit inm die Thafnezi des GB in Erinnerung (S. $173 \mathrm{fl}$ ). Natürlich läßt sich nicht sagen, ob dle Serben den an der unteren Donau gelegenen Obergang tatsächlich benutzten, nur macht die Wiederkehr des Namens als Ethnonym stutzig. Auch spricht die Lage von Transmarisca-Daphne im weiter östlichen Donau-Bereich dafur, daß die Serben eben hier erstmals byzantinisches Territorium betraten". Jedenfalls läßt es die Reihenfolge der Namen Thafnezi, Zeriuani, Prissani wahrscheinlich erschelnen, daß in allen drei Fällen Serben gemeint sind, die mögllcherweise bei Transmarisca-Daphne die Donau uberschritten, zuerst in Thessalien angesiedelt und darauf in Dalmatien seBhaft wurden. Von ihnen werden sich $z u$ verschiedenen Zeiten der etwas komplizierten serbischen Landnahme größere und kleinere Gruppen abgespalten haben und nach Norden weltergewandert sein.

Irgendwann im Laufe des 7. oder 8. Jhds. mussen einzelne Slppschaften oder Kleinverbände auch den 2 weiten und endgültigen Siedelplatz der Serben in Dalmatien verlassen haben, um sich in Mitteldeutschland unter

- Ein Oberschreiten der Donau kann freilich auch dort erfolgt sein. wo die ehemaligen römischen Grenzbefestigungen verliefen (Vulpe 1950; Condurach 1967), z.B. beim heutigen rumänischen Serbeştii Vechl, nun ortsteil von Galafl, am Ufer des Sereth in der Provinz Moesia inferior. 
den Namen Daleminci oder Glomaci niederzulassen. Wie der tschechische Chronist Cosmas zu Beginn des 12. Jhds. mitteilt, breltete sich der Sorbenname auch auf den Gau Daleminze aus. was ja wohl besagt, das "das Ethnonym Daleminzier bzw. Glomazi offensichtlich zugunsten der Bezeichnung Serb- bzw. Sorb- aufgegeben wurde" (Eichler 1976, 69). Das Erlöschen der Ethnonyme Daleminci und Glomaci ist gewiB nicht allein mit der Expansion des Sorbennamens zu erklären, vielmehr ist anzunehmen, daß Daleminci, Glomaci u.a. Sozusagen Sub-Namen waren, die sich von einzelnen Gebleten oder Orten herleiteten, während der Sorbenname gewissermaBen ein Oberbegriff war. Damit vergleichen lassen sich heutlge Herkunfts bezeichnungen wie Egerländer, Gablonzer. Krumlauer u.a., zu denen der Oberbegriff Sudetendeutsche gehört. Daß aber die Serben aus Mitteldeutschland zum Balkan abgewandert sind, wie es noch vor kurzem Relja Novakovic glauben machen wollte?. ist völlig auszuschlleßen. Wenn sich die Namen der Abodriten. Daleminci. Zirzipanen, Serimunti. Kaschuben und vieler anderer eindeutig von Sprachen und Toponymen des Balkans herleiten. ist die Annahme, die Serben seien von Sachsen nach Dalmatien gezogen. unrealistisch und verfehlt.

Die Etymologie von Serb-/Sorb- ist trotz unendlich vieler Bemühungen (Nlederle II, 486 fr.) im Grunde noch immer unsicher. Im allgemeinen herrscht die Ansicht vor. Formen wie russ. paserb 'Stiefsohn', poln. pasierb. pasierbica 'Stiefsohn, -tochter'. ukrain. pryserbytysja 'sich an jmd. heften, anschlleßen' könnten auf ein slavisches Grundwort 'ssrbs zurückPuhren ${ }^{10}$, wogegen es allerdings auch Vorbehalte gibt. Vorsichtiger āuBerten sich schon Preobrazenskij (1910-18, 276 f.) und Slawski (SlowStarslow V. 135). wenngleich auch sie die Entstehung von paserb aus "pa-síb rür am wahrscheinlichsten hielten ${ }^{11}$.

1921 ăußerte der bekannte Dorpater Slavist Leonhard Masing die Vermutung. daß der „Name der sudslavischen Serben und der gleichbedeutende der nordwestslavischen (lausitzischen) Serben (auch Sorben

- Vgl. zu Novakovic 1977 auch die sehr positive Rezension von Jan Lesny. Kwartalnik historyczny 86, 1979, 498-503, der die "erste Wiege" der Serben seltsamerweise in "Obersachsen" (? Górna Saksonia) sehen möchte.

10 Solmsen, F. 1904: Kallma, J.; Mikkola 1928, 91: Trautmann 1947, 54: Vasmer REW II. 611 l.; Popovic 1960, 347. Anm. 1.

11 Für Eichler 1966, 21 \%., ist diese Lósung ,am ansprechendsten". 
genannt)" von lat. servus herrühre (Masing 1921, 91) ${ }^{12}$. Die nămliche Ansicht vertrat zur gleichen Zeit (und daher wohl unabhangig von Masing) der bedeutende russische Philologe A. Sobolevskij (1921-22, 323), der szrbs, paşrbs (pasynok) auf lat. servare, servus zurückführte und mit 'beschützen, bewachen, Wächter' (oberegat', ochranjat', storoz) deutete. Sobolevskij zufolge war die ursprüngliche Bedeutung von Sbrbs somit: oberegatel', Celovek godnyj dlja oberegan'ja ${ }^{13}$. Die Etymologie Serb-< servus wurde zuletzt von dem französischen Byzantinisten H. Grégolre (1944-5. 89 ก.) vertreten, was freilich ohne große Resonanz blieb.

Der erste aberlleferte Deutungsversuch des Serbennamens stammt bekanntlich von Kaiser Konstantinos Porphyrogennetos, dessen an den Haaren

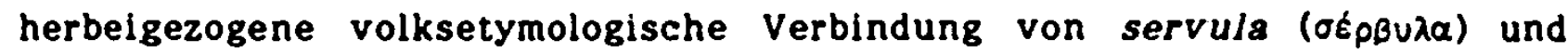

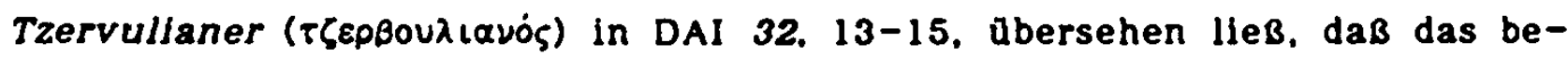
treffende Serbenkapitel (32) auch Hinweise enthălt, die entscheidend zur Klărung des Sachverhaltes beitragen können. Konstantinos sagt zunächst

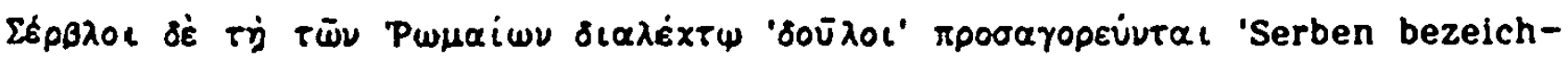
net In der Sprache der Römer (= Byzantiner!) soviel wie sSklavene' (32.

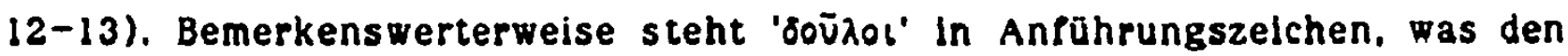
SchluB erlaubt, daß hier etwas anderes als "Sklaven" gemeint sein kann.

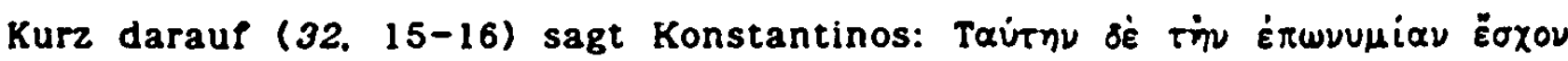

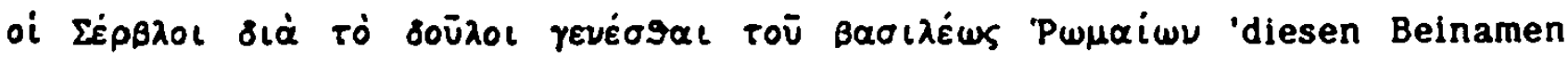
bekamen die Serben, weil sie zu Sklaven des römischen Kaisers geworden

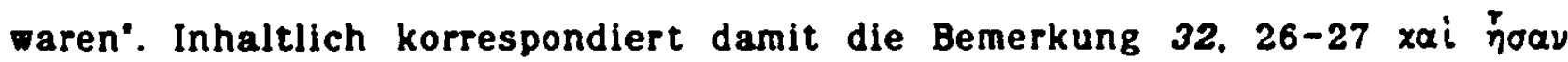

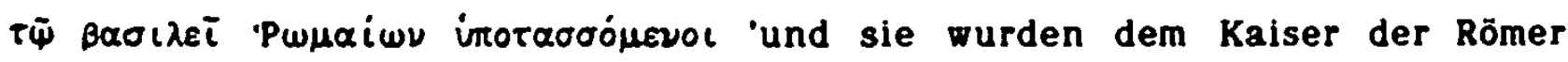
unterworfen'. Damit wird gesagt, daß die Serben nun, nachdem man ihnen neue Sledelplătze in Dalmatien-Paganien zugewiesen hatte, endgültig zu Untertanen von Kaiser Herakleios I. geworden waren, ihm unterwor-

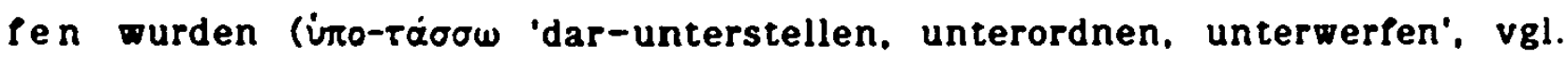

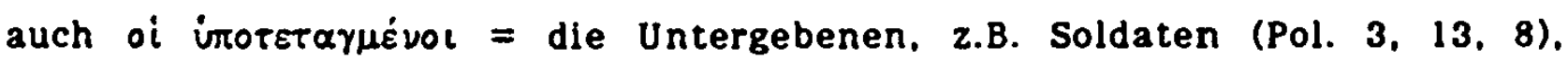
Untertanen). Das aber besagt auch, daß sich die Serben in ihre neue Rolle als Untertanen des römischen Kaisers fügten, so daß es kein Zufall ist. wenn Konstantinos auch an anderen Stellen „nicht müde wird zu erklären. daß die Serben und Kroaten nach ihrer Ankunft auf dem Balkan die Hoheitsrechte des byzantinischen Kaisers anerkannten" (Ostrogorsky 1975.

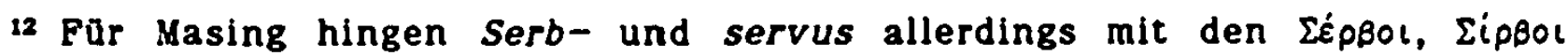
des Ptolemaios und Plinius zusammen.

13 Gegenuber dieser Etymologie zeigte sich Machek 1930, , $_{\text {s }}$ skeptisch 
74). Die Bedeutung von soũaos ist im Fall von Konstantinos' Serbenbericht also nicht so sehr 'Sklave', sondern Untertan, was Im Einklang steht

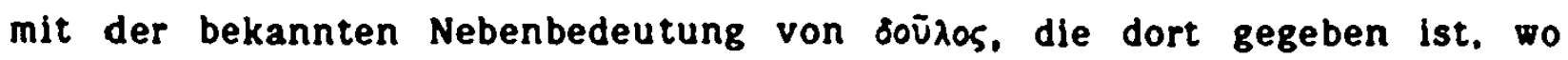
von Untertanen eines Monarchen (oder Despoten) die Rede ist. Pür die Griechen waren zum Belsplel alle Perser, selbst die Satrapen ihrer Könige

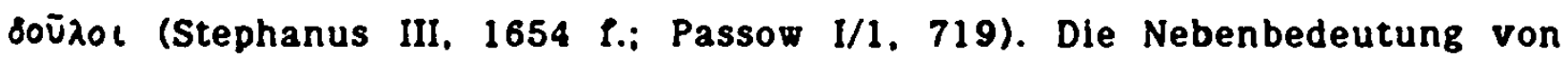
Untertan. Diener ist aber auch für lat. servus gegeben (Klotz II, 1321); hier klingt noch die semantische schicht des ursprünglichen Verbaladjektivs servus 'dlenend. dienstbar' an (Hofmann-Szantyr 155) 14 .

Aus den Mittellungen Kaiser Konstantinos' über die Aufnahme der Serben in das byzantinische Reich wird ersichtlich, daß deren erste Ansiedlung in Thessalien, also auf griechischsprachigem Gebiet erfolgte, Ihre endgültigen Siedelplätze aber nördlich der Jirecek-Linie, das heißt auf dem Boden der Latinität lagen. Daraus erklärt sich die „Obersetzung" der griechischen soũzol in lateinische servi. Die Aufnahme der Serben in das byzantinische Imperium als Untertanen macht aber auch die Etymologie von 'sbrbz aus serv-us historisch plausibel. Gegen elne Herleitung von - sbrbb aus Formen wie russ. pa-serb. ukrain. pry-serb-ytysja u.a. sprechen verschiedene Faktoren, In erster Linie die Beobachtung, daB diese Wörter nur sehr vereinzelt vorkommen, also unproduktiv geblieben sind. weshalb es schwerfăllt, darin die erforderliche Dynamik für die Entfaltung bedeutender slavischer Stammesnamen zu vermuten. Hinzu kommt. daß -şrbs niemals präfigiert erscheint, sondern immer Simplex ist. während pa-serb U.a. stets als Kompositum vorkommen. Ein weiterer, gravierender Einwand gegen eine Verbindung von Serb- und paserb ist die Tatsache. daB sich bislang noch kein elnziger autochthoner slavischer Stammesname nachweisen lieB. Ausgerechnet das unproduktive -serb (pa-serb) soll zu einem elgenen slavischen Ethnonym geführt haben?

14 Dazu gehören natürlich auch servitus im Sinne von Grunddienstbarkelt (Kl. Pauly V, 145 l.) sowie servitus 'Untertanenschaft' der Conversio Bagoariorum et Carantanorum, vgl. Mitterauer, M. 1960, 720 l.; auch an die Gleichsetzung von servus und captivus in den Volksrechten ist zu erinnern, vgl. Bosel. K. 1964, 196. - Sehr schōn kommt der Sinn des Dienens außerdem in dem slav. PN Zeruo des Salzburger Verbrüderungsbuches (Ende 8. Jhd.) zum Ausdruck (Herrmann, E. Higig65:Kungtongnn-9783954792238 
28. Was sich aus den Untersuchungen erglbt

Vorangehende Einzeluntersuchungen gewähren erste Einblicke in verschüttete und verkannte Siedelvorgänge Nord- und Mitteldeutschlands. Sie sind der Beginn von Erkenntnissen, die durch weitere Detallforschungen zum Mosaik-Bild der slavischen Besledlung besagter Regionen zusammenwachsen werden. Die grundlegende, elgentlich schon mit der Etymologisierung des Abodriten-Namens aufgekommene Einsicht, daB Nord- und Mitteldeutschland nicht, wie seit jeher angenommen, vom Osten, sondern vom Sũden, vom Balkan her mit Slaven bevolkert wurden, steht im vollen Einklang mit der mittlerweile mehrfach bestätigten Beobachtung. wonach das Territorium Polens analoge Siedlungsvorgänge aufzuweisen hat. Die Vorstellungen vom sogenannten polnischen Autochthonismus sowie von der Urheimat der Siaven $z$ wischen Elbe-Oder-Weichsel sind ebenso uberholt wie die von der slavischen Expansion aus dem Osten; das bestätigen sowohl bereits veröffentlichte (Kunstmann ${ }^{2} 1984,{ }^{3} 1985,{ }^{1} 1986,{ }^{3} 1987$ ) als auch noch nicht veröffentlichte (ders. ${ }^{2} 1988$ ) Erkenntnisse darüber, daß die ausschlaggebenden protopolnischen Ethnika weder uransäßig waren noch vom Dnepr oder gar aus Asien, sondern ebenfalls von der Balkanhalbinsel zugewandert waren. Genau das trifft - mutatis mutandis - auch aue die protorussischen Ethnika am Ilmensee und anderwärts in NordwestruBland zu (ders. '1984, '1985, 21985, '21986, '1988).

Die uberwiegende Mehrzahl obiger Einzeluntersuchungen ist mit der etymologischen Entschlusselung von vermeintlichen Stammesnamen sowie von Orts- und Landschaftsnamen befaßt. Dabei zeigt sich, daß die Herkunftsbezeichnung, wenngleich nicht immer, so doch häufig. den Vorrang hat. weshalb meist die Herkunft der Zuwanderer bestimmbar ist. Das diesen Obertragungen von Orts- oder Landschaftsnamen zugrundeliegende Prinzip ist alt. wahrscheinlich so alt wie menschliche Siedeibewegungen überhaupt: Zur Bestimmung der Herkunft oder zur Erinnerung an die alte Heimat wird der Name des alten auf den neuen Siedelplatz übertragen. Auf eben diese Weise entstanden New Hannover. New Glasgow. New Iberia, New Plymouth, New Orleans, aber auch Moscow (Idaho), Berlin (New Hampshire) und Paris (Texas und Canada). So wie diese und unendlich viele weitere Namen im Laufe des Spätmittelalters und der Neuzeit durch Engländer. Deutsche, Russen oder Franzosen aus Europa nach obersee gelangten, wurden im 
Frühmittelalter unzăhlige geographische Begriffe durch Slaven vom Balkan nach Mittel- und Osteuropa übertragen.

Wie die bisherigen Ermittlungen zeigen, stammten die meisten slavischen Zuwanderer Nord- und Mitteldeutschlands aus den ehemaligen römischen Provinzen Dalmatia, Praevalitana und Epirus nova ${ }^{1}$, also aus dem westlichen, der adriatischen Küste zugekehrten Tell des Balkans. Eindeutig auf den Namen der Provinz Dalmatia verweisen in erster Linie jene in Sachsen seßhaft gewordenen Daleminci oder Glomaci. was man bislang verkannt hat. Auf dalmatinische Herkunft kann aber auch im Fall der Surbi geschlossen werden, und 2 war deshalb, weil Teile Dalmatiens unter Kaiser Herakleios zum ständigen Siedelplatz der Serben wurden (Konst. Porphyr.). Die südlich an Dalmatia anrainende Provinz Praevalitana scheint die Heimat der Drevani gewesen zu sein: besagte Provinz ist außerdem mit den Namen ihrer Städte Scodra (Scheuder) und Lissos (Liezizi; Lesane?) im Norden vertreten. Als prominenter Ort der Epirus nova spiegelt sich mit einiger Wahrscheinlichkeit der Name der Hafenstadt Oricum in dem mittelelbischen Bezirksnamen Jerichow wider. Aus eben dieser Provinz kamen wohl auch die slavischen Doxani in das Gebiet der brandenburgischen Dosse. Aup die Epirus vetus verweist dagegen der Name der Kaschuben. Damit wird deutlich, daß das ehemalige Illy ricum unter denjenigen Balkanprovinzen, aus denen Slaven nach Norden abwanderten, an erster Stelle steht. Diese Feststellung korrespondiert mit der Beobachtung, daB aus eben diesen illyrischen Gebieten auch andere slavische Gruppierungen ihre Namen bezogen, unter welchen bedeutende slavische Stämme wie Russen (Ragusa) und Polen (Apollonia) heranwuchsen.

Schwächer vertreten sind unter dem gegebenen Gesichtspunkt die Provinzen Macedonia und Thracia. Aus ersterer stammen vermutlich die Wagrier, sicher aber die Prissani (Brisae), deren Siedelgebiet im Umfeld des Strymon zu suchen ist und das mit der ersten, auf Geheiß von Herakleios erfolgten Ansiedelung der Serben auf byzantinischem Boden identisch sein dürte. Zwischen Strymon und Maroneia soll sich auch jene alte, von Odysseus zerstörte Kikonen-Stadt Ismaros befunden haben, die gewissermaßen zur "Patenstadt" von Wismar wurde. Der Provinz Thracis zuzu-

1 Entsprechend Lippolt, Kirsten (1959) werden hier als Provinznamen in der Regel - was 2 war problematisch, aber technisch nicht $2 u$ vermeiden ist - die Bezeichnungen der hohen römischen Kaiserzeit um das 2. Jhd. verwendet. 


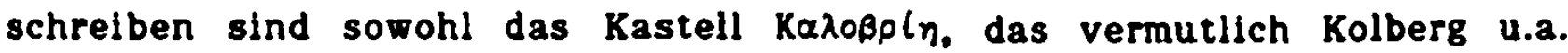
den Namen gab, als auch die stadt Siris in der Paionia, von wo mit Sicherheit die Zirzipanen an der Peene stammten. Wahrscheinlich kamen aus den Provinzen Thracia und Macedonia aber auch jene Slaven, von denen die Agăis-Inseln Imbros (Fehmarn) und Skiathos (Stettin) heimgesucht murden.

Beachtung verdient ferner die namentliche Repräsentanz mehrerer prominenter Städte der Antike in Nord- und Mitteldeutschland. An erster Stelle ist hier die alte römische Stadt Sirmium der Pannonia inferior zu nennen, deren Name sich als Bezeichnung einer Landschaft zwischen Elbe und Saale wiederfindet. Dazu stellt sich das verkehrsgeographisch und strategisch so wichtige Naissus in der Moesia superior, dessen Name als vermeintliche Stammesbezeichnung (Nisane. Nizizi) zwischen Elbe und Mulde bzw. Freiberger Mulde belegt ist. Vielleicht ist in diesem Zusammenhang auch Ulpiana, die spätere Iustiniana secunda in der Dardania zu erwăhnen, deren Name sich in Ottos d. Gr. marca Lipâni widerspiegeln könnte. Mit Sicherheit läbt sich dagegen der Name der Dessauischen Stadt Scheuder auf Scodra, die unter Diokletian zur Hauptstadt der Praevalitana erhobene illyrische Siedlung zurückführen. Aus der nămlichen Provinz ist im gleichen Atemzug die berühmte, an der Mündung der Drina in die Adria gelegene Hafenstadt Lissos bzw. Lissus zu erwähnen. nach welcher sich jene zwischen Elbe und Havel seBhaft gewordenen Liezizi benannten. Von Bedeutung ist nicht zuletzt auch die paionische Stadt Siris, die den Zirzipanen an der Peene ihren Namen gab. Wichtige balkanische Plätze waren zweifellos auch Oricum in der Epirus nova, Ismaros in der Thracia und das kleine, strategisch bedeutsame Kastell Daphne an der unteren Donau: Die drei Namen haben sich in Jerichow. Wismar und in den Thainezi des Geographus Bavarus niedergeschlagen.

Es fallt auch auf, daB eine Reihe von slavischen Toponymen nach fremden Inselnamen gebildet ist oder im weiteren Sinne mit dem Meere zu tun hat. Ersteres ist der Fall in Fehmarn < "lubpos und stettin < Exiasos. Dazu zăhlt wohl ebenfalls die pommersche Ostsee-Insel Wollin (poln. Tolin), die ihren Namen gewiB der epirotischen Hafenstadt Valona verdankt (Kunstmann '1985, 247 fl.). Erwähnt sel auBerdem der Inselname Usedom. der, das soll separat erörtert verden, mit einiger Wahrscheinlichkeit auf den thrakischen ON Uscudama, das einstige Adrianopel zurückgeht und soviel wie 'Wasserburg' bedeutet (ders. ${ }^{2} 1985,397$ ). Adrianopolis, vor dessen 
Mauern erstmals 550 Slaven standen, war für diese, wie oben gesagt (S. 63), eine wichtige Station auf dem Weg nach Konstantinopel (Schramm 1981, 190). Das Phănomen der slavischen Inselnamen, das auch in anderen Zusammenhängen untersucht $z u$ werden verdient, spiegelt offensichtlich die slavische "Seetüchtigkeit" wider. Es ist ganz gewiß auch kein Zufall. daß das slavische Wort für 'Schiff, aksl. korabl'b, russ. korablb, skr. körab. poln. korab, c. koráb usf., ein altes Lehnwort aus dem Griechischen ist,

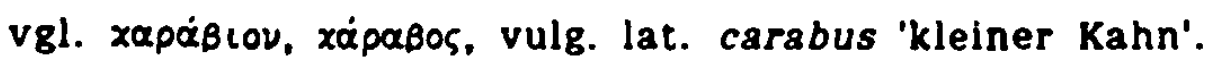

Nicht ohne Interesse sind im ubrigen bestimmte kultische oder mythologische Elemente, die ebenfalls Verbindungen mit dem Balkan schaffen. Außer den beiden Kultstätten Rethra und Arkona, die eindeutig griechische Namen haben, ist sowohl an den holsteinischen Ukleisee zu denken, als auch an den Prove-Hain bei Putlos, dessen Götze ohne Frage dem Namen des römischen Kaisers $M$. Aurelius Probus verpflichtet ist. Griechischer Provenienz ist gewiß ebenso der Name jenes Triglav, dessen Kult für Stettin und andere Orte bezeugt ist. Die Problematik der slavischen, von Baikan-Kulten beeinflußten Mythologie wird in größeren Zusammenhängen noch gesondert untersucht (Kunstmann '1988).

Weitaus geringer als die Herkunftsbezeichnungen sind jene Obernahmen ins Slavische, die einfache Lehnwörter darstellen. Als solche sind fraglos die kultischen Toponyme Rethra und Arkona zu bewerten. vielleicht auch der aus xáotpoy entstandene ON Küstrin. DaB Sachbezeichnungen selbst zu Flußnamen werden konnten, zeigt sich an $\alpha \dot{u} \lambda \dot{\eta}$ '(Wohn-)Sitz', woraus offenbar der Name der Havel entstanden ist. Hybride Lehnwörter sind schlleBlich auch die Ethnonyme der Abodriten ( $\dot{\alpha} \pi \dot{\alpha} \tau(\delta \varepsilon s)$, Redarier (< óńropes) und Milzener (< milites).

Isoglossen von Ethnonymen

Von eminenter Bedeutung ist die auf vorhergehende Untersuchungen gestützte Feststellung. daß verschiedene sog. slavische Stammesnamen. die auf balkansprachlichen Grundlagen beruhen, auch an mehreren anderen Punkten Mittel- und Osteuropas aufscheinen. Dieses Phănomen ist insofern von Belang, als es gewisse Einblicke in die frühmittelalterlichen Wanderbewegungen der Slaven gewăhrt und vielleicht sogar auf Wander-Routen aufmerksam macht. Diese, der Einfachheit halber Isoglossen genannten Vorkommen von gleichnamigen Ethnonymen an geographisch weit auseinan- 
derllegenden Stellen lassen eindeutig elne Süd $\rightarrow$ Nord $\rightarrow$ Ost-Bewegung erkennen, die in der Regel vom Balkan uber Böhmen nach Nord- und Mitteldeutschland und von hier nach Polen, in mehreren Fallen sogar bis Nordwest - und MittelwestruBland gerichtet ist. Die bedeutenderen bislang erkannten Isoglossen, denen künftige Forschungen ein besonderes Augenmerk widmen werden, lassen sich folgendermaßen beschreiben:

1. Besonders aufschluBreich unter allen Isoglossen bildenden Ethnonymen ist der Kroaten-Name, der sich vom Balkan uber Nordostböhmen und Sachsen bis nach NordwestruBland verfolgen läBt (Kunstmann '1987. 39 (f.). Gegen einen Nord-Süd-Trend bel dieser Isoglosse sprechen verschiedene Faktoren: voran die sehr wahrscheinlich griechische Etymologie des Namens selbst (ders. 1982), aber auch der galizische ON Belz und dessen dalmatinischer Hintergrund (ders. 1'1985, 239 ff.). Die nur durch drei ONn (Typ Charvatce) bestätigten sogenannten böhmischen Kroaten und die ebenfalls wenigen ON-Belege der westlich der Daleminci zu lokalisierenden sächsischen Kroaten (Typ Korbetha. Chorwete) lassen auf eine gewisse Kohärenz der Siedelvorgänge schließen, und zwar in der Form, daß slavische Gruppen, die sich eben Kroaten nannten, von Süden her durch das Elbetal In das Elbe-Saale-Geblet vordrangen (ders. '1987, 27; zu den „sũdöstlichen Einnüssen" vgl. auch Coblenz 1966). Anders liegen die Dinge bei den von der PVL zwar mehrmals erwähnten, siedlungsgeographisch aber nicht aumndbaren nordrussischen Kroaten (Typ Chorvaty. Chrovaty) (Kunstmann '1985. 241 (.). Auch wenn ihr Siedelgebiet nicht auszumachen 1st, lassen sich die Angaben der PVL wohl nicht anfechten. Diese kroatische Gruppe könnte frellich auch die Donauschiene entlang gezogen und über einen der Karpaten-Pässe nach Nordwestrußland gelangt sein ${ }^{2}$.

2. Bezelchnenderweise läßt sich auch für den Serben-Namen eine ähnliche, mit dem Kroaten-Ethnonym jedoch nicht Identische Isoglosse aufzeigen. Auch im Fall der Serben verweist die Etymologie ihres Namens auf den Balkan. Weiter ist an ihre unter der Bezeichnung Sorben bekannte mitteldeutsche Repräsentanz zu erinnern. Auch konnte bereits an anderer Stelle auf das Vorkommen dieses Ethnonyms in Böhmen aufmerksam gemacht werden (Kunstmann 11987, 26, Anm. 1), vgl. dle ONn Srbce (Vys.

2 Zur Bedeutung des Dukla-Passes in den Karpaten ausführlich Kunstmann ${ }^{2} 1988$ (ders. kurz ${ }^{1} 1985,252$ P.). 
Mýto: Podébrady), Srbec (Slany), Srbice (Kdynè, Klatov, Teplice-Sanov. Otice), Srbin (Kostelec n.C.1.), Nizká Srbská (Police n.M.). Srbsko (Beroun, Mnich. Hrad.), Srby (Nové Straseci, Slany, Hostoun) u.a. (Profous, Svoboda 1957. 150-3). Neben mitteldeutschen und böhmischen Niederschlägen ist aber auch noch eine polnische Variante des Serben-Namens zu verzeichnen. An rund 36 ONn wie Zarben, Sarbsko, Zerbow (Serbów), Sarbia, Sarbice. Sarbiewo u.a. läßt sich dieses Ethnonym auf einer Linie vom östlichen Pommern uber die Zlemia Lubuska. Großpolen und Kujawy bis in den nordwestlichen Teil von Masowien verfolgen (Lewicki 1956. 23 fl.). Lewicki hielt dies für das "Staatsgeblet der WeiBserben" zu Beginn des 7. Jhds. Verfehlt ist es allerdings, diese "polnischen” Serben mit den Weißserben von Kaiser Konstantinos Porphyrogennetos zu identifizieren, da unter

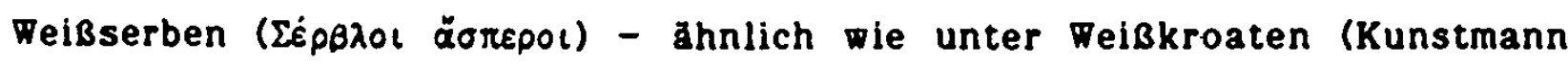
'1984) - Großserben oder vielmehr Altserben zu verstehen sind. Die polnischen Serben-Toponyme erklären sich vermutlich so, daB Teile von den über Böhmen nach Mitteldeutschland eingewanderten Balkanslaven namens Serben nach Osten weitergezogen sind und sich im heutigen Polen niedergelassen haben. Weiter nach Osten, also bis RuBland, scheint diese Isoglosse nicht $z u$ reichen. Im gegebenen Ball kann freilich auch wieder an eine Zuwanderung über die Karpaten-Pæ̋sse gedacht werden.

3. Nicht weniger bedeutsam wie die Kroaten- und Serben-Namen ist die Isoglosse der Doks-Namen, die wir als Doxani, Dassia, Dosse u.a. sowohl Im Bereich der brandenburgischen Havel als auch in Nordböhmen (Typ Doksy. Doksany) und darüber hinaus in NordwestruBland (Typ Doksicy) vorflinden (Kunstmann 11985, 245 ff.: 1987, 41 f.). Das diesen Bildungen zugrundeliegende Wort 'dazā, $\delta \dot{\alpha} \xi \alpha$ ist illyrisch-epirotischer Provenienz und bestätigt erneut den Süd $\rightarrow$ Nord $\rightarrow$ Ost-Trend slavischer Wanderbewegungen.

4. Elne weitere Isoglosse lassen die Volyn-Toponyme erkennen, die zwar in diesem Buch nicht zur Sprache kommen, doch schon an anderer Stelle abgehandelt wurden (Kunstmann '1985, 247 fl.). Auch an ihnen bestätigt sich der Tenor der slavischen Wanderbewegung vollauf. Der westlichste Volyn-Name ist in dem pommerschen Inselnamen Wollin (poln. Wolin) enthalten: östliche Entsprechungen dazu sind das mittelwestrussische Ethnonym Volynjane sowie der Gebietsname Wolhynien. Volyn-Namenotogegnen 
aber auch im tschechischen Bereich (Typ Volynë). Ausgangspunkt ist in allen Făllen der Name der südillyrisch-neuepirotischen Hafenstadt Valona (Aن̀núva).

5. Von den vorangehenden Isoglossen unterscheiden sich die Drevani, deren Name sich mit einiger Wahrscheinllchkeit von den illyrischen Dervani. Derbani herleitet. Ihr Name scheint nur als Ethnonym des bekannten westslavischen Polabenstammes, vielleicht auch als ON im ehemaligen Kreis Köslin (Typ Drawehn, poln. Drzewiany) und als ostslavischer Stammesname Drevljane vorzukommen. Für Böhmen ist er also nicht nachgewiesen.

6. Vom Drevani-Typ wiederum unterscheidet sich die $\mathbf{N}$ is a ne-Isoglosse, die aus Naissus (h. Nis), den Namen der bedeutenden Stadt der Dacia mediterranea zurückgeht und aus den vermeintlichen Stammesnamen der Nisane um Dresden und Nizizi an der Elbe sowie den ONn Nezene bei Köslin und Naisa bel Bamberg besteht. Die Wander-Route dieser Slaven ist möglicherweise über Ostfranken und Thüringen nach Sachsen verlaufen.

7. Unvollständig und nur ungenau $2 u$ verfolgen ist die Abodriten-Isoglosse, die mit Sicherheit lediglich aus den an der Donau und im Ostseebereich nachzuweisenden Ethnonymen besteht, wenngleich sich eine Repräsentanz dieses Namens auch rar Böhmen und Polen vage abzuzeichnen scheint.

Die erwähnten und wahrscheinlich weitere Isoglossen, die naturgemäß nicht synchron entstanden zu sein brauchen, markieren offenbar gemeinsame slavische Migrations-Trends, bei denen sich neben dem allgemeinen Süd-Nord-Veriauf zugleich eine deutliche Nord-Ost-Trift abzeichnet. Diese Bewegungen sind selbstredend eng verbunden mit der slavischen Besiedlung Polens sowie Nordwest- und Mittelwestrußlands.

Eine Ausnahme innerhalb der Isoglossen-Bildungen $z u$ machen scheint Oberfranken, das im gegebenen Zusammenhang nur ein einziges Mal (Naisa) zu nennen war. Oberhaupt erweckt die slavische Besiedlung Süddeutschlands einen völlig anderen Eindruck als die Nord- und Mitteldeutschlands, wo ja die Kolonisation der Slaven erheblich weiter nach Westen, bis an die Elbe ausgegriffen hat. "Systematisch" slavisch besiedelt wurde in Süd- 
deutschland im Grunde nur Oberfranken, wăhrend Schwaben ganz und das westliche altbairische Kerngebiet weitgehend ausgespart blleben. Insgesamt hält sich die slavische Besiedlung Nord- und Mitteldeutschlands an Limes Saxoniae und Diedenhofer Linie (805), also an die von Karl dem GroBen initiierten Demarkationen.

Noch ein Unterschied zwischen der slavischen Besiedlung Nord- und Mitteldeutschlands und der Süddeutschlands făllt ins Auge. Während im Norden Dutzende von sogenannten slavischen Stammesnamen nachzumeisen sind, fehlen diese im Süden so gut wie ganz. Die Bezeichnungen Mainoder Regnitzwenden (Moinuuinidi et Ratanzuuinidi, $793 / 4$ ?) bilden keine Ausnahme, da dies von den Franken gegebene Bezeichnungen, also nicht slavischen Ursprungs sind und nichts über die Herkunft ihrer Träger aussagen. Geblieben sind von den Main- und Regnitzwenden - dies Jedoch in reichlichem Maße - lediglich Ortsnamen, einige Flußnamen und geringe Spuren ihrer materiellen Kultur. Allerdings ist das onomastische Material von Oberfrankens Slaven auch noch nie unter dem Aspekt ihrer denkbaren Zuwanderung vom Balkan betrachtet worden. 


\section{Vom Balkan zur Ostsee}

Als die Slaven während des 6. Jhds. an der unteren Donau aus dem Barbaricum auf den Balkan vordrangen, waren sie vermutlich aus ihrer von der Forschung noch heute wie die Blaue Blume gesuchten Urheimat gekommen. Sie waren im Grunde anonym und ohne untergliedernde Stammesna-

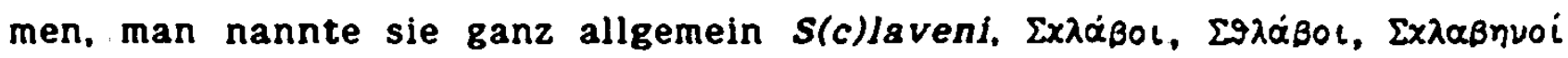
oder auch Anti. Antae, Antes. "Avtal. Erst nach ihrer Invasion des Balkans kamen differenzierende Namen wie Kroaten, Serben, Polen, Russen aup. Allein, daß es vordem auBer den etymologisch noch immer unklaren und wahrscheinlich doch nicht slavischen Begriffen S(c)laveni und Anti keine ethnonymische Vielfalt gegeben hat, spricht hinsichtlich der ursprünglichen slavischen Population gewiß für ein nur geringes Volumen und damit zugleich für eine territorial wenig umfassende Urheimat. Liegt in den bescheidenen Proportionen des Anfangs vielleicht einer der Gründe für die archäologisch so schwer zu Passende protoslavische Ethnie?

Die entscheidende Frage für die Beurteilung der weiteren Landnahme der Slaven ist die nach ihrer Urheimat ${ }^{2}$. Lag diese im Norden. in Galizien. den Karpaten oder bei Kiev? Dann müBten Nord- und Mitteldeutschland aus dem Osten, der slavische Süden dagegen aus dem Norden besiedelt worden sein. Oder aber lag diese Urheimat im Süden. vielleicht im Bereich des Schwarzen Meeres? Das würde zweifellos bedeuten, daß die Besiedlung des slavischen Nordens vom Süden her erfolgte. Die Meinungen sowohl der mittelalterlichen Chronistik als auch der modernen Wissenschaft sind in eben diese belden Lager geteilt.

Wie es scheint, sind es insbesondere die mittelalterlichen Chroniken (und Sagen) der Südslaven, denen zufolge die Urheimat im Norden gelegen habe. Am deutlichsten kommt dies bei dem byzantinischen Schriftsteller Konstantinos Porphyrogennetos (um 950) zum Ausdruck, wenn nach ihm die

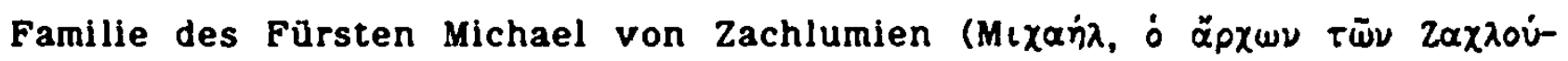

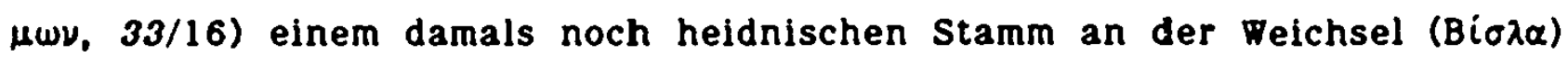
entstammte. Dieser seither viel zitierten Behauptung steht indes jener Be-

1 Professor Pritsaks neueste Slaven-Etymologie (1982) bedarf frellich noch der Veriflzierung.

2 Unter archäologischem Aspekt dazu verschiedene Arbeiten von J. Werner 2.B. 1971,1981 u.a. 
richt der PVL entgegen, demzufolge gerade Slaven von der Donau an die Weichsel abgewandert waren (PVL 5: Kunstmann ${ }^{2} 1987.154$ (.). Wieder andere Ursprungsgeschichten bei Konstantinos sind Kombinationen des 10. Jhds., die infolge gewisser Namensähnlichkeiten zwischen slavischen Stämmen im Süden und Norden zustandekamen (Jireček 1911, I, 108). Dazu gehören auch die seitdem durch die wissenschaftliche Literatur geisternden Weißkroaten, unter denen in Wirklichkeit die alten Kroaten $z u$ verstehen sind (Kunstmann '1984). Rund 300 Jahre nach Konstantinos behauptete Preilich noch der Archidiaconus Thomas von Spalato, daB die Kroaten „de Polonia seu Bohemia" nach Dalmatien gekommen seien (Klaic. N. 1971, 21 Pf.). Von einiger Bedeutung für die slavische Geschichte des 14. und 15. Jhds.

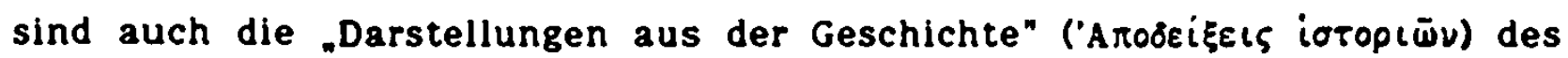
Laonikos Chalko(ko)ndyles, von dem die für die Geschichtsschreibung folgenreiche Legende von der Zuwanderung der Balkanslaven aus Preußen und Rußland stammt (SlowStarSlow I, 237: H. Kappesowa).

In dieser Frage anders als die Chronisten des Sūdens urteilen die nordslavischen mittelalterlichen schriftsteller. Für die namhaftesten russischen. polnischen und böhmischen Chronisten liegt die Urheimat im Süden. an der Donau und in den Balkanländern. Berühmt ist der Satz in Nestors (PVL) Kosmographie: Po mnozechs ze vremjanéchs seli sutb Slovéni po Dunaevi. gdé estb nyne Ugorbska zemlja i Boigarbska (5). Dazu paßt ebenfalls die erwăhnte, von der PVL mitgeteilte obersiedlung von slaven an die Weichsel. Gewiß wirkt das wahrscheinlich meist mündlich tradierte wissen um die slavische Migration von süd nach Nord auch in den mittelalterlichen Chroniken der Polen so etwa bei Kadlubek oder Dlugosz bereits unscharf und mythologisiert, doch gibt es darunter ebenfalls deutliche Hinweise sowohl auf verlorene schriftliche Quellen als auch auf die Herkunft der Slaven aus dem Sũden wie etwa in der CPM (468, 10-12): Scribitur enim in vetustissimis codicibus, quod Pannonia sit mater et origo omnium slavonicarum nationum. Daneben werden hin und wieder freilich auch erstaunlich genaue Vorstellungen von der südlichen Herkunft der Slaven transparent. zum Beispiel in der alttschechischen Reimchronik des sog. Dalimil. der die Urheimat der Slaven in die Nachbarschaft von Griechen und Römern rūckt: Mezi nimi Srbové, tu. kdez bydlé Rekové. podlé moře sé usadichu, az do Rima se rozplodichu (I, 29-32). Diese Angaben entsprechen überraschend präzise dem von Slaven besiedelten Gebiet. das sich vom griechischsprachigen Epiros südlich der Jirecek-Linie die adriatische Kũste 
entlang bis zu den romanisierten (Rim!) Vlachen um Dubrovnik erstreckte (Kunstmann $\left.{ }^{2} 1987,25\right)$.

Dle diametral verschiedenen Auffassungen vom Verlauf der slavischen Migration haben sich natürlich auch auf die historischen Wissenschaften ubertragen. Seit den noch in der Romantik verwurzelten Anfängen der siavischen Altertumskunde gilt so die aus dem Osten nach Westen ausgreifende Landnahme der Slaven als unanfechtbar. Bedenkenlos wurden frellich auch Vorstellungen des 19. und 20. Jhds. insbesondere von der slavischen Population In das Frühmittelalter projiziert, so daß "riesige" oder "mächtige" Slavenstämme entstehen konnten, deren Namen sich in Wirklichkeit allerdings als bloße Herkunftsbezeichnungen oder Insassennamen erweisen. Noch Jagic und Zupanic (1928, 28) dachten an eine Million oder mehr Serben zu Beginn von deren Balkan-Invasion, woran gewiB aber nur einige wenige Tausende Menschen beteiligt waren. Die angeblich von Osten nach Westen verlaufende Kolonisation der Slaven hat sich naturgemäB in vielen modernen historischen und archäologischen Arbeiten niedergeschlagen, ohne daß dies hier im einzelnen verfolgt werden soll ${ }^{3}$. Die zwelfellos umfassendste Darstellung einer vermeintlichen Nord-Süd-Wanderung. konkret dargelegt am Modell der angeblich aus Sachsen stammenden Serben und ihrer Migration zum Balkan, hat jedoch 1977 der serbische Historiker Relja Novakovic in seinem 400 Seiten starken Buch gellefert. Jan Leśny. sein polnischer Rezensent". sieht daraur nicht in Sachsen. sondern in Niedersachen (?) dle "ursprüngliche Wiege der Serben".

agl. etwa folgende Arbeiten: Z. Sulowski: Migracja Slowian na zachód w pierwszym tysiacleciu n.e. In: Roczniki historyczne 27, 1961, 10 凡.; B. Krüger: Zur Nordwestausbreitung der frühslawischen Keramik im weiteren Elbe-Saale-Gebiet. In: Varia archaeologica. Fs. W. Unverzagt. Berlin 1964. 219 IY.: J. Zak: Migracja Slowian $w$ kierunku zachodnim $w$ V/VI-VII w.n.e. In: Studia historica slavogermanica 6, 1977, 3 fl.: ders.: Problematik der westlichen Ausbreitung der Westslawen zu Beginn des Fruhmittelalters (5./6.-7. Jhd.). In: Rapports du III Congrès International d'Archéologie Slave. Bratislava 7-14 sept. 1975. Bratislava 1979, 917 H.: Lech A. Tyszkiewicz: Podzialy plemienne i problem jednosci Slowian serbolużyckich. In: Slowianszczyzna polabska 1981, 109 ff.; K. Gochlowski: Die Slawen im 5. und 6. Jhd. und die Frage Ihrer Expansion gegen Westen. In: Die Bayern und ihre Nachbarn. II. Hgb. H. Friesinger, F. Daim. Wien 1985, $137 \mathrm{ff}$.

1 Kwartalnik historyczny 86, 1979, $498 \mathrm{fl}$., wo recht unbekümmert mit den Sitzen der sog. Weißkroaten und Weißserben umgesprungen wird und selbst von Slaven aus der Umgebung von $K \delta l n$ (!) die Rede ist, was eindeutig mit Lübeck verwechselt wird. 
Allerdings hat eine Reihe von Historikern und Archăologen auch eine völlig andere Ansicht vertreten. So etwa war Walter Schlesinger schon 1941 (213) der Meinung. „daß seit dem letzten Drittel des 6. Jhds. slawische Stămme unter awarischem Druck nach Mitteldeutschland einsickerten" bzw. „daß slawische Bevölkerung von den Awaren von der Balkanhalbinsel mit nach Norden gerissen worden ist" (212) und "die mitteldeutschen Siawen aư diesem Wege in ihre späteren Wohnsitze gelangt sind" (ebda.). Ahnlich wie Schlesinger dachte dann der Berliner Archäologe J. Herrmann an Flucht der Slaven vor den Awaren, aber auch an teilweise Stämmeteilung: „Aus dem Verband der Serben schieden die Sorben aus, die über Măhren und Böhmen in das Elbe-Saalegebiet zogen und sich dort ansiedelten. Ein weiterer Teil der Serben nahm seinen Wohnsitz anscheinend in Großpolen (sog. Weißsorben). Dort Indet sich eine gröBerer Anzahl von Ortsnamen vom Typ Sarbia" (1971, 20 1.). Herrmanns Ansicht entspricht exakt unsere obige Isoglosse (S. 195 \%.). In gleicher Weise sind laut Herrmann auch andere slavische stämme auseinandergerissen worden, zum Beispiel die Kroaten und Obodriten. Wie Schlesinger und Herrmann beurteilte der Altertumskundler Robert Werner die slavisch-awarischen Ereignisse. Seiner Ansicht nach ermöglichte es die unter Khan Bajan erfolgte Eingliederung der Slaven in den awarischen Machtbereicht, daß diese .sich bei den Vorstößen der Awaren, die 582 Sirmium (Sremska Mitrovica) besetzten, durch das Drautal und Kărnten. über die Balkaninsel bis hinab zur Peloponnes und nordwărts bis in die Altmark und nach Thüringen ausbreiteten" (1979, 192). Sehr konkret hat anhand der altslavischen Keramik und des gesamten Kulturinventars der neubesiedelten Gebiete zwischen Elbe und Saale

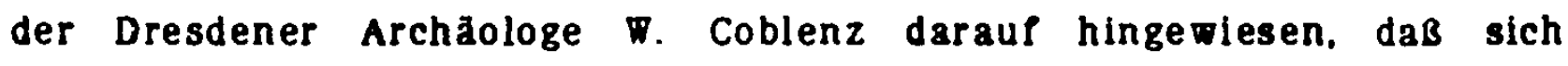
"deutliche Verbindungen zum Raum südlich der Gebirge - zumindest bis nach Rumănien" erkennen lassen (1964, 320). Neben Coblenz, der ăhnliche Ansichten auch in anderen Arbeiten vertritt, ist es immer wieder $\mathrm{J}$. Herrmann. der meint. Sorben. Wilzen und Lausitzer könnten von Süden nach Norden gewandert sein (1972) und. so zuletzt (1985, 27), es „wahrscheinllch (sei), daß aus dem Stamm der Serben/Sorben, der am Ende des 6. Jhds. im mittleren Donaugebiet an den Grenzen von Byzanz stand und der sich mit den Awaren auseinanderzusetzen hatte, ein Teil ausschied und nordwarts wanderte...Elnige Gruppen aus dem Stamm der Kroaten, der zusammen mit den Serben an der mittleren Donau operierte, scheinen sich dieser 
Nordwanderung angeschlossen $2 u$ haben"s. In bemerkenswerten Studien tritt neuerdings, nach Richtigstellung der Jahrhundertelang verkannten "WeiBkroaten" (Kunstmann '1984), auch die Zagreber Historikerin Nada Klaic Pur eine kroatische Süd-Nord-Wanderung ein ${ }^{6}$.

Anders verhält sich hinsichtlich der slavischen Süd-Nord-Wanderung die Sprachwissenschaft-Onomastik, die bisher nicht nur auf der alten Lehrmeinung beharrt, sondern dort. wo im Grunde die Einsicht in die wahre Lage der Dinge zu erwarten wäre, eher bereit ist, "neue Völker" zu entdecken, als ihre Ansicht zu revidieren. Als "neu" wurden so etwa die angeblich aus einem rechtsrheinischen Gebiet nach Osten abgewanderten Belgae entdeckt, denen das Land Belcsem zuzuschreiben sei. Ebenso wurde der Stammbaum der Daleminci (und Glomaci) auf ein nicht näher bekanntes "alteuropäisches" Volk zurückgefūhrt, obgleich der Schluß auf Dalmatien für den Onomastiker gewissermaßen auf der Hand liegen muBte. Die fraglos eindrucksvollste Verirrung auf dem Gebiet künstlicher Ethno-Kreationen aber waren die inzwischen "abgestorbenen" Nordillyrier: Max Vasmers Meinung. was sich $z$ wischen Elbe und Weichsel weder germanisch noch slavisch erklären lasse, müsse illyrisch sein. gründete, genau genommen, auf der Illyrierthese des deutschen Prähistorikers G. Kosinna, nach dessen Ansicht nordlllyrische Stämme aus dem Gebiet der Lausitzer Kultur nach Süden abgewandert waren (Eggers 1974, 237, 247 f.). Kosinna treilich ging es im wesentlichen um eine ethnische Zuweisung der "herrenlosen" Lausitzer Kultur. Vasmers weniger auf toponomastisches als hydronymisches Material gestützte These traten in der Folge Krahe und Pokorny bei. Krahes späterem Widerruf (1957) ist im Grunde niemand ernsthaft entgegengetreten (Untermann 1981, 16, 31 f.). Der linguistische Ausgangspunkt der Nordillyrier-These war die Beobachtung gewisser Parallelen zwischen balkanischem und norddeutschem Namengut: Doch war man eher bereit, an illyrische Ethnika zu denken, als slavischen Transfer anzunehmen. Eine noch anders

- Gegenüber der Hypothese von der Süd-Nord-Wanderung der Abodriten. wofur auch J. Herrmann vordem eintrat (1972), zeigte sich dieser Gelehrte Jedoch dann (1983, 97 f.) reserviert, was fraglos mit der von Witkowski (1983) vorgebrachten Kritik zusammenhängt. Dabei bestätigt Witkowski im Grunde nur die richtige Etymologisierung des AbodritenNamens (vgl. oben), auch wenn fur ihn eine Zuwanderung dieser Slaven aus griechischsprachigem Gebiet noch unvorstellbar ist.

- Vgl. N. Klaic: Sjever I Jug. In: Oko 19-30/1/1987; dies.: Poganska Stara ili Vela Hrvatska cara Konstantina Porfirogeneta. In: Starohrvatska prosvjeta, III/16. 
gelagerte Variante stellt Trubacevs neue illyrische These dar, nach welcher die Urheimat der Slaven in Illyricum $2 u$ suchen sei. Unreflekt:ert bleibt dabei freilich, daß die als Illyrisch $z u$ beurtellenden Elemente der ostslavischen Hydronymie und Toponymie (Trubacev 1968; 1982) richt.ger als slavische Obertragungen zu erklären sind. Aus scharfsinnigen Beobachtungen werden so verfehlte Schlüsse gezogen.

Immerhin hat die Onomastik inzwischen auch erkannt, daß „die weitere Ausbreitung der Slaven nach Westen unklar ist". weil die Namen keine Auskunft darüber geben, „auf welchen Wegen die spāteren Polaben und Ostseeslaven in ihre Wohnsitze gelangt sind" (Udolph 1979, 626).

Der polnische Historiker G. Labuda hat die an sich nicht uninteressante Ansicht vertreten, die slavische Migration habe dem archāologischen Material zufolge sowohl von Nord nach süd als auch von süd nach Nord verlaufen können, doch erscheine im Lichte der sprachlichen Fakten (wie auch der literarischen Quellen) nur Ersteres begründet (SlowStarSlow V. 142). Da Jedoch viele, ja sehr viele sprachliche Fakten fehlgedeutet wurden. entstand in Laufe der Zeit ein entstelltes Bild von der slavischen Frühgeschichte, das nur schrittweise wieder korrigiert werden kann. In erster Linle waren es seit Safariks Zeiten tradierte falsche Etymologien, die zur Verzerrung von Sledelgeschichte und Landnahme der Slaven gefuhrt haben. Später war es das "reine”. das heißt shistorische Etymologisieren. das weder geschichts - noch realitätsbezogen war. Unklares, mit der Lehrmeinung Unvereinbares wurde als "vorslavisch" abgetan und damit spuren verwischt. die historisch brauchbare Lösungen hätten erbringen können.

Von ausschlaggebender Bedeutung für die Besiedlung Nord- und Mitteldeutschlands mit Balkanslaven sind die historischen Geschehnisse des 6. Jhds., die mit dem Sieg der Franken über die Thüringer beginnen und 531 den Untergang des thüringischen Königreiches auslösen. In das dadurch entstandene Vakuum vermochten in der Folge tremde Siedler. Insbesondere Slaven einzudringen. Eng mit diesen Vorgängen verknüpft waren dle Vorstöße des eurasischen Reiternomadenvolkes der Awaren nach Thüringen, sowohl der von 562, bei welchem diese an der Elbe, vielleicht auch bel Magdeburg oder Riesa (Schlesinger 1941. 325; Kollautz. Mlyakawa 1970. I. 165) vermutlich infolge logistischer Engpässe von Frankens Konig Sigibert geschlagen wurden, als auch der wohl glückhaftere vom Sommer 565. Diese awarischen Angriffe gegen Thüringen, die sich später wiederholten. so daß Brunichild und Theudebert II. 596 ihre Einstellung mit Geld erkau- 
fen muBten, wurden nicht nur $2 u$ einem ernstlichen Problem der Reichsgewalt (Löwe, H. 1973, 85 ९.), sondern hatten Ereignisse von welthistorischer Tragweite zur Folge, wie dies schon Carl Mülenhoff treffend formulierte. Sie führten nämlich 566 zum Vertrag zwischen dem Merowinger-König Sigibert, dem Langobarden-König Alboin und dem Awaren-Khan. Aufgrund dieses Vertrages räumten die Schwaben die ältesten Germanen-Sltze 2 wischen Elbe und Oder, wurden die ursprünglich gotischen Gepiden im TheiB-Donau-Karpaten-Raum 567 von den Awaren vernichtet und zogen 568 die Langobarden aus Pannonien nach Italien (Werner, J., 1962; Bóna 1976). Das alles hatte zur Folge, daB den Awaren, „die an der Donau ihre Stellung einnahmen, und ihrem Gefolge, den Slaven, der ganze Osten, so weit ihn die Germanen beherrscht hatten. preisgegeben und alle Oberreste derselben. die noch innerhalb dieses Gebietes saBen, unrettbar über kurz oder lang verloren waren..." (Müllenhoff, C. 1870-1900, II. 103). Diese in der Tat welthistorischen Ereignisse bedeuteten eine völlige Umstrukturierung der ThelB-Donau-Karpaten-Gebiete und schufen zugleich Ober- oder Zugănge vom Balkan nach Mittel- und Norddeutschland. Die awarischen Angriffe gegen das thüringische Reich, die bezeichnenderweise vom Nordosten her, über Karpaten und nördliche Sudeten vorgetragen wurden, machen deutlich, daß im Sog dieser Reiternomaden auch Slaven nach Norden vordringen konnten, was für das Gebiet ostlich der Saale archäologisch schon fur die 2. Hălfte des 6 . Jhds. angenommen wird?. In welchem Verhältnis die Slaven $z u$ den Awaren standen, läßt sich nicht mit Sicherheit sagen. Auch wenn, wie vermutet, die Siaven uberwiegend vor den Awaren Mohen, ist nicht auszuschließen, daB auch Teile der Slaven mit den Awaren zogen und sich an deren kriegerischen Unternehmen beteiligten. Wenngleich also das slavisch-awarische Verhältnis noch schwer zu durchschauen ist, darf angenommen werden, daß schon $a b$ der 2 . Hälfte des 6 . Jhds. Slaven nach Mitteldeutschland einsickerten.

Die slavische Sud-Nord-Migration hat eine spätmittelalterliche Paralleie, die rund 1000 Jahre nach dem Awaren-Sturm stattfand. Es sind die im 15. Jhd. einsetzenden, im 16. und noch im 17. Jhd. durch das Vordringen der Osmanen auf dem Balkan fortgesetzten Wanderbewegungen erst der

1 Schmidt, B. 1965/6, besonders 215. - Die hier u.a. geāuBerte Ansicht. die Surben des Dervanus seien für Mitteldeutschland zu 630 schriftlich bezeugt, ist irrefuhrend, da Fredegars Mittellung (IV, 68) nichts uber die Lage dieser Sorben aussagt. 
Serben, dann der Kroaten. Auf der Flucht vor den Türken - auch die Awaren waren bekanntlich ein Turkvolk - begannen ab 1514, nachdem Sũddalmatien bis Knin besetzt war. Kroaten in das venezianische Küstenland und nach Norden abzuwandern. So gelangten auch die sogenannten Vlahi in das südliche Burgenland. wo sie noch heute in mehreren kleinen Dörfern ihr inzwischen gut erforschtes Kroatisch sprechen". Selbst wenn diese Slaven nicht bis an die Ostsee gelangten, so gleichen sich doch die historischen Fluchtbewegungen des 6 . und 16. Jhds. nach Ursache und Wirkung auf überraschende Weise.

- Zur neuesten. geradezu lawinenartig angeschwollenen Literatur vgl. S. Tornow: Die Herkunft der kroatischen Vlahen des südlichen Burgenlandes. Berlin 1971: L. Hadrovics: Schrifttum und Sprache der burgenländischen Kroaten im 18. und 19. Jhd. Wien 1974; G. Neweklowsky: Die kroatischen Dialekte des Burgenlandes und der angrenzenden Gebiete. Wlen 1978: $H$. Koschat: Die Cakavische Mundart von Baumgarten im Burgenland. Wien 1978; E. Paikovits: Wortschatz des Burgenländischkroatischen. 1985; S. Geosits (Hg.): Die burgenländischen Kroaten im Wandel der Zeiten. 1986. 


\section{Blbllographische Anmerkungen} zu bereits publizerten Arbeiten

4. Abodriti. Obodriti. Praedenecenti Oberarbeitete und erweiterte Fassung der Erstpublikation "Zwel Beiträge zur Geschichte der Ostseeslaven. 1. Der Name der Abodriten". In: Die Welt der Slaven 26, 1981, 395-419.

6. Mecklenburgs Zirzipanen und der Name der Peene Erstveröffentlichung: Die Welt der Slaven 29. 1984, 353-359.

7. Rethra. Redarier. Arkona

Oberarbeitete und ergänzte Fassung der Erstveröffentlichung „Rethra. die Redarier und Arkona”. In: Die Welt der Slaven 26.1981, 419-432.

10. Der Name der Kaschuben.

Erstveröffentlichung. Woher die Kaschuben ihren Namen haben". In: Die Welt der Slaven 30, 1985, 59-65.

19. Der anhaitische Landschaftsname Serimunti

Erstveröffentlichung in: Text. Symbol. Weltmodell. Johannes Holthusen zum 60. Geburtstag. Herausgegeben von Johanna Renate Döring-Smirnov. Peter Rehder. Wolf Schmid. München 1985, S. 335-344.

24. Sachsens Daleminci und Glomacl

Oberarbeitete und erweiterte Fassung der Erstveröffentlichung "Kamen die westslavischen Daleminci aus Dalmatien?" In: Die Welt der Slaven 28, 1983, 364-371. 


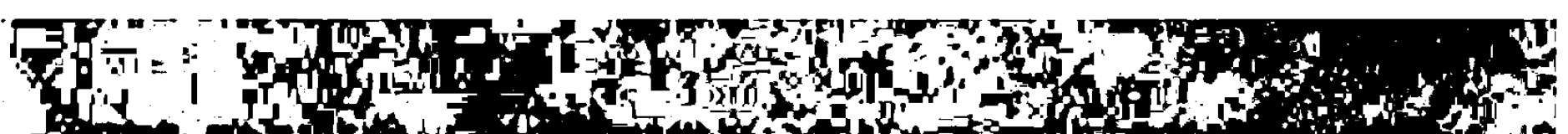

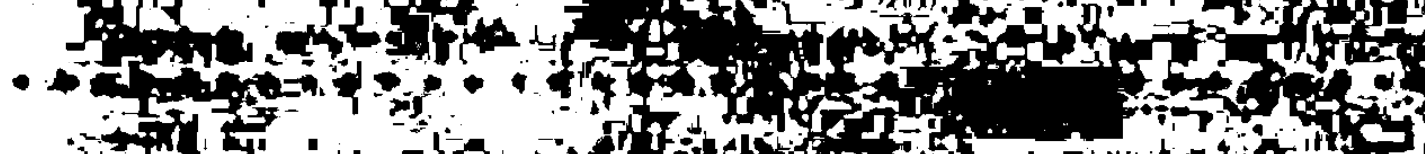

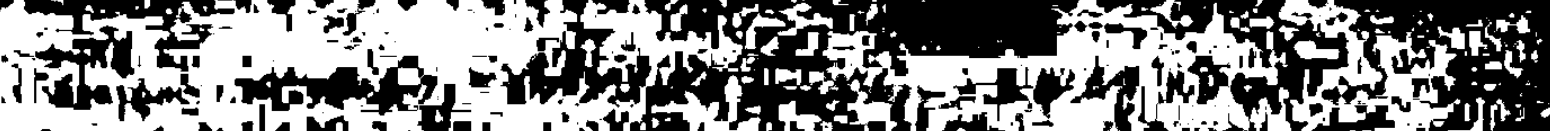

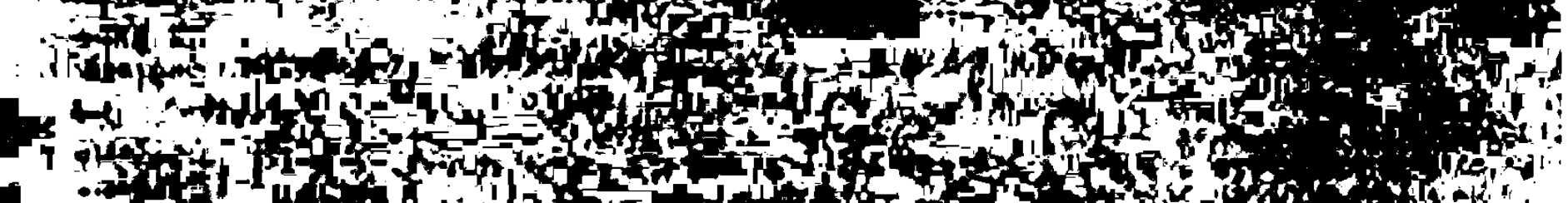

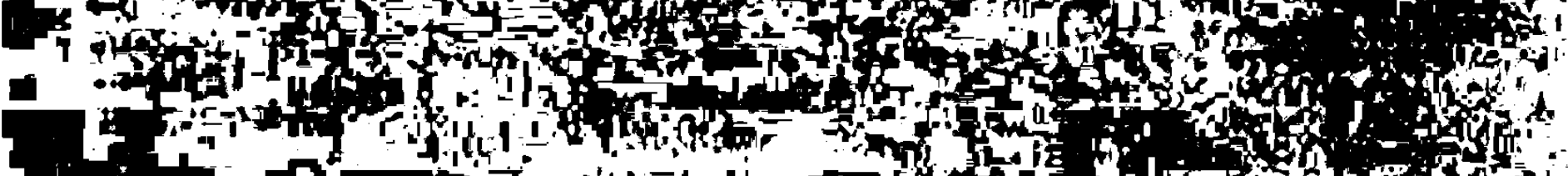

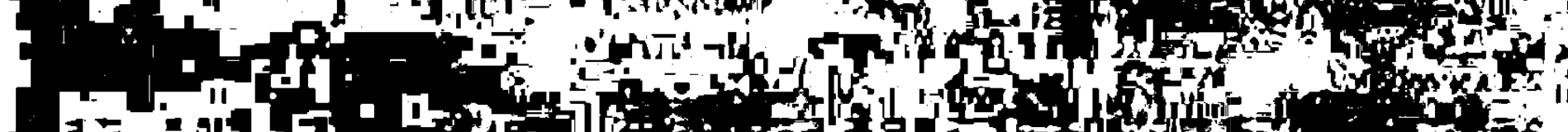
Find

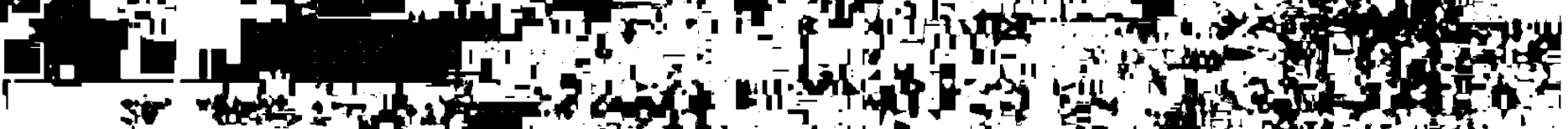

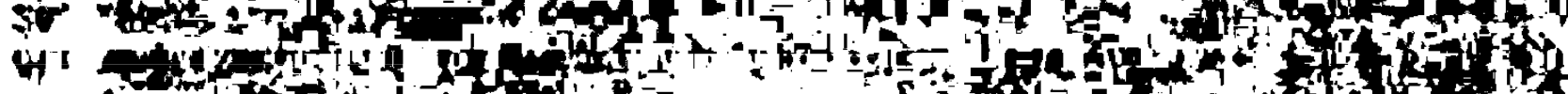

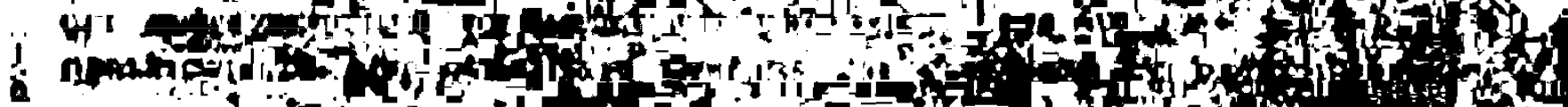

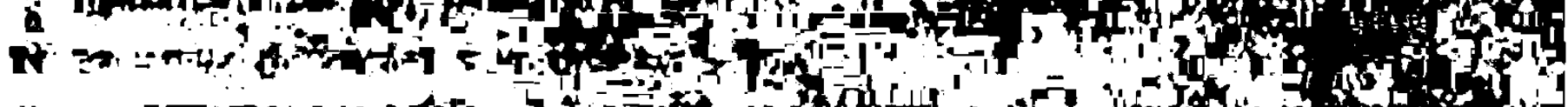
An

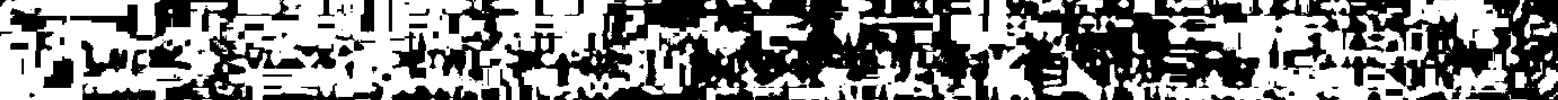

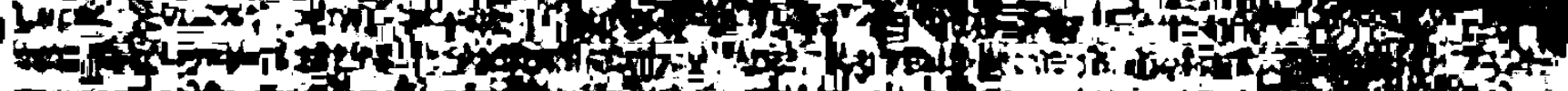
rwien

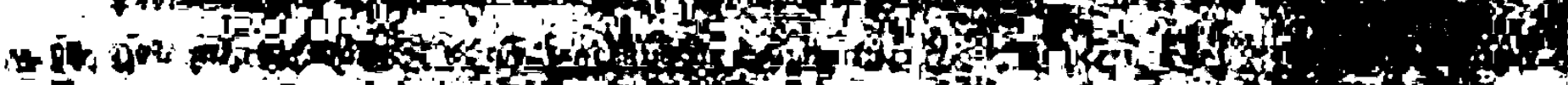

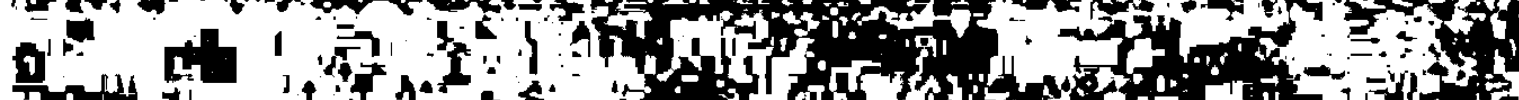

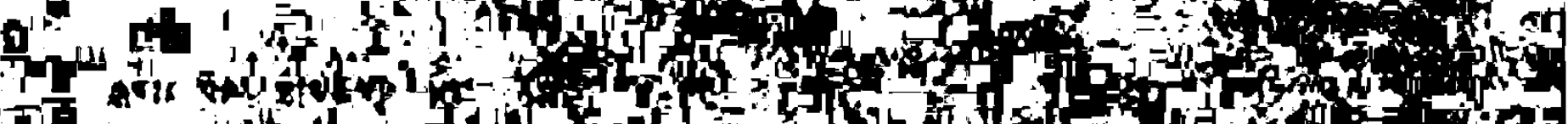

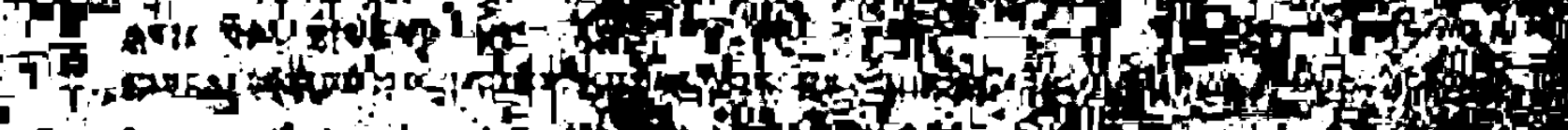

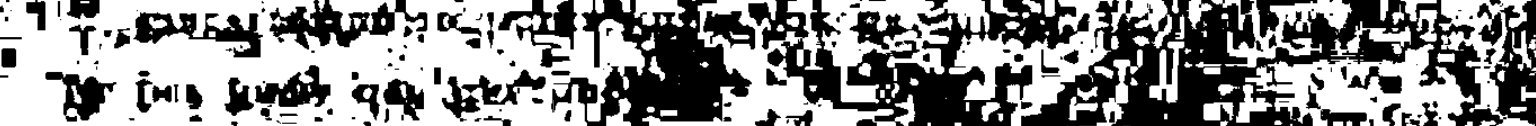

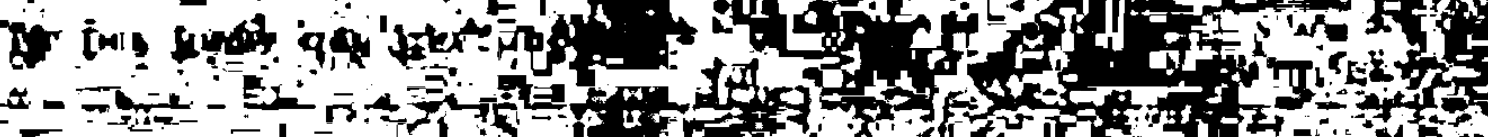
mond

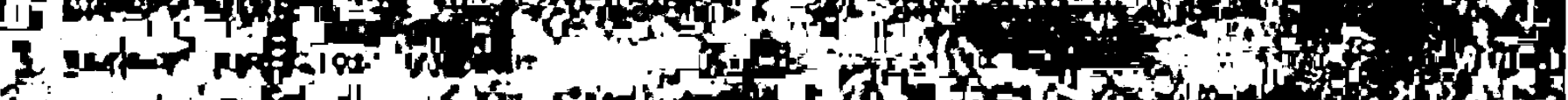

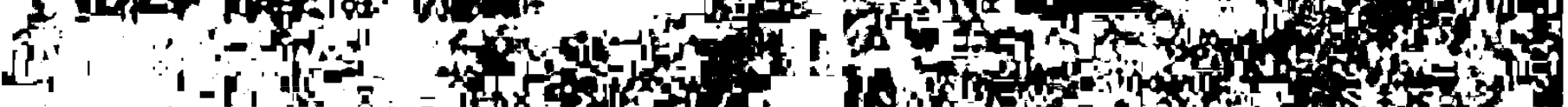

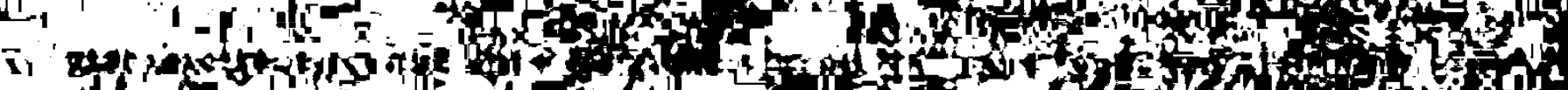
74 is

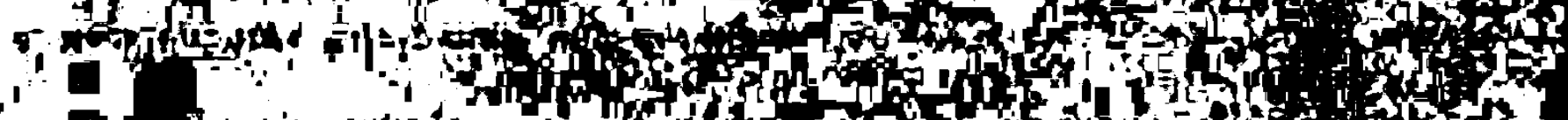

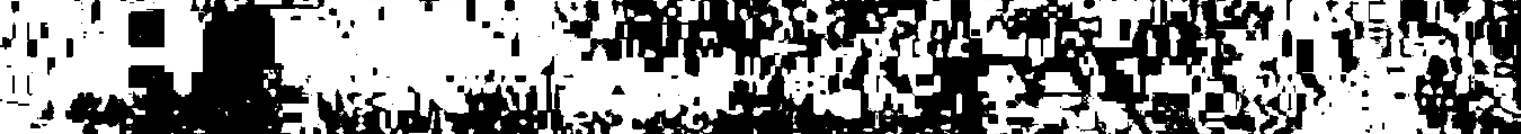

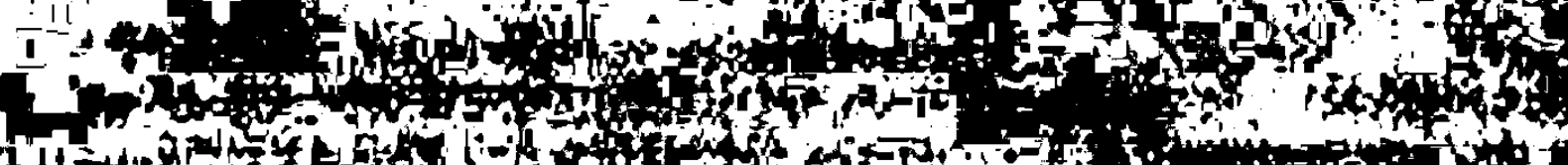

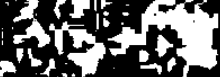

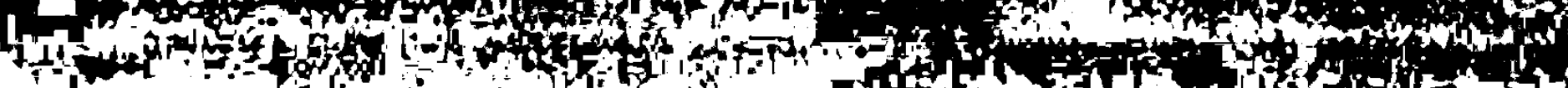

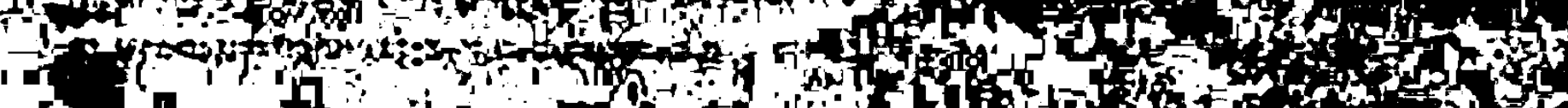

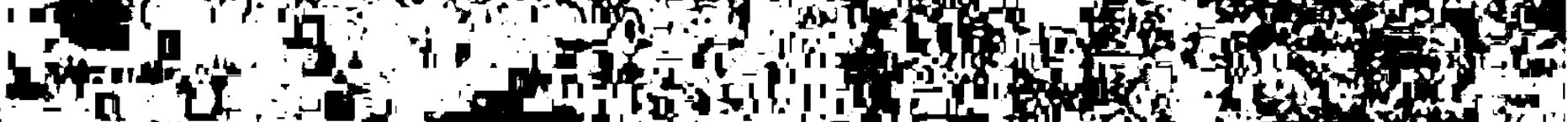

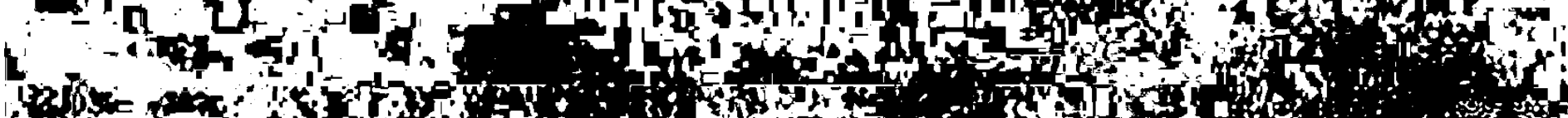

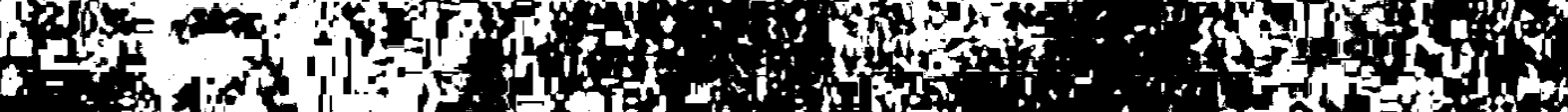

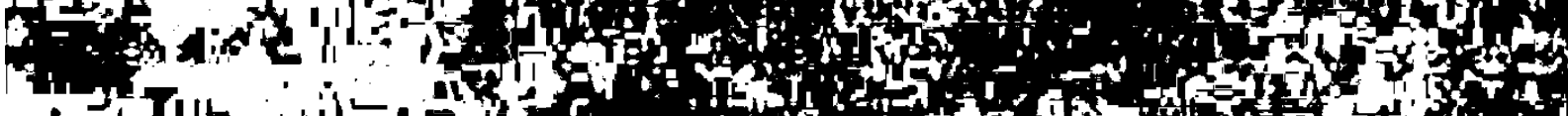

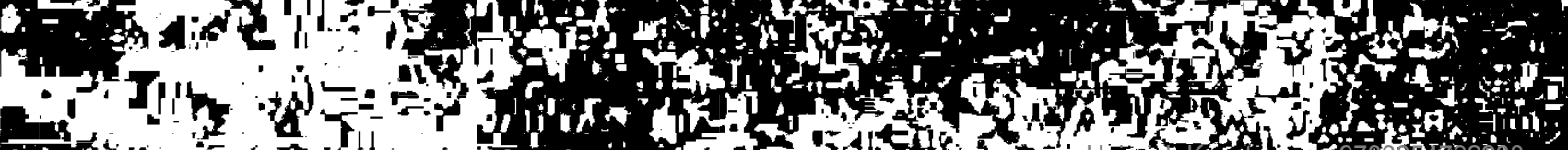

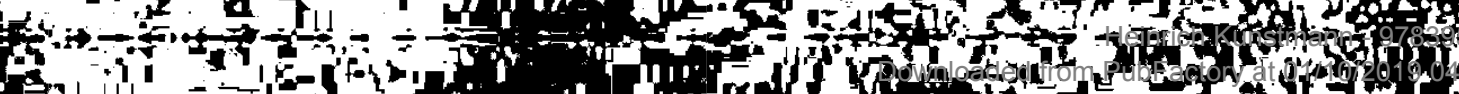

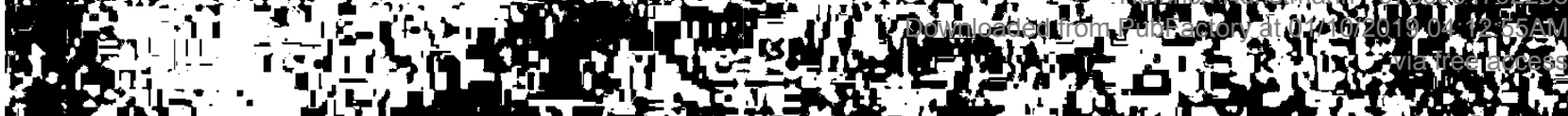




\section{Literaturverzelchnis und siglen}

Adam von Bremen. Gesta Hammaburgensis ecclesiae pontificum. Script. rer. german. In usum scholarum. Hannoverae ${ }^{2} 1876$.

AfslPh. Archiv für slavische Philologie. Berlin 1876-1929.

Alföldy. G. (1969). Die Personennamen in der römischen Provinz Dalmatien. Heidelberg.

Annales regni Francorum. Annales regni Francorum inde ab a. 741 usque ad a. 829 qui dicuntur Annales Laurissenses malores et Einhardi. Post editionem G. H. Pertzil recognovit Fr. Kurze. MGH Script. rer. german. in usum scholarum. Hannoverae 1895.

Arnold von Lubeck. Arnoldl Chronica Slavorum. Script. rer. german. in usum scholarum. Ed. G. H. Pertz. Hannoverae 1868.

Atlas po bslgarska istoria. Bblgarska Akademija na Naukite. Institut za istorija. Sofija 1963.

Bach. A. (1978). Deutsche Namenkunde. I-IIl. Heidelberg ${ }^{3} 1978$.

Bahlow, H. (1985). Deutschlands geographische Namenwelt. Frankfurt a. M.

v. Barloewen, W.-D. (1961). AbriB der Geschichte antiker Randkulturen. München.

Bartoli. M. G. (1906). Das Dalmatische. 1-II. Wien.

Bathe. M. (1940). Die Sicherung der Reichsgrenze an der Mittelelbe durch Karl den Großen. In: Sachsen und Anhalt 16, I 1 .

Bathe, M. (1963). Der deutsche Zetazismus im Spiegel slawischer Ortsnamen aus ottonischer Zeit. In: Slawische Namenforschung. Berlin. $119 \%$.

Bathe. M. (1967). Belxem, eln Gau- und Flußname? In: Wissenschaftliche Zeitschrift der Humboldt-Universität zu Berlin. Gesch.- u. Sprachwiss. Reihe 16, H. 5, 629 If.

Beck. H.-G. (1959). Kirche und theologische Literatur im byzantinischen Reich (= Byzantinisches Handbuch II/1). Munchen.

Beckmann. P. (1959). Die Rethra-Sagen in Mecklenburg. In: Deutsches Jahrbuch für Volkskunde 5. $44 \mathrm{ff}$.

Bengtson. H. (1959). Neues zur Geschichte der Naristen. In: Historica 8. $213 \mathrm{ff}$.

Bengtson, H. (1977). Griechische Geschichte von den Anfängen bis in die römische Kaiserzeit. München ' 1977.

Berneker, E. (1924). Slavisches etymologisches Worterbuch. I-II. Heidelberg.

Bezlaj. F. (1956-61). Slovenska vodna imena. I-II. Wubljana.

Bilek, J. (1960). Die Bedeutung des Flußnamens Dosse. In: Märkische Helmat 4. $177 \mathrm{fr}$.

Birnbaum, H. (1986). Noch einmal zu den Millngen auf der Peloponnes. In: Fs für Herbert Bräuer zum 65. Geburtstag. Hg. R. Olesch u. H. Rothe. Köln-Wien $15 \mathrm{ff}$. 
Bischolf, B. (1974). Die sudostdeutschen Schreibschulen und Bibliotheken der Karolingerzelt. I. Wiesbaden ${ }^{3} 1974$.

Bischoff. K. (1967). Sprache und Geschichte an der mittleren Elbe und der unteren Saale. Köln. Graz.

Blöndal. S., Benedikz, B. S. (1978). The Varangians of Byzantium. Cambridge.

Boba. I. (1984). "Abodriti qui vulgo Praedenecenti vocantur" or "Marvani praedenecenti"? In: Palaeobulgarica 8, $29 \mathrm{ff}$.

Bohm, E. (1980). Slawische Burgbezirke und deutsche Vogteien. Zur Kontinuität der Landesgliederung in Ostholstein und Lauenburg im hohen Mittelalter. In: Germania Slavica. I. Hg. W. H. Fritze. Berlin. $143 \mathrm{fl}$.

Bóna. I. (1971). Ein Vierteljahrhundert Völkerwanderungszeitforschung in Ungarn (1945-1969). In: Acta Archaeologica 23. 265 ff.

Bóna. I. (1976). Der Anbruch des Mittelalters. Gepiden und Langobarden im Karpatenbecken. Budapest.

Bóna. I. (1984). A népvándorlás kor ès a korai középkor története Magyarországon. In: Magyarország törtènete. Elözmènyek és magyar tơrtènet 1242-ig. Budapest. 1. kötet. 5. Pejezet. 265 ff.

Bosel. K. (1964). Freiheit und Unfreiheit. In: K. Bosei: Frühformen der Gesellschaft im mittelalterlichen Europa. München. Wien $180 \mathrm{fr}$.

Böttger. H. (1876). Diözesan- und Gaugrenzen Norddeutschlands. IV. Halle.

Braune, W.. Eggers, H. (1975). Althochdeutsche Grammatik. 13. Auflage bearbeitet von H. Eggers. Tübingen.

Bretschneider. A. (1981). Die brandenburgische Sprachlandschaft. Zur Geschichte und Gliederung (mit EinschluB von Berlin). GieBen.

Brückner. A. (1879). Die slavischen Ansiedelungen in der Altmark und im Magdeburgischen. Leipzig. ND: Köln. Wien 1984.

Brückner. A. (1900). Slowianie I Niemcy. T. I. Darszawa.

Brückner. A. (1919). O pocátcich dëjin Jeských a polských. In: CCH 24.

Brückner, A. (1922/23). Poczatki Slowianszczyzny zachodniej. In: Slavia 1. $379 \mathrm{ff}$.

Brückner, A. (1924-25). Wzory etymologii i krytyki łródlowej. In: Slavia 3.

Brückner. A. (1927). Slownik etymologiczny jezyka polskiego. Kraków.

Brückner. A. (1929). Methodologisches. 1. „Lechitisch". In: ZfslPh 6.

Brückner, A. (1980). Mitologia slowianska I polska. Wstep i oprac. S. Urbatczyk. Warszawa.

Brüske, W. (1983). Untersuchungen zur Geschichte des Lutizenbundes. Deutsch-wendische Beziehungen des 10.-12. Jhds. Köln. Wien ${ }^{2} 1983$.

Bruns, F.. Weczerka, H. (1962-67). Hansische Handelsstraßen. Textband. Auf Grund von Vorarbeiten von F. Bruns bearbeitet von H. Weczerka. Atlas bearbeitet von H. Weczerka. Köln. Graz.

Bulín. H. ('1958). Pocátky státu obodrického. In: Právnêhistorické studie 4. $5 \mathrm{Pf}$.

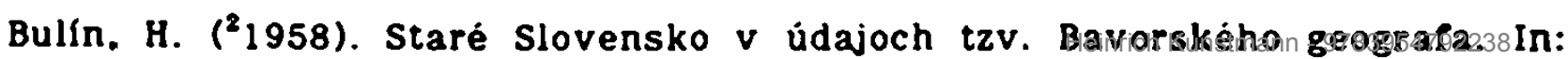
Historický Casopis 6. Bratislava, 429 lod from PubFactory at 01/10/2019 04:12:55AM 
Bulín. H. (1960). Podunajstí „Abodriti". Príspěvek $k$ dẻjinám podunajských Slovanú v 9. století. In: Slovanské historické studle 3, $5 \mathrm{ff}$.

Bulın. H. (1968). A propos des formations politiques des Slaves à la periphérie méridionale du bassin du moyen Danube au cours du $\mathrm{IX}^{\bullet}$ siècle. In: Byzantinoslavica 29, 360 fl.

Buschhausen, H. \& H. (1976). Die Marienkirche von Apollonia in Albanien. Byzantiner. Normannen und Serben im Kampl um die Vla Egnatia. Wlen.

Cabej. E. (1961). Die älteren Wohnsitze der Albaner au der Balkanhalbinsel im Lichte der Sprache und der Ortsnamen. In: Atti del VII Congresso Internazionale di scienze onomastiche. Firenze. $241 \mathrm{ff}$.

Carsten, R. H. (1948). Hammaburg. In: Hammaburg 1, 4 \%.

CCH. Ceský casopis historický.

Charanis, P. (1972). On the Slavic Settlement in the Peloponnesus. In: P. Charanis: Studies on the Demography of the Byzantine Empire. London. Hier: XVI.

Claude. D. (1972-75). Geschichte des Er:-bistums Magdeburg bis in das 12. Jahrhundert. I-II. Köln, Wien.

Coblenz, W. (1959). Slawisches Skelettgräberfeld von Altlommatzsch. Kr. Meißen. In: Ausgrabungen und Funde 3/1959. $137 \%$.

Coblenz. W. (1964). Archäologische Bemerkungen zur Herkunft der ăltesten Slawen in Sachsen. In: Arbeits - und Forschungsberichte zur sächsischen Bodendenkmalpflege 13, $296 \mathrm{fP}$.

Coblenz, W. (1966). Frühmittelalterliche Burgen mit steinerner Blendmauer aus dem Gebiet nördlich und südlich des Erzgebirges. In: Sbornik Národního muzea V Praze. Rada A - historie. Sv. XX, 1966. ¿. 1/2. $191 \pi$.

Coblenz. W. ('1977). Archåologische Betrachtungen zur Gana-Frage im Rahmen der alterslawischen Besiedlung des Gaues Daleminze. In: Beiträge zur Archivwissenschaft und Geschichtsforschung (= Schriftenreihe des Staatsarchivs Dresden, 10). Weimar. $354 \mathrm{f}$.

Coblenz. W. $\left({ }^{2} 1977\right)$. Bemerkungen zum Slawengau Nisane. In: Archăologie als Geschichtswissenschaft. Otto-Fs. Schriften zur Ur- und Frügeschichte des Zentralinstituts fur Alte Geschichte und Archåologie der Akademie d. Wiss. der DDR. Berlin. 343 \%.

Condurachi. E. (1967). Neue Probleme und Ergebnisse der Limesforschung in Scythia minor. In: Studien zu den Militărgrenzen Roms. Köln. Graz. 162 \%.

Cons, H. (1882). La province romaine de Dalmatie. Paris.

CPD. Codex Pomeraniae diplomaticus. I. Greifswald 1843.

CPM. Chronica Poloniae maioris: Kronika Boguchwala 1 Godyslawa Paska. Ed. W. A. Maciejowski. MPH II. 454 ff.

Creifelds, C. (1978). Rechtswörterbuch. München ${ }^{3} 1978$.

Crepajac, L. (1975). Glamod-Delminium-Dalmatia. In: Onomastica jugoslavica 5. 65 ?.

CSCH. Ceskoslovenský casopis historický. 
Curschmann, F. (1906). Die Dlözese Brandenburg. Lelpzig.

DAI. De administrando Imperio (des Konstantinos Porphyrogennetos).

Danicic. D. (1863-64). Rjexnik iz književnih starina srpskih. I-III. Biograd. ND: Graz 1962.

Danov, Ch., M. (1976). Altthrakien. Berlin-New York.

Detschew, D. (1957). Die thrakischen Sprachreste (= Schriften der Balkankommission. Linguistische Abteilung, XIV). Wien.

Dickenmann, E. (1966). Studien zur Hydronymie des Savesystems. I-II. Heidelberg ${ }^{2} 1966$.

Dieterich, K. (1912). Byzantinische Quellen zur Länder- und Völkerkunde (5.-15. Jhd.). I-II. Leipzig. ND: Hildesheim. New York 1973.

Dindorf. G. \& L. D. (1831-36). Thesaurus Graecae Linguae. Paris.

Ditten, H. (1978). Bemerkungen zu den ersten Ansätzen zur Staatsbildung bei Kroaten und Serben im 7. Jhd. In: Beiträge zur byzantinischen Geschichte im 9.-11. Jhd. Praha. 441 Pf.

Dobrowolska, A. (1958). O nazwie Kaszuby. In: Onomastica 4, 333 Pf.

Donat. P. (1984). Die Mecklenburg - eine Hauptburg der Obodriten. Berlin.

Dralle. L. (1981). Slaven an Havel und Spree. Studien zur Geschichte des hevellisch-wilzischen Fürstentums (6. bis 10. Jhd.). Berlin

Dralle. L. (1984). Rethra. Zu Bedeutung und Lage des redarischen Kultortes. In: Jahrbücher für die Geschichte Mittel- und Ostdeutschlands 33. $37 \mathrm{ff}$.

Ducange. Graec. Glossarium ad scriptores mediae et infimae graecitatis. Lyon 1688. ND: Graz 1958.

Ducange, Lat. Glossarium mediae et infimae latinitatis. I-X. Niort 1883-87. ND: Graz 1954.

Dukljanin-Chronik. Letopis popa Dukljanina. Uredio F. Slsic. BeogradZagreb 1928.

Duridanov. I. (1975). Die Hydronymie des Vardarsystems als Geschichtsquelle. Köln. Wien.

Duridanov. I. (1985). Die Sprache der Thraker. Neuwied.

Eggers, H. J. (1974). Einführung in die Vorgeschichte. München ${ }^{2} 1974$.

Eichler, E. (1956). Eine westslawische Bezeichnung für .Sumpp, Feuchtigkeit": altsorbisch "mroka. In: Zeitschrift für Slawistik 1, $39 \mathrm{ff}$.

Eichler, E. ('1962). Zur Deutung und Verbreitung der altsorbischen Bewohnernamen auf -jane. In: Slavia $31,348 \mathrm{ff}$.

Eichler, E. $\left({ }^{2} 1962\right)$. Studien zur Frühgeschichte slawischer Mundarten 2 wischen Saale und NeiBe. Berlin.

Eichler, E. $\left({ }^{3} 1962\right)$. Daleminze und Dalmatien. In: Linguistique balcanique V. 2. Solija. 45 ss.

Eichler, E. (1963). Aus der slawischen Toponomastik der Landschaft Puonzowa. In: Studia linguistica in honorem Thaddei Lehr-Splawinski. Warszawa. $455 \mathrm{fP}$.

Eichler. E. (1964). Ergebnisse der Namengeographie im altsorbischen Sprachgebiet. In: Materialien zum slawischen 
Eingel. u. red. v. R. Fischer, bearb. v. Eichler, H. Naumann, H. Walther. Berlin. $13 \mathrm{ff}$.

Eichler. E. (1965). Aus dem altsorbischen Namenwortschatz. In: Arbeitsund Forschungsberichte zur sächsischen Bodendenkmalpflege 14/15. $227 \mathrm{PP}$.

Eichler, E. (1966). Völker- und Landschaftsnamen im altsorbischen Sprachgebiet. In: Lètopis. A 13. Bautzen. Heft 1, 1 fl.

Eichler, E. (1968). Grundsätzliche Bemerkungen zur Erforschung des vorslawischen Substrats in der altsorbischen Onomastik. In: Zeitschrift für Archäologie 2. $117 \mathrm{fr}$.

Eichler, E. (1975). Zur altsorbischen Ethnonymie: Daleminze und Glomaci. In: Létopis. A 22/1. Bautzen. 67 ff.

Eichler. E. (1976). Die slawische Landnahme im Elbe/Saale- und Oder-Raum und ihre Widerspiegelung in den Siedlungs- und Landschaftsnamen. In: Onomastica Slavogermanica 10,67 fl.

Eichler, E., Walther, H. (1966-67). Die Ortsnamen im Gau Daleminze. Studien zur Toponymie der Kreise Döbeln. Großenhain, Meißen, Oschatz und Riesa. Berlin.

Elchler, E. Walther, H. (1970). Ortsnamen und Besiedlungsgang in der Landschaft Nisane im frūhen Mittelalter. In: Beiträge zum slawischen onomastischen Atlas. Fs Theodor Frings. Hg. Ru. Fischer. E. Eichler. Berlin. $75 \mathrm{~N}$.

Eichler, E., Walther, H. (1975-78). Ortsnamenbuch der Oberlausitz. Studien zur Toponymie der Kreise Bautzen. Bischofswerda, Görlitz. Hoyerswerda. Kamenz, Löbau, Niesky, Senftenberg. TelBwasser und Zittau. I-II. Berlin.

Eichler, E., Walther, H. (1984). Untersuchungen zur Ortsnamenkunde und Sprach- und Siedlungsgeschichte des Gebietes zwischen mittlerer Saale und WeiBer Elster. Berlin.

Ekblom, R. (1954). Der Inselname Fehmarn. In: Uppsala Universitets Arsskrift 10. 1 If.

Engel. F. (1970). Beiträge zur Siedlungsgeschichte und historischen Landeskunde. Mecklenburg-Pommern-Nledersachsen. Hg. u. eingel. v. R. Schmidt. Köln, Wien.

ESSJ. Etymologický slovnik slovanských jazykú. Slova gramatická a zájmena. 1-2. Praha 1973-1980.

Europa Slavica. Europa slavica - Europa orientalis. Fs H. Ludat 2 um 70. Geburtstag. Berlin 1980.

Fischer, R. E. (1967). Die Ortsnamen der Zauche. Weimar.

Fischer, R. E. (1970). Die Ortsnamen des Kreises Belzig (= Brandenburgisches Namenbuch. Tell 2). Weimar.

Fischer, R. E. (1976). Die Ortsnamen des Havellandes (= Brandenburgisches Namenbuch. Teil 4). Welmar.

Fischer, R. E., Schlimpert. G. (1971). Vorslawische Namen In Brandenburg. In: Zeitschrift für Slawistik 16, $661 \mathrm{\mu}$.

Fischer, R. E., Witkowski. T. (1967). Zur Geographie altpolabischer Namen-

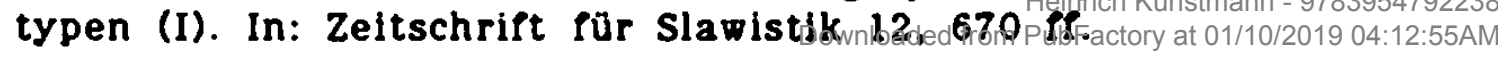


Flajshans, V. (1930). Nejstarši Cechy. Jazykový rozbor nëkterých nejstarsích jmen osadnich. In: Od pravěku $k$ dnesku. Pekařuv sbornik I. Praha. $38 \mathrm{ft}$.

Formirovanie. Formirovanie rannefeodal'nych slavjanskich narodnostej. Moskva 1981.

Förstemann, E., Jellinghaus, H. (1913). Altdeutsches Namenbuch. II. Band: Orts- und sonstige geographische Namen. I-II. Hg. H. Jellinghaus. Bonn ${ }^{3}$ 1913. ND: Hildesheim. München 1967.

Fraenkel, E. (1910-12). Geschichte der griechischen Nomina agentis auf

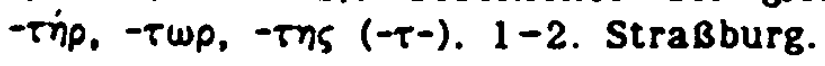

Franck. J. (1971). Altfränkische Grammatik. 2. Aufl. v. R. Schützeichel. Göttingen.

Fredegar. Fredegarii et allorum chronica. Edidit B. Krusch. Hannoverae 1888. MGH Script. rer. merovingicarum, t. II.

Fredrich, C. (1908). Imbros. In: Mitteilungen des kais. Dtsch. Archãologischen Instituts. Athenische Abteilung $37.81 \mathrm{fP}$.

Frisk. H. (1973). Griechisches etymologisches Wörterbuch. I-III. Heidelberg 21973-79.

Fritze. W. H. (1958). Beobachtungen zu Entstehung und Wesen des Lutizenbundes. In: Jahrbuch Pür Geschichte Mittel- und Ostdeutschlands 3. $1 \mathrm{fl}$.

Fritze. W. H. (1982). Frühzeit zwischen Ostsee und Donau (= Germania Siavica, III). Berlin.

Garaj. J. (1963). Prispevok k popisu hradských obci tzv. Bavorskèho geografa. In: Sbornik Csl. spolec. zemépisnè 68, $125 \%$.

Gardthausen. K. (1891). Augustus und seine Zeit. Leipzig.

GB. Geographus Bavarus

Gemoll. W. Gemoll: Griechisch-deutsches Schul- und Handwörterbuch. München, Wien '1954.

Geographus Bavarus. Nach Herrmann. E. 1965, 212 ff.

Georgakas. D. (1941-49). Beiträge zur Deutung als slavisch erklärter Ortsnamen. I-II. In: Byzantinische Zeitschrift $41,351 \mathrm{fP} . \quad(=1), 42$ (pubi. 1960), 384 fr. (= II).

Georges, K. H. Ausführliches lateinisch-deutsches Handwörterbuch. I-II. Hannover ${ }^{14} 1976$.

Georgiev, V. (1977). Trakite i technijat ezik. Soflja 1977.

Georgiev, V. (1986). Nepravilno pisane i proiznasjane na njakoj stari slavjanski imena. In: Palaeobulgarica 10, $10 \mathrm{fl}$.

Glãser. M. (1983). Die Slawen in Ostholstein. Studien zu Siedlung. Wirtschaft und Gesellschaft der Wagrier. Hamburg (Diss.).

Glossar A/B. Glossar zur frühmittelalterlichen Geschichte im ostlichen Europa. Begründet von J. Ferluga, M. Hellmann. H. Ludat. Hgb. von F. Kämpler. K. Zernack. Serie A Lateinische Namen bis 900. I-II. Wiesbaden 1973 \%.. Serie B Griechische Namen bis 1025. I-II. Wiesbaden $1980 \mathrm{PP}$. 
Göner, F. (1963). Die Bildung der Ethnika von Ortsnamen im serbokroatischen Sprachraum. Berlin.

Górnowicz. H. (1976). Najstarsze typy nazw geograflcznych Pomorza Srodkowego. In: Ze studiów nad toponimia Pomorza Srodkowego. Praca zbiorowa pod redakcja E. Homy. Koszalin. 8 ff.

Górnowicz. H. (1980). Toponimia Powiśla Gdanskiego. Gdansk.

Graf. A. (1964). Obersicht der antiken Geographie von Pannonien. Budapest.

Grégoire, H. (1944-45). L'origine et le nom des Croates et des Serbes. In: Byzantion 17. 89 fl.

Gröber, B., Müller, L. (1977-86). Handbuch zur Nestorchronik. Hg. L. Müller. Bd. III: B. Gröber, L. Müller: Vollstăndiges Wörterverzeichnis. I, 1-4. München.

Györffy. G. (1984). Államszervezés. In: Magyarorszàg története. Elözmények és magyar történet 1242-ig. Budapest. $717 \mathrm{ff}$.

Haberkorn, E., Wallach, J. F. (1972). Hilfswörterbuch für Historiker. Mittelalter und Neuzeit. I-II. München ${ }^{3} 1972$.

Hamann, M. (1962). Das staatliche Werden Mecklenburgs. Köln. Graz.

Hammond, N. G. L.. Griffith, G. T. (1979). A history of Macedonia. II. 550336. b.C. Oxford.

Hatzidakis, G. N. (1892). Einleitung in die neugriechische Grammatik. Leipzig.

Haussig. H. W. (1966). Kulturgeschichte von Byzanz. Stuttgart ${ }^{2} 1966$.

Havlik, L. (1964). Slované v anglosaské chorografil Alfréda Velikèho. In: Vanik a pocátky Slovanù V. 53 ff.

Helbig, H. (1960). Die slawische Siedlung im sorbischen Gebiet. In: Ludat, H., 1960, $27 \mathrm{ff}$.

Hellmann. M. (1960). Grundzüge der Verfassungsstruktur der Llutlzen. In: Ludat. H., 1960, $103 \mathrm{ff}$.

Helmold von Bosau. Helmoldl presbyteri Bozoviensis Cronica Slavorum. Ed. B. Schmeidler. Script. rer. german. in usum scholarum. Hannoverae ${ }^{3} 1937$.

Herrmann. E. (1963). Zu Entstehung und Bedeutung des sog. Geographus Bavarus (Descriptio civitatum). In: Jahrbuch 1963 für altbayerische Kirchengeschichte. Deutingers Beiträge Bd. 23/1, $77 \%$.

Herrmann, E. (1965). Slawisch-germanische Beziehungen im südostdeutschen Raum von der Spätantike bis zum Ungarnsturm. Ein Quellenbuch mit Erläuterungen. München.

Herrmann, J. ('1968). Slawische Stämme zwischen Elbe und Oder. Berlin.

Herrmann, J. $\left({ }^{2} 1968\right)$. Siedlung. Wirtschaft und gesellschaftliche Verhältnisse der slawischen Stämme $z$ wischen Oder/NeiBe und Elbe. Berlin.

Herrmann, J. (1970). Feldberg, Rethra und das Problem der wilzischen Höhenburgen. In: Slavia Antiqua 16, 33 fl.

Herrmann, J. (1971). Zwischen Hradschin und Vineta. Frühe Kulturen der Westslawen. München. 
Hermann. J. (1972). Byzanz und die Slawen "am āußersten Ende des westlichen Ozeans." In: Kllo. Beitr. zur Alten Geschichte 54, 309 ff.

Herrmann, J. ('1974). Die Slawen in Deutschland. Geschichte und Kultur der slawischen Stămme westlich von Oder und NeiBe vom 6. bis 12. Jhd. Ein Handbuch. Herausgegeben von J. Herrmann. Berlin.

Herrmann, J. $\left({ }^{2} 1974\right)$. Arkona auf Rügen. Tempelburg und politisches Zentrum der Ranen vom 9. bis 12. Jhd. Ergebnisse der archăologischen Ausgrabungen 1969-1971. In: Zeitschrift für Archäologie 8, 177 Æ1.

Herrmann, J. (1983). Wanderungen und Landnahme im westslawischen Geblet. In: Settimane di studio del Centro italiano di studi sull'alto medioevo 30, $75 \mathrm{fr}$.

Herrmann. J. (1985). Die Slawen in Deutschland. Geschichte und Kultur der slawischen Stämme westlich von Oder und NeiBe vom 6. bis 12. Jhd. Ein Handbuch. Neubearbeitung. Herausgegeben von J. Herrmann. Berlin.

HeBler. W. (1957). Mitteldeutsche Gaue des frühen und hohen Mittelalters. (= Abhandlungen d. Sächs. Akad. d. Wiss., philol.-hist. Klasse. Bd. 49. H. 2). Leipzig.

Hey. G. (1893). Die slavischen Siedlungen im Königreich Sachsen. Dresden. ND: Köln. Wien 1981 .

Hey. G., Schulze, K. (1905). Die Siedlungen in Anhalt. Ortschaften und Wüstungen mit Erklărung ihrer Namen. Halle a. S.

Hofmann. J. B., Szantyr, A. (1972). Lateinische Syntax und Stilistik. Neubearbeitet von A. Szantyr. München ${ }^{2} 1972$.

Holder, A. (1896). Alt-celtischer Sprachschatz. I-II. Leipzig.

Homa. E. (1976). Ze studiów nad toponimia Pomorza Srodkowego. Praca zbiorowa pod redakcja E. Homy. Koszalin.

Hoppe, W. (1965). Die Mark Brandenburg. Wettin und Magdeburg. Ausgewăhlte Aứsätze. Eingel. u. herausgeg. v. H. Ludat. Köln. Graz.

Horák. B., Trávnicek, D. (1956). Descriptio civitatum ad septentrionalem plagam Danubil (t. zv. Bavorský geograf). (= Rozpravy Csl. Akad. véd. Rada spolet. vêd. Ročnik 66, ses. 2). Praha.

Hosák. L.. Srámek, R. (1970-80). Místni jména na Moravé a ve Slezsku. I-II. Praha.

Hübbe. H. W. C. (1903). Hamburgs Zerstörungen und die Obotriten. In: Mitteilungen $d$. Vereins $\rho$. hamburgische Geschichte 26. 312 Pf.

IT. Itineraria Romana. Römische Reisewege an der Hand der Tabula Peutingeriana dargest. v. K. Miller. Stuttgart 1916. ND: Roma 1964.

Jacobsohn. H. (1930). Zu den griechischen Ethnika. In: Zeitschrift für Vergleich. Sprachforschung (KZ) $57,76 \mathrm{fl}$.

Jakubski. A. W. (1934). Czerwiec polski. I. Warszawa.

Jenkins, R. J. H. (1962). Constantine Porphyrogenitus: De Administrando Imperio. Vol. II. Comentary. By F. Dvornik. R. J. H. Jenkins, B. Lewis, Gy. Moravcsik. D. Obolensky, S. Runciman. Ed. by R. J. H. Jenkins. London.

Jirecek. K. (1877). Die Heerstraße von Belgrad nach Constantinopel 4 HAd die

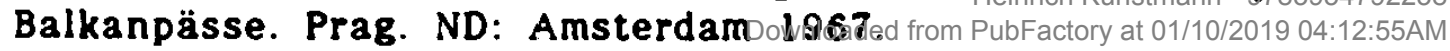


Jireðek, K. (1902). Die Romanen in den Städten Dalmatiens wăhrend des Mittelalters. I-II. Wien.

Jire`ek. K. (1911). Geschichte der Serben. I-II. Gotha.

Jirecek. K. ('1916). Die Handelsstraßen und Bergwerke von Serbien und Bosnien während des Mittelalters. Historisch-geographische Studien. (= Abhandlungen d. königl. böhm. Ges. d. Wlss. VI. Folge. 10. Bd. Cl. . Philos., Gesch. und Philol. Nr. 2). Prag.

Jirecek, K. ( $\left.{ }^{2} 1916\right)$. Valona im Mittelalter. In: Illyrisch-albanische Forschungen. Zusammengest. v. L. v. Thallóczy. I. Bd. München. Leipzig $168 \mathrm{Pl}$.

Jirecek, K. (1978). Istorija na Bblgarite. Sofuja.

Kahl, H.-D. (1964). Slawen und Deutsche in der brandenburgischen Geschichte des zwölften Jahrhunderts. Die letzten Jahrzehnte des Landes Stodor. Köln, Graz.

Kaiser, E. (1968). Untersuchungen zur Geschichte des Stammsilbenvokalismus im Dravänopolabischen. AuP der Grundlage des toponomastischen Materials (= Universität Regensburg. Slavistische Arbeiten. Hg. v. Karl-Heinz Pollok). München.

Kalima, J. (1941). Slav. 'sebrb 'Nachbar, Kamerad' und balt. 'sebras. In: ZlslPh 17, $342 \mathrm{fP}$.

Karayannopulos. J. (1959). Die Entstehung der byzantinischen Themenordnung. München.

Kawecki, 2. (1935). Gospodarcze znaczenie czerwców. In: Przyroda 1 technika.

v. Kienie, R. (1969). Historische Laut- und Formenlehre des Deutschen. Tübingen ${ }^{2} 1969$.

Kiersnowski, R. (1951-52). Plemiona Pomorza Zachodniego w swietle najstarszych zródel pisanych. In: Slavia Antiqua 3, 73 1 .

Kiss, L. (1983). Földrajzi nevek etimológlai szótára. Budapest. ${ }^{3} 1983$.

Klaic, N. (1971). Povijest Hrvata u ranom srednjem vijeku. Zagreb.

Klotz, R. Handwörterbuch der lateinischen Sprache. I-II. Braunschweig 31879. ND: Graz 1963.

Kl. Pauly. Lexikon der Antike. I-V. München 1979.

Kluge, F. (1967). Etymologisches wörterbuch der deutschen Sprache. Bearbeitet v. Mitzka. Berlin ${ }^{20} 1967$.

Kniezsa, I. (1963). Charakteristik der slawischen Ortsnamen in Ungarn. In: Studia Slavica 9, 27 ff.

Kollautz, A., Miyakawa, H. (1970). Geschichte und Kultur eines völkerwanderungszeitlichen Nomadenvolkes. Die Jou-Jan der Mongolei und die Awaren in Mitteleuropa. I-II. Klagenfurt.

Kötzschke, R. (1961). Deutsche und Slaven im mitteldeutschen Osten. Ausgewăhlte Aưsätze. Hbg. v. W. Schlesinger. Darmstadt.

Koroljuk, V. D. (1962). Gosudarstvo bodricej v pravlenii knjazja. In: Slavia occidentalis $22,215 \mathrm{fP}$.

Kossack, G. (1966). Beiträge zur Ur- und Frühgeschichte Mecklenburgs. Ein Forschungsbericht. In: Orfa 23, $7 \mathrm{Pl}$. 
Krahe, H. (1925). Die alten balkanillyrischen geographischen Namen auf Grund von Autoren und Inschriften. Heidelberg.

Krahe, H. (1928). Die Illyrischen $\Delta \dot{\xi} \xi \alpha \rho \circ$. In: $20 N F 4.272$ f.

Krahe. H. (1929). Lexikon altillyrischer Personennamen. Heidelberg.

Krahe, H. (1935). Beiträge zur Makedonenfrage. In: 2ONF 11, 78 ff.

Krahe. H. (1955). Die Sprache der Illyrier. Wiesbaden.

Krahe, H. (1957). Vorgeschichtliche Sprachbeziehungen von den baltischen Ostseeländern bis zu den Gebieten um den Nordteil der Adria. (= Akad. d. Wiss. u. d. Lit. Mainz. Geistes. u. Sozialwiss. Kl.). Wiesbaden.

Krenzlln, A. (1983). Beiträge zur Kulturlandschaftsgenese in Mitteleuropa. Gesammelte Aufsätze aus vier Jahrzehnten. Hgb. v. H.-J. Nitz und H. Quirin. Wiesbaden.

Krogmann. W. (1938). Obodriti. In: Zeitschrift f. Vergl. Sprachforschung (KZ) $65,138 \mathrm{fP}$.

Kucharski. E. (1925). Polska w zapisce karolinskiej. zwanej niewlasciwie "Geografem bawarskim". In: IV Zjazd historyków polskich w Poznaniu 1925. Sekcja II. Lwów.

Kühnel, P. (1928). Die slavischen Orts- und Flurnamen im Lüneburgischen. Mit einem Vorwort und einem Verzeichnis der slavischen Wortstämme herausgegeb. v. E. Eichler. Köln. Wien.

Kühns, F. (1865). Geschichte der Gerichtsverfassung und des Prozesses in der Mark Brandenburg. I-II. Berlln.

Kürbisówna, B. (1959). Dziejopisarstwo wielkopolskie XIII i XIV wieku. Warszawa.

Kuhn. W. (1973). Vergleichende Untersuchungen zur mittelalterlichen Ostsiedlung. Köln, Wien.

Kunstmann, H. (1979). Die Pontius-Pilatus-Sage von Hausen-Forchheim und Wogastisburg. In: WdS 24, $225 \mathrm{ff}$.

Kunstmann, H. (1980). Samo. Dervanus und der Slovenenfürst Wallucus. In: WdS 25. $171 \mathrm{fl}$.

Kunstmann, H. (1981). Der oberfränkische Ortsname Banz. In: WdS 26. 62 ll.

Kunstmann. H. (1982). Ober den Namen der Kroaten. In WdS 27, 131 Pf.

Kunstmann, H. (21982). Noch einmal Banz. In: WdS 27, 352 ff.

Kunstmann, H. ('1983). Ober den Namen der Bulgaren. In: WdS 28, 122 fl.

Kunstmann. H. $\left({ }^{2} 1983\right)$. Kamen die westslavischen Daleminci aus Dalmatien? In: WdS 28, $364 \%$.

Kunstmann. H. ('1984). Ter waren die WeiBkroaten des byzantinischen Kaisers Konstantinos Porphyrogennetos? In: WdS 29. $111 \%$.

Kunstmann, H. $\left(^{2} 1984\right)$. Ober dle Herkunft der Polen vom Balkan. In: WdS 29. $295 \mathrm{PP}$.

Kunstmann, H. ( $\left.{ }^{3} 1984\right)$. Nestors Dulebi und die Glopeani des Geographus Bavarus. In: WdS 29, $44 \mathrm{lP}$. 
Kunstmann, H. ('1985). Die Namen der ostslavischen Derevbane, Polocane und Volynjane. In: WdS 30. $235 \mathrm{fP}$.

Kunstmann, H. $\left({ }^{2} 1985\right)$. Wie die Sloverne an den Ilmensee kamen. In: WdS 30. 387 Pf.

Kunstmann, H. $\left({ }^{3} 1985\right)$. Mazowsze - Land der Amazonen? Die Landschaftsnamen Masowien und Masuren. In: WdS 30, $77 \mathrm{fP}$.

Kunstmann. H. $\left({ }^{1} 1986\right)$. Der Wawel und die Sage von der Gründung Krakaus. In: TdS 31, $47 \mathrm{fP}$.

Kunstmann, H. $\left({ }^{2} 1986\right)$. Woher die Russen ihren Namen haben. In: WdS 31. $100 \mathrm{fr}$.

Kunstmann, H. ( $\left.{ }^{1} 1987\right)$. Waren die ersten Přemysliden Balkanslaven? In: WdS 32. $25 \mathrm{fP}$.

Kunstmann. H. $\left({ }^{2} 1987\right)$. Der alte Polenname Lach, Lech und die Lendizj des Geographus Bavarus. In: WdS 32, $145 \%$.

Kunstmann, H. ( $\left.{ }^{3} 1987\right)$. Gniezno und Warta. In: WdS $32.302 \mathrm{fP}$.

Kunstmann, H. (1988). Die Anfänge der russischen Geschichte in neuer Sicht. (Erscheint voraussichtlich 1988 in München)

Kunstmann, H. $\left({ }^{2} 1988\right)$. Die balkansprachlichen Grundlagen einiger polnischer Toponyme und Hydronyme. In: WdS 33.

Kupka. P. L. B. (1936). Die Altslawen in der Nord-, d.h. der späteren Altmark. In: Sachsen und Anhalt 12, $16 \mathrm{ff}$.

KZ. Zeitschrift für vergleichende Sprachforschung auf dem Gebiete der indogermanischen Sprachen. Begründet v. A. Kuhn.

Labuda. G. (1960-75). Fragmenty dziejów slowiańszczyzny zachodniej. I-III. Poznan.

Labuda, G. (1968). O nazwie plemienia: Glomacze. In: Studia linguistica slavica baltica Canuto Olavo Palk sexagenario. Lund. $97 \mathrm{fP}$.

Lasch, A. (1974). Mittelniederdeutsche Grammatik. Tübingen ${ }^{2} 1974$.

Laur. W. (1967). Historisches Ortsnamenlexikon von Schleswig-Holstein. Schleswig.

Lehr-Splawinski. T. (1947). Obodriti - Obodrzyce. In: Slavia occidentalis 18. 223 Pl.

Lehr-Splawinski. T. (1958). Z onomastyki Slowian lechickich. In: Onomastica 4. $289 \mathrm{fP}$.

Lehr-Splawinski. T. (1960). Jeszcze raz Gniezno czy Szczecin w regeście dokumentu Dagome iudex. In: Slavia occidentalis 20. $95 \mathrm{ff}$.

Leumann. M. (1977). Lateinische Laut- und Formenlehre. München ${ }^{3} 1977$.

Lewicki. T. (1956). Litzike Konstantyna Porfirogenety 1 Biali Serbowie w pólnocnej Polsce. In: Rocznik historyczny 22, $16 \mathrm{ff}$.

Lex. d. AW. Lexikon der Alten Welt. Zürich, Stuttgart 1965.

Lex. d. MA. Lexikon des Mittelalters. I, 1980. II. 1983. München, Zürich.

Liddell. H. G.. Scott. R. (1925). A Greek-English Lexicon. I. Oxford.

Lippold. A., Kirsten, E. (1959). Donauprovinzen. In: Lexikon fär Antike und Christentum. Hgb. Th. Klauser. Bd. IV. Stuttgarteinrly/gun 1 Prann - 9783954792238 
Löwe. H. (1973). Deutschland im frănkischen Reich (= Gebhardt, Hantbuch d. deutschen Geschichte., 2). München.

Lokotsch, K. (1975). Etymologisches Wörterbuch der europäischen (gernanischen, romanischen und slavischen) wörter orientalischen Ursprungs. Heidelberg ${ }^{2} 1975$.

Lotter. F. (1974). Bemerkungen zur Christianisierung der Abodriten. In: Fs W. Schlesinger. II. Köln. Wien $58 \mathrm{lP}$.

Lotter. F. (1977). Die Konzeption des Wendenkreuzzuges. Sigmaringen.

Lowmianski, H. (1958). O Identyfikacji nazw Geografa bawarskiego. In: Studia Zródloznawcze 3, 1 rl.

Lowmianski, H. (1964-73). Początki Polski. Z dziejów Słowian w I tysiącleciu n.e. I-V. Warszawa.

Lowmianski. H. (1978). Geneza politeizmu polabskiego. In: Przeglad historyczny $69,1 \mathrm{fP}$.

Lowmianski, H. (1979). Religia Slowian I Jej upadek (w. VI-XII). Warszawa.

Ludat. H. (1934). Die Namen der brandenburgischen Territorien. In: Forschungen zur Brandenburgischen und PreuBischen Geschichte 46. $166 \mathrm{PP}$.

Ludat. H. (1960). Siedlung und Verfassung der Slawen zwischen Elbe, Saale und Oder. In Verbindung mit H. Jankuhn, W. Schlesinger und E. Schwarz hgb. v. H. Ludat. Gießen.

Ludat, H. (1969). Deutsch-slawische Frühzeit und modernes polnisches Geschichtsbewußtsein. Köln. Wien.

Ludat. H. (1971). An Elbe und Oder um das Jahr 1000. Skizzen zur Politik des Ottonenreiches und der slavischen Mächte in Mitteleuropa. Köln, Wien.

Ludat. H. (1982). Slaven und Deutsche im Mittelalter. Ausgewăhlte Aứsãtze zu Fragen ihrer politischen, sozialen und kulturellen Beziehungen. Köln, Wlen.

Machek. V. (1930). Studie o tvoreni výrazú expresivnich. Praha.

Machek, V. (1968). Etymologický slovnik jazyka Ceskeho. Praha ${ }^{2} 1968$.

Mader. B. (1986). Die Alpenslawen in der Stelermark. Eine toponomastischarchäologische Untersuchung. Wien.

Marquart, J. (1903). Osteuropäische und ostasiatische Streilzüge. Leizig. ND: Darmstadt 1961.

Masing. L. (1921). Drei Etymologien. In: Prace lingwistyczne oflarowane J. Baudouinowi de Courtenay. Kroków. 84 fP.

Mayer, A. (1936). Der Satem-Charakter des Illyrischen. In: Glotta 24, 161 ll. Mayer. A. (1957-59). Die Sprache der alten Illyrier. I-II. Wien.

Melich. J. (1929). Ober zwel Eigennamen. In: Sišlev zbornik. Zagreb. $107 \mathrm{Pr}$.

Meyer-Lũbke. W. (1972). Romanisches etymologisches Wōrterbuch. Heidelberg 21972.

MGH. Monumenta Germaniae Historica

Migne, J.-P. Patrologia Graeca 
Mikkola, J. J. (1928). Samo und sein Reich. In: AfslPh 42, $77 \mathrm{fl.}$

Miklosich EWB. Etymologisches Worterbuch der slavischen Sprachen. Wien 1886.

Miklosich LEX. Lexicon palaeoslovenico-graeco-latinum. Wien 1862-85. ND: Aalen 1977.

Miklosich, F. (1858). Monumenta serbica. Wien. ND: Graz 1964.

Miklosich, F. (1864). Die Bildung der Ortsnamen aus Personennamen im Slavischen. Wien.

Mitterauer, M. (1960). Slawischer und bayrischer Adel am Ausgang der Karolingerzeit. In: Carinthia I, $150,693 \mathrm{fl}$.

Mladenov, St. (1927). Arda, Marica i Tundža. In: Sbornik Boris Djakovic. Soryja. $295 \mathrm{ll}$.

MNyTESz. A Magyar nyelv történeti-etimológiai szótára. I-IV. Budapest $1967-84$.

Mócsy, A. (1970). Gesellschaft und Romanisation in der römischen Provinz Moesia Superior. Amsterdam. Budapest.

MPH. Monumenta Poloniae Historica. Pomniki dziejowe Polski. I-VI. Wydal A. Bielowski. Lwów 1864-93. ND: Warszawa 1960-1.

MUB. Mecklenburgisches Urkundenbuch. I. Schwerin 1863.

Much, R. (1925). Widsith. Beiträge zu einem Commentar. In: Zeitschrift . deutsches Altertum u. Literatur 62, $113 \mathrm{fP}$.

Muka, E. (1926-28). Slownik dolnoserbskeje rêcy a jeje narécow. I-III. Praha.

Müllenhoff. C. (1880-1900). Deutsche Altertumskunde. 1-5. Berlin.

Müller. K. E. (1972-80). Geschichte der antiken Ethnographie und ethnologische Theoriebildung. Von den Anfängen bis auf die byzantinischen Historiographen. I-II. Wiesbaden.

Nalepa, J. (1957). Obla, Oblica, Oblicko. Pierwotna nazwa rzeki Havel i jej derywatów. In: Sprágliga Bidrag. Meddelanden irán seminarierna i slaviska sprak...vid Lunds Universitet. II, Nr. 9, 12 fl.

Nalepa, J. (1957-58). Z badan nad nazwami plemiennymi u Slowlan zachodnich. Thafnezi Geografa bawarskiego - Dobnicy. In: Arsbok, Lund 1961. 64 Pl.

Natanson-Leski, J. (1961). Nazwy plemienne w Polsce. In: Onomastica 5. 195 \%f., 415 \%.

Naumann, H. (1961). Serimunt-Sermuth. Ein Beitrag zur Namenkunde. In: Wissenschaftl. Zeitschr. đ. Karl-Marx-Univ. Lelpzig 10, Heft 5. Gesellsch. - u. Sprachwiss. Reihe. $817 \mathrm{ff}$.

Naumann, H. (1962). Die Orts- und Flurnamen der Kreise Grimma und Wurzen. Berlin.

Niederle, L. (1902-24). Slovanské starozitnosti. I $=1902$, II $=1910$, III $=$ 1919. IV = 1924. Praha.

Niederle, L. (1906). Pưvod a pođátky Slovanú jižních. Praha.

Nilsson. M. P. (1955). Geschichte der griechischen Religion. I-II. München ${ }^{2} 1955$ 
Notit. dignit. Notitia dignitatum accedunt Notitia urbis Constantinopolitanae et Latercula prouinciarum. Ed. O. Seeck. 1876. ND: Frankfurt 1983.

Novakovic. R. (1977). Odakle su Srbi dosli na balkansko poluostrvo. Beograd.

Nový. R. (1968). Die Anfănge des böhmischen Staates. I. Teil. Prag.

Oberhummer, E. (1898). Imbros. In: Beitrăge zur Alten Geschichte u. Geographie. Fs P. H. Kiepert. Berlin. 277 1.

Olesch. R. (1983-87). Thesaurus linguae dravaenopolablcae. I-IV. Köln. Wien.

Ostrogorsky, G. (1975). Geschichte des byzantinischen Staates. München.

Otrebski. J. (1966). Oder, Obodriten. In: Studia linguistica slavica baltica Canuto-Olavo Falke sexagenario. Lund. $203 \%$.

Papazoglu. F. (1969). Srednjobalkanska plemena u predrimsko doba. Sarajevo.

Pape. W. (1914). Griechisch-deutsches Handwörterbuch. I-II. Braunschweig. ND: Graz 1954.

Passow. F. (1841). Handwörterbuch der griechischen Sprache. I-III. Leipzig. ND: Darmstadt 1983.

Patsch. C. (1904), Der Sandschak Berat in Albanien. Wien.

Patze, H., Schlesinger, W. (1968). Geschichte Thüringens. I. Köln, Graz.

Paul. H., Moser. H., Schröbler, I. (1975). Mittelhochdeutsche Grammatik. Tübingen ${ }^{21} 1975$.

Pauly RE. Realencyclopädie der classischen Altertumswissenschaft. Neue Bearbeitung $1894 \mathrm{fl}$.

Perwolf. J. (1883-84). Slavische Völkernamen. In: AfslPh 7. 590 ff: 8, I ff.

Petersohn. J. (1972). Forschungen und Quellen zur pommerschen Kulturgeschichte vornehmlich des 12. Jahrhunderts. Köln. Wlen.

Petersohn, J. (1979). Der südliche Ostseeraum im kirchlich-politischen Kräftespiel des Reichs. Polens und Dänemarks vom 10. bis 13. Jhd. Mission - Kirchenorganisation - Kulturpolitik. Köln, Wien.

Philippson, A., Kirsten, E. (1950-59). Die griechischen Landschaften. I-IV. Frankfurt.

Pilar̆. O. (1974). Dílo neznámého bavorského geografa. In: Historická geografle 12, 205 fl.

v. Polenz. P. (1961). Landschafts - und Bezirksnamen im frühmittelalterlichen Deutschland. Marburg.

Popovic. I. (1958). Siaven und Albaner in Albanien und Montenegro. In: ZfslPh 26, $301 \mathrm{fP}$.

Popovic. 1. (1959). Die Einwanderung der Slawen in das Oströmische Reich im Lichte der Sprachforschung. In: Zeitschrift $f$. Slawistik 4, 70 ff.

Popovic, I. ('1960). Geschichte der serbokroatischen Sprache. Wiesbaden.

Popovic. I. $\left({ }^{2} 1960\right)$. Bemerkungen uber die vorslavischen Ortsnamen in Serbien. In: ZfslPh 28, $101 \mathrm{fl}$. 
Preobrazenskij. A. EWB. Etimologiðeskij slovar' russkogo jazyka. 1-14. Moskva 1910-18.

Pritsak, O. (1981). The Origin of Rus'. I. Cambridge, Mass.

Pritsak, 0 . (1982). The Slavs and the Avars. In: Settimane di studio del Centro italiano di studi sull'alto medioevo $30,353 \mathrm{fl}$.

Procházka, V. (1962). Politické zrízeni polabsko-pobaltských Slovanú v závèrexném údobí rodové spolecnosti. In: Slavia occidentalis 22. 197 ९l.

Profous, A. (1947-57). Místni jmèna v Cechảch, jejich vznik, pưvodni význam a zmény. I-IV. Praha.

Prokop I-V. I = Anekdota, II = Gotenkriege, III = Perserkriege, IV = Vandalenkriege, $V=$ Bauten. Werke. Griech.-deutsche Edition Otto Veh. München ${ }^{2} 1970-77$.

Pucic, M. (1858). Spomenici srpski. Beograd.

PVL. Handbuch zur Nestorchronik. Hgb. L. Müller. Bd. I = Text. München 1977.

Radojicic. Dj.. S. (1957). Srpsko Zagorje, das spätere Raszien. Zur Geschichte Serbiens in der 2. Hälfte des 10. u. 11. Jhds. In: Südostforschungen 16, $262 \pi$.

Rajkovic. M. (1958). Oblast Strimona i tema Strimon. In: Zbornik radova Vizantoloskog instituta SAN 5, 1 ff.

Rav. Geogr. Ravennatis anonymi cosmographia et Gvidonis geographica. Ediderunt M. Pinder et G. Parthey. Berolini 1860.

Reischel, G. (1932). Politische und kirchliche Bezirke der Kreise Bitterfeld und Delitzsch im Mittelalter. In: Sachsen und Anhalt 8, $44 \mathrm{ff}$.

Reiter, N. (1973). Mythologie der alten Slaven. In: Worterbuch der Mythologie. Hgb. H. W. Haussig. Bd. II: Götter und Mythen im alten Europa. Stuttgart. $163 \pi$.

RGN. Russisches Geographisches Namenbuch. Begründet v. M. Vasmer. Hgb. V. H. Bräuer. I-X. Tiesbaden $1964 \mathrm{fl}$.

Richter, A. (1962). Die Ortsnamen des Saalkreises. Berlin.

Rospond, S. (1947). Pierwotna nazwa Szczecina a pólnocno-zachodnia granica Polski piastowskiej. In: Slavia occidentalis 18. $291 \mathrm{ff}$.

Rospond. S. (1951). Słownik nazw geograficznych Polski Zachodniej I Pólnocnej. I-II. Warszawa.

Rospond, S. (1966-68). Struktura pierwotnych etnonimów slowianskich. I-II. In: Rocznik slawistyczny 26, $21 \%$., 29, 9 \%.

Rőssler, H., Franz, G. (1958). Sachworterbuch zur deutschen Geschichte. III. München.

Rozwadowski, J. (1923). Historyczna fonetyka. In: T. Benni, J. Los, K. Nitsch, J. Rozwadowski, H. Ulaszyn: Gramatyka jezyka polskiego. Kraków. 57 fl.

Rudnicki, M. (1958). "Geograf bawarski" w oswietleniu jezykoznawczym. In: 2 polskich studiów slawistycznych. I. Warszawa. $187 \mathrm{fP}$. 
Rudnicki, M. (1959). Nazwy Slowian polabskich I luzyckich a Geograia Bawarskiego. In: Opuscula Cas. Tymieniecki septuazenario dedicata. Poznat. 249 lf.

Rudnicki. M. (1959-61). Praslowianszczyzna Lechia-Polska. I. Wylomienie sif Slowian sposród ludów indoeuropejskich i ich pierwotne siedziby. Pozná 1959. II. Wspólnota slowianska. Wspólnota lechicka-polska. Poznań 1961.

Rymut, K. (1980). Nazwy miast Polskí. Kraków.

Safarík. P. J. (1837). Slovanské starožitnosti. I-II. Praha.

Safar̆ik. P. J. (1868). Zivot sv. Symeona od krále Stépána. Z rukopisu XIII. stol. vydal P. J. Safar̃ik. Praha ${ }^{2} 1868$.

Safařik. P. J. (1870). Okázky obcanskèho pisemnictvi. Vydal P. J. Safařik. Praha ${ }^{2} 1870$.

Salivon. A. N. (1981). Samosoznanie obodritov (k voprosu ob obrazovanii obodritskoj rannefeodal'noj narodnosti. In: Formirovanie $130 \mathrm{fP}$.

Schall. H. (1958). Der Sorbengau Plisni als Siedlungseinhelt und Sprachdenkmal. In: Zeitschrift für Slawistik 3.272 \% .. 780 \%l.

Schall. H. (1963). Die baltisch-slavische Sprachgemeinschaft zwischen Elbe und Weichsel. In: Atti e Memorie del Congresso delle sezione toponomastica. Vol. II. Toponomastica. Parte seconda. Firenze. $385 \mathrm{ff}$.

Scheil. U. (1962). Zur Genealogie der einheimischen Fürsten von Rügèn. Köln. Graz.

Schindler, R. (1959). Die Datierungsgrundlagen der slawischen Keramik in Hamburg. In: Praehistorische Zeitschrift 37. 187 \&f.

Schlesinger, W. (1941). Die Entstehung der Landesherrschaft. Untorsuchungen vorwiegend nach mitteldeutschen Quellen. Dresden. ND: Darmstadt ${ }^{3} 1974$.

Schlesinger, W. (Hgb.). Die deutsche Ostsiedlung des Mittelalters als Problem der europäischen Geschichte. Reichenzu-Vorträge 1370-72 (= Vorträge und Forschungen, 18). Sigmaringen.

Schlimpert, G. (1972). Die Ortsnamen des Teltow (= Brander.burgisches Namenbuch. 3). Teimar.

Schlimpert, G. (1973). Germanisch-slawische Kontakte im Lichte Jer Namen Brandenburgs. In: Berichte über den II. Internat. KongreB für Slawische Archäologie. II. Berlin 471 ff.

Schlimpert. G. (1978). Slawische Personennamen in mittelalterlichen Quellen zur deutschen Geschichte. Berlin.

Schlimpert, G., Witkowski. T. (1969). Namenkundliches zum "Rethra"-Problem. In: Zeitschrift für Slawistik 14.529 $\mathrm{fl}$.

Schmidt. B. (1965-66). Zur Keramik des 7. Jhds. zwischen Main und Havel. In: Praehistorische Zeitschrift 43-44, $167 \mathrm{~N}$.

Schmidt. R. (1974). Rethra. Das Heiligtum der Lutizen als Heiden-Metropole. In: Fs W. Schlesinger. II. Hgb. v. H. Beumann. Köln. Wien. $366 \mathrm{ff}$.

Schmitt. J. (1904). The Chronicle of Morea. Edited by John Schmitt. London. ND: Groningen 1967. 
Schmitz, A. (1981). Die Orts- und Gewässernamen des Kreises Ostholstein. Neumünster.

Schönfeld. M. (1965). Wörterbuch der altgermanischen Personen- und Völkernamen. Nach der Oberlieferung des klassischen Altertums bearbeitet von $M$. Schönfeld. Heidelberg ${ }^{2} 1965$.

Schramm, G. (1981). Eroberer und Eingesessene. Geographische Lehnnamen als Zeugen der Geschichte Südosteuropas im ersten Jahrtausend $n$. Chr. Stuttgart.

Schroeder. H.-D., Hornemann, W. (1972-73). Die Sitze der Redarier und die Lage Rethras. In: Grelfswald-Strahlsunder Jahrbuch 10, 33 ff.

Schuchhardt, C. (1926). Arkona - Rethra - Vineta. Ortsuntersuchungen und Ausgrabungen. Berlin ${ }^{2} 1926$.

Schultheis, J. (1968). Umstrittene Deutungen von Ortsnamen des rechtseibischen Anhalt. In: Onomastica Slavogermanica 4, 85 lf.

Schultze, J. (1957). Nordmark und Altmark. In: Jahrbuch $\ell$. d. Geschichte Mittel- und Ostdeutschlands 6,77 ff.

Schulze, H. K. (1963). Adelsherrschaft und Landesherrschaft. Studien zur Verfassungs- und Besitzgeschichte der Altmark, des ostsächsischen Raumes und des hannoverschen Wendlandes im hohen Mittelalter. Köln, Graz.

Schulze, H. K. (1973). Die Besiedlung der Altmark. In: Fs W. Schlesinger. I. Hgb. v. H. Beumann. Köln, Wien. 138 ff.

Schuster-Sewc, H. (1972). Das altsorbische Dialektgebiet und seine sprachliche Stellung im Rahmen des Westslawischen. In: Lêtopis. Ser. B. Nr. 19. 203 ff.

Schütz, J. (1957). Die geographische Terminologie des Serbokroatischen $(=$ Veröffentlichungen d. Instituts $\mathrm{f}$. Slawistik. Hgb. H. H. Bielfeldt. Nr. 10). Berlin.

Schützeichel. R. (1955). Zur Geschichte einer aussterbenden lautlichen Erscheinung (bit 'mit). In: ZMAF 23, $201 \mathrm{fr}$.

Schützeichel, R. (1974). Althochdeutsches Wörterbuch. Tübingen ${ }^{2} 1974$.

Schwarz. E. (1929). Zur Geschichte der Nasalvokale im Slovenischen, Cechischen und Sorbischen. In: 2fs!Ph 5, $124 \mathrm{fl}$.

Schwarz. E. (1950). Deutsche Namenforschung. II. Göttingen.

Schwarz, E. (1960). Sprache und Siedlung in Nordostbayern. Nürnberg.

Schwarz, E. (1965). Daleminze und Lommatzsch. In: Zeitschrift für Ostforschung 18, $261 \mathrm{fP}$.

Schwarz, E. (1969). Vorkeltisches 'daksā 'Wasser' in Ortsnamen Böhmens. In: Bohemia 10, $71 \mathrm{ll}$.

Schwyzer. E. (1977). Griechische Grammatik. I. (= Handbuch der Altertumswissenschaft. II. Abtl., 1. Teil. 1. Bd.). München '1977.

Shevelov. G. Y. (1964). A prehistory of slavic. Heidelberg.

SJS. Slovnik Jazyka staroslověnského.

Skalová, H. (1965). Topografická mapa ûzemi Obodricư a Veletú-Luticú ve

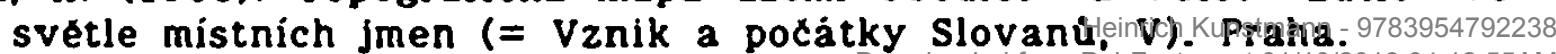


Skok, P. (1928). Ortsnamenstudien zu De administrando imperio des Kaisers Constantin Porphyrogennetos. In: Zeitschrift für Ortsnamenforschung 4. $213 \mathrm{Pl}$.

Skok, P. (1938). Konstantinova Srbica na Bistrici u Grčkoj. In: Glas Srpsk. kral. Akad. 176, drugi razred, $243 \%$.

Skok. P. (1950). Slavenstvo I romanstvo na jadranskim otocima. I-II. Zagreb.

Skok. P. (1971-74). Etimologijski rjexnik hrvatskoga ili srpskoga jezika. IIV. Zagreb.

Slavia Antiqua. Czasopismo poswifcone starozytnosciom slowianskim. Organ katedry archeologii polskiej uniwersytetu poznanskiego. Redaktor w. Hensel. 1 \%.. 1948 \%.

Slov. Jaz. star. Slovnik jazyka staroslovènskèho. Praha. I $\mathrm{fl.,} 1958$ fl.

Slowiańszczyzna Polabska. Slowianszczyzna polabska mięzy Niemcami i Polska. Materialy z konferencji naukowej zorganizowanej przez Instytut Historil UAM $w$ dniach 28-29 IV 1980 r. Pod redakcja J. Strzelczyka. Poznat 1981.

Slownik Praslowlathski. Pod redakcja F. Slawskiego. Wroclaw-Warszawa-Kraków-Gdansk. I lf., 1974 lf.

Slownik geogr.-kraj. Polski. Slownik geograficzno-krajoznawczy Polski. WarSzawa 1983.

Slownik Staropolskl. Warszawa. I ff.. 1953 ff.

Slownik staropol. nazw osob. Slownik staropolskich nazw osobowych. Pod redakcja i ze wstepem W. Taszyckiego. Wroclaw-Warszawa-KrakówGdansk. 1965-1983. I-VI.

SlowStarSlow. Slownik starozytnosci slowianskich. I-VII. Wroclaw-WarszawaKraków-Lódz. 1961-1986.

Sobolevskij. A. (1921-22). Russko-skifskie ètjudy. In: Izvestija otdelenija russkogo jazyka 26, 1 \%., 27, 252 ff.

Solmsen, F. (1904). Slavische Etymologien. In: Zeitschrift $\uparrow$. vergleichende Sprachforschung (KZ) 37 (N.F. 17). 592 \%.

Solta, G. R. (1980). Einführung in die Balkanlinguistik mit besonderer Berücksichtigung des Substrats und des Balkanlateinischen. Darmstadt.

Spiridonov, T. (1983). Istoriceska geografija na trakijskite plemena do III v. pr.n.e. Atlas. Sorija.

Sreznevskij. I. I. (1893). Materialy dlja slovarja drevnerusskogo jazyka. IIII. Sanktpeterburg.

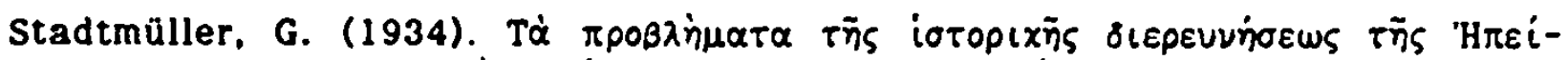

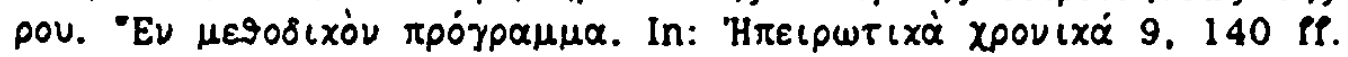

Stadtmüller, G. (1966). Forschungen zur albanischen Frühgeschichte. Wiesbaden ${ }^{2} 1966$.

Stadtmüller, G. (1976). Geschichte Südosteuropas. München, Wien ${ }^{2} 1976$.

Stanislav, J. (1978). Starosloviensky jazyk. I. Bratislava.

Stein. E. (1919). Studien zur Geschichte des byzantinischen Reichess 4 Stutt gart. 
Steinberg, R. (1962). Die Mark Lipani. In: Jahrbuch \&. d. Geschichte Mittelund Ostdeutschlands $11,273 \mathrm{ff}$.

Steinhauser. W. (1953). Wagrien. In: Beiträge zur Namensforschung 4, 95 ff.

Stephanus. Thesaurus graecae linguae. I-IX. ND: Graz 1954.

Steph. v. Byz. Stephani Byzantil ethnicorum quae supersunt ex recensione Augusti Meinekil. Berlin 1849. ND: Graz 1958.

Stieber, Z. (1972). O nazwie wsi Mlądz pod Warszawa. In: Wiener slavistisches Jahrbuch 17, 287 ff.

Stowasser. Der kleine Stowasser. Lateinisch-deutsches Schulwörterbuch. München 1971.

Struwe. K. W. (1981). Die Burgen in Schleswig-holstein. I. Die slawischen Burgen. Textband + Pläne. Neumünster.

Strzelczyk. J. (1968). Drzewianie polabscy. In: Slavia Antiqua 15, 61 Pf.

v. Sufflay, M. (1924). Städte und Burgen Albaniens hauptsächlich während des Mittelalters. In: Denkschriften d. Akad. d. Wiss. in Wien. 63. Bd. 1. Abh. Wien, Lelpzig.

Szädeczky-Kardoss, S. (1972). Ein Versuch zur Sammlung und chronologischen Anordnung der griechischen Quellen der Awarengeschichte nebst einer Auswahl von anderssprachigen Quellen. (= Acta ant. et archaeolog. 16. Opuscula Byz. 1). Szeged.

Szädeczky-Kardoss, S. (1986). Avarica. Ober die Awarengeschichte und ihre Quellen. Mit Beiträgen von Th. Olajos. Szeged.

Theophyl. Simoc. Theophylacti Simocattae Historiae. Edidit C. d. Boor. Leipzig 1887. ND: Stuttgart 1972.

Thietmar v. Merseburg. Thietmarl Merseburgensis episcopi Chronicon. Ed. R. Holtzmann. MGH rer. german. NS IX. Berlin ${ }^{2} 1955$.

TIR K 34. Tabula Imperil Romani. K 34. Naissus-Dyrrhachion-Scupi-Serdica-Thessalonike. Lubljana 1967.

TIR L 34. Tabula Imperil Romani. L 34. Aquincum-Sarmizegetusa-Sirmium. Amsterdam 1968.

TIR L 35. Tabula Imperil Romani. L 35. Romula-Durostorum-Tomis. Bucarest 1969.

Tomaschek. W. (1880). Die vor-slawische Topographie der Bosna, Herzegowina. Crna-gora und der angrenzenden Gebiete. In: Mitteilungen der k.u.k. geographischen Ges. Bd. 23. Wien. 497 fl., 545 fl.

Tomaschek. W. (1882-86). Zur Kunde der Hämus-Halbinsel. Topographische, archäologische und ethnologische Miscellen. I-II. In: Sitzungsber. d. philos.-histor. Classe d. kais. Akad. d. Wiss. 99. Bd. Wien. $437 \mathrm{ff}$. 113. Bd. 1886285 ff.

Tomaschek. W. (1893-94). Die alten Thraker. I-II. In: Sitzungsber. d. Philos.-hist. Cl. d. Akad. d. Wiss. Bd. 128, 130. Wien. 1 ff., 1 ff.

Toporov, V. N., Trubacev, O. N. (1962). Lingvisticeskij analiz gidronimov verchnego Podneprov'ja. Moskva.

Trautmann, R. (1947). Die slavischen Völker und Sprachen. Eine Einführung in die Slavistik. Göttingen. 
Trautmann, R. (1948-56). Die Elb- und Ostseeslavischen Ortsnamen. I-III. Berlin. I = 1948; II = 1949; III = 1956 (Register).

Trautmann, R. (1950). Die slavischen Ortsnamen Mecklenburgs und Holsteins. Berlin ${ }^{2} 1950$.

Trubacev, O. N. (1968). Nazvanija rek pravoberežnoj Ukrainy. Slovoobrazovanie. Etimologija. EtniCeskaja interpretacija. Moskva.

Trubacev, O. N. (1982). Jazykoznanie i étnogenez slavjan. Drevnie slavjane po dannym ètimologii i onomastiki. In: Voprosy jazykoznanija 4. 10 fl., 5, 3 ff.

Turek, R. (1952). Kmenová územi v Cechách. In: Casopis Národniho muzea. Otdíl vèd spol. Roc. 131, c. 1, 33 fl.

Tuscul.-Lex. Tusculum-Lexikon griechischer und lateinischer Autoren des Altertums und des Mittelalters. Hgb. W. Buchwald. A. Hohlweg. O. Prinz. München ${ }^{3} 1983$.

Tymieniecki. K. (1946). Ledzicze (Lechici) czyli Wielkopolska w wieku IX. In: Przeglad wielkopolski 2, $161 \mathrm{fl}$.

Udolph, J. (1979). Studien zu slavischen Gewässernamen und Gewässerbezeichnungen. Ein Beitrag zur Frage nach der Urheimat der Slaven. Heidelberg.

Unger, E. (1952). Rethra. Das Heiligtum der Wenden in Mecklenburg. In: Offa 11. $101 \mathrm{fP}$.

Unger. E. (1958). Rethra = Wanzka, das seit 575 Jahren gesuchte slavische Heiligtum im Spiegel von Sagen und Flurnamen. In: Forschungsfragen unserer Zeit $5,39 \mathrm{ff}$.

Unger, E. (1959). Rethra, das heidnische Heiligtum in Wanzka und das christliche Sachsen (Merseburg, Halberstadt) und Bayern (Rinchnach). In: Das Carolinum 25, 3 \%.

Untermann, J. (1981). Indogermanische Restsprachen als Gegenstand der Indogermanistik. In: Le lingue indoeuropee dl frammentaria attestazione. Pisa.

Urbahczyk, S. (1947). Religia pogatiskich Slowian. Kraków.

Urbanczyk, S. (1966). O pochodzeniu nazwy Obodrytów. Uwagi krytyczne. In: Studia linguistica slavica baltica Canuto-Olavo Falk sexagenario. Lund. $309 \mathrm{PP}$.

Urosevic. A. (1953-54). Lipljan - antropo-geografska ispitivanja. In: Glasnik Etnografskog instituta SAN. II-III. 337 ff.

Vaillant. A. (1974). Grammaire comparée des langues slaves. IV. La formation des noms. Paris.

Vanæ̌cek, V. (1949). Prvních tisic let ... Predstátni spolecenská organisace a vznik státu u ceských Slovanú. Praha.

Vasmer, M. ('1929). Beiträge zur alten Geographie der Gebiete zwischen Elbe und Weichsel. In: ZfsiPh 5, 360 ff. (= Vasmer 1971, II. $540 \mathrm{fl}$.).

Vasmer. M. ( $\left.{ }^{2} 1929\right)$. Beiträge zur slavischen Altertumskunde: I. Nochmals die Nordillyrier. In: ZfsiPh 6, 145 ff. (= Vasmer 1971. II. 548 fl.).

Vasmer, M. (1931). Beiträge zur slavischen Altertumskunde:n Vף.83lewess und

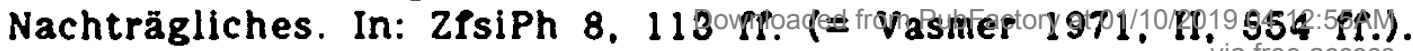


Vasmer, M. (1939). Der Name der Obodriten. In: ZfslPh 16, 361 f. (= Vasmer 1971. II. 731 P.).

Vasmer. M. (1941). Die Slaven in Griechenland. Berlin. ND: Leipzig 1970.

Vasmer, M. REW. Russisches etymologisches Wörterbuch. I-III. Heidelberg 1950-58.

Vasmer, M. Schriften I-II. Schriften zur slavischen Altertumskunde und Namenkunde. Hgb. H. Bräuer. Berlin 1971.

Velkov, V. (1980). Roman cities in Bulgaria. Collected studies. Amsterdam.

Vogel. V. (1972). Slawische Funde in Wagrien. Neumünster.

Vondrák, V. (1924). Vergleichende slavische Grammatik. I. Lautlehre und Stammbildungslehre. Göttingen ${ }^{2} 1924$.

Vukanović, T. (1974). Etnogeneza južnich Slovena. Vranje.

Vulpe, R. (1950). La date du vallum romain de la Bessarabie inférieure. In: Izvestija na archeologiceskajat institut 16. Sofija, 89 fl.

Waidmüller, L. (1976). Die ersten Begegnungen der Slawen mit dem Christentum und den christlichen Völkern vom VI. bis VIII. Jhd. Die Slawen zwischen Byzanz und Abendland. Amsterdam.

Walther. H. (1967). Ortsnamenchronologie und Besiedlungsgang in der Altlandschaft Daleminzi. In: Onomastica Slavogermanica 3, $99 \mathrm{ff}$.

Wattenbach, W.. Holtzmann, R. (1978). Deutschlands Geschichtsquellen im Mittelalter. II. Neuausgabe besorgt von F.-J. Schmale. Darmstadt.

WdrG. Wörterbuch der russischen Gewässernamen. I-V. Hgb. v. M. Vasmer. Berlin. Wiesbaden 1961-73.

WdS. Die Welt der Slaven

Weigand, G. (1927). Sind die Albaner die Nachkommen der Illyrer oder der Thraker? In: Balkan-Archiv 3, 227 \% .

Weinhold, K. (1863). Alemannische Grammatik. Berlin. ND: Amsterdam 1967.

Weinhold, K. (1867). Bairische Grammatik. Berlin. ND: Nendeln 1980.

Weithmann, M. W. (1978). Die slavische Bevölkerung auf der griechischen Halbinsel. Ein Beitrag zur historischen Ethnographie Südosteuropas. München.

Werner, J. (1950). Slawische Bügelnbeln des 7. Jhds. In: Fs zum 75. Geburtstag von P. Reinecke am 15. Sept. 1947. Mainz. $150 \mathrm{fP}$.

Werner, J. (1962). Die Langobarden in Pannonien. Beiträge zur Kenntnis der langobardischen Bodenfunde vor 568. Teile A u. B. München.

Werner, J. (1971). Zur Herkunft und Ausbreitung der Anten und Sklavenen. In: Actes du VIII Congrès Internat. des sciences prehistoriques et protohistoriques. Beograd 9-15 sept. 1971. I. 243 Pf.

Werner, J. (1981). Bemerkungen zum nordwestlichen Siedlungsgebiet der Slawen im 4.-6. Jhd. In: Beiträge zur Ur- und Frühgeschichte. I. AFD Beiheft 16. Berlin. 695 ff.

Werner. R. (1979). Die Frühzeit Osteuropas. In: Handbuch der Geschichte RuBlands. I. Stuttgart. $122 \mathrm{fP}$. 
Widajewicz. J. (1947). Studia nad relacja o Slowianach Ibrahima ibn Jakuba. Kraków.

Wienecke, E. (1940). Untersuchungen zur Religion der Westslaven. Leipzig.

Wiepert, P., Vasmer, M. (1934). Slavische Spuren auf Fehmarn. In: ZfslPh 11. 72 ff.

Wilkes, J. J. (1969). Dalmatia. London.

Witkowski, T. (1968). Der Name der Redarier und ihres zentralen Heiligtums. In: Symbolae philologicae in honorem Vitoldi Taszycki. Wroclaw-Warszawa-Kraków. 405 fl.

Witkowski. T. (1983). Bemerkungen zu den Namen der Obodriten und Redarier. In: Onomastika jako spolecenská vêda (= Sbornik praci pedagogické fakulty $v$ Ostrave 86. Rada D-19). $277 \%$.

Wojciechowski. 2. (1951). Uwagi nad powstaniem panstwa polskiego i czeskiego. In: Przeglad zachodni 7, 142 fr.

Wojtyla-Swierzowska. M. (1974). Praslowianskie nomen agentis. Wroclaw.

Wolfram. H. (1979). Geschichte der Goten. München.

Wossidlo, R. (1909). Volkssagen über Rethra. In: Korrespondenzblatt des Gesamtvereins der deutschen Geschichts - und Altertumsvereine. 57. $226 \mathrm{lf}$.

Zajaczkowski. S. (1962). Podzialy plemienne Polski. Geografia plemienna ziem polskich. In: Począki panstwa polskiego. Ksiega tysiaclecia. I. Poznat. 73 Pf.

Zakrzewskl. S. (1917). Opis grodów i terytorjów z pólnocnej strony Dunaju. czyli t.z. Geogral Bawarski. In: Archivum Naukowe. Wyd. Tow. dla popierania Nauki polskiej. Dzial I. z. IX. zesz. 1. Lwów.

Zakythinos, D. A. (1979). Byzantinische Geschichte 324-1071. Wien, Köln. Graz.

Zareba. A. (1976). Zur Geschichte und Geographie der slav. Wörter: urslav. - velijb. "vellkwib. In: WdS 21, $180 \mathrm{ff}$.

Zástérová. B. (1971). Les Avares et les Slaves dans la Tactique de Maurice. (= Rospravy Csl. Akad. 81, 3). Praha.

Zernack. K. (1967). Die burgstädtischen Volksversammlungen bei den Ostund Testslaven. Wiesbaden.

Zeuß. K. (1837). Die Deutschen und ihre Nachbarståmme. München. Manuldruck Heidelberg 1925.

ZfslPh. Zeitschrift für slavische Philologie

Ziegelhöfer. A., Hey, G. (1911). Die Ortsnamen des ehemaligen Hochstifts Bamberg. Bamberg.

ZMAF. Zeitschrift für Mundartforschung

Zoladz. D. (1981). Redarowie. In: Slowianszczyzna polabska. 217 ff.

2upanic. N. (1927-28). Les Serbes à Srbčiste (Macèdoine) au VII siècle. In: Byzantion 4. $277 \mathrm{Pf}$.

Zupanic, N. (1928). The Serb Settlement in the Macedonian Town of Srbciste in the $\mathrm{VII}^{\text {tb }}$ century and the Ethnological and Sociological 
Moment in the Report of Constantinus Porphyrogenetes concerning the Advent of Serbs and Croats. In: Etnolog 2, $26 \mathrm{fl}$. 


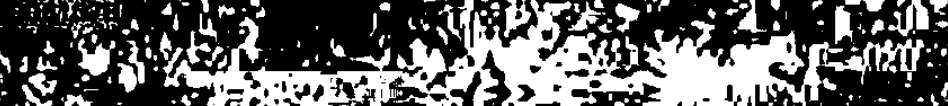

a 11.

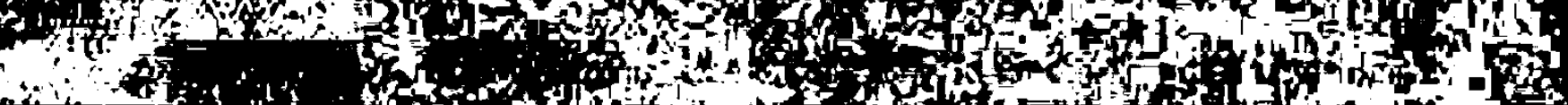
(1)

20

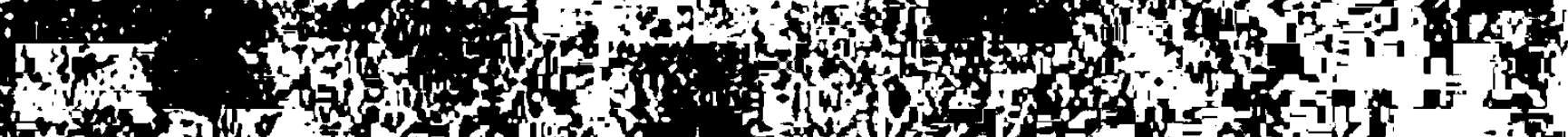

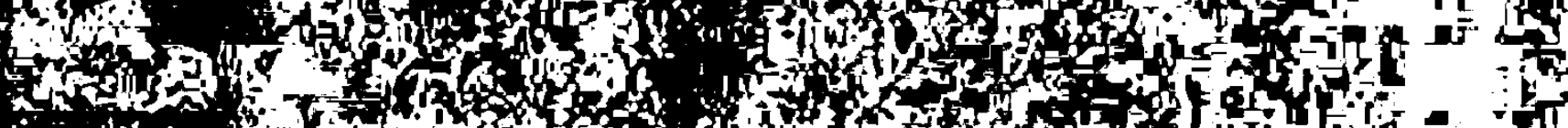
at

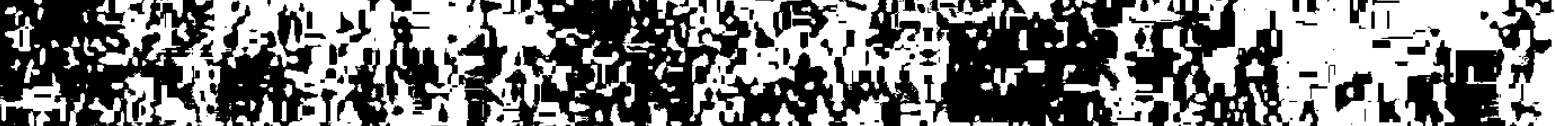
row

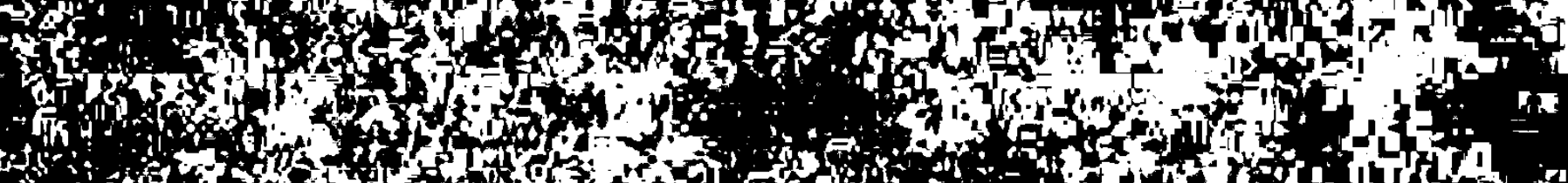
itist

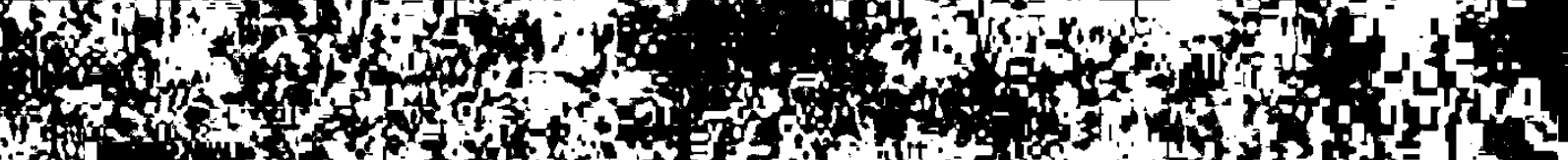
(x)

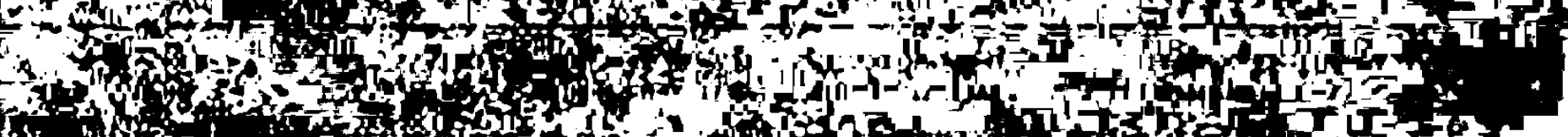
Tis

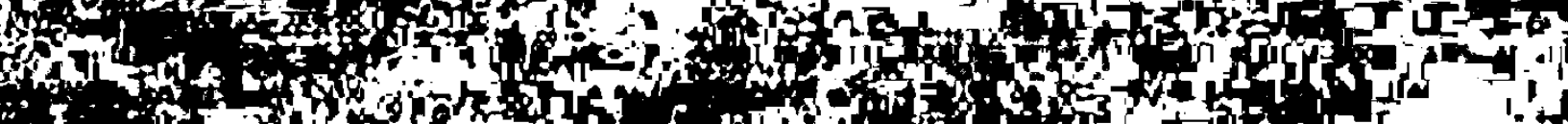

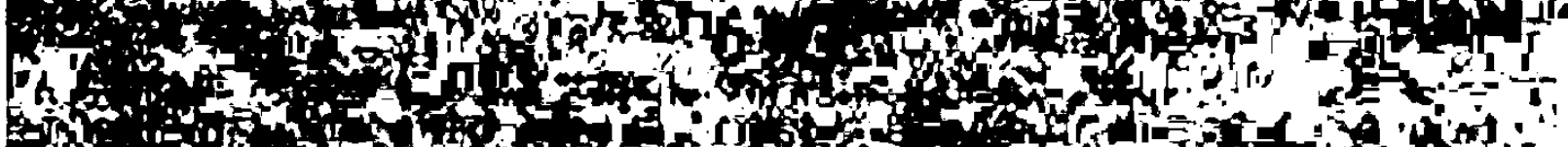
a

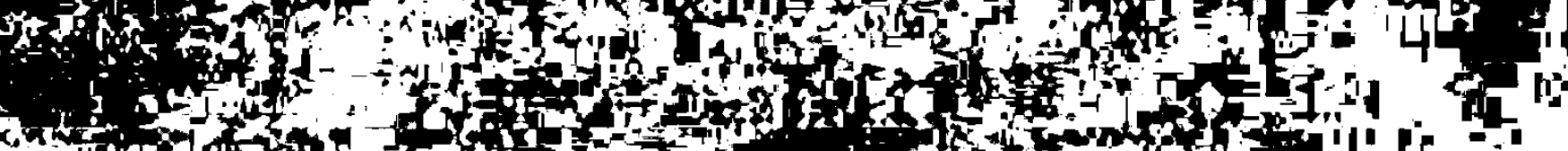

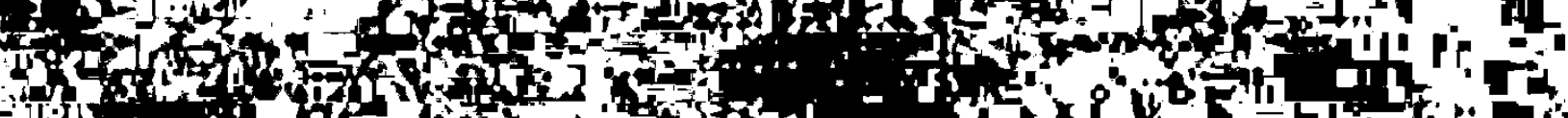
Fif E

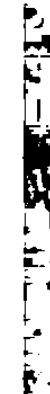
par

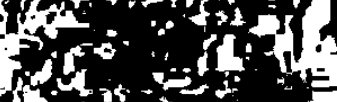

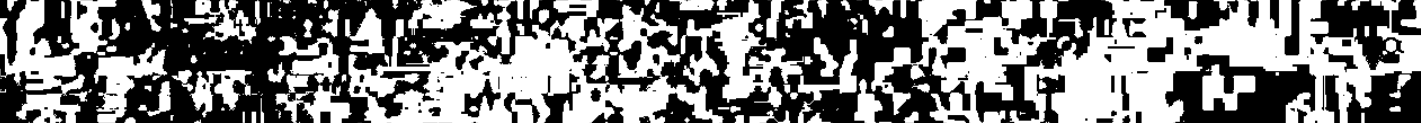

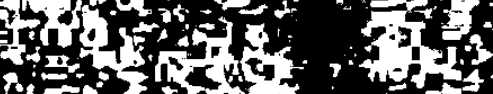

ond Fof

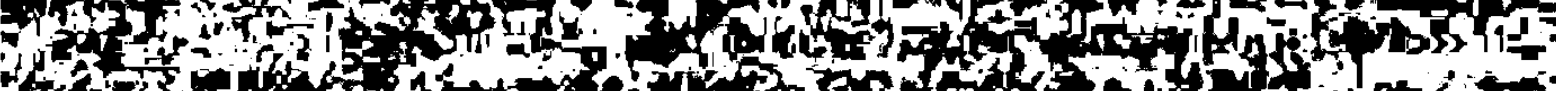
Hefof 1.7ne Find

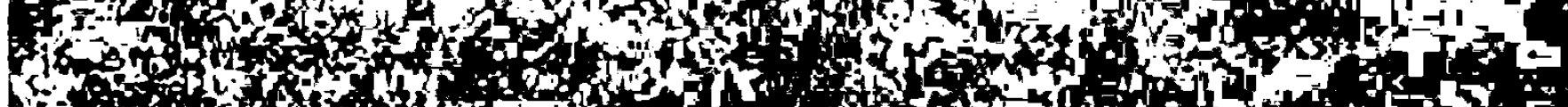
$6+4 x^{2}$ ind 


\section{Allgemeines Register}

Diakritische Zeichen bleiben unberücksichtigt. Die slavischen Halbvokale $b$ und $z$ stehen nach $i$ bzw. $u$.

Abitriti 29

Abodriten 11, 17, 18, 25-43, 45ff., 83, 136, 171, 188, 191, 194. 197, 202, 203 A. 5

Abola 120

Abroditi 29

Adam von Bremen 11, 14, 15, 45\%., 49, 51, 57, 60, 61f., 109

Adolf II. v. Holstein 11

Adria 163, 193, 200 .

Adrianopolis 19 A.6, 63, $193 \mathrm{f}$.

Agäis 12, 15, 20, 71, 193

Agathias 172

Agrianer 191 .

Aken 130

Akrokeraunisches Gebirge 152 A.2

Akropolis 73

Albanien 142

Albānus 90

Alboin 205

Albrecht d. Bär 181

Aldenburg. Aldinburg 17, 46

Alessio 116

Alexander d. Gr. 30

Alfred, König 133, 166९., 184

Al-Mas'ūdi 79

alpha privativa 32 .

Altenburg 166

"alteuropăisch"163, 164, 166

Altmark 85, 95-101, 202

Ambrakia, Golf 81

ana $=89$

Andarba, Anderba, Anderva 89

Angermünde 42

-Angriwariōs 59

Anhalt 127-132, $133 f$.

-āni, -ānus 178, 179, 185

Ankona 66

Annales Bertiniani 29

Annales Danicl Colbazenses 66

Annales Fuldenses 29

Annales Lundenses 29

Annales regni Francorum 25, 34. 35, 37, 38, 39, 40,95, 120 A. 4, 184

Annalista Saxo 87

Antae, Anten, Antes, Anti 172, 199

Antiocheia 175
Antipatria 112

Aous 19

Apatride 32

apatryda 32

Apodritae, Apodriti 29, 33

Apolide 31

Apollonia 84, 192

Applanos 53, 88, 89 A. 4

Apsos 112

Arda 63

Ardabur 63

Ardagastos, Ardogastos 62-64

Ardaricus 63

Ares 50 A. 3

Arkadien 22, 48, 123 A. 8

Arkona 57, 65-68, 194

-Arkona svetyni 67

Arnold von Lübeck $45 \mathrm{~A} .2,51$

Artemis-Eukleia-Kult 221 .

Asien 191

Asowsches Meer 183

Astakos 50 A. 3

Athen 13, 19, 71

Attila 149

Attischer Seebund 71

Augusta 122

Augustinus 122

Augustus, Kaiser 88

auksılé 21

aula (regia) 122 A. 6

aula, kasach. 123

Aula, Aule 124

Aulon 112 A. 4, 125

Auma 156

Autonomus 122

Auxentius 122

Auxibius 122

avgarbskb 122

Avgustija 122

avbgustb 122

Avsgustins 122

Avrksivii 122

-avslb 124

avstonomb 122

Avs

Avli 123

avlie $123 \mathrm{~A} .7$

avly, osm. 123 
Awaren 28, 40, 41\%., 106, 123, 142. 149, 186, 202, 204, 205 f. awla 123

Axios 179

Bács(-Bodrog) 36

Bahlow. H. 120 A. 3

- Baiwariōs 59

Bajan, Khan 106, 202

Balistarii Daphnenses 176

Balkan 18, 22, 40,41, 76, 89, 106 , 123. 139, 141, 142, 142 A.3. 164, 186, 187, 188, 1911., 194, 195, 196, 199-206

Balsamia, Balsamien, Balsam-Bann, Balsamerland, Balsem, Belsamis 96ft.

Balsmar-lant 99

Bamberg 14, 145, 147, 156, 157. 197

Banijanac 166

Banz 157

Banzgau. Banzgouwe 157

Bathe. M. 96rf.

Bauerberg 58

Baumert, L. 93

Bautzen 158, 169

Bayreuth 156

Bechelenz1. Bechel-bnbci 137

Beckmann. P. 58

bedr, bodr 26

Beeskov-Storkow 75

- Béla 97

Belcsem 91, 95-101, 203

Beleknegini 99

Belgae 97, 203

Belgard (Bialogard) 177

Belgern 105, 145, 147

-Belg(i)s-o-haima(m) 97

-Belg(i)sos 97

Belgrad 35, 149, 184, 186

Belk 96

Belckesheim, Belkesheim, Belkisheim 96fl.

- Béla zemja, 'Bel-o-zemja 979.

Belsheim 96, 98

Belxem 979.

Belz 89, 195

Belzig 105

Bengtson, H. 179 A. 10

Beograd 35, 149, 184, 186

Bereznoje Maloje 147

-berg 76

'bèrgъ. 'brěgz 178, 179
Berlin 105, 124

Berlin (New Hampshire) 191

Beroun 196

-berza 178, 179

Besut 58

Betazismus 99, 130, 178 A. 8

Bethenici 96

bezgradbnikb 32

Bialogard (Belgard) 177

Biderike, Biderize 146

Biese 95, 97

Biesenbrow 42

Bilek, J. 110

Bilsen-Kraut 97

Bischoff, B. 171

biskups 33, 83

Bistonis-See 50

biups 83

bljudo 83

blota 81

Boba, I. 39 .

Bóbr 128

Bodrici, Bodrici 26, 27

Bodrog. Bodrok 36

Bogochvai 159

Bohdiek 159

Böhmen 40. 48, 110 .. 156, 195\%., 197. 200, 202

Bohochval 159

Boleslaw Chrobry 75

Bóna. I. 106

Borisov 111

Borus. 'Borus 148

Bosanac 166, 185

Bosau 155

Böttger, H. 115

Brandenburg. Bistum u. Mark 73. 95, 109, 110, 111, 119\%., 127. 174. 181,192

Branicābin 36

Branicevci 36

Branicevo 36, 40

-bregs 76

BreitengüBbach 156

- Breżane 178

Briesenlang 180

Brigas, Brygas 179

brisa 179

Brisae 179, 180, 187, 192

Brisani $179 \mathrm{ft}$.

Brisengowe 180 A. 12

Brisenlank 180

Brizani 119, 180 r.

Brno, Brünn 48

brod 156 
Brūckner, A. 21, 27, 35, 62, 66, 80ff., 92, 96, 115, 1341.. 151

Brunichild 204 .

Brüske. W. 46. 103

Budissina, Budissa 169

Budivoj, Budvoj 47

Büdrici 27

Budva 47

Budysin 169

Bug, westl. 89

Bugojno 89 A. 4

Bühler. W. 31

Bukovec 147

Bulgaren 35, 123, 169

Bulín, H. 35f?.

Buls 89

- bur 64

Burakovo 111

Burg a. Fehmarn 11 A. 2

Burgas 33, 83

Burgenland 206

Burgwerben 156

Burstaborg. Burstenburgh 70

Butua. Butue, Buthue 47

Buzane 89

Byzacium 48

Byzanz 20, 34, 39, 40, 53, 63, 92 , 142. 148, 172, 176, 1791., 187. 189, 190, 202

Cadola, Chadaloh 67

Caesar 64, 97, 117, 152

Caganus. Chaganus 67

Calăbria, Calabria 771 .

captivus 190 A. 14

carabus 194

casa 80

Casinia 93

Casinum 93

Cassius Dio 53

Cassiopea 83

Cassopael 81

Cassubae. Cassubl, Cassubia 83

castrum 73

Cedb. Cedi 37

Ceská Lipa 169 A. 3

- Chabrla 121

Chadaloh. Cadola 67

Chaganus, Kaganus 67

Chalko(ko)ndylas, L. 186, 200

Charvatce 195

Chasabin 79

Chersonesos, Thrak. 12

cheude 142
Chilonô, Kielau 67

chmielisko 131

chochol. chochslb 67

Cholidici 130

Chorvaty, Chrovaty 195

Chorwete 166, 195

Chrabrovo, Chrabrow 67

Chronica magna seu longa Polonorum 80 .

Chronica Poloniae Maioris 86

Chronik von Morea 49

Chutici 155

Chyzane 80

Cersz, Cerzb 52

Cerven, Cervenec 131 A.5

Cervenéves 131

- cerviste 128

Cervonnaja Rus' 131 A. 5

circa, circi(ter) 52

Cieruisti 127 1 .. 178, 181

cirv 129

'cirv́ 129

- Cirvisce 129

citra 52

civitas Schinesghe 69

-bcb, -bci 136, 148, 165f., 175

- carvb 131

Clenze 85

clipeus, clupeus 69

Cnēus 47

Coblenz, W. 161 A.2, 195, 202

Coccus polonicus 131

Cochenille 129. 131

Colberg 75-78

Colditz 138

Colebeke. Colebize 146

Coledici 133, 138

Constantini Daphnenses 176

Conversio Bagoariorum et Carantanorum 190 A. 14

Cosmas von Prag 161, 188

CPM vgl. Chronica Poloniae Maioris

Crepajac, L. 163, 167

crěsı, črezъ, crèsı 52

-Crezpénjane 52

Crva 131

-ctuiste 132

Curschmann. F. 174

Cyprinus alburnus 21

Czerwiec 131

Czerwiszcze 131

Dacia, Dazien 35, 40, 41, 142 A. 4. 169 
Dacia Mediterranea 142 A.4, 149. 197

Dagome-iudex-Regeste 69, 169

dahs, das 111 A. 3

-daksā 110. 111 f.

Daksa 112

-dal-am 164

Dalam. Dalem Delem 164

- Dal(e)ment 163

Daleminci 134, 136, 137, 138, 145. 148, 161-168, 185, 186 A.7. 188, 192, 195, 203

Dalimil 200

Dalbmat - 164

Dal(b)mbnbcb, Dal(b)mbnbci 137. 166. 178

dalmăta 165

Dalmatae, Delmatae 162 A.5, 166. 186 A. 7

Dalmatia, Dalmatien 891., 93, 137. 142. 1631., 184, 187, 192, 195. 200, 203, 206

dálmine 165

Dänen 45. 65

Danov, Ch. M. 179

Danubianer 36

Danzig 42, 75, 79

Daphne 175-177, 187, 193

Daphnenses $175 \%$.

Daphneci 179

Dardania, Dardanien 92, 149, 193

Dasa 112

Dassa 111

Dassaretae 112

Dassia 109-113, 196

Dassius 112

-Dasswāriōs, 'Dassārjōz 109, 112

Dauba 110

-dazā 111. 196

Dazas 112

Dazien vgl. Dacia

Depbnice 175

Deleminci vgl. Daleminci

-delm-. "dhelm- 163, 165

Delmatae, Delmater 88, 89, 163f., 166

Delminium 166

Delphi 22

Demmin 51

Dentubrisa 179

Dephense 174

Derba 881 .

Derbani 88\%., 197

Dereva 871 .

derevbja 88
Derevljane 85-90

derevbskb, derbvbsks 87

Derevsskaja zemlja 87 .

Derva 881.. 184

Dervani 881.. 184. 197

Dervanus 85. 891., 1831., 205 A. 7

-dervbhb dux 90

-dervo 86

Desna (Bassin) 121 A.5, 177

Dessau 141, 193

Desseri 109-113

Detschew, D. 142 A. 4, 179

Deuri 89 A. 4

- $d(h) e \hat{g}(h) 111$

-dhe(i) - 163

Diedenhofer Linie 198

Diepensee, Dypensey 174

Ding 60

Dickenmann, E. $121 \mathrm{~A} .5$

Diokletian 117, 142, 149, 193

Dionysios I. von Syrakus 117

Dipsacus 70

dl $>$ gl 167

Diamoc 167

-Diom- 167

Dlugosz, J. 80?., 200

Dnepr 177, 191

Doberan 541.

- dober-jane 55

Dobëres, Doberer 54

Dobēros. Dobera 54

Dobna, Dobnica 175

- Dobtane 541.

Dobłené. Dobrane 54

Dobrovský. J. 171, 185

Dobrowolska, A. 79 f.

Doclea $141 \%$.

Dojran-See 54

Doks-Namen 196

Doksany 110, 196

Doksicy, Dokszyce 89, 111, 196

Dokšina 111

-Doks-jane, Doksane 109

Doksy 110. 196

-dokz- 110 r.

-Dol'ane. Dolany 147

Domintian 176

Don 183

Donau 36, 39, 40, 149, 172, 174, 175f\%., 180, 184, 185, 186, 193. 195, 1991., 205

Donau-Abodriten 17, 34-40, 171

- Dosa 109

dosan $110 \mathrm{~A} .2$

Döschütz. Dōsitz 148 
Dosse 109-113, 180, 192, 196

Dossow 110

-Dosbj-ja zem'a 109

dox $110 \mathrm{~A} .2$

Doxani 58, 109-113, 192, 196

Drahim 174

Dralle, L. 58

Drasco 47

Drau 104. 1061., 202

Dráva-Muraköz 106

drâvka 106

Drawåhnen, 91, 96

Drawän 85

Drawczanie 174

Drawehn 85

Drawehn, poln. Drzewiany 86, 197

Drawein 85

Drawnane 86

Drawsko Pomorskie 174

Drawsko-See 174

Dresden 145, 197

Drevani 85-90, 192, 197

drevesa 88

Drevljane 86ff., 197

drèvo. derevo 86

Drewnanye. Drewnyanye. Drawnane 86

Drina, Drinica 104, 117, 193

Drozko 47

Drzewiany (Drawehn) 86, 197

Dubá 110

Dubrovnik 112, 201

Duchcov 110

Dukla-PaB 195 A. 2

Duklja 141

Dukljanin-Chronik 138

dûl 147

Duibinci 175

Dulébl 175

Duridanov, I. 104 A. 5

Durych. F. 37

Dux 110

dworzyszcze 131

Dyrrhachion 142

Dzierzgon 177

Ebros 19 A. 6

Edirne 63

Eger 110

Egerlănder 188

Egli, J.J. 124 .

Ehle 127

Eichler. E. 59, 105, 106, 128ff., 134. 135, 141, 145 A. $2,146$.
1559., 158, 161, 162-167, 170. 183 A. 1,188

Einhard, Annales Einhardl 25, 29

Ekblom, E. 12

Elbe 25, 95, 103, 106, 110, 119. 124, 127, 128, 133, 135, 138, 145, 161, 166, 168, 181, 191. 193. 195. 197, 202, 203, 204. 205

Elster vgl. Schwarze u. Teiße Elster 156

Encheleer 112 A.4

Epameinondas 48

Epeiros. Epirus Nova. Epirus $\mathrm{Ve}^{-}$ tus, epirotisch 81Pf., 84, 112. 152, 192, 193, 196, 197, 200

Erfurt 156

Ergene 19 A. 6

Erichi 151 A. 1

Erichino 151 A. 1

Erichova 151 A. 1

Erichovo 151 A.1

Euklelos 22

Eumolpos 50 A. 3

Eutin 21

-eva 156

exsillium 31

Pater 13

Farve 14

Fehmarn 11-16, 20, 34, 71, 193

Feldberg $57 \%$.

Fembre 14

filu 13

flmba 12

- Fimber 12

Fischer, R. E. 105, 1091., 111, 120. 135, 136, 178 A. 9

Fissau 14

Fitschkau 14

Flajshans, V. 110

Fläming(wälder) 127, 181

Forchheim 157

Francia, Franken 113, 204

-Frankenstraße" 156

Frankfurt a.M. 35

Fredegar 891., 107, 136, 183, 184. 205 A. 7

Freiberger Mulde 134, 161, 166. 168. 193

Fuhne 133

Fulda 124

ruoz 13

Furt 156 
Gablonzer 188

Gacko polje 88

Galaţi 187 A. 8

Galizien 199

Gallipoli 12

Garaj. J. 177

gastb 62

Gelell 156

Geographus Bavarus 25, 28, 35, 39 ,

$79,84,89,96,103,136,138,161$.

171, 1731., 175, 177, 178, 180.

181, 1841., 186, 193

Georgiev, V. 38

Georgios Monachos (Hamartolos) 123

Gepiden 205

Gera 156

Germania 113

Germanus, Magister militum 149

Géza 99

gláma 167 A. 13

Glamoc 167

gleupé 142

Gliniane (Linionen) 25

- Glomac 162 A. 6

Glomaci. Glomaci 161-168, 169, 188. 192. 203

-glum- 167 A. 13

Gnaeus, Gnejus 47

Gnesen 72, 75

Gneus 47

Gnèv 47

Gohlis 148

Gōkçeada 12

Golus, "Golus 148

Gornij Vakue 89 A. 4

Gorynb 87

Goten 172. 176

Gotescalcus 47

Gottschalk 47

gradowisko 131

gradbniks 32

grandfather, grandmother 100

grandpère, grandmère 100

Grégoire, H. 189

Griebenow. W. 76 A. 3

Grimma 134

grochowisko 131

groother, grootvrouwe 100

GroB-Blederstedter Holz 92

GroBer Stechlin 58

Großpolen 196, 202

Großvater, Großmutter 100

Grucza, F. 70

Gussanin 79 'hab- 120

Habola 120, 122

Habriti 29

- Hab(u)la 120

Hadrianopolis 19 A.6. 63

Hafen 120 f.

Haff 120 .

Halberstadt 65,97

Halle 141

Hamburg 26

Hanow, W. 80

'harioz- 159 A. 8

Hašābin 79

Hasjabin 79

háuli 123

Havel 109, 110, 115, 119-125, 180. 181, 193, 194, 196

Havela 120

Havelberg 103, 104, 115, 119, 129. 180

Havelland 105, 109, 110,148

Haveller 119 A. 1. 180 .

Havlik, L. 135

havly. osm. 123

Hebros 63

Hehfeldi 185

-heim, -hem 97, 99

Heinrich der Löwe 43

Helbig, H. 105, 133 ?.

Hellespont 12

Helmold von Bosau 14, 17, 45f., $51,57,66,68,100,119,180$

Herakleios I. 176, 184, 186, 192

v. Herberstein, S. 17

Herodot 13, 19, 53, 54

Herrmann, E. 171 A. 6

Herrmann, J. 42, 45, 48, 58, 66 . 127, 184, 202, 203 A. 5

Hessen 124

Hesych 111

HeBler, W. 91, 96f., 105, 115. $133 \uparrow$.

Heveid 121

Heveler 185

Hey. G. 128, 132, 134, 170

Hierokles 77

- Himbra 12

-himmer 12

Himmerland 12

Himmersyssel 12

Hirschberg 110

Hof 156

höla, tarantsch. 123

Holstein 17, 46, 86, 194 
Holsten 86

Holtsatium 86

Holzsaezen 86

Homer 13,50, 53

Horâk, B.. Trávnícek, D. 177

Horigti, Horoti 167

Hornemann. W. 58

Hosák, L., Srámek, R. 147

Hostíkovice 169 A. 3

hostis 62

Hostoun 196

huba 80

hukleja, huklej 21

Hunnen 40, 172

Ibn Ja'qūb, I. 46, 60,79

- -ica 104

-ici 185

$-b c b,-b c i 185$

Ihle 127

Illyricum, Illyrien, Illyrisch 112, 117. 142. 142 A.4, 166, 184, 192. 196. 197, 204

Illyrier 110\%., 203

Ilmensee 142 A. 3. 191

Ilovec $121 \mathrm{~A} .5$

Imbra 15 A. 5

Imbros 12-15, 20, 71, 193

- Immer 12

Imroz adasI 12

Imvroz 12

-inci 165

-inium 166

-inb, -ina, -ino 158, 159, 165

Inselnamen 1939 .

Insula Muro-Dravana 106

- -iskio 128

-isko 131

Ismaros 50, 192, 193

Ismarus, Ismara 50

-iste 128

-iszcze 131

Italien 77f., 82, 205

Iustinian I. 42, 92, 149, 172, 176

Iustiniana Secunda 92, 193

Jadera 142

Jagic. V. 201

Jajce 89 A. 4

Jambol 33, 93

Jambor 33, 83

-jane 109, 178, 179

Jankuhn, H. 41 A. 18
Jarchow 152

Jaroch 151 .

Jaroslav 151

Jaroslavl' 151 A. 1

Jellinghaus, H. 96

Jerich 151

Jericho 152

Jerichow 145, 147, 151-153, 192. 193

Jerichow, Herren von 151

Jerychy 151 A. 1

(j)evangeljje 122

Jevrips 122

Jirecek, K. 176

Jirecek-Linie 117, 190, 200

Jizera 40

Joȧnnina, Janina 82

Jublitz 121

juns. Junbcb 165

Kadlubek 200

Kaganus, Caganus 67

Kahl. H.D. 103 A. 2

Kaisarios aus Nazianz 36

Kaiser, E. 85 f.

Kaköhl 67

Kanaliter 186

Kananos, Laskaris 42 f.

Kantzow. Th. 69

kanuns 83

Karamzin, N.M. 171,185

Karayannopulos, J. 172 A. 7

kare 93

Karl d. Große 17, 25, 84, 95, 96, 198

Kårnten 105, 1061., 202

Karpaten 195, 196, 199, 205

Kaschuben 33, 75, 79-84, 188, 192

Kassiopē 82

Kassopaler, Kassoper $81 \mathrm{l}$.

kasza 80

Kasubitae 83

Kaszuby 80

Kaunas $121 \mathrm{A.} 5$

Kâzina 93

Kdyne 196

Kellersee 21

Kessiner 51

Kielau, Chilonô 67

Kiersnowski, R. 177, 178, 179

Kiev 199

Kikonen, thrak. 50, 192

Kimbern 12

Kirillov 111 
KIruistl 130, 178

Kizyni 80

Klaik, N. 200, 203 U. A. 6

Klatov 196

Klei tomachos 30, 31

kllnec 93

Klinizua 93

Klostersee 20

Klützer Ort 49

Knauth, P. 135

Knin 206

Knuust (Fehmarn) 12

Knýtlinga saga 66

Koblischke, J. 96, 120

Kolberg 69, 75-79, 177, 193

Köln 201 A. 4

-kolo-. 'kols 75 r.

Kolobfeg 75

-Kolobregb 76

Kolobrzeg 75-78

Königs Wusterhausen $174 \mathrm{~A} .3$

Konstantinopel 15, 149, 194

Konstantin d. Gr. 149, 176

Konstantinos V. Kopronymos 16

Konstantinos Porphyrogennetos $87 \mathrm{f}$., 93. 99, 132, 169 A. 4, 176, 177. $186,187,189,190,192,196,1991$.

Kopitar, B. 49

korabl'b, korabb, körab 194

Korbetha, GroB-, Klein-166, 195

Körbzige 166

Korfu vgl. Korkyra

Korinth 22

Korkyra (Korfu) 22. 81

Kosinna, G. 203

Köslín (Koszalin) 86, 145, 147, 197

Kosovo Polje 92

Kostelec n.C.1. 196

kostb 92

-kostèrb. "kostera 72 ?.

'Kosterinek, 'Kostrinek 72

Kostrschin 72

Kostrza 72

Kostrzyn 721.

Kostrzyt 72

Koszalin (Köslin) 86

Köthen 141

Krahe, H. 56, 77, 111, 142 A. 4. 203

Krälicek, A. 171

Kranzmayer, E. 157

Krbava 93

Kribci 93

krivs 93

Krivixi 93
Kroaten 1661., 195, 196, 199, 200. 202. 206

Krogmann, W. 27

Kronach 156

Krotossa, Krotosza 83

Krum 123

Krumbacher, K. 42 A. 19

Krumiauer 188

-krvavs 93

Krzyøicki. L. 80

Kucharski. E. 174

Kühnei. P. 27, 40

Kujawy 196

Kujot. S. 81

Kulpa, Kupa 36

Kummerower See 51

Kupa. Kulpa 36

Kupica 104

Kupka, P. L. B. 97

Kurze, F. 36 A. 15

Küstrin 69, 72-73, 194

Küstrinchen 72

Küstrin-See 72

$K$ wisa (Queis) 128

Labeaten 142

Labuda, G. 79, 91, 161 A.4. 204

laevus 55

Langobarden 172. 205

Larissa 71

Lassan 58, 116 A. 3

Laur, W. 12, 13, 14, 18

Lausitz(er) 115, 202

Lausitzer Kultur 203

Lechiten 174

Leciejewicz. L. 46

legio XI Claudia 176

Lehr-Splawinski. T. 27, 52, 59, 97. 167 A. 13, 170.. 175

Leipzig 156

Leitzkau 103

Lemberg 173

Lemnos 12

Leon Grammatikos 123

Lêš 116

- lèş 116

Lesane, 'Lěsane 115, 1161., 149. 192

Lesh, Lezhë 116

'Lesicl. 'Lešici 116 .

Lesny, J. 188 A. 9, 201 u. A. 4

Lessium, Lessus 116

Leto 22

Leucopolis $\mathbf{3 4}$ 
l'eudi 142

lěvs 55

Lewicki, T. 177, 196

Liburni 31

Lichtenfels 156

Ligzice 115

Lieps 58

Lietze 58

Liezizi 95, 104, 115-117, 149, 192. 193

Lika 93

Limes Saxoniae 17, 25, 198

LInionen (Gliniane) 25

llpa $92 f$.

Lipãni (marca) 91-93

-Lipiany 91

Lipljan 92

lis 115

'Lisici, 'Lisici, "Lišbci 1169., 149

Lissani 116

Lissium 116

Lissos, Lissus 92, $116 \mathrm{f} ., 142,149$. 192, 193

Litauen 169

Liubeme $91 \%$.

Livius 53

Lizzizi 115-117

Ljès 116

Lobdeburg 180 A. 12

Loewenthal. W. 21

Lommatzsch 162, 168

Lothar III., König 57

Lovatb 142 A. 3

Lowmianski. H. 27\%., 401., 179

Lübeck 25, 42\%., 201 A. 4

Lubusz 73

Ludat. H. 120 .

Ludwig d. Fromme 35, 124 A. 12

Lukanien 172

Lüneburg 79, 81

Lungau 107

Lusici $115 \mathrm{~A} .1$

Lutizenbund 51,57, 60

Lychnidos 112

Lychnitissee (Ochrida) 112 A. 4

Lykurgos 61

macedonicus 83

Machek, V. 21, 189 A. 13

Magdeburg 34, 103, 151, 204

Magnesia 71

Magnopolls $45 \%$.

magnus, maior. maximus 100

Mähren 48, 202
Mainwenden 198

maiores (natu) 100

Macedonia, Makedonien 15, 18, 71. 82, 104 A. 5, 192, 193

Manczak, W. 70

-Maraki(s) 104 A. 5

marca, marc(h)a, marke 91, 100. 106

marca Lipâni 91-93, 193

Marcane 105

marca Vinedorum 107

Marica 63

-mark - 105

Maroneia 50, 192

Marquart. J. 36

Martzan 105

Marvani 39

Marzahne 105

Marzehns 105

Masing. L. $188 \%$.

Masowien 196

Massow 21

Mas'ūdi 36

Mathilde, Tochter Ottos d. Gr. 91

mątitl 134

Matusiak. Sz. 80

Maurikios, Kaiser 41, 63, 172

Mayer, A. 88, 111

mech 46

Mechlin 46

Mecklenburg 25f., 45-50, 51-56, 57. 79, 119

Medimorec, Medimorka. Medumurac. Medumurka 106

Medimorje, Medumurje 106

Medzilaborce 147

Meißen, Mark 161

mêl. 'mélıkъ 170

-melko 171

Merowinger 205

Merseburg 156, 166

més to 55

Method 48

- -met-. -mpt- 135

metropolis Sclavorum 57, 61

meucho 142

Mexico 131

Mezumroka 105 .

Michael v. Zachlumien 199

Michelenburg. Michilenburg 45

michil, mihhal, mih(h)il, mi(h)kll. mikil 46

Michilinstat 46

Mieszko 1. 69, 169

Mihilunfeld 46 
Mikilinburg 45, 49

Miklosich, F. 37, 60

Mikulunhurst 46

-Mélbcb, 'Melbca 170

Mélčane, 'Mélbcane 169 r.

MilCany 169 A. 3

Milci 169

Milek 169

milex, millis 171

-Milisa 170

milites, miles 171,194

milites voluntaril 172

Milobud, Miloslav 169

Miloxi 171

Milsca 170

Milsko 169 .

-miltjane 171

-Milbtjane, Militjane 171

Milzane, Milzeni, Milzini 169-172

Milzener 169-172, 194

miľzinas 169

-minc- 165

Minsk 111

Miracula s. Demetrii 71

Misimianen 172

Missizla 46 r.

Mitrovica (Sirmium) 149, 202

mladb, mladbnbcb 165

Mlava 36

mleko 171

mloko 171

miost 171

Mnichovské Hradisté 196

moczary 81

Mogilno 75 A. 1

Moinuuinidl 198

mokradla 81

Molossi, Molosser 82

molost 171

-moists 171

Montenegro 89

- Mora. 'Muora, Mura 104

Morava 149

Moraca 104 A. 5.

Moracanin 104 A. 5

Moraciani. Morazani, Morazena

104 A.5, 127

Moravane 149

Moravec 185

mor'e 55

-Morica 103 f.

- Morici 104

Morizani 103-107, 151

Morka. Murka 106

-morka 105, 106
Mortzan 105

Moscow (Idaho) 191

Moesia inferior $175,187 \mathrm{~A} .8$

Moesia superior

Mösien 40

-mpts 135

Mozyrb 89

Mrongowiusz (Mrąga), K. C. 80 f.

Mstislavs 47

Much, R. 12

Muka, E. 75

Mukacevo 147

Mulde 105, 128, 133, 135, 141, 145. 193

Müllenhoff. C. 120, 205

-mündung 137

-munt 136

-munti 134

Mur 105 fe

Mura, Mur 104

Murica 104, 105

Murinsel 106

Müritz 104, 105

Müritz (Land) 103

Müritzer 58, 103-107

Müritzsee $103 \%$.

Murizzi 103-107

Mürz 104 ff.

Musacius 63

muth 135

moutiti, mutiti 134

Naisa 145, 147, 197

Naissus 92, 1481.. 193, 197

Nakon 47

Nakona 47

Nakoniden 47

Nalepa, J. 46, 120, 170, 171, 175

Narona 89, 142

Naruszewicz, A. 80

Natanson-Leski, J. 75, 179

Naugaard 21

Naumann, h. 134 P.

Nebel 51

Neletici 119, 130

Neolithikum 157

Nestor vgl. PVL

Nestos 1791., 187

Netze 73

Neubrandenburg 58

Neußen 145, 147

Neustrelitz 58

New Glasgow 191

New Hannover 191 
New Iberia 191

New Orleans 191

New Plymouth 191

Nezene 145, 147, 197

nic 146

Nidkike 146

Niederle, L. 27, 36, 40, 51, 85f., 103, 115 A. 1, 128, 146, 148, 173

Nielitizi 104

Nieminen, E. 63

Nienburg 97

-nik, niknpti 146

Nikephoros I., Kaiser 15\%., 77, 123

Nikiki 146

Niklot 26

Niksic 89

Nis 148P., 197

-Nisane 117

Nisane, Nišanè 145-149, 169, 193. 197

Nišanin, Niševac, Niseveanin, NiSevljanin 148

Nisava 149

-Nisici 117, 130

-Nišbcb, "Niśbci 148, 149

Nitra 37

Nitzahn 145. 147

Nizká Srabská 196

nizb, niz 146. 147

- Niżane 146

Nizici 146, 193

Nizizi 105 u. A. 6, 145-149, 197

- Niznjane 147

-bnbci, -bnbcb 137, 165 .

Nopalschildlaus 131

Nordhalben 156

Nordillyrier 56, 82, 111, 203

Nordmark 95

Nord(west)ruBland 111, 191, 195r., 197

Nordwestslaven 48

Nortabtrezi 28, 351., 391., 136

Notec 73

Novakovic. R. 188, 201

Nová Strašeci 196

Novgorod 60,111

Nový, R. 181 A. 14

-nt-(Suffix) 165

numeri militum ex catalogis 172

Nürnberg 156

Nuthe 127

Oberbarmin 174

obdarti, obterti 27 oberegat', oberegatel' 189

Oberfranken 157, 1971.

Obersorben 169

-obls, "obbls 1201..

- Obsla. Obblia 120

Obla Brda 121 A. 5

Oblica 121

Oblovka 121 A. 5

Obodt 40

Obodrb 27, 28

Obodrici 26

Obodriten 25-43

ob-odriti 26

Obodrowska (ląka) 40

Obra 28

- Obŭdrici 27

Obula 120, 122

ochranjat' 189

Ochrida-See 112 A. 4

Odagra 36

Oder, Odra 26fl., 30, 36, 69, 72. 73, 191, 205

Odr, Odrov, Odry 27

Odryser 63

Odysseus 50, 192

Ohlau 124

Ohre 95

Oka 121 A. 5

ökle 21

oklèj 21

Oldenburg i. Holstein 17, 25, 45, 46

Olesch, R. 85

Olomutici 135

Oitenica 176

Opolini 84

Orakel 65

Orakelkult 60, 64

Oranienburg 110

-ordz 63

Oricum 152, 192, 193

Orikon 112 A. 4. 1521.

orkn, erkn 66

Orosius 133, 184

Osmanen 205

Osterabtrezi 28, 35fl., 39f., 136. 171

Ostholstein 21 1 f., 41

Ostmakedonien 54, 55

Ostrogorsky, G. 1891.

ostrogb 48

Ostrome/pcko 135

ostryj 48

Ostsee 17, 29, 34, 35, 39, 40, 41, 42, 75, 163, 169, 197, 199-206 
Ostseeslaven 60,61

Otice 196

Otrebski, J. 28

Ottonen 133

Otto d. Gr. 91, 103, 104, 127, 193

Otto II. 155

Otto III. 155

Otto v. Bamberg 71

Oulaho 124

Ovell 124

Ovid 50

Ovlaho 124

-ovo 156

Owilah 124

Paganien 186, 189

păgānus 32

pagus 91

Paiones 521 .

Paionia, Paionien 20, 55, 193

Paioplen 54

Palaeokastro 152 A. 2

Pallene 71

Pana. Panis 55r.

Pannonien, Pannonier 53, 205

Pannonia Inferior 138, 193

Pannonia Secunda 106

pant 156

Păonen, Paeones 53

Parchotin. Parkotin 67 u. A. 16

Paris (Texas. Canada) 191

Parthenopolis 34

pascha 83

paserb, pasierb, pasierbica 188. 190

- $(P a)$-seria 177

-pa-strb. pasbrbb 1881.

Paslęki. Passarge 177

Passarge, Pasleki 177

patres 37

Păwesin 148

Payr. Th. 39 A. 17

Peanis, Penis, Penus 55 f.

Peene 51-56, 58, 116, 193

Pegau 156

Peloponnes 22, 48, 169, 193

péna 55 ?.

- Periss - 179

Persante 75, 79

Pertz, G. H. 36 A. 15

Perwolf, J. 27, 169

Pferdeorakel 60, 66

Pllaum. H. G. 179 A. 10

Phesnuzi 171
Philipp II. v. Maked. 71

Philipp V. v. Maked. 117

piana $55 \%$.

Pilat. 0. 28, 174, 177

Pintar, L. 167 A. 13

Piraterie, slav. 15f., 71

Piringebirge 53

Plroborus 63 A. 9

planinac 166

Plauen 175

Plinius d. A. 179, 183

Pliska 123

Plock 124

Plón 17, 67

Ploni 127

Plutarchos 53, 61

-pQc- 155

Podébrady 196

Poel 49

pogans 32

-pok-. 'puk- 155

Pokorny, J. 56, 111. 203

Polaben, Polabeslavisch 25, 85, 142. 148, 156, 197

pol'e 55

Polen, Polonia 40, 84, 131, 169, 191 , 192, 195, 196, 197, 199, 200

v. Polenz, P. 97

Police n.M. 196

polnoglasie 138, 178

Polybios 112

Pommern 22, 69 1\%., 72, 75, 76, 177. 196

Pompejus $117,152 \mathrm{~A} .2$

Ponevez 121 A. 5

poniknouti 146

ponikva 146

Pontius 157

Pontos Euxeinos (Schwarzes Meer) 13. 123 A. 8. 199

Popowska-Taborska, H. 135

Porphyrophora polonica 131

Posa (= Bosau) 155 A.2

Poseidon 22

Posen. Poznat 72, 75. 138 .

Posin 148

-pptb 155 fr.

pQtbrikb 157

- Pot'ova 156

pout'. poutka 157

Pozowe 155 A. 2

Praedenecenti 25, 34-40

praedones Sclavi 39

Praevalitana 117, 142, 142 A. 4, 192. 193 
Prag 110. 161

Pteddunajci 36

Pteddunajevci 36

predbnil, predbnil 37

prědınb, prědbn'b 37

predki 37

Prednècenici. Prednécovci 37

Premysliden 47

Preobraženskij, A. 60,188

Preußen 200

Pribina 37

Pribislav 26

Priegnitz 109

Prillwitz 58

Pripjetb 87

Priskos 63

Prisrani 174

Prissani 34, 119, 173, 178-182, 187. 192

Pritsak, 0. 135, 199 A. 1

Pritzwalk 180 A. 11

Prizrénb. Prizren 67 A. 14. 174, 178

Probus, M. Aurelius 17, 64, 194

Profous, A. 40, 110, 146, 157, 159. 169 A. 3

Prokop(ios) aus Kaisareia 82, 172

Properz 50

Propontis 13

Prove 17, 194

pryserbytysja 188, 190

Przemet 135

Pseudo-Kaisarios 36

Ptolemaios 183

puc 155

Pulhorn, W. 176 A. 6

Puonzouua 155-157, 158

put' 155

Putlos 17, 194

PVL 87९.. 177, 195, 200

-Pyricane 179

Pyritz 179

Pyrzanie 179

Pyrzyczanie 179

Quedlinburg 91

Queis (Kwisa) 128

rads 62\%., 65

- Radari, 'Redarí 64

Radigast, Radogast 62, 631 .

raditi $59,62,64,65$

Rana 177

Ratanzuuinidi 198 -ratb 59

Ragusa 192

- Ratari. 'Retari 59

Ratiaria 92

Ratzeburg 25

Recknitz 51

Redarier 51, 57\%.. 641.. 194

- Redegosc. 'Redegost 62

'Redigoš 59

redryj 59

Regensburg 183 A.3

"Regensburger Straße" 156

Regnitzwenden 198

Reichenau 171

Reichel, G. 133

Reric 45

Rethra 57-65, 66, 68, 194

Rhetre 57, 62, 64

Reval 42

Rezica 111

Rhein 97

Rhin 180

Rhinthon 77

Rhodopen 19. 179

-Riad-wariós 59

Riedegost 57, 62 Pf.

Riesa 204

Riga 42, 81

Rjazan' 121 A. 5

Rochelinze 134, 137

Rokitovey 147

Rom 172. 187. 189, 200 r.

Romānus 90

Roskow. Roskov 148

Rospond. S. 177

Roudnice 110

Rozwadowski. J. 124 f.

-ruda 59

Rudnicki, M. 21 A. 2, 28, 38, 49, 66. 70, 76 A. 3, 135, 146, 170, 177. 183 A. 3

Rügen 57, 65-68, 177

Rugier 66

Ruiana, Rugla 177

Rumänien 202

rumins 83

Rundling, slav. 11

Russen 192, 199

Rußland, russisch 131, 172, 196. 200

Rzetelska-Feleszko, E. 49

Saale 128, 133, 135, 138, 141, 193, 195, 202, 205 
Sachsen 85, 100,161-168, 188, 195 , 197, 201

Safařik, J. P. 26, 36, 52, 59, 96. 134, 169, 173, 175, 204

Salebeke. Salebize 146

Salona 66, 93, 142

Saloniki 54

Salzwedel $91 \%$.

Samothrake 16 A. 6

San 173

Santok 73

Sarajevo 121 A. 5

Saramati 135

Sarbia 196. 202

Sarbice 196

Sarbiewo 196

Sarbsko 196

Sarja 135

Satrapen 190

Sava, Save, Savica 104, 106, 138. 183 A. 3

Saxo Grammaticus 66

Scardona 142

Schall, H. 27, 135

Scharlachwurm 131

Scharstorf 17

Scheuder 117, 141-143, 192, 193

Schildläuse 129 个f.

Schleiz 156

Schlesien 28, 41

Schlesinger, W. 202

Schlimpert, G. 59, 89, 109\%., 120

Schlobberg (Feldberg) $57 f$.

Schmidt. B. 205 A. 7

Schmitz, A. 12, 13, 15, 18, 21, 221.

Schönfeld. M. 159 A. 8

Schramm, G. 141

Schrimm 1381 .

Schroeder, H. -D. 58

Schuchhardt, C. 57, 66

Schulthels, J. 129, 131

Schultze, J. 100

Schulze, H. K. 91, 96

Schulze, K. 128

Schuster-Sewc, H. 128, 133, 183

Schütz, J. 167 A. 13

Schwaben 198, 205

Schwarz, E. 110\%., 120, 135, 163fl., 184 A. 6

Schwarze Elster 128

Schweden 42, 131

Schwentine 17, 22

Schwerin 25

Schwürbitz 184 A. 6

Schwyzer, E. 33
Scerwist 130

'scits 69

S(c)laveni 199

Scodra 89, 116r., 141fl., 149, 192. 193

Scodrihensis, regio 142 A. 4

Scutari 141

scutarius 142 A. 2

Scutarum 142 A. 2

Sedlec (Zettlitz) 52

-Sedlic 130

Selfldže, Serfidže 132

selo 55

-Sĕnišce 129, 130

-ser- 135

Serabici. Sorabici 185

Serauici 138, 164, 185

-Serav - 195

Serben/Sorben 90, 128ff., 132, 133. 161, 166, 169-172, 176f\%., 181\%.. 183-190, 192, 195\%., 201, 202. 205 A. 7

Serbeştii Vechi 187 A. 8

Serbia 132, 186

-Serbiste 128, 132

Serbitium 183 A. 3

Serb, Sérb 53

Serdica 149

Serfidže. Selfidže 132, 186

Seres, Seresb, Serra, Serrhai, Serrä 53

Sereth 187 A. 8

-Seria 177

-Ser(1)-munt(h) 135

Serimunti 133-139, 164, 188

-Serimbnbci 137. 178

-Seri-vani, Ser(j)vane 177

Sermende 133

Sermium (Sirmium) 116, 13711., 178

Sermuth, Klein-. GroB-134, 138

- sermbcb 138

-Sermb 138

Serrae 19

Seruitio 183 A. 3

serv - 183 A. 3

servare 189

Servia 132

Serviodurum 183 A. 3

Servitti 183 A. 3

servitus 190 A. 14

servula 189

servus 189,190

Sèverjane 177

Shkodër $141 \mathrm{f}$.

Sierimpt 135 
Siewlerzanie 177

Sigibert 2041.

Singidunum 149

Sirgaune, Sorge 177

Siris, Sirra 52, 53, 149, 193

Sirispaiones $51-56,130$

Sirmium (Sermium) 17, 92, 116. 137ff., 149, 193, 202

-Sirosor 129

-Sirov 129

Sisinnios, byz. Admiral 71

'sbrbs, 'sțbs 183, 188, 190

Skảdar 141 l.

Skiathos 7019.. 73, 193

Skok, P. 21, 132, 167

Skutarisee 142 u. A. 3

Skylitzes-Kedrenos 123

-Skrdr- 141

Slany 196

Slawskl. F. 188

Sliven 123

Slobodsk 12LA. 5

Sluc 87

Smolensk 121 A. 5, 151 A. 1

Sobolevskij. A. 189

-Sobor 130

Sorija 142 A. 4.149

Sorabi 183, 184

Sorben/Serben 90, 128ff., 132. 133. 161. 169-172, 183-190, 202. 205 A. 7

Sorge. Sirgaune 177

sotona 32

Sparta 61. 71

Sporaden 12, 71

Spree 124. 170, 174, 181

Srbce 195

Srbeiste 186

Srbec 196

Srbica 132, 186

Srbice 196

'Srrbici 129

Srbijanac 166

Srbin 196

-Stbisce 132

Sîb(in) 183

Srbiste 132

'Srbjane 178

Srbsko 196

'sţbs (<'sbrbb) 129, 136

Srby 196

Srubisce, Srabbisce 132

-Srbiste 128

Srem 138 .

Sremska Mitrovica vgl. Sermium bzw.

\section{Sirmium}

- Srèms 138

Srijem 138

Stadtmüller, G. 48

Staffelstein 156

Starigard (Holstein) 17

Starigrad (Budva) 47

Staszewski, J. 76 A. 3

Steinberg, R. 93

Steinhauser, W. 18

Stendal 105

Stephanos v. Byzanz 19, 53, 77. 112 A. 4

Stettin 34, 69-73, 75, 193, 194

Stieber. 2. 55, 59

stit 69

Stodorane 119, 180 .

Stoob, H. 180 A. 11

Stör 124

Stormarn 124

storoz 189

Strabon 50, 77

Stramin 20

Struma 19, 53, 54

Strumica 54

Struminbci 20, 54

Stryme 50. 54

Strymon 191.. 54, 1791.. 187. 192

strymonis 20

Strymoniten 54

Strzelczyk. J. 65 A. 13

Sturmi (Abt) 124A. 12

stuzdb 83

Sucha (Zauche) 52, 129

-Suchovec 129

Sudeten 205

Sudetendeutsche 188

Sulchov (Zolchow) 52

Sulowski, 2. 59, 79

Surabi, Surbi 137, 183, 192, 205 A. 7

Surfe 184

Surpe 184

Suurbi 184

Svalova 147

Svantevit 66

Svarum 172

-Svrb 184 A. 6

Swurbelant 137

Svurbez, Swuerbs, Swurbz 184 A. 6

-Sykorbns 130

Szczawnbcy 174

szczec. szczota, szczotka 69

Szczecin 69-73

Szczek, Szczeka, Szczet, Szczeta, Szczota 70 
szczyt 69

Swoboda. W. 36

Szerem, Szerém 138

Tabula Peutingeriana 183 A. 3

Talaminzí. Talmenze 138

tálmine 165

Tanev 173

Tanev'cl, Tanf'ci 173

Targossa, Targosza 83

Tatimir 172

Tatra 169

Taucherschin 159

Taucherwald 158

taul- 93

Taulantil 93

Tauromenion 22

Taygetos 43

Templin 72

Tenedos 12, 16 A. 6

Teplice-Sanov 196

Tesice 148

Teterevb 87

Teucharia, Theucaria, Theucharia 159

Teucharius, Theucario, Theuchario 159

Teuchern 1579.

Thafnezi 34, 173-177, 179, 180. 181\%., 187. 193

Theben 30

TheiB 36, 205

Theophanes Homologetos 63, 123

Theophylaktos Simokat(t)es 41\%., 63. 172

Thessalien 16, 71, 132, 187, 190

Thessalonike 20,92, 186

Theudebert II. 2041 .

Thietmar v. Merseburg 29. 33, 57. $60,62 \% .64,99,158,161 \% ., 157$

Thomas v. Spalato 200

Thracia, Thrakien 19 A.6, 41, 42. 47. 50, 77, 123 A. 8, 149, 1929.. 193

Thrasuco, Thrasco 47

Thukydides 13, 19

Thüringen, Thüringer 197, 202, $204 \mathrm{f}$.

Tlchomirov, J.A. 151 A. 1

Tifenze 174

-tjudjo 83

-Tocla 141

Tofa 47

Tollense-See 58

Tollenser 51

Tomaschek, W. 88, 172 A. 7, 179

Tonzos 63
Topchin 67 A. 16

Touchoriny 158 .

Trafnezi 174

Tragurium 142

Traianus 64,176

Transmarisca 176,187

Trautmann, R. $28,49,55,59,70$, 75, 105, 1281., 151, 157, 183 A. 1

Trave 17

Travnik 174

Travuner 186

Trebel 51

Triballer, Triballoi 186 A. 7

Triglav 71\%., 194

Troiānus 90

Trubacev, O. N. 204

-Tuchar-ja, 'Tuchari 158 f.

- Tuchara. "Tuchora 159

-Tuchomir. 'Tuchomysl, "Tuchorad 158

tuchot 158

Tuchotice 158 .

Tuchorin, Tucharin 155, 157-159

Tuchorza 158

Tuchurin 158

Tuklaca 141

Tulci 93

tulec 93

Tulius 93

Tundza 63

Turek. R. 96

Türken 206

Tusculānus 90

tusiti, tuszyc 159 A. 7

Tutenberg 180 A. 12

Tutrakan 176

Tymieniecki. K. 174, 177

Tzervulianer 189

Tzetzes, loannes 30,31

Uckelei 21

Udolph. J. 204

Uherské Hradiste 48

uk(e)lei 21

Uklei-Bach 21

Ukleisee 21-23, 194

'ukleja 21, 22

ukleja, uklejka, úkleje, uklej, uklija 21

- $-(u) l a 120$

Ula, Ulla, Ulanka 124

Ulica. Ulicka 124 u. A. 11

Ulicl 123

Ulpiana 92, 193 
Ungarn 131

Unger. 2.58

Unhoš 110

Urbanczyk. S. 28, 29f., 33, 62, 103. 105, 120, 170, 179

urbānus 90

Uscudama $193 f$.

Usedom 69, 116, 1931.

vāgr 18

- Vágverjar 18

Vaillant, A. 32

vajce, vejci 19

Valona 89, 152, 193, 197

Vandalen 172

Vanécek, V. 37

Varäger 17. 151 A.1

Vardar 179

Varjazskoe more 17

- Vartíslavs 19

Vasil'ev, A. 42 A. 19

Vasmer, $M .18,21,27,46,47,48$. 56. $60,66,80 \% .82,111,120$. 131 A. 5, 135, 203

vece, vece $60,68,72$

Velehrad 48

-Veligords 49

Veligostb, Veligoste 49

velii grads 46

-velb $981 f$.

- Velbchrōbatol 99

-velbjz gords 48

Vel'ký Berezný 147

- velbkb 98ff.

- Velbkъnegyti 99

velbmoza, velbmpża. velbmoźaninb. velbmožb, velsmužb 98

- Velbzemja $98 f f$.

Venetlen 206

- V(e)rba 14

Vergil 50

Verona 66

Vilejka 111

Viminacium 36

Vismarus 49

Vitebsk 111, 124

Vjatka 121 A. 5, 151 A. 1

Vlachen 201

Vlahi 206

Vobla, Voblica 121 A. 5

Voblja 121 A. 5

Voblovica. Voblovka 121 A. 5

Vobolb 121 A. 5

Vobolbniki 121 A. 5
Vogtland 175

Vojuša 19

Volksversammlung $60,64,72$

Vologda 151 A. 1

Volyn-(Namen) 1961.

Volyne 197

Volynb 125

Volynjane 125, 196

.vorslavisch" 134, 141, 155, 162f.. 167. 170, 204

$v$-Prothese 19

Vratislav 19

Vrba 89 A. 4

Všerąby 148

Vukanovic, T. 135 A. 4

-Vysecane 147

-Vyseckovo 14

Vysegradz 48

-Vysemet 49

Vysemir 49

- Vystiane 147

-Vysozane 147

Vysokè Mýto 195 P.

- Vysor 14

Wagira 18

Wagrien, Tagrier 11, 16, 17-20. 22\%., 25, 45, 192

- Wãgwarijōz 18

Waigri 18

Wallfahrt 147

Wallucus 107, 136

Walther, H. 59, 145 A. 2. $155 \%$., 158, 161 A.2. 170

Tanzkaer See 58

Warnow. Warnower 25

Warta. Warthe 19,72, 73

Weichsel 177, 191, 1991., 203

WeiBe Elster 155f.. 157, 175

Weißenburg 1.E. 34

WeiBenfeld 166

WeiBenfels 17

Weißkroaten 99, 196, 200, 201 A.4, 203

WeiBrubland 131

WeiBserben, Weißsorben 177, 196. 201 A. 4, 202

Weleter 115

Wendenkreuzzug 43

Wendland 85f?.

Werner. J. 199 A. 2

Werner. R. 202

Werrinberg 180 A. 12

Weseram 148 
Westermarkelsdorf (Fehmarn) 11 A. 2 Westpommern 69, 179

Widajewicz. J. 173

Widukind von Corvey 29, 33, 64 Wiligrad 46

Wilkes, J. J. 89 A. 4

Wilna 111

Wilci, Wiltze, Wiltzi, Wilzi, Wilzen 25. 136, 181, 202

Wismar 25, 34, 45, 49?., 192, 193

Witkowski, T. 34 A. $10,381 . .59$. 64. 65, 68, 106 A.7, 128, 134. 178 A. 9, 203 A. 5

Wittstock 110

Woblitz 120

Wojciechowski, 2. 179

Wolfger v. Würzburg 124 A. 12

Wolga 183

Wolgast 58

Wolhynien 86, 89, 125, 196

Wollin (poln. Wolin) 69, 125, 193. 196

Wossidlo, R. 58

Wublitz $120 \%$.

Wuhle 124

wuklija, wuklica 21

Würzburg 14

Wyszemir. Wyszomierz 49

Xanthol 50

Zachlumer 186, 199

Zajaczkowski. S. 174

Zakrzewski. S. 174

Zaluz'Je 147

Zarajsk 121 A. 5

Zarben 196

Zauche 52, 105, 129
Zauchwitz 129

Zeickhorn 130

Zeitz $155 \mathrm{ff}$.

zemja, sorb. 156

Zemzizi 104, 115

Zerbiste 129, 178

Zerbow (Serbów) 196

Zerbst 127-132, 178, 181

Zeriuani 130, 138, 164, 173, 177 ., 179, $180-182,185,187$

Zer(i)v - 185

Zernack. K. 60, 61

Zeromut 134

Zeruo 190 A. 14

Zetazismus 130, 145, 146, 162 A. 6.

Zettlitz 52, 130

Zeus 22

Zеuß, J. K. 26, 96, 120, 174, 178

Ziemia Lubuska 196

Zierov 129

Zierzow 129

Zingst 129,130

Zirmunti, Zirmunty, Zirmuny 134

Zirwisti 129

Zirzipanen 18\%.. 34, 51-56, 130. 180, 188,193

Zitici 133

Zlomekia, Zlomizi 162

Zỏberitz 130

Zolchow 52. 129

Zonaras, Johannes 123, 132

Zorbig 129. 137

zrêti 134

Zuarasici 62

Zribia 161

Zurb 134

Zupanic. N. 201

Zwenkau 156

Zwickauer Mulde 134

Zygioten 43 


\section{Griechische Wörter}

'A غ̇ंбтратоร 47

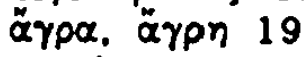

'A үра́) 19

'A Ypā̄u Eัง

ápeviw 19

"Ayplal, 'A ypai 19

-Aypial 19

Arpiáuns 19 A. 6

'A prōãves 19

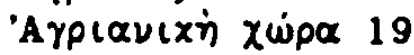

-Aypleis 19

'arpós 19

äxpov 48

'Axpórodes 48

$\dot{\alpha} \mu \dot{\eta} \tau \omega \rho \quad 31$

äข9porol 38

"Avtal 199

$\dot{\alpha} \pi \dot{\alpha} \rho \times 0 \mu \alpha \iota, \dot{\alpha} \pi \alpha \rho x \dot{0} \mu \varepsilon \nu 0 \varsigma 68$

$\dot{\alpha} \pi \alpha \tau \rho i \alpha, \dot{n} 31$

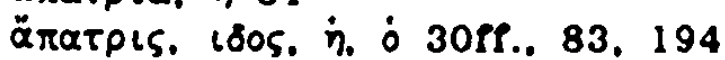

$\dot{\alpha} \pi \dot{\alpha} \tau \omega \rho$ 31

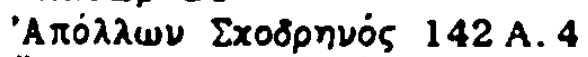

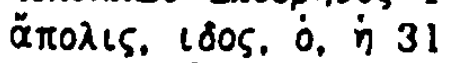

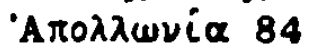

-Apsaboúp los 63

-Apdáraotos 62-64

-Apdákavas 112

- Apts 50 A.3

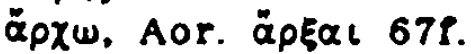

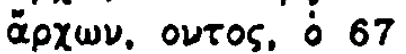

Aotaxós 50 A. 3

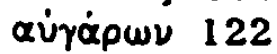

aũyovotos 122

Aú̉aion TEIXOS $123 \mathrm{~A} .8$

वنं $\lambda \dot{1} 122.194$

Aं่วทे 123 A. 8

Quंगis 122

aن̀ंos 122

Aùxw่u 125

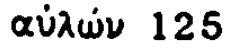

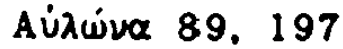

Aúgévт 105122

Aúgiolos 122

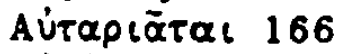

Aบंтóvonos 122

-Aquptioes 31

"A quptos 31

-Aūos 19

Bexiyootn 48f.

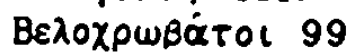

Bioda 199

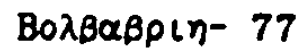

Boúrova. Bougón 47

-Bpเn. $-B \rho\llcorner\alpha 77$

BpiodL 179

Bpiowy 179

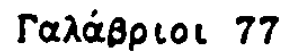

repovoia 61

Tuaios 47

Tpaiol 19

$\triangle \alpha \beta p \alpha \gamma \dot{\alpha} \zeta \alpha \varsigma 172$

$\triangle \dot{\alpha} \zeta 05112$

$\Delta \dot{\alpha} \lambda \mu L O \nu 166$

AQvoviblol 36

$\delta \dot{\alpha} \xi \alpha$ 111. 196

$\Delta \alpha \sigma \sigma \alpha \rho \bar{T}$ та, 112

$\Delta \dot{\alpha} \varphi \cup \eta 175$

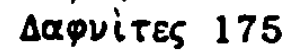

$\Delta E \lambda \mu i v i O U 166$

$\triangle \dot{\varepsilon} \xi \alpha \rho \circ 112$

$\triangle E P B Q U O T$ i 88

$\triangle E P B \lambda E V I V O L ~ 879$.

$\Delta(\iota) \dot{\alpha} \mu \pi 0 \lambda \iota s \quad 33,83$

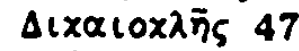

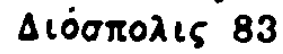

$\triangle 0 \times \lambda \varepsilon \bar{\alpha} \tau \alpha \iota 166$

$\triangle \dot{\xi} \alpha \rho \in \varsigma 112$

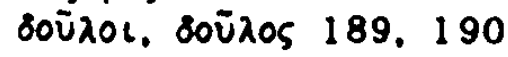

$\dot{\varepsilon} \lambda \varepsilon i \alpha \lambda_{1 \mu \nu \alpha i \alpha .} \lambda \iota \mu \nu \bar{\alpha} T l \varsigma 22$

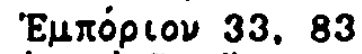

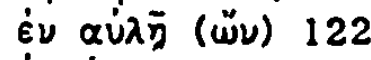

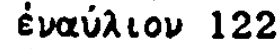

Eัvavios 122, 123

$\dot{\varepsilon} \nu \quad x \alpha \lambda \bar{\varphi} 77$

Érioxotos 33, 83

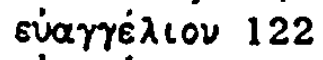

Evarpia 19

$\varepsilon \dot{u} \times \lambda \in \dot{n} 5, \varepsilon \dot{u} \times \lambda \bar{\varepsilon}$ ws 22

$\varepsilon \ddot{v} \times \lambda \varepsilon i \alpha, \varepsilon \dot{v} \alpha \times \lambda \varepsilon i \alpha 22$

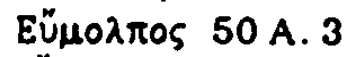

EŨpitos 122

Znvòs $\alpha \dot{\lambda} \lambda \dot{\eta} 123$

OÉorvis 159

Oéóovinos 47

Oeódwpos 159

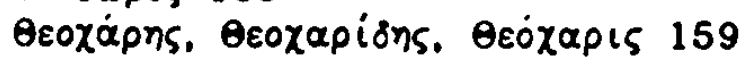


Qeūrucs 159

Oeúswpos 159

Oouxapiwu 159

Opaoxias. o. Opaxias 47

Opāō $\sigma \sigma \alpha, ~ \Theta p \alpha \dot{\sigma \alpha \alpha} 47,50$

Opq̄द 47

i-aúw 122

-I

-iviov 166

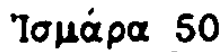

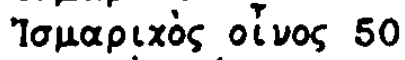

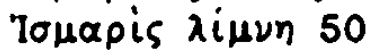

"lopapos 34, 50

\section{Kasivas 93 \\ $K \alpha \lambda \dot{\eta} \dot{\alpha} x \div \dot{\eta} 77$ \\ K $\alpha \lambda \dot{\eta} \quad x \dot{\omega} \mu \eta \bar{\eta} 77$ \\ K $\alpha \lambda \dot{\eta} \pi \varepsilon \dot{x} \times \overline{77}$ \\ $K \alpha \lambda \lambda l-76$ \\ K $\alpha \lambda \lambda i \alpha \rho \alpha 77$

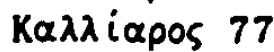

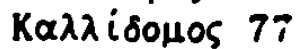

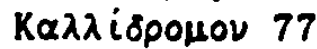 \\ K $\alpha \lambda \lambda i \pi 0 \lambda เ 577$

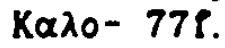

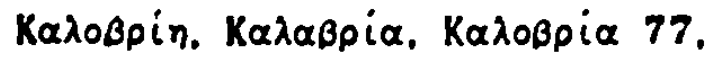 193}

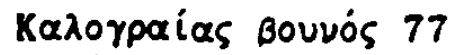

Kaגóswpos 77

Kaגógetos 77

Kaגoixivol 77

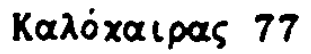

Kaxovixn 77

Kaxóvixos 77

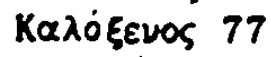

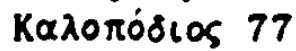

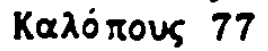

Kaxos 761 .

Kaגóruxos 77

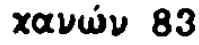

$x \alpha \rho \dot{\alpha} \beta\llcorner O \nu, x \dot{\alpha} \rho \alpha \beta O \varsigma 194$

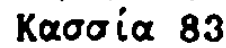

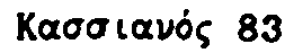

K $\alpha \sigma \sigma \iota \dot{\varepsilon} \pi \varepsilon\llcorner\alpha 83$

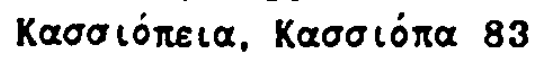

$K \alpha \sigma(\sigma)\llcorner\dot{\pi} \pi \eta, K \alpha \sigma \dot{\omega} \pi \eta, K \alpha \sigma(\sigma)\llcorner\dot{\omega} \pi \eta$ $81 \mathrm{ff}$.

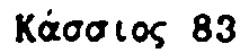

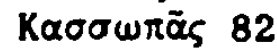

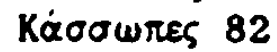

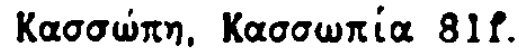

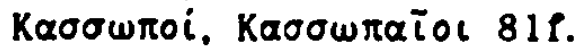

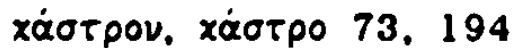

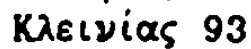

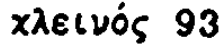

Kpi $\beta \alpha \subset \alpha 93$

KWBpia 77

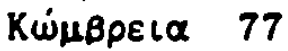

$\Lambda \alpha \beta \varepsilon \tilde{\alpha} \tau$ เ५ 31

$\lambda \alpha_{6}(F) \operatorname{os} 55$

ALBupuises 31

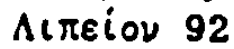

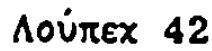

Mapw்veเ $\alpha 50$

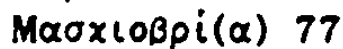

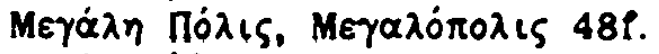

$\mu \varepsilon \gamma \dot{\alpha} \lambda \eta \dot{\rho} \dot{\eta} \rho \alpha{ }^{2} 61$

$\mu \varepsilon \gamma \dot{\alpha} \lambda \eta$ 'P $\dot{\omega} \mu \eta 100$

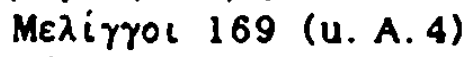

Mévtopes 31

Mevtopiðes 31

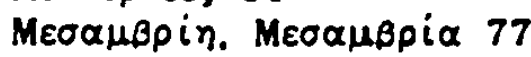

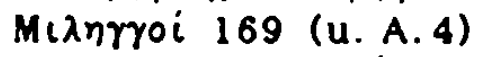

Movowxios. Movoouxos 63

Natooós $148 \%$.

vं்Xos 47

Ná̧os 47

Nīoos 148

Nioos. Nioos, 148

ósotrópos 157

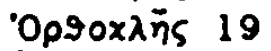

ópgós 19

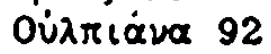

Пaioves 53

กגบขóvioเ 53

$\pi \dot{\alpha} \sigma \chi \alpha 83$

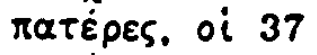

$\pi \alpha$ rńp 31

$\pi \dot{\alpha} \tau p \operatorname{los} 31$

$\pi \alpha \tau p i \varsigma, i \delta \circ \varsigma 31$

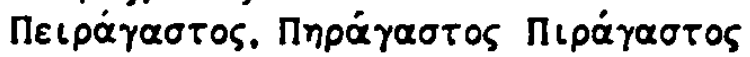
63

ПגioxOUBa 123

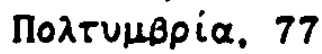

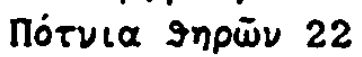

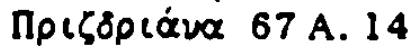

חúpros 33.83

pंทंทे 65

pं்

рं̄̄tpal 61

р̈́rpn 62

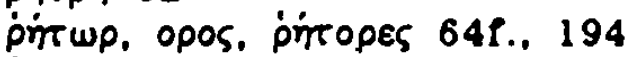

pwuaios 83 


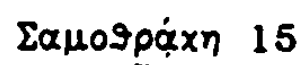

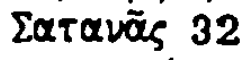

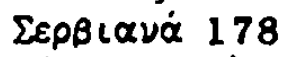

$\sum \dot{\rho} \rho \beta \lambda<\alpha, \tau \dot{\alpha} 132$

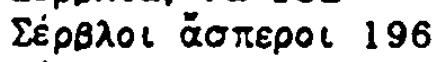

LÉPBOL 183, 189 A. 12

$\sigma \dot{\varepsilon} \rho \beta \cup \lambda \alpha 189$

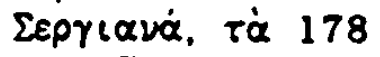

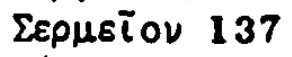

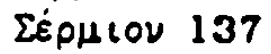

$\sum \nabla \lambda \dot{\alpha} \beta O l \quad 199$

EiPBOL 183, 189 A. 12

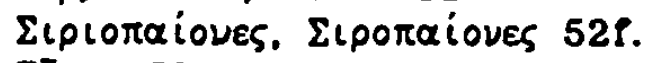

Eipls 53

Eiphlov 137

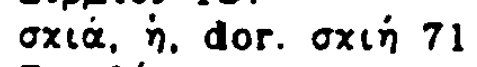

Exiasia 70

Excasis 71

Exidisos 70-73

$\sum x i \dot{\alpha} s 71$

Ex เं்ท 71

$\Sigma x \lambda \dot{\alpha} \beta O L, \Sigma x \lambda \alpha \beta \eta \cup \circ i 199$

Exóspa 1411\%.

Exospia 142 A. 4
Exoutáplos 142 A. 2

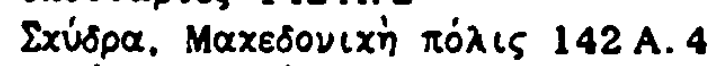

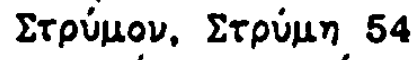

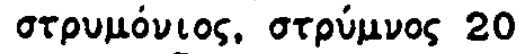

Eтpuнovital 20

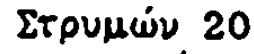

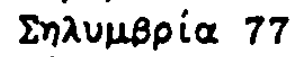

Eúpulov 137

Taن̀as 93

Tஷ்

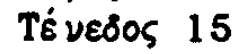

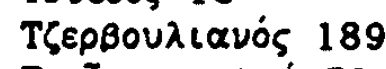

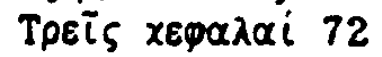

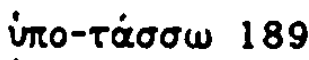

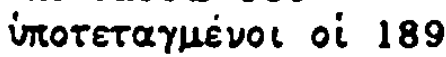

Xáoves 112 A. 4

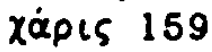

'Qplxóv. 'Qplxós 152

'Fpn- 61 
or

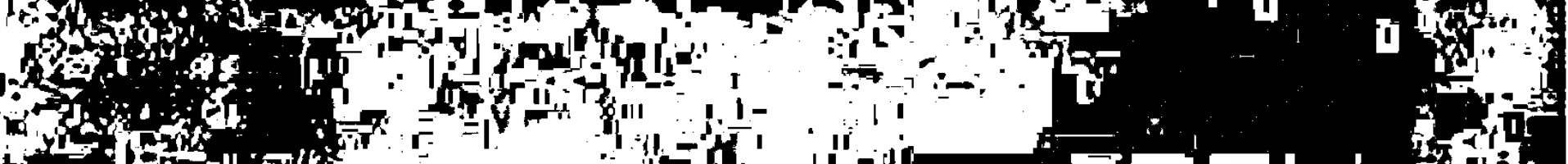

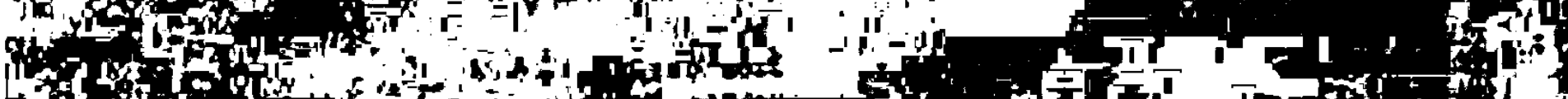

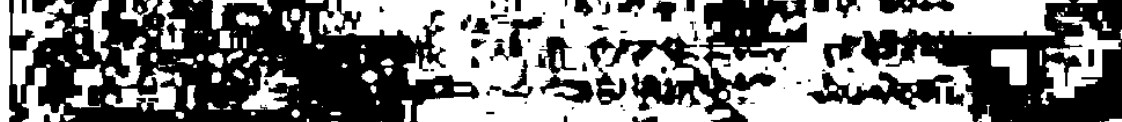

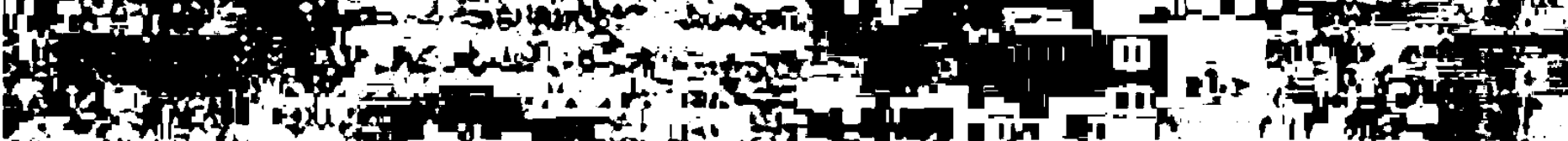

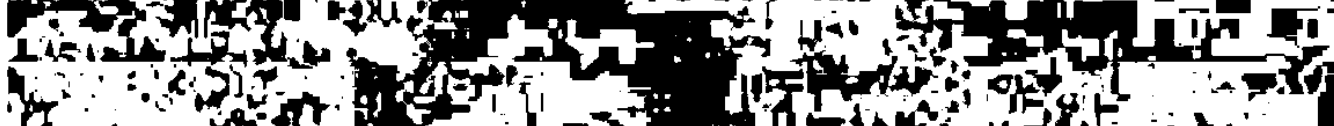
1.

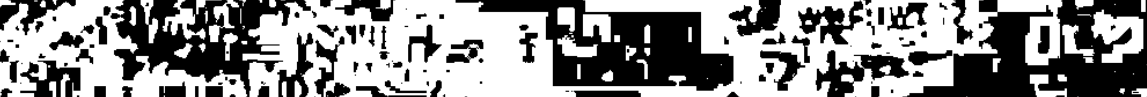

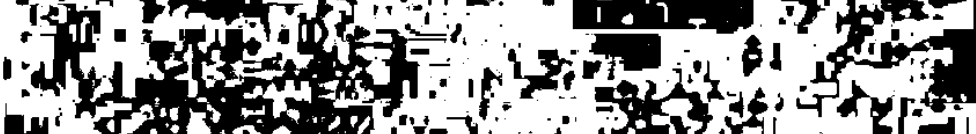

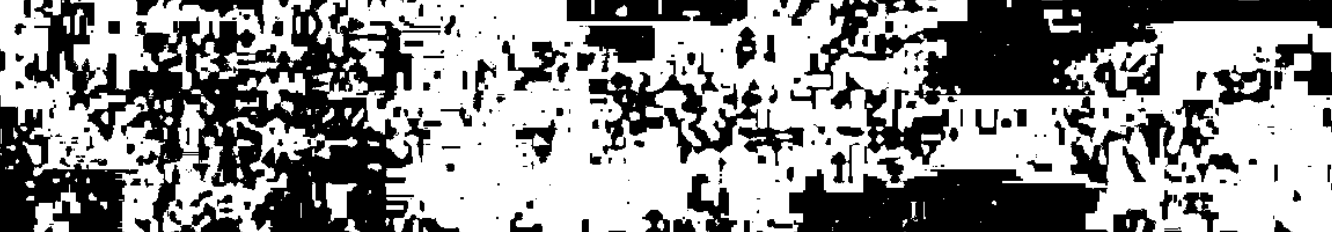
intoris (1)

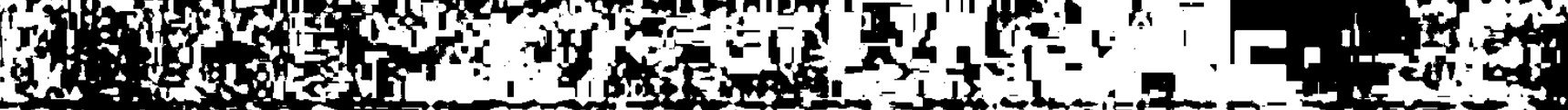
P. If $=$ to

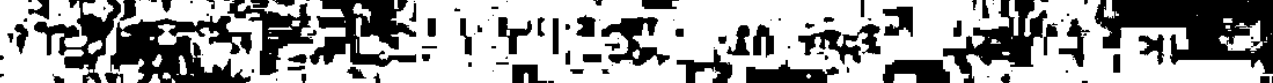

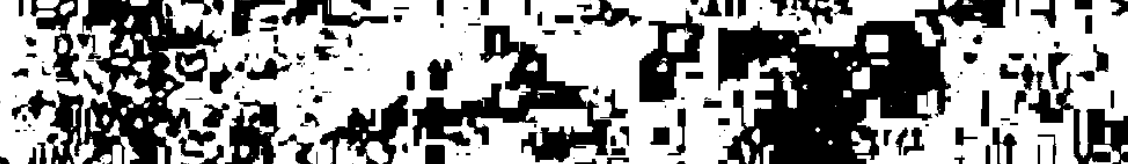

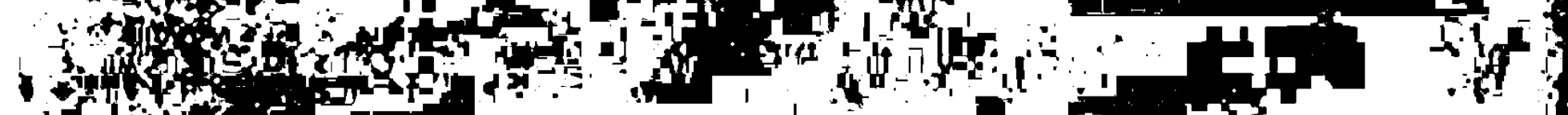

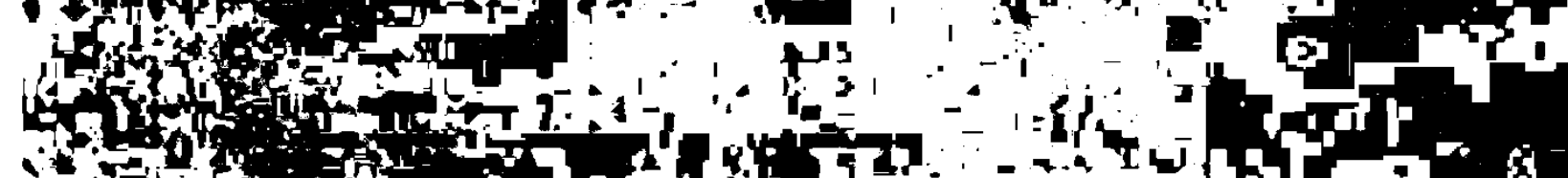
(1)

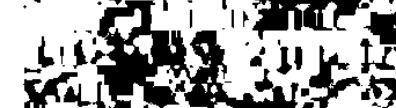

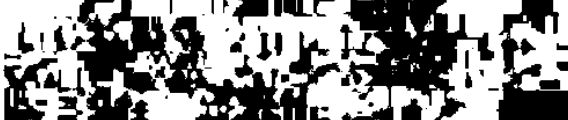

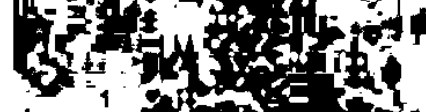

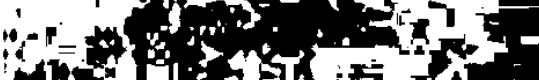

Hith

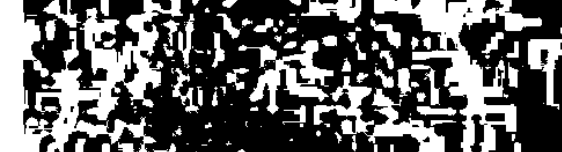

initist.

Qinging $\rightarrow 11$

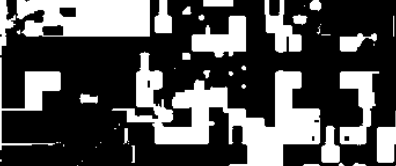

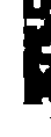

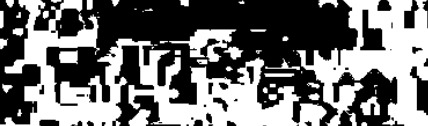

ant

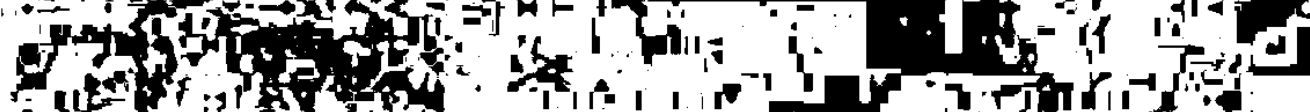

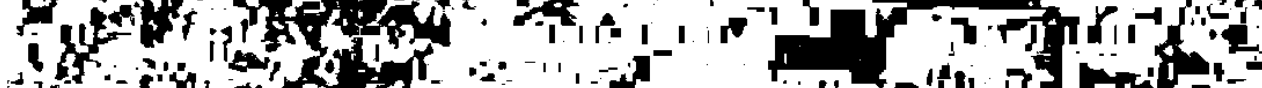

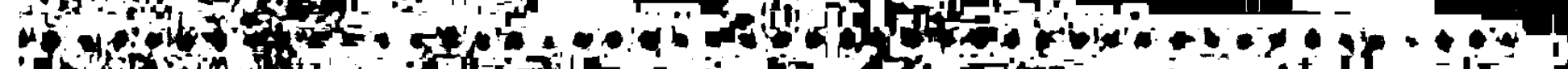

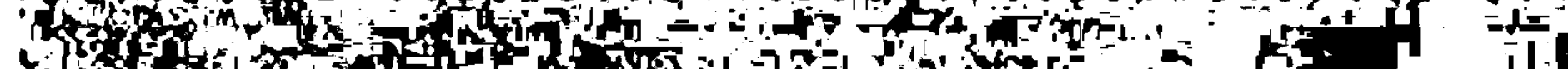
4 S

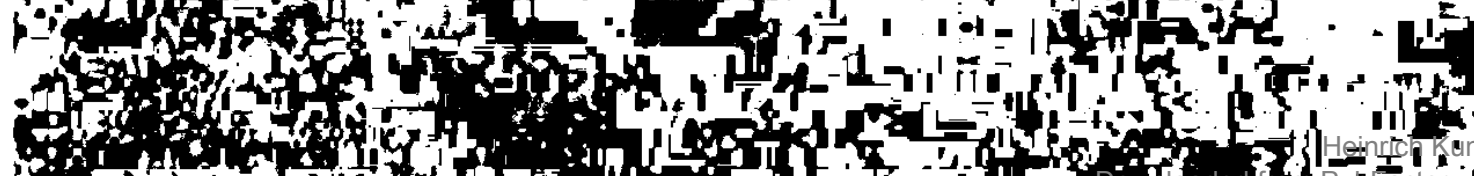

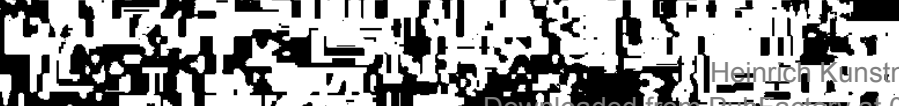
Q

-1, The 15 I. 20

$$
\text { . }
$$




\section{SLAVISTISCHE BEITRAGE}

$(1987-1988)$

206. Deschler, Jean-Paul: Kleines wörterbuch der kirchenslavischen Sprache. (Wortschatz der gebrăuchlichsten liturgischen Texte mit deutscher Ubersetzung, Tabelle des kyrillischen Alphabets mit Angabe der Aussprache, Verzeichnis der Abkürzungen in Handschriften und auf Ikonen.) 1987. IV, $260 \mathrm{~s}$.

207. Meyer, Angelika: "Sestra moja - iizn'" von Boris Pasternak. Analyse und Interpretation. 1987. $253 \mathrm{~S}$.

208. Miemietz, Bărbel: Nominalgruppen als Textverweismittel. Eine Untersuchung 2 um Polnischen unter Berücksichtigung des polnisch-deutschen Sprachvergleichs. 1987. $288 \mathrm{~s}$.

209. Störmer, Olaf: Die altrussischen Handschriften liturgischer Gesänge in sematischer Notation als Hilfsmittel der slavischen Akzentologie. 1987. VIII, $116 \mathrm{~S}$.

210. Winter, Una: Zum Problem der Kategorie der Person im Russischen. 1987. VIII, $354 \mathrm{~S}$.

211. Fuchs, Ina: Die Herausforderung des Nihilismus. Philosophische Analysen zu F.M. Dostojewskijs Werk .Die Dämonen". 1987. $314 \mathrm{~S}$.

212. Slavistische Linguistik 1986. Referate des XII. Konstanzer Slavistischen Arbeitstreffens Frankfurt am Main/ Riezlern 16.-19.9.1986. Herausgegeben von Gerd Freidhof und Peter Kosta. 1987. $398 \mathrm{~S}$.

213. Antalovsky, Tatjana: Der russische Frauenroman 1890-1917. Exemplarische Untersuchungen. 1987. XII, 202 S.

214. Jovanovic Gorup, Radmila: The Semantic Organization of the Serbo-Croatian Verb. 1987. X, $447 \mathrm{~S}$.

215. Eberspächer, Bettina: Realität und Transzendenz.- Marina Cvetaevas poetische Synthese. 1987. VIII, 244 S.

216. Dohrn, Verena: Die Literaturfabrik. Die frühe autobiographische Prosa V.B. Śklovskijs.- Ein Versuch zur Bewältigung der Krise der Avantgarde. 1987. X, 242 S.

217. Kunstmann, Heinrich: Beiträge zur Geschichte der Besiedlung Nord- und Mitteldeutschlands mit Balkanslaven. 1987. $253 \mathrm{~S}$. 
218. Besters-Dilger, Juliane: Zur Negation im Russischen und Polnischen. 1988. VI, $400 \mathrm{~S}$.

219. Menke, Elisabeth: Die Kultur der Weiblichkeit in der Prosa Irina Grekovas. 1988. VI, 309 S.

220. Hong. Gabriel: Palatalisation im Russischen und Chinesischen. 1988. X, $193 \mathrm{~S}$.

221. Kannenberg. Gudrun: Die Vokalwechsel des Polnischen in Abhängigkeit von Flexion und Derivation. Eine generative Beschreibung. 1988. $353 \mathrm{~S}$. 
HEM

Thes

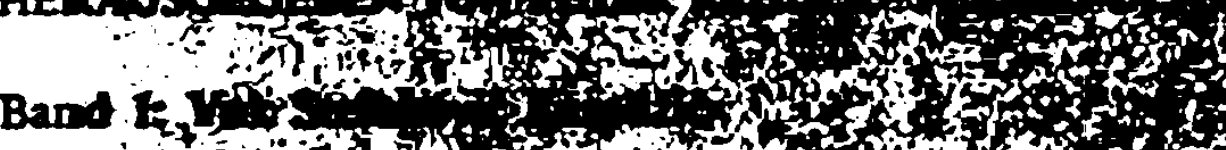

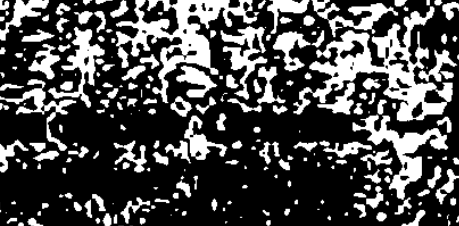

1974120

3 sota

1974. Vi

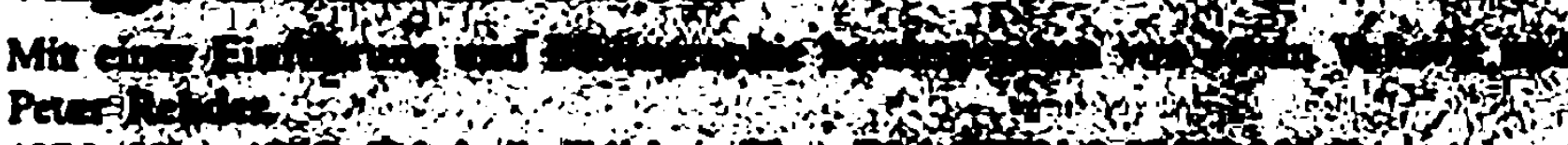

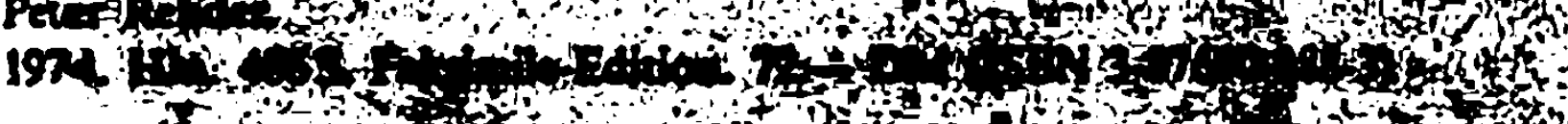

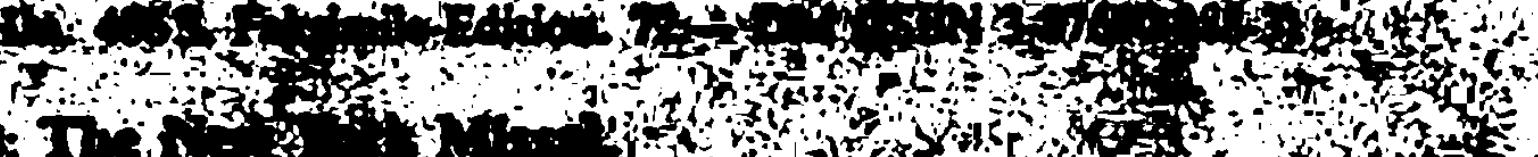

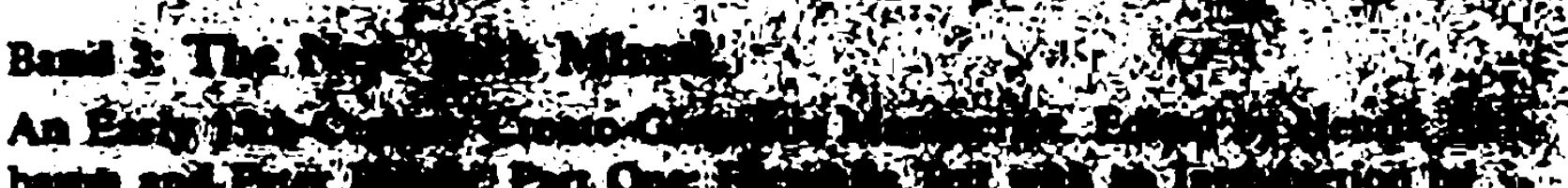
Hew

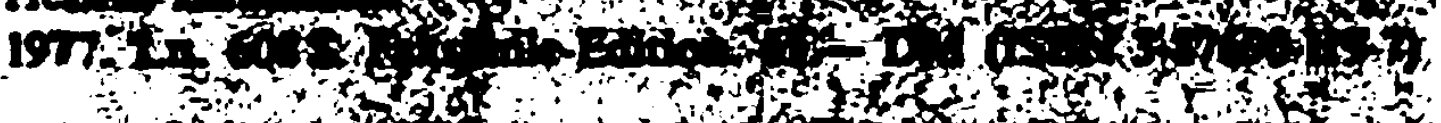

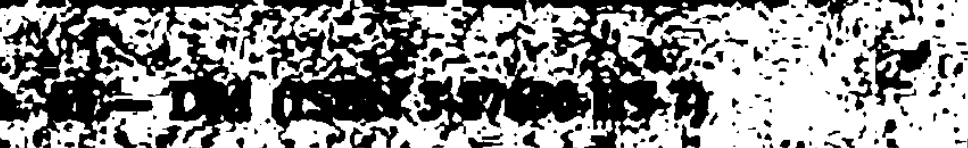

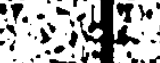
i- 



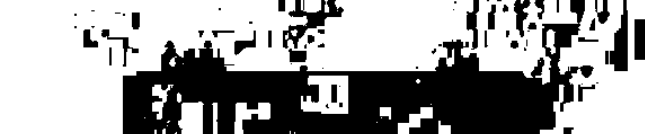

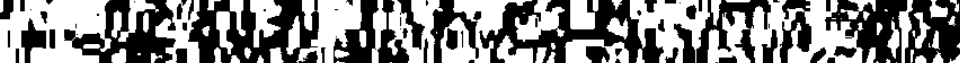

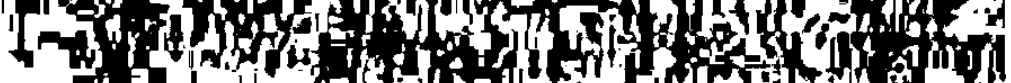

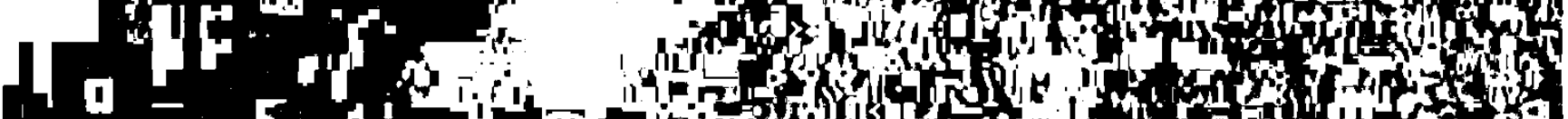

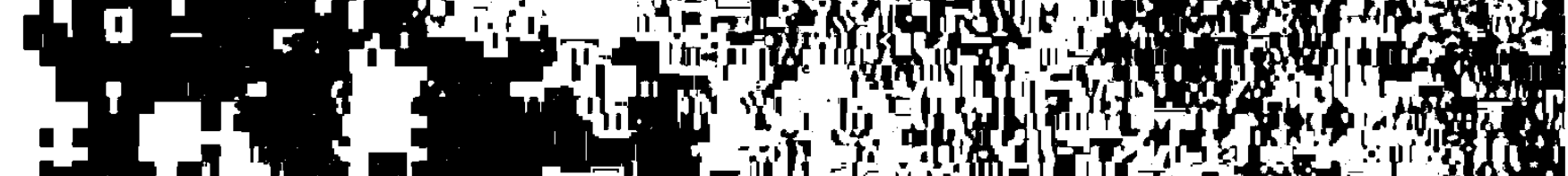
$14=-7$.

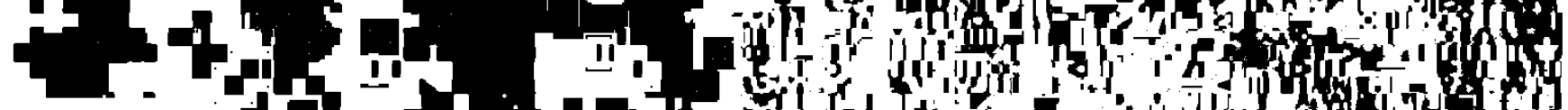
Q ? ? 1 \% . 1

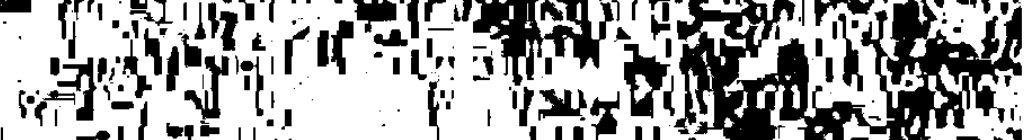

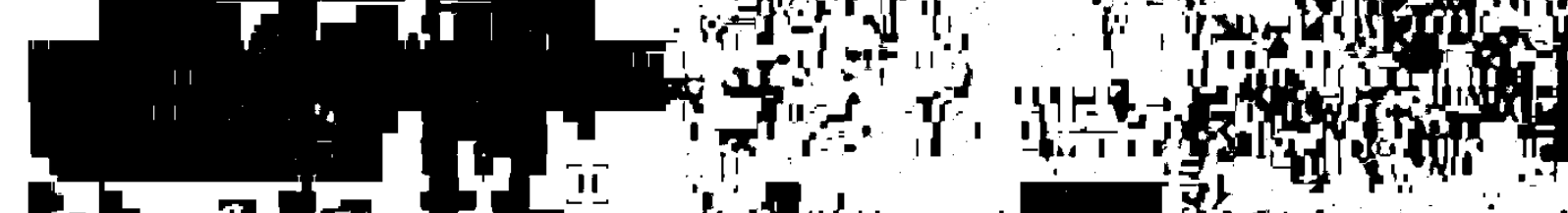

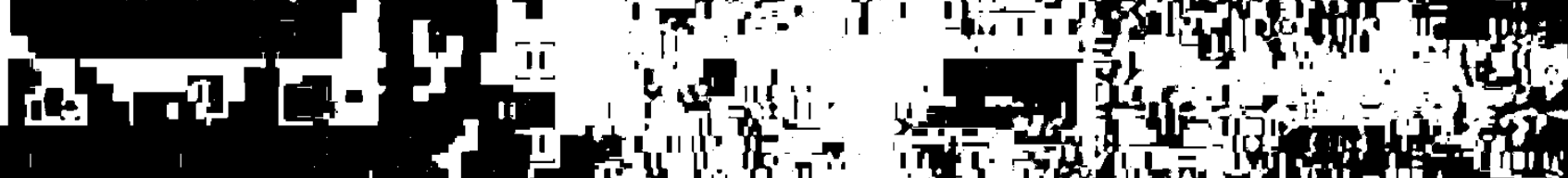
TI

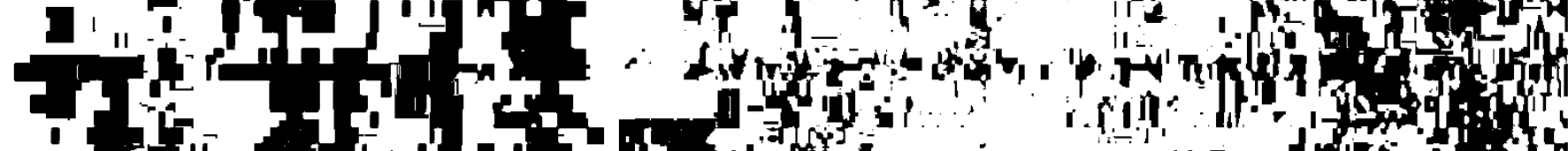
1.

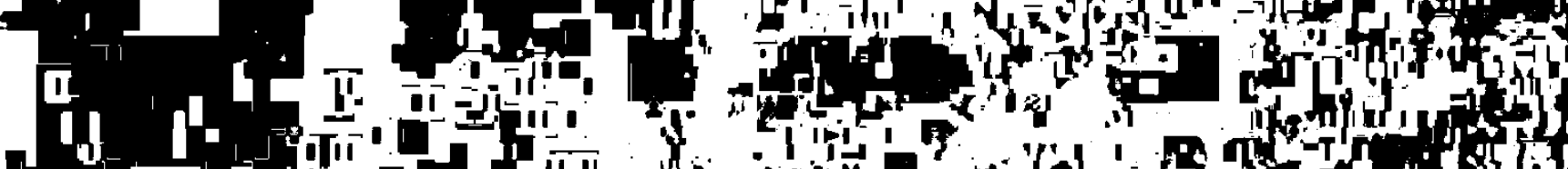

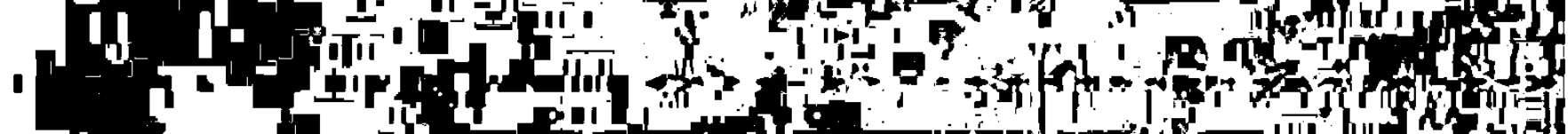

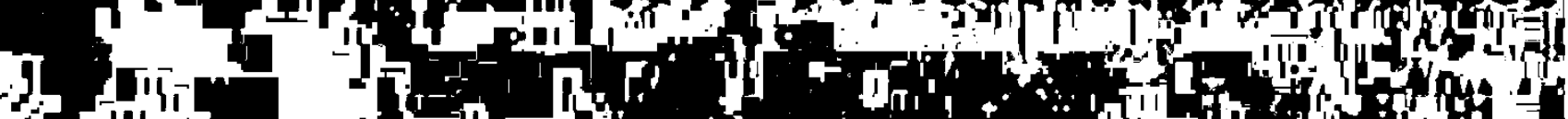
年 I1 7 , 1, ,

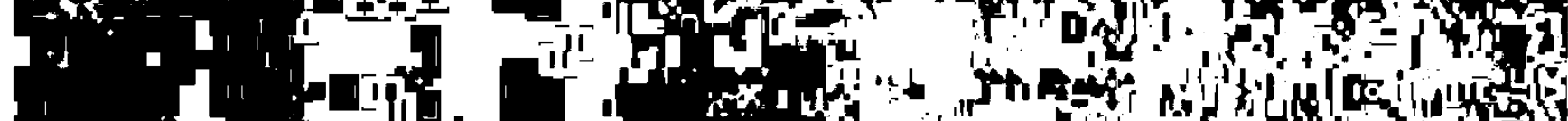

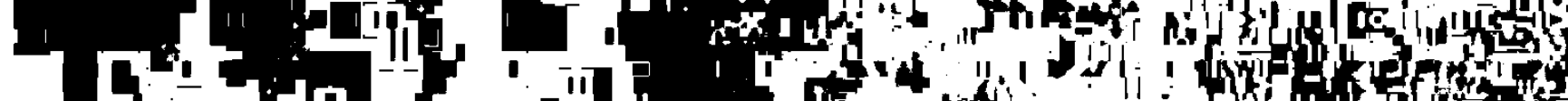
4.

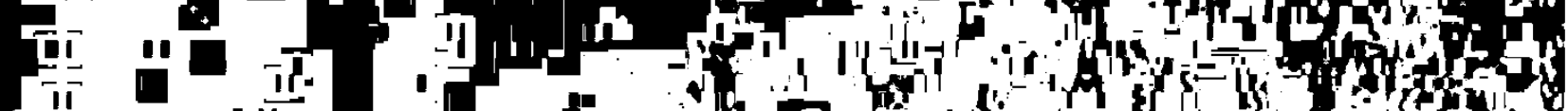
r

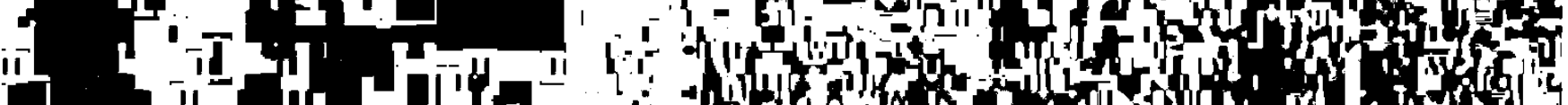
15 